\title{
Strukturanalyse von antibiotischen Peptiden in Lipidmembranen mittels Röntgenreflektivität
}

\author{
Dissertation \\ zur Erlangung des Doktorgrades \\ der Mathematisch-Naturwissenschaftlichen Fakultäten \\ der Georg-August-Universität zu Göttingen
}

vorgelegt von

Chenghao Li

aus Jilin/VR China

Göttingen, 2004 
D7

Referent: Prof. Dr. Tim Salditt

Koreferent: PD Dr. Helmut Grubmüller

Tag der mündlichen Prüfung: 27. 01. 2005 


\section{Inhaltsverzeichnis}

\begin{tabular}{lll}
\hline 1 & Einleitung & 1
\end{tabular}

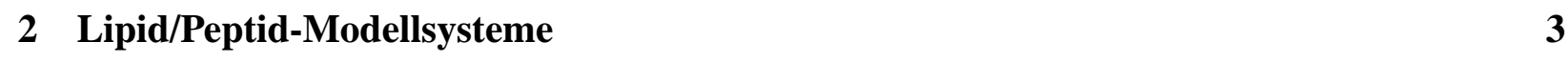

2.1 Biologische Membranen und ihre Funktion $\ldots \ldots \ldots$. . . . . . . . . 3

2.2 Aufbau der Lipiddoppelschicht $\ldots \ldots \ldots \ldots \ldots$

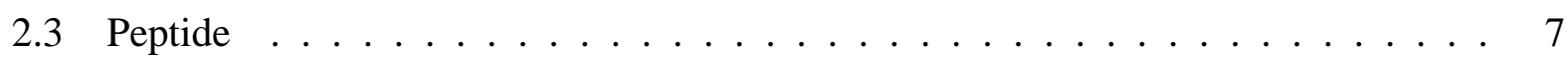

2.3 .1 Aufbauprinzip der Peptide . . . . . . . . . . . . . . 7

2.3 .2 Allgemeine Funktion der Proteine in der Natur $\ldots \ldots \ldots$

2.3 .3 Häufig vorkommende Sekundärstrukturen der Peptide . . . . . . . . . . 9

2.3 .4 Untersuchte Peptide . . . . . . . . . . . . . . . . 10

2.3.5 Modelle der Wechselwirkung zwischen Peptiden und Lipidmembranen . . 15

2.4 Freie-Energie-Betrachtung . . . . . . . . . . . . . . . . 23

2.5 Probenpräparation . . . . . . . . . . . . . . . . . 26

2.5 .1 Vorbereitung zur Präparation . . . . . . . . . . . . . 26

2.5 .2 Präparation von Membranstapeln mit geringer Doppelschichtzahl $(1 \leq \mathrm{N} \leq$

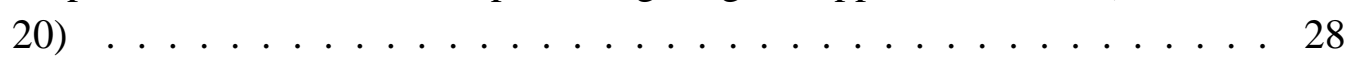

2.5.3 Präparation von Membranstapeln mit hoher Doppelschichtzahl $(\mathrm{N} \geq 200)$. 29

\begin{tabular}{|lll}
\hline 3 & Reflektometer-Aufbau und Experiment & 31
\end{tabular}

3.1 Erläuterung der Streugeometrie . . . . . . . . . . . . . . . . 31

3.2 Verwendete Messverfahren . . . . . . . . . . . . . . . . . . . . 32

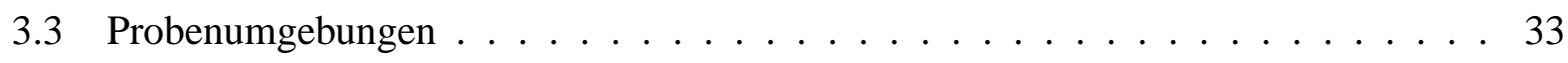

3.3 .1 Feuchtigkeitskammer . . . . . . . . . . . . . 33

3.3 .2 Nasskammer . . . . . . . . . . . . . . . 35

3.4 Reflektometer mit Stehanoden-Generator . . . . . . . . . . . . . . . . 36 
$3.4 .1 \quad$ Bauteile des Reflektometers . . . . . . . . . . . . . . . . . 36

3.4 .2 Aufbau des Reflektometers: 1. Ausbaustufe . . . . . . . . . . . . . . 37

3.4.3 Aufbau des Reflektometers: 2. Ausbaustufe . . . . . . . . . . . . . . . . 42

3.4.4 Aufbau des Reflektometers: 3. Ausbaustufe . . . . . . . . . . . . . . . . . 44

3.5 Ablenkmagnet-Reflektometer D4/HASYLAB . . . . . . . . . . . . . . 47

3.5 .1 Reflektometeraufbau . . . . . . . . . . . . . . . 47

3.5.2 Messung von multilamellaren Lipidstapeln in der Feuchtigkeitskammer . . 48

3.5.3 Messung der Oligo-Lipidmembranen in der Feuchtigkeitskammer . . . . . 48

3.5 .4 Messung von multilamellaren Lipidstapeln in Lösung. . . . . . . . . . . . 49

4 Röntgenstreuung an Membranstapeln $\quad 51$

4.1 Grundlagen und Allgemeines . . . . . . . . . . . . . . . . . 51

4.1 .1 Formfaktor und Strukturfaktor . . . . . . . . . . . . . . . . 51

4.1.2 Phasenproblem und Rekonstruktion des Elektronendichteprofils . . . . . . 54

4.2 Korrekturfaktoren: Absorption, Polarisation, Lorentzfaktor . . . . . . . . . . . . . 56

4.3 Fouriersynthese: Eichung anhand von reinem POPC . . . . . . . . . . . . . 61

4.4 Anwendung auf Peptid/Lipid-Systeme . . . . . . . . . . . . . . . 63

$4.4 .1 \quad$ Probleme bei Anwendung der Fouriersynthese . . . . . . . . . . . 65

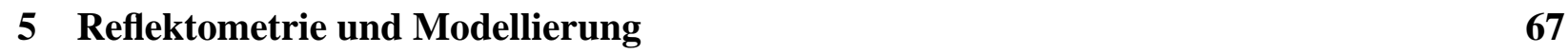

5.1 Reflexion an Grenzflächen . . . . . . . . . . . . . . . . . . . . . . 67

5.1 .1 Geometrie der Reflexion . . . . . . . . . . . . . . . 67

5.1 .2 Brechungsindex . . . . . . . . . . . . . . 68

5.1 .3 Brechungskorrektur . . . . . . . . . . . . . . . . . . 69

$5.1 .4 \quad$ Fresnelreflektivität des Röntgenstrahls . . . . . . . . . . . . . . . . . 71

5.2 Fluktuationen und Defekte $\ldots \ldots \ldots \ldots \ldots \ldots \ldots$. . . . . . . . . . . . . . .

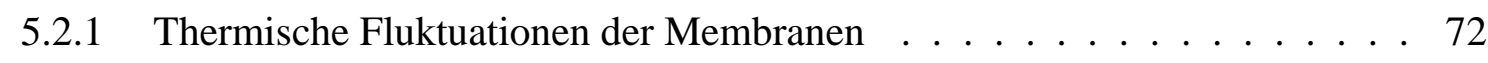

5.2 .2 Diffuse Streuung durch Fluktuationen oder durch Grenzflächen . . . . . 74

5.2 .3 Statische Defekte der Membranen . . . . . . . . . . . . . . . . 76

5.3 Semi-kinematisches Modell für die Reflektivität . . . . . . . . . . . . . . . . . . 77

$5.3 .1 \quad$ Elektronendichte der fluktuierenden Membranstapeln . . . . . . . . . . . 77

5.3 .2 Reflektivitätsmodell in wässriger Umgebung . . . . . . . . . . . . 78

$5.3 .3 \quad$ Formfaktor der Membranstapel $\ldots \ldots \ldots$. . . . . . . . . . . . 81 
5.3 .4 Reflektivitätsmodell in Feuchtigkeitsumgebung . . . . . . . . . . . . . . 82

5.4 Faltung der Reflektivitätskurve durch die Modellfunktion . . . . . . . . . . . . . . 87

5.4 .1 Proben in Feuchtigkeitsumgebung . . . . . . . . . . . . . . . 88

5.4 .2 Proben in wässriger Umgebung $\ldots \ldots$. . . . . . . . . . 93

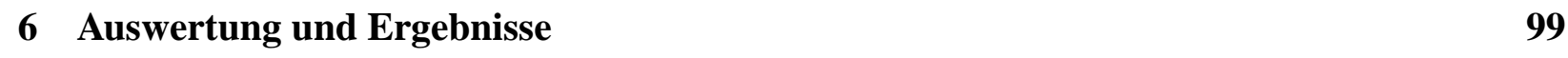

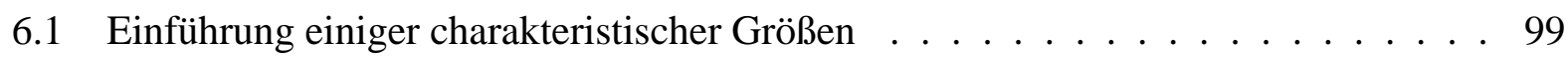

6.2 Auswertung der Messdaten aus reinen Lipiden . . . . . . . . . . . . . . . . . 101

$6.2 .1 \quad$ OPPC bei verschiedenen Membranstapeldicken . . . . . . . . . . . . 102

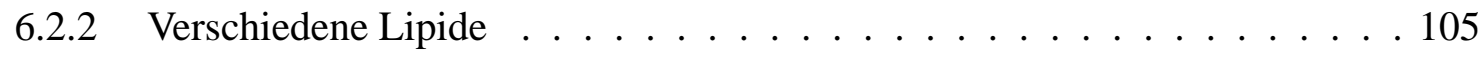

6.3 Auswertung der Messdaten aus Alamethicin/Lipid . . . . . . . . . . . . . . 111

6.3 .1 Alamethicin/DLPC . . . . . . . . . . . . . . 111

6.3 .2 Alamethicin/DMPC . . . . . . . . . . . . . . . . . 114

6.3 .3 Alamethicin/DMPC+DMPG . . . . . . . . . . . . . . . 117

6.3 .4 Alamethicin/DOPC . . . . . . . . . . . . . . . . . . . . . 119

6.3 .5 Alamethicin/DPPC . . . . . . . . . . . . . . . . 122

6.3 .6 Alamethicin/POPC . . . . . . . . . . . . . . . . 125

6.3 .7 Alamethicin/DMPC unter PEG-Lösung . . . . . . . . . . . . . . . . . 127

6.3 .8 Zusammenfassung . . . . . . . . . . . . . . . 130

6.4 Auswertung der Messdaten aus Magainin2/Lipid . . . . . . . . . . . . . . 133

$6.4 .1 \quad$ Magainin2/DMPC . . . . . . . . . . . . . . . . . . 134

$6.4 .2 \quad$ Magainin2/DMPC+DMPG . . . . . . . . . . . . . . . 138

6.4 .3 Magainin2/OPPC . . . . . . . . . . . . . . . . 143

6.4 .4 Magainin2/POPC . . . . . . . . . . . . . . 146

6.4 .5 Magainin $2 / \mathrm{POPC}+\mathrm{POPS}$. . . . . . . . . . . . . . . . 148

6.4 .6 Zusammenfassung . . . . . . . . . . . . . . . . 151

\begin{tabular}{ll}
\hline Zusammenfassung & 157
\end{tabular}

\begin{tabular}{lr}
\hline Literaturverzeichnis & 169
\end{tabular}

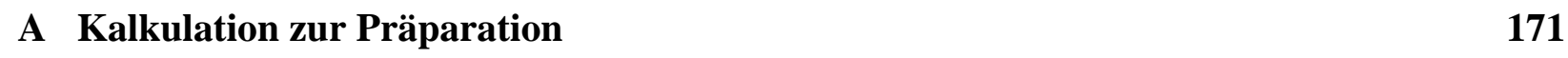

\begin{tabular}{lll}
\hline B & C-Quelltext des Programms zur Anpassung & 175
\end{tabular} 


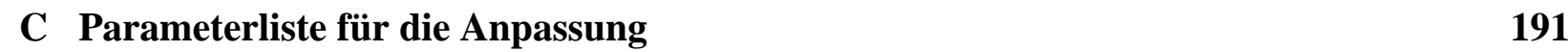

C.1 Alamethicin/Lipid . . . . . . . . . . . . . . . . . . . 191

C.2 Multilamellare Membranstapeln aus Magainin2/Lipid . . . . . . . . . . . . . 193

C.3 Oligo-Membranen aus Magainin2/Lipid . . . . . . . . . . . . . . . . . . . . . . . 194

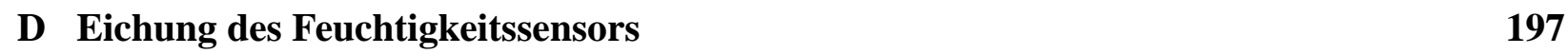

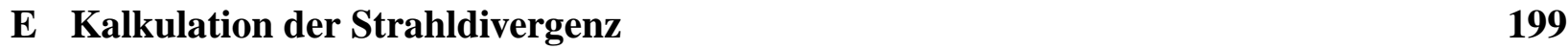

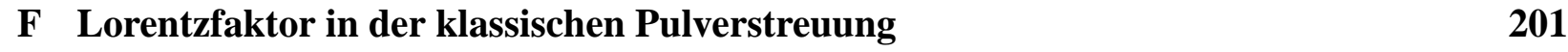




\section{Kapitel 1}

\section{Einleitung}

Antibiotika sind Wirkstoffe, die von Bakterien oder Pilzen gebildet werden und das Wachstum anderer Organismen beeinträchtigen [1]. Gemeinhin bezeichnet man auch synthetische Substanzen, die antibiotisch wirken, als Antibiotika. In jüngerer Zeit ist überdies deutlich geworden, dass Wirbeltiere und darunter auch Säugetiere, körpereigene Antibiotika exprimieren. Diese meist kurzen Polypeptide werden häufig zusammenfassend als antibiotische Peptide bezeichnet. Sie spielen in der aktuellen Wirkstoffforschung zur Umgehung des Resistenzproblems eine wichtige Rolle. Generell können Antibiotika auf Bakterien zwei grundsätzlich unterschiedliche Wirkungen haben. Die erste besteht in der Hemmung des Wachstums bzw. der Vermehrung von Bakterien (Bakteriostase), die zweite in der Abtötung der Bakterien (Bakterizide). Das antibiotische Peptid Magainin 2 aus der Haut des südafrikanischen Klauenfrosches Xenopus laevis und Alamethicin aus dem Kulturfiltrat des Pilzes Trichoderma viride gehören zu den Bakteriziden [2, 3, 4, 5, 6]. Heute wissen wir, dass diese beiden antibiotischen Peptide sowie die meisten Vertreter dieser Klasse weniger mit anderen Proteinen, als vielmehr mit der Zellwand und insbesondere der Lipidmembran von Bakterien und Mikroben wechselwirken, um ihre Wirkung zu entfalten. Die molekularen Mechanismen, die der antibiotischen Funktion dieser beiden antibiotischen Peptide zu Grunde liegen, sind aber weitgehend unklar.

Zum besseren Verständnis der Eigenschaften der beiden Peptidantibiotika und in Zukunft auch zur Ermöglichung der Entwicklung neuer Peptidantibiotika ist es notwendig, Mischsysteme aus Peptiden und Lipiden zu untersuchen. Es bleibt herauszufinden, wie die Struktur der Lipidmembrane durch Wechselwirkung mit den Peptiden geändert wird und wie sich diese Änderungen je nach Lipidzusammensetzung spezifisch unterscheiden. Für dieses Ziel müssen Methoden verwendet und weiterentwickelt werden, die uns in die Lage versetzen, die fluide Struktur der Membrane und die Konformation von Makromolekülen in der Membran mit molekularer Auflösung zu untersuchen. Diese Methodenentwicklung und ihre Anwendung auf Modellsysteme zur Klärung grundlegender Wechselwirkungsmechanismen ist ein Teilgebiet der modernen molekularen Biophysik.

In der vorliegenden Arbeit werden Peptid/Lipid-Modellsysteme aus Magainin 2 und Alamethicin 
sowie aus verschiedenen Phospholipiden untersucht. Um die Strukturinformation zu erhalten, werden ausschließlich Röntgenreflektivitätsexperimente durchgeführt. Zur Klärung grundlegender, struktureller Fragen wird die Methode der Röntgenreflektivität erweitert und auf Peptid/LipidModellsysteme angewendet. Als ein Ergebnis dieser Arbeit werden die Elektronendichteprofile in der Richtung senkrecht zur Membran für eine Reihe von Systemen in Abhängigkeit der Peptidkonzentration ermittelt. Das methodisch wichtigste Ziel dieser Arbeit ist die Modellierung der Röntgenreflektivität von orientierten Membranstapeln und die Entwicklung der experimentellen Grundlagen, wie zum Beispiel Probenpräparation und instrumentelle Auslegung der Messplätze an Röntgenröhren und Synchrotronstrahlungsquellen. Mit Hilfe der semi-kinematischen Reflektivitätstheorie kann eine Modellfunktion der Reflektivität für einen multilamellaren Membranstapel mit thermischen Fluktuationen und statischen Defekten entwickelt werden, mit der die Anpassung an die Messdaten durchgeführt werden kann. Der zweite Fokus der Arbeit liegt auf der Frage, inwiefern die klassische Methode der vereinfachten Auswertung der Streukurven von Lipidmembranen (Fouriersynthese auf der Basis der Bragg-Intensitäten) im Nachhinein durch Vergleich mit der besser begründeten semi-kinematischen Reflektivitätstheorie zu rechtfertigen ist. Außerdem wird untersucht, inwieweit die Qualität der Proben von organischen Lösungsmitteln beeinflusst wird und welche Rolle die Lipidfilmdicke bei der Rekonstruktion des Elektronendichteprofils spielt.

Die vorliegende Arbeit ist wie folgt gegliedert: Nach der Einleitung wird im zweiten Kapitel das Peptid/Lipid-Modellsystem vorgestellt, zudem werden die Eigenschaften von Alamethicin und Magainin 2 beschrieben. Kapitel 3 skizziert die physikalische Grundlage der experimentellen Methoden und den Aufbau der Instrumente, sowie deren Anwendung auf die zu untersuchenden Lipidmembranen. Außerdem wird das im Rahmen dieser Arbeit aufgebaute Reflektometer vorgestellt. Im vierten Kapitel wird die theoretische Grundlage der Röntgenstreuung an Membranstapeln erläutert. Im Kapitel 5 wird die Modellierung der Reflektivität an Membranstapeln durchgeführt. Dazu gehören die entsprechenden Korrekturen, z.B. für die Absorption der Membranen und die instrumentelle Auflösung. Dieses Kapitel ist der wichtigste Teil dieser Arbeit. Im Ergebnisteil, dem Kapitel 6, werden die Auswertungen auf der Basis der in der Literatur gebräuchlichen Fouriersynthese den Ergebnissen der Reflektivitätsanpassung gegenüber gestellt. Die Darstellung und Diskussion der Ergebnisse ist nach Systemen gegliedert: Im ersten Teil werden Systeme aus reinen Lipiden behandelt, während in den weiteren Abschnitten Peptid/Lipid-Systeme betrachtet werden. Es sei auch auf die Anhänge verwiesen, die die Analysemethoden der Arbeit durch Tabellen und Programme weiter im Detail erläutern. 


\section{Kapitel 2}

\section{Lipid/Peptid-Modellsysteme}

\subsection{Biologische Membranen und ihre Funktion}

Die Grundeinheit des Lebens ist die Zelle. Einer ihres wichtigsten Bestandteil ist die Membran, eine elastisch verformbare, häutchenartige Struktur, die die Zelle und ihre Organellen umgibt und deren inneres Milieu aufrecht erhält. Ihre grundlegende Funktion ist, Stoffe selektiv durchzulassen, also zu regulieren, was in die Zelle hereinkommt und sie wieder verlässt. Im Jahre 1925 erkannten E. GORTER und F. GRENDEL, dass eine Lipiddoppelschicht ein gutes Modell für die Membran abgeben würde. 1935 postulierten H. DAVSON und J. F. DANIELLI, dass die Proteine dieser Doppelschicht aufgelagert seien. J. S. SINGER und G. NICOLSON entwickelten 1972 das "Fluid mosaic model", das inzwischen vielfach experimentell bestätigt wurde. Nach diesem Modell besteht die biologische Membran als Mosaik von Proteinen in einer zähflüssigen Lipiddoppelschicht, wie Abb. 2.1 zeigt [7]. In die Lipiddoppelschicht sind Proteinmoleküle eingebettet. Manche der Prote-

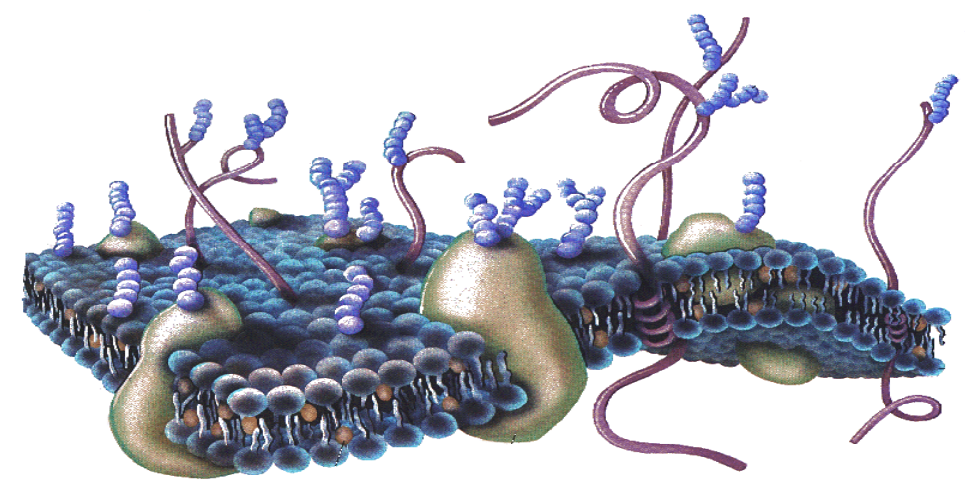

Abbildung 2.1: Dreidimensionale schematische Darstellung einer biologischen Membran nach dem" Fluid mosaic model" (aus [8]).

ine reichen durch die Membran hindurch und sind auf beiden Seiten der Membran dem wässrigen Medium ausgesetzt. Die Lipidmoleküle können lateral hin- und herdiffundieren. Auch die Proteine sind innerhalb der Lipiddoppelschicht beweglich und können lateral ungehindert diffundieren. Es 
ist dagegen für die Proteine wie auch für die Lipide nahezu unmöglich, von einer Membranoberfläche zur anderen zu wandern (engl. flip-flop), denn die relativ flexible Struktur der Membran ist durch ihre Hydrophobizität für die meisten wasserlöslichen Moleküle eine unüberwindliche Barriere (ca. $15 \mathrm{~kJ} / \mathrm{Mol}$ )[9]. Wasser und andere polare Moleküle können sich der Membran annähern und sich an ihrer Außenseite anlagern.

Die Membran ist, wie schon Eingangs erwähnt, selektiv permeabel. Kleine ungeladene Moleküle und Gase können durch sie diffundieren, während die meisten gelösten Substanzen zurückgehalten werden. Für den Transport der meisten Stoffe sorgen die Proteine. Kanäle, die von den Proteinen gebildet werden, dienen dem Transport von Stoffen (wie z. B. Wasser, andere Proteine, Lipide und Zucker) nach außen oder ins Zellinnere. Polymere Substanzen und Partikel können nicht durch die Membran transportiert werden.

\subsection{Aufbau der Lipiddoppelschicht}

Die Lipiddoppelschicht wird von den Lipiden gebildet. Das Lipid hat ein polares und ein unpolares Ende, und daher einen hydrophilen Kopfteil und einen hydrophoben Fettsäurekettenteil, wie Abb. 2.2 zeigt. Durch den Bau der Lipidmoleküle entsteht in wässriger Umgebung eine Doppelschicht.

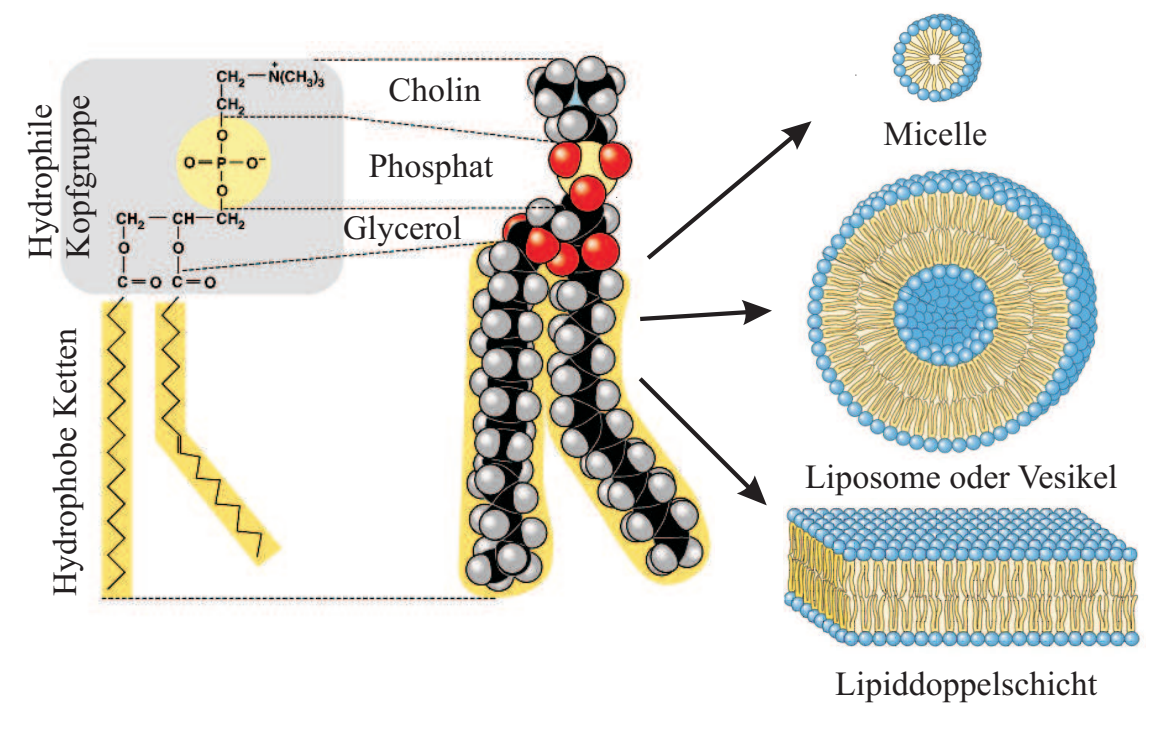

(a)

(b)

(c)

Abbildung 2.2: Struktur eines Lipidmoleküls (Phosphatidylcholin). (a) Chemische Grundstruktur; (b) Space-filling-Modell; (c) Querschnitte der drei typischen Strukturen, die von Phospholipiden in wässriger Lösung gebildet werden können ([10]).

Bei Bildung der Membran stehen die hydrophoben Kettenteile beider Schichten gegenüber, während die hydrophilen Kopfteile die Außenseite und die Innenseite der Zelle bilden.

In biologischen Membranen gibt es eine Reihe natürlich vorkommender Lipide. Davon stellen Phospholipide die dominierende Gruppe dar und bestehen aus einem Glycerolrückgrat, an das 


\begin{tabular}{clccccc}
\hline Kurzbez. & vollständiger Name & $\mathrm{R} 1$ & $\mathrm{R} 2$ & Ladung & $\mathrm{pK}-$ Wert & Molmasse \\
\hline \hline DLPC & 1,2-Dilauroyl-sn-Glycero-3-Phosphocholin & $12: 0$ & $12: 0$ & 0 & $13.9^{a}$ & 621.83 \\
DMPC & 1,2-Dimyristoyl-sn-Glycero-3-Phosphocholin & $14: 0$ & $14: 0$ & 0 & $13.9^{a}$ & 677.94 \\
DMPE & 1,2-Dimyristoyl-sn-Glycero-3-Phosphoethanolamin & $14: 0$ & $14: 0$ & 0 & $9.8^{c}$ & 635.86 \\
DMPG & 1,2-Dimyristoyl-sn-Glycero-3-[Phospho-rac-(1-glycerol)] & $14: 0$ & $14: 0$ & -1 & $2.9^{b}$ & 665.86 \\
DOPC & 1,2-Dioleoyl-sn-Glycero-3-Phosphocholin & $18: 1$ & $18: 1$ & 0 & $13.9^{a}$ & 788.72 \\
DPPC & 1,2-Dipalmitoyl-sn-Glycero-3-Phosphocholin & $16: 0$ & $16: 0$ & 0 & $13.9^{a}$ & 734.05 \\
OPPC & 1-Oleoyl-2-Palmitoyl-sn-Glycero-3-Phosphocholin & $18: 1$ & $16: 0$ & 0 & $13.9^{a}$ & 760.09 \\
POPC & 1-Palmitoyl-2-Oleoyl-sn-Glycero-3-Phosphocholin & $16: 0$ & $18: 1$ & 0 & $13.9^{a}$ & 760.09 \\
POPS & 1-Palmitoyl-2-Oleoyl-sn-Glycero-3-[Phospho-L-Serine] & $16: 0$ & $18: 1$ & -1 & $2.21^{d}$ & 784.00 \\
\hline
\end{tabular}

Tabelle 2.1: Bezeichnungen, Kettenlängen, Nettoladungen und Molmassen einiger häufig in der Natur vorkommender Phospholipide. R1 bzw. R2 bezeichnet die Länge der ersten bzw. zweiten Kette (R: Rest) in Anzahl von C-Atomen. Die Nettoladung ist in Einheiten der Elementarladung $e^{-}$, und die Molmasse versteht sich in Einheit $\mathrm{g} / \mathrm{Mol}$. [a: $\mathrm{pK}$-Wert (auch $\mathrm{p} K_{a}$ genannt) für Cholin [11]; $b$ : Aus [12]; c: Aus [13]; d: $p K$-Wert für die Carboxylgruppe.[14]]

\begin{tabular}{lcccc}
\hline Sorte & PG & PE & Kardiolipin $^{a}+$ LysoPG & andere \\
\hline Gram-positiv & & & & \\
Staphylococcus aureus & 57 & 0 & 43 & 0 \\
Staphylococcus epidermidis & 90 & 0 & $1^{b}$ & 9 \\
Bacillus megaterium & 40 & 40 & $5^{b}$ & 15 \\
Bacillus subtilis & 29 & 10 & $47^{b}$ & 14 \\
Gram-negativ & & & & \\
Escherichia coli & 6 & 82 & $12^{b}$ & 0 \\
Salmonella typhimurium & 33 & 60 & $7^{b}$ & 0 \\
Burkholderia cepacia & 18 & 82 & 0 & 0 \\
\hline
\end{tabular}

Tabelle 2.2: Phospholipidkomposition verschiedener Bakterien: In Gewichtsprozent der totalen Phospholipide der cytoplasmatischen Membran [15]. ( ${ }^{a}$ Ein Glycerophospholipid; ${ }^{b}$ Nur Kardiolipin.)

\begin{tabular}{lcl}
\hline Phospholipid & Prozentsatz & Membranteil \\
\hline Phosphatidylcholin & 31.0 & äußerer \\
Sphingomyelin & 23.5 & äußerer \\
Phosphatidylethanolamin & 28.4 & innerer \\
Phosphatidylserin & 13.4 & innerer \\
Phosphatidylinositol & 1.2 & innerer \\
Phosphatidsäure & 2.2 & innerer \\
\hline
\end{tabular}

Tabelle 2.3: Phospholipidkomposition (\% des Lipidphosphors) einer menschlichen Erythrozytenmembran und ihre dominierende Lokalisierung [15]. 
jeweils durch Veresterung einerseits eine Phosphatkopfgruppe mit angehängtem Rest (Cholin, Serin, etc.) und andererseits zwei Fettsäurereste gebunden sind (Abb. 2.2). In Tabelle 2.1 werden die allgemeinen Daten einiger häufig in der Natur vorkommender Lipide aufgelistet. Die typische Lipidzusammensetzung in der cytoplasmatischen Membran von Bakterien und in der menschlichen Erythrozytenmembran ist in Tabelle 2.2 und Tabelle 2.3 gezeigt.

Aufgrund der amphipathischen Eigenschaft können Phospholipide in wässrigen Lösungen unterschiedliche Strukturen wie etwa Mizellen, Liposome, oder Lipiddoppelschichten ausbilden (Abb. 2.2) [16]. Mizellen sind kugelförmig mit einem hydrophoben Zentrum, das nur von Fettsäureketten gebildet wird. Wegen der amphiphilen Eigenschaft des Phospholipidmoleküls sind die hydrophoben Fettsäureketten bei Bildung der Mizellen innen verborgen, die hydrophilen Kopfgruppen sind dagegen zum wässrigen Medium hin, an der Oberfläche liegend, angeordnet. Solche Mizellen können Tausende von Lipidmolekülen enthalten. Die Liposome sind ebenfalls kugelförmig. Sie bestehen aus einer Phospholipiddoppelschicht, die einen wässrigen Innenraum umgibt. Als Grenzfall großer Radien können Liposome als planare Lipiddoppelschicht angesehen werden.

Abhängig von Temperatur und Feuchtigkeit kann sich eine Lipiddoppelschicht in verschiedenen Phasen befinden. Abb. 2.3zeigt häufig ausgebildete lamellare Phasen: Die kristalline $L_{c}$-Phase, die kristalline $L_{c^{\prime}}$-Phase, in der die Lipidketten um etwa $30^{\circ}$ zur Membrannormalen geneigt sind, die gelartige $L_{\beta}$-Phase, die gekippte gelartige $L_{\beta^{\prime}}$-Phase, in der die Lipide leicht gegenüber der Membrannormalen gekippt sind, die fluide $L_{\alpha}$-Phase, die $P_{\beta^{\prime}}$-Phase (ripple), in der die Lipidmoleküle sowohl zur Membrannormalen geneigt als auch gewellt sind. Physiologisch von großer Bedeutung ist die fluide $L_{\alpha}$-Phase. Die hier vorliegende Arbeit behandelt ausschließlich die fluide $L_{\alpha}$-Phase.
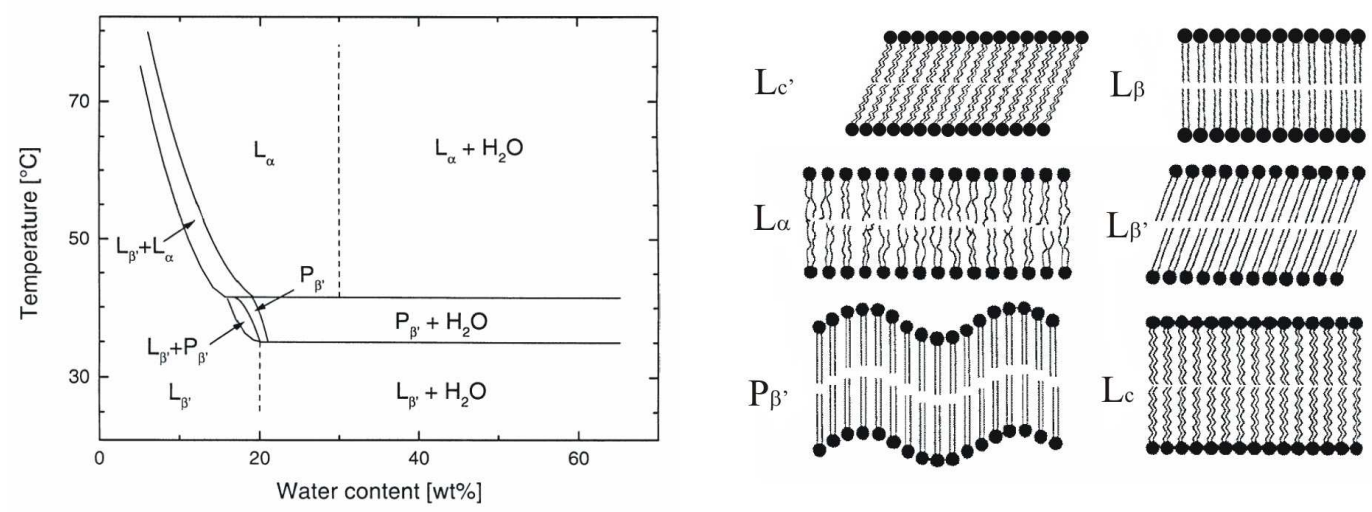

Abbildung 2.3: Links: Das Phasendiagramm von DPPC-Lipiddoppelschichten in Abhängigkeit der Temperatur und Wasserkonzentration [17]. Rechts: Schematische Darstellung verschiedener lamellarer Lipidphasen: Die Subgel- $L_{c^{\prime}}$-Phase, die Subgel- $L_{c}$-Phase, die gelartige $L_{\beta}$-Phase, die gekippte gelartige $L_{\beta^{\prime}}$-Phase, die fluide- $L_{\alpha^{-}}$-Phase und die ripple $P_{\beta^{\prime}}$-Phase. 


\subsection{Peptide}

\subsubsection{Aufbauprinzip der Peptide}

Die elementaren Bausteine der Peptide sind die 20 natürlich vorkommenden verschiedenen Aminosäuren, die sich in Größe, Gestalt, Ladung, sowie in ihrer chemischen Reaktivität unterscheiden. Peptide sind Verbindungen, bei denen zwei oder mehr natürliche Aminosäuren über Peptidbindungen (Säureamid-Bindungen) zwischen der Carboxylgruppe der einen und der Aminogruppe der nächsten Aminosäure (Abb. 2.4(a)) kettenförmig miteinander verknüpft sind.

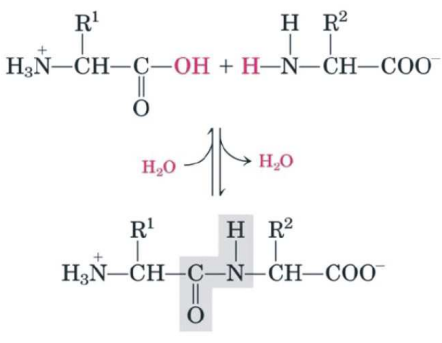

(a)

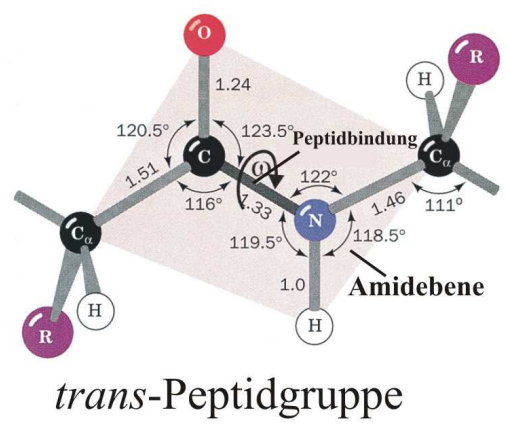

(b)

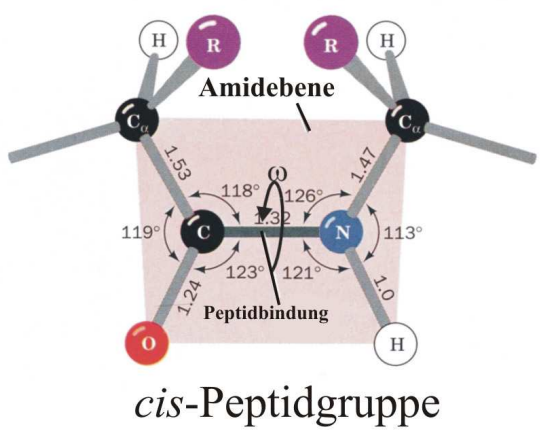

(c)

Abbildung 2.4: (a) Bildung und chemische Struktur einer Peptidbindung; (b,c) Schematische Darstellung zweier unterschiedlicher Konfigurationen der Peptidgruppen mit entsprechendem Torsionswinkel $\omega$ zwischen $\mathrm{C}=\mathrm{O}$ und $\mathrm{N}-\mathrm{H}\left(180^{\circ}\right.$ bei der trans-Peptidgruppe und $0^{\circ}$ bei der cis-Peptidgruppe).

Zwei Aminosäuremoleküle können zu einem Dipeptid zusammengefügt werden, drei zu einem Tripeptid, vier zu einem Tetrapeptid usw. Man spricht von Oligopeptiden, wenn nicht mehr als zehn Aminosäuren miteinander verbunden sind, darüber hinaus von Polypeptiden. Die Peptidgruppe ist eine starre und planare Struktur, aufgrund eines partiellen Doppelbindungscharakters ist praktisch keine freie Rotation um die $\mathrm{C}-\mathrm{N}$-Bindungen möglich, da dabei eine Rotationsbarriere von ca. $105 \mathrm{~kJ} / \mathrm{mol}$ existiert [18]. Für die Peptidbindung gibt es deshalb zwei Rotationsmöglichkeiten: die $\operatorname{trans}\left(\omega=180^{\circ}\right)$ - und die $\operatorname{cis}\left(\omega=0^{\circ}\right)$ - Peptidgruppe. Wegen der Abstoßung benachbarter Seitenketten ist die trans-Peptidgruppe energetisch günstiger als die cis-Peptidgruppe, daher kommen fast alle Peptide in Form von trans-Peptidgruppen vor.

Proteine sind große Peptide, welche aus mehreren hundert Aminosäuren aufgebaut sein können und auch als „Makropeptide“ bezeichnet werden [19]. In Tabelle 2.4 werden die Eigenschaften der 20 Standardaminosäuren dargestellt. Die willkürliche Grenze zur Unterscheidung zwischen Proteinen und Peptiden wählt man heute bei ca. 50 am Aufbau beteiligten Aminosäuren. Die kurzkettigen Vertreter sind die Peptide, die langkettigen die Proteine. 


\begin{tabular}{cccccc}
\hline Name & Abk. & Molmasse & Lin. Strukturformel & hydro. Charak.(scale) & Polarität \\
\hline \hline Isoleucin & ILe (I) & 131.17 & CH3-CH2-CH(CH3)-CH(NH2)-COOH & hydrophob(0.73) & unpolar \\
Phenylalanin & Phe (F) & 165.19 & Ph-CH2-CH(NH2)-COOH & hydrophob(0.61) & unpolar \\
Valin & Val (V) & 117.15 & CH3-CH(CH2)-CH(NH2)-COOH & hydrophob(0.54) & unpolar \\
Leucin & Leu (L) & 131.17 & (CH3)2-CH-CH2-CH(NH2)-COOH & hydrophob(0.53) & unpolar \\
Tryptophan & Trp (W) & 204.23 & Ph-NH-CH-C-CH2-CH(NH2)-COOH & hydrophob(0.37) & unpolar \\
Methionin & Met (M) & 149.21 & CH3-S-(CH2)2-CH(NH2)-COOH & hydrophob(0.26) & unpolar \\
Alanin & Ala (A) & 89.09 & CH3-CH(NH2)-COOH & hydrophob(0.25) & unpolar \\
Glycin & Gly (G) & 75.07 & NH2-CH2-COOH & nicht hydrophil(0.16) & polar \\
Cystein & Cys (C) & 121.15 & HS-CH2-CH(NH2)-COOH & nicht hydrophil(0.04) & polar \\
Tyrosin & Tyr (Y) & 181.19 & HO-p-Ph-CH2-CH(NH2)-COOH & nicht hydrophil(0.02) & polar \\
Prolin & Pro (P) & 115.13 & NH- $(\mathrm{CH} 2) 3-\mathrm{CH}-\mathrm{COOH}$ & nicht hydrophob(-0.07) & unpolar \\
Threonin & Thr (T) & 119.12 & CH3-CH(OH)-CH(NH2)-COOH & hydrophil(-0.18) & polar \\
Serin & Ser (S) & 105.09 & HO-CH2-CH(NH2)-COOH & hydrophil(-0.26) & polar \\
Histidin & His (H) & 155.16 & N=C-NH-C=C-CH2-CH(NH2)-COOH & hydrophil(-0.40) & pos. geladen \\
Glutaminsäure & Glu (E) & 141.13 & HOOC-(CH2)2-CH(NH2)-COOH & hydrophil(-0.62) & neg. geladen \\
Asparagin & Asn (N) & 132.12 & H2N-CO-CH2-CH(NH2)-COOH & hydrophil(-0.64) & polar \\
Glutamin & Gln (Q) & 146.15 & H2N-CO-(CH2)2-CH(NH2)-COOH & hydrophil(-0.69) & polar \\
Asparaginsäure & Asp (D) & 132.12 & H2N-CO-CH2-CH(NH2)-COOH & hydrophil(-0.72) & neg. geladen \\
Lysin & Lys (K) & 146.19 & H2N-(CH2)4-CH(NH2)-COOH & hydrophil(-1.1) & pos. geladen \\
Arginin & Arg (R) & 132.12 & H2N-CO-CH2-CH(NH2)-COOH & hydrophil(-1.8) & pos. geladen \\
\hline
\end{tabular}

Tabelle 2.4: Bezeichnungen und Eigenschaften der natürlich vorkommenden Aminosäuren; geordnet wird nach absteigender Reihenfolge der hydrophoben Eigenschaft. Die Molmasse ist in Einheit g/Mol. Die hydrophobe Eigenschaft wird mit der Eisenberg hydrophobicity consensus scale dargestellt; je positiver der Zahlenwert ist, umso größer ist die hydrophobe Wirkung. Negative Werte zeigen eine größere Affinität zu Wasser [20].

\subsubsection{Allgemeine Funktion der Proteine in der Natur}

Proteine spielen eine Schlüsselrolle in allen biologischen Systemen. In einer lebenden Zelle übernehmen sie fast alle funktionellen Aufgaben. Sie dienen als enzymatische Katalysatoren und als Transport- und Speichermedium, um Energie oder Baustoffe bereitzustellen. Weiter sind sie an der Regulierung des Zellstoffwechsels und der Interaktion zwischen Zellen beteiligt und werden für den Aufbau spezifischer Strukturen benötigt. Beim Körper der Wirbeltiere sorgen sie für eine kontrollierte Bewegung der Muskeln und sind mechanische Stütze in Haut und Knochen. Außerdem dienen manche Proteine, wie z.B. die Peptid-Antibiotika, der Immunabwehr des Körpers und sind somit eine wirksame Waffe gegen andere Lebewesen. Sie kontrollieren zudem das Wachstum und die Differenzierung von Zellen. Die Sequenz, also die Reihenfolge der Aminosäuren im Protein, wird als Primärstruktur bezeichnet und bestimmt zusammen mit der Struktur (Konformation) die Funktionalität des Proteins. 


\subsubsection{Häufig vorkommende Sekundärstrukturen der Peptide}

Durch Wechselwirkung der Aminosäure-Seitengruppe, die am Peptidrückgrat (peptide backbone) gebunden ist, mit der Umgebung kommt es zu unterschiedlichen regulären lokalen Konformationen. Periodische Kettenformationen, wie Helizes oder Faltblattstrukturen, bezeichnet man als Sekundärstruktur. Die Konformation der Peptidrückgrate wird durch drei Torsionswinkel $\phi, \psi$ und $\omega$ definiert. Jede Aminosäure hat zwei Torsionsfreiheitsgrade, charakterisiert durch $\phi$ und $\psi$ (Abb. 2.5). Der Winkel $\phi$ entspricht der Rotation zwischen der Stickstoffsäure und $\mathrm{C}_{\alpha}$. Befindet sich die Peptidbindung in einer cis-Konformation, dann ist $\phi=0^{\circ}$. Der Winkel $\psi$ stellt die Rotation zwischen $\mathrm{C}_{\alpha}$ und dem Carbonyl-Carbon dar, bei der cis-Konformation dieser Peptidbindung ist $\psi=0^{\circ}$. Beide Winkel sind $180^{\circ}$, wenn das Polypeptid sich in völlig ausgedehnter Konformation befindet und alle Peptidgruppen in gleicher Ebene sind. Von besonderer Bedeutung ist eine

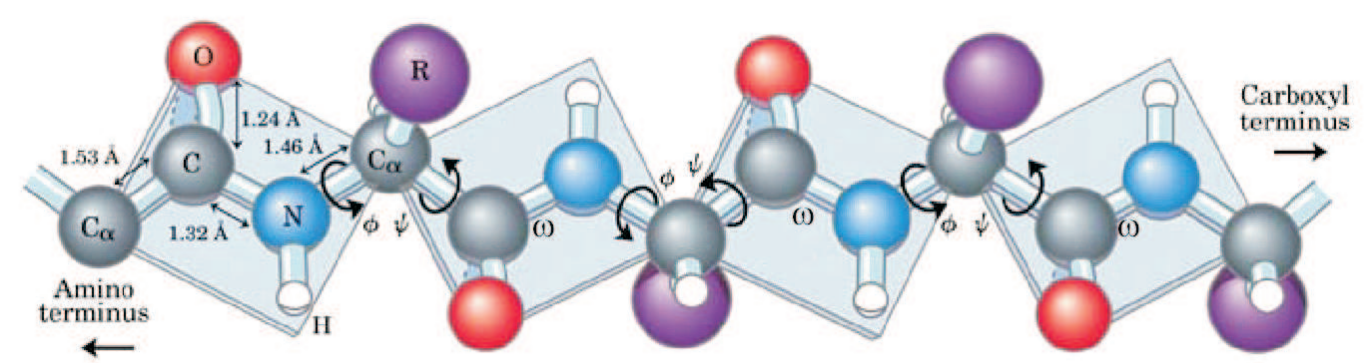

Abbildung 2.5: Schematischer Aufbau einer Polypeptidkette: Durch drei Torsionswinkel ist die Konformation des Peptidrückgrates zu beschreiben. Um das zentrale $C_{\alpha}$-Atom gibt es zwei mögliche Torsionen; $\phi$ : Rotation des Peptidrückgrates um $\mathrm{N}$ - $C_{\alpha^{-}}$-Bindung; $\psi$ : Rotation des anderen Peptidrückgrates um $\mathrm{C}_{-} \mathrm{C}_{\alpha^{-}}$ Bindung.

Konformationsstabilisierung durch sog. Wasserstoffbrückenbindungen. Zwischen Molekülen, die ständig einen positiven und einen negativen Pol besitzen, treten bei kleinem Abstand Anziehungskräfte (Dipol-Dipol-Kräfte) auf. Moleküle, in denen ein Wasserstoffatom mit einem Sauerstoffoder Stickstoffatom verbunden ist, bilden besonders starke Dipole aus. Der Grund dafür liegt in der hohen Elektronegativität der Sauerstoff- und Stickstoffatome. Das Wasserstoffatom erhält eine relativ starke positive Teilladung, während das Akzeptoratom $(\mathrm{O}, \mathrm{N})$ eine entsprechende negative Teilladung trägt. Derartige Moleküle, die einen starken Dipol besitzen, ziehen sich auch gegenseitig stärker an, wobei das kleine Wasserstoffatom besonders stark angezogen werden kann, da sein Kern (Proton) nur schwach abgeschirmt ist. Aus der starken zwischenmolekularen Anziehung resultiert die Wasserstoffbrückenbindung. So kann sich zwischen dem Sauerstoffatom (H-Akzeptor) und dem N-Atom (H-Donor) zweier Peptidbindungen bei einem Abstand von etwa $0.28 \mathrm{~nm}$ eine Wasserstoffbrücke ausbilden. Diese durch eine Wasserstoffbrücke resultierende Bindung ist im Vergleich zu kovalenten Bindungen relativ schwach, aber die Vielzahl der an dieser Konformationsstabilisierung beteiligten Wasserstoffbrücken führt zur Ausbildung eines kooperativen Systems mit großer Stabilität. Einer deren wichtigsten Vertreter ist die rechtshändige $\alpha$-Helix.

Die rechtshändige $\alpha$-Helix als die am häufigsten vorkommende Sekundärstruktur mit $\phi=-57^{\circ}$ und $\psi=-47^{\circ}$ bildet eine spiralförmige Struktur aus. Eine eng aufgewickelte Polypeptidkette bildet den 


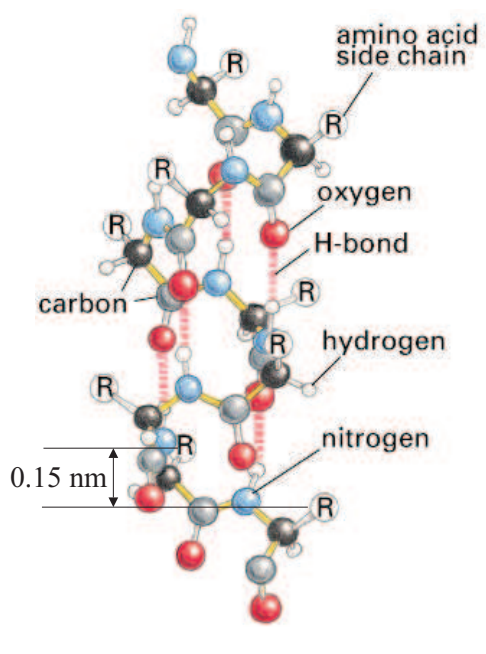

(a)

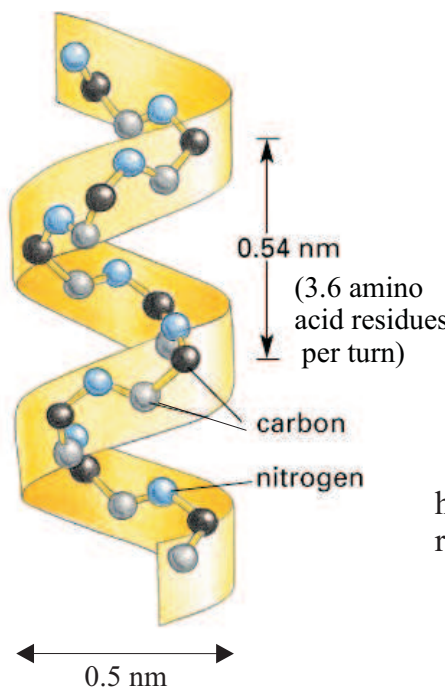

(b)

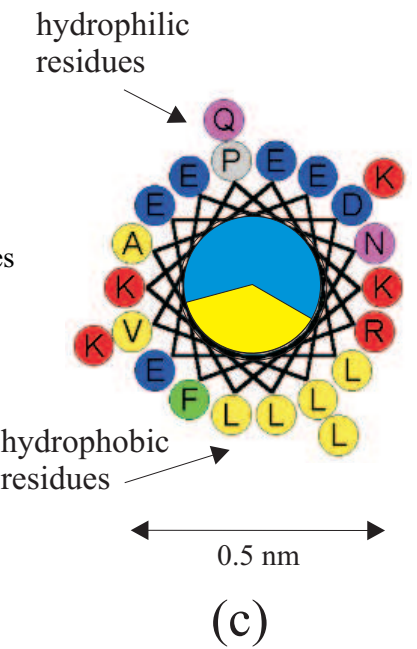

(c)

Abbildung 2.6: $(a, b)$ Modell einer rechtshändigen $\alpha$-Helix mit gekennzeichneter H-Brückenstruktur. Das Rückgrat des Polypeptids ist zu einer Spirale aufgewunden, die durch H-Brückenbindungen zwischen Sauerstoff- und Wasserstoffatomen im Peptidrückgrat stabilisiert wird [21]; (c) Beispiel eines sogenannten Schiffer-Edmundson-Helixrades (helical wheel) mit Leucin-Zipper.

inneren Teil des Rückgrates, während die Seitenketten in schraubenartiger Anordnung nach auBen weisen. Jeder Aminosäurerest ist gegen den nächsten Rest um $1.5 \AA$ entlang der Helixachse versetzt und um $100^{\circ}$ verdreht, so dass eine volle Umdrehung der Helix 3.6 Aminosäureresten entspricht. Pro Windung beträgt die Ganghöhe der typischen $\alpha$-Helix $5.4 \AA$ A. Blickt man entlang der zentralen Helixachse, bilden die Aminosäuren eine radförmige Ordnung (Abb. 2.6(c)). Typische Vertreter für die $\alpha$-Helix-Struktur sind die Peptidantibiotika wie z.B. Alamethicin und Magainin 2. Diese $\alpha$-Helizes weisen auf der einen Seite der Helix hydrophile und auf der anderen Seite hydrophobe Seitenketten auf [10]. Dies ist dann der Fall, wenn sich die entsprechenden Aminosäuren regelmäßig um drei oder vier Aminosäuren voneinander entfernt auf der Polypeptidkette befinden. Bei einer amphiphilen $\alpha$-Helix befinden sich viele oder manchmal auch alle hydrophilen Seitenketten auf der einen Seite des Helixrades, während die hydrophoben Seitenketten auf der anderen zu finden sind. Diese einzigartige Eigenschaft wird genutzt, um den hydrophilen Charakter der $\alpha$-Helix zu erkennen.

\subsubsection{Untersuchte Peptide}

Die vorliegende Arbeit untersucht zwei Peptide, Alamethicin und Magainin 2. Alamethicin und Magainin 2 sind antibiotische Peptide mit $\alpha$-Helixstruktur, sie sind amphiphil, d.h. die eine Seite der Helix ist hydrophob und die andere Seite hydrophil. Aufgrund der amphiphilen Eigenschaft können sie in Lipidmembranen Ionen-Kanäle oder Poren ausbilden ([22],[23]). Im folgenden werden die Eigenschaften dieser beiden Peptide vorgestellt. 


\section{Alamethicin}

Alamethicin ist ein Peptidantibiotikum, das aus dem Kulturfiltrat des Pilzes Trichoderma viride isoliert wird [24]. Alamethicin zeigt bakteriostatische, fungizide, cytostatische und hämolytische Effekte. Es zählt zu den amphiphilen Peptidantibiotika, die in Lipidmembranen einen fluktuierenden, spannungsabhängigen Ionenfluss erzeugen können. Durch Aggregation der Peptidstrukturen werden Poren gebildet, die unterschiedliche Leitfähigkeitszustände annehmen können [18].

Alamethicin ist in hohem Maßen hydrophob und kann in Lipidmembransystemen stark auf den Membranen adsorbiert werden und unter bestimmten Bedingungen Ionenkanäle bilden. Durch solche Ionenkanäle kann ein Verlust des cytoplasmatischen Materials auftreten und so zum Zelltod führen. Diese charakteristische Eigenschaft ist für die antibiotische Aktivität sowie Toxizidität (Hämolyse) bei Säugetieren verantwortlich [2]. Das Hauptinteresse an Alamethicin ist jedoch auf eine einzigartige und spezifische Aktivität zurückzuführen, mit der es elektrische Eigenschaften der künstlichen Lipidmembrane beeinflusst [25]. Bei einer sehr niedrigen Konzentration induziert Alamethicin in den Lipidmembranen eine spannungsabhängige Leitfähigkeit, die Ähnlichkeit mit dem in Nervenmembranen und Muskeln höherer Organismen beobachteten Effekt aufweist. [25, 26, 27, 28, 29]. Diese Effekte sind zu verstehen, wenn man annimmt, dass die Alamethicine aggregieren und die Lipidmembran überspannen, dabei bilden sie ionenleitende Kanäle aus [30, 31, 32]. Es ist zur Zeit wissenschaftlicher Konsens, dass Bündel von parallelen AlamethicinHelizes ionenleitende Poren bilden [33]. Wegen seiner interessanten Kanalbildung und kleinen Struktur ist Alamethicin ein wichtiges Modell für spannungsabhängige Ionenleitungen in Lipidmembranen geworden. Alamethicin wurde auch als Modell für die Wechselwirkungen zwischen Protein und Membran und als Modell für die Wechselwirkungen zwischen den Helizes untersucht [34, 35, 36]. Außerdem gibt es ein steigendes Interesse an den kanalbildenden Peptiden mit neuartigen Eigenschaften für den möglichen Einsatz in der Biosensor-Technologie und den nanodevices [37].

In Membranen können Alamethicine sich mit bis zu 12 Molekülen zur Bildung eines HelixBündels assoziieren, die Ionen leiten können [30, 27]. Die Innenseite der Bündel nehmen vermutlich den hydrophilen Teil der Helizes auf, um einen Ionenkanal auszubilden; die hydrophoben Teile der Helizes wechselwirken dann mit den Lipidketten [38].

\section{Die Struktur von Alamethicin}

Alamethicin ist ein amphiphiles Peptidantibiotikum mit 20 Aminosäureresten, davon sind 8 ungewöhnliche $\alpha$-Aminoisobuttersäurereste (Aib). Der hydrophobe N-Terminus des Alamethicins wird acetylisiert, der polare C-Terminus ist L-Phenylalaninol (Pheol) und biegt von der Helixachse ab Position Pro14 (Prolinaminosäurereste) weg. Es liegt deshalb nahe, dass der N-Terminus des Peptids sich in das Lipidmembraninnere einlagert. Die Primärstruktur von Alamethicin ist:

\section{Ac-Aib $^{1}$-Pro-Aib-Ala-Aib ${ }^{5}$-Ala-Gln-Aib-Val-Aib ${ }^{10}$-Gly-Leu-Aib-Pro-Val ${ }^{15}$-Aib-Aib-Glu- GIn-Pheol $^{20}$.}

Wegen des hohen Anteils der $\alpha$-Aminoisobuttersäureresten (Aib) hat Alamethicin eine starke Neigung zur Bildung einer Helixstruktur [39, 40]. Die Röntgen-Kristallstrukturanalyse für 
Alamethicin zeigt, dass Alamethicin überwiegend eine $\alpha$-Helixstruktur ausbildet, mit einer Biegung durch eine zweite Helixstruktur, die durch den Prolin-Aminorest in der Position 14 [38] verursacht wird (Abb. 2.7). Eine ähnliche Struktur wurde durch NMR (nukleare magnetische Resonanz) für Alamethicin in einem Lösungsmittel (Methanol) gefunden [41]. Die drei polaren Aminosäurereste, Gln-7, Glu-18 und Gln-19 strecken ihre Seitenketten von der konvexen Helixoberfläche aus und befinden sich alle auf der gleichen Seite der Helix. Sie bilden wahrscheinlich einen Teil des Ionenkanal-Lumens [42]. Die Existenz von Pro-14 macht es möglich, dass die Rückgratscarbonyle von Aib-10 und Gly-11 auch auf dieser Helixoberfläche liegen, die leichte Biegung durch Pro-14 lassen die Carbonyloxygene von Aib-10 und Gly-11 auch eine polare Seite der Helix bilden. Es steht zu vermuten, dass Pro-14 für das Einlagern von Alamethicin in

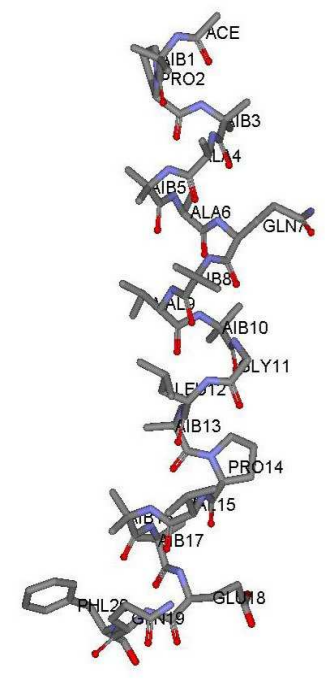

(a)

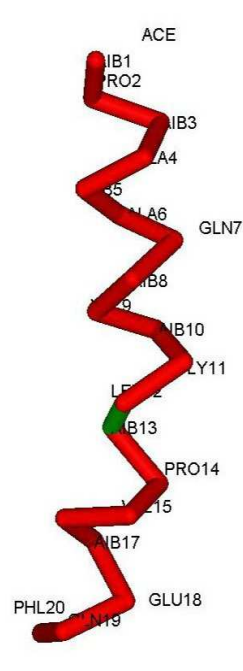

(b)

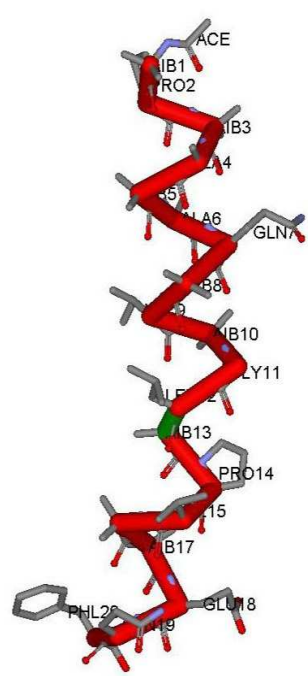

(c)

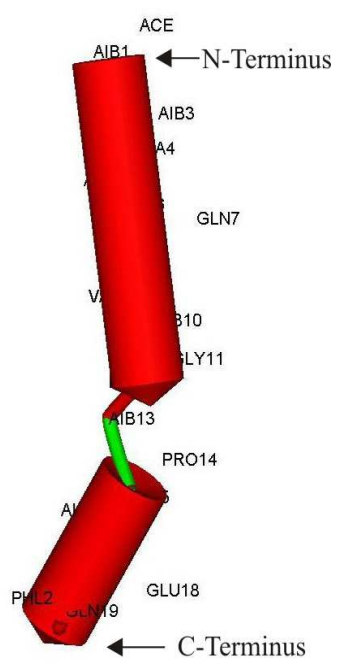

(d)

Abbildung 2.7: Sekundärstruktur von Alamethicin. (a) Kristallstruktur von Alamethicin im Stick-Modell, gezeigt sind hier die Aminosäurereste mit Positionsnummern; (b) Die Peptid-Rückgrate der Alamethicinmoleküle im Stick-Modell, die nur aus $\alpha$-Kohlenstoffatomen bestehen, verdeutlichen die $\alpha$-Helixstruktur von Alamethicin; (c) Beide Modelle zusammengefügt. (d) Schematische Darstellung der $\alpha$-Helix, es ist deutlich $z$ erkennen, dass die $\alpha$-Helix bei Prol 4 unterbrochen und abgebogen wird; (Aus der Protein-Datenbank: http://www.rcsb.org (30.04.2004).)

die Lipidmembrane eine Schlüsselrolle spielt, da Pro-14 einen Biegungspunkt (siehe Abb. 2.7) zwischen zwei Helixsegmenten erzeugt [38]. Alamethicin ist überall ziemlich hydrophob, aber in seiner Kristallstruktur zeigt es mit zwei Gln-Aminoresten, die auf einer Helixseite liegen, einen seitlich schwach amphiphilen Charakter [43].

Alamethicin hat wegen der negativ geladenen Glu (Glutaminsäure hat eine negative Ladung und $p K_{a}$-Wert von ca. 4)[44] in einer neutralen Umgebung - 1 geladen und einen $p K_{a}$-Wert (Maß für die Stärke einer Säure) von ca. 4.4 [2]. Die Kristallstruktur weist eine Länge von $30 \AA$ auf, dies reicht aus, um die Lipiddoppelschicht zu überspannen [42]. In Abb2.7 sind die Sekundärstrukturen von Alamethicin dargestellt. 


\section{Magainin 2}

Eines der beiden ersten in Wirbeltieren entdeckten antibiotischen Peptide ist Magainin 2 [18]. Es wurde aus der Haut südafrikanischer Klauenfrösche (Xenopus laevis) isoliert [3]. Dieses Peptid beschützt den Frosch vor Infektionen und zeigt ein breites Spektrum antimikrobieller Aktivität. Es tötet nicht nur Gram-negative und -positive Bakterien, sondern auch Fungi und Protozoon [3, 4, 45]. Eine der am meisten überraschenden Funktionen von Magainin 2 ist die hohe selektive Toxizität. Magainin 2 führt seine defensive biologische Funktion durch selektive Durchdringung bakterieller Membrane durch, dabei wird der Ionengradient in der Membran zerstört [46]. Diese selektive Toxizität von Magainin 2 kann mindestens teilweise dadurch erklärt werden, dass Magainin 2 bevorzugt mit anionischen Phospholipiden wechselwirkt, die sich reichlich in Bakterienmembranen befinden [47, 48].

Magainin 2 hat bei neutralem pH-Wert $(\mathrm{pH}=7)$ eine Nettoladung von +4 [49, 23]. Aufgrund elektrostatischer Wechselwirkung zwischen dem alkalischen Magainin 2 und säuerlichen Lipiden verbindet und durchdringt Magainin 2 vorzugsweise säuerliche Phospholipide enthaltende Lipiddoppelschichten, wie z.B. Phosphatidylglycerol (PG), Phosphatidylserin (PS) und Phosphatidylsäure [50, 51, 47, 52]. Bakterienmembranen enthalten reichlich säuerliche Lipide, z.B. Lipopolysaccharide (LPS), Phosphatidylglycerol (PG) und Cardiolipin (CL), während die äußere Zellmembran der Säugetiere hauptsächlich aus zwitterionischen Phospholipiden zusammengesetzt ist [5]. Dies führt wohl auch dazu, dass Magainin 2 effektiv Bakterien tötet. Magainin 2 induziert den Tod der Escherichia coli-Zellen, begleitend mit Abfluss von intrazellulärem $\mathrm{K}^{+}$[53]. Es durchdringt künstliche Lipidvesikeln (Liposomen) [50, 54] und bildet in planaren Lipiddoppelschichten Ionenkanäle [55, 56]. In der Tat verursacht die Behandlung der Escherichia coli-Zellen durch Magainin 2 Blasen an der Bakterienoberfläche [53]. Es zerstört auch die Ordnung der anionischen Lipopolysaccharide (LPS), die sich auf der äußeren Zellmembran Gram-negativer Bakterien befinden [57, 58]. Im Gegensatz dazu ist die Affinität von Magainin 2 zu zwitterionischen Lipiden wegen seiner niedrigen hydrophoben Eigenschaft äußerst schwach, daher verbindet sich Magainin 2 nicht effektiv mit zwitterionischen Phospholipiden. Außerdem enthalten Säugetierzellmembranen erhebliche Mengen Cholesterin $(\mathrm{CH})$, dessen Verbindung mit Phosphatidylserin(PS)Doppelschichten die Membrandurchdringung von Magainin 2 verhindert [47]. Es herrscht breite Übereinstimmung, dass die Interaktion zwischen Magainin 2 mit neutralen Phospholipiden wie Palmitoyl-Oleoyl-Glycero-Phospho-Cholin (POPC) ziemlich schwach ist [56, 59, 60]. Magainin 2 hat also kaum oder wenig Toxizität gegen Säugetierzellen. Die minimale Toxizitätskonzentration von Magainin 2 bezüglich verschiedener Mikroorganismen liegt im Bereich von 10-100 $\mu \mathrm{g} / \mathrm{ml}$, während die Toxizitätskonzentration bezüglich der Lysis der Säugetierzellen (d.h. rote Blutkörperchen) mehr als $1 \mathrm{mg} / \mathrm{ml}$ beträgt [3, 61, 53]. Darüber hinaus zeigt Magainin 2 Antitumoraktivität [62, 63].

\section{Die Struktur von Magainin 2}

Magainin 2 besteht aus 23 Aminosäureresten. Es kann in wässriger Lösung bei physiologischem pH-Wert bis zu hohen Konzentrationen gelöst werden. Die Primärstruktur von Magainin 2 lau- 


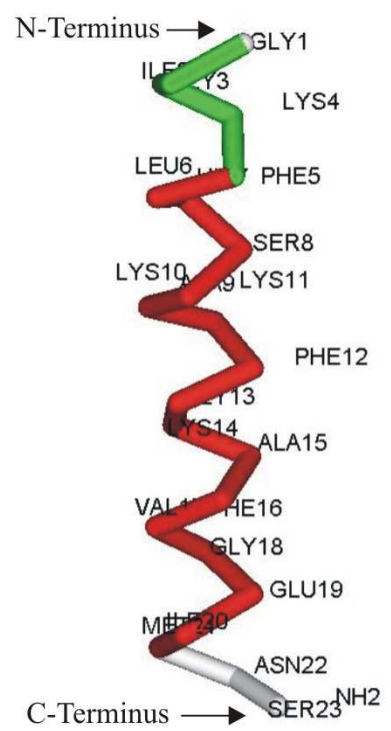

(a)

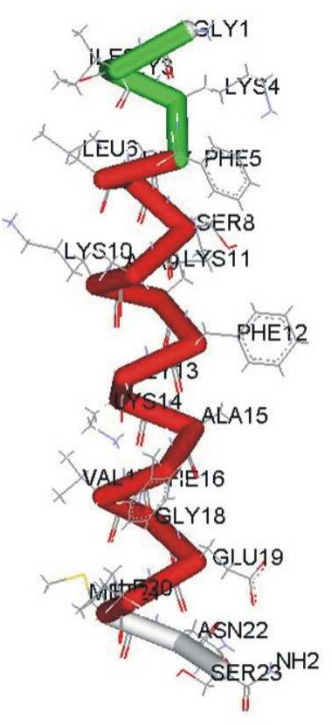

(b)

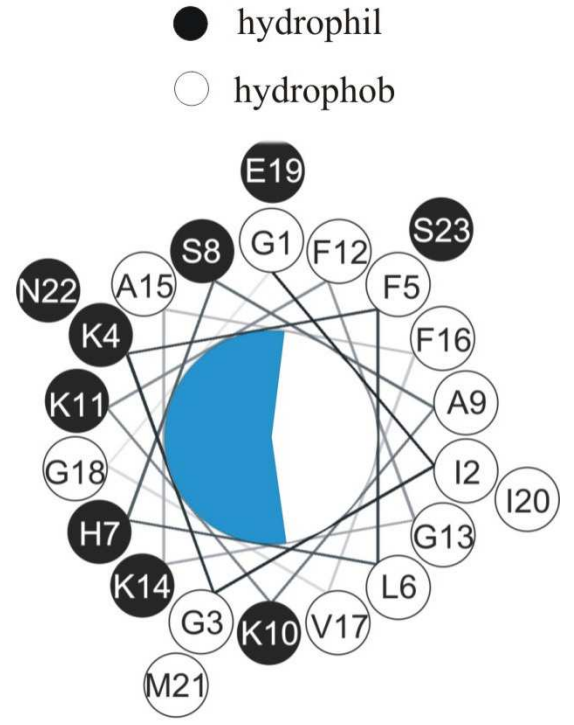

(c)

Abbildung 2.8: Eine der 10 Sekundärstrukturen von Magainin 2 in DPC-Mizellen [64]. (a) Die PeptidRückgrate des Magainin 2-Moleküls, die nur aus $\alpha$-Kohlenstoffatomen bestehen, zeigen die $\alpha$-Helixstruktur von Magainin 2; (b) Peptid-Rückgrate mit Seitenkette in Line-Modell. (Aus der Protein-Datenbank http://www.rcsb.org (03.05.2004)); (c) Schematische Darstellung eines Maganin2-Moleküls in der helical wheel representation. Hydrophobe Aminosäurereste sind weiß und hydrophile Reste schwarz dargestellt. Wenn man entlang der $\alpha$-Helixachse blickt, sind die Aminosäurereste in Form eines Rades angeordnet und die hydrophoben Reste befinden sich fast alle auf einer Seite (weiße Seite), während die hydrophilen Reste auf der anderen Seite (schwarze Seite) sind [48].

tet: Gly-Ile-Gly-Lys-Phe-Leu-His-Ser-Ala-Lys-Lys-Phe-Gly-Lys-Ala-Phe-Val-Gly-Glu-IleMet-Asn-Ser (oder mit einbuchstabigem Code: GIGKF LHSAK KFGKA FVGEI MNS). Obwohl es in wässrigen Lösungen gut lösbar ist, zeigt es auch eine starke Affinität zu Phospholipidmembranen. In wässriger Umgebung hat Magainin 2 mit neutralem $\mathrm{pH}$-Wert eine kaum oder gar nicht wohldefinierte Sekundärstruktur [50, 65, 52, 66]. Experimente durch ZirkulardichroismusSpektroskopie (CD) [67, 51], Raman [66], Fourier-Transform-Infrarot-Spektroskopie (FTIR) [65] und auch die Festkörper-Kernresonanz-Spektroskopie (NMR) [68] zeigen, dass Magainin 2 in Phospholipiddoppelschichten oder in organischen Lösungen eine rechtshändige $\alpha$-Helixstruktur einnimmt [69]. Zahlreiche Untersuchungen weisen auch darauf hin, dass es in Verbindung mit säuerlichen Phospholipiddoppelschichten hauptsächlich eine $\alpha$-Helixstruktur bildet [50, 51, 65, 52, 66, 68, 70]. Der Helixanteil, der von den Experimentierbedingungen abhängig ist, liegt in Bereich von 60-90\%. Multidimensionale Lösungs-NMR-Experimente zeigen, dass Magainin 2 in wässriger Lösung unstrukturiert und hoch flexibel ist, aber in Umgebung der Modellmembran von Dodecylphosphocholin-Mizellen (DPC-Mizellen), Dodecylsulfat-Mizellen und in Trifluoroethanol/Wasser-Lösung eine fast vollständige $\alpha$-Helixstruktur aufweist [69, 68]. Dies wird in Abb. 2.8 (a,b) anschaulich gemacht [64]. Es sollte beachtet werden, dass die Sekundärstruktur von Magainin 2 in Mischlösung aus Trifluoroethanol/Wasser nicht unbedingt die Kon- 
formation in der Lipidmembran wiederspiegelt [52, 66, 71], obwohl solche Mischlösungen oft als Membran-nachahmendes Mittel verwendet wurden [61]. In Abb. 2.8(c) wird das SchifferEdmundson-Helixrad von Magainin 2 gezeigt, anhand dessen man feststellen kann, dass Magainin 2 eine typische amphiphile $\alpha$-Helixstruktur mit fast gleichem hydrophoben und hydrophilen Winkel hat, was auf seine Neigung hindeutet, auf der Membranoberfläche zu liegen [72]. Eine MonteCarlo-Integration des molekularen Modells ergibt für Magainin 2 ein Volumen von $3500 \AA^{3}$ [73]. Mit einer Axiallänge von $34.5 \AA$ erhält man dann einen effektiven Durchmesser der $\alpha$-Helix von $10-12 \AA$.

\subsubsection{Modelle der Wechselwirkung zwischen Peptiden und Lipidmembra- nen}

Die Wechselwirkung zwischen Peptiden und Lipidmembranen spielt im biologischen Prozess eine Schlüsselrolle und es ist bekannt, dass sie ihre strukturelle Ordnung wechselseitig beeinflussen. Diese Aktivität der antimikrobiellen Peptide in Lipidmembranen induziert Deformationen und Defekte der Lipidmembranen, wie z.B. Phasenseparation, Membranverdünnung, Kanalbildung und Lipiddoppelschichtstörung. Abhängig sind all diese Effekte von den molekularen Eigenschaften der Lipide und Peptide [15]. Antibiotische Peptide wie Magainin 2 und Alamethicin vermitteln einfache antimikrobielle Abwehrmechanismen in vielen Organismen [74]. Eine allgemein bei membranaktiven Peptiden beobachtete charakteristische Eigenschaft ist ihre Fähigkeit zur Störung der Vollständigkeit der Lipiddoppelschichten entweder durch ihre Zerstörung oder durch Porenbildung in ihnen. Die dadurch resultierenden Leckraten in den Lipiddoppelschichten führen zum Einsturz des elektrochemischen Transmembrangradienten und können somit die zelltötende Wirkung dieser Peptide erklären [75, 76, 77, 78, 79]. Die Porenbildung entzieht den empfindlichen Organismen ihre Energiequelle und ergibt erhöhten Wasser- und Ionenfluss quer durch die Membranen mit gleichzeitiger Zellschwellung und Osmolyse [80, 81].

Obwohl es eine Menge experimenteller Daten für antimikrobielle Peptide gibt, ist ihr Wirkungsmechanismus immer noch etwas ungewiss [82, 77, 83, 79]. Viele antibiotische Peptide scheinen sich mit den Lipidkopfgruppen der Bakterienmembran zu verbinden. Dies führt zum Vorschlag des Carpet-Effekts [84], wobei die Peptide auf der Doppelschichtoberfläche adsorbiert werden und sich parallel zu dieser Oberfläche orientieren. Dies wird durch Experimente von Festkörper-NMR [68] mit Magainin und durch Fluoreszenzexperimente [49] bestätigt und weist durch die beobachtete Leckrate der Membran auf eine Zerstörung der Lipidmolekülordnung hin. Andererseits können antibiotische Peptide wie Magainin und Alamethicin bei hohen Konzentrationen senkrecht zu Lipiddoppelschicht eingelagert werden [67, 60], d.h. sie übernehmen eine Transmembranorientierung. Die Transmembran-Peptidhelizes können sich dann aggregieren, um wassergefüllte Poren in Lipiddoppelschichten zu bilden [85].

Im Umgang mit antibiotischen Peptiden zeigen elektrophysiologische Experimente eine schrittweise Leitwerterhöhung quer durch die Lipiddoppelschichten. Diese Ergebnisse werden als Beweis für das Vorhandensein diskreter Ionenkanäle durch Bündelung der parallelen $\alpha$-Helizes interpretiert, die die Lipiddoppelschichten überspannen [86, 77]. Allerdings ist für diese alkalischen Peptide, die mit Lipidkopfgruppen stark wechselwirken, auch ein alternativer Mechanismus denk- 
bar. Um die Anordnung der wassergefüllten Poren und die spezifische Wechselwirkung der Peptide mit Lipidkopfgruppen zu erklären, wurde die Bildung von Toroidporen vorgeschlagen [60]. In diesem Mechanismus nimmt ein $\alpha$-Helixpeptid eine Orientierung senkrecht zur Oberfläche der Lipiddoppelschicht ein, behält jedoch wegen der lokalen Reorganisierung der Lipidwicklung eine enge Wechselwirkung mit den Lipidkopfgruppen über seine gesamte Länge bei. Dies resultiert in einer wässrigen Pore, durch die Ionen fließen können, und führt zu Zellendurchdringung der Lipidschicht und zum etwaigen Zelltod. Die molekulare Struktur des Peptids unterscheidet sich jedoch von derjenigen der $\alpha$-Helixbündeln, die auf andere Weise in intakte Lipiddoppelschichten eingelagert werden, ziemlich stark. So kann man zwischen kanalbildenden Peptiden wie Alamethicin und alkalischen antibiotischen Peptiden wie Magainin 2 unterscheiden. Die ersteren erzeugen $\alpha$-Helixbündel und die letzteren bilden einen Teppich von oberflächengebundene $\alpha$-Helizes, die bei einer hinreichend hohen Peptidkonzentration zur Toroidporenbildung durch lokale Reorganisierung der Lipiddoppelschichten führen können [79]. Außerdem haben H.W. Huang u.a. durch Röntgenbeugungsexperimente bei niedriger Peptidkonzentration sowohl mit Alamethicin als auch mit Magainin 2 einen Membranverdünnenden Effekt beobachtet [87, 73]. Darüber hinaus berechnete man die so genannte Helix-Peaks (Strukturfaktoren der Helix) entlang der Helixachse im reziproken Raum, und verglich dies mit einem Röntgenbeugungsbild zur Bestimmung der Orientierung der Peptidhelix [88].

Um die antibiotische und porenbildende Aktivität membranaktiver Peptide zu erklären, wurden urspünglich zwei allgemeine Mechanismen vorgeschlagen, nämlich das Barrel-Stave- [89] und das Carpet-Modell [84]. Darüber hinaus wurden auch andere Modelle, deren Charakteristika in vielen Experimenten beobachtet wurden, ins Gespräch gebracht, nämlich das Wormholes-Modell, der detergent-like-Effekt und die In-plane-Diffusion [90, 5, 91, 92], Auch ein Zweizustände-Modell (two-state model) wurde angeregt [93].

\section{Das Barrel-Stave-Modell}

Der Barrel-Stave-Mechanismus beschreibt eine Ausbildung der Transmembrankanäle oder Transmembranporen durch Peptidbündel. Nach diesem Modell verbinden Peptide sich zuerst als Monomere oder Multimere mit Membranen; die Peptidmonomere mit niedriger Oberflächenkonzentration wechselwirken miteinander im gebundenen Zustand mit der Membran. Sie lagern sich dann in den hydrophoben Membrankern ein und bilden Poren in der Membran aus, dabei wechselwirken sie mit Membranlipiden. Progressive Rekrutierung zusätzlicher Peptidmonomere führt zu einer ständigen Porenvergrößerung. Das Durchsickern der intrazellulären Bestandteile durch diese Poren verursacht den Zelltod. Die helikale Achse der Peptide steht mehr oder weniger senkrecht zur Membranoberfläche. Zur Porenbildung sollten die eingelagerten Moleküle besondere Strukturen haben, wie z.B. eine amphiphile oder hydrophobe $\alpha$-Helix, ein $\beta$-Sheet oder beide zusammen [94]. Es ist aber für eine einzelne amphiphile $\alpha$-Helix energetisch ungünstig, als Monomer die Membrane quer zu überspannen, deshalb müssen sich solche Monomere kollektiv in die Membran einlagern. Die eingesetzten Peptide ordnen sich dann in der Membran so an, dass die hydrophilen Seiten der Peptide zum Poreninneren hin orientiert sind und die hydrophoben Seiten nach außen zeigen, anschließend sind die Peptide zwischen den hydrophoben Lipidketten verankert. Da sich 


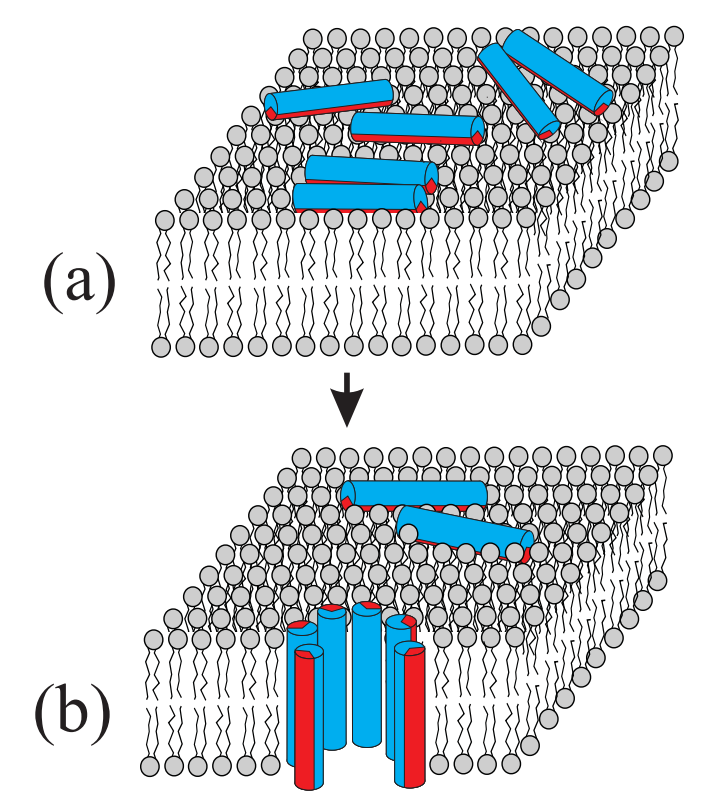

Abbildung 2.9: Eine schematische Darstellung des Barrel-Stave-Modells. Die Peptidmonomere werden durch einen Zylinder dargestellt, die graue Fläche stellt die hydrophile Oberfläche und die schwarze Fläche die hydrophobe Oberfläche der Peptidhelix dar. (a) Die Peptide versammeln sich zuerst auf der Membranoberfläche; (b) dann lagern die Peptide in den Membrankern ein und es folgt eine Aggregation der zusätzlichen Peptidmonomere [94].

solche Peptide in den hydrophoben Membrankern einlagern, sollten sie zwei wichtige Eigenschaften haben [94]. Erstens, ihre Wechselwirkung mit der Zielmembran sollte überwiegend hydrophob sein. Zweitens, wenn sie eine amphiphile $\alpha$-Helix-Struktur annehmen, sollte ihre Nettoladung entlang des Peptidrückgrats nahe Null sein. Sie können alternativ auch überwiegend aus hydrophoben Aminosäuren bestehen [95]. Als Konsequenz dieser Eigenschaften verbinden sich die Peptide ungeachtet der Membranladung mit Phospholipidmembranen, und folglich sollten sie für Bakterienebenso wie für normale Säugetierzellen giftig sein. In der Tat wurde gezeigt, dass Alamethicin Bakterien und rote Blutkörperchen durch den Barrel Stave-Mechanismus tötet [96, 97].

Tieleman u.a. haben Poren von Alamethicin in Lipidmembranen durch molekulardynamische Simulation untersucht und festgestellt, dass Alamethicin Poren wie im Barrel-Stave-Modell ausbilden [98]. Abb.2.10zeigt eine Draufsicht und Seitenansicht einer Pore, die durch 8 Alamethicinmoleküle in der POPC-Membran ausgebildet wurde, die stabilste Pore ist aber ein Hexamer, während 4 Alamethicinmoleküle keine stabile Pore ausbilden.

\section{Das Wormhole-Modell}

Frühe Studien über antibiotische Peptide gehen davon aus, dass diese vermutlich durch Transmembranporenbildung per Barrel-Stave-Modell Mikroorganismen töten [51]. Aber die Wechselwirkung bestimmter antibiotischer und lytischer Peptide, z. B. Magainin 2 mit den Membranen sind deutlich von der Barrel-Stave-Porenbildung zu unterschieden. Um die Aktivität solcher Peptide zu beschreiben, wurde das Wormhole-Modell (oft auch Toroidal-Modell genannt) entwickelt 


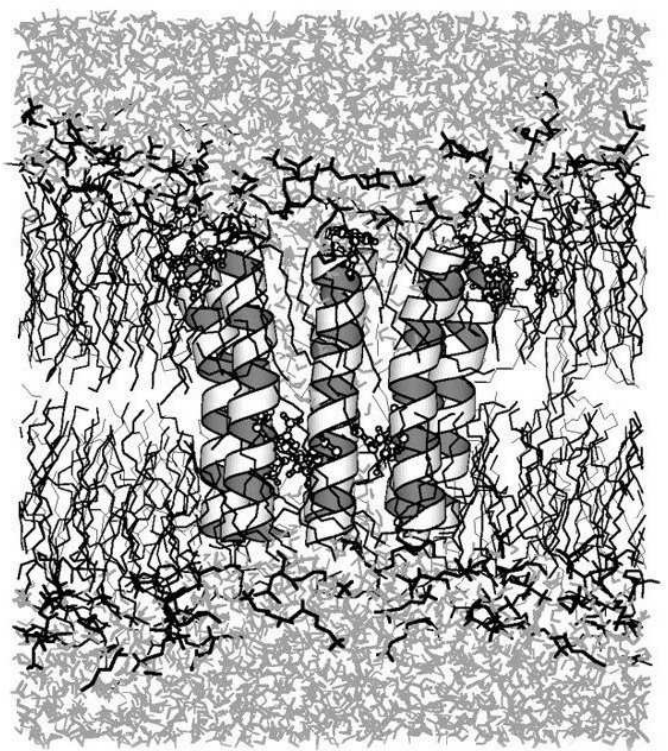

(a)

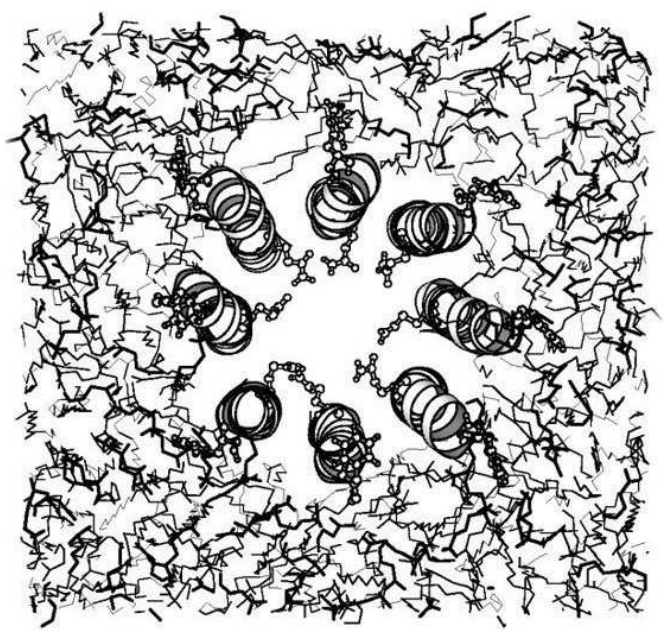

(b)

Abbildung 2.10: Die von 8 Molekülen des Alamethicin ausgebildete Pore, die sich aus MD-Simulation ergeben hat [98]. (a) Seitenansicht und (b) Draufsicht der Pore. Das Alamethicin wurde hier als ein Band dargestellt, die Kopfgruppe des Lipidmoleküls wurde hellgrau gezeichnet.

[23, 99, 60]. Im Gegensatz zum Barrel-Stave-Modell, bei dem nur Peptide an der Porenbildung beteiligt sind, bestehen beim Wormhole-Modell die Poren aus Peptiden und Lipiden. Das Wormhole-Modell unterscheidet sich vom Barrel-Stave-Modell im Wesentlichen dadurch, dass die Peptide immer mit den Lipidkopfgruppen verbunden sind, selbst wenn sie senkrecht in die Lipiddoppelschichten eingelagert werden. Bei der Porenbildung verbiegt sich die Lipidmonoschicht kontinuierlich von der Ober- zur Unterseite in Art und Weise einer Toroidbohrung, so dass die Pore durch die Peptide und die Lipidkopfgruppen gesäumt wird [100]. In der Tat wird dieses Modell dadurch bestätigt, dass die amphiphilen Peptide einen schnellen Übergang der Lipide zwischen den beiden Schichten der Lipiddoppelschicht induzieren [101]. Der Durchmesser der Poren wird in der Größenordnung von 20-30 Å geschätzt [60, 6].

Murzyn u.a. konstruierten die Pore aus 5 Molekülen von Magainin 2 in einer hydratisierten POPE/POPG(3:1)-Membran mit einer entsprechenden Anzahl von $\mathrm{Na}^{+}$-Ionen nach dem Wormhole-Modell und führten eine MD-Simulation durch [102]. Die MD-Simulation ergibt tatsächlich eine Toroidal-Pore von Magainin 2. In Abb. 2.12 wird die konstruierte Pore und das Ergebnis der MD-Simulation dargestellt.

\section{Das Carpet-Modell}

Das Carpet-Modell wurde zum ersten Mal von Pouny zur Beschreibung des Wirkungsmodus eines Peptidantibiotikums (Dermaseptin S) vorgeschlagen [84], und später zur Beschreibung des Wirkungsmodus anderer antibiotischer Peptide eingesetzt. Nach diesem Modell verbinden sich die Peptide zuerst mit der Oberfläche der Zielmembran. Die Membran wird dann durch teppichähn- 


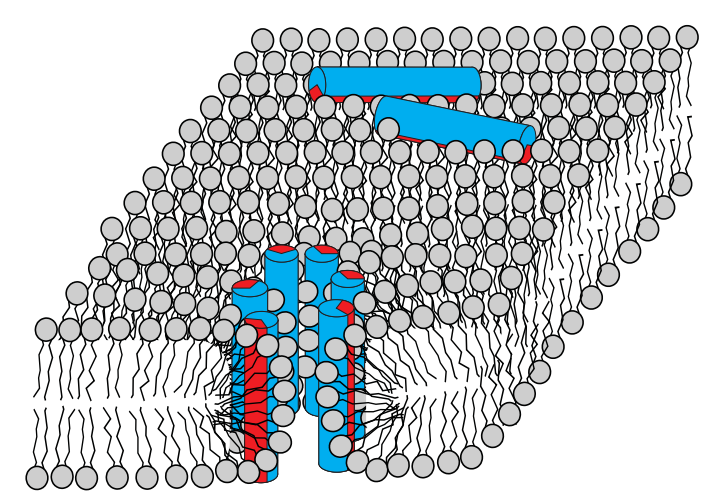

(a)

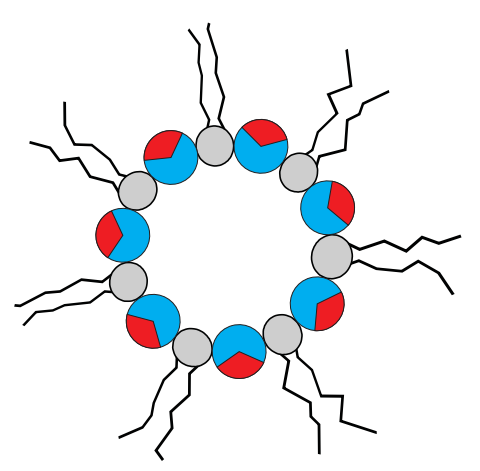

(b)

Abbildung 2.11: Schematische Illustration des Wormhole-Modells. (a) Die durch Peptide erzeugte positiven Krümmung spannt die Membran durch Expandierung der Kopfgruppen an und bildet Toroidporen aus, bei denen auch Lipidkopfgruppen beteiligen sind; (b) Aufsicht auf die Pore [5].

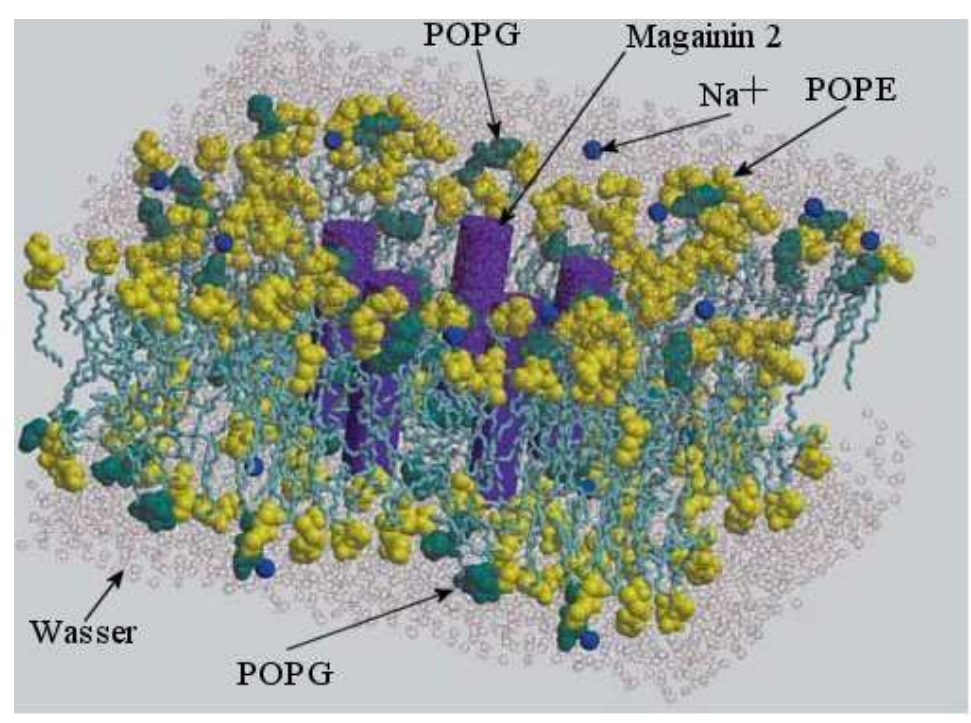

(a)

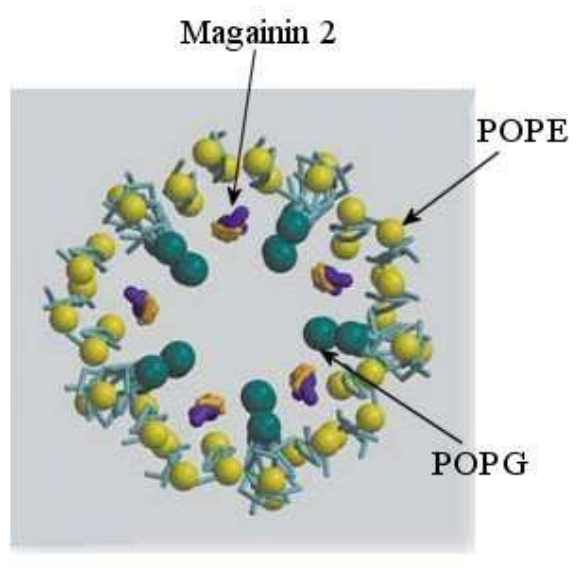

(b)

Abbildung 2.12: Die von 5 Molekülen aus Magainin 2 ausgebildete Pore, die durch MD-Simulation bestätigt wurde [102]. (a) Seitenansicht auf die Pore, hier wurde das Molekül des Magainins als Zylinder gezeichnet; (b) Aufsicht auf die konstruierte Pore.

liche Peptidcluster bedeckt. Die Anfangswechselwirkung mit der negativ geladenen Zielmembran wird elektrisch geführt, und deshalb sollten die Peptide positiv geladen sein. Nachdem eine Grenzkonzentration erreicht ist, durchdringen die Peptide im nächsten Schritt die Membran. Folglich wird die Membran in Stücke zerrissen, dies bedeutet eine Mikrobenzelllyse [79]. Die hohe lokale Konzentration auf der Membranoberfläche hängt von der Zielmembransorte ab. Eine lokale, teppichähnliche Ausbildung kann entweder nach Bedeckung der ganzen Membranoberfläche mit Peptiden oder alternativ nach Verbindung der Peptide mit der Membranoberfläche vorkommen. Der mögliche Ablauf in diesem Modell wird folgendermaßen beschrieben [79]: (a) Vorzugsweise 
(a)

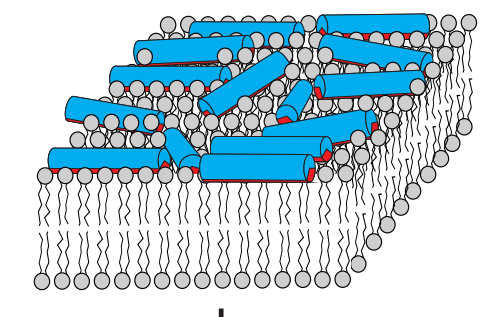

(b)

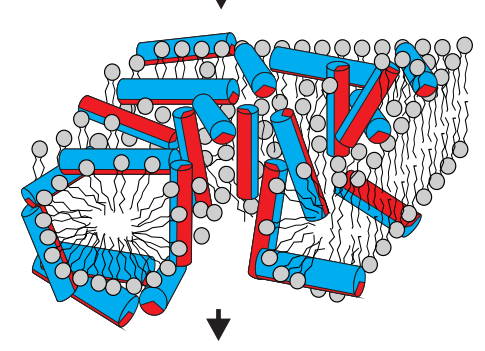

(c)

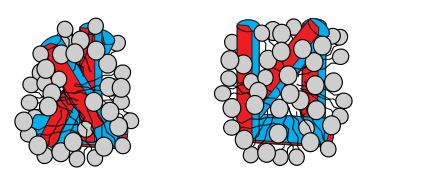

Abbildung 2.13: Schematische Illustration des Carpet-Modells; (a) Die Peptide werden an die Membranoberfläche gebunden, ihre hydrophobe Oberfäche orientiert sich zur Membran und ihre hydrophile Oberfäche zu wässrigen Lösung; (b) Wenn eine kritische Peptidkonzentration erreicht ist, wird die Membran durchdrungen und es können vorübergehend Poren gebildet werden; (c) Es kann auch zur Auflösung der Membran kommen [94].

wechselwirken die positiv geladenen Peptidmonomere mit den negativ geladenen Phospholipiden, (b) die amphiphilen $\alpha$-Helixpeptidmonomere lagern sich auf der Membranoberfläche an, so dass die positiven Ladungen der Basisaminosäuren mit den negativ geladenen Phospholipidkopfgruppen oder mit Wassermolekülen wechselwirken, (c) Molekülrotation führt zu Neuausrichtung der hydrophoben Aminosäurereste in Richtung des hydrophoben Membrankerns, (d) und die Membran wird durch Zerstörung der Lipiddoppelschichtkrümmung in kleine Mizellenformen aufgelöst. Ein möglicher Vorgang vor der Zerstörung des Membranaufbaus sind vorübergehende Poren in der Membran. Durch die Poren können Moleküle mit kleinem Molekulargewicht passieren, bevor eine komplette Membranlysis eintritt. Die Poren können den Durchgang der Peptidmoleküle von der äußeren Membran in die innere Membran z.B. von Gram-negativen Bakterien zulassen [103], wie in Abb. 2.13 schematisch dargestellt ist. Solche Poren wurden durch das Wormhole-Modell (oder das Toroidal-Modell) beschrieben [23, 60, 99].

Dieses Modell beschreibt eine Situation, in der die Peptide während des gesamten Prozesses der Membrandurchdringung immer in Verbindung mit der Lipidkopfgruppe sind. Außerdem kann ein Peptid, das die Membran über den carpet-Mechanismus durchdringt, unterschiedliche Sekundärstrukturen und Längen annehmen. Peptide, die über den carpet-Mechanismus wirken und in Verbindung mit den säuerlichen Phospholipidkopfgruppen bleiben, sollten hoch positiv geladen sein, und sich entlang der Peptidkette verbreiten. Darüber hinaus sollten sie sich nur sehr schwach oder gar nicht mit zwitterionischen Membranen verbinden [94] und als Folge sind sie nicht hämolytisch (hämolysierend). Überdies sollte keine bestimmte Struktur erforderlich sein, solange ein bestimm- 
tes Niveau der hydrophoben Eigenschaft vorliegt und die Zahl der positiven Ladungen erhalten bleibt [94]. Das Vorhandensein der negativ geladenen Membranlipide ist wichtig für die Bildung des Peptidclusters, da solche Lipide eine Verringerung der abstoßenden elektrostatischen Kraft zwischen positiv geladenen Peptiden bewirken können [90].

\section{Der Detergent-Like-Effekt}

Die cytotoxische Aktivität wird einfach durch ihre doppelschichtzerstörenden amphiphilen Eigenschaften erklärt. Lipiddoppelschichtzerfall ergibt den Verlust der Membranbarriere, den Zusammenbruch der transmembranen elektrochemischen Gradienten und den Verlust der zellplasmatischen Bestandteile sowie die Störung des Energiemetabolismus der lebenden Zelle. Für die Zelle bedeutet dies letztlich deren Tod. Eine Untersuchung zur Zellzerstörungs- und Zelllysewir-

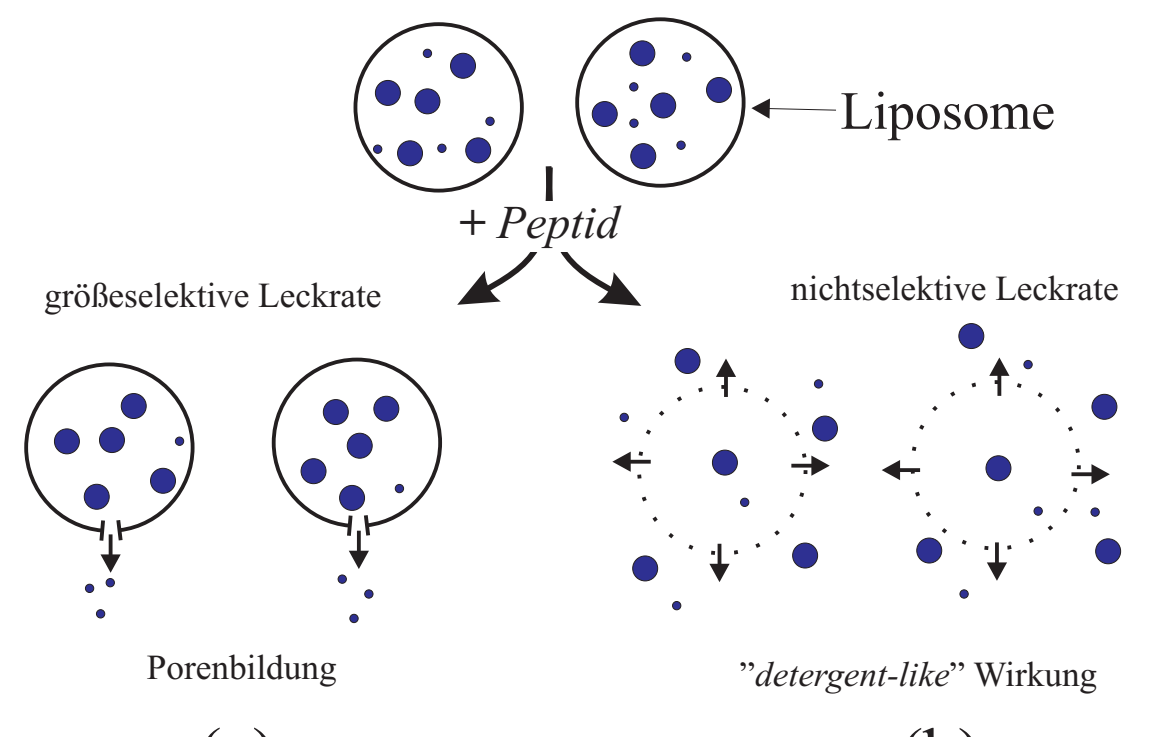

(a)

(b)

Abbildung 2.14: Schematische Darstellung der Vesikeldurchdringung durch (a) Porenbildung- und (b) durch den "Detergent-Like"-Mechanismus. Der prinzipielle Unterschied ist die Selektivität des Durchlassinhaltes. Der "Detergent-Like"-Mechanismus bedeutet eine komplette Auflösung der Vesikelmembran bedeutet [104].

kung von $\alpha$-Hämolysin (Proteintoxin) in Vesikeln zeigt, dass das $\alpha$-Hämolysin keinen Membranrezeptor erfordert, um seine Wirkung zu entfalten. Eine Leckage durch nichtosmotische detergensähnliche Lipiddoppelschichtzerreißung tritt auf, die durch das Protein verursacht wird [105]. Ein gleicher Effekt wurde auch bei Melittin in POPG-Vesikel und Triton X-100 oder Octylglycosid in Phosphatidylserin-Vesikel beobachtet [104, 106, 107]. Diese Leckage hat bei Freigabe des Membraninhalts keine selektive Funktion, d.h. sie ist unabhängig von ihrer Größe [104]. Solche Wirkung der nichtselektiven Leckage wird oft als detergensähnlicher (engl: detergent-like) Effekt bezeichnet [105, 77, 108, 109]. Die Peptide bilden in diesem Modell keine Transmembranporen, sondern verbinden sich eher mit der Membranoberfläche und bedecken die Membran mit 
einer carpet-ähnlichen Form, dann lösen sie die Membran wie ein Detergens auf. Man schlug deshalb folgende mögliche Schritte zur Beschreibung des Modells vor [108]: Die Peptidmonomere verbinden sich vorzugsweise mit negativ geladenen Phospholipiden, sie lagern sich dann auf der Membranoberfläche an, so dass die positiv geladene Basisaminosäuren mit den negativ geladenen Lipidkopfgruppen oder mit Wassermolekülen wechselwirken. Die Reorganisation der Moleküle führt zu Reorientierung der hydrophoben Aminosäurereste zum hydrophoben Membrankern hin, und anschließend zerstören sie den Lipidaufbau. Dadurch wird die Membran zerrissen.

In ähnlicher Weise hängt der Ausfluss von Fluoreszenzfarbstoff aus künstlich hergestellten Vesikeln mit der membranauflösenden Wirkung von membranaktiven Peptiden zusammen. Der Ausfluss von Fluoreszensfarbstoff tritt ab einer kritischen Konzentration von 3 mol\% auf [107]. Auch Detergenzien wie Triton X-100 oder Octylglycosid entfalten bei dieser Konzentration ihre Wirkung [107, 23].

\section{Das in-plane-Diffusions-Modell}

Bei Röntgenbeugungsexperimenten wurde beobachtet, dass die Wechselwirkung zwischen Membran und amphiphilen Peptidhelizes im Bereich von etwa $120 \AA$ signifikante Eigenschaftsstörungen reiner Lipiddoppelschichten sowie die Verringerung der durchschnittlichen Doppelschichtdicke [73, 110, 111] ergibt. Durch das Aufzwingen amphiphiler Peptide auf

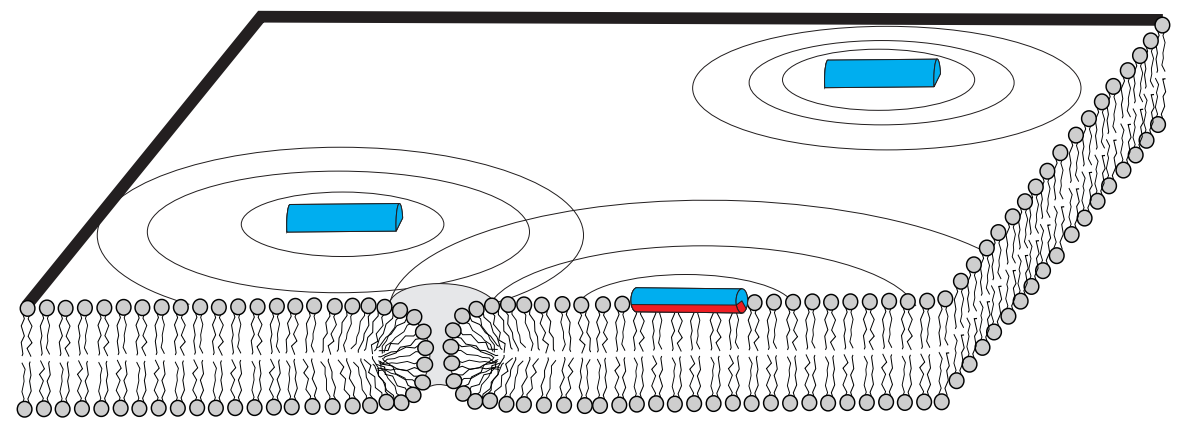

Abbildung 2.15: Schematische Darstellung des in-plane-Diffusionsmodells: Die Peptidmonomere werden durch die "Doppelschichtoberfläche mit elastischem Verzerrungsfeld" umgeben, sie diffundieren entlang dieser und induzieren eine vorübergehende Membranöffnung, wenn die metastabilen Regionen sich überlappen [90].

die Membranoberfläche entsteht eine Membrankrümmung [90][111]. Man schlägt vor, dass der Krümmungsdruck auf die Lipidmembran einen metastabilen Zustand in Umgebung der Peptide verursacht. Auch bei niedrigeren Konzentrationen der amphiphilen Peptide wurde ein solcher Effekt beim Röntgenbeugungsexperiment beobachtet [112]. Um diesen Effekt der Lipid-Peptid-Wechselwirkung zu erklären, lässt sich ein alternatives Modell, das keine Ausbildung der Peptidaggregate erfordert, einführen. Wie die Messung mit FET (fluorescence energy transfer) [113] zeigt, diffundieren die Peptidmoleküle in der Membran kontinuierlich und ändern ihren Abstand zueinander, dann orientieren sie sich aufeinander. Wenn diese diffundierende Moleküle einen kritischen Abstand unterschreiten, wird die Destabilisierung lokal verstärkt 
und ergibt eine transiente Öffnung der Lipiddoppelschicht. Dabei wird ein vergleichsweise niedriges Peptid/Lipid-Verhältnis benötigt, um den Ionengradienten quer durch die Zellmembran zu zerstreuen oder um antibiotische Wirkung zu entwickeln [79, 114, 54, 115]. Das in-plane Diffusions-Modell wurde deshalb dort vorgeschlagen, wo Lipid-vermittelte Kanalbildung auf dem Krümmungsdruck an der Lipidmembran mit eingelagerten amphiphilen Peptiden basiert. Dieses Modell ist unabhängig von kationischer Peptidaggregation, die entropisch und elektrostatisch ungünstig ist, selbst wenn negativ geladene Phospholipide vorhanden sind [77]. Peptiddiffusion innerhalb der Membran verursacht eine Überlappung der Instabilitätsregionen und eine Anreicherung der Lipidaufbaustörungen, dabei können vorübergehende Membranöffnungen auftreten [77]. Dies wird experimentell für Cecropin [114, 116, 97, 117] und für Magainin 2 bei Konzentrationen $\leq 5 \mathrm{Mol} \%$ beim FET-Experiment (Fluorescence energy transfer) [118] beobachtet. Unterstützt wird das in-plane-Diffusions-Modell durch weitere Beobachtung von kurzen Peptiden wie z. B. Mastoparan (14 Aminosäuren) [119] oder eine Cecropin-Melittin-Mischung [120]. Eine Reihe synthetischer Peptide der Länge aus 8-14 Aminosäuren [121, 122, 123] zeigen auch eine kanalähnliche Ausbildung, obwohl diese Peptide zu kurz sind, um die Membran durchqueren zu können.

\subsection{Freie-Energie-Betrachtung von Peptid/Lipid-Modellsys- temen}

Fundamentales Verständnis der Energetik im Peptid/Lipid-System ist ein zentrales Problem in der Membranbiophysik [124]. Dies bezieht sich vor allem auf die Wechselwirkung zwischen antibiotischen Peptiden und Zellmembranen. Zwischen der Lokalisierung der Peptide in der Membran und dem Energiebeitrag zur Verbindung mit der Membran gibt es eine starke Beziehung. Beispielsweise entsteht die Energieabgabe der Verbindung zwischen Alamethicin und der Membran hauptsächlich aus seiner Wechselwirkung mit hydrophoben Lipidkettenregionen [44]. Es ist daher hilfreich, die freie Energie nach der Lage der Peptide in der Membran zu betrachten. Nir Ben-Tal und seine Kollegen haben ein Continuum Solvent Model auf Basis der Thermodynamik entwickelt. In diesem Modell wird der Energiebeitrag in Abhängigkeit von der Peptidsituation behandelt. Danach kann der totale Freie-Energie-Unterschied $\Delta G_{t o t}$ bezüglich der zwei Situationen, nämlich des Peptids in der Membran und des Peptids in wässriger Umgebung, als Summe folgender Einzelteile geschrieben werden: Die elektrostatische $\left(\Delta G_{e l c}\right)$ und nichtpolare $\left(\Delta G_{n p}\right)$ Energiedifferenz auf Grund von Solvatisierung, Energiedifferenz auf Grund von Peptidkonformation $\left(\Delta G_{c o n}\right)$, Energiedifferenz auf Grund von Peptidimmobilisierung $\left(\Delta G_{i m m}\right)$, Energiedifferenz auf Grund von Lipidstörung $\left(\Delta G_{l i p}\right)$, Energiedifferenz auf Grund von Membrandeformation $\left(\Delta G_{d e f}\right)$ und Energiedifferenz auf Grund von Änderung der Dissoziationsneigung ( $\mathrm{pK}_{a}$-Wert auch $\mathrm{pK}$-Wert genannt) der titrierbaren Aminoreste $\left(\Delta G_{p k a}\right)$ [125, 126, 127, 128, 129, 130, 131, 124], also:

$$
\Delta G_{t o t}=\Delta G_{e l c}+\Delta G_{n p}+\Delta G_{c o n}+\Delta G_{i m m}+\Delta G_{l i p}+\Delta G_{d e f}+\Delta G_{p k a}
$$




\section{Solvatisierungsenergie:}

Die beiden Energieabgaben $\Delta G_{\text {elc }}$ und $\Delta G_{n p}$ zusammen werden als Solvatisierungsenergie $\Delta G_{\text {sol }}$ bezeichnet, die die Übergangsenergie des Peptides von Wasser zur Lipidkettenregion beschreibt, also:

$$
\Delta G_{s o l}=\Delta G_{e l c}+\Delta G_{n p}
$$

$\Delta G_{s o l}$ enthält die elektrostatische Energieabgabe, die sich aus der Änderung der Dielektrizitätskonstante der Lösung ergibt, sowie die Energiedifferenz wegen des van-der-Waals-Effekts. Der Hauptteil von $\Delta G_{\text {sol }}$ resultiert aus der Wechselwirkung zwischen Peptid und Lipidkettenregionen. Durch mean-field-Kalkulation stellt man fest, dass für hydrophobe Peptide $\Delta G_{\text {sol }}$ der dominierende Anteil von $\Delta G_{t o t}$ ist, und sein Wert für kurze membranaktive Peptide mit einer Länge von ca. 20 Aminosäuren beträgt typischerweise -41.868 bis $-83.736 \mathrm{~kJ} / \mathrm{mol}$ [131, 44]. Das negative Vorzeichen der Energie bedeutet eine spontane Reaktion des Peptids und eine Energieabgabe des Peptid/Lipid-Systems, damit wird das System stabiler als vorher.

\section{Konformationsenergie:}

Der Transfer eines Peptides von einer polaren Umgebung (z. B. Wasser) zu einem wenig polaren Medium (z. B. eine Membran) kann zur Konformationsänderung des Peptides führen. Diese Konformationsänderung erfolgt normalerweise durch Erniedrigung der Energie des Transfers für die ungesättigte H-Brücke, wenn das Peptid von wässriger Umgebung zur Lipiddoppelschicht verlegt wird [125, 132]. Im Allgemeinen ist $\Delta G_{c o n}$ für kurze Peptide bis zur Länge von 15 Aminosäureresten in wässriger Umgebung klein und kann manchmal sogar vernachlässigt werden.

\section{Immobilisierungsenergie:}

Jeder Verbindungsvorgang, wie etwa das Einlagern der Peptide in die Lipiddoppelschicht, hat Translationsfreiheitsgrade und Rotationsfreiheitsgrade; ein Ligand in Lösung zum Beispiel hat drei Translationsfreiheitsgrade und drei Rotationsfreiheitsgrade. Abhängig von der Ligandmolekülkonzentration ist ein bestimmtes Volumen $(V)$ des Ligandmoleküls und sein ganzer Orientierungsraum (d.h. das Integral über die drei Euler-Winkel: $\int_{0}^{\pi} \sin \theta d \theta \int_{0}^{2 \pi} d \phi \int_{0}^{2 \pi} d \psi=8 \pi^{2}$ ) zugänglich für den Verbindungsvorgang, wenn es in Lösung frei ist. Wegen der Verbindung mit der Membran können manche Freiheitsgrade begrenzt sein, deshalb sind nur ein Teilvolumen $\left(V_{b}\right)$ des Ligandmoleküls und ein Teilorientierungsraum $(\gamma)$ für das Ligandmolekül erreichbar. Außerdem ist die Energieabgabe der Immobilisierung $\Delta G_{\text {imm }}$ gleich der Summe der Energieabgabe aus dem beschränkten Translations- $\left(\Delta G_{t r}\right)$ und Rotationsfreiheitsgrad $\left(\Delta G_{r o t}\right)$ [133]:

$$
\Delta G_{i m m}=\Delta G_{t r}+\Delta G_{r o t}=-k T \ln \left(V_{b} / V\right)-k T \ln \left(\gamma / 8 \pi^{2}\right) .
$$

Es ist aber relativ schwierig, $\Delta G_{\text {imm }}$ direkt zu messen, weil $\Delta G_{\text {imm }}$ nicht die einzige entropiebasierte Energieabgabe ist. Zum Beispiel beinhalten $\Delta G_{s o l}$ und $\Delta G_{c o n}$ gewöhnlich auch wichtige entropische Komponenten [124]. Man hat daher eine theoretische Abschätzung von $\Delta G_{i m m} \approx$ 
$62.802 \mathrm{~kJ} / \mathrm{mol}$ für die Proteindimerisierung erhalten, in dem $V_{b}$ und $\gamma$ (durch das root mean square fluctuations-Verfahren) in Proteinkristallen berechnet wird [134]. Weiterhin hat man versucht, den $\Delta G_{i m m}$-Wert mit verschiedenen Peptiden in Lipiddoppelschichten zu ermitteln, z. B. $\Delta G_{i m m} \approx$ $15.491 \mathrm{~kJ} / \mathrm{mol}$ für das Einlagern einer $\alpha$-Helix von Polyalanin mit 25 Aminosäureresten in die Lipiddoppelschicht [131, 135] und $\Delta G_{\text {imm }} \approx 5.442 \mathrm{~kJ} / \mathrm{mol}$ für elektrostatisch getriebene Adsorption von positiv geladenen Peptiden auf einer Membran mit negativ geladenen Lipiden [136]. Diese beiden Werte sind viel kleiner als die theoretische Abschätzung beim Verbindungsvorgang. Die Ursache dafür ist die Steifheit der Peptide, so dass die Freiheitsgrade der Peptidkonfigurationen beschränkt wurden. Man hat sich deshalb für $\Delta G_{i m m} \approx 8.374 \mathrm{~kJ} / \mathrm{mol}$ in einem solchen Fall entschieden [137, 138]. Das positive Vorzeichen der Energie bedeutet eine Energieaufnahme durch das Peptid/Lipid-System und weist darauf hin, dass die Reaktion des Peptids nicht spontan ist. Das System wird instabiler als vorher.

\section{Lipidstörungsenergie:}

Das Einlagern der Peptide in die Lipidmembran kann die Lipidketten in ihrer Umgebung versteifen, folglich wird die Konformationsentropie des Systems erniedrigt. Diese Wechselwirkung zwischen den Peptiden und den Lipiden resultiert aus der niedrigen Elastizität (Freiheitsgrade der Kettenkonformation) der Membran, und liefert einen positiven Beitrag zu $\Delta G_{t o t}$, die dadurch abgegebene freie Energie wird als $\Delta G_{l i p}$ bezeichnet. Für das Einlagern einer $\alpha$-Helix von Polyalanin wird $\Delta G_{\text {lip }} \approx 9.63 \mathrm{~kJ} / \mathrm{mol}$ geschätzt [135, 131]. Das positive Vorzeichen der Energie weist darauf hin, dass Energie für die Reaktion des Peptids zugeführt werden muss, das bedeutet auch eine Energieaufnahme durch das Peptid/Lipid-System. Das System wird durch die Einlagerung des Peptids in die Lipidmembran instabiler als vorher.

\section{Membrandeformationsenergie:}

Das Einlagern der Peptide in die Lipiddoppelschicht führt auch zu ihrer Deformation, damit die Lipidkettenregion sich der hydrophoben Strecke des Peptides anpassen kann [139]. Diese Deformation erfolgt durch Kompression und Expansion der Lipidketten und geht mit Energieabgabe $\Delta G_{d e f}$ einher. $\Delta G_{d e f}$ wurde von einigen Forschungsgruppen mit unterschiedlichen Methoden ermittelt. Die Werte sind aber ähnlich, z.B. bei einem hydrophoben Peptid mit einem Helix-Durchmesser von $5 \AA$ und einer Länge von $34 \AA$ beträgt $\Delta G_{d e f} \approx 2.721 \mathrm{~kJ} / \mathrm{mol}$ [130].

\section{Dissoziationsenergie der Aminosäurereste:}

Der Übergang eines geladenen Aminosäurerestes von Wasser zur Lipiddoppelschicht bezieht eine Energieabgabe aus elektrostatischer Desolvatisierung mit ein. Diese Energieabgabe kann durch Protonisierung oder Deprotonisierung des Aminosäurerestes erheblich verringert werden, was zu seiner Neutralisierung führt [127]. Daher kann die Peptid-Membran-Verbindung Änderungen im Protonisierungszustand der titrierbaren Aminosäurereste im Peptid verursachen. Diese Änderungen können eine direkte Konsequenz der Peptidwechselwirkungen mit der polaren Kopfgruppen- 
region [140] oder der Lipidkettenregion sein [127]. Ohne Rücksicht auf die Ursache der Änderung im Protonisierungszustand einer Aminosäure kann die Energieänderung $\Delta G_{p k a}$ geschrieben werden als:

$$
\Delta G_{p k a}=-2.3 k T\left(p K_{a}-p H\right)
$$

wobei gilt: $k$ ist die Boltzmannkonstante, $T$ die absolute Temperatur und $p K_{a}$ die Gleichgewichtskonstante der Ionisierung (ein Maß für die Stärke einer Säure) für die Aminosäuren. Für die Neutralisierung der Asparagin- oder Glutaminsäure $\left(p K_{a}=4\right)$ bei neutralem $p H$ ist $\Delta G_{p k a} \approx 16.747$ $\mathrm{kJ} / \mathrm{mol}$ [124]. Das positive Vorzeichen der Energie bedeutet eine Energieaufnahme durch das Peptid/Lipid-System und weist darauf hin, dass die Neutralisierung der Asparagin- oder Glutaminsäure nicht spontan ist. Das System wird durch die Neutralisierung der Asparagin- oder Glutaminsäure instabiler als vorher.

Die totale Freie-Energie-Abgabe $\Delta G_{t o t}$ wurde mit $-15.072 \mathrm{~kJ} / \mathrm{mol}$ für Alamethicin bei einer Lipiddoppelschicht mit 30 A Dicke angegeben [44]. Das negative Vorzeichen der Energie bedeutet eine spontane Reaktion von Alamethicin und eine Energieabgabe des Peptid/Lipid-Systems. Durch das Einfügen von Alamethicin wird das System stabiler.

\subsection{Probenpräparation}

Die vorliegende Untersuchung verwendet zwei verschiedene Probenpräparationsarten. Zum einen wurden Lipid-Peptid-Systeme durch Spin-Coater-Verfahren auf Silizium-Substraten präpariert [141]. Diese Proben sind hochorientiert und besitzen wenige Lipiddoppelschichten $(2 \sim 30$ Doppelschichten). Der wesentliche Vorteil bei diesem Verfahren darin liegt, dass man Proben mit einer kontrollierbarer Anzahl von Lipiddoppelschichten präparieren kann. Zum anderen kommen dickere Lipidstapeln aus orientierten bzw. hochorientierten Membranen zum Einsatz. Solche Proben wurden nach einer Methode, die von Seul und Samon vorgeschlagen wurde [142], auf SiliziumSubstraten oder Glasscheiben präpariert. Sie liefern beim Streuexperiment ein verstärktes Streusignal, so dass die von Röntgenstrahlen reflektierte Intensität in Richtung $q_{z}$ und $q_{\|}$(siehe im Kapitel 3) klar getrennt werden kann. Dadurch kann man ungestörte Strukturinformation über das LipidPeptid-System in Richtung senkrecht zur Oberfläche von Lipiddoppelschichten gewinnen. Ziel der Präparation ist die Herstellung von Peptid/Lipid-Modellsystemen aus einem homogen auf dem Substrat verteilten Lipidfilm.

\subsubsection{Vorbereitung zur Präparation}

\section{Verwendete Materialien}

Für die Präparation der beiden Probensorten wurden die benötigten Lipide ausschließlich bei der Fa. Avanti Lipids (Avanti Polar Lipids, Inc. 700 Industrial Park Drive Alabaster, Alabama 350079105; USA) bestellt. Die Reinheit der Lipide ist $>99 \%$. Die verwendeten Peptide (Alamethicin und Magainin 2) wurden bei der Fa. Sigma Aldrich (Sigma-Aldrich Chemie GmbH München, 
Deutschland) gekauft, ihre Reinheit ist besser als $99 \%$.

Lipide: (Fa. Avanti Lipids, Reinheit >99\%)

- DLPC (1,2-Dilauroyl-sn-Glycero-3-Phosphocholin)

- DMPC (1,2-Dimyristoyl-sn-Glycero-3-Phosphocholin)

- DMPE (1,2-Dimyristoyl-sn-Glycero-3-Phosphoethanolamin)

- DMPG (1,2-Dimyristoyl-sn-Glycero-3-[Phospho- rac-(1-glycerol)] )

- DOPC (1,2-Dioleoyl-sn-Glycero-3-Phosphatidylcholin)

- DPPC (1,2-Dipalmitoyl-sn-Glycero-3-Phosphocholin)

- OPPC (1-Oleoyl-2-Palmitoyl-sn-Glycero-3-Phosphocholin)

- POPC (1-Palmitoyl-2-Oleoyl-sn-Glycero-3-Phosphocholin)

- POPS (1-Palmitoyl-2-Oleoyl-sn-Glycero-3-[Phospho-L-Serin])

- POPE (1-Palmitoyl-2-Oleoyl-sn-Glycero-3-Phosphoethanolamin)

Peptide: (von der Fa. Sigma Aldrich, Reinheit >99\%)

- Alamethicin (Produkt-Nummer: A4665)

- Magainin 2 (Produkt-Nummer: M7402)

Probenträger:

- Si-Substrat mit $25 \times 15 \mathrm{~mm}^{2}$, Dicke $\approx 625 \mu \mathrm{m}$, Richtung $<100>$ (von der Fa. Silchem Handelsgesellschaft mbH, Freiberg, Deutschland).

- Glasscheibe (Objektträger) (von der Fa. Paul Marienfeld GmbH \& Co. KG, LaudaKönigshofen, Deutschland)

\section{Reinigung und Ätzen der Probenträger}

Zuerst wurden die Silizium-Substrate so gut wie möglich gereinigt. Je nach verwendetem Lösungsmittel sollte die Oberfläche definiert hydrophil oder hydrophob sein. Dazu wurden die Substrate über 10 Minuten in einen Behälter mit dem organischen Lösungsmittel Methanol gelegt. Danach wurden sie einige Minuten in ein Ultraschallbad aus Methanol getaucht, um kleine Partikel aus der Substratoberfläche zu entfernen. Anschließend wurde ein Ultraschallbad mit Reinstwasser (MQ, Millipore, $\rho \geq 18 \mathrm{M} \Omega / \mathrm{cm}$ ) verwendet, um das organische Lösungsmittel Methanol aus den Substraten wegzuwaschen. Nach mehrmaliger Spülung mit Reinstwasser wurden bei manchen Proben, 
wenn eine hydrophile Substratoberfläche erforderlich war, die Substrate ca. 30 Sekunden in Ethanol mit 5Mol KOH oder 20 Sekunden im Plasma-Cleaner (Modell:PDC-002; Fa. Harrick Scientific Corporation 88 Broadway Ossining, NY 10562) geätzt. Danach folgte wieder mehrmaliges Waschen mit Reinstwasser. Zum Schluss der Reinigung wurden die Substrate durch Anblasen mit Stickstoffgas getrocknet.

\section{Herstellung der Stammlösungen}

Stammlösungen wurden mit verschiedenen Lösungsmitteln angefertigt. Die Lipide und Peptide wurden vorher genau gewogen, gegebenenfalls in einem bestimmten Molverhältnis gemischt, in ein Lösungsmittel (oder ein Lösungsmittelgemisch) bestimmten Volumens je nach beabsichtigter Konzentration gegeben und anschließend mit einem Schüttler gut homogen gelöst. Die genauen Berechnungen wurden mit dem Programm Mathcad durchgeführt. Im Anhang wird der Quelltext für die Berechnung bei der Präparation als Beispiel wiedergegeben. In Tabelle 2.5 wird die Lösbarkeit der Lipide und Peptide in einigen Lösungsmitteln aufgelistet. Um den Einfluss der Lösungsmittel auf die Probenqualität festzustellen, wurden mittels Lichtmikroskopie von den Proben aus reinem DMPC Bilder aufgenommen (Abb. 2.16). Die Aufnahmen zeigen, dass die mit der Mischung aus TFE/Chloroform präparierte Probe (a) besonders geeignet ist.

(a)

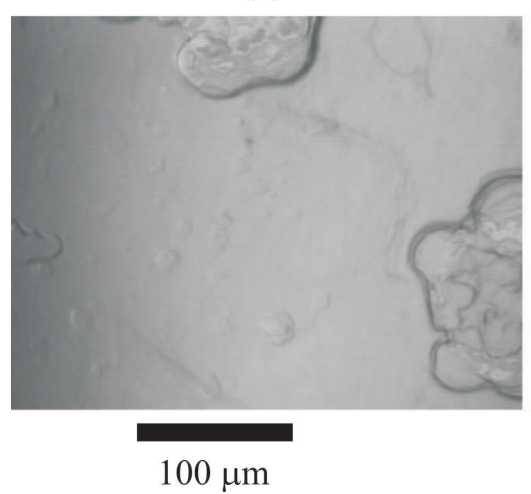

(b)

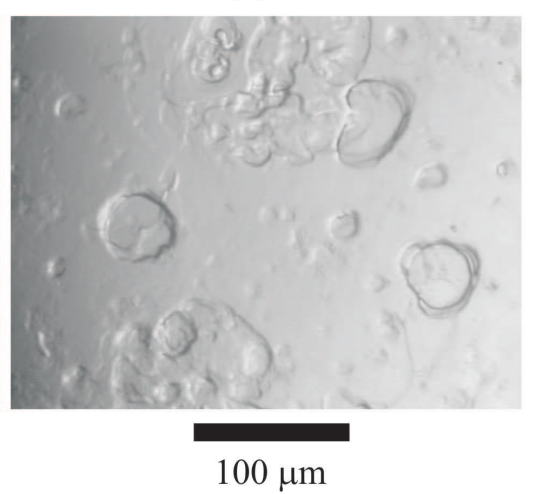

(c)

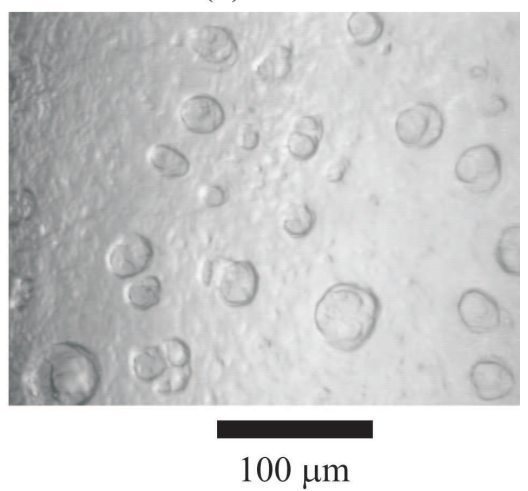

Abbildung 2.16: Lichtmikroskopie-Bilder der Proben aus reinem DMPC, die mit dem Lösungsmittel (a) TFE/Chloroform (Volumenverhältnis 1:1), (b) TFE und (c) Isopropanol präpariert wurden.

\subsubsection{Präparation von Membranstapeln mit geringer Doppelschichtzahl $(1 \leq \mathbf{N} \leq 20)$}

Das gereinigte Silizium-Substrat wurde auf einen Drehteller in der Lackschleuder (Spin-Coater, Modell: Delta 10, Fa. BLE Laboratory Equipment $\mathrm{GmbH}$ ) gelegt. Ein bestimmte Menge der Stammlösung $(0,1 \sim 0.2 \mathrm{ml})$ wurde sorgfältig auf die Substratmitte pipettiert. Die Lösung wurde auf der Substratoberfläche ausgestreut, anschließend wurde das Substrat beschleunigt. Gewöhnlich wird der Beschleunigungsvorgang in zwei Schritten durchgeführt: Zuerst wird die Stammlösung 


\begin{tabular}{|c|c|c|c|c|c|c|c|c|c|c|c|}
\hline & Isop. & TFE & Methan. & Ethan. & Chlorof. & $\begin{array}{c}\text { Chlorof. } \\
\text { /Methan. } \\
(1: 1)\end{array}$ & Acetone & $\begin{array}{c}\text { TFE } \\
\text { /Chlorof. } \\
(1: 1)\end{array}$ & $\begin{array}{c}\text { TFE } \\
\text { /Ethan. } \\
(1: 1)\end{array}$ & $\begin{array}{c}\text { HFI } \\
\text { /Chlorof. } \\
(1: 1)\end{array}$ & HFI \\
\hline DLPC & $\mathrm{Ja}$ & $\mathrm{Ja}$ & & & $\mathrm{Ja}$ & & & & & $\mathrm{Ja}$ & Ja \\
\hline DMPC & $\mathrm{Ja}$ & $\mathrm{Ja}$ & & & $\mathrm{Ja}$ & & & $\mathrm{Ja}$ & $\mathrm{Ja}$ & $\mathrm{Ja}$ & $\mathrm{Ja}$ \\
\hline DOPC & $\mathrm{Ja}$ & & & & & & & & & $\mathrm{Ja}$ & $\mathrm{Ja}$ \\
\hline DPPC & $\mathrm{Ja}$ & $\mathrm{Ja}$ & & & $\mathrm{Ja}$ & & & & & $\mathrm{Ja}$ & $\mathrm{Ja}$ \\
\hline OPPC & $\mathrm{Ja}$ & Nein & & & $\mathrm{Ja}$ & & & $\mathrm{Ja}$ & $\mathrm{Ja}$ & $\mathrm{Ja}$ & Ja \\
\hline DMPE & & Nein & & & $\begin{array}{c}\mathrm{Ja} \\
\text { (bis ca. } \\
1 \mathrm{mg} / \mathrm{ml} \text { ) }\end{array}$ & & & $\begin{array}{c}\mathrm{Ja} \\
\text { (nach } \\
24 \mathrm{~h})\end{array}$ & & $\mathrm{Ja}$ & Nein \\
\hline POPE & & Nein & & & & & & $\mathrm{Ja}$ & & $\mathrm{Ja}$ & $\mathrm{Ja}$ \\
\hline DMPG & & Nein & & & $\begin{array}{c}\mathrm{Ja} \\
\text { (bis ca. } \\
1 \mathrm{mg} / \mathrm{ml} \text { ) }\end{array}$ & & & Ja & & $\mathrm{Ja}$ & $\mathrm{Ja}$ \\
\hline POPS & & Nein & & & $\mathrm{Ja}$ & & & $\begin{array}{c}\mathrm{Ja} \\
\text { (TFE/chlorf. } \\
\geq 1 / 3 \text { ) }\end{array}$ & & $\mathrm{Ja}$ & Nein \\
\hline Alam. & $\mathrm{Ja}$ & & Nein & Nein & Nein & $\mathrm{Ja}$ & Nein & & & & \\
\hline Mag.2 & & $\begin{array}{c}\mathrm{Ja} \\
\text { (typisch } \\
\text { 1mg/ml) }\end{array}$ & & & Nein & & & $\mathrm{Ja}$ & $\mathrm{Ja}$ & $\mathrm{Ja}$ & $\mathrm{Ja}$ \\
\hline
\end{tabular}

Tabelle 2.5: Lösbarkeit der reinen Lipide und reinen Peptide in verschiedenen Lösungsmitteln.

durch relativ langsame Umdrehung des Drehtellers (500 Umdrehungen/min) auf der Substratoberfläche homogen verteilt. Im zweiten Schritt erzwingt die hohe Umdrehung (3000 U/min) ein schnelles Trocknen der Probe und entfernt die Reststammlösung. Nach der schnellen Verdampfung des Lösungsmittels wurde auf dem Substrat eine wohl definierte Anzahl von Lipiddoppelschichten hergestellt [141]. Um alle Spuren des organischen Lösungsmittels zu entfernen, wurden die Proben über 20 Stunden einem hohen Vakuum ausgesetzt. Danach wurden sie gekühlt und bis zu nächster Messung aufbewahrt.

\subsubsection{Präparation von Membranstapeln mit hoher Doppelschichtzahl (N $\geq 200)$}

Die gereinigten Silizium-Substrate (oder Glasscheiben) wurden auf einen absolut waagerechten Tisch gelegt, um die Stammlösung möglichst homogen auf den Substraten zu verteilen. Die Stammlösung eines bestimmten Volumens $\left(\sim 0.2 \mathrm{ml}\right.$ auf $25 \times 15 \mathrm{~mm}^{2}$ Substrat $)$ wurde dann gleichmäßig auf das Silizium-Substrat gespritzt. Danach verdunstete das Lösungsmittel langsam und das Lipid/Peptid-System konnte sich gut ordnen. Dieser Trocknungsvorgang dauerte meistens mehrere 
Stunden abhängig vom verwendeten Lösungsmittel. Nach dem Trocknen wurden die Lösungsmittelrückstände aus den Proben extrahiert, indem die Proben in einem Exsikkator über mehrere Stunden im Vakuum aufbewahrt wurden. Im Anschluss daran wurde die Hydrierung und Temperierung durchgeführt, um die Defekte in den Membranstapeln auszuheilen und die Lipiddoppelschichten sich besser orientieren zu lassen. Die Mosaizität $(\eta=F W H M / \sqrt{8 \ln 2})$ [143] der Membranstapeln konnte dadurch reproduziert auf weniger als $0.02^{\circ}$ herabgesenkt werden. Die Dicke des Lipidfilms $D$ sowie Anzahl $N$ der Lipiddoppelschichten auf dem Substrat können folgendermaßen berechnet werden:

$$
\begin{aligned}
D & =\frac{K_{L} V_{S} N_{A}}{M_{m o l}} \cdot \frac{V_{L}}{F_{\text {sub }}} \\
N & =\frac{K_{L} V_{S} N_{A}}{M_{m o l}} \cdot \frac{V_{L}}{F_{\text {sub }} d_{p p}},
\end{aligned}
$$

wobei die auftretenden Variablen folgende Bedeutung haben:

$D(\AA)$ : Dicke des Lipidfilms auf dem Substrat,

$N$ : Anzahl der Lipiddoppelschichten auf dem Substrat,

$K_{L}(\mathrm{~g} / \mathrm{ml})$ : Konzentration des Lipids in der Stammlösung,

$V_{S}(\mathrm{ml})$ : Menge der Stammlösung auf dem Substrat,

$M_{\text {mol }}(\mathrm{g} / \mathrm{mol})$ : Molmasse des Lipids,

$N_{A}:$ Avogadrozahl $=6.0221415 \cdot 10^{23}$,

$V_{L}\left(\AA^{3}\right)$ : Volumen eines Lipidmoleküls,

$F_{\text {sub }}\left(\AA^{2}\right)$ : Fläche des Substrates,

$d_{p p}(\AA)$ : Membrandicke in der Probe.

Für eine Probe aus DMPC mit $V_{L}=1100 \AA^{3}$ [144], $M_{m o l}=677.95 \mathrm{~g} / \mathrm{mol}, K_{L}=10 \mathrm{mg} / \mathrm{ml}, V_{S}=0.2$ $\mathrm{ml}, d_{p p}=34(\AA)$ (siehe Kapitel 6) und $F_{\text {sub }}=25 \cdot 15 \AA^{2}$ ergibt sich für $D$ ca. $5 \mu m$ und für $N$ ca. 1500 . 


\section{Kapitel 3}

\section{Reflektometer-Aufbau und Experiment}

Die Strukturuntersuchung biologischer Membranen erfordert experimentelle Methoden, die im Bereich der Nanometer-Längenskalen hinreichend empfindlich sind. Zu diesem Zweck wurde das Reflektometer an verschiedenen Messplätzen verwendet. In diesem Kapitel werden die eingesetzten Instrumente und Probenumgebungen erläutert. Dazu gehören Instrumententest und Instrumentenentwicklung am lokalen Messplatz. Durch Messdatenanalyse werden die Instrumente weitgehend optimiert. Ziel ist es, mit solchen Instrumenten möglichst viele ungestörte Strukturinformationen der Lipidmembran zu ermitteln.

Um die Funktionsweise der Instrumente und die Experimente besser verstehen zu können, sei zunächst die Streugeometrie erläutert, die bei jeder Messung verwendet wurde. Im Anschluss daran werden die am häufigsten eingesetzten Messverfahren vorgestellt. Den Schluss bildet die Darstellung der verwendeten Instrumente und der entsprechenden Experimente.

\subsection{Erläuterung der Streugeometrie}

Seien $\vec{k}_{i}, \vec{k}_{r}$ und $\vec{k}_{f}$ die Wellenvektoren der jeweils einfallenden, reflektierten und gebeugten Welle mit Wellenlänge $\lambda$ (Abb. 3.1), wobei $\left|\vec{k}_{i}\right|=\left|\vec{k}_{r}\right|=\left|\vec{k}_{f}\right|=\frac{2 \pi}{\lambda}$. Der Wellenvektor $\vec{k}_{i}$ und die Oberflächennormale der Probe bestimmen die Einfallsebene. Der Röntgenstrahl trifft unter dem Einfallswinkel $\alpha_{i}$ auf die Probenoberfläche und wird von der Probe unter einem Winkel $\alpha_{r}$ zur Probenoberfläche und einem Winkel $\phi$ zur Einfallsebene gestreut. Der Streuvektor oder der Impulsübertrag $\vec{q}=\overrightarrow{k_{f}}-\vec{k}_{i}$ lässt sich beschreiben durch:

$$
\begin{aligned}
q_{x} & =\frac{2 \pi}{\lambda}\left(\cos \phi \cos \alpha_{r}-\cos \alpha_{i}\right) \\
q_{y} & =\frac{2 \pi}{\lambda} \cos \alpha_{r} \sin \phi \\
q_{z} & =\frac{2 \pi}{\lambda}\left(\sin \alpha_{i}+\sin \alpha_{r}\right) .
\end{aligned}
$$

Abb. 3.1 stellt die Streugeometrie an einer Lipiddoppelschicht schematisch dar. In dieser Arbeit 


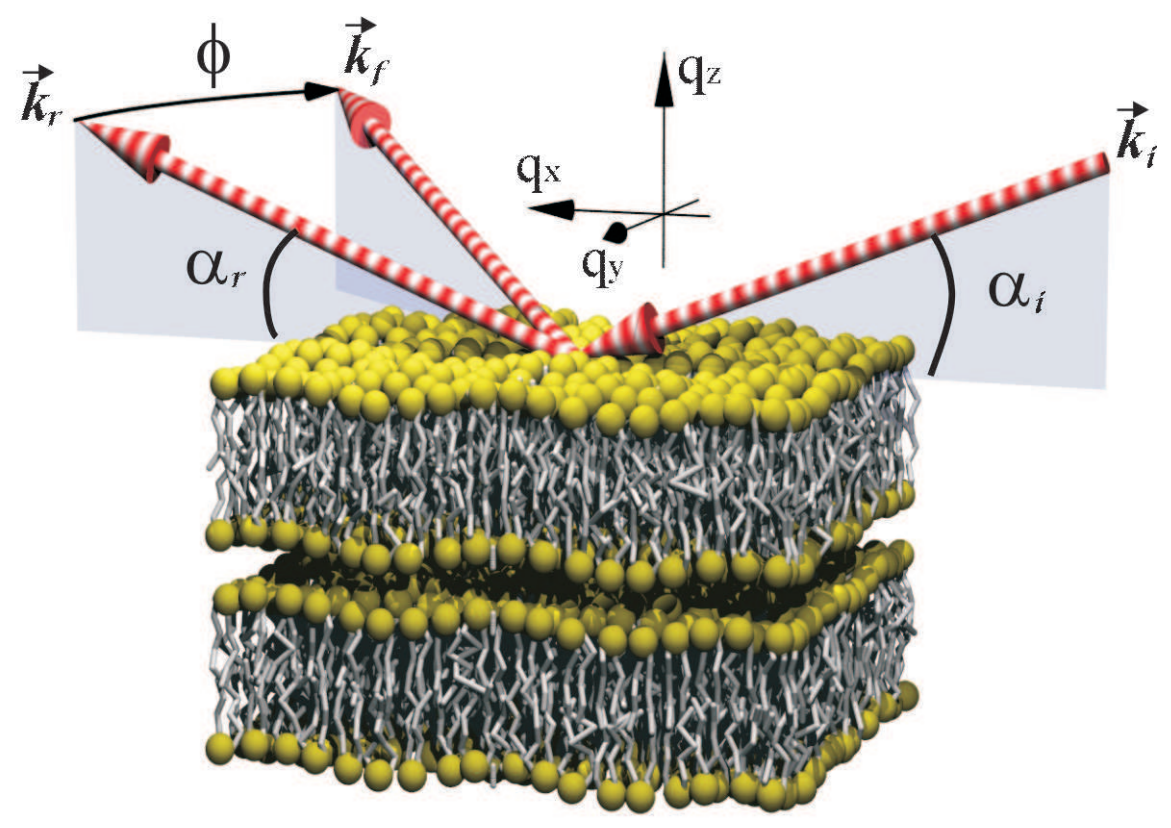

Abbildung 3.1: Streugeometrie an Lipiddoppelschichten. Mit der grauen Kopfgruppe und der hellen Kettenregion wird ein einzelnes Lipidmolekül dargestellt. Die gestreiften Pfeile stellen jeweils den einfallenden Strahl $\vec{k}_{i}$, den reflektierten Strahl $\vec{k}_{r}$ und den gebeugten Strahl $\vec{k}_{f}$ dar [145].

wird allerdings nur von $q_{z}$ und $q_{x}$ in spekulären bzw. offset-spekulären Messungen Gebrauch gemacht.

\subsection{Verwendete Messverfahren}

Um die verschiedenen Messziele zu erreichen, braucht man auch unterschiedliche, dazu passende Messverfahren. Beim Reflektivitäts-Scan misst man unter der „,spiegelnden“ Bedingung $\alpha_{i}=\alpha_{r}$ den spekulär reflektierten Röntgenstrahl. Es wird folglich die Intensität entlang der $q_{z}$-Achse erfasst. Die Reflektivität an Lipiddoppelschichten ist sensitiv in senkrechter Richtung zur Probenoberfläche, daher kann man durch Reflektivitätsmessungen Informationen über Lipiddoppelschichten in senkrechter Richtung zu ihrer Oberfläche gewinnen. Im offset-Scan ist die Geometrie ähnlich zu der des Reflektivitäts-Scans. Die Eichung zwischen $\alpha_{i}$ und $\alpha_{r}$ ist hier jedoch um einen offset-Winkel $\Delta \alpha_{i}$ absichtlich dejustiert. Mit dem offset-Scan kann die diffuse Streuung neben der spekulären Reflektivität gemessen und für den diffusen Untergrundabzug der spekulären Reflektivität extrapoliert werden. Ein Verfahren, mit dem die Orientierung (Mosaizität) der multilamellaren Lipiddoppelschichten bestimmt werden kann, ist der Rocking-Scan. Dabei wird der Detektor auf einer Position fixiert, und die Probe wird von 0 bis $2 \alpha_{r}$ gedreht, so dass die Summe $\alpha_{i}+\alpha_{r}$ immer konstant bleibt. Abb. 3.2 zeigt schematisch den reziproken Raum eines Membranstapels und einige Bahnen zu den Messverfahren. Die lamellare Struktur führt zu den Bragg-Maxima (bzw. quasi Bragg-Maxima) bei $q_{z}=\frac{2 \pi}{d} n$ ( $n$ ist die Nummer des Bragg-Maximums), die aufgrund der korrelierten Fluktuation in diffuse Ebenen (engl. Bragg sheets) in $q_{x}$ - und $q_{y}$-Richtung ausge- 


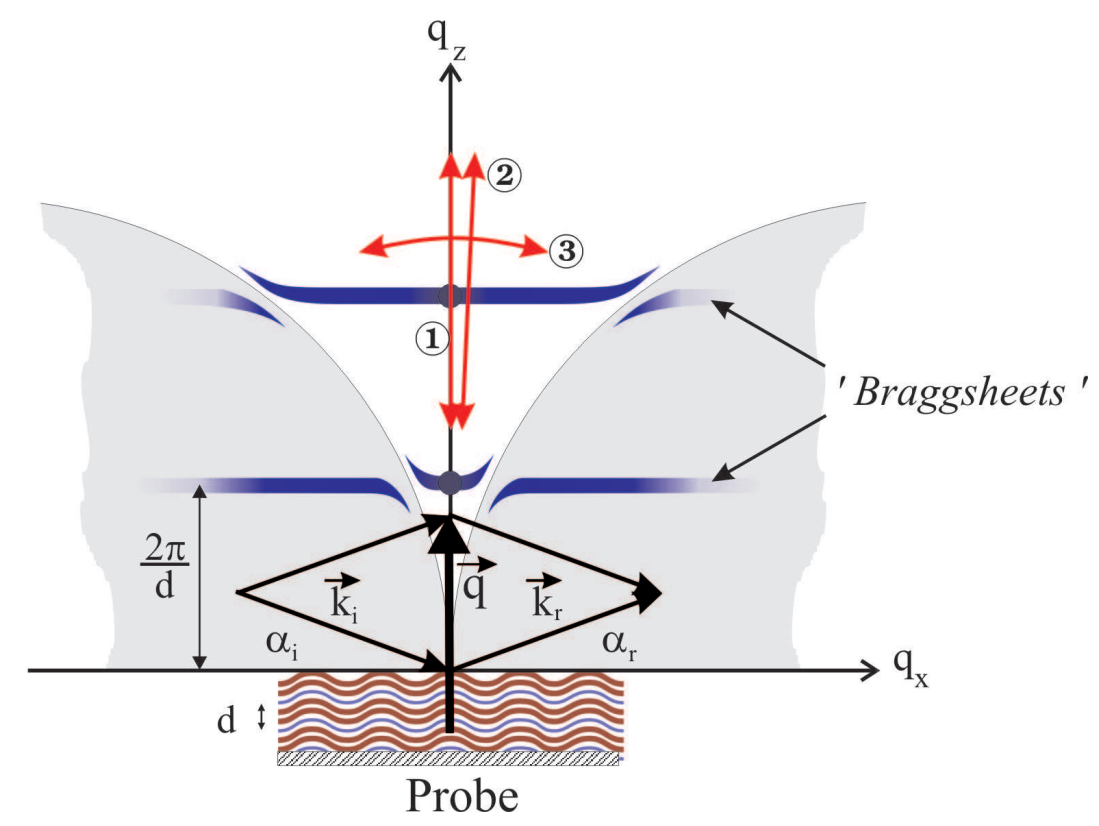

Abbildung 3.2: Schematische Darstellung der Intensitätsverteilung von multilamellaren Membranstapeln und der Bahnen der verschiedenen Messverfahren im reziproken Raum. (1): Reflektivitäts-Scan, (2): OffsetScan, (3): Rocking-Scan. Wegen Brechungseffekten ist die Intensitätsverteilung in der Umgebung der beiden halbkugelförmigen Laue-Bereiche $\left(\alpha_{i} \leq 0\right.$ oder $\left.\alpha_{f} \leq 0\right)$ nach oben bzw. nach unten verbogen. Die graue Zone ist für $\vec{q}$ bei der Röntgenstreuung wegen der Absorption des Substrates nicht zugänglich. $d$ ist die Periode der Lipiddoppelschichten.

dehnt werden [146]. Die eben erklärten Messverfahren werden durch ihre eindimensionale Bahn charakterisiert.

\subsection{Probenumgebungen}

Die Phase der Membranstapeln ist von Temperatur und Hydratisierung der Umgebung abhängig, deshalb benötigt man eine stabile Probenumgebung mit einstellbarer Temperatur und Hydratisierung. Um diese Anforderungen zu erfüllen, wurden zwei Probenmesskammern zum Einsatz gebracht. Eine Feuchtigkeitskammer wurde zur Hydratisierung aus der Gasphase einer mit Wasserdampf gesättigten Atmosphäre eingesetzt, und eine Nasskammer wurde zur Hydratisierung durch direkten Kontakt mit einem Wasserbad verwendet.

\subsubsection{Feuchtigkeitskammer}

Die Feuchtigkeitskammer besteht, wie in Abb. 3.3 (a) dargestellt, aus einem inneren und äußeren Kammerteil. Die innere Kammer wird von einem Temperierflüssigkeitskreislauf gleichmäßig durchströmt, der von einem handelsüblichen Kühl- und Heiztemperiergerät der Firma JULABO aufrecht erhalten wird [147]. Zur Temperaturrückkopplung ist ein Platin-Dünnschichtwiderstand 
(Pt-100) direkt in der inneren Kammer befestigt. Um die Wärmeverluste der Zuleitungen und die Temperaturträgheit der Kammer zu kompensieren, verwendet das Gerät iterativ gefundene Regelparameter (PID-Regelung). Zwischen innerer und äußerer Kammer liegt ein evakuierbarer Zwischenraum. Dieser Zwischenraum minimiert Wärmeverluste durch Wärmeleitung und Wärmekonvektion. Die Temperaturstabilität in der Kammer ist mit $\pm 0.1^{\circ}$ angegeben. Für das Strahleintrittsund Strahlaustrittsfenster wurde Kapton als Fenstermaterial eingesetzt. Die Feuchtigkeitskammer bietet nicht nur die Möglichkeit der Messung bei stabiler Temperatur, sondern auch bei verschiedenen Feuchtigkeitsbedingungen. Dazu wurde ein Wasserbehälter in die Kammer eingesetzt. Die relative Feuchtigkeit in der Kammer kann durch einen eingebauten Feuchtigkeitssensor kontrolliert werden (Abb. 3.3(b)). Sie kann auch eingestellt werden, indem die zwei Heizkörper in der Feuchtigkeitskammer unterschiedlich geheizt werden. Z.B. ist bei $\mathrm{T}_{\text {oben }}=45.8^{\circ} \mathrm{C}$ und $\mathrm{T}_{\text {unten }}=42^{\circ} \mathrm{C}$ die relative Feuchtigkeit ca. 99.6\%.

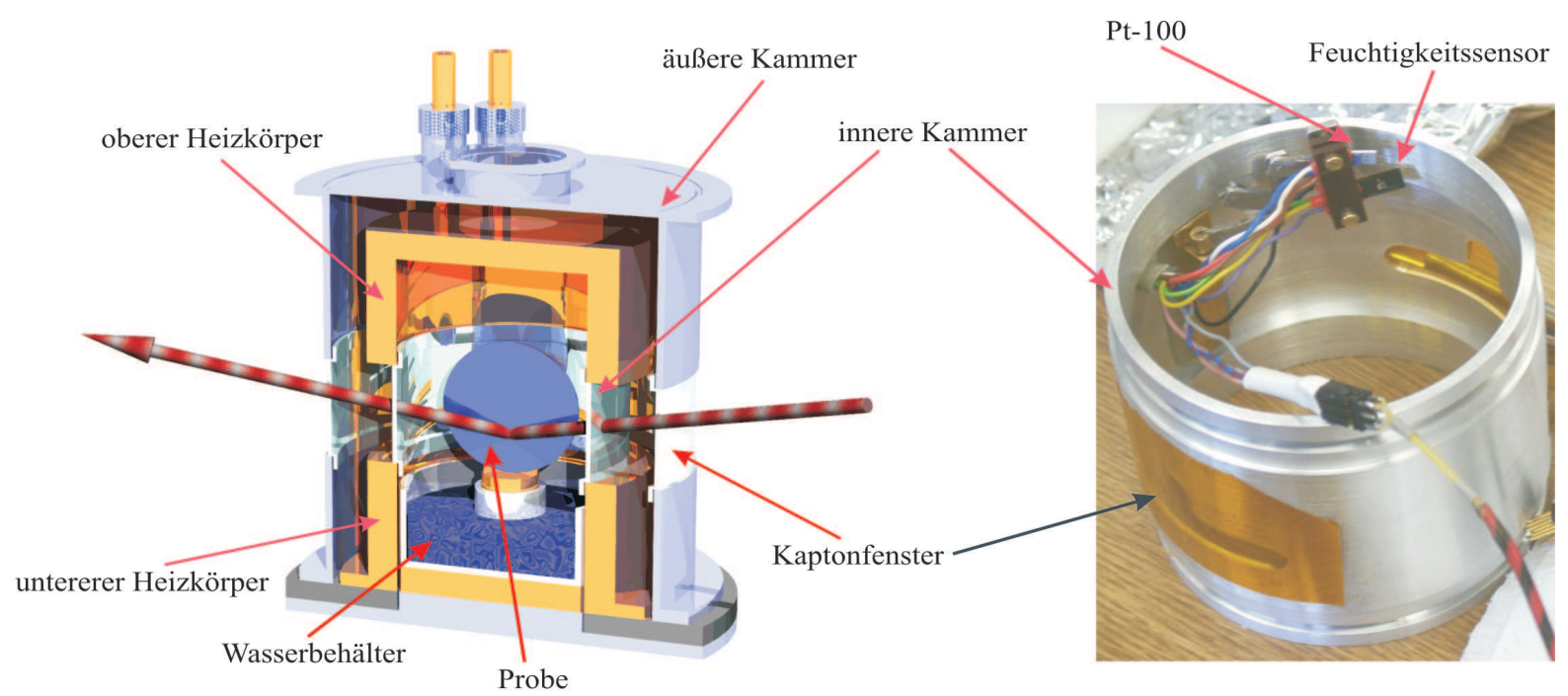

(a)

(b)

Abbildung 3.3: (a) Schematische Darstellung der Feuchtigkeitskammer; (b) Aufnahme des inneren Kammerteils mit zwei eingebauten Sensoren.

\section{Eichung des Feuchtigkeitssensors}

Der Feuchtigkeitssensor von Typname HIH-3610-003 wurde bei der Fa. Honeywell International Inc. gekauft. Er besteht aus Polymerschichten, und sein Funktionsmechanismus basiert darauf, dass die elektrische Leitfähigkeit zu der Feuchtigkeit in den Polymerschichten proportional ist. Obwohl der Sensor bei der Herstellung schon geeicht wurde, fand im Institut nochmals eine Eichung statt. Die konventionelle Methode zur Eichung eines Feuchtigkeitssensors ist die Methode der gesättigten Salzlösung, da durch diese unter fixierter Temperatur eine konstante Feuchtigkeit in der Umgebung herrscht. In Tabelle 3.1 wird die relative Feuchtigkeit bei gesättigter Salzlösung unter $\mathrm{T}=25^{\circ} \mathrm{C}$, die zur Kalibrierung des Feuchtigkeitssensors oft verwendet wird, aufgelistet. 


\begin{tabular}{cccc}
\hline $\mathrm{Salz}$ & Relat. Feuchtigkeit (\%) & $\mathrm{Salz}$ & Relat. Feuchtigkeit (\%) \\
\hline \hline $\mathrm{LiCl}$ & 11.3 & $\mathrm{KI}$ & 68.9 \\
$\mathrm{KAc}$ & 22.5 & $\mathrm{NaCl}$ & 75.3 \\
$\mathrm{MgCl}_{2}$ & 32.8 & $\mathrm{KCl}$ & 84.3 \\
$\mathrm{~K}_{2} \mathrm{CO}_{3}$ & 43.2 & $\mathrm{KNO}_{3}$ & 93.6 \\
$\mathrm{Mg}\left(\mathrm{NO}_{3}\right)_{2}$ & 52.9 & $\mathrm{~K}_{2} \mathrm{SO}_{4}$ & 97.3 \\
$\mathrm{NaBr}$ & 57.6 & & \\
\hline
\end{tabular}

Tabelle 3.1: Relative Feuchtigkeit bei gesättigter Salzlösung unter einer Temperatur von $25^{\circ}$ C [148].

Im Anhang werden eine vollständige Tabelle der relativen Feuchtigkeit bei gesättigter Salzlösung unter verschiedener Temperatur sowie eine Eichkurve für den Feuchtigkeitssensor von Typ HIH3610-003 dargestellt.

\subsubsection{Nasskammer}

Messungen bei voller Hydratisierung mit kontrolliertem osmotischen Druck und kontrollierter Temperatur erfolgten in einer Nasskammer aus Edelstahl mit Kaptonfenstern.

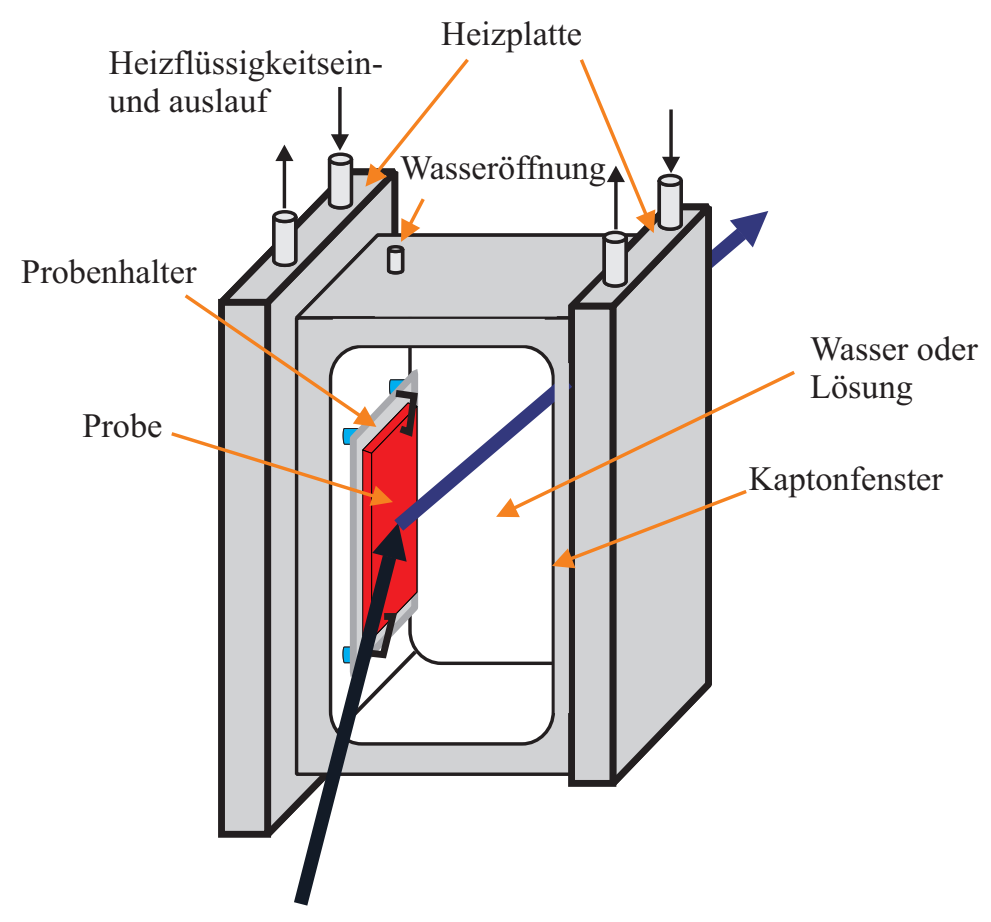

Abbildung 3.4: Schematische Darstellung der Nasskammer

Eine schematische Darstellung der Nasskammer wird in Abb. 3.4 gezeigt. Diese Nasskammer wird durch zwei Heizkörper an beiden Kammerseiten geheizt, damit die Temperatur im von Wasser oder Lösung gefüllten Kammerinnenraum während der Messung konstant gehalten werden kann. Mit dieser Nasskammer ist es möglich, die Probe im trockenen Zustand zu montieren und später die 
Kammer mit Wasser bzw. Polymerlösung zu füllen. Zur Messung in der Nasskammer wurde eine Polymerlösung verwendet, dadurch befand sich die Probe unter einem osmotischen Druck. Diese Methode beruht darauf, dass man große Polymere in der Wasserphase löst. Die Polymere müssen so groß sein, dass sie nicht in die nur einige nm dicke Wasserschicht eindringen können [149]. Für das ungeladene Lipid DMPC wurde das ungeladene Polymer Polyethyleneglycol (PEG) der mittleren Masse 20000 u und der Konzentration von 14.2\% verwendet. Mit dieser Konzentration ergibt sich ein osmotischer Druck unter PEG-Lösung zu 1.95 bar.

\subsection{Reflektometer mit Stehanoden-Generator}

Im Rahmen dieser Arbeit wurde im Institut ein Röntgenreflektometer zur Messung der Lipidmembran aufgebaut. Dieses Reflektometer wurde unter Verwendung unterschiedlicher Bauteile konstruiert und in den verschiedenen Ausbaustufen optimiert. Alle Motoren des Reflektometers wurden durch ein PC-kontrolliertes Steuerprogramm namens spec von Certified Scientific Software gesteuert.

\subsubsection{Bauteile des Reflektometers}

Die wichtigsten Bestandteile des Reflektormeters sind Hochspannungs-Generator, Röntgenröhre, Goniometer und Detektoren.

- Hochspannungs-Generator

Der Generator mit dem Typnamen ISO-DEBYEFLEX 3003 wurde bei der Fa. RICHARD SEIFERT \& $C O$ gekauft. Seine Ausgangsleistung liegt bei $3.5 \mathrm{~kW}$. Er kann bis zu einer Umgebungstemperatur von $35^{\circ}$ betrieben werden und liefert eine Röhrenspannung bis zu $60 \mathrm{kV}$ und einen Röhrenstrom bis zu 80 mA mit einer Absolutgenauigkeit von $\pm 2 \%$ bzw. $\pm 1 \%$. Der ganze Generator wird durch einen eingebauten Minicomputer mit Digitalanzeige gesteuert.

- Röntgenröhren

Die Röntgenröhren mit dem Typnamen FK 61-04×12 wurden auch bei der Fa. RICHARD SEIFERT \& CO gekauft. Insgesamt werden zwei Röntgenröhrensorten zum Einsatz gebracht, und zwar Mo- und Cu-Röhren. Beide Röntgenröhren besitzen einen gleich großen Brennfleck von $0.4 \times 12 \mathrm{~mm}^{2}$. Je nach Ziel des Experiments kann entweder ein Strichfokus oder ein Punktfokus gewählt werden. Der Strichfokus ist $0.04 \times 12 \mathrm{~mm}^{2}$ groß und der Punktfokus $0.4 \times 1.2 \mathrm{~mm}^{2}$. Die Röhrenleistung von beiden ist unterschiedlich, für die Mo-Röhre liegt sie bei $3 \mathrm{~kW}$, für die $\mathrm{Cu}-\mathrm{Röhre} \mathrm{jedoch} \mathrm{bei} 2.2 \mathrm{~kW}$.

- Goniometer

Das Goniometer zusammen mit einem XY-Tisch und einem Kreis-Segment sind von der Fa. HUBER Diffraktionstechnik GmbH \& Co. KG. Das eingesetzte Goniometer ist ein zweiKreis-Goniometer und kann daher beide Kreisebenen unabhängig voneinander bewegen. Die 
Genauigkeit des Goniometers beträgt für beide Kreisbewegungen $0.00694^{\circ}$. Die zulässige Schwankung liegt bei $0.00083^{\circ}$. Der XY-Tisch hat eine Genauigkeit von $4 \mu \mathrm{m}$ bezüglich der beiden senkrechten Translationsrichtungen. Die Kreis-Segmente (Euler-Wiege) bestehen aus zwei halbkreisähnlichen Segmenten, die sich in senkrechter Richtung im Bereich $\pm 20^{\circ}$ drehen können. Die Genauigkeit für die Einzelachsen liegt bei ca. $10 \mu \mathrm{m}$.

- Schrittmotorsteuerung

Die Schrittmotorsteuerung von Modell IXE $\alpha$-A ist von Fa. Phytron-Elektronik GmbH (Industriestr. 12 D-82194 Gröbenzell). Diese Schrittmotorsteuerung hat eine IEEE 488Schnittstelle und kann bis zu 8 Achsenrechnerkarten haben, damit kann sie bis zu 8 Schrittmotoren steuern.

- Blende

Die Blende ist von Fa. JJ X-ray Aps (Liselundsallé 10 DK-3360 Liseleje Denmark). Diese Blende wurde mit 4 Schrittmotoren von Modell ARSAPE 0.45 A ausgerüstet und hat eine maximale Öffnung von $6 \mathrm{~mm}$ (horizontal und vertikal) sowie eine maximale Translation von $\pm 7 \mathrm{~mm}$ (horizontal und vertikal). Ihre Genauigkeit liegt bei $\pm 3 \mu \mathrm{m}$.

- Detektoren

Für das Reflektometer gelangten zwei Detektoren zum Einsatz. Einer davon ist der Fast Scitillation Detector mit dem Typnamen Cyberstar ${ }^{x 1000}$ von der Fa. OXFORD DANFYSIK. Dieser Cyberstar-Detektor hat ein $0.2 \mathrm{~mm}$ dickes Beryllium-Fenster mit einer sensitiven Fensterfläche von $32 \mathrm{~mm}$ Durchmesser und verwendet einen thallium-aktivierten NatriumIodid-Einkristall als Szintillator. Er kann einer Energie bis zu $50 \mathrm{keV}$ ausgesetzt werden und hat bei einer Energie von $5 \mathrm{keV}$ einen Untergrund von weniger als 0.2 cps (Ereignisse pro Sekunde). Außerdem hat der Cyberstar-Detektor einen Photoverstärker photomultiplier mit 10 Dynoden, seine Todzeit (rise time) liegt bei $2.8 \mathrm{~ns}$.

Der zweite verwendete Detektor ist der energiedispersive Detektor mit Typname XFlash1000 von der Fa. RÖTEC. Dieser Detektor hat ein $8 \mu$ m dickes Beryllium-Fenster mit einer sensitiven Fensterfläche von $5 \mathrm{~mm}^{2}$. Er kann bis zu $10^{6} \mathrm{cps}$ ausgesetzt werden und hat eine Auflösung von ca. $245 \mathrm{eV}$ bei $5 \times 10^{5}$ cps FWHM mit Mn- $k_{\alpha}$. Seine energieabhängige Todzeit beträgt 150 bis 250 ns. Er ordnet die detektierte Information energieabhängig 4096 Kanälen zu, die einem Energiebereich entsprechen.

\subsubsection{Aufbau des Reflektometers: 1. Ausbaustufe}

Aus den oben erwähnten Bestandteilen wurde das 1. Reflektometer, wie Abb. 3.5 zeigt, aufgebaut. Der Abstand zwischen Brennfleck und Primärblende beträgt $195 \mathrm{~mm}$, zwischen Primärblende und Eingangsblende $1752 \mathrm{~mm}$. Unter einem $0.4 \times 1.2 \mathrm{~mm}^{2}$ (Horiz. L. $\times$ Vertik. L.) großen Punktfokus ergibt sich die Winkeldivergenz bei PB(Primärblenden)-Größe $10 \times 5 \mathrm{~mm}^{2}$ und $\mathrm{EB}$ (Eingangsblenden)-Größe $1 \times 1 \mathrm{~mm}^{2} \mathrm{zu} 0.021^{\circ}$ in horizontaler Richtung und zu $0.032^{\circ}$ in vertikaler Richtung. Zur Bestimmung der Winkeldivergenz wurde ein Programm in Mathcad geschrieben, im Anhang wird dieses Programm beigefügt. Nach Bedarf können die beiden Blendengrößen 
PB und EB in horizontaler und vertikaler Richtung variiert werden. Die zwei Strahlrohre können evakuiert werden, um Intensitätsverlust durch Absorption und Streuung von Luft zu vermeiden. Die lange Entfernung zwischen Brennfleck und EB bewirkt eine kleine Strahldivergenz und folglich eine gute Auflösung. Diese Konstruktion hat aber den Nachteil, dass die Intensität wegen des kleines Wirkungsquerschnitts stark reduziert wird.

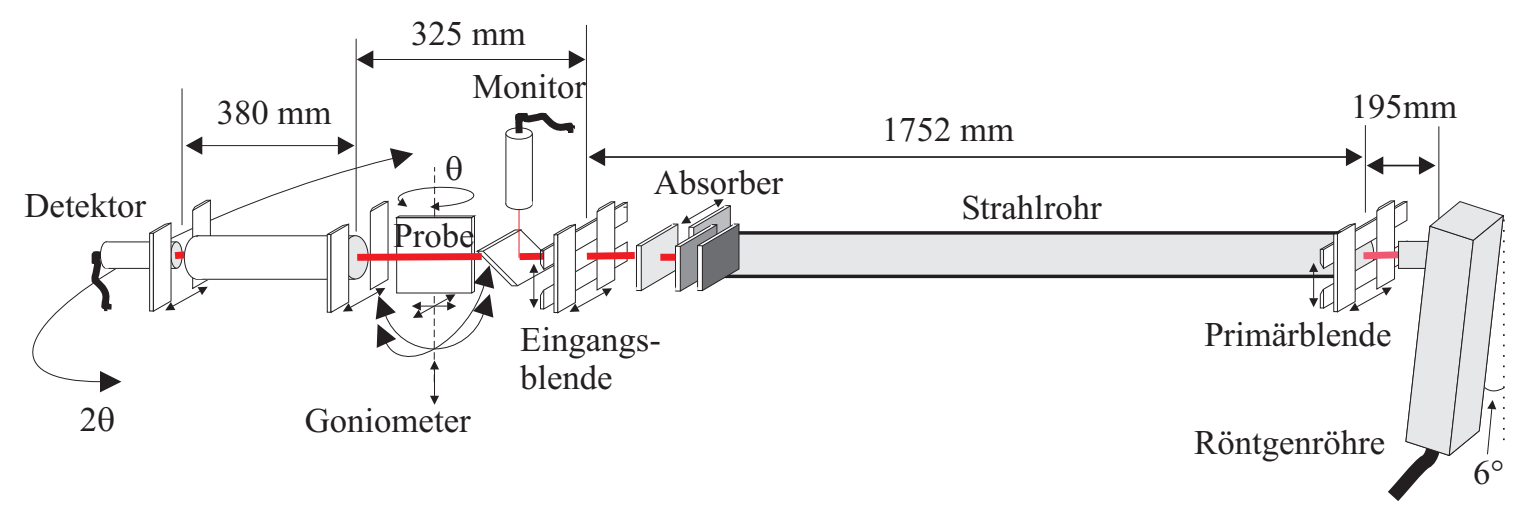

Abbildung 3.5: Schematische Darstellung zum Aufbau des 1. Reflektometers am Lehrstuhl.

\section{Erste Strahlcharakterisierung mit Silizium(100)}

Eine Überlegung zur Strahlcharakterisierung lautet, wie stark einerseits die Intensität eines Primärstrahls ist, und andererseits, wie die spektrale Verteilung aussieht, damit man entscheiden kann, ob die Intensität des Primärstrahls zur Untersuchung eines biologischen Systems ausreichend ist. Dies erfordert entsprechende Optimierungen der Reflektometerkonstruktion. Dazu wurde das Spektrum des Strahls mit Siliziumsubstrat (100) aufgenommen. Dabei wurde die Generatorleistung auf 40 $\mathrm{kV} \times 30 \mathrm{~mA}$ eingestellt und eine Mo-Röntgenröhre verwendet. Außerdem wurde der CyberstarDetektor zum Einsatz gebracht, und ein Zirkoniumfilter mit einer Dicke von $125 \mu \mathrm{m}$ wurde eingesetzt, um mögliche unerwünschte Strahlen mit hoher Energie abzuschwächen. Unter einer Blendgröße von $0.4 \times 4 \mathrm{~mm}^{2}$ für die Eingangsblende (EB) und von $4 \times 4 \mathrm{~mm}^{2}$ für die Detektorblende (DB) erhält man im Energiebereich von 0-40 keV eine Primärintensität von $\sim 3 \cdot 10^{5} \mathrm{cps}$. In Abb. 3.6 wird eine Reflektivitätskurve von $\mathrm{Si}(100)$ logarithmisch gegen $2 \theta$ aufgetragen. Man sieht hier vier klar getrennte Peaks, die zu den Reflexionen der charakteristischen Strahlen gehören. Die hier gezeigten Peaks sind die Reflektivität von $\mathrm{Si}(400)$, da die Reflektivität von $\mathrm{Si}(200)$ und $\mathrm{Si}(300)$ verboten ist. Der Einsatz von Zr-Filtern reduziert die Reflektivität von kurzwelligen (hochenergetischen) Strahlen und ergibt einen Sprung von etwa einer Größenordnung zwischen den $\mathrm{K}_{\alpha}$ - und $\mathrm{K}_{\beta}$-Peaks, wo gerade eine Absorptionskante (ca. $17.998 \mathrm{keV}$ ) von Zirkonium liegt. Der Intensitätsunterschied zwischen der $\mathrm{K}_{\alpha}$ - und $\mathrm{K}_{\beta}$-Linie liegt bei ca. 3 Größenordnungen. Die maximale Intensität findet man bei der $\mathrm{K}_{\alpha 1}$-Reflexion; diese beträgt $\sim 11000$ cps. Das entspricht einem Intensitätsanteil für diese Energie im Bereich von 0-40 keV (ca. $17.489 \mathrm{keV}$ ) von $~ 3.67 \%$. 


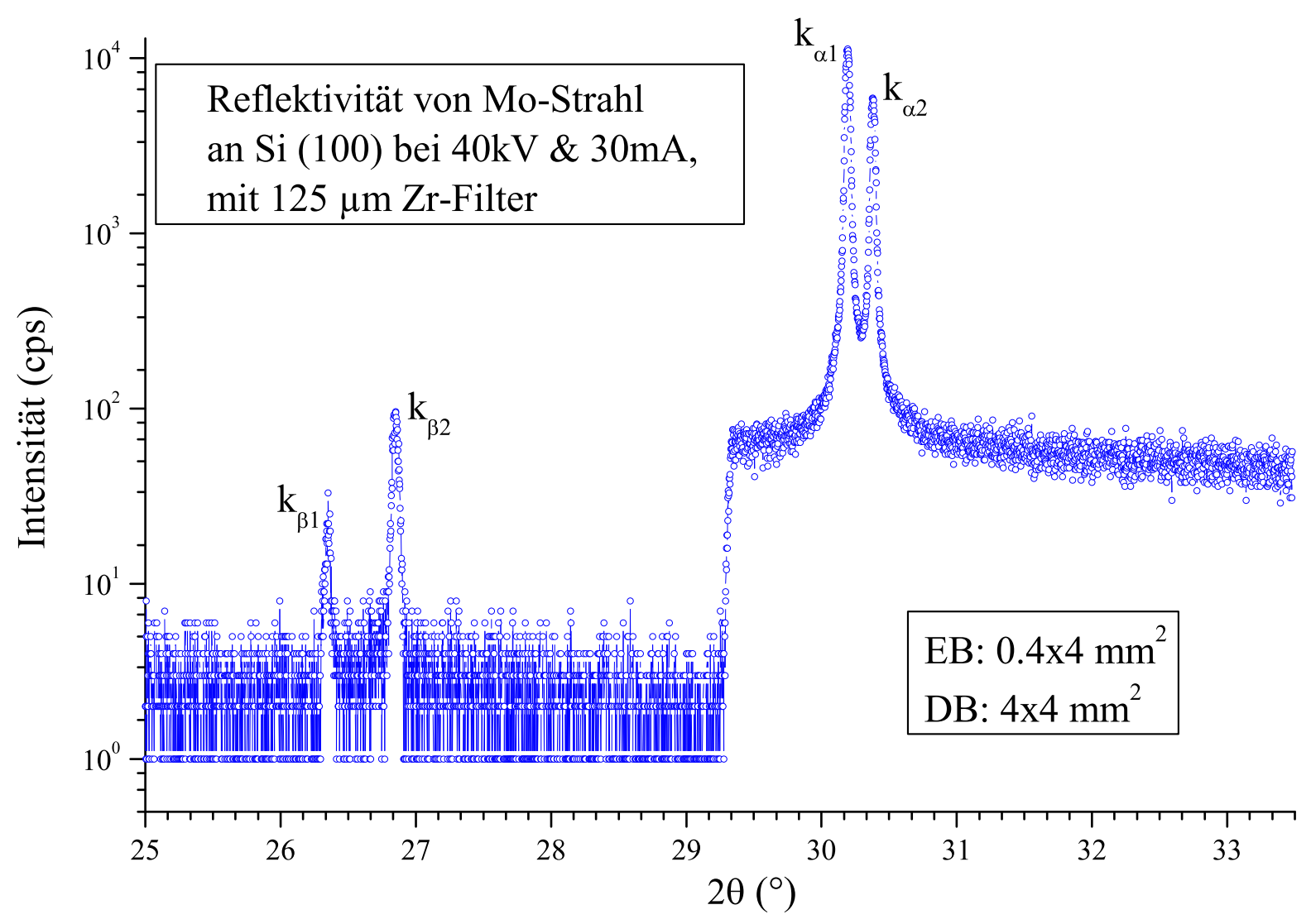

Abbildung 3.6: Reflektivitätskurve von Si(100) durch eine Mo-Röntgenröhre. Die Reflektivitätsrate ist unter $40 \mathrm{kV} \times 30 \mathrm{~mA}$ Leistung, EB: $0.4 \times 4 \mathrm{~mm}^{2}$ und $\mathrm{DB}: 4 \times 4 \mathrm{~mm}^{2} \mathrm{ca}$. $3.78 \%$ für $K_{\alpha 1}$-Strahl. Die hier gezeigten 4 Peaks sind von Si(400), da die Reflektivität von Si(200) und Si(300) verboten ist.

\section{Weitere Strahlcharakterisierung mit Germanium(111) und Graphit(002)}

Zur weiteren Strahlcharakterisierung wurden $\operatorname{Ge}(111)(d=3.26636 \AA$ mit einer Gitterkonstante von $5.6575 \AA)$ und Graphit(002) ( $d=3.3555 \AA$ mit einer Gitterkonstante von $6.711 \AA$ ) zum Einsatz gebracht. Bei Anwendung von Ge(111) wurde die Generatorleistung auf $40 \mathrm{kV} \times 30 \mathrm{~mA}$, bei Graphit(002) auf $30 \mathrm{kV} \times 10 \mathrm{~mA}$ eingestellt. Die beiden Strahlcharakterisierungen wurden unter Einsatz von Zr-Filtern mit einer Dicke von $125 \mu \mathrm{m}$ unter gleicher Detektorblendegröße (DB: $4 \times 4 \mathrm{~mm}^{2}$ ), aber unterschiedlicher Eingangsblendgröße $\left(\mathrm{EB}: 0.5 \times 1 \mathrm{~mm}^{2}\right.$ für $\mathrm{Ge}(111)$ und $0.4 \times 4$ $\mathrm{mm}^{2}$ für Graphit(002)) durchgeführt. In Abb. 3.7 werden die Reflektivitätskurven für beide Einkristalle gegen $2 \theta$ aufgetragen. Die Reflektivitätsrate für die beiden Einkristalle an $\mathrm{K}_{\alpha}$-Strahl ist unterschiedlich und von der Primärintensität abhängig. Für Ge(111) beträgt sie bei einer Primärintensität von $\sim 3 \cdot 10^{5} \mathrm{cps}$ ca. $8.6 \%$. Für Graphit(002) beträgt sie bei einer Primärintensität von $\sim$ $2.8 \cdot 10^{4}$ cps ca. $20 \%$ und bei einer Primärintensität von $\sim 7.6 \cdot 10^{4}$ cps ca. $35 \%$. Der Unterschied der Reflektivitätsrate beider Einkristalle ist ziemlich groß, die Ursache dafür liegt in der unterschiedlichen Darwin-Breite und der unterschiedlichen Absorption. Einerseits beträgt die Darwin-Breite bei Ge(111) für den Mo-K $\alpha_{\alpha 1}$-Strahl ca. $7^{\prime \prime}$ ( $\operatorname{arcsec}$ ), während sie bei Graphit(002) ca. 10.5" beträgt (berechnet mit dem Programm XOP Version 2.0, ESRF Grenoble). Andererseits absorbiert 
(a)

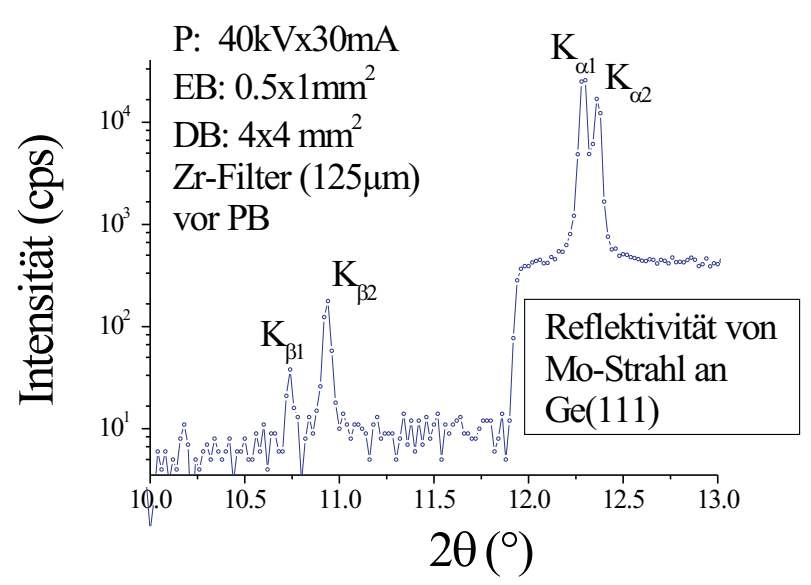

(b)

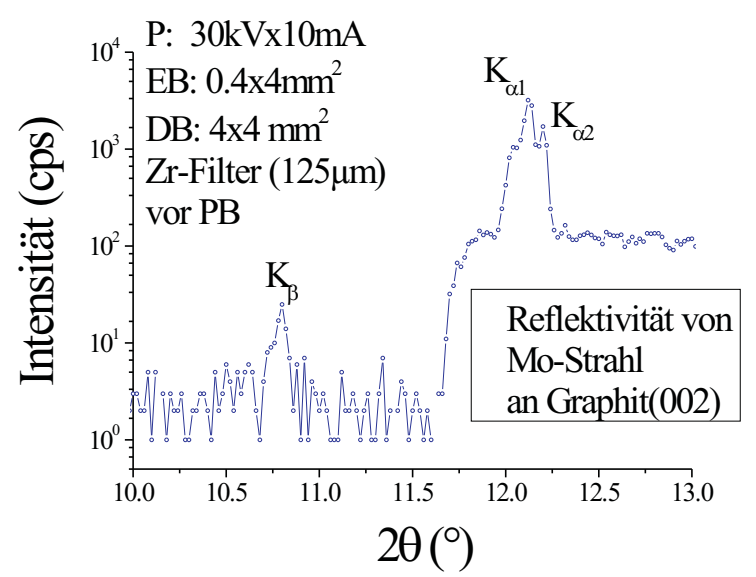

Abbildung 3.7: (a) Reflektivitätskurve von Ge(111) und (b) Reflektivitätskurve von Graphit(002) mit einer Mo-Röntgenröhre unter verschiedenen Bedingungen (siehe Text).

Ge(111) den Mo-K $\alpha_{\alpha 1}$-Strahl fast um den Faktor 10 mehr als Graphit(002).

Ein Röntgenstrahl mit solcher Primärintensität kann nicht eingesetzt werden, um ein biologisches System wie z. B. ein Lipid/Peptid-System zu untersuchen. Es ist deshalb notwendig, die Konstruktion des Reflektometers zu verbessern, damit man eine genügend große Intensität zur Untersuchung biologischer Systeme hat. Zu diesem Zweck wurde die Reflektometerkonstruktion stufenweise modifiziert.

\section{Einsatz des Graphit(002) als Analysator}

Wenn man zur Messung einen nichtmonochromatischen Röntgenstrahl verwendet, sind die Messdaten kaum auszuwerten, da der mehrwellige Röntgenstrahl ein sehr unsauberes Messergebnis liefert, z. B. viele Bragg-Peaks innerhalb eines kleinen Winkelintervalls. Es ist deshalb notwendig, den Röntgenstrahl zu monochromatisieren. Für die Reflektometerkonstruktion, die in Abb. 3.5 schematisch dargestellt ist, wurde Graphit(002) hinter der Probe und vor dem CyberstarDetektor als Analysator, wie in Abb. 3.8 schematisch dargestellt ist, eingebaut, um den von der Probe gestreuten Röntgenstrahl zu monochromatisieren. Der Graphit sollte so eingestellt werden, dass der $\mathrm{K}_{\alpha 1}$-Strahl maximal reflektiert wird. In der Praxis wurde der Graphit auf den zweiten maximal reflektierenden Winkel justiert, da er beim ersten Bragg-Peak wegen ungenügender Breite nicht den ganzen Strahl umfassen konnte.

\section{Testmessung mit OPPC-Lipidmembranen}

Zur Überprüfung der Verwendbarkeit des Graphit-Analysators wurde eine Probe damit gemessen. Die Probe bestand aus multilamellaren OPPC-Lipiddoppelschichten und wurde mit dem Mischungslösungsmittel TFE/Chloroform durch Spreiten der Stammlösung auf Si-Substrat(111) präpariert. Die Konzentration der Stammlösung war $10 \mathrm{mg} / \mathrm{ml}$. Die Messung wurde unter 40 


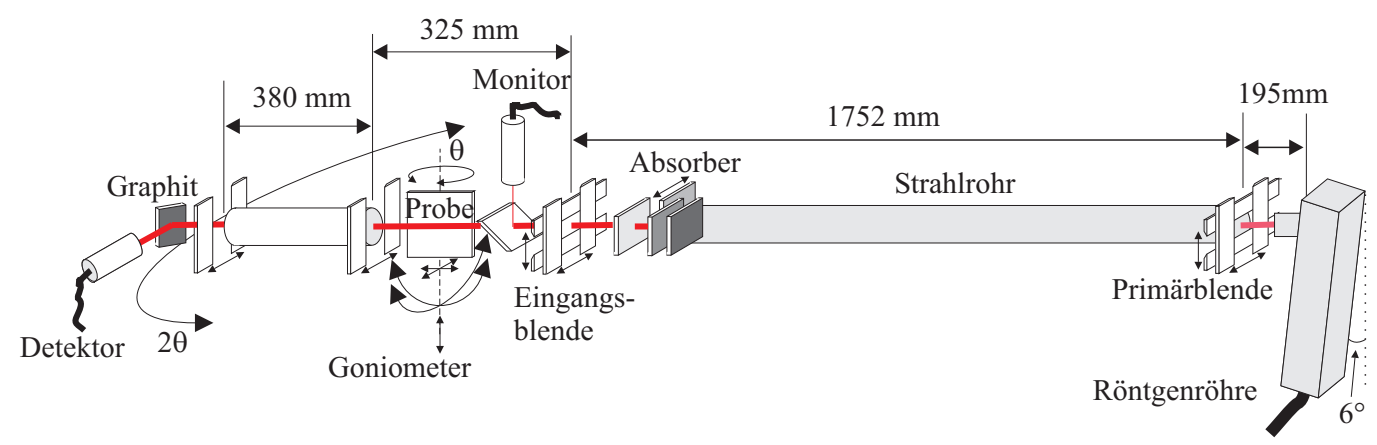

Abbildung 3.8: Schematische Illustration der Reflektometerkonstruktion mit Graphit als Analysator.

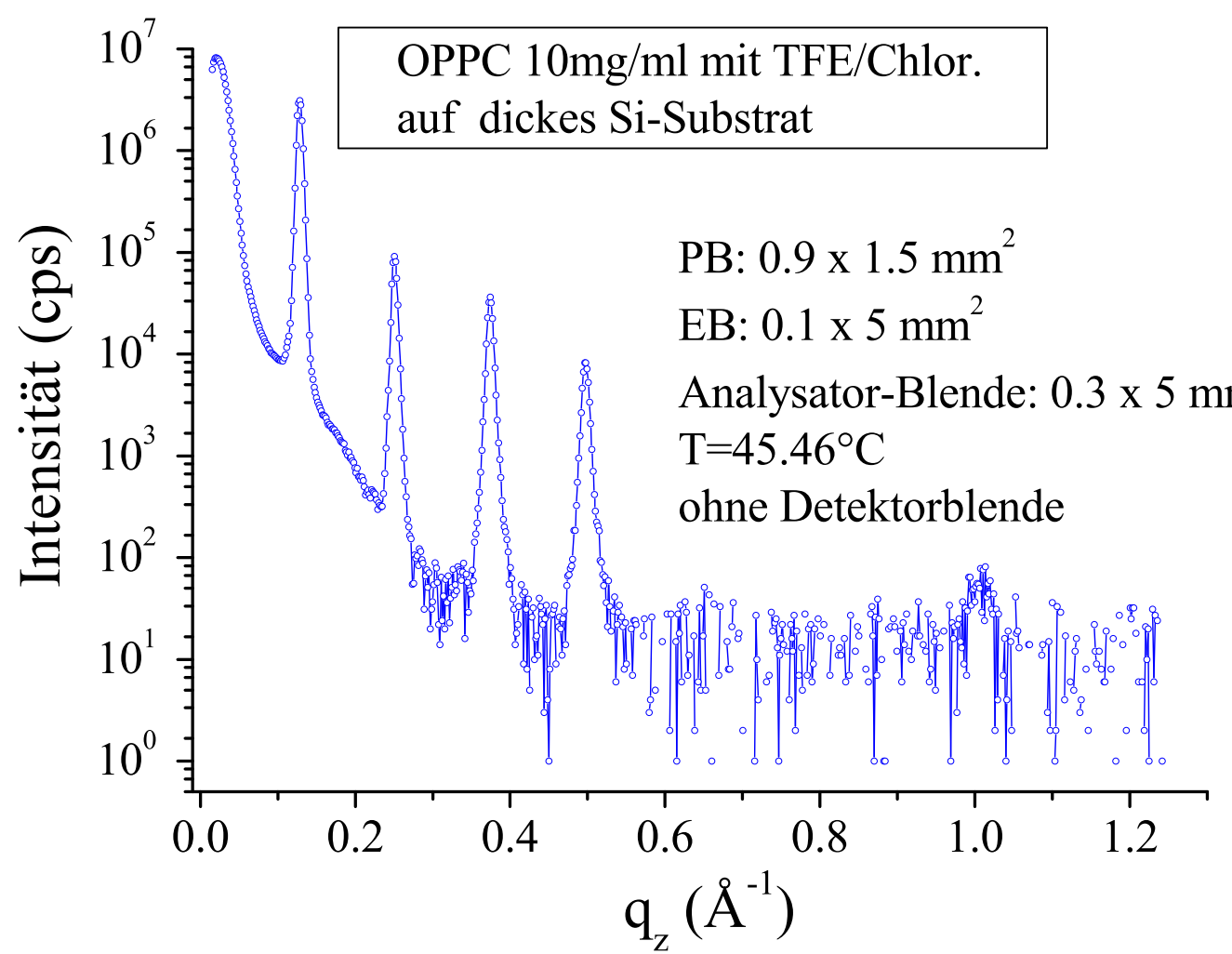

Abbildung 3.9: Die Reflektivitätskurve von multilamellaren OPPC-Lipiddoppelschichten ergibt sich nach Abzug der diffusen Streuung von der spekularen Reflektivität. Gemessen wurde mit $40 \mathrm{kV} \times 40 \mathrm{~mA}$ Leistung mit einem Graphit(002)-Analysator ohne Detektorblende.

$\mathrm{kV} \times 40 \mathrm{~mA}$ Generatorleistung durchgeführt, dabei wurde die Einzugsblende auf $0.1 \times 5 \mathrm{~mm}^{2}$ und die Analysatorblende auf $0.3 \times 5 \mathrm{~mm}^{2}$ eingestellt. Durch Benutzung der Feuchtigkeitskammer konnte die Probe unter einer RH von $\sim 98 \%$ und einer Temperatur von $45.46^{\circ} \mathrm{C}$ gemessen werden, damit befand sich die Probe in einer $\mathrm{L}_{\alpha}$-Phase. In Abb. 3.9 wird die gemessene Reflektivitätskurve gegen $\mathrm{q}_{z}$ aufgetragen. Bei der Kurve sind vier Bragg-Peaks zu sehen, dies scheint für die Datenanalyse, insbesondere für die Fourieranalyse, zu wenig zu sein. Außerdem ist das FWHM der vier Peaks in etwa $0.007 \AA^{-1}$. Dies zeigt, dass die Intensität des Röntgenstrahls nicht stark genug ist 
und die Anwendung des Graphits als Analysator nicht ideal zu sein scheint. Ein Verbesserungsvorschlag ist:

- Die Röntgenröhre nah an die Probe zu bringen, um die Strahlintensität an der Probe zu erhöhen.

- Einen energiedispersiven Detektor einzusetzen, um bei gleicher spektraler Auflösung Verlust durch Reflexion am Analysator zu minimieren.

\subsubsection{Aufbau des Reflektometers: 2. Ausbaustufe}

Die Reflektometerkonstruktion wurde also nach obig beschriebenem Verbesserungsvorschlag modifiziert, indem die Röntgenröhre ganz nah an die Probe gebracht und ein energiedispersiver Detektor eingesetzt wurde. In Abb. 3.10 wird diese neue Konstruktion schematisch dargestellt. Hier wurde der Strichfokus von $0.04 \times 12 \mathrm{~mm}^{2}$ (Horiz. L. $\times$ Vertik. L.) verwendet. Unter dieser Konstruktion und mit den Blendegrößen PB: $1 \times 8 \mathrm{~mm}^{2}$ sowie EB: $0.1 \times 4 \mathrm{~mm}^{2}$ beträgt die Winkeldivergenz $\sim 0.009^{\circ}$ in horizontaler Richtung (Y-Richtung) und $\sim 1.01^{\circ}$ in vertikaler Richtung (Z-Richtung).

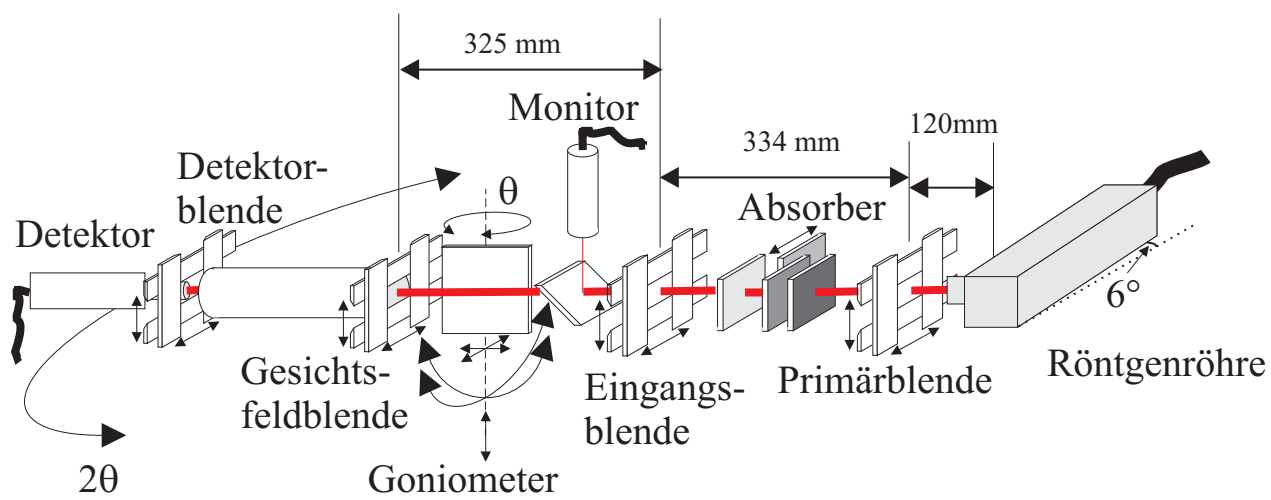

Abbildung 3.10: Schematische Illustration des 2. Reflektometeraufbaus.

Anhand von Abb. 3.10 läßt sich sogleich erkennen, dass der Abstand zwischen Strahlquelle und Primärblende sowie der Abstand zwischen Primärblende und Eingangsblende gekürzt ist. Das Strahlrohr wurde weggenommen, weil die Absorption und Streuung durch Luft wegen des kürzeren Abstands zwischen PB und EB entsprechend kleiner ist. Zusätzlich wurde eine Gesichtsfeldblende zum Einsatz gebracht, um den diffusen Untergrund zu vermindern. Im Vergleich mit der ersten Reflektometerkonstruktion hat diese Konstruktion den großen Vorteil des Intensitätsgewinns ( $\sim$ Faktor 40$)$, außerdem ist die Winkeldivergenz in horizontaler und vertikaler Richtung nicht größer als vorher, da der Strichfokus der Röntgenröhre verwendet wurde. Die Primärblende verhindert vor allem in horizontaler Richtung die Vergrößerung der Winkeldivergenz. 
(a)

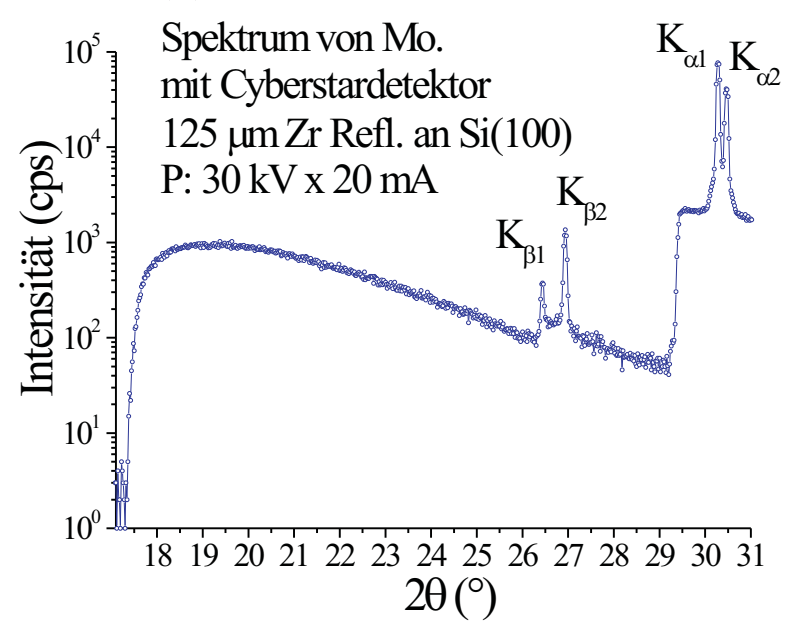

(b)

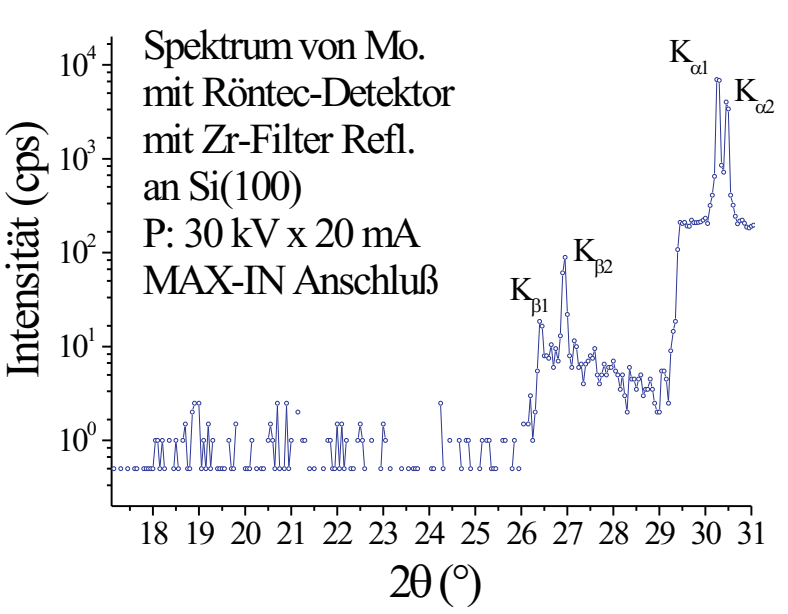

Abbildung 3.11: Reflektivitätskurve von Si(100) mit (a) dem Cyberstar-Detektor und (b) dem Röntec XFlash1000.

\section{Strahlcharakterisierung mit zwei Detektoren}

Zur Charakterisierung des Röntgenstrahls und zur Konfiguration des Steuerprogramms mit der neuen Konstruktion sowie zum Vergleich der Fähigkeit der zwei Detektoren wurde die Reflektivitätskurve von Silizium(100) mit zwei Detektoren gemessen. Dabei wurde eine Mo-Röhre eingesetzt. Eine $125 \mu \mathrm{m} \mathrm{Zr-Folie} \mathrm{wurde} \mathrm{als} \mathrm{K}_{\beta}$-Strahlfilter zum Einsatz gebracht. In Abb. 3.11 werden zwei Reflektivitätskurven von $\mathrm{Si}(100)$, die jeweils mit dem Cyberstar-Detektor und dem Röntec-Detektor unter gleicher Bedingung gemessen wurden, gegen $2 \theta$ aufgetragen. Bei der Messung mit dem Röntec-Detektor wurde dieser Detektor als Einzelkanal-Detektor (single channel detector) eingesetzt, d.h. seine energieauflösende Funktion wurde nicht genutzt, um so gleiche Bedingungen für beide Detektoren zu schaffen. Der Cyberstar-Detektor löst den ganzen gezeigten Bereich sehr gut auf, hat aber einen großen Untergrund von ca. 44 cps. Der Röntec-Detektor kann die Bremsstrahlung überhaupt nicht auflösen und hat damit einen kleinen Untergrund von ca. $2.5 \mathrm{cps}$. Vergleicht man das Verhältnis zwischen dem Untergrund und der sensitiven Fensterfläche (0.0547 cps $/ \mathrm{mm}^{2}$ für den Cyberstar-Detektor und $0.5 \mathrm{cps} / \mathrm{mm}^{2}$ für den Röntec-Detektor), so kann man feststellen, dass der Cyberstar-Detektor viel empfindlicher als der Röntec-Detektor ist. Der Cyberstar-Detektor zeigt für die charakteristische Röntgenstrahlung mehr Intensität als der Röntec-Detektor, z. B. beim $\mathrm{K}_{\alpha}$-Strahl etwa um den Faktor $11 \mathrm{mehr}$. Dies kann dadurch verursacht werden, dass die sensitive Fensterfläche des Cyberstar-Detektors $\left(804.24 \mathrm{~mm}^{2}\right)$ viel größer als die $\left(5 \mathrm{~mm}^{2}\right)$ des anderen ist. Um die energieauflösende Funktion des Röntec-Detektors zu testen, wurde auch die Reflektivität von Si(100) ohne Zr-Filter gemessen. Dabei wurde der Energiebereich auf das Maximum $40 \mathrm{keV}$ eingestellt. In Abb. 3.12 wird die Reflektivität von $\mathrm{Si}(100)$ gegen Energie aufgetragen. Es ist klar zu sehen, dass der Röntec-Detektor mit Einstellung der energieauflösenden Funktion den $\mathrm{K}_{\alpha^{-}}$und $\mathrm{K}_{\beta^{-}}$-Strahl gut auflösen kann, hingegen aber den $\mathrm{K}_{\alpha 1^{-}}$und $\mathrm{K}_{\alpha 2}$-Strahl (Energiedifferenz $\approx 105.13 \mathrm{eV}$ ) nicht. Diese Energieauflösung kann man auch an den technischen Daten (Energieauflösung $\sim 210 \mathrm{eV}$ ) des Detektors erkennen. 


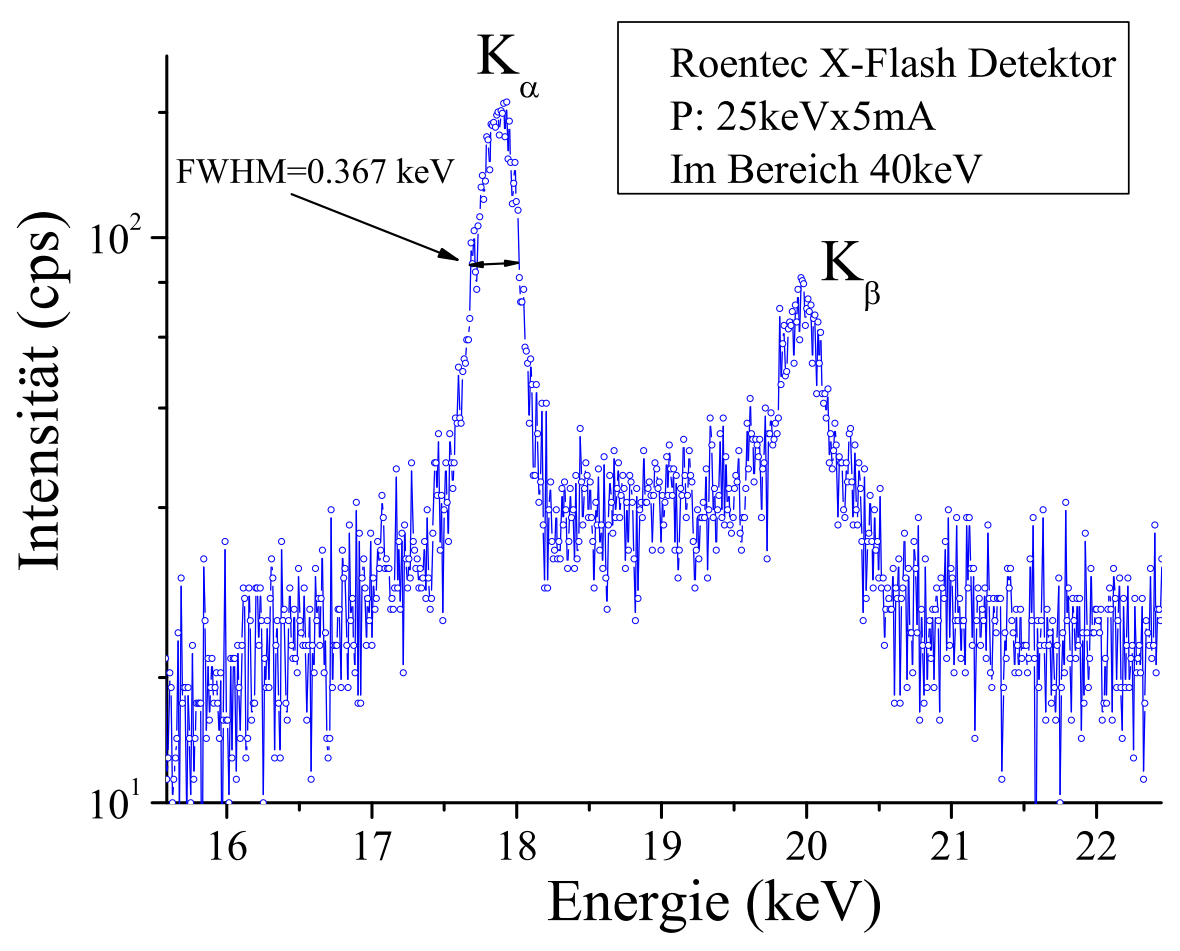

Abbildung 3.12: Die mit dem Röntec XFlash 1000-Detektor gemessene Reflektivitätskurve von Si(100) ohne Zr-Filter. Dieser Detektor kann den $K_{\alpha 1}-$ und $K_{\alpha 2}$-Strahl nicht auflösen.

\section{Messung der DMPC-Lipidmembranen}

Eine Probe von DMPC-Lipiden wurde mit der 2. Reflektometerkonstruktion gemessen. Die verwendete Stammlösung wurde durch eine Mischung von TFE/Chloroform(Volumenverhältnis 1:1) hergestellt. Durch Spreiten auf Si(100) wurde die Probe präpariert. Die Messung mit einer Generatorleistung von $35 \mathrm{kV} \times 50 \mathrm{~mA}$ erfolgte durch Spekular- und offset-scan und wurde unter der Temperatur von $\sim 45^{\circ}$ sowie der relativen Feuchtigkeit von $\sim 99 \%$ durchgeführt. Der offset-Winkel wurde auf $0.1^{\circ}$ gesetzt, um die diffuse Streuung zu messen. Nach dem Abzug der diffusen Streuung (offset-scan) durch spekulare Reflektivität und einer Ausleuchtungskorrektur erhält man eine korrigierte Reflektivitätskurve, die in Abb. 3.13 dargestellt wird. Vergleicht man die FWHM vom 2. Bragg-Peak $\left(\sim 0.0058 \AA^{-1}\right)$ mit der Reflektivitätskurve, die in Abb. 3.9 dargestellt ist $(\sim 0.007$ $\left.\AA^{-1}\right)$, so stellt man fest, dass die Auflösung und die Divergenz des Strahls besser geworden ist.

\subsubsection{Aufbau des Reflektometers: 3. Ausbaustufe}

Zur weiteren Optimierung der Reflektometerkonstruktion wurden folgende Maßnahmen durchgeführt:

- Anstatt des Röntec-Detektor wurde ein Cyberstar-Detektor zum Intensitätsgewinn (wegen der größeren Fensterfläche) angewendet. 
(a)

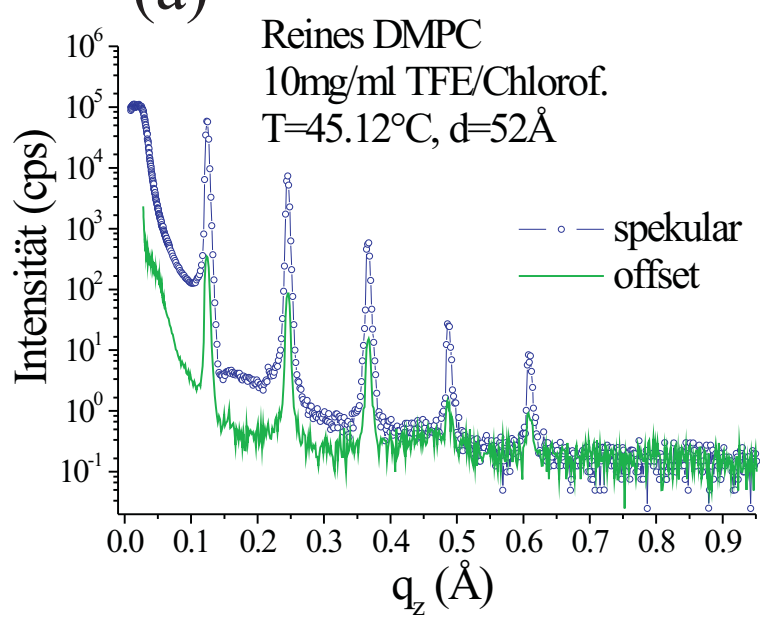

(b)

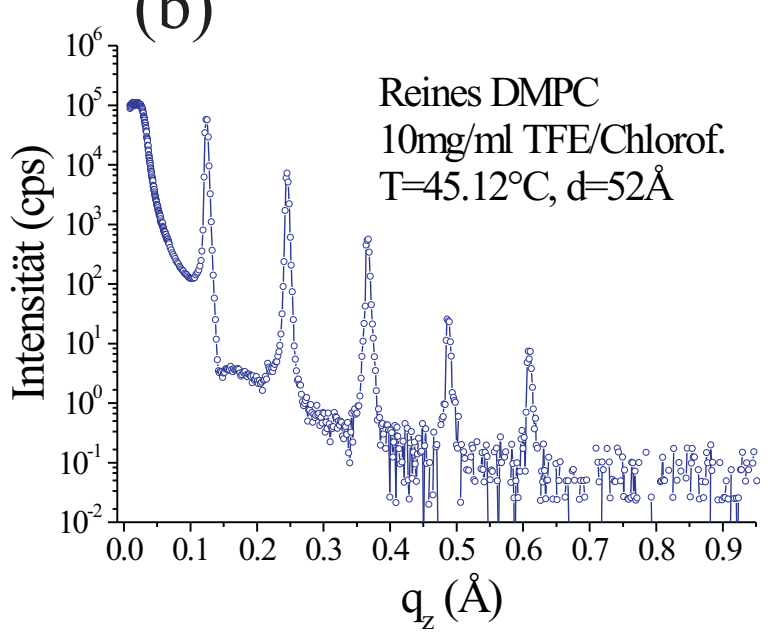

Abbildung 3.13: Die mit dem Röntec-Detektor unter $35 \mathrm{kV} \times 50 \mathrm{~mA}$ Anlagenleistung gemessene Reflektivitätskurve. (a) spekulare Reflektivitätskurve und offset-Kurve der Probe aus DMPC-Membranstapeln; (b) nach dem Abzug der diffusen Streuung von spekularer Reflektivität.

- Ebenfalls zum Intensitätsgewinn und zur teilweisen Strahlenmonochromatisierung wurde ein Multischichtgöbelspiegel aus dem Material W/Si (Modell: Max-Flux 18-061 der Fa. GE Inspection Technologies Ahrensburg GmbH \& Co.KG) eingesetzt. Dieser Multischichtgöbelspiegel hat folgende wichtige Parameter:

Abmessung: $\mathbf{L} \times \mathbf{H} \times \mathbf{B}: \quad 80 \times 20 \times 16 \mathrm{~mm}^{3}$

Zentraler d-Abstand: $37.2 \AA$

Mittlere Reflektivität: $73.1 \%$

Max. lokale Reflektivität: $76 \%$

Min. lokale Reflektivität: $67 \%$

Abweichung vom theoretischen d-Abstand: $<0.35 \AA$

Abweichung von der theoretischen Krümmung: 0.11 arcmin

- Gegebenenfalls kann ein Ge(110)-channel-cut Monochromator zusammen mit dem Multischichtgöbelspiegel verwendet werden.

Abb. 3.14 zeigt die schematische Illustration der 3. Ausbaustufe des Reflektometers. Da der Göbelspiegel nur für den $\mathrm{Cu}-\mathrm{Strahl}$ geeignet ist, musste man die $\mathrm{Cu}$-Röhre verwenden. Das so konstruierte Reflektometer kann die Intensität mindestens um einen Faktor 10 erhöhen. Mit der Generatorleistung von $35 \mathrm{kV} \times 40 \mathrm{~mA}$, EB: $0.1 \times 7 \mathrm{~mm}^{2}$, GB: $4 \times 10 \mathrm{~mm}^{2}$ und DB: $0.3 \times 15 \mathrm{~mm}^{2}$ erreicht die Primärintensität in der Feuchtigkeitskammer $\sim 2 \cdot 10^{7}$ cps. In Abb. 3.15 wurde das Primärstrahlprofil gegen $2 \theta$ dargestellt, dabei war die Leistung der Anlage $20 \mathrm{keV} \times 5 \mathrm{~mA}$. Mit EB: $6 \times 6$ $\mathrm{mm}^{2}$, DB: $0.23 \times 4 \mathrm{~mm}^{2}$ und einem $0.3 \mathrm{~mm} \mathrm{Al-Absorber} \mathrm{beträgt} \mathrm{die} \mathrm{primäre} \mathrm{Intensität} 1.143 \cdot 10^{5}$ cps. 


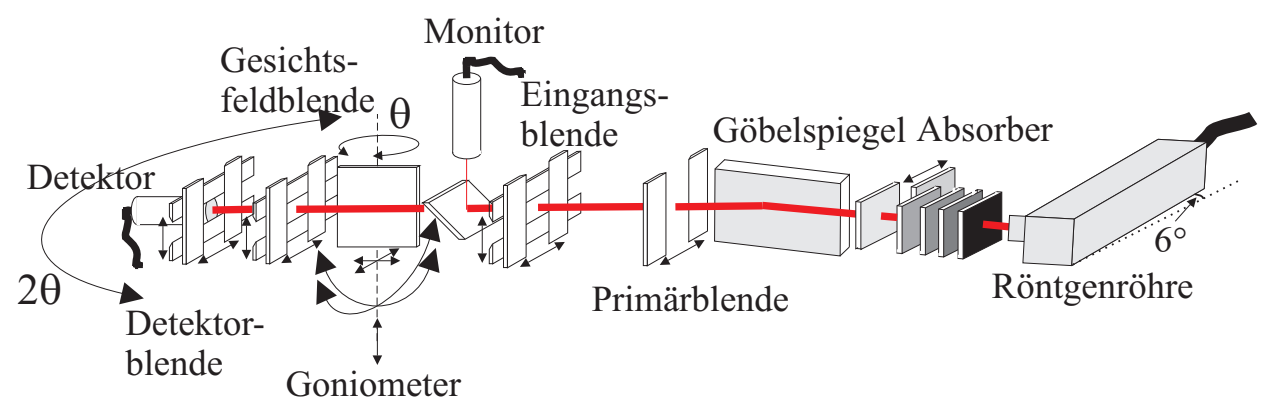

Abbildung 3.14: Schematische Darstellung des 3. Reflektometeraufbaus mit Göbelspiegel, jedoch ohne Ge-channel-cut Monochromator.

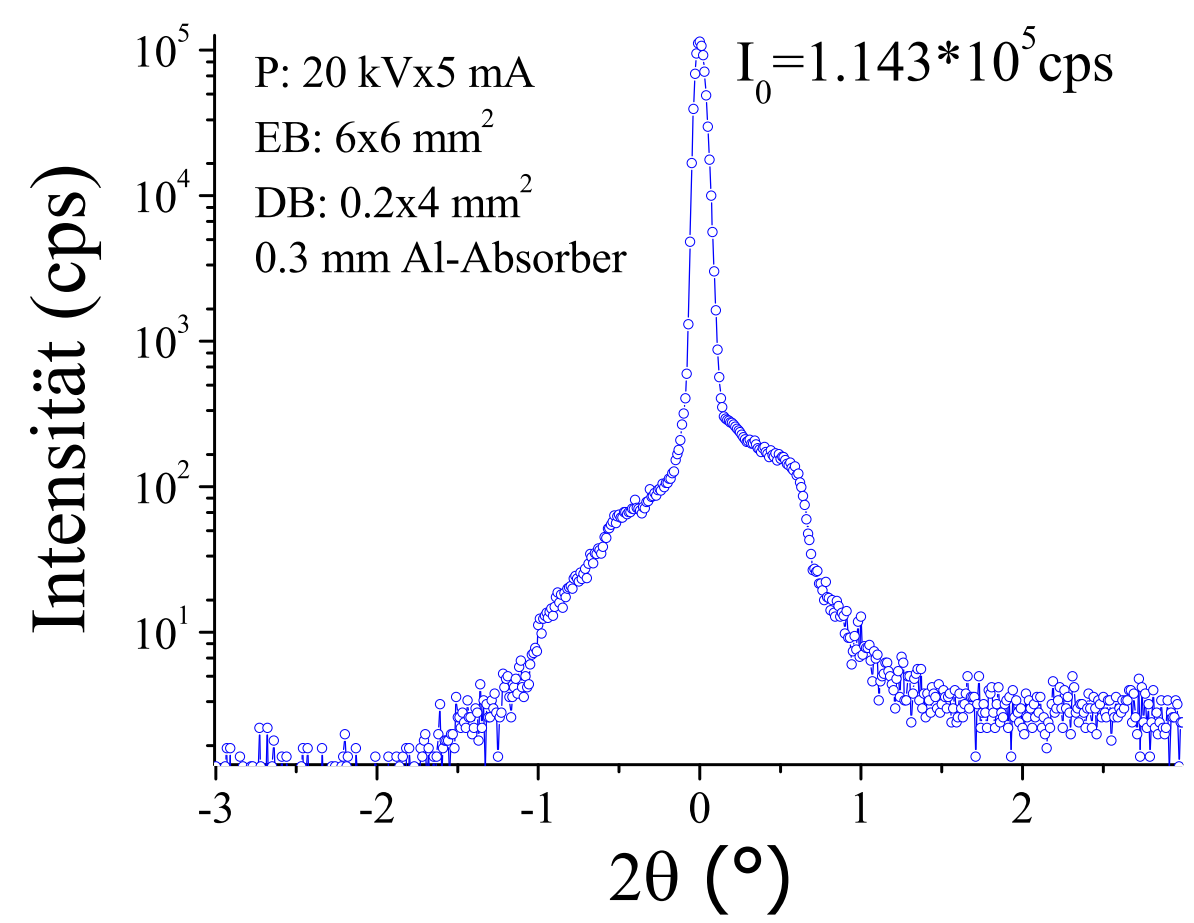

Abbildung 3.15: Das Primärstrahlprofil unter $20 \mathrm{keV} \times 5 \mathrm{~mA}$ Leistung und $0.3 \mathrm{~mm}$ Al-Absorber, die maximale Intensität beträgt $1.143 \cdot 10^{5}$ cps.

\section{Messung der DMPC-Lipidmembranen}

Für die 3. Reflektometerkonstruktion wurde auch eine Messung durchgeführt. Die hier gemessene Probe wurde genauso wie die im Abschnitt 3.4 .3 vorgestellte Probe präpariert. Die Stammlösung zur Präparation hat eine Lipidkonzentration von $20 \mathrm{mg} / \mathrm{ml}$. Bei der Messung hat man eine Generatorleistung von $35 \mathrm{kV} \times 40 \mathrm{~mA}$ verwendet, dabei wurde die $\mathrm{EB}$ auf $0.1 \times 7 \mathrm{~mm}^{2}$, die GB auf $4 \times 10$ $\mathrm{mm}^{2}$ sowie die DB auf $0.3 \times 15 \mathrm{~mm}^{2}$ eingestellt. Durch Benutzung einer Feuchtigkeitskammer konnte die Probe unter einer RH (relative Feuchtigkeit) von $\sim 99.5 \%$ und einer durchschnittlichen Temperatur von $\sim 45.2^{\circ} \mathrm{C}$ gemessen werden; damit befand sich die Probe in einer $\mathrm{L}_{\alpha}$-Phase. In Abb. 3.16 wird die gemessene Reflektivitätskurve, die durch einen offset-scan und einer Ausleuchtungskorrektur korrigiert wurde, gegen $\mathrm{q}_{z}$ aufgetragen. Der FWHM für das 2. Peak beträgt 


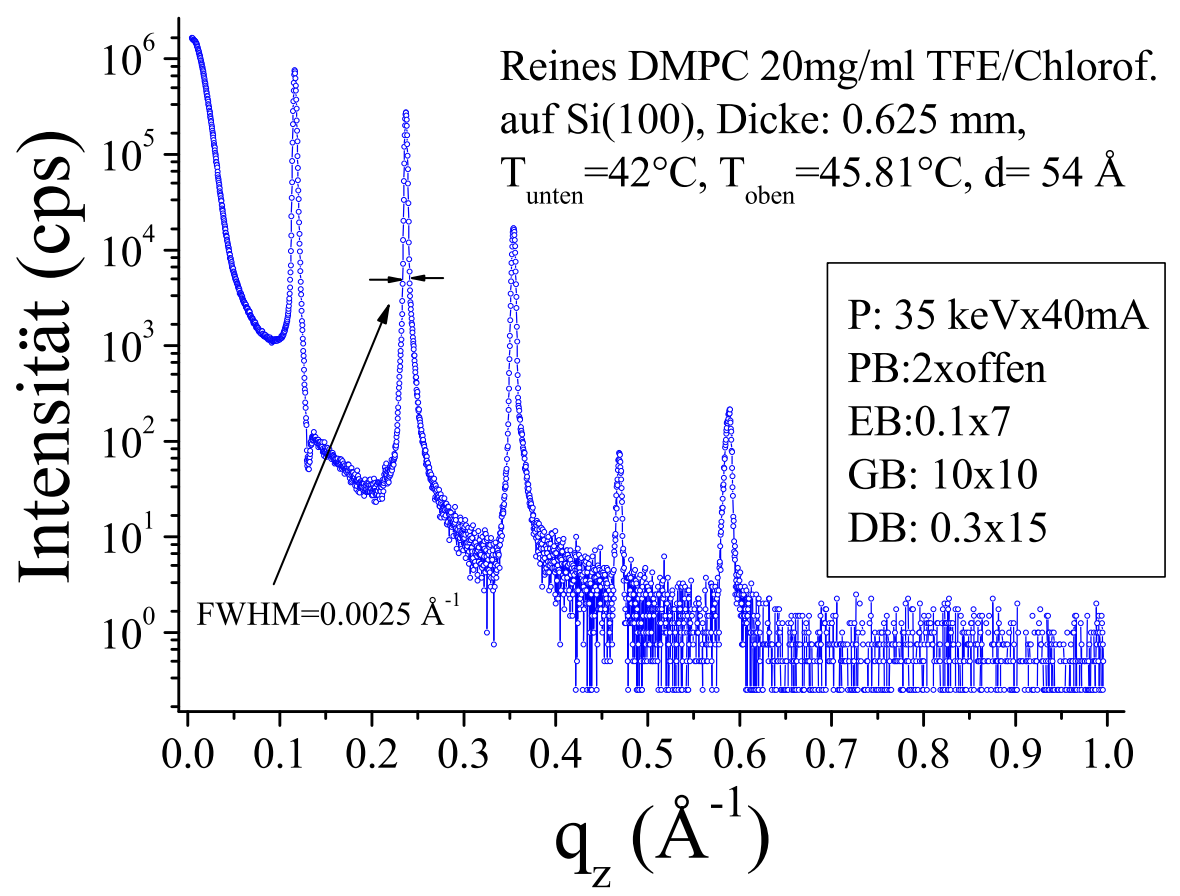

Abbildung 3.16: Reflektivitätskurve der Probe aus reinem DMPC-Membranstapeln in der 3. Ausbaustufe des Reflektometers, dabei war die Anlagenleistung $35 \mathrm{kV} \times 40 \mathrm{~mA}$.

$\sim 0.0025 \AA^{-1}$. Man sieht hier bei der Primärintensität und bei der Auflösung merkliche Verbesserungen.

\subsection{Ablenkmagnet-Reflektometer D4/HASYLAB}

Die Reflektivitätsmessungen wurden meistens am Strahlrohr des Ablenkmagneten D4 am DESY (Deutsches Elektronen-Synchrotron) Labor HASYLAB in Hamburg durchgeführt.

\subsubsection{Reflektometeraufbau}

In Abbildung 3.17 ist der Aufbau des Reflektometers schematisch dargestellt. Durch eine Primärblende wurde die Größe des Synchrotronstrahls grob ausgewählt. Zum Filtern eines unerwünschten hochenergetischen Photonenanteils im Strahl wurde dieser zunächst an einem Rh-Spiegel knapp unterhalb des Grenzwinkels für externe Totalreflexion für die gewünschte Energie reflektiert. Danach wurde der Strahl durch einen Si(111)-Monochromator zu einer Wellenlänge von $\lambda=0.622$ $\AA$ (19.92 keV) monochromatisiert. Die relativ hohe Energie von $19.92 \mathrm{keV}$ wurde gewählt, um die Strahlenschäden in der Probe gering zu halten. Nach dem Monochromator wurde der Strahl durch eine Eingangsblende horizontal und vertikal räumlich definiert, so dass er in einer Breite von $0.1 \sim 0.5 \mathrm{~mm}$ auf die Probe im Drehzentrum eines Goniometers traf. Der an der Probe reflektierte Strahl wurde nach dem Passieren einer Gesichtsfeldblende und einer Kollimationsstrecke mit 
einem Cyberstar-Detektor (siehe Abschnitt 3.4.1) detektiert.

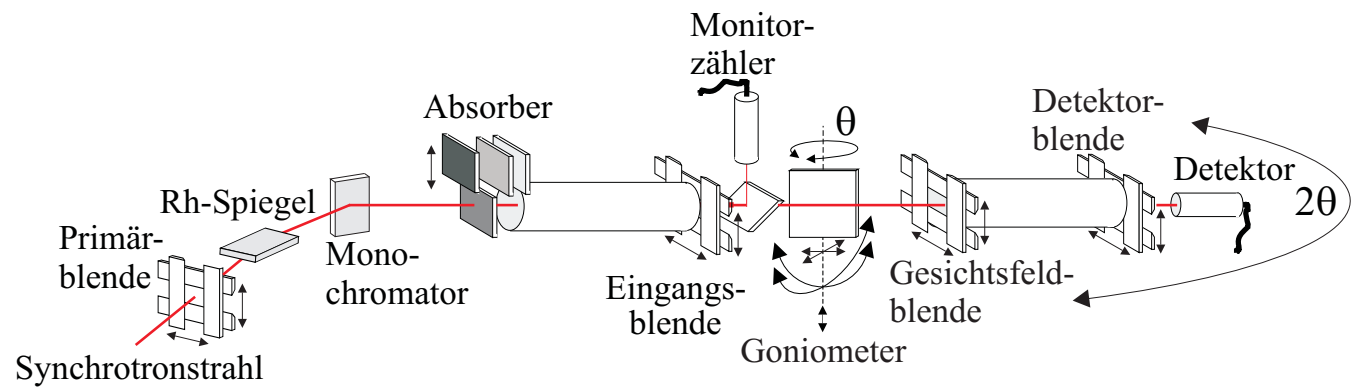

Abbildung 3.17: Schematische Darstellung des Reflektometers am Strahlrohr D4 des HASYLAB im DESY Hamburg.

\subsubsection{Messung von multilamellaren Lipidstapeln in der Feuchtigkeitskam- mer}

Durch Anwendung der Feuchtigkeitskammer wurden multilamellare Lipidstapeln gemessen. Die Temperatur in der Feuchtigkeitskammer wurde während der Messung konstant gehalten, ebenso die relative Feuchtigkeit (RH). Die Proben wurden, wie in Kapitel 2 (Abschnitt Präparation) beschrieben wird, durch Spreiten der Stammlösung mit einer Konzentration von 20mg/ml präpariert. Drei Reflektivitätsmessungen von Probenserien Alamethicin/DMPC werden als Beispiel in der Abb. 3.18 gezeigt. Die Messungen wurden mit einem Multiprobenhalter, auf dem man 3 oder 4 Proben gleichzeitig einbauen kann, durchgeführt, so dass man alle drei Proben zu gleichen physikalischen Bedingungen messen konnte. Die Temperatur in der Feuchtigkeitskammer betrug ungefähr $45^{\circ} \mathrm{C}$ und relative Feuchtigkeit etwa 98\%. Unter diesen Bedingungen befanden sich die Proben in $\mathrm{L}_{\alpha}$-Phase.

\subsubsection{Messung der Oligo-Lipidmembranen in der Feuchtigkeitskammer}

Die Oligo-Lipidmembranen wurden auch in der Feuchtigkeitskammer bei konstanter Temperatur und konstanter Feuchtigkeit gemessen. Die Messungen wurden unter gleichen Bedingungen wie im Abschnitt 3.5.2 durchgeführt. Der einzige Unterschied zu den Messungen im Abschnitt 3.5.2 sind die Proben. Die Proben hier wurden mit dem Spincoater präpariert, so dass die Anzahl der Lipiddoppelschichten viel weniger war ( $\sim 20$ Doppelschichten) als bei den Proben aus multilamellaren Lipidstapeln. In Abb. 3.19 werden als Beispiel zwei Reflektivitätskurven von reinem DMPC mit einer Konzentration von fs $20 \mathrm{mg} / \mathrm{ml}$ und $5 \mathrm{mg} / \mathrm{ml}$ dargestellt. Die Temperatur bei den Messungen betrug ca. $45.02^{\circ} \mathrm{C}$ und die relative Feuchtigkeit ungefähr $98 \%$. Unter dieser Bedingungen befanden sich die Proben dann in der Feuchtigkeitskammer in $\mathrm{L}_{\alpha}$-Phase. 


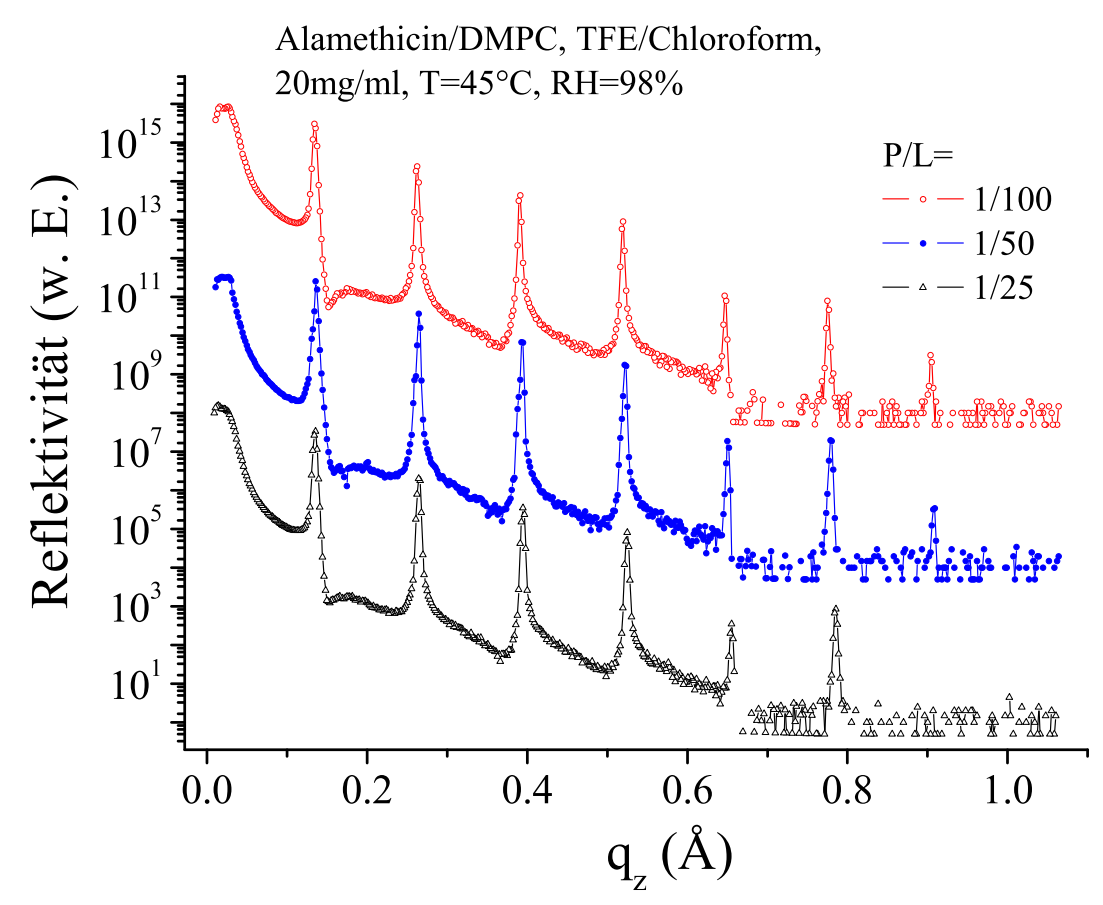

Abbildung 3.18: Beispiel für Reflektivitätsmessungen von multilamellaren Lipidstapeln. Gezeigt werden die Reflektivitätskurven der Probenserie Alamethicin/DMPC unter konstanter Feuchtigkeit und unter konstanter Temperatur. Das Peptid/Lipid-Molverhältnis P/L ist jeweils 1/100, 1/50 und 1/25.

\subsubsection{Messung von multilamellaren Lipidstapeln in Lösung}

In der Nasskammer wurden multilamellaren Lipidstapeln am Strahlrohr D4 HAS YLAB gemessen. Die hier gemessenen Proben sind dieselben, die im Abschnitt 3.5.2 vorgestellt worden sind. Die Messungen wurden aber unter anderen Bedingungen durchgeführt. Die Temperatur während der Messung betrug ca. $30.53^{\circ} \mathrm{C}$ und die Probe lag in einer PEG-Lösung mit einer Konzentration von 14.2\%; damit ergibt sich ein osmotischer Druck von 1.95 bar in der Nasskammer. Die Proben befanden sich unter diesen Bedingungen in der Nasskammer in $\mathrm{L}_{\alpha}$-Phase. In Abb. 3.20 werden beispielhaft drei Reflektivitätskurven, die unter Nasskammer gemessen wurden, dargestellt. 


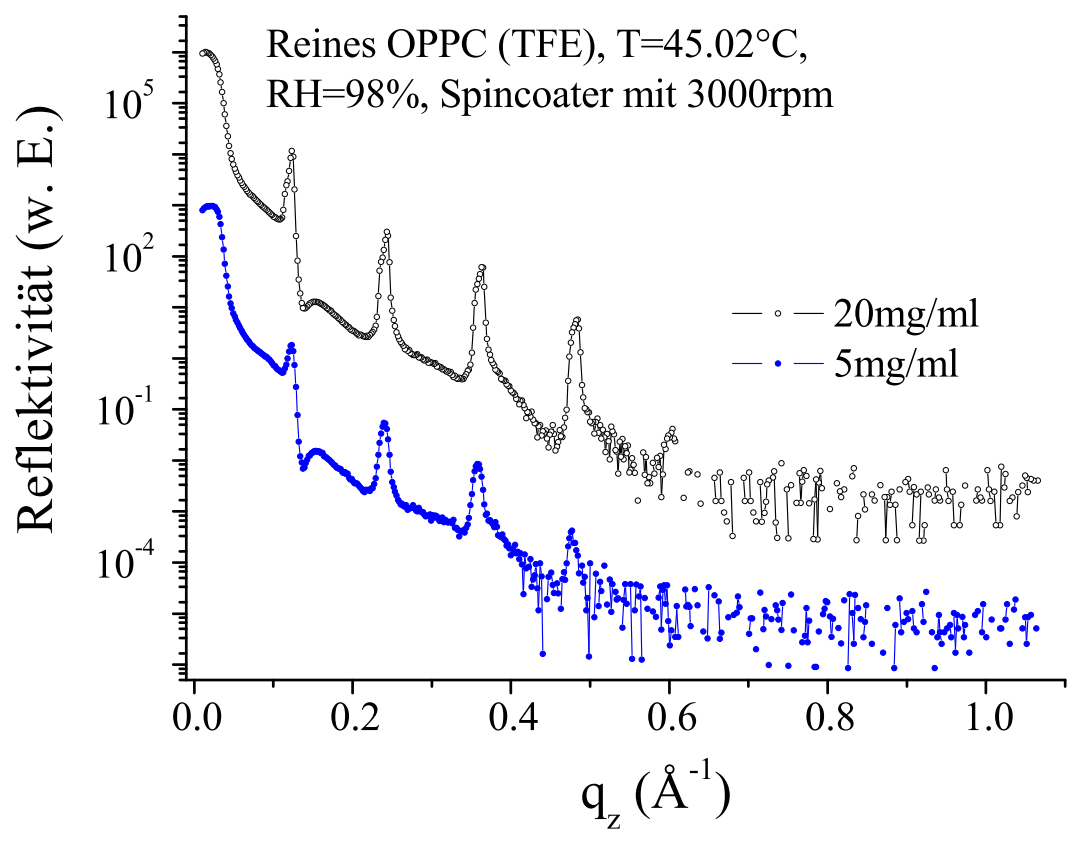

Abbildung 3.19: Beispiel für die Reflektivitätsmessung von Oligo-Lipidmembranen in der Feuchtigkeitskammer bei konstanter Temperatur und bei konstanter Feuchtigkeit.

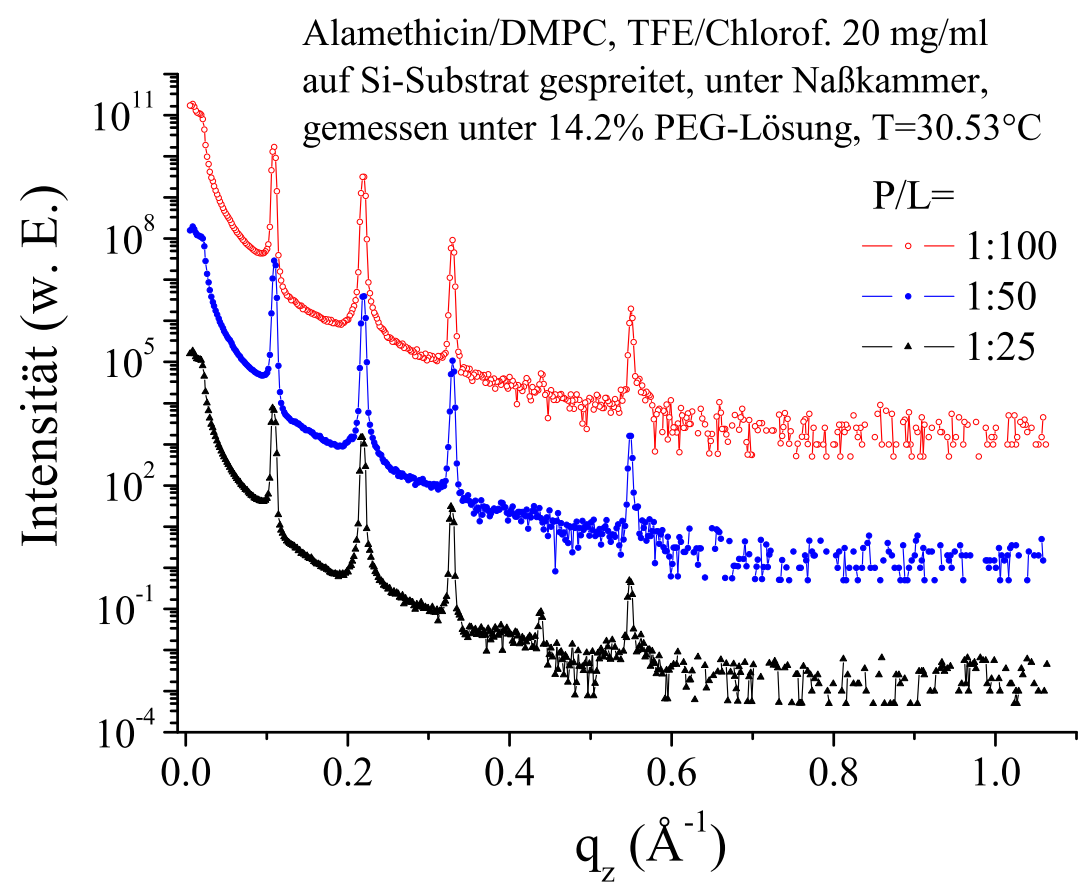

Abbildung 3.20: Beispiel für Reflektivitätsmessungen von multilamellaren Lipidstapeln in Lösung. Gezeigt sind die Reflektivitätskurven der Probenserie Alamethicin/DMPC in PEG-Lösung und bei konstanter Temperatur. Das Peptid/Lipid-Molverhältnis P/L ist jeweils 1/100, 1/50 und 1/25. 


\section{Kapitel 4}

\section{Röntgenstreuung an Membranstapeln in lamellaren Phasen}

In diesem Kapitel werden zuerst allgemeine Grundlagen der Streuung an lamellaren Phasen diskutiert. Es werden die in der Literatur üblichen Begriffe wie Strukturfaktor, Formfaktor, Lorentzfaktor, Polarisation und Absorption eingeführt und die gebräuchliche Methode der Fouriersynthese erörtert. Dabei werden sowohl die gemessenen spekularen als auch die gemessenen diffusen Reflektivitätskurven analysiert. Da wir es aber mit hochorientierten Proben zu tun haben, kommen diese z.T. auch eher empirischen Auswerteverfahren an eine systematische Grenze. Wichtige Effekte, wie die der Fresnelreflektivität, kann diese "Volumen-Streutheorie" nicht erklären, deshalb wenden wir uns im nächsten Kapitel den Grundlagen der grenzflächensensitiven Streuung, d.h. der eigentlichen Röntgenreflektivität zu und konstruieren auf dieser Basis ein Reflektivitätsmodell für orientierte Membranen.

\subsection{Grundlagen und Allgemeines}

\subsubsection{Formfaktor und Strukturfaktor}

Man betrachte einen multilamellaren Membranstapel mit periodischem Elektronendichteprofil in Richtung senkrecht zu Membranoberfläche. Für Röntgenstrahlung ist die Streulängendichte proportional zu Elektronendichte in der Probe (Abb. 4.1). Wenn $\rho(\vec{r})$ die zeitlich durchschnittliche Elektronendichte im Punkt $\vec{r}$ bezeichnet, dann lässt sich die Streuamplitude des Röntgenstrahls am Membranstapel in Bornscher Näherung schreiben als:

$$
f(\vec{q})=\int_{V} \rho(\vec{r}) \exp (i \vec{q} \cdot \vec{r}) d \vec{r}
$$

wobei die Integration über das ganze Volumen der Probe durchzuführen ist. Das Integral in Gl. (4.1) hat die Form eines Fourierintegrals und stellt eine Beziehung zwischen Elektronendichtefunktion $\rho(\vec{r})$ und Streuamplitude $f(\vec{q})$ dar. $f(\vec{q})$ wird im $\vec{q}$-Raum definiert, es ist die Abbildung 


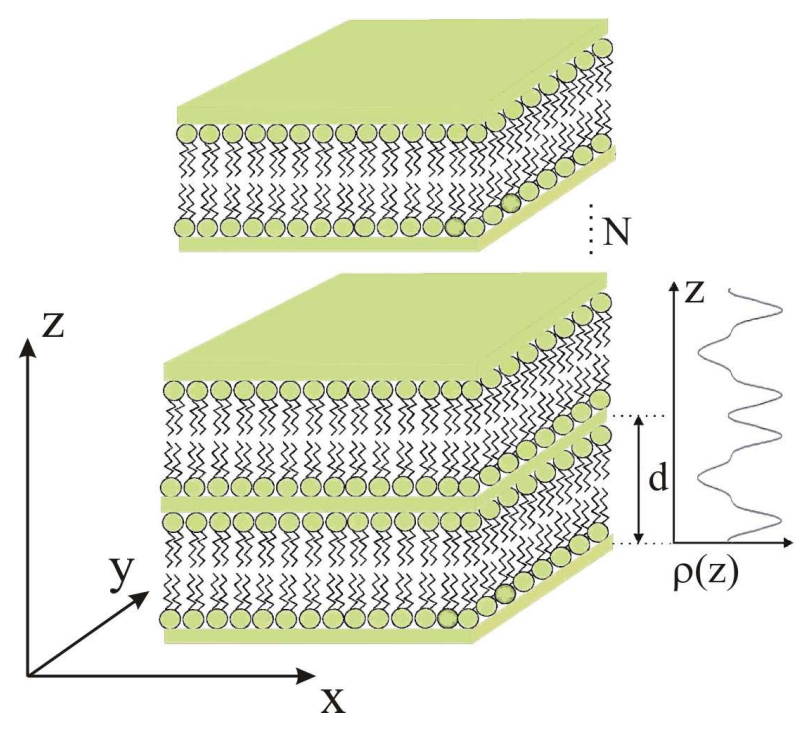

Abbildung 4.1: Schematische Darstellung multilamellarer Membranstapeln und ihrer Geometrie. Die Elektronendichte ist in $x$ - und $y$-Richtung gleich verteilt.

von $\rho(\vec{r})$ in diesem Raum. Die Elektronendichtefunktion kann durch Umkehrfouriertransformation geschrieben werden als:

$$
\rho(\vec{r})=\frac{1}{(2 \pi)^{3}} \int_{V_{q}} f(\vec{q}) \exp (-i \vec{q} \cdot \vec{r}) d \vec{q},
$$

wobei die Integration über den ganzen reziproken Raum erfolgt. Wenn der Membranstapel in der lateralen Richtung überall die gleiche Struktur hat, kann man die Elektronendichte des Membranstapels als planare Matrix mit $N$ Lipiddoppelschichten und mit Periodizität $d$ ausdrücken, nämlich:

$$
\rho(x, y, z+n d)=\rho(x, y, z), \quad 0 \leq z \leq d, \quad n=1,2, \ldots N-1 .
$$

Die Streuamplitude, die sich durch Fouriertransformation aus Gl. (4.3) ergibt, ist

$$
f\left(q_{x}, q_{y}, q_{z}\right)=\int_{-\infty}^{\infty} \int_{-\infty}^{\infty} \int_{0}^{N d} \rho(x, y, z) \exp \left[i\left(q_{x} x+q_{y} y+q_{z} z\right)\right] d x d y d z
$$

Da die Elektronendichtefunktion $\rho(x, y, z)$ unabhängig von $x$ und $y$ ist, kann der von diesen Variablen abhängige Teil in Gl. (4.4) faktorisiert werden als

$$
f\left(q_{x}, q_{y}\right)=\left[\int_{-\infty}^{\infty} \exp \left(i q_{x} x\right) d x\right]\left[\int_{-\infty}^{\infty} \exp \left(i q_{y} y\right) d y\right]
$$

Dieses Integral kann wegen

$$
\int_{-\frac{C}{2}}^{\frac{C}{2}} \exp \left(i q_{x} x\right) d x=\frac{1}{\pi\left(q_{x} / 2 \pi\right)} \sin \left[\pi C\left(q_{x} / 2 \pi\right)\right]
$$

gelöst werden. Entsprechend der Identität

$$
\delta(x)=\lim _{a \rightarrow 0} \frac{1}{\pi x} \sin \left(\frac{x}{a}\right)
$$


wird die Funktion (4.6) zur Dirac- $\delta$-Funktion, wenn $C \rightarrow \infty$ ist. Die Gl. (4.5) wird also

$$
f\left(q_{x}, q_{y}\right)=\delta\left(\frac{q_{x}}{2 \pi}\right) \delta\left(\frac{q_{y}}{2 \pi}\right)=(2 \pi)^{2} \delta\left(q_{x}\right) \delta\left(q_{y}\right) .
$$

$f(\vec{q})$ ist damit nur eine eindimensionale Funktion entlang der $q_{z}$-Achse und kann geschrieben werden als

$$
f\left(q_{x}, q_{y}, q_{z}\right) \propto f\left(q_{z}\right)=\int_{0}^{N d} \rho(z) \exp \left(i q_{z} z\right) d z .
$$

Aufgrund der Periodizität der Elektronendichte $\rho(z)$ lässt sich Gl. (4.7) als Summe der Integrale über einzelne Streueinheiten schreiben:

$$
\begin{aligned}
f\left(q_{z}\right) & =\int_{0}^{d} \rho(z) \exp \left(i q_{z} z\right) d z+\int_{d}^{2 d} \rho(z) \exp \left(i q_{z} z\right) d z+\ldots+\int_{(N-1) d}^{N d} \rho(z) \exp \left(i q_{z} z\right) d z \\
& =\int_{0}^{d} \rho(z) \exp \left(i q_{z} z\right) d z \sum_{n=0}^{N-1} \exp \left(i q_{z} n d\right)=f_{u}\left(q_{z}\right) \underbrace{\sum_{n=0}^{N-1} \exp \left(i q_{z} n d\right)}_{s\left(q_{z}, N\right)}
\end{aligned}
$$

wobei $f_{u}\left(q_{z}\right)$ als Formfaktor einzelner Streueinheiten und $s\left(q_{z}, N\right)$ als Strukturfaktor ( oder Interferenzfunktion ) bezeichnet wird. Der Strukturfaktor $s\left(q_{z}, N\right)$ kann geschrieben werden als:

$$
\begin{aligned}
& s\left(q_{z}, N\right)=\sum_{n=0}^{N-1} \exp \left(i q_{z} n d\right)=\frac{\exp \left(i q_{z} N d\right)-1}{\exp \left(i q_{z} d\right)-1} \\
= & \frac{-2 \sin ^{2}\left(q_{z} N d / 2\right)+i \sin \left(q_{z} N d\right)}{-2 \sin ^{2}\left(q_{z} d / 2\right)+i \sin \left(q_{z} d\right)}=\exp \left[i\left(\frac{N-1}{2}\right) q_{z} d\right] \frac{\sin \left(N q_{z} d / 2\right)}{\sin \left(q_{z} d / 2\right)}
\end{aligned}
$$

Diese Funktion nimmt Maxima bei

$$
q_{z} d=2 m \pi, \quad m=0, \pm 1, \pm 2, \ldots
$$

an, welche die Bragg-Bedingung erfüllen. Der exponentielle Faktor in Gl. (4.9) liefert einen Phasenfaktor. Der Betrag des Strukturfaktors ist

$$
\left|s\left(q_{z}\right)\right|=\left|\frac{\sin \left(N q_{z} d / 2\right)}{\sin \left(q_{z} d / 2\right)}\right| .
$$

Beim m-ten Bragg-Peak ist $q_{z} d=2 m \pi$, und der Betrag $\left|s\left(q_{z}\right)\right|$ hat den Wert $N$. Die Gl. (4.8) lässt sich beim m-ten Bragg-Peak schreiben als:

$$
\left|f\left(\frac{2 m \pi}{d}\right)\right|=N\left|f_{u}\left(\frac{2 m \pi}{d}\right)\right|
$$

Im Streuexperiment wird nicht die Streuamplitude gemessen, sondern die Intensität der Streuung, nämlich

$$
I\left(q_{z}\right)=f\left(q_{z}\right) f^{*}\left(q_{z}\right)=\left|f\left(q_{z}\right)\right|^{2}=\left|f_{u}\left(q_{z}\right)\right|^{2}\left|s\left(q_{z}\right)\right|^{2}
$$


Daher geht die Information der Streuphasen verloren, welche man zur eindeutigen Rekonstruktion des Elektronendichteprofils benötigt (Gl. (4.18)). Beim m-ten Bragg-Peak kann Gl. (4.12) geschrieben werden als:

$$
I\left(\frac{2 m \pi}{d}\right)=N^{2}\left|f_{u}\left(\frac{2 m \pi}{d}\right)\right|^{2} \Longrightarrow\left|f_{u}\left(\frac{2 m \pi}{d}\right)\right|=\frac{1}{N} \sqrt{I\left(\frac{2 m \pi}{d}\right)} .
$$

\subsubsection{Phasenproblem und Rekonstruktion des Elektronendichteprofils}

Der Formfaktor $f_{u}\left(q_{z}\right)$ in Gl. (4.8) ist eine komplexe Größe und gegeben durch

$$
f_{u}\left(q_{z}\right)=\int_{0}^{d} \rho(z) \exp \left(i q_{z} z\right) d z=A\left(q_{z}\right)+i B\left(q_{z}\right) .
$$

wobei $A\left(q_{z}\right)$ und $B\left(q_{z}\right)$ der Real- und Imaginärteil im Formfaktor sind. Man kann den Formfaktor $f_{u}\left(q_{z}\right)$ durch seinen Betrag $\left|f_{u}\right|$ und den Phasenwinkel $\alpha$ folgendermaßen ausdrücken:

$$
\begin{aligned}
f_{u}\left(q_{z}\right) & =\left|f_{u}\right| \exp (\alpha)=\left|f_{u}\right| \cos \alpha+i\left|f_{u}\right| \sin \alpha \\
\text { mit } \quad\left|f_{u}\left(q_{z}\right)\right|^{2} & =A^{2}+B^{2} ; \quad \cos \alpha=\frac{A}{\left|f_{u}\right|} \quad \text { und } \quad \sin \alpha=\frac{B}{\left|f_{u}\right|} .
\end{aligned}
$$

Die Elektronendichtefunktion ist, wie Abb. 4.1 veranschaulicht, eine reelle periodische Funktion mit Periodizität $d$, sie ist eine gerade Funktion, d.h. $\rho(-z)=\rho(z)$. Der Formfaktor (4.14) kann deshalb wie folgt umgeschrieben werden:

$$
f_{u}\left(q_{z}\right)=\int_{0}^{d} \rho(z) \exp \left(i q_{z} z\right) d z=\int_{-d / 2}^{d / 2} \rho(z) \exp \left(i q_{z} z\right) d z=\int_{-d / 2}^{d / 2} \rho(z) \cos \left(q_{z} z\right) d z
$$

wobei die Elektronendichtefunktion $\rho(z)$ im Bereich $(-d / 2 \leq z \leq d / 2)$ umdefiniert wird. Da $B\left(q_{z}\right)=\left|f_{u}\right| \sin \alpha=0$ ist, lässt sich ableiten, dass

$$
\sin \alpha=0 . \quad \Longrightarrow \quad \alpha=n \pi ; \quad n=0, \pm 1, \pm 2, \ldots
$$

Daraus geht hervor, dass nach Gl. (4.15) der Formfaktor $f_{u}\left(q_{z}\right)$ entweder positiv oder negativ sein kann. Für symmetrische Membranen hat die Phase des Formfaktors entweder +1 oder -1 .

Die Elektronendichtefunktion von Membranstapeln (Abb. 4.1) kann aufgrund ihrer periodischen Eigenschaft durch eine Fourierreihe wie folgt dargestellt werden:

$$
\rho(z)=\frac{c(0)}{d}+\frac{2}{d} \sum_{k=1}^{N-1} c(k) \cos (2 k \pi z / d)
$$

wobei

$$
\rho(z)=\rho(z+n d), \quad-d / 2 \leq z \leq d / 2 \quad n=0, \pm 1, \pm 2, \ldots
$$

Die Koeffizienten $c(k)$ sind gegeben durch:

$$
c(k)=\int_{d / 2}^{-d / 2} \rho(z) \cos (2 k \pi z / d) .
$$


Dies ist identisch mit dem Formfaktor der einzelnen Streueinheit $f_{u}\left(q_{z}\right)$ bei $q_{z}=2 \mathrm{k} \pi / d$ ( $k$-ter Bragg-Peak). Die Elektronendichtefunktion $\rho(z)$ lässt sich dann schreiben als:

$$
\begin{aligned}
\rho(z) & =\frac{c(0)}{d}+\frac{2}{d} \sum_{k=1}^{N-1} f_{u}(2 k \pi / d) \cos (2 k \pi z / d) \\
& =\frac{f_{u}(0)}{d}+\frac{2}{d} \sum_{k=1}^{N-1} f_{u}(2 k \pi / d) \cos (2 k \pi z / d) \\
& =\frac{f_{u}(0)}{d}+\frac{2}{d} \sum_{k=1}^{k_{\max }} v_{k}\left|f_{u_{k}}\right| \cos (2 k \pi z / d),
\end{aligned}
$$

wobei die auftretenden Variablen folgende Bedeutung haben:

$$
\begin{aligned}
& f_{u_{k}}: \text { Formfaktor der Streueinheit am } k \text {-ten Bragg-Peak } \\
& v_{k}: \text { Phasenfaktor am } k \text {-ten Bragg-Peak } \\
& k_{\text {max }}: \text { Anzahl der Bragg-Peaks }
\end{aligned}
$$

Der Formfaktor $f_{u_{m}}$ kann also im Prinzip bis auf das Vorzeichen (Phasenproblem !) nach Gl. (4.13) ermittelt werden, wenn die Intensitätsfunktion $I\left(\frac{2 k \pi}{d}\right)$ bei $k$-tem Bragg-Peak bekannt ist. Der Phasenfaktor $v_{k}$ kann ja nach Gl. (4.16) nur zwei Werte (+1 oder -1) haben. Zur Behandlung des eingeschränkten Phasenproblems wurden verschiedene Methoden vorgeschlagen, z.B. die so genannte Schwellungsmethode (swelling-method). Die Schwellungsmethode wurde als erste von Blaurock 1971 auf Lipidmembranen verwendet [150]. Diese Methode beruht auf dem MinimumWellenlängen-Prinzip (minimum wavelength principle), welches aussagt, dass die Maxima und Minima der Fouriertransformation durch das Minimum des reziproken Abstandes abgetrennt werden müssen, der mit dem Kehrwert des größten Abstandes in der Membranstruktur vergleichbar ist [151]. Man geht bei dieser Methode davon aus, dass die Struktur der Lipiddoppelschichten konstant bleibt [150], während sich ihre Periodizität ändert. Wenn die Struktur bei der Membranschwellung nicht verändert wird, trassiert die gemessene Streuamplitude den Modul der Fouriertransformation von der zentralsymmetrischen Einheitszelle. Nach dem Minimum-WellenlängenPrinzip muss sie ein positives oder negatives Vorzeichen haben [152]. Eine kombinatorische Methode wurde von Luzzati et al. präsentiert [153]. Nach dieser Methode generiert man die $2^{N}$ verschiedenen Elektronendichteprofile mit allen möglichen Phasen, und überprüft, ob die Ergebnisse physikalisch und biologisch sinnvoll sind. Anschließend werden die am besten passenden Elektronenprofile als Lösung selektiert. In der vorliegenden Arbeit wird entsprechend verfahren.

Die Elektronendichterekonstruktion setzt jedoch voraus, dass alle weiteren Effekte, die die Streuintensität bestimmen, absepariert und unabhängig korrigiert werden können, also z.B. Effekte der Polarisation, der Absorption, der Brechung, der Reflektivität des Streuvolumens, usw. Dies ist für hochorientierte Proben wegen der auftretenden Fresnelterme streng genommen nicht wirklich der Fall. Auf diesen Punkt gehen wir im nächsten Kapitel noch ein. Aber auch unabhängig von der Frage der Korrekturterme hat die Rekonstruktion der Elektronendichte (4.18) grundsätzliche Unsicherheiten, weil man z.B. den Formfaktor bei $q_{z}=0$ nicht genau messen kann; d.h. die Streuintensität in exakter Vorwärtsrichtung ist nicht zu messen [154]. Der konstante Term $f_{u}(0) / d$ in der 
Fourierreihe ist daher meist undefiniert. Es ist deshalb wichtig zu beachten, dass das Elektronendichteprofil (4.18) nicht die absolute Elektronendichte des Membranstapels repräsentiert, sondern eher die Abweichung von der mittleren Elektronendichte [154]. Diese mittlere Elektronendichte kann geschrieben werden als:

$$
\overline{\rho(z)}=\frac{1}{d} \int_{-d / 2}^{d / 2} \rho(z) d z=\frac{1}{d} \int_{-d / 2}^{d / 2} \rho(z) \cos (0) d z=\frac{f_{u}(0)}{d} .
$$

$\rho(z)$ ist hier eine Kontrastfunktion der Elektronendichte, sie kann deshalb entweder positiv oder negativ sein, abhängig davon, ob die lokale Elektronendichte größer oder kleiner als die durchschnittliche Elektronendichte in den Membranstapeln ist. Die Kontrastfunktion der Elektronendichte kann auch geschrieben werden als: $\rho(z)=\rho_{L}(z)-\rho_{M}$, wenn sich die Proben in einem Medium befinden; hier bezeichnen $\rho_{L}(z)$ die Elektronendichte von Membranen und $\rho_{M}$ die mittlere Elektronendichte des Mediums ( z.B. Wasser ). Als weitere Einschränkung ist zu bemerken, dass der Formfaktor $f_{u_{k}}$ in Gl. (4.18) einen unbekannten Proportionalitätsfaktor enthält, so dass er nicht auf absoluter Skala bestimmt werden kann, es sei denn, man misst auch die gestreute Intensität in absoluten Einheiten, was bei der Reflektivität grundsätzlich möglich ist. Im entsprechenden Abschnitt weiter unten wird das Problem näher diskutiert. Was man im Streuexperiment leicht messen kann, ist in jedem Fall das Verhältnis $\left|f_{u_{1}} / f_{u_{k}}\right|$ der Formfaktoren.

Der Formfaktor $f_{u}(0)$ kann näherungsweise berechnet werden, wenn die Strukturparameter des einzelnen Lipidmoleküls und die Elektronendichte des Umgebungsmediums bekannt sind. Bezeichnen $A, n_{l}, V_{L}, \rho_{L}$ jeweils die Querschnittsfläche, die Anzahl der Elektronen, das Volumen und die durchschnittliche Elektronendichte des Lipidmoleküls, wird der Formfaktor $f_{u}(0)$ durch folgende Beziehung gegeben [155]:

$$
A f_{u}(0)=2\left(n_{L}-\rho_{M} V_{L}\right)=2\left(\rho_{L}-\rho_{M}\right) V_{L},
$$

wobei $\rho_{M}$ die Elektronendichte des Umgebungsmediums ist.

\subsection{Korrekturfaktoren: Absorption, Polarisation, Lorentzfak- tor}

Bisher sind wir davon ausgegangen, dass die gemessene Streuverteilung idealisierterweise als Produkt aus Form- und Strukturfaktor geschrieben werden kann:

$$
I(q)=|s(q) f(q)|^{2} .
$$

Im Allgemeinen beeinflussen aber noch andere Faktoren das Messsignal $I(q)$, z.B. Absorption, Mosaizität, Polarisation, usw. Vereinfachend wird in der Literatur häufig die Annahme gemacht, dass sich diese Einflüsse in einem effektiven Faktor $L_{z}(q)$ abseparieren lassen:

$$
I(q)=L_{z}(q)|s(q) f(q)|^{2} .
$$

Dieser Faktor heißt in der klassischen Pulverstreuung Lorentz-Polarisationsfaktor [156] und ergibt sich vor allem aus Effekten der Polarisation und der Rotationsmittelung. Vor diesem Hintergrund 
betrachten wir in im Folgenden nun zunächst die Effekte der Absorption auf die Streuintensität, dann die Polarisation und schließlich den Lorentzfaktor.

\section{Absorption:}

Bei Streuung eines Röntgenstrahls an Membranstapeln wird dieser teilweise absorbiert. Der Imaginärteil $\beta$ vom Brechungsindex $n$ ( siehe nächstes Kapitel ) bestimmt den sog. linearen Absorptionskoeffizienten, der durch $\mu=\frac{4 \pi}{\lambda} \beta$ gegeben ist. Die Intensität des Röntgenstrahls nimmt dann mit der Weglänge der durchlaufenen Membranstapeln $l$ exponentiell ab:

$$
I=I_{0} e^{-\mu l}
$$

wobei $I_{0}$ die Primärintensität bezeichnet. Für einen Membranstapel der Dicke D kann die Absorp-

(a)

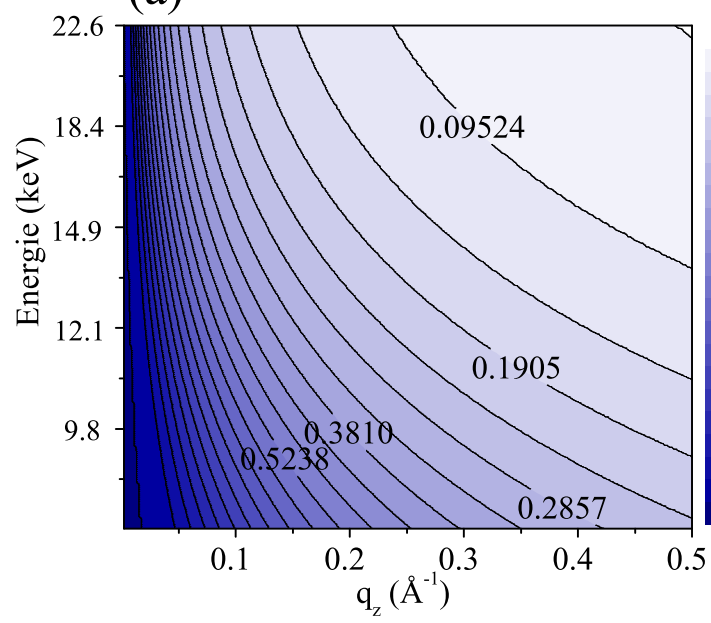

(b)

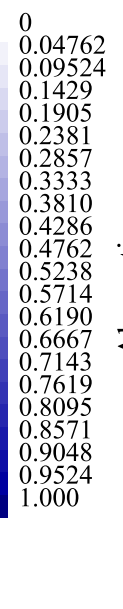

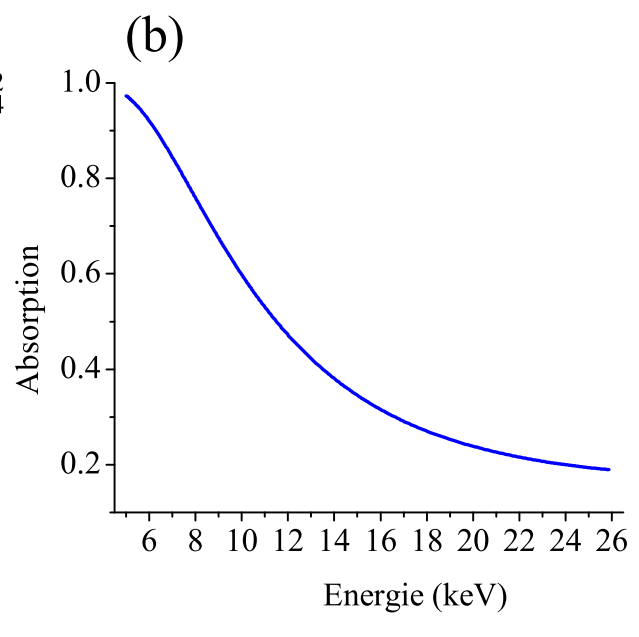

Abbildung 4.2: Absorption der Röntgenstrahlen durch DMPC-Film. (a) Konturbild in Abhängigkeit von der Energie und $q_{z}$ mit einer Filmdicke von $10 \mu \mathrm{m}$; (b) Absorption bei $q_{z}=0.1^{-1}$ in Abhängigkeit von der Energie mit einer Filmdicke von $10 \mu \mathrm{m}$.

tion der Intensität bei Streuung geschrieben werden als:

$$
I=I_{0} e^{-2 \mu \frac{D}{\sin \alpha_{i}}}=I_{0} e^{-\frac{8 \pi D \beta}{\lambda \sin \alpha_{i}}}=I_{0} e^{-\frac{32 \pi^{2} D \beta}{\lambda^{2} q_{z}}} .
$$

Es ist wichtig zu beachten, dass sich Gl. (4.24) auf die Abschwächung der Intensität bezieht, nicht aber auf die Abschwächung der Amplitude. Für die Amplitude beträgt der Abschwächungsfaktor nur $e^{-\frac{16 \pi^{2} D \beta}{\lambda^{2} q_{z}}}$. In Abb. 4.2 werden ein Absorptionskonturbild vom DMPC-Film in Abhängigkeit von der Energie und $q_{z}$ sowie eine Absorptionskurve bei $q_{z}=0.1$ in Abhängigkeit von der Energie dargestellt. Es ist deutlich zu sehen, dass die Absorption mit zunehmender Energie und mit zunehmendem $q_{z}$ abnimmt. 


\section{Polarisation:}

Die Röntgenstrahlen können polarisiert werden, vor allem ist das bei der Synchrotronstrahlung der Fall. Die Streuintensität an einem einzelnen Elektron in Abstand $R$ zum Elektron kann nach der Thomsonschen Streutheorie geschrieben werden als: [156]

$$
I=I_{0} \frac{r_{0}^{2}}{R^{2}} \sin \alpha
$$

wobei $r_{0}$ den klassischen Elektronenradius, $I_{0}$ die Intensität des Einfallstrahls und $\alpha$ den Winkel zwischen dem gestreuten Strahl und der Beschleunigungsrichtung des Elektrons bezeichnet. Angenommen wird ein einfallender Röntgenstrahl in Ox-Richtung (Abb. 4.3), er stößt auf ein

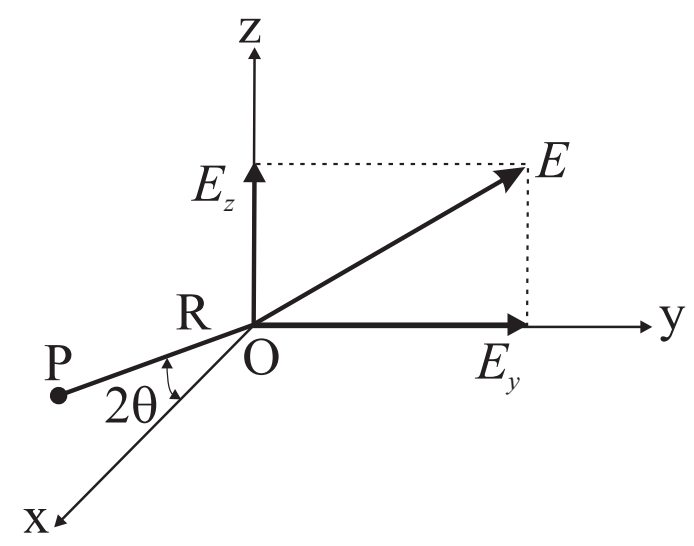

Abbildung 4.3: Thomson-Streuung des Röntgenstrahls durch ein Elektron. Der Röntgenstrahl fällt in die Ox-Richtung ein und trifft das Elektron am Punkt $O$.

Elektron am Punkt O. Die Streuintensität am Punkt P in der xz-Ebene, wobei OP einen Winkel von $2 \theta$ zum Einfallstrahl hat, ist nun zu bestimmen. Bei einem nicht polarisierten Strahl, z.B. aus der Röntgenröhre, hat ein elektrischer Feldvektor $\vec{E}$ in yz-Ebene eine willkürliche Richtung. Dieser elektrische Feldvektor kann in y- und z-Richtung zerlegt werden, nämlich in $\vec{E}_{y}$ und $\vec{E}_{z}$. Es gilt dann

$$
|\vec{E}|^{2}=\left|\vec{E}_{y}\right|^{2}+\left|\vec{E}_{z}\right|^{2}, \quad \Rightarrow \quad E^{2}=E_{y}^{2}+E_{z}^{2} .
$$

Da die Richtung von $\vec{E}$ völlig willkürlich ist, lässt sich die folgende Ableitung angeben:

$$
E_{y}^{2}=E_{z}^{2}=\frac{1}{2} E^{2}
$$

Die Streuintensität ist proportional zum Quadrat der E-Feldstärke, das gilt auch für die Komponenten des E-Feldes; daher gilt folgende Beziehung:

$$
I_{O y}=I_{O z}=\frac{1}{2} I_{0}
$$

Die y-Komponente des Einfallstrahls beschleunigt das Elektron in der Oy-Richtung, nach Gl. (4.25) kann die Streuintensität am Punkt $\mathrm{P}$, die durch $E_{y}$ erzeugt wird, wegen $\alpha=\measuredangle y O P=\pi / 2$ 
geschrieben werden als:

$$
I_{P y}=I_{O y} \frac{r_{0}^{2}}{r^{2}}
$$

In gleicher Weise lässt sich die Streuintensität am Punkt $\mathrm{P}$, die durch $E_{z}$ erzeugt wird, wegen $\alpha=\pi / 2-2 \theta$ schreiben als:

$$
I_{P z}=I_{O z} \frac{r_{0}^{2}}{r^{2}} \cos ^{2} 2 \theta
$$

Die gesamte Streuintensität am Punkt P ist dann die Summe der beiden Komponenten $I_{P y}$ und $I_{P z}$ :

$$
\begin{aligned}
I_{P} & =I_{P y}+I_{P z} \\
& =\frac{r_{0}^{2}}{r^{2}}\left(I_{O y}+I_{O z} \cos ^{2} 2 \theta\right) \\
& =\frac{r_{0}^{2}}{r^{2}}\left(\frac{I_{0}}{2}+\frac{I_{0}}{2} \cos ^{2} 2 \theta\right) \\
& =I_{0} \frac{r_{0}^{2}}{r^{2}}\left(\frac{1+\cos ^{2} 2 \theta}{2}\right),
\end{aligned}
$$

wobei $\left(1+\cos ^{2} 2 \theta\right) / 2$ Polarisationsfaktor genannt wird [156]. Der Einfluss des Polarisationsfaktors ist stärker für große Einfallswinkel $\theta$, so dass er meistens die Messdaten mit hoher Auflösung beeinflusst. Dieser Polarisationsfaktor ist abhängig von den Strahlquellen, da die Röntgenstrahlen aus der Röntgenröhre nicht polarisiert, aber die Röntgenstrahlen aus den Synchrotronquellen in der horizontalen Elektronenbahn (oder Positronenbahn) polarisiert sind; somit ist der Polarisationsfaktor für beide Quellen unterschiedlich.

Im Allgemeinen wird für der Polarisationsfaktor $P$ folgende Fallunterscheidung angegeben [157] [156]:

$$
P= \begin{cases}1 & \text { für Synchrotronquelle mit vertikaler Streuebene, } \\ \cos ^{2}(2 \theta) & \text { für Synchrotronquelle mit horizontaler Streuebene, } \\ \cos ^{2}(2 \theta) \cos ^{2}\left(2 \theta_{M}\right) & \text { für Synchrotronquelle mit horizontaler Streuebene, } \\ & \text { und Monochromator; } \\ \left(1+\cos ^{2}(2 \theta)\right) / 2 & \text { für unpolarisierte Quelle, } \\ \left(1+\cos ^{2}(2 \theta) \cos ^{2}\left(\theta_{M}\right)\right) / 2 & \text { für unpolarisierte Quelle mit Monochromator }\end{cases}
$$

wobei $\theta$ den Einfallswinkel und $\theta_{M}$ den Bragg-Winkel des Monochromators bezeichnen. In Hinblick auf die Reflektivitätskurven dieser Arbeit ist jedoch zu bemerken, dass auf Grund der relativ kleinen Einfallswinkel die Effekte der Polarisation auf den Korrekturfaktor $L_{z}(q)$ ( G1. (4.22) ) als gering zu betrachten sind, so beträgt z.B. für Synchrotronstrahlen bei $\theta_{M}=5.674^{\circ}$ ( $\operatorname{Si}(111)$ Monochromator bei $20 \mathrm{keV}$ ) und $\theta=3^{\circ}$ der Polarisationsfaktor $P$ nur ca. 0.951.

\section{Lorentzfaktor:}

In der klassischen Literatur der Röntgenstreuung gibt es noch weitere wichtige einfallswinkelabhängige Faktoren, die die Streuintensität beeinflussen. Einer davon ist der Lorentzfaktor, welcher 
zwei winkelabhängige Terme zusammenfasst: Zum Einen den Einfluss der unterschiedlichen Summation von Streubeiträgen innerhalb der Braggkurve in Abhängigkeit des Braggwinkels. Die entsprechende geometrische Konstruktion nach Cullity ist im Anhang skizziert. Zum Anderen die gleichmäßige Verteilung von Kristalliten auf der Einheitssphäre bei der Pulverstreuung, die je nach Braggwinkel zu unterschiedlichem geometrischen Gewicht führt. Für eine nicht orientierte (Pulver-) Probe ist die Anzahl der Kristallite, deren Winkelorientierung nahe dem Bragg-Winkel sind, nicht konstant, selbst wenn die Orientierung der Kristalle gleich verteilt ist. Die genaue Betrachtung führt zu einem Gewichtungsfaktor $1 / \cos (\theta)$. Dazu kommt der Effekt, dass die gestreute kegelförmige Strahlung bei der Pulvermessung in Abhängigkeit des Winkels vom Detektor (bei gleicher Detektorblende) unterschiedlich aufgesammelt wird. Deswegen muss noch ein weiterer Faktor $1 / \sin (\theta)^{2}$ für die Pulvermessung berücksichtigt werden. Insgesamt wird folgender Lorentzfaktor $L_{z}$ zur Korrektur der Streuintensität von Kristallen vorgeschlagen [158][156]:

$$
L_{z}= \begin{cases}1 / \sin (2 \theta) & \text { für orientierte Kristalle } \\ 1 /\left(\sin ^{2} \theta \cos \theta\right) & \text { für nicht orientierte Kristalle (Pulver) }\end{cases}
$$

wobei $\theta$ der Einfallswinkel ist. Für Lipidmembranen ist der Lorentzfaktor $L_{z}$ dann entsprechend gegeben durch [159][160][144]

$$
L_{z} \propto \begin{cases}1 / h \propto 1 / q_{z} & \text { für orientierte Membranen (Lipiddoppelschichten) } \\ 1 / h^{2} \propto 1 / q_{z}^{2} & \text { für nicht orientierte Membranen (Vesikel) }\end{cases}
$$

wobei $h$ die Ordnungszahl des Bragg-Peaks ist. Da der Streuvektor in z-Richtung $q_{z} \propto h$ ist, ist es üblich, statt $h$ den Streuvektor $q_{z}$ in Gl. (4.29) einzusetzen. Es bleibt aber zweifelhaft, inwieweit die im Anhang skizzierte Herleitung des Terms $1 / \sin 2 \theta$ aus der klassischen Pulverstreuungsliteratur auch für hochorientierte Membranstapel übertragen werden kann. In der Reflektivität verwendet man in der Regel parallele Strahlung und hochorientierte Proben. Wenn die Breite der Braggreflexe vom Instrument aufgelöst werden kann, ist mit Sicherheit kein Korrekturfaktor anzunehmen. Anders sieht es evtl. bei endlicher Mosaizität, hoher Strahldivergenz bzw. instrumenteller Peakverbreiterung aus. Hier ist die Annahme einer geometrischen $1 / \sin 2 \theta$ Abhängigkeit eventuell plausibel.

Zusammenfassend lässt sich sagen, dass die Intensität des $n$-ten Bragg-Peak $I_{n}$ sich in der klassischen Literatur der Röntgenstreuung an Membranen schreiben lässt als [159][160][144]:

$$
I_{n}=\left|f_{n}\right|^{2} P L_{z} X
$$

wobei die Variablen folgende Bedeutung haben:

$f_{n}$ : Formfaktor der Membranen beim $n$-ten Bragg-Peak

$P$ : Polarisationsfaktor ( Gl. (4.27) )

$L_{z}$ : Lorentzfaktor ( G1. (4.29))

$X$ : Proportionalitätsfaktor 
Für (orientierte und nicht orientierte) Membranen kann der Formfaktor der Einheitszelle nach dieser Theorie bestimmt werden; am $n$-ten Braggreflex kann er nach Gl. (4.27)(4.29)(4.30) geschrieben werden als:

$$
\left|f_{u_{n}}\right|= \begin{cases}\sqrt{\frac{I_{n}}{X}} \cdot \frac{\sqrt{q_{z}}}{\cos 2 \theta_{B_{n}} \cos 2 \theta_{M}}=\sqrt{\frac{I_{n}}{X}} \cdot \frac{4 \sqrt{2 m \pi d}}{\left(2 d^{2}-m^{2} \lambda^{2}\right) \cos 2 \theta_{M}} \sqrt{I_{m}} \text { mit Lorentzfaktor } 1 / q_{z}, \\ \sqrt{\frac{I_{n}}{X}} \cdot \frac{q_{z}}{\cos 2 \theta_{B_{n}} \cos 2 \theta_{M}}=\sqrt{\frac{I_{n}}{X}} \cdot \frac{8 m \pi}{\left(2 d^{2}-m^{2} \lambda^{2}\right) \cos 2 \theta_{M}} \sqrt{I_{m}} \quad \text { mit Lorentzfaktor } 1 / q_{z}^{2},\end{cases}
$$

wobei $\theta_{B_{n}}$ der $n$-te Bragg-Winkel für Lipiddoppelschichten und $\theta_{M}$ der Bragg-Winkel für den Monochromator ist. $X$ ist ein Proportionalitätsfaktor, der evtl. durch Eichung zu bestimmen ist, z.B. durch die Tatsache, dass die Wasserschicht in den Membranstapeln der Elektronendichte von ca. $0.333 e^{-} / 3$ ( bei $\mathrm{T}=25^{\circ} \mathrm{C}$ ) entsprechen sollte. Schwerer als der offene Proportionalitätsfaktor wiegt jedoch die Frage, ob es für den Fall der Reflektivität überhaupt einen Korrekturfaktor gibt. Wir sind daher experimentell wie folgt vorgegangen: Zuerst wird das Verfahren der Fouriersynthese auf OPPC angewendet, anschließend wird das ermittelte Elektronendichteprofil mit dem, das durch Molekulardynamik ermittelt wurde, verglichen. Danach wird das Verfahren auf Mag.2/OPPC-Probenserie mit zwei verschiedenen Lorentzfaktoren angewendet und verglichen. Darüber hinaus wird das Verfahren auch bei diffuser Streuung eingesetzt. Am Ende des Kapitels wird die Anwendung des Verfahrens der Fouriersynthese für die Reflektivität diskutiert und zusammengefasst. Im Kapitel 6 wird das Elektronendichteprofil weiter mit dem, das durch Anpassung mit der Modellfunktion aus der semi-kinematischen Reflektivitätstheorie ermittelt wurde, verglichen und über die daraus resultierenden Ergebnisse diskutiert.

\subsection{Fouriersynthese: Eichung anhand von reinem POPC}

Beim Verfahren der Fouriersynthese muss der unbekannte Proportionalitätsfaktor $X$ in Gl. (4.31) bestimmt werden. Dieser Proportionalitätsfaktor kann durch eine vorhandene Elektronendichte von reinem POPC aus der Molekulardynamik (MD) geeicht werden. Die Reflektivitätskurve wurde mit dem Röntgenstrahl der Photonenenergie von $8.048 \mathrm{keV}\left(\mathrm{Cu}-\mathrm{K}_{\alpha}\right)$ gemessen. Zur Ermittelung des Elektronendichteprofils wird zuerst die integrierte Intensität an jedem Bragg-Peak, wie in Abb. 4.4 (a) gezeigt wird, bestimmt. Die ermittelte integrierte Intensität wird dann in die Gl. (4.31) eingesetzt, um den Formfaktor $f_{u}$ zu bestimmen. Da $\theta_{M}=5.674^{\circ}$ ( Bragg-Winkel von Si(111)Monochromator für $20 \mathrm{keV}$ ) klein ist ( $\cos 2 \theta_{M} \approx 1$ ), wird hier der Polarisationsterm für den Monochromator vernachlässigt. Nach Gl. (4.18) kann das Elektronendichteprofil in z-Richtung ( senkrecht zu Membranoberfläche, siehe Abb. 4.1) rekonstruiert werden als:

$$
\begin{array}{ll}
\rho(z)=\frac{f_{u}(0)}{d}+\frac{1}{\sqrt{X}} \sum_{m=1}^{5} \frac{4 \sqrt{2 m \pi d}}{2 d^{2}-m^{2} \lambda^{2}} \sqrt{I_{m}} \cos (2 m \pi z / d) & \text { mit } L_{z}=1 / q_{z} \\
\rho(z)=\frac{f_{u}(0)}{d}+\frac{1}{\sqrt{X}} \sum_{m=1}^{5} \frac{8 m \pi}{2 d^{2}-m^{2} \lambda^{2}} \sqrt{I_{m}} \cos (2 m \pi z / d) & \text { mit } L_{z}=1 / q_{z}^{2}
\end{array}
$$

wobei $f_{u}(0) / d$ durch die Elektronendichte von Wasser ersetzt werden kann. Durch Vergleich mit einem Elektronendichteprofil desselben Lipids aus der MD [161] kann der freie Proportionalitäts- 
(a)

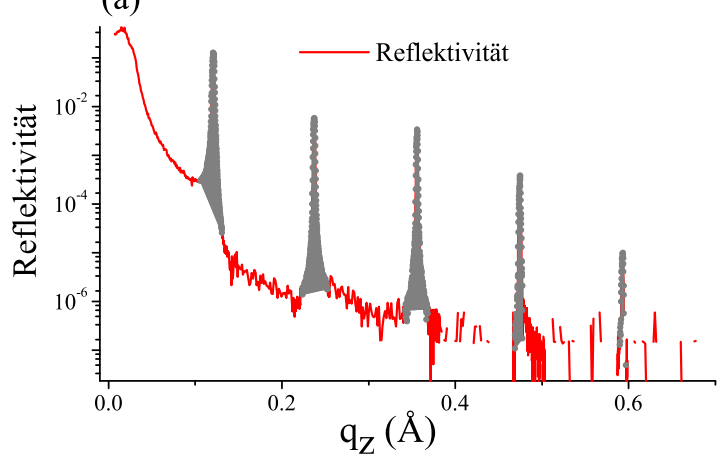

(c)

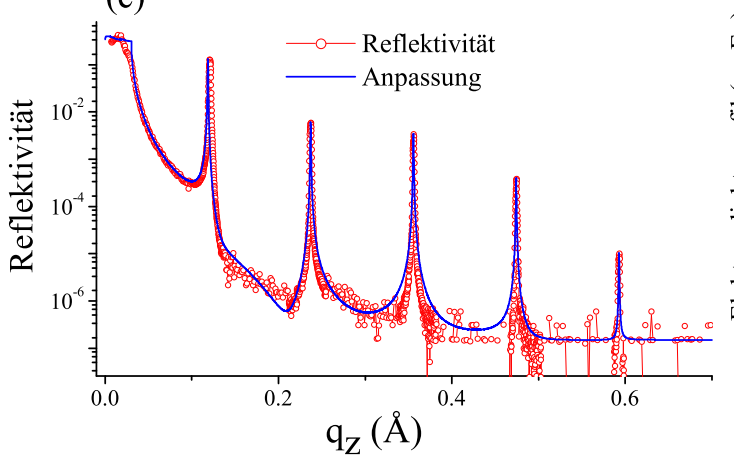

(b)

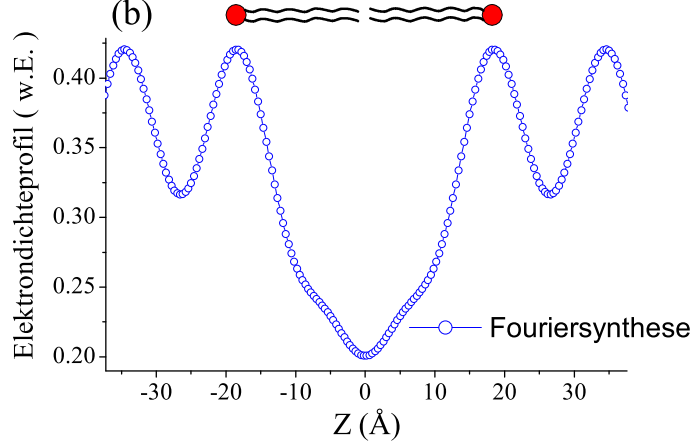

(d)

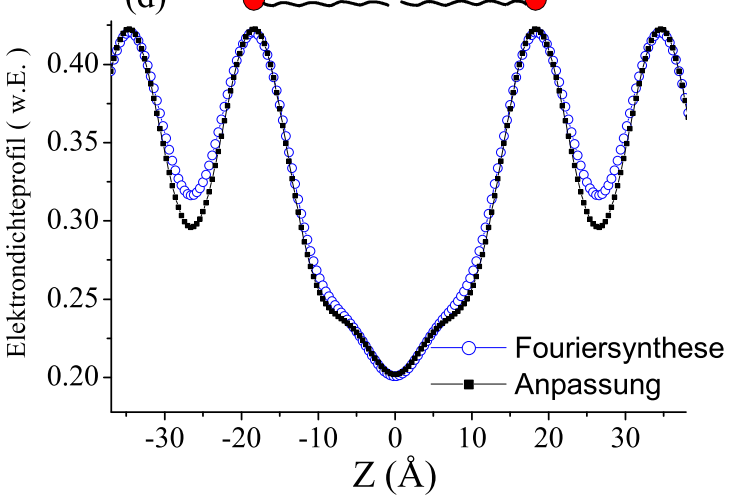

Abbildung 4.4: (a) Die graue Fläche wird integriert zur Bestimmung des Formfaktors; (b) Das durch Fouriersynthese ermittelte Elektronendichteprofil mit $L_{z}=1 / q_{z}^{2}$; (c) Die nach der Modellfunktion angepasste Reflektivitätskurve (siehe Kapitel 5); (d) Die Elektronendichteprofile aus beiden Verfahren. Die Reflektivitätskurve wurde mit einem Röntgenstrahl der Photonenenergie von $8.048 \mathrm{keV}$ gemessen.

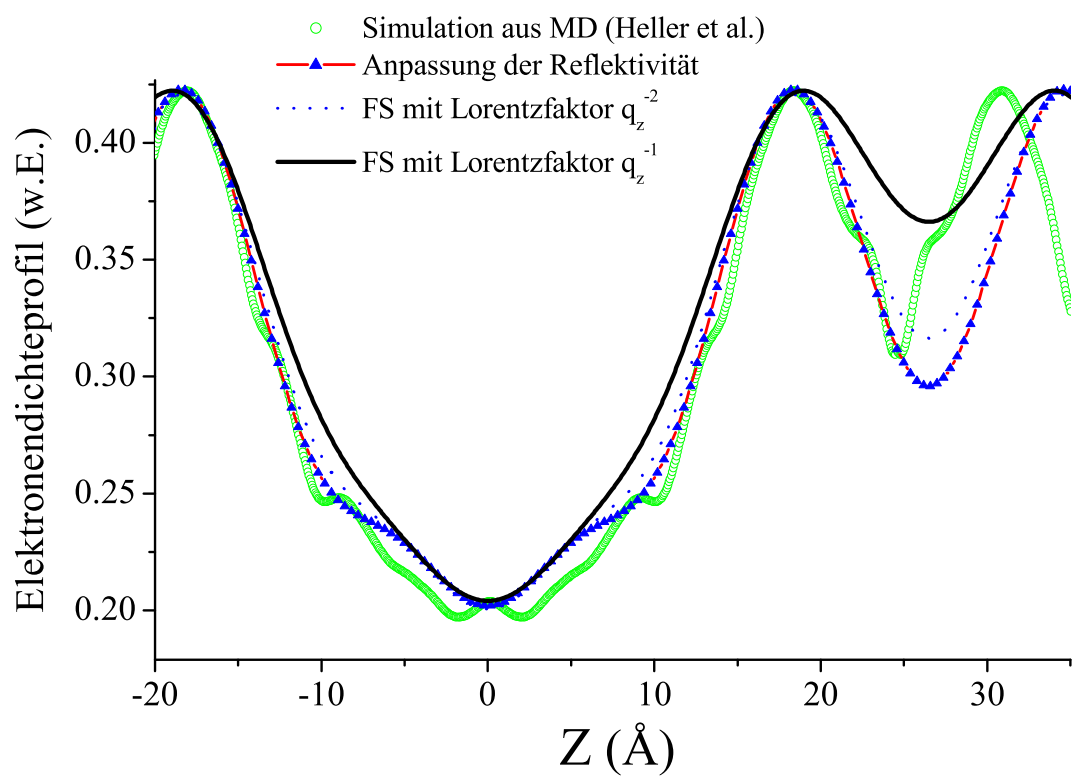

Abbildung 4.5: Die freien Parameter des Elektronendichteprofils von reinem POPC werden durch Vergleich mit dem Elektronendichteprofil desselben Lipids aus der Molekulardynamik geeicht. Anschließend werden die beiden Elektronendichteprofile mit einem Profil aus der MD und einem Profil aus der Anpassung nach der semi-kinematischen Reflektivitätstheorie (siehe Kapitel 5) verglichen. Die hier verwendete Probe wurde mit einem Röntgenstrahl der Photonenenergie von $8.048 \mathrm{keV}$ gemessen. 
faktor bestimmt werden; dabei wird ein Lorentzfaktor von $1 / q_{z}^{2}$ angenommen, weil das Elektronendichteprofil mit $L_{z}=1 / q_{z}^{2}$ besser als das Elektronendichteprofil mit $L_{z}=1 / q_{z}$ zu dem Elektronendichteprofil aus der MD passt. Die Parameter werden hier zu $1 / \sqrt{X}=18.3$ und $f_{u}(0) / d=0.31$ ermittelt. Nun lässt sich das Elektronendichteprofil von reinem POPC schreiben als:

$$
\rho(z)=0.31+18.3 \sum_{m=1}^{5} \frac{8 m \pi}{2 d^{2}-m^{2} \lambda^{2}} \sqrt{I_{m}} \cos (2 m \pi z / d) .
$$

In Abb. 4.4(b) wird das durch Fouriersynthese ermittelte Elektronendichteprofil dargestellt, dabei sind die Phasen des Formfaktors $v_{k}$ ( siehe Gl. (4.18) ) (- - +- ). In Abb. 4.4(c) wird auch eine nach der Modellfunktion der Reflektivität ( siehe nächstes Kapitel ) angepasste Kurve gegen $q_{z}$ aufgetragen, in Abb. 4.4(d) wird dann das durch Anpassung ermittelte Elektronendichteprofil mit dem aus der Fouriersynthese ermittelten zusammen dargestellt. Es ist eindeutig zu erkennen, dass das Elektronendichteprofil im Kopfgruppen- und Kettenbereich gut übereinstimmt, während es im Wasserschichtenbereich einen großen Unterschied gibt. Mit dem Lorentzfaktor $1 / q_{z}$ wird auch das Elektronendichteprofil ( Gl. (4.32) ) von reinem OPPC ermittelt und mit dem Elektronendichteprofil aus der Simulation der Molekulardynamik [161] verglichen. Man kann in Abb. 4.5 deutlich sehen, dass das Elektronendichteprofil aus der Anpassung am besten mit dem aus der MD harmoniert. Weiterhin passt das Elektronendichteprofil mit Lorentzfaktor $1 / q_{z}^{2}$ viel besser als das mit Lorentzfaktor $1 / q_{z}$.

\subsection{Anwendung auf Peptid/Lipid-Systeme}

\section{Magainin2/POPC:}

Das Verfahren der Fouriersynthese wurde in der Probenserie aus Mag.2/POPC verwendet. Die Proben wurden mit Röntgenstrahlen mit $\lambda=1.54 \AA$ ( $\left.8.048 \mathrm{keV}, \mathrm{Cu}-K_{\alpha}\right)$ gemessen. Hier werden die spekularen und diffusen Reflektivitätskurven mit jeweils zwei Lorentzfaktoren ausgewertet. Um zu vergleichen, welches Elektronendichteprofil physikalisch sinnvoll ist, werden in Abb. 4.6 alle vier möglichen Elektronendichteprofile dargestellt, dabei sind alle Phasen der Formfaktoren gleich und mit $(--+--)$ eingesetzt. Die Elektronendichteprofile aus diffuser Streuung mit Lorentzfaktor $1 / q_{z}^{2}$ sind nicht glaubwürdig, da manche Elektronendichteprofile im Wasserschichtenbereich viel niedriger als die mittlere Elektronendichte sind. Auch den Elektronendichteprofilen aus spekularer Streuung mit Lorentzfaktor $1 / q_{z}^{2}$ sind aus dem gleichen Grund nicht zu vertrauen. Im Gegensatz zu den Elektronendichteprofilen von reinem POPC sind die Elektronendichteprofile von Mag.2/POPC aus spekularer und diffuser Streuung mit Lorentzfaktor $1 / q_{z}$ viel besser als die Elektronendichteprofile mit Lorentzfaktor $1 / q_{z}^{2}$. Die Ursache dafür liegt vermutlich darin, dass das Einfügen von Magainin 2 in Lipidmembranen das Elektronendichteprofil des Systems beeinflusst.

\section{Alamethicin/DMPC:}

Eine Probenserie aus Alam./DMPC wurde auch mit dem Verfahren der Fouriersynthese ausgewertet. Spekulare und diffuse Reflektivitätskurven der Proben wurden mit Synchrotronstrahlen mit 

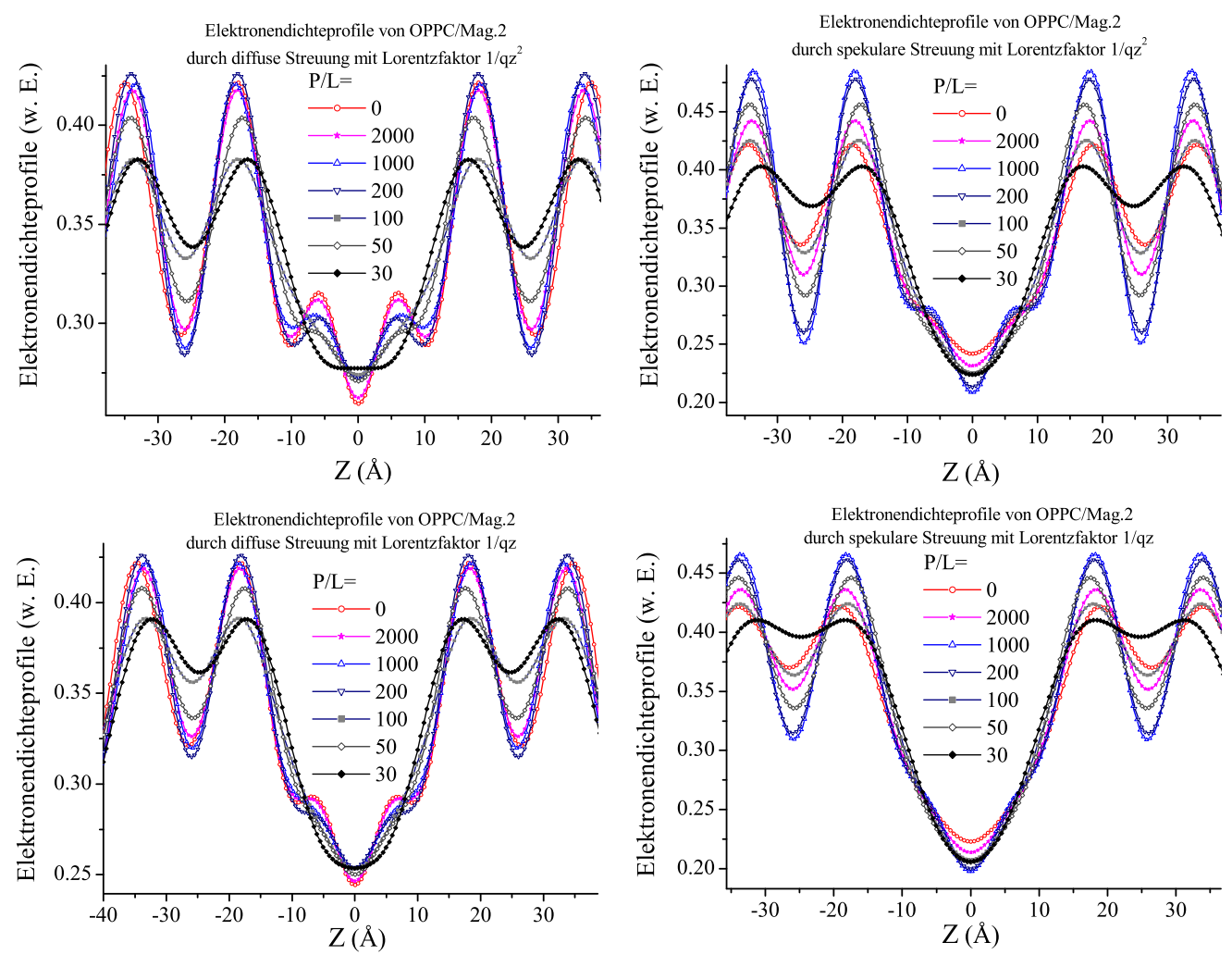

Abbildung 4.6: Elektronendichteprofile der Probenserie Mag.2/POPC, die durch Fouriersynthese mit jeweils zwei Lorentzfaktoren durch spekulare und diffuse Streuung ermittelt wurden. Gemessen wurden die Proben mit einem Röntgenstrahl der Photonenenergie von $8.048 \mathrm{keV}$.
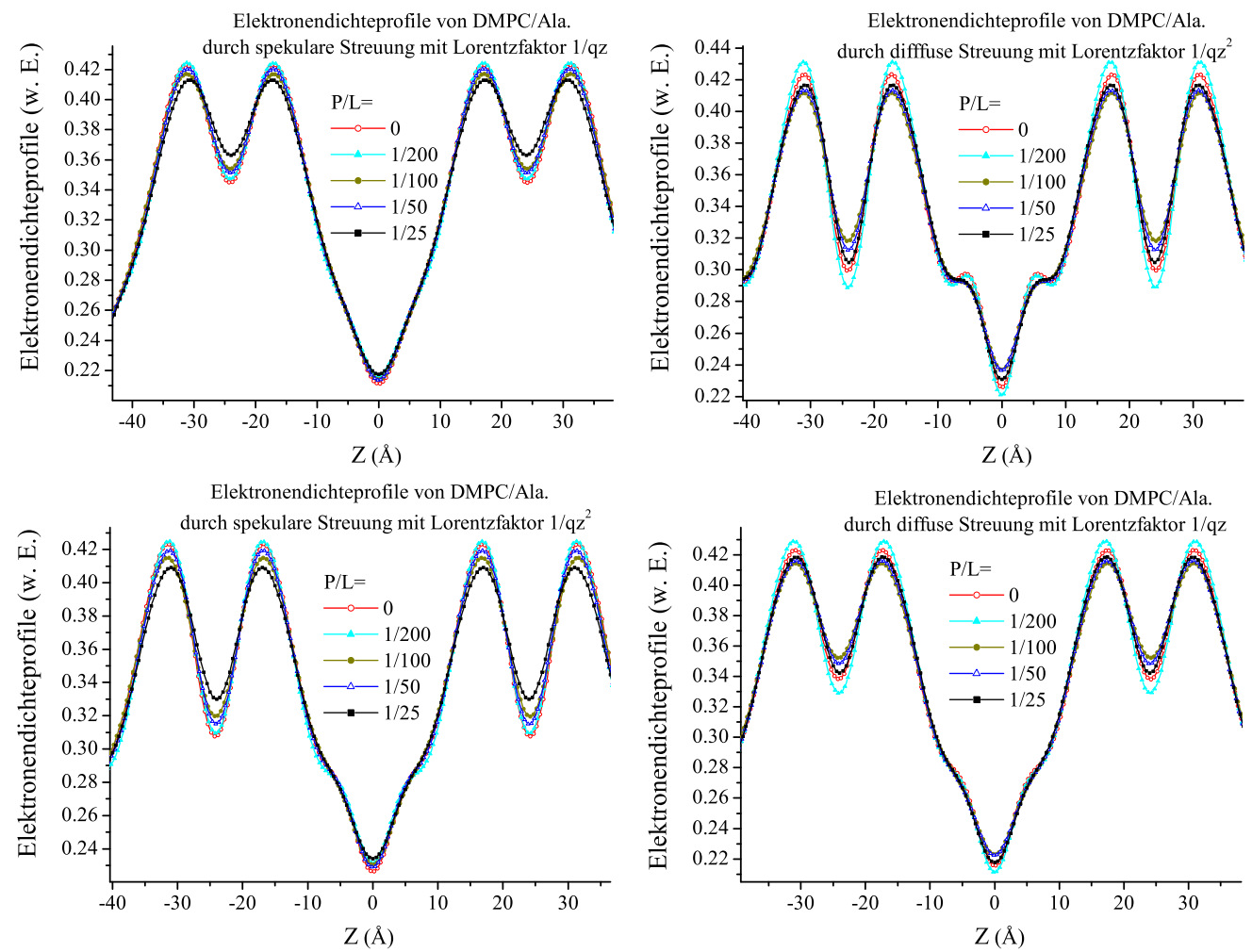

Abbildung 4.7: Elektronendichteprofile der Probenserie Alam./DMPC, die durch Fouriersynthese mit jeweils zwei Lorentzfaktoren durch spekulare und diffuse Streuung ermittelt wurden. Gemessen wurden die Proben mit einem Synchrotronstrahl der Photonenenergie von $20 \mathrm{keV}$. 
$\lambda=0.62 \AA(20 \mathrm{keV})$ gemessen. Analog zur Ermittelung der Elektronendichteprofile der oben erwähnten Probenserie wurden Elektronendichteprofile durch spekulare und diffuse Reflektivitätskurven mit jeweils zwei Lorentzfaktoren bestimmt, dabei wurden alle Phasen der Formfaktoren $(--+--)$ angenommen. Die ermittelte Elektronendichteprofile werden in Abb.4.7zusammen dargestellt. Es ist leicht zu erkennen, dass die Elektronendichteprofile aus spekularen Reflektivitätskurven mit Lorentzfaktor $1 / q_{z}^{2}$ und aus diffusen Reflektivitätskurven mit Lorentzfaktor $1 / q_{z}$ besser als die anderen zwei Elektronendichteprofile die Elektronendichte der Probenserie repräsentieren, da bei den anderen zwei Elektronendichteprofilen, die durch spekularen und diffuse Reflektivitätskurven mit Lorentzfaktor $1 / q_{z}$ und $1 / q_{z}^{2}$ ermittelt wurden, die Elektronendichteprofile im Wasserschichtenbereich entweder zu hoch oder zu niedrig sind.

\subsubsection{Probleme bei Anwendung der Fouriersynthese}

Aus den im vergangenen Abschnitt dargestellten Elektronendichteprofilen ist zu erkennen, dass es keinen einheitlichen Lorentzfaktor gibt, der zur Auswertung aller Reflektivitätskurven einsetzbar ist. Ein möglicher Grund dafür ist die Abhängigkeit der Absorption von Energie (siehe Abb. 4.2). Es ist aber empirisch zu erkennen, dass für Synchrotronstrahlen der Energie von $20 \mathrm{keV}$ der Lorentzfaktor $1 / q_{z}^{2}$ für spekulare Reflektivität und der Lorentzfaktor $1 / q_{z}$ für diffuse Reflektivität verwendet werden kann, während für Röntgenstrahlen der Energie von ca. $8.048 \mathrm{keV}$ der Lorentzfaktor $1 / q_{z}$ für spekulare und diffuse Reflektivität einzusetzen ist. Nach dieser Folgerung werden im Ergebnisteil die empirisch gefundene Lorentzfaktoren verwendet, und die Strukturanalyse durch Fouriersynthese wird auf dieser Basis durchgeführt. 


\section{Kapitel 5}

\section{Reflektometrie und Modellierung}

Die Reflektivität wird in der vorliegenden Abhandlung als Hauptuntersuchungsmethode verwendet. Daher werden in diesem Kapitel zuerst die Grundlagen der Röntgenreflektivität, wie etwa Brechungsindex und Fresnelreflektivität, vorgestellt. Wegen der Sensitivität der Reflektivität ist es sinnvoll, entsprechende Korrekturen, wie z.B. die Brechungskorrektur, zu berücksichtigen. Darüber hinaus ist auch die thermische Fluktuation der Membranstapeln eine Einflussquelle auf die Reflektivität, die deshalb bei der Modellierung der Reflektivität berüicksichtigt wird. Die Modellierung der Reflektivität wird auf der Basis semi-kinematischer Näherung entwickelt. Dabei wird das Modell für zwei unterschiedliche Probenumgebungen, nämlich für Wasser und für Feuchtigkeit, separat konstruiert. Die durch diese Methode hergeleitete Modellfunktion basiert auf idealisierten Annahmen, d.h. es werden ideale Röntgenstrahlen (keine Divergenz) und unbegrenzte Auflösung des Instruments angenommen. In realen Experimenten ist das jedoch anders: Die verwendete Röntgenstrahlung hat eine endliche Divergenz, und die Messanlage besitzt eine endliche Auflösung. Aus diesem Grund wird bei der Modellierung der Reflektivität eine Faltungsfunktion eingefügt, um die möglichen instrumentellen Einflüsse auf Reflektivität zu korrigieren. Zur Optimierung des Einsatzes der Faltungsfunktion werden verschiedene Varianten des Gebrauchs der Faltungsfunktion getestet und diskutiert. Im nächsten Kapitel werden dann die Ergebnisse, die durch Anpassung der Modellfunktion an die gemessenen Reflektivitätskurven gewonnen wurden, dargestellt.

\subsection{Reflexion an Grenzflächen}

\subsubsection{Geometrie der Reflexion}

Die Reflexion des Röntgenstrahls wird als Streuung von Photonen durch Elektronen im Medium behandelt. Wenn ein Röntgenstrahl eine Grenzfläche trifft, wird er reflektiert und transmittiert.

Wenn $\lambda$ die Wellenlänge bezeichnet, lässt sich der Streuvektor $\vec{q}=\vec{k}_{r}-\vec{k}_{i}$ nach Abb. 5.1 in x- und 


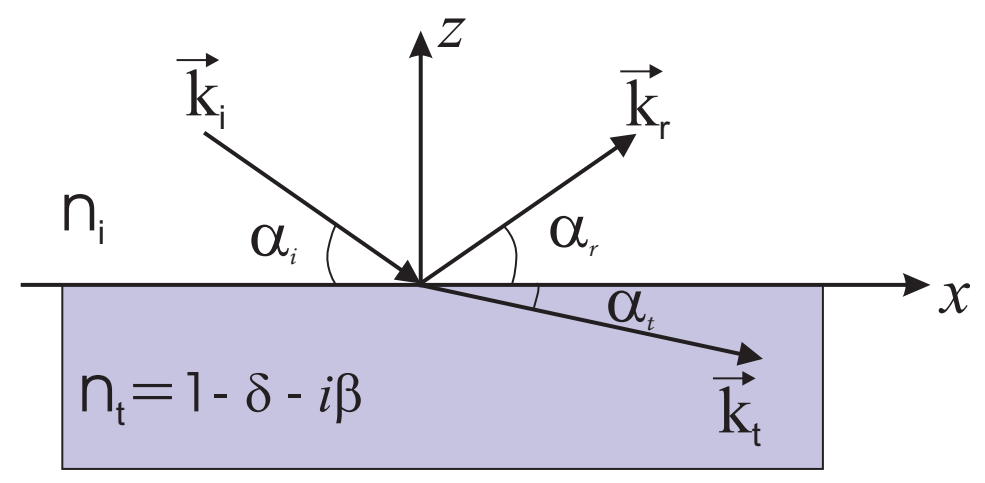

Abbildung 5.1: Geometrie der Reflexion und Transmission des Röntgenstrahls an einer Grenzfläche.

z-Richtung in folgender Form schreiben:

$$
\begin{aligned}
& q_{x}=\frac{2 \pi}{\lambda}\left(\cos \alpha_{r}-\cos \alpha_{i}\right) \\
& q_{z}=\frac{2 \pi}{\lambda}\left(\sin \alpha_{i}+\sin \alpha_{r}\right) .
\end{aligned}
$$

Bei einer späkularen Reflexion ist $\alpha_{i}=\alpha_{r}$, dann kann $q_{z}$ geschrieben werden als:

$$
q_{z}=\frac{4 \pi}{\lambda} \sin \alpha_{i}
$$

\subsubsection{Brechungsindex}

Der Brechungsindex $n$ eines Lichtstrahls ist material- und wellenlängenabhängig und wird definiert durch:

$$
n=\frac{c}{v} .
$$

$c$ : Phasengeschwindigkeit der Welle im Vakuum

$v$ : Phasengeschwindigkeit der Welle im Medium.

Im sichtbaren Bereich der elektromagnetischen Welle gilt dabei $v<c$ und damit $n>1$. Beispielsweise liegt der Brechungsindex $n$ der meisten transparenten Materialien zwischen 1.2 und 2.0. Für Röntgenstrahlung ist die Phasengeschwindigkeit der Welle in Materie größer als $c$, deshalb ist $n<1$. Für den Röntgenstrahl lässt sich der Brechungsindex eines Materials, das aus $\mathrm{m}$ Elementen besteht, schreiben als: [162]

$$
n=1-\frac{r_{0} N_{A} \lambda^{2}}{2 \pi} \sum_{i=1}^{m} \frac{\rho_{i} f_{i}}{A_{i}},
$$

wobei die Variablen folgende Bedeutung haben:

$r_{0}=2.81794092 \cdot 10^{-5} \AA$ : der klassische Elektronenradius,

$\lambda$ : Wellenlänge des Röntgenstrahls,

$N_{A}$ : Avogadrozahl $\left(6.0221367 \cdot 10^{23}\right)$, 
$\rho_{i}$ : partielle Massendichte des i-ten Elements,

$A_{i}$ : partielle relative Atommasse des i-ten Elements,

$f_{i}$ : Atomformfaktor des i-ten Elements.

Der Atomformfaktor beschreibt das wellenlängenabhängige Streuvermögen der Atome. Er kann durch die folgende komplexe Formel dargestellt werden [162]:

$$
f=f^{0}+f^{\prime}+i f^{\prime \prime}
$$

$f^{0}$ ist der unkorrigierte Atomformfaktor, der beim Grenzfall $\vec{q}=0$ gleich Z (Kernladungszahl) ist [157]. $f^{\prime}$ wird als Dispersionskorrektur und $f^{\prime \prime}$ als Absorptionskorrektur zu $f^{0}$ bezeichnet. Der Brechungsindex $n$ kann wegen Gl. (5.6) ebenfalls durch seine komplexe Form dargestellt werden:

$$
n=1-\delta-i \beta
$$

Dabei beschreibt $\delta$ die Dispersion und $\beta$ die Absorption im Material. Man kann $\delta$ und $\beta$ aus Gl. (5.5) und Gl. (5.6) ableiten:

$$
\begin{aligned}
\delta & =\frac{r_{0} N_{A} \lambda^{2}}{2 \pi} \sum_{i=1}^{m} \frac{\rho_{i}}{A_{i}}\left(f_{i}^{0}+f_{i}^{\prime}\right), \\
\beta & =\frac{r_{0} N_{A} \lambda^{2}}{2 \pi} \sum_{i=1}^{m} \frac{\rho_{i}}{A_{i}}\left(f_{i}^{\prime \prime}\right) .
\end{aligned}
$$

Durch Einführung einer mittleren Elektronendichte

$$
\bar{\rho}=\sum_{i=1}^{m} \frac{\rho_{i}}{A_{i} / N_{A}} \underbrace{\left(f_{i}^{0}+f_{i}^{\prime}\right)}_{=Z(\text { bei } \vec{q}=0)}=\sum_{i=1}^{m} \frac{\rho_{i}}{A_{i} / N_{A}} Z
$$

für das Material kann $\delta$ geschrieben werden als: [157][162]

$$
\delta=\frac{r_{0} \bar{\rho}}{2 \pi} \lambda^{2}
$$

\subsubsection{Brechungskorrektur}

Die Wellenzahl für die Einfalls- und Reflexionswelle ist in Vakuum $k=\left|\vec{k}_{i}\right|=\left|\vec{k}_{r}\right|$ und in Materie $n k=\left|\vec{k}_{t}\right|$. Wegen der Brechung des Röntgenstrahls in Materie (siehe Abb. 5.1) wird die Phase der Welle verschoben, und damit die Wellenlänge in Materie geändert. Seien $\lambda$ und $\lambda^{\prime}$ die Wellenlängen in Vakuum und in Materie, dann gilt:

$$
n_{t} k=\left|\vec{k}_{t}\right| \Longrightarrow(1-\delta) \frac{2 \pi}{\lambda}=\frac{2 \pi}{\lambda^{\prime}} \Longrightarrow(1-\delta) \lambda^{\prime}=\lambda .
$$

Nach Snelliusschem Brechungsgesetz lässt sich schreiben:

$$
\underbrace{\underbrace{n_{i}}_{=1}}_{\text {(in Vakuum oder Luft) }} \cos \alpha_{i}=\underbrace{\underbrace{n_{t}}_{1-\delta}}_{(\text {in Materie) }} \cos \alpha_{t} \Longrightarrow \cos \alpha_{i}=(1-\delta) \cos \alpha_{t} .
$$


Beim Grenzfall der externen Totalreflexion ist $\alpha_{t}=0$ und $\alpha_{i}=\alpha_{c}$, es gilt dann:

$$
\delta=1-\frac{\cos \alpha_{i}}{\cos \alpha_{t}}=1-\cos \alpha_{c}
$$

Für kleines $\alpha_{c}$ kann $\cos \alpha_{c}$ nach $\alpha_{c}$ entwickelt werden. Man setzt $n_{t}$ in die Gl. (5.7) ein und leitet unter Vernachlässigung der Absorption des Mediums folgenden Ausdruck ab:

$$
\delta \approx 1-\left(1-\frac{1}{2} \alpha_{c}^{2}\right) \Longrightarrow \alpha_{c} \approx \sqrt{2 \delta}
$$

Unter Anwendung der Gl. (5.10) lässt sich die mittlere Elektronendichte des Materials durch den kritischen Winkel $\alpha_{c}$ für die externe Totalreflexion wie folgt beschreiben:

$$
\bar{\rho}=\frac{2 \pi \delta}{r_{0} \lambda^{2}} \approx \frac{\pi}{r_{0} \lambda^{2}} \alpha_{c}^{2}=\frac{\pi}{r_{0}}\left(\frac{\alpha_{c}}{\lambda}\right)^{2}
$$

Nach Gl. (5.12) kann folgender Ausdruck abgeleitet werden:

$$
\begin{array}{r}
\sin \alpha_{i}=\sqrt{1-\cos ^{2} \alpha_{i}}=\sqrt{1-(1-\delta)^{2} \cos ^{2} \alpha_{t}}=\sqrt{1-(1-\delta)^{2}\left(1-\sin ^{2} \alpha_{t}\right)} \\
=\sqrt{1-(1-\delta)^{2}+(1-\delta)^{2} \sin ^{2} \alpha_{t}}=\sin \alpha_{t} \sqrt{(1-\delta)^{2}+\frac{2 \delta-\delta^{2}}{\sin ^{2} \alpha_{t}}}
\end{array}
$$

Bezeichnet man $q_{z}, \lambda$ und $q_{z t}, \lambda_{t}$ als Streuvektor, Wellenlänge in Vakuum und in Materie, so haben die beiden Streuvektoren folgende Beziehung:

$$
\begin{array}{r}
q_{z}=\frac{4 \pi}{\lambda} \sin \alpha_{i}=\frac{4 \pi}{(1-\delta) \lambda_{t}} \sin \alpha_{t} \sqrt{(1-\delta)^{2}+\frac{2 \delta-\delta^{2}}{\sin ^{2} \alpha_{t}}} \\
=q_{z t} \frac{1}{1-\delta} \sqrt{(1-\delta)^{2}+\left(2 \delta-\delta^{2}\right) \frac{16 \pi^{2}}{q_{z t}^{2} \lambda^{2}}}
\end{array}
$$

Entsprechend lässt sich $q_{z t}$ auch durch $q_{z}$ folgendermaßen ausdrücken:

$$
q_{z t}=\frac{4 \pi}{\lambda_{t}} \sin \alpha_{t}=q_{z} \sqrt{1+\frac{16 \pi^{2}}{q_{z}^{2} \lambda^{2}}\left(\delta^{2}-2 \delta\right)}
$$

Gl. (5.16) und Gl. (5.17) werden als Brechungskorrekturen für Streuvektoren bezeichnet. Diese Korrekturen werden in den folgenden Abschnitten bei der Modellierung der Reflektivität und der Anpassung mit einer Modellfunktion an gemessenen Reflektivitätskurven verwendet. G1. (5.17) kann auch durch $q_{z}$ und $q_{c}$ (kritischer Streuvektor für externe Totalreflexion) ausgedrückt werden. Da nach Anwendung der Gl. (5.13) gilt: $q_{c}=\frac{4 \pi}{\lambda} \sin \alpha_{c}=\frac{4 \pi}{\lambda} \sqrt{1-\cos ^{2} \alpha_{c}}=\frac{4 \pi}{\lambda} \sqrt{1-(1-\delta)^{2}}=$ $\frac{4 \pi}{\lambda} \sqrt{2 \delta-\delta^{2}}$, lässt sich G1. (5.17) schreiben als:

$$
q_{z t}^{2}=q_{z}^{2}-q_{c}^{2}
$$




\subsubsection{Fresnelreflektivität des Röntgenstrahls}

Von besonderer Bedeutung ist die reflektierte Intensität des Röntgenstrahls an einer ideal glatten Oberfläche. Solche reflektierte Intensität wird als Fresnelreflektivität bezeichnet. Es seien:

$$
\vec{E}_{i}(\vec{r}, t)=\vec{E}_{0 i} \exp \left[i\left(\vec{k}_{i} \vec{r}-\omega_{i} t\right)\right]
$$

die einfallende ebene Welle (Abb5.1) und

$$
\vec{E}_{r}(\vec{r}, t)=\vec{E}_{0 r} \exp \left[i\left(\vec{k}_{r} \vec{r}-\omega_{r} t\right)\right]
$$

die reflektierte Welle sowie

$$
\vec{E}_{t}(\vec{r}, t)=\vec{E}_{0 t} \exp \left[i\left(\vec{k}_{t} \vec{r}-\omega_{t} t\right)\right]
$$

die transmittierte Welle. Man definiere die Reflexionsamplitude $r$ und die Transmissionsamplitude $t$ [163] wie folgt:

$$
r \equiv \frac{\left|\vec{E}_{0 r}\right|}{\left|\vec{E}_{0 i}\right|}, \quad t \equiv \frac{\left|\vec{E}_{0 t}\right|}{\left|\vec{E}_{0 i}\right|}
$$

Daraus kann mit den Fresnelschen Gleichungen folgendes abgeleitet werden [157]:

$$
r=\frac{n_{i} \sin \alpha_{i}-n_{t} \sin \alpha_{t}}{n_{i} \sin \alpha_{i}+n_{t} \sin \alpha_{t}}, \quad \quad t=\frac{2 n_{i} \sin \alpha_{i}}{n_{i} \sin \alpha_{i}+n_{t} \sin \alpha_{t}}
$$

Die entsprechenden Intensitäten erhält man dann als Betragsquadrat der Amplitude

$$
R=|r|^{2} \quad \text { und } \quad T=|t|^{2} \text {. }
$$

Bei gegebenem kritischen Winkel $\alpha_{c}$ für externe Totalreflexion und $n_{i}=1$ in Vakuum (oder Luft) lässt sich die Fresnelreflektivität unter Anwendung des Snelliusschen Brechungsgesetzes schreiben als:

$$
R_{F}=\left|\frac{\sin \alpha_{i}-\sqrt{\sin \alpha_{i}^{2}-\sin \alpha_{c}^{2}}}{\sin \alpha_{i}+\sqrt{\sin \alpha_{i}^{2}-\sin \alpha_{c}^{2}}}\right|^{2} .
$$

Mit $q_{z}=\frac{4 \pi}{\lambda} \sin \alpha_{i}$ und $q_{c}=\frac{4 \pi}{\lambda} \sin \alpha_{c}$ lässt sich Gl. (5.19) durch $q_{z}$ und $q_{c}$ ausdrücken:

$$
R_{F}\left(q_{z}\right)=\left|\frac{q_{z}-\sqrt{q_{z}^{2}-q_{c}^{2}}}{q_{z}+\sqrt{q_{z}^{2}-q_{c}^{2}}}\right|^{2} .
$$

Im Fall $q_{z}<q_{c}$ ist $\sqrt{q_{z}^{2}-q_{c}^{2}}$ eine reine imaginäre Zahl, so dass $R_{F}\left(q_{z}\right)=1$. Entsprechend tritt in diesem Fall externe Totalreflexion auf. Wenn dagegen $q_{z}>q_{c}$, dann ist $\sqrt{q_{z}^{2}-q_{c}^{2}}$ eine reelle Zahl, so dass $R_{F}\left(q_{z}\right)<1 . R_{F}\left(q_{z}\right)$ nimmt dann mit steigendem $q_{z}$ immer mehr ab. Diese Abnahme kann 
für großes $q_{z}$ gut charakterisiert werden, indem man den Zähler und den Nenner in Gl. (5.20) durch $q_{z}$ dividiert und $\sqrt{q_{z}^{2}-q_{c}^{2}}$ für $q_{z} \gg q_{c}$ entwickelt. Mit Gl. (5.20) kann dann folgendes abgeleitet werden:

$$
R_{F}\left(q_{z}\right) \approx\left|\frac{q_{c}^{2}}{4 q_{z}^{2}-q_{c}^{2}}\right|^{2} \propto q_{z}^{-4} \quad\left(q_{z} \gg q_{c}\right) .
$$

Die Fresnelreflektivität fällt also mit $q_{z}^{-4}$ ab.

\subsection{Einfluss der thermischen Fluktuation und der statischen Defekte}

\subsubsection{Thermische Fluktuationen der Membranen}

Die Membranstapeln unterliegen thermischen Fluktuation in der wässrigen Umgebung. Die Fluktuation ist abhängig von der Bedingung der Umgebung. Sei $u(x, y, z)$ die Amplitude der Fluktuation. Sie wird als lokale Auslenkung der Membran aus der Gleichgewichtslage beschrieben (siehe Abb. 5.2). Wenn $d$ die Periodizität ( Membrandicke + Wasserschichtdicke ) der Lipiddoppelschicht in der Gleichgewichtslage und $D$ die deformierte Periodizität der Lipiddoppelschicht bezeichnet, kann die Abweichung der lokalen Periodizität geschrieben werden als:

$$
D=D(x, y, z)=d+u(x, y, z)=d+u
$$

Die freie Energie in Bezug auf die Deformation der Periodizität der Lipiddoppelschicht ist gegeben durch [164]:

$$
\begin{gathered}
F=\frac{1}{2} \int_{V} d \vec{r}\left[B\left(\frac{\partial u\left(\mathbf{r}_{\|}, z\right)}{\partial z}\right)^{2}+K\left(\Delta_{\|} u\left(\vec{r}_{\|}, z\right)\right)^{2}\right] \\
+\frac{\gamma}{2} \int_{S} d \vec{r}_{\|}\left(\nabla_{\|} u\left(\vec{r}_{\|}, N d\right)^{2},\right.
\end{gathered}
$$

wobei $\vec{r}_{\|}=(x, y)$, $\mathrm{N}$ die gesamte Anzahl der Lipiddoppelschichten, $\gamma$ die Oberflächenspannung der Membran, $B$ den Kompressionsmodul $\left(\mathrm{J} / \mathrm{m}^{2}\right)$ der Lipiddoppelschichtdicke und $K$ den Biegemodul $(J)$ der Membran bezeichnet. Der Biegemodul $K$ hängt mit der Biegesteifigkeit $K_{S}$ einer einzelnen Membran mit $K=K_{s} / d$ zusammen. Für die festkörpergestützte multilamellare Lipidmembran hängt die Fluktuationsamplitude stark von Zahl und Lage der Lipiddoppelschichten ab, weil das starre und steife Substrat die Fluktuation der nahe beieinander liegenden Membranen stark dämpfen kann; die Fluktuation ist daher bei $z=-d / 2$ Null. Da das angrenzende Medium an der Grenzfläche $z=(N-1 / 2) d(N$ : Anzahl der Lipiddoppelschichten in der Probe) Wasser ist, kann die Oberflächenspannung $\gamma$ als Null angenommen werden [165]. Somit lassen sich die Randbedingungen für die freie Energie schreiben als:

$$
\begin{aligned}
u(x, y,-d / 2) & =0 \\
\left.\frac{\partial u(x, y, z)}{\partial z}\right|_{z=(N-1 / 2) d} & =0 .
\end{aligned}
$$




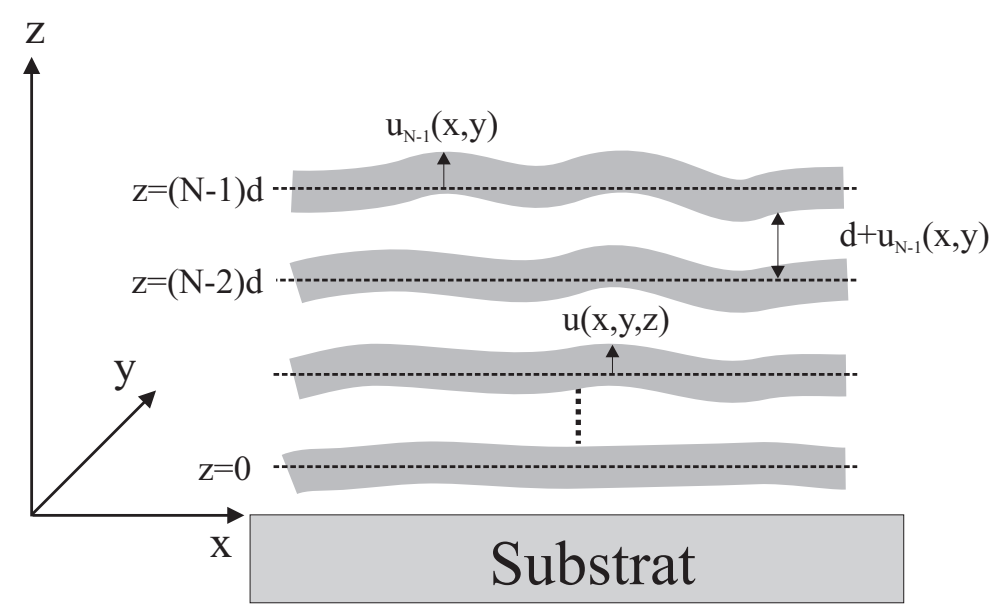

Abbildung 5.2: Schematische Darstellung der Fluktuation der festkörpergestützten multilamellaren Lipidmembranen in wässriger Umgebung. Die dicken grauen Kurven präsentieren fluktuierende Lipiddoppelschichten. Die gestrichelte Linie bezeichnet die Gleichgewichtslage bei $z=n d$. Die Amplitude der Fluktuation $u(x, y, z)$ wird als lokale Auslenkung der Lipidmembranen aus der Gleichgewichtslage dargestellt. Jede Lipiddoppelschicht dehnt sich in der $\vec{r}_{\|}=(x, y)$-Ebene aus.

In Abb. 5.2 wird die Fluktuation der festkörpergestützten multilamellaren Lipidmembranen schematisch dargestellt. Sei $\vec{u}_{n}$ die Fluktuationsamplitude der n-ten Lipidmembran. Die Streuintensität eines Membranstapels kann geschrieben werden als [157]:

$$
\begin{aligned}
I & =\left\langle f(\vec{q}) f^{*}(\vec{q})\right\rangle \\
& =\left\langle f(\vec{q}) \sum_{m=0}^{N-1} e^{i \vec{q} \cdot\left(\vec{r}_{m}+\vec{u}_{m}\right)} f^{*}(\vec{q}) \sum_{n=0}^{N-1} e^{i \vec{q} \cdot\left(\vec{r}_{n}+\vec{u}_{n}\right)}\right\rangle \\
& =\sum_{m=0}^{N-1} \sum_{n=0}^{N-1} f(\vec{q}) f^{*}(\vec{q}) e^{i \vec{q} \cdot\left(\vec{r}_{m}-\vec{r}_{n}\right)}\left\langle e^{i \vec{q} \cdot\left(\vec{u}_{m}-\vec{u}_{n}\right)}\right\rangle
\end{aligned}
$$

wobei $\vec{r}_{m}=(x, y, z)$ die Koordinate für die m-te Membran ist und das Zeichen $\langle\cdots\rangle$ den zeitlichen Mittelwert bezeichnet. Der Einfluss der Membranfluktuation auf die Streuintensität in $q_{z}$-Richtung kann bewertet werden, indem man im letzten Kapitel in Gl. (4.8) $n d$ durch $n d+u_{n}$ ersetzt und anschließend in Gl. (4.12) einsetzt.

$$
\begin{aligned}
I & =\left\langle f\left(q_{z}\right) f^{*}\left(q_{z}\right)\right\rangle \\
& =\left\langle f_{u}\left(q_{z}\right) \sum_{m=0}^{N-1} e^{i q_{z}\left(m d+u_{m}\right)} f_{u}^{*}\left(q_{z}\right) \sum_{n=0}^{N-1} e^{-i q_{z}\left(n d+u_{n}\right)}\right\rangle \\
& =\sum_{m=0}^{N-1} \sum_{n=0}^{N-1} f_{u}\left(q_{z}\right) f_{u}^{*}\left(q_{z}\right) e^{i q_{z} d(m-n)}\left\langle e^{i q_{z}\left(u_{m}-u_{n}\right)}\right\rangle,
\end{aligned}
$$

wobei $u_{n}$ die Fluktuationsamplitude der n-ten Lipidmembran bezeichnet. Da nach dem BakerHausdorff Theorem $\left\langle e^{i x}\right\rangle=e^{-\frac{1}{2}\left\langle x^{2}\right\rangle}$ [157], kann der letzte Term in G1. (5.25) wie folgt abgeleitet 
werden:

$$
\begin{aligned}
\left\langle e^{i q_{z}\left(u_{m}-u_{n}\right)}\right\rangle & =e^{-\frac{1}{2}\left\langle q_{z}^{2}\left(u_{m}-u_{n}\right)^{2}\right\rangle} \\
& =e^{-\frac{1}{2} q_{z}^{2}\left\langle\left(u_{m}-u_{n}\right)^{2}\right\rangle} \\
& =e^{-\frac{1}{2} q_{z}^{2}\left\langle u_{m}^{2}\right\rangle} e^{-\frac{1}{2} q_{z}^{2}\left\langle u_{n}^{2}\right\rangle} e^{q_{z}^{2}\left\langle u_{m} u_{n}\right\rangle} .
\end{aligned}
$$

Formt man den letzten Term um zu $\quad e^{q_{z}^{2}\left\langle u_{m} u_{n}\right\rangle}=1+\left(e^{q_{z}^{2}\left\langle u_{m} u_{n}\right\rangle}-1\right)$, so lässt sich die Streuintensität als Summe zweier getrennter Terme schreiben:

$$
\begin{aligned}
I & =\sum_{m=0}^{N-1} \sum_{n=0}^{N-1} f_{u}\left(q_{z}\right) e^{-\frac{1}{2} q_{z}^{2}\left\langle u_{m}^{2}\right\rangle} e^{i q_{z} m d} f_{u}^{*}\left(q_{z}\right) e^{-\frac{1}{2} q_{z}^{2}\left\langle u_{n}^{2}\right\rangle} e^{-i q_{z} n d} \\
& +\sum_{m=0}^{N-1} \sum_{n=0}^{N-1} f_{u}\left(q_{z}\right) e^{i q_{z} m d} f_{u}^{*}\left(q_{z}\right) e^{-i q_{z} n d}\left[e^{q_{z}^{2}\left\langle u_{m} u_{n}\right\rangle}-1\right]
\end{aligned}
$$

Diese Aufspaltung in den beiden Termen aus Gl. (5.27) ist formal einfach, jedoch gibt es ein Problem bei der Interpretation des Ausdrucks $\left\langle u_{m} u_{n}\right\rangle$. Während $\left\langle u_{n}^{2}\right\rangle$ einen Mittelwert ergibt, der als Zahlenwert der rms-Fluktuationsamplitude entspricht und nicht mehr von $\mathrm{x}, \mathrm{y}$ und $\mathrm{z}$ abhängt, stellt sich bei der Berechnung des Ausdrucks $\left\langle u_{m} u_{n}\right\rangle$ die Frage der lateralen Längenskala, über die der Ausdruck $\left\langle u_{m} u_{n}\right\rangle$ gemittelt wird. Genauer muss man schreiben: $\left\langle u_{m}\left(\overrightarrow{r^{\prime}}\right) u_{n}\left(\overrightarrow{r_{\|}^{\prime}}-\overrightarrow{r_{\|}}\right)\right\rangle_{\vec{r}_{\|}^{\prime}}$ bzw. die Fourier-Transformation dieses Ausdrucks in Bezug auf $\vec{r} \|$ durchführen. Eine exakte Diskussion zeigt, dass der 2. Term in Gl. (5.27) auf die diffuse Streuung führt, während der 1. Term die reine spekulare Reflektivität bei $q_{x}=0$ und $q_{y}=0$ beschreibt (siehe auch nächsten Abschnitt).

Der Term $\left\langle u_{m} u_{n}\right\rangle$ in Gl. (5.27) wird Korrelationsfunktion der Fluktuation genannt. Für von x, y, und $\mathrm{z}$ abhängiges $u_{n}$, d.h. $u_{n}=u(x, y, n d)$ kann die Korrelationsfunktion bei $x=y=0$ geschrieben werden als [166] :

$$
\begin{aligned}
C\left(0, z, z^{\prime}\right) & =\left\langle u(0,0, z) u\left(0,0, z^{\prime}\right)\right\rangle \\
& =\eta\left(\frac{d}{\pi}\right)^{2} \sum_{n=1}^{N} \frac{1}{2 n-1} \sin \left(\frac{2 n-1}{2} \pi \frac{z}{N d}\right) \sin \left(\frac{2 n-1}{2} \pi \frac{z^{\prime}}{N d}\right),
\end{aligned}
$$

wobei $\eta=\pi K_{B} T /\left(2 d^{2} \sqrt{K B}\right)$ (Caillé Parameter $\eta$ ) und $N$ die Gesamtanzahl der Lipiddoppelschichten sind ( $K_{B}:$ Boltzmannkonstante). Die bisherigen Formulierungen die thermische Fluktuation betreffend gelten auch für die Fluktuation der Membranen aufgrund der Wechselwirkung zwischen Lipidmembranen und Peptiden.

\subsubsection{Diffuse Streuung durch Fluktuationen oder durch Grenzflächen}

\section{Diffuse Streuung durch raue Grenzflächen:}

Die diffuse Streuung aufgrund der Rauigkeit oder Fluktuation einer Grenzfläche kann durch eine Höhenkorrelationsfunktion $\langle\delta z(0) \delta z(\vec{R})\rangle$ charakterisiert werden, wobei $\delta z(\vec{R})$ die Abweichung 
von der mittleren lokalen Grenzfläche bei einer lateralen Position $\vec{R}$ in $\operatorname{der}(x, y)$-Ebene ist. Man definiert also die Höhenkorrelationsfunktion wie folgt [167] :

$$
C(\vec{R}) \equiv\langle\delta z(0) \delta z(\vec{R})\rangle, \text { mit } C(0)=\sigma^{2}
$$

wobei $\sigma$ die Rauigkeit der Grenzfläche bezeichnet. Für eine einzelne Grenzfläche kann die diffuse Streuung geschrieben werden als [167]:

$$
I(\vec{q})_{d i f f u s}=\frac{A(\Delta \rho)^{2}}{q_{z}^{2}} e^{-q_{z}^{2} \sigma^{2}} \iint\left[e^{q_{z}^{2} C(\vec{R})}-1\right] e^{-i\left(q_{x} x+q_{y} y\right)} d x d y
$$

wobei $A$ die bestrahlte Fläche der Probe ist und $\Delta \rho$ den Kontrast der Elektronendichte zwischen beiden Medien bezeichnet, die die Grenzfläche bilden. Für Mehrfachgrenzflächen kann die Korrelationsfunktion entsprechend definiert werden durch [167]:

$$
C_{i j}(\vec{R})=\left\langle\delta z_{i}(0) \delta z_{j}(\vec{R})\right\rangle
$$

wobei $\delta z_{i}$ und $\delta z_{j}$ die Abweichung von der $i$-ten und $j$-ten mittleren Grenzfläche ist. Die diffuse Streuung der Mehrfachgrenzflächen lässt sich in Bornscher Näherung schreiben als [167] :

$$
I(\vec{q})_{d i f f u s}=\frac{A}{q_{z}^{2}} \sum_{i, j=1}^{N} e^{-0.5 q_{z}^{2}\left(\sigma_{i}^{2}+\sigma_{j}^{2}\right)} \Delta \rho_{i} \cdot \Delta \rho_{j} \cdot e^{i q_{z}\left(z_{i}-z_{j}\right)} \cdot \varepsilon_{i j}(\vec{q}),
$$

wobei

$$
\varepsilon_{i j}(\vec{q})=\iint\left[e^{q_{z}^{2} C_{i j}(\vec{R})}-1\right] e^{-i\left(q_{x} x+q_{y} y\right)} d x d y .
$$

$\sigma_{i}$ ist hier die Rauigkeitsamplitude der $i$-ten Grenzfläche, $\Delta \rho_{i}$ bezeichnet den Kontrast der Elektronendichte über diese Grenzfläche, $z_{i}$ ist die entsprechende mittlere Höhe.

\section{Die Höhenkorrelationsfunktion von festkörpergestützten Membranen:}

Die Höhenkorrelationsfunktion für die Fluktuationen lässt sich bei smektischer Phase der Membranen auf Substrat schreiben als [166]:

$$
\begin{aligned}
& C(r, k d, l d)=\langle u(x, y, k d) u(x, y, l d)\rangle=\left\langle u_{k} u_{l}\right\rangle \\
= & \eta\left(\frac{d}{\pi}\right)^{2} \cdot \sum_{n=1}^{N} \frac{4}{(2 n-1) \pi} \sin \left(\frac{2 n-1}{2} \pi \frac{k}{N}\right) \sin \left(\frac{2 n-1}{2} \pi \frac{l}{N}\right) \mathscr{M}\left(\frac{r}{\xi_{n}}\right),
\end{aligned}
$$

wobei $\xi_{n}=\sqrt{\frac{2 N d \sqrt{K / B}}{(2 n-1) \pi}}$ ist. Die Funktion $\mathscr{M}$ kann durch Meijer G-Funktion wie folgt ausgedrückt werden:

$$
\mathscr{M}(x)=\frac{1}{4} G_{0}^{04} \frac{4}{2}\left(\left.\frac{x^{4}}{256}\right|_{0, \frac{1}{2}, \frac{1}{2}, 0}\right)
$$


Wenn man nun Gl. (5.34) in die Gl. (5.33) einsetzt, kann die diffuse Streuung durch Fluktuation unter Anwendung der Gl. (4.8) folgendermaßen ausgedrückt werden:

$$
\begin{aligned}
I_{\text {diffus }}= & \frac{A}{q_{z}^{2}} \cdot \sum_{m=0}^{N-1} \sum_{n=0}^{N-1}\left[f_{u}\left(q_{z}\right) e^{i q_{z} m d} f_{u}^{*}\left(q_{z}\right) e^{-i q_{z} n d} e^{-0.5 q_{z}^{2}\left(\sigma_{i}^{2}+\sigma_{j}^{2}\right)}\right. \\
& \cdot \iint\left[\exp \left(q_{z}^{2} \eta\left(\frac{d}{\pi}\right)^{2} \cdot \sum_{k=1}^{N} \frac{4}{(2 k-1) \pi} \sin \left(\frac{2 k-1}{2} \pi \frac{m}{N}\right) \sin \left(\frac{2 k-1}{2} \pi \frac{n}{N}\right) \mathscr{M}\left(\frac{r}{\xi_{n}}\right)\right)\right. \\
& \left.-1] e^{-i\left(q_{x} x+q_{y} y\right)} d x d y\right] .
\end{aligned}
$$

\subsubsection{Statische Defekte der Membranen}

Die Membranstapeln, die auch als multilamellare Lipiddoppelschichten bezeichnet werden, sind im Mittel gut orientiert. Trotzdem treten oft Defekte in den Membranen auf. Dabei bildet die lokale Normale der Membran zur z-Richtung einen großen Winkel. Solche Defekte sind die mögliche Ursache, warum im CCD-Bild scharfe Ringe bei $q_{z}=2 n \pi / d$ vorkommen können, wie in Abb.5.3(a) für die Probe Alamethicin/DMPC mit Molverhältnis von 1/30 dargestellt wird. [168]. Gemessen wurde diese Probe unter einer PEG-Lösung (20000 Molgewicht) mit $100 \mathrm{mM} \mathrm{NaCl}$. In Abb.5.3 b)

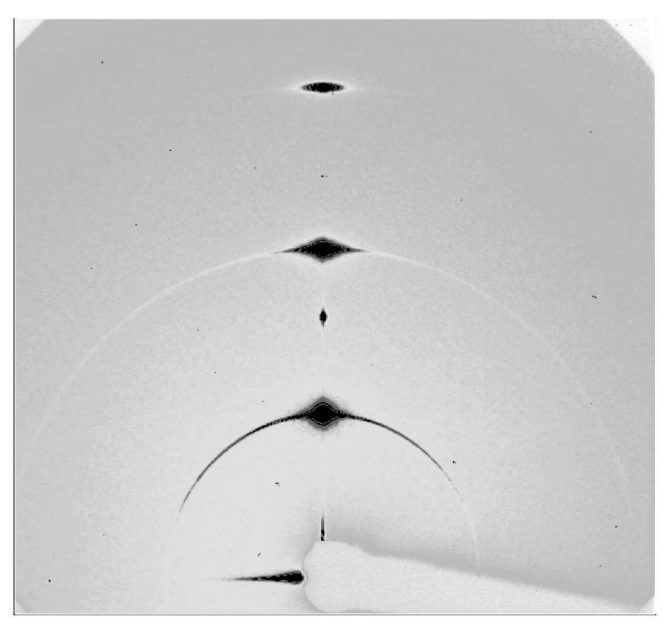

(a)

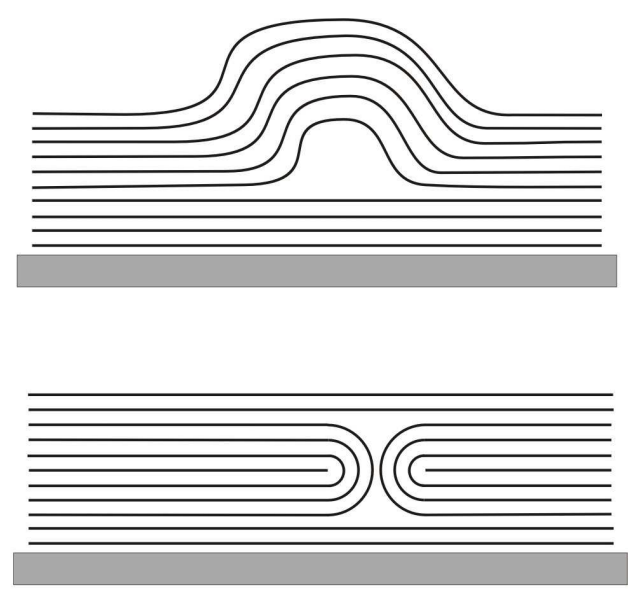

(b)

Abbildung 5.3: (a) CCD-Bild der diffusen Streuung von Alamethicin/DMPC = 1/30, die Ringe quer durch die drei diffusen Bragg-Sheets wurden möglicherweise durch statische Defekte verursacht; (b) Mögliche Strukturen der Defekte.

werden die möglichen Strukturen der Defekte schematisch illustriert. Solche statischen Defekte können durch sorgfältige Präparation oder durch Tempern in einem Ofen reduziert werden. 


\subsection{Semi-kinematisches Modell für die Reflektivität}

\subsubsection{Elektronendichte der fluktuierenden Membranstapeln}

Die Elektronendichte der n-ten Lipiddoppelschicht kann wegen der Periodizität (Abb. 4.1, Abb. 5.2) geschrieben werden als:

$$
\begin{aligned}
\rho_{n}(x, y, z) & =\rho_{0}\left(z-n d-u_{n}(x, y)\right), \\
\rho_{0}(z) & = \begin{cases}\neq 0 & -d / 2 \leq z \leq d / 2, \\
=0 & \text { sonst } .\end{cases}
\end{aligned}
$$

$\rho_{0}$ bezeichnet dabei das Elektronendichteprofil einzelner Lipiddoppelschichten (ohne Fluktuation) in z-Richtung (siehe Gl. (5.54)), $u_{n}(x, y)$ ist die Ablenkung der n-ten Lipiddoppelschicht aus der Gleichgewichtslage. In der Tat weicht das Elektronendichteprofil wegen der Membranfluktuation von Gl. (5.36) etwas ab (Abb. 5.4). Somit sollte die Elektronendichte umgeschrieben werden als:

$$
\rho_{n}(x, y, z)=\rho_{0}\left[\left(z-n d-u_{n}(x, y)\right) \cos \alpha\right] .
$$

$\alpha$ ist der Winkel zwischen der lokalen Normalen der fluktuierenden Lipiddoppelschicht und der zAchse (siehe Abb. 5.4). Das Elektronendichteprofil in Gl. (5.38) berücksichtigt die lokale Fluktua-

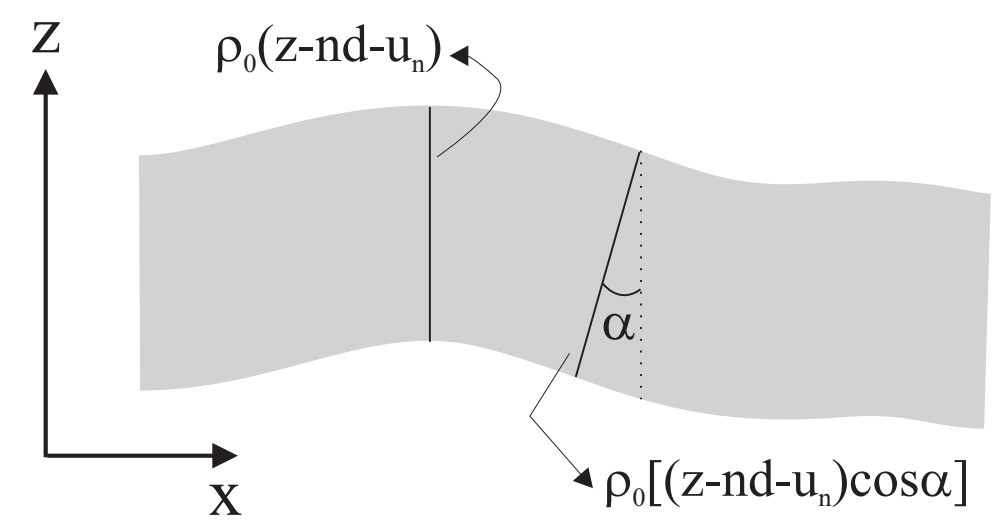

Abbildung 5.4: Das Elektronendichteprofil einer Lipiddoppelschicht bei Membranfluktuation.

tion in der Lipiddoppelschicht. Der Einfluss der lokalen Fluktuation auf das Elektronendichteprofil ist aber vernachlässigbar klein, selbst wenn die Proben voll hydratisiert wurden [144],[169], daher lässt sich das Elektronendichteprofil einfach durch Gl. (5.36) beschreiben. Für $N$ Lipiddoppelschichten kann das Elektronendichteprofil in z-Richtung geschrieben werden als:

$$
\rho(x, y, z)=\sum_{n=0}^{N-1} \rho_{0}\left(z-n d-u_{n}(x, y)\right) .
$$

Bei festen $(x, y)$-Koordinaten kann Gl. (5.39) wie folgt geschrieben werden:

$$
\rho(z)=\sum_{n=0}^{N-1} \rho_{0}\left(z-n d-u_{n}\left(x_{0}, y_{0}\right)\right)
$$

wobei $\left(x_{0}, y_{0}\right)$ die festen Koordinaten in $x y$-Ebene sind. 


\subsubsection{Reflektivitätsmodell in wässriger Umgebung}

\section{Betrachtung des Elektronendichtekontrasts der Proben:}

In Abb. 5.5 wird der Elektronendichteunterschied der Proben in 2 Konfigurationen betrachtet: (i) unter Feuchtigkeit und (ii) unter Wasser. Es könnte möglicherweise eine Wasserschicht zwischen dem Si-Substrat und der ersten Lipiddoppelschicht geben, außerdem gibt es eine Wasserschicht zwischen der N-ten Lipiddoppelschicht und der Luft in der Feuchtigkeitsumgebung. Wegen des kleinen Unterschieds der Elektronendichte zwischen Lipiden und Wasser kann die Grenzfläche zwischen diesen beiden Medien vernachlässigt werden. Folglich gibt es zwei Grenzflächen der Proben in der Feuchtigkeitsumgebung, nämlich Si-Wasser und Wasser-Luft (siehe Abb. 5.5). Unter

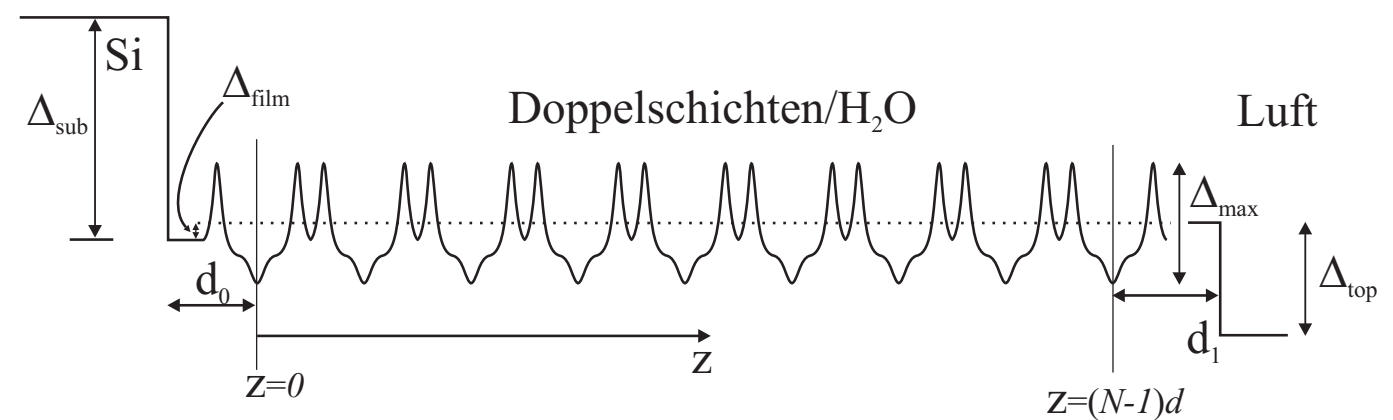

Abbildung 5.5: Schematische Darstellung des Elektronendichteprofils der multilamellaren Lipiddoppelschichten mit Parametern.

wässriger Umgebung hingegen kann nur eine Grenzfläche Si-Wasser vorhanden sein. Das Kontrastprofil der Elektronendichte der gesamten Probe wird in Abb. 5.5 schematisch dargestellt. $d_{0}$ bezeichnet hier die Schichtdicke einer möglichen Wasserschicht zwischen dem Si-Substrat und der ersten Lipiddoppelschicht mit einer Lipidmonoschicht. $d_{1}$ ist die Schichtdicke der Wasserschicht zwischen der N-ten Lipiddoppelschicht und Luft mit einer Lipidmonoschicht. Die übrigen physikalischen Größen werden parametrisiert, und alle sind durch den Gesamtkontrast der Elektronendichte $\rho_{12}=q_{c}^{2} /\left(16 \pi r_{0}\right)$ (siehe Gl. (5.41) $)$ normierte relative Größen, wobei $q_{c}$ der kritische Streuvektor für externe Totalreflexion ist. $\Delta_{s u b}$ ist der Elektronendichtekontrastfaktor zwischen dem Si-Substrat und der Wasserschicht, die sich zwischen dem Substrat und dem Membranstapel befindet, $\Delta_{\text {film }}$ bezeichnet den Kontrastfaktor zwischen Wasser und Lipidfilm, $\Delta_{\max }$ ist der Amplitudenfaktor der Elektronendichteschwankung um die mittlere Elektronendichte des Membranstapels, $\Delta_{t o p}$ bezeichnet den Kontrastfaktor zwischen Wasser und Luft.

\section{Separation des Form- und Strukturfaktors aus der Reflektivität:}

Die Reflektivität an einer gestuften Grenzfläche kann in semi-kinematischer Näherung durch ein Elektronendichteprofil $\rho(z)$ zwischen Medium 1 mit Elektronendichte $\rho_{1}$ und Medium 2 mit Elek- 
tronendichte $\rho_{2}$ dargestellt werden [170] :

$$
R\left(q_{z}\right)=R_{F}\left(q_{z}\right)\left|\frac{1}{\rho_{12}} \int \frac{d \rho(z)}{d z} e^{i q_{z} z} d z\right|^{2} .
$$

$q_{z}$ bezeichnet dabei den Streuvektor in z-Richtung, $R_{F}\left(q_{z}\right)$ ist die Fresnelreflektivität der Grenzfläche zwischen Si-Substrat und Wasser (oder Lipidfilm, wenn keine Wasserschicht zwischen SiSubstrat und Lipidfilm vorhanden ist.), $\rho_{12}$ ist der Gesamtkontrast der Elektronendichte von Wasser (oder Lipidmembran, abhängig von der Probenumgebung) [171] zum Si-Substrat. $\rho_{12}$ wird direkt durch $q_{c}=4 \pi / \lambda \sin \alpha_{c} \simeq 4 \sqrt{\pi r_{0} \rho_{12}}$ mit dem kritischen Streuvektor oder mit dem kritischen Winkel für externe Totalreflexion verbunden. Das Elektronendichteprofil des Membranstapels wird in Gl. (5.41) als intrinsisches Grenzflächenprofil behandelt. Das Elektronendichteprofil der gesamten, aus $N$ Lipiddoppelschichten bestehenden Probe auf einem Si-Substrat in wässriger Umgebung lässt sich dann unter Anwendung der Gl. (5.40) beschreiben als:

$$
\rho(z)=\underbrace{\left(\rho_{s i}-\rho_{\text {Wasser }}\right)}_{\rho_{12}} \cdot \operatorname{erf}\left(\frac{z+d_{0}}{\sqrt{2} \sigma}\right)+\sum_{n=0}^{N-1} \rho_{0}\left(z-n d-u_{n}\left(x_{0}, y_{0}\right)\right) .
$$

Dabei beschreibt $\rho_{s i}$ das Elektronendichteprofil des Si-Substrats. Das Elektronendichteprofil der Si-Wasser-Grenzfläche wird zusätzlich durch eine Gauß-Funktion mit einer charakteristischen Breite $\sigma$ korrigiert. Durchgeführt wird diese Korrektur durch eine Fehlerfunktion $\operatorname{erf}\left(\frac{z+d_{0}}{\sqrt{2} \sigma}\right)$, die das Elektronendichteprofil einer möglichen Wasserschicht zwischen erster Lipiddoppelschicht und Si-Substrat mit Schichtdicke $d_{0}$ berücksichtigt (siehe Abb 5.5), wobei $\sigma$ die Rauigkeit der Grenzfläche ist. Der Term $u_{n}\left(x_{0}, y_{0}\right)$ bezeichnet die Fluktuationen der Membranen. Da wir uns nur für das Elektronendichteprofil in Richtung der Normalen zu Membranoberfläche ( z-Richtung ) interessieren, kann der Term $u_{n}\left(x_{0}, y_{0}\right)$ einfach durch $u_{n}$ ersetzt werden, so dass er nur von der Doppelschichtzahl $n$ abhängig ist. Man setze Gl. (5.42) in Gl. (5.41) ein, es gilt dann:

$$
\begin{aligned}
R\left(q_{z}\right) & =R_{F}\left(q_{z}\right) \mid \int \frac{1}{\sqrt{2 \pi \sigma^{2}}} e^{-\frac{1}{2}\left(\frac{z+d_{0}}{\sigma}\right)^{2}} \cdot e^{i q_{z} z} d z \\
& +\left.\frac{1}{\rho_{12}} \int \sum_{n=0}^{N-1} \frac{d \rho_{0}\left(z-n d-u_{n}\right)}{d z} e^{i q_{z} z} d z\right|^{2} .
\end{aligned}
$$

Nach Substitution durch $z^{\prime}:=z-n d-u_{n}, \rho_{0} / \rho_{12}:=\rho_{0}^{\prime}$ und Vereinfachung lässt sich obige Gleichung schreiben als:

$$
\begin{aligned}
R\left(q_{z}\right) & =R_{F}\left(q_{z}\right)\left|e^{-i q_{z} d_{0}} e^{\frac{-q_{z}^{2} \sigma^{2}}{2}}+\int \sum_{n=0}^{N-1} \frac{d \rho_{0}^{\prime}\left(z^{\prime}\right)}{d z^{\prime}} e^{i q_{z}\left(z^{\prime}+n d+u_{n}\right)} d z^{\prime}\right|^{2} \\
& =R_{F}\left(q_{z}\right)\left|e^{-i q_{z} d_{0}} e^{\frac{-q_{z}^{2} \sigma^{2}}{2}}+\int \frac{d \rho_{0}^{\prime}(z)}{d z} e^{i q_{z} z} d z \sum_{n=0}^{N-1} e^{i q_{z} n d} e^{i q_{z} u_{n}}\right|^{2} \\
& =R_{F}\left(q_{z}\right)\left|e^{-i q_{z} d_{0}} e^{\frac{-q_{z}^{2} \sigma^{2}}{2}}+f\left(q_{z}\right) s\left(q_{z}\right)\right|^{2}
\end{aligned}
$$

wobei

$$
f\left(q_{z}\right)=\int_{-\infty}^{\infty} \frac{d \rho_{0}^{\prime}(z)}{d z} e^{i q_{z} z} d z \quad \text { und } \quad s\left(q_{z}\right)=\sum_{n=0}^{N-1} e^{i q_{z} n d} e^{i q_{z} u_{n}}
$$


als Formfaktor und Strukturfaktor (genauer Strukturfaktor-Amplitude) bezeichnet werden. Der Term $e^{-i q_{z} d_{0}} e^{\frac{-q_{z}^{2} \sigma^{2}}{2}}$ in Gl. (5.44) ist der Reflektivitätsanteil aus der Grenzfläche zwischen Wasser und Si-Substrat mit Rauigkeit $\sigma$.

\section{Modellfunktion der Reflektivität für Proben in wässriger Umgebung:}

Für Oligo-Membranen $(\mathrm{N}<30$ ) kann die Absorption innerhalb des Membranstapels wegen der geringen Doppelschichtzahl vernachlässigt werden. Die Reflektivität für Oligo-Membranen lässt sich daher direkt aus Gl. (5.44) ableiten. Da die bei den Messungen ermittelte Intensität proportional zur Summe der detektierten Photonenzahl über den gemessenen Zeitabschnitt ist, muss für die Intensität bzw. Reflektivität der Mittelwert über die Zeit genommen werden [157]. Gl. (5.44) kann also geschrieben werden als:

$$
R\left(q_{z}\right)=R_{F}\left(q_{z}\right)\left\langle\left(e^{-i q_{z} d_{0}} e^{\frac{-q_{z}^{2} \sigma^{2}}{2}}+f\left(q_{z}\right) s\left(q_{z}\right)\right) \cdot\left(e^{-i q_{z} d_{0}} e^{\frac{-q_{z}^{2} \sigma^{2}}{2}}+f\left(q_{z}\right) s\left(q_{z}\right)\right)^{*}\right\rangle,
$$

wobei $\langle\cdots\rangle$ den zeitlichen Mittelwert und $\left(^{*}\right)$ die komplexe Konjugation bezeichnen. Nach Ausmultiplizieren aller Teile zerfällt der Term in den spitzen Klammern in drei Summanden:

$$
R\left(q_{z}\right)=R_{F}\left(q_{z}\right)\left[R 1\left(q_{z}\right)+R 2\left(q_{z}\right)+R 3\left(q_{z}\right)\right],
$$

mit

$$
\begin{aligned}
& R 1\left(q_{z}\right)=\left\langle e^{-q_{z}^{2} \sigma^{2}}\right\rangle=e^{-q_{z}^{2} \sigma^{2}}, \\
& R 2\left(q_{z}\right)=\left\langle\left|f\left(q_{z}\right)\right|^{2} \cdot\left|s\left(q_{z}\right)\right|^{2}\right\rangle, \\
& R 3\left(q_{z}\right)=\left\langle f\left(q_{z}\right) \cdot s\left(q_{z}\right) e^{i q_{z} d_{0}} e^{\frac{-q_{z}^{2} \sigma^{2}}{2}}+f^{*}\left(q_{z}\right) \cdot s^{*}\left(q_{z}\right) e^{-i q_{z} d_{0}} e^{\frac{-q_{z}^{2} \sigma^{2}}{2}}\right\rangle .
\end{aligned}
$$

Für den zweiten Summanden $R 2\left(q_{z}\right)$ gilt nach Anwendung des Baker-Hausdorff-Theorems ( bei $\left.\operatorname{dem}\left\langle e^{i x}\right\rangle=e^{-\frac{1}{2}\left\langle x^{2}\right\rangle}\right)$ [157]:

$$
\begin{aligned}
R 2\left(q_{z}\right) & =\left\langle\left|f\left(q_{z}\right)\right|^{2} \cdot\left(\sum_{m=0}^{N-1} e^{i q_{z} m d} \cdot e^{i q_{z} u_{m}}\right) \cdot\left(\sum_{n=0}^{N-1} e^{i q_{z} n d} \cdot e^{i q_{z} u_{n}}\right)^{*}\right\rangle \\
& =\left|f\left(q_{z}\right)\right|^{2} \cdot \sum_{m=0}^{N-1} \sum_{n=0}^{N-1} e^{i q_{z} d(m-n)} e^{-\frac{q_{z}^{2}}{2}\left\langle\left(u_{m}-u_{n}\right)^{2}\right\rangle} \\
& =\left|f\left(q_{z}\right)\right|^{2} \cdot \sum_{m=0}^{N-1} \sum_{n=0}^{N-1}\left(e^{i q_{z} d(m-n)} e^{-\frac{q_{z}^{2}}{2}\left(\left\langle u_{m}^{2}\right\rangle-2\left\langle u_{m} u_{n}\right\rangle+\left\langle u_{n}^{2}\right\rangle\right)}\right) .
\end{aligned}
$$

Der Term $\left\langle u_{m} u_{n}\right\rangle$ liefert den Beitrag der diffusen Streuung. Für die rein spekulare Streuung entfällt dieser Term [166]. Die Gl. (5.51) ist daher folgendermaßen zu vereinfachen:

$$
\begin{aligned}
R 2\left(q_{z}\right) & =\left|f\left(q_{z}\right)\right|^{2} \cdot \sum_{m=0}^{N-1} \sum_{n=0}^{N-1}\left(e^{i q_{z} d(m-n)} e^{-\frac{q_{z}^{2}}{2}\left(\left\langle u_{m}^{2}\right\rangle+\left\langle u_{n}^{2}\right\rangle\right)}\right) \\
& =\left|f\left(q_{z}\right)\right|^{2} \cdot \sum_{m=0}^{N-1} e^{i q_{z} d m-\frac{q_{z}^{2}}{2}\left\langle u_{m}^{2}\right\rangle} \sum_{n=0}^{N-1} e^{-i q_{z} d n-\frac{q_{z}^{2}}{2}\left\langle u_{n}^{2}\right\rangle}
\end{aligned}
$$


wobei $\left\langle u_{m}^{2}\right\rangle$ und $\left\langle u_{n}^{2}\right\rangle$ durch Gl. (5.28) bestimmt werden. Der dritte Summand $R 3\left(q_{z}\right)$ lässt sich umformen zu:

$$
\begin{aligned}
R 3\left(q_{z}\right) & =\left\langle e^{i q_{z} d_{0}-\frac{q_{z}^{2} \sigma^{2}}{2}} \cdot f\left(q_{z}\right) \cdot \sum_{n=0}^{N-1} e^{i q_{z} n d} e^{i q_{z} u_{n}}+e^{-i q_{z} d_{0}-\frac{q_{z}^{2} \sigma^{2}}{2}} \cdot f^{*}\left(q_{z}\right) \cdot \sum_{n=0}^{N-1} e^{-i q_{z} n d} e^{-i q_{z} u_{n}}\right\rangle \\
& =e^{-\frac{q_{z}^{2} \sigma^{2}}{2}} \sum_{n=0}^{N-1}\left\langle f\left(q_{z}\right) \cdot e^{i q_{z}\left(n d+d_{0}\right)} e^{i q_{z} u_{n}}+f^{*}\left(q_{z}\right) \cdot e^{-i q_{z}\left(n d+d_{0}\right)} e^{i q_{z} u_{n}}\right\rangle .
\end{aligned}
$$

Unter Anwendung des Baker-Hausdorff-Theorems kann wiederum geschrieben werden: [157]

$$
R 3\left(q_{z}\right)=e^{-\frac{q_{z}^{2} \sigma^{2}}{2}} \sum_{n=0}^{N-1}\left(f\left(q_{z}\right) \cdot e^{i q_{z}\left(n d+d_{0}\right)} e^{-\frac{q_{z}^{2}}{2}\left\langle u_{n}^{2}\right\rangle}+f^{*}\left(q_{z}\right) \cdot e^{-i q_{z}\left(n d+d_{0}\right)} e^{-\frac{q_{z}^{2}}{2}\left\langle u_{n}^{2}\right\rangle}\right) .
$$

Da der Formfaktor $f\left(q_{z}\right)$ rein imaginär ist (siehe unten), gilt $f^{*}\left(q_{z}\right)=-f\left(q_{z}\right) \cdot R 3\left(q_{z}\right)$ lässt sich folglich schreiben als:

$$
R 3\left(q_{z}\right)=2 i \cdot f\left(q_{z}\right) e^{-\frac{q_{z}^{2} \sigma^{2}}{2}} \sum_{n=0}^{N-1}\left(\sin \left(q_{z}\left(n d+d_{0}\right)\right) e^{-\frac{q_{z}^{2}}{2}\left\langle u_{n}^{2}\right\rangle}\right)
$$

wobei $\left\langle u_{n}^{2}\right\rangle$ durch Gl. (5.28) bestimmt wird.

\subsubsection{Formfaktor der Membranstapel}

Die periodische Elektronendichte eines Membranstapels kann als Fourierreihe geschrieben werden [171] :

$$
\rho_{0}(z)=\rho_{m}+\Delta_{\max } \cdot \rho_{12} \cdot \sum_{n=1}^{N_{0}} f_{n} \cdot \cos \left(\frac{2 n \pi z}{d}\right)
$$

wobei $\rho_{m}$ die mittlere Elektronendichte des Membranstapels ist. $\Delta_{\max }$ bezeichnet die Amplitude der Elektronendichteschwankung um die mittlere Elektronendichte $\rho_{m}$ des Membranstapels (Abb. 5.5), $\rho_{12}$ ist der Elektronendichtekontast der angrenzenden Medien, also die Differenz der Elektronendichte zwischen zwei angrenzenden Medien, $f_{n}$ bezeichnet die $N_{0}$ Fourierkoeffizienten. Der Formfaktor in G1. (5.45) repräsentiert nur den Formfaktor einzelner Lipiddoppelschichten, weil $\rho_{0}(z)$ bzw. $\rho_{0}^{\prime}(z)$ nur in Bereich $\left[-\frac{d}{2}, \frac{d}{2}\right]$ ausgewertet werden. Dieser Formfaktor kann explizit berechnet werden, indem man die Gl. (5.54) in den Formfaktor aus Gl. (5.45) einsetzt und anschließend über den Bereich $\left[-\frac{d}{2}, \frac{d}{2}\right]$ integriert. Dadurch lässt sich der Formfaktor schreiben als:

$$
\begin{aligned}
f\left(q_{z}\right) & =\int_{-d / 2}^{d / 2} \frac{d \rho_{0}^{\prime}(z)}{d z} e^{-i q_{z} z} d z=\int_{-d / 2}^{d / 2} \frac{1}{\rho_{12}} \cdot \frac{d \rho_{0}(z)}{d z} e^{-i q_{z} z} d z \\
& =\sum_{n=1}^{N_{0}} f_{n} \cdot \Delta_{\max } \cdot \frac{i 8 n^{2} \pi^{2} \sin \left(q_{z} d / 2\right)}{q_{z}^{2} d^{2}-4 n^{2} \pi^{2}} \cdot \cos (n \pi) .
\end{aligned}
$$




\subsubsection{Reflektivitätsmodell in Feuchtigkeitsumgebung}

\section{Modellfunktion:}

Da es gemäß Abschnitt 5.3.2 in einer Feuchtigkeitsumgebung bei den Proben zwei Grenzflächen gibt und die thermische Fluktuation der Membranen vernachlässigbar klein ist, kann das Elektronendichteprofil der gesamten Probe, die aus $N$ Lipiddoppelschichten besteht, auf einem Si-Substrat (siehe auch Abb. 5.5) geschrieben werden als:

$$
\begin{aligned}
\rho(z)= & \underbrace{\left(\rho_{\text {si }}-\rho_{\text {Wasser }}\right)}_{\text {Si-Wasser-Grenzfläche }} \cdot \operatorname{erf}\left(\frac{z+d_{0}}{\sqrt{2} \sigma_{0}}\right)+\sum_{n=0}^{N-1} \rho_{0}(z-n d) \\
& +\underbrace{\left(\rho_{\text {Wasser }}-\rho_{\text {Luft }}\right)}_{\text {Wasser-Luft-Grenzfläche }} \cdot \operatorname{erf}\left(\frac{z-N d-d_{1}}{\sqrt{2} \sigma_{1}}\right),
\end{aligned}
$$

wobei die Elektronendichteprofile der Si-Wasser- und Wasser-Luft-Grenzfläche durch die Gaußfunktionen mit jeweils charakteristischer Breite von $\sigma_{0}$ bzw. $\sigma_{1}$ korrigiert werden. Dies erfolgt durch die Fehlerfunktionen $\operatorname{erf}\left(\frac{z+d_{0}}{\sqrt{2} \sigma_{0}}\right)$ und $\operatorname{erf}\left(\frac{z-N d-d_{1}}{\sqrt{2} \sigma_{1}}\right)$. Diese berücksichtigen dabei zwei Elektronendichteprofile, die aus einer möglichen Wasserschicht zwischen erster Lipiddoppelschicht und Si-Substrat mit Schichtdicke $d_{0}$ (siehe Abb. 5.5) und aus einer Wasserschicht zwischen der N-ten Lipiddoppelschicht und Luft stammen. $\sigma_{0}$ und $\sigma_{1}$ sind die Rauigkeiten jeweils für diese beide Grenzflächen. Nach Einfügen der Gl. (5.56) in Gl. (5.41) lässt sich die Reflektivitätsfunktion der Probe in der Feuchtigkeitsumgebung darstellen als:

$$
\begin{aligned}
R\left(q_{z}\right) & =R_{F}\left(q_{z}\right) \mid \Delta_{\text {sub }} \int \frac{1}{\sqrt{2 \pi \sigma_{0}^{2}}} e^{-\frac{1}{2}\left(\frac{z+d_{0}}{\sigma_{0}}\right)^{2}} \cdot e^{i q_{z} z} d z+\frac{1}{\rho_{12}} \int \sum_{n=0}^{N-1} \frac{d \rho_{0}(z-n d)}{d z} \cdot e^{i q_{z} z} d z \\
& +\left.\Delta_{\text {top }} \int \frac{1}{\sqrt{2 \pi \sigma_{1}^{2}}} e^{-\frac{1}{2}\left(\frac{z-N d-d_{1}}{\sigma_{1}}\right)^{2}} \cdot e^{i q_{z} z} d z\right|^{2} \\
& =R_{F}\left(q_{z}\right)|\underbrace{\Delta_{\text {sub }} e^{-i q_{z} d_{0}} e^{\frac{-q_{z}^{2} \sigma_{0}^{2}}{2}}}_{\text {Si-Wasser }}+\underbrace{f\left(q_{z}\right) s\left(q_{z}\right)}_{\text {Lipiddoppelschicht }}+\underbrace{\Delta_{\text {top }} e^{i q_{z}\left(N d+d_{1}\right)} e^{\frac{-q_{z}^{2} \sigma_{1}^{2}}{2}}}_{\text {Wasser-Luft }}|^{2},
\end{aligned}
$$

wobei

$$
f\left(q_{z}\right)=\int_{-d / 2}^{d / 2} \frac{d \rho_{0}^{\prime}(z)}{d z} e^{i q_{z} z} d z \quad \text { und } \quad s\left(q_{z}\right)=\sum_{n=0}^{N-1} e^{i q_{z} n d}
$$

mit $\rho_{0}^{\prime}(z)=\rho_{0}(z) / \rho_{12}$. Aufgrund der partiellen Hydration der Proben in Feuchtigkeitsumgebung ist die thermische Fluktuation der Membranstapel so klein, dass sie vernachlässigt werden kann, deshalb beinhaltet der Strukturfaktor hier keine Fluktuationsamplitude.

\section{Absorption:}

Die Reflektivität dicker Lipidmembrane ist oft merkbar abgeschwächt, insbesondere beim Röntgenstrahl niedriger Photonenenergie (z.B. Cu- $K_{\alpha}$-Strahlung). Dieser Effekt kommt dadurch zu- 
stande, dass die Intensität des Röntgenstrahls durch die Membranen absorbiert wird. Diese Absorption sollte deshalb bei Behandlung der Reflektivität für multilamellare Lipiddoppelschichten berücksichtigt werden. Nach Anwendung der Gl. (4.24) aus dem vorangehenden Kapitel 4 kann die $z$ - und $q_{z}$-abhängige Absorption geschrieben werden als:

$$
a\left(q_{z}, z\right)=\exp \left(\frac{16 \pi^{2} \beta(z-D)}{\lambda^{2} q_{z}}\right),
$$

wobei $\beta$ der Imaginärteil des Brechungsindexes für Lipidmembranen ist, $D$ bezeichnet die gesamte Dicke der Lipidfilme auf dem Substrat.

\section{Faktoren für die Bedeckung der Membranen auf Substrat:}

Die Proben, die durch Spreiten der Stammlösung präpariert wurden, sind in den meisten Fällen auf einer lateralen Skala von einigen $\mu m$ nicht homogen auf dem Substrat verteilt. Manche Stellen wurden durch den Lipidfilm überhaupt nicht überdeckt. Folglich wird ein Bruchteil des Strahls direkt durch das Substrat (ohne Lipidfilm) reflektiert, dies beeinflusst insbesondere den Bereich totaler externer Reflexion ziemlich stark. Wenn $x(0 \leq x \leq 1)$ der Bedeckungsgrad der Lipidmembranen auf dem Substrat ist, lässt sich die gesamte Reflektivität nun schreiben als [171]:

$$
R\left(q_{z}\right)=(1-x) R_{s i}\left(q_{z}\right)+x R_{\text {Lipid }}\left(q_{z}\right)
$$

wobei $R_{s i}$ und $R_{\text {Lipid }}$ die Reflektivitäten aus Si-Substrat ohne und mit Lipidfilm bezeichnen. Mit einer Oberflächenrauigkeit $\sigma$ des Si-Substrats kann die Reflektivität von Si-Substrat ohne Lipidfilm wie folgt ausgedrückt werden:

$$
R_{s i}\left(q_{z}\right)=R_{F_{s i}}\left(q_{z}\right) \cdot\left|\Delta_{s i} \cdot \exp \left(-\frac{1}{2} \sigma^{2} q_{z}^{2}\right)\right|^{2},
$$

wobei $R_{F_{s i}}\left(q_{z}\right)$ die Fresnelreflektivität des Si-Substrats ist. $\Delta_{s i}$ bezeichnet das normierte Elektronendichteprofil des Si-Substrats, es beträgt $\rho_{s i} / \rho_{12}$.

In dem durch den Lipidfilm bedeckten Bereich auf Si-Substrat ist die Anzahl der Lipiddoppelschichten nicht überall gleich. Der Bedeckungsfaktor ist abhängig von der gesamten Zahl der Lipiddoppelschichten $N$ und der mittleren Lipiddoppelschichtenzahl. Man definiere empirisch eine Bedeckungsfunktion $r(n)$ mit Randbedingung $r(1)=1$ und $r(N) \simeq 0$ durch eine geeignet parametrisierte Funktion, z.B.:

$$
r(n)=\left[1-\left(\frac{n-1}{N}\right)^{\alpha}\right]^{\beta}
$$

wobei $\alpha$ und $\beta$ zwei Skalierungsparameter sind, die den Phasenverlauf beeinflussen (siehe Abb. 5.6). Aus dieser Überlegung heraus kann der Strukturfaktor nun geschrieben werden als:

$$
s\left(q_{z}\right)=\sum_{n=0}^{N-1} e^{i q_{z} n d} \cdot\left[1-\left(\frac{n-1}{N}\right)^{\alpha}\right]^{\beta} .
$$

Die Bedeckungsfunktion (G1. 5.62) beschreibt die Bedeckung der Lipiddoppelschichten auf dem Substrat relativ gut (siehe Abb. 5.6), aber wegen der Summation tritt bei Kurvenanpassung ein sehr 

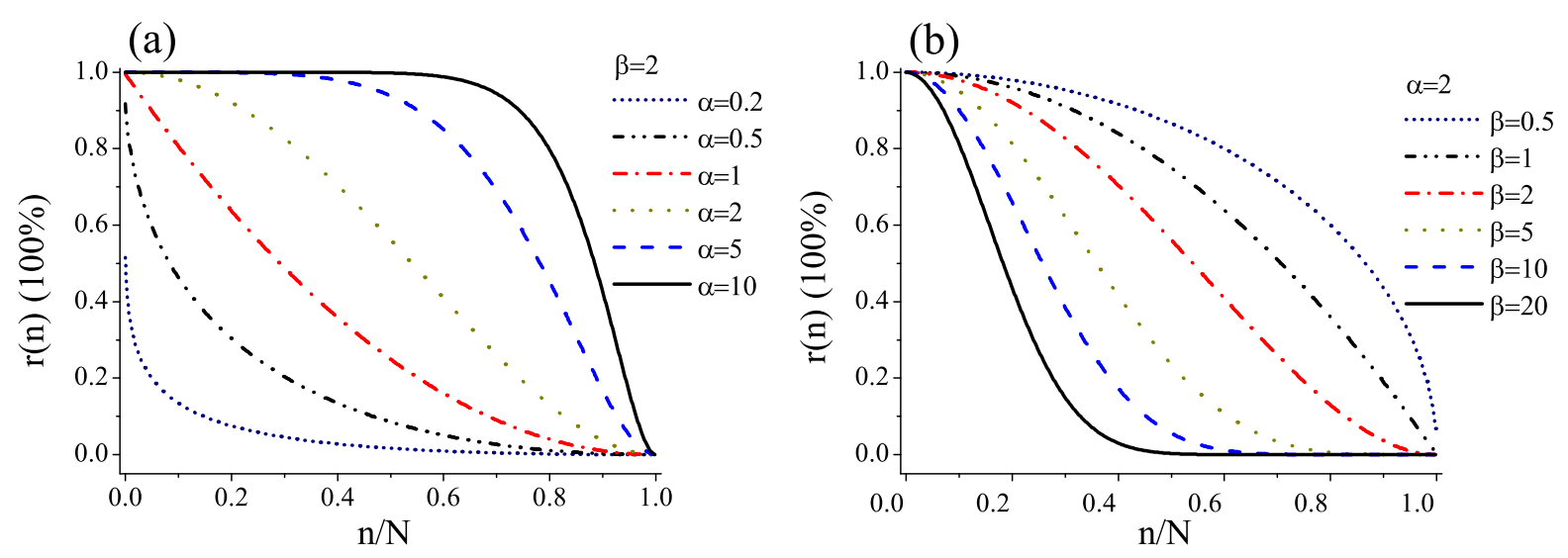

Abbildung 5.6: Bedeckungsfunktion $r(n)$ für verschiedene Kombinationen der Parameter $\alpha$ und $\beta$ mit (a) festem $\beta$ und (b) festem $\alpha$.

großer Zeitaufwand auf, wenn man den Strukturfaktor mit dieser Bedeckungsfunktion aus G1. 5.62 verwendet, so dass er zur Kurvenanpassung kaum zu verwenden ist. Andererseits sollte für den dicken Lipidfilm die Absorption der Strahlen, die vom Einfallswinkel abhängig ist, berücksichtigt werden. Deshalb wurde eine andere Bedeckungsfunktion eingesetzt, die durch eine exponentielle Funktion ausgedrückt wird. Durch Einfügen einer so genannten effektiven Domänengröße [171] und einer effektiven Absorptionslänge (die maximale Streckenlänge, die die Strahlen im Lipidfilm zurücklegen) lässt sich die 2. Bedeckungsfunktion schreiben als:

$$
r(n)=\underbrace{e^{-(N-n) d 4 \pi /\left(L_{A} \lambda q_{z}\right)}}_{\text {Absorptionsteil }} \cdot \underbrace{e^{-n d / L}}_{\text {Domaenenteil }},
$$

wobei $d$ die Periodizität, $L$ die effektive Domänengröße der Lipiddoppelschichten und $L_{A}$ die effektive Absorptionslänge bezeichnen. Für dicke Lipidfilme beträgt $L$ normalerweise mehr als 50000 $\AA$ und $L_{A}$ betragen je nach Photonenenergie häufig mehr als $0.5 \mathrm{~mm}$. In Abb. 5.6 werden beide Bedeckungsfunktionen anschaulich gemacht, dabei wurden $\alpha=2, \beta=1, N=5000, d=50 \AA$, $L=10^{5} \AA$ und $L_{A}=10 \mathrm{~mm}$ angenommen. Der Strukturfaktor kann also mit der 2. Bedeckungsfunktion geschrieben werden als:

$$
\begin{aligned}
s\left(q_{z}\right) & =\sum_{n=0}^{N-1} e^{i q_{z} n d} e^{-(N-n)\left[d 4 \pi /\left(L_{A} \lambda q_{z}\right)\right]} e^{-n d / L} \\
& =e^{-N \frac{d 4 \pi}{L_{A} \lambda q_{z}}} \cdot \frac{e^{\left(i q_{z} N d-N d\left[1 / L-4 \pi /\left(L_{A} \lambda q_{z}\right)\right]\right)}-1}{e^{\left(i q_{z} d-d\left[1 / L-4 \pi /\left(L_{A} \lambda q_{z}\right)\right]\right)}-1} .
\end{aligned}
$$

Abb. 5.7 zeigt den Einfluss der effektiven Absorptionslänge auf die Reflektivität. Mit sinkender Absorptionslänge nimmt die Reflektivität ab, bei $L_{A}=10 \mathrm{~mm}$ gibt es kaum eine merkbare Absorption, d.h. ab $L_{A}=>10 \mathrm{~mm}$ ist die Absorption zu vernachlässigen, dies ist bei großem Winkel der Fall. Da die Absorption für die Strahlen mit einer Wellenlänge $0.62 \AA$ (ca. 20keV Photonenenergie) bei effektiver Absorptionslänge $L_{A}=10^{7} \AA$ nur ungefähr $6.4 \%$ beträgt und sie nur bei kleinen Einfallswinkeln zu berücksichtigen ist, ist sie für unsere Auswertung oder für die Modellierung der Reflektivität nicht so entscheidend. Zur Vereinfachung der weiteren Entwicklung 

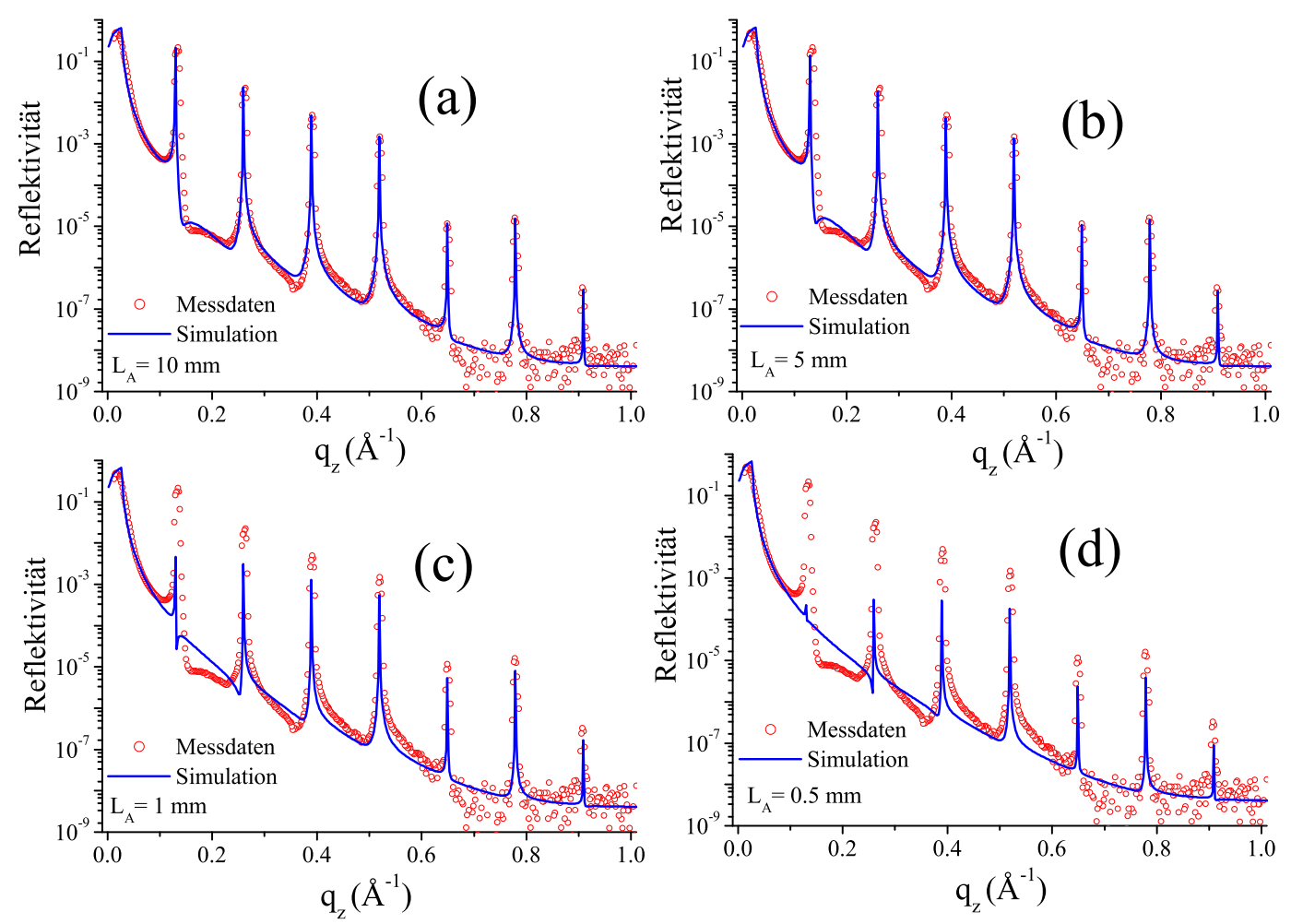

Abbildung 5.7: Der Einfluss der effektiven Absorptionslänge auf die Reflektivität für Synchrotronstrahlung mit Photonenenergie von $20 \mathrm{keV} \mathrm{bei} \mathrm{(a)} L_{A}=10 \mathrm{~mm}$, (b) $L_{A}=5 \mathrm{~mm}$, (c) $L_{A}=1 \mathrm{~mm}$ und (d) $L_{A}=0.5 \mathrm{~mm}$.

der Modellfunktion wird im folgenden der Absorptionsteil in der Gl. (5.65) vernachlässigt. Der Strukturfaktor kann dann geschrieben werden als:

$$
s\left(q_{z}\right)=\sum_{n=0}^{N-1} e^{i q_{z} n d} e^{-n d / L}=\frac{e^{\left(i q_{z} N d-N d / L\right)}-1}{e^{\left(i q_{z} d-d / L\right)}-1} .
$$

Gl. (5.66) wird bei Kurvenanpassung als korrigierter Strukturfaktor verwendet. Für die Reflektivität von Lipiddoppelschichten wird die Absorption vernachlässigt, für die Reflektivität des Substrats wird sie jedoch durch $a\left(q_{z}, z\right)$ (siehe Gl. (5.59)) berücksichtigt. Die Reflektivitätsmodellfunktion für die multilamellaren Lipiddoppelschichten kann somit folgendermaßen geschrieben werden [171] :

$$
\begin{aligned}
R\left(q_{z}\right) \quad & (1-x) R_{\text {si }}\left(q_{z}\right)+x R_{\text {lipid }}\left(q_{z}\right) \\
= & (1-x) R_{F_{s i}}\left(q_{z}\right) \cdot\left|\Delta_{s i} \cdot e^{-\frac{q_{z}^{2} \sigma^{2}}{2}}\right|^{2}+ \\
x R_{F_{\text {lipid }}}\left(q_{z}\right) \cdot \mid & \Delta_{\text {sub }} e^{-i q_{z} d_{0}} e^{\frac{-q_{z}^{2} \sigma_{0}^{2}}{2}} a\left(q_{z}, 0\right)+f\left(q_{z}\right) s\left(q_{z}\right)+\left.\Delta_{\text {top }} e^{i q_{z}\left(N d+d_{1}\right)} e^{\frac{-q_{z}^{2} \sigma_{1}^{2}}{2}}\right|^{2}
\end{aligned}
$$


mit

$$
\begin{aligned}
f\left(q_{z}\right) & =\sum_{n=1}^{N_{0}} f_{n} \cdot \Delta_{\max } \cdot \frac{i 8 n^{2} \pi^{2} \sin \left(q_{z} d / 2\right)}{q_{z}^{2} d^{2}-4 n^{2} \pi^{2}} \cdot \cos (n \pi), \\
s\left(q_{z}\right) & =\sum_{n=0}^{N-1} e^{i q_{z} n d} e^{-n d / L}=\frac{e^{\left(i q_{z} N d-N d / L\right)}-1}{e^{\left(i q_{z} d-d / L\right)}-1} . \\
a\left(q_{z}, 0\right) & =\exp \left(-\frac{16 \pi^{2} \beta D}{\lambda^{2} q_{z}}\right) .
\end{aligned}
$$

\section{Ausdruck der Modellfunktion durch reelle Funktionen:}

Die Modellfunktion in Gl. (5.67) wird durch verschiedene komplexe Funktionen ausgedrückt, jedoch ist diese Formulierung ungünstig für die spätere Programmierung zur Kurvenanpassung und zur weiteren Entwicklung der Modellfunktion. Es ist also notwendig, die Modellfunktion in Gl. (5.67) durch reelle Funktionen auszudrücken, vor allem ist es nützlich, den Anteil für Lipiddoppelschichten auf diese Weise zu beschreiben. Sei

$$
A\left(q_{z}\right)=\Delta_{\text {sub }} e^{-i q_{z} d_{0}} e^{\frac{-q_{z}^{2} \sigma_{0}^{2}}{2}} a\left(q_{z}\right)+\Delta_{t o p} e^{i q_{z}\left(N d+d_{1}\right)} e^{\frac{-q_{z}^{2} \sigma_{1}^{2}}{2}}
$$

es gilt dann:

$$
A^{*}\left(q_{z}\right)=\Delta_{s u b} e^{i q_{z} d_{0}} e^{\frac{-q_{z}^{2} \sigma_{0}^{2}}{2}} a\left(q_{z}\right)+\Delta_{t o p} e^{-i q_{z}\left(N d+d_{1}\right)} e^{\frac{-q_{z}^{2} \sigma_{1}^{2}}{2}},
$$

wobei $a\left(q_{z}\right)=a\left(q_{z}, 0\right)$ die Absorption durch die Membranstapel ist. Der Anteil für Lipiddoppelschichten in Gl. (5.67) kann geschrieben werden als:

$$
\begin{aligned}
& \left|\Delta_{s u b} e^{-i q_{z} d_{0}} e^{\frac{-q_{z}^{2} \sigma_{0}^{2}}{2}} a\left(q_{z}\right)+f\left(q_{z}\right) s\left(q_{z}\right)+\Delta_{t o p} e^{i q_{z}\left(N d+d_{1}\right)} e^{\frac{-q_{z}^{2} \sigma_{1}^{2}}{2}}\right|^{2} \\
= & \left(A\left(q_{z}\right)+f\left(q_{z}\right) s\left(q_{z}\right)\right)\left(A\left(q_{z}\right)+f\left(q_{z}\right) s\left(q_{z}\right)\right)^{*} \\
= & \left(A\left(q_{z}\right)+f\left(q_{z}\right) s\left(q_{z}\right)\right)\left(A\left(q_{z}\right)^{*}+f^{*}\left(q_{z}\right) s^{*}\left(q_{z}\right)\right) \\
= & A\left(q_{z}\right) A^{*}\left(q_{z}\right)+\left(A\left(q_{z}\right) \cdot f^{*}\left(q_{z}\right) s^{*}\left(q_{z}\right)+f\left(q_{z}\right) s\left(q_{z}\right) \cdot A^{*}\left(q_{z}\right)\right) \\
& \left.++f\left(q_{z}\right) f^{*}\left(q_{z}\right) s\left(q_{z}\right)\right) s^{*}\left(q_{z}\right) \\
= & \underbrace{A\left(q_{z}\right) A^{*}\left(q_{z}\right)}_{r 1\left(q_{z}\right)}+\underbrace{\left(A\left(q_{z}\right) \cdot f^{*}\left(q_{z}\right) s^{*}\left(q_{z}\right)+A^{*}\left(q_{z}\right) \cdot f\left(q_{z}\right) s\left(q_{z}\right)\right)}_{r 2\left(q_{z}\right)} \\
& +\underbrace{\left.f\left(q_{z}\right) f^{*}\left(q_{z}\right) s\left(q_{z}\right)\right) s^{*}\left(q_{z}\right)}_{r 3\left(q_{z}\right)} \\
= & r 1\left(q_{z}\right)+r 2\left(q_{z}\right)+r 3\left(q_{z}\right) .
\end{aligned}
$$

Nach Ausmultiplizieren können $r 1\left(q_{z}\right), r 2\left(q_{z}\right)$ und $r 3\left(q_{z}\right)$ folgendermaßen dargestellt werden:

$$
\begin{aligned}
r 1\left(q_{z}\right)= & \Delta_{\text {sub }}^{2} e^{-q_{z}^{2} \sigma_{0}^{2}} a\left(q_{z}\right)^{2}+\Delta_{\text {top }}^{2} e^{-q_{z}^{2} \sigma_{1}^{2}} \\
& +2 \Delta_{\text {sub }} \Delta_{t o p} a\left(q_{z}\right) e^{-q_{z}^{2}\left(\sigma_{0}^{2}+\sigma_{1}^{2}\right)} \cos \left(d_{0}+d_{1}+n d\right)
\end{aligned}
$$




$$
\begin{aligned}
r 2\left(q_{z}\right)= & f\left(q_{z}\right)\left[\sum _ { n = 0 } ^ { N - 1 } \left[2 i \Delta_{s u b} a\left(q_{z}\right) e^{-n d / L-q_{z}^{2} \sigma_{0}^{2} / 2} \cdot \sin \left(q_{z} n d-q z d_{0}\right)\right.\right. \\
& \left.\left.+2 i \Delta_{t o p} e^{-n d / L-q_{z}^{2} \sigma_{1}^{2} / 2} \cdot \sin \left(q_{z} n d-q_{z} N d-q_{z} d_{1}\right)\right]\right] \\
= & 2 i f\left(q_{z}\right)\left[\sum _ { n = 0 } ^ { N - 1 } \left[\Delta_{s u b} a\left(q_{z}\right) e^{-n d / L-q_{z}^{2} \sigma_{0}^{2} / 2} \cdot \sin \left(q_{z} n d-q z d_{0}\right)\right.\right. \\
& \left.\left.+\Delta_{t o p} e^{-n d / L-q_{z}^{2} \sigma_{1}^{2} / 2} \cdot \sin \left(q_{z} n d-q_{z} N d-q_{z} d_{1}\right)\right]\right] \\
r 3\left(q_{z}\right)= & \left|f\left(q_{z}\right)\right|^{2}\left[\frac{1+e^{-2 N d / L}-2 e^{-N d / L} \cdot \cos \left(q_{z} N d\right)}{1+e^{2 d / L}-2 e^{-d / L} \cdot \cos \left(q_{z} d\right)}\right]
\end{aligned}
$$

\subsection{Faltung der Reflektivitätskurve durch die Modellfunktion}

Die zur Messung verwendeten Instrumente haben eine beschränkte Auflösung. Außerdem besitzen die verwendeten Strahlen eine bestimmte Divergenz. Dies alles zusammen verursacht eine Verbreiterung der Bragg-Peaks. Die Modellfunktion für die Reflektivität, die oben vorgestellt wurde, beinhaltet keine Korrekturfaktoren, durch die solche Effekte berücksichtigt werden, wie in Abb. 5.8(a) zu sehen ist. Es ist deshalb nötig, die entsprechende Abweichung zu korrigieren. Zu diesem

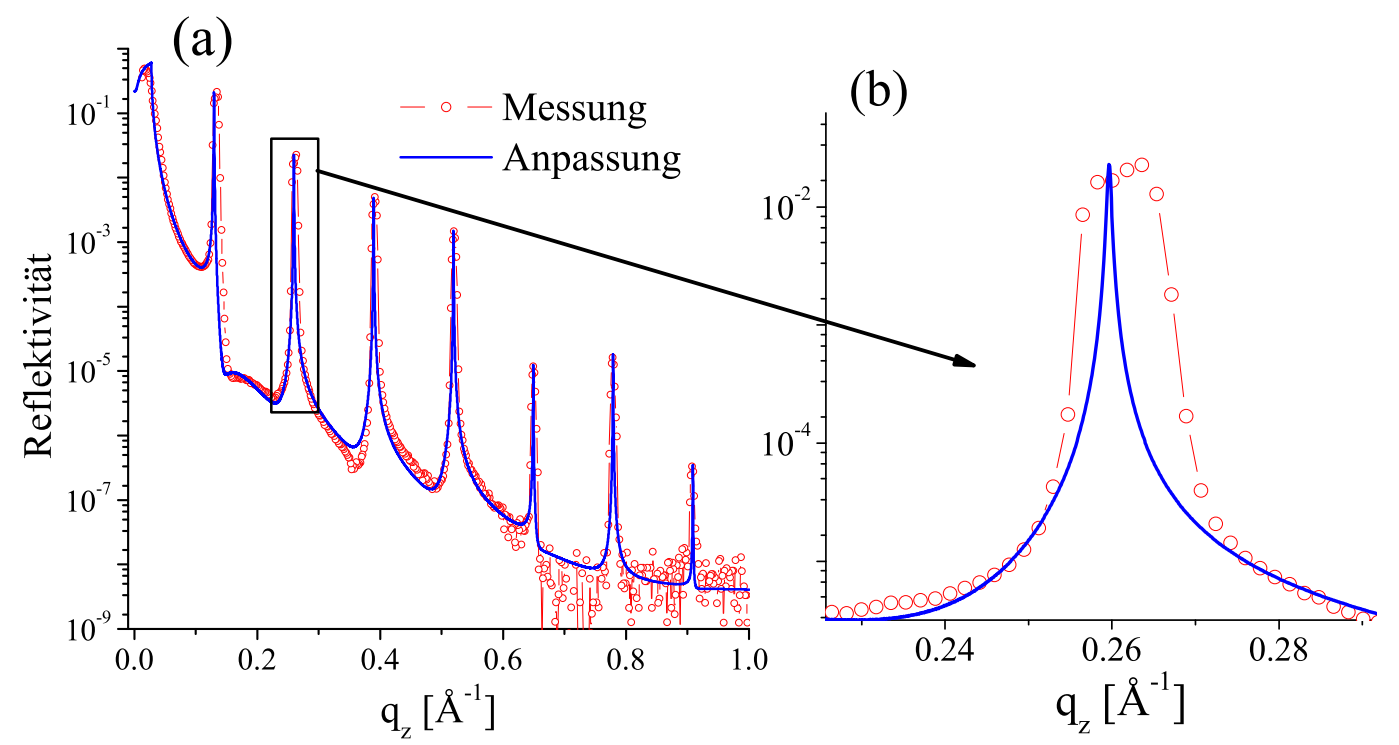

Abbildung 5.8: Zur Erklärung der Einführung einer Auflösungsfunktion wird hier die angepasste Kurve mit der gemessenen Kurve zusammen dargestellt. (a) Anpassung der Messkurve; (b) vergrößerte Darstellung des zweiten Bragg-Peaks.

Zweck wird hier eine Faltungsfunktion als Auflösungsfunktion eingesetzt. In Abb. 5.8 wird die Notwendigkeit der Faltung der Modellfunktion zur Anpassung an eine Reflektivitätskurve gezeigt. Die Probe wurde mit einer Stammlösung der Konzentration von 20mg/ml reinem DMPC präpariert 
und unter ca. $\mathrm{RH}=99 \%$ und $\mathrm{T}=45 \mathrm{C}^{\circ}$ am Messplatz D4 Hasylab mit der Wellenlänge $\lambda=0.62 \AA$ gemessen. Man erkennt deutlich die instrumentelle Verbreitung des Maximums, die durch das idealisierte Modell nicht erklärt werden kann. Im folgenden wird der Einsatz der Faltungsfunktion an drei verschiedenen Stellen der Modellfunktion in zwei unterschiedlichen Probenumgebungen probiert und anschließend diskutiert, wie sie zur Kurvenanpassung optimal verwendet werden kann. Die hier eingesetzte Faltungsfunktion ist eine normierte Gauß-Funktion mit der charakteristischen Breite von $\frac{1}{\sqrt{2 C}}$, deren Integration über $(-\infty,+\infty)$ gleich eins ist:

$$
G\left(q_{z}\right)=\sqrt{\frac{C}{\pi}} e^{-C q_{z}^{2}}, \quad \text { mit } \quad \int_{-\infty}^{\infty} \sqrt{\frac{C}{\pi}} e^{-C q_{z}^{2}} d q_{z}=\sqrt{\frac{C}{\pi}} \sqrt{\frac{\pi}{C}}=1
$$

\subsubsection{Proben in Feuchtigkeitsumgebung}

Faltung einer einzelnen Strukturfaktor-Amplitude in der durch komplexe Funktionen ausgedrückten Modellfunktion:

Die Faltung wird zuerst nur auf der Strukturfaktor-Amplitude für Proben in Feuchtigkeitsumgebung in Gl. (5.66) durchgeführt, bevor die Strukturfaktor-Amplitude mit dem Formfaktor in der G1. (5.67) multipliziert wird. Nach dem Faltungstheorem lässt sich die Faltung der StrukturfaktorAmplitude mit der Faltungsfunktion aus Gl. (5.72) schreiben als:

$$
\begin{aligned}
& s\left(q_{z}\right) \otimes G\left(q_{z}\right)=\int_{-\infty}^{\infty} s\left(q_{z}-t\right) G(t) d t=\int_{-\infty}^{\infty} s(t) G\left(q_{z}-t\right) d t \\
= & \sqrt{\frac{C}{\pi}} \cdot \sum_{n=0}^{N-1} \int_{-\infty}^{\infty} \exp \left(-C\left(q_{z}-t\right)^{2}+i t n d-n d / L\right) d t=\sum_{n=0}^{N-1} \exp \left(i q_{z} n d-\frac{n d}{L}-\frac{n^{2} d^{2}}{4 C}\right)
\end{aligned}
$$

dabei wird folgende Integrationsformel verwendet:

$$
\int_{-\infty}^{\infty} \exp \left(-C\left(q_{z}-t\right)^{2}+i t x-t^{2} y / 2\right) d t=\sqrt{\frac{\pi}{C+y / 2}} \cdot \exp \left(\frac{2 C q_{z}\left(2 i x-q_{z} y\right)-x^{2}}{2(2 C+y)}\right) .
$$

Die gefaltete Strukturfaktor-Amplitude wird in Gl. (5.67) zurïck eingesetzt, anschließend wird eine Simulation an einer Probe aus reinem DMPC, deren Reflektivitätskurve und Anpassung in Abb. 5.8 (a) und Abb. 5.9 (a) gezeigt wird, mit gleichen Parametern durchgeführt. Die simulierte Kurve wird mit der angepassten Kurve verglichen, um die Wirkung der Faltung zu beurteilen, dabei ist der Parameter $C=10^{8}$. In Abb. 5.9 ist klar zu sehen, dass die simulierte Kurve mit gefaltetem Strukturfaktor kaum eine Änderung der Breite des Bragg-Peaks liefert. Diese Beobachtung weist darauf hin, dass die Faltung des einzelnen Strukturfaktors vor der Multiplikation mit dem Formfaktor nicht funktioniert. Die Ursache für die Unwirksamkeit der Faltung an $s\left(q_{z}\right)$ ist, dass die Fläche unter einem Peak durch die Faltung der Strukturfaktor-Amplitude erhalten bleibt, so dass die Peakbreite schmaler wird, um die gleiche Peakhöhe zu erreichen; dadurch geht die Wirkung der Faltung verloren. 


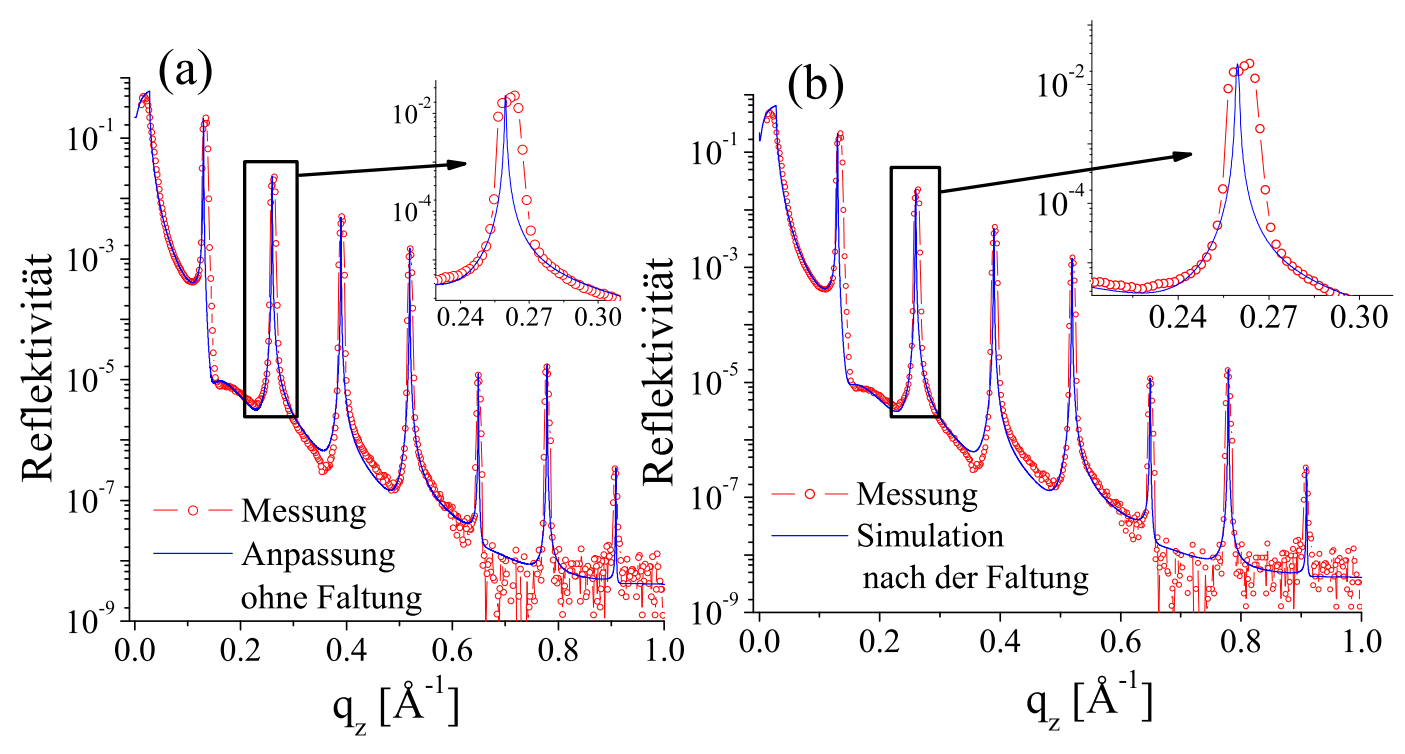

Abbildung 5.9: Vergleich der Anpassung mit und ohne Faltung des Strukturfaktors von reinem DMPC. (a) Die Anpassung der Messkurve ohne Faltung; (b) Die Simulation der Messkurve mit Faltung der Strukturfaktor-Amplitude vor der Multiplikation mit dem Formfaktor. Die Fläche unter einem Peak kann durch die Faltung nicht geändert werden; um die gleiche Peakhöhe zu erhalten, muss die Peakbreite schmaler werden.

\section{Faltung der Strukturfaktor-Amplitude in der durch reelle Funktionen ausgedrückten Mo-} dellfunktion:

Nach der Ausmultiplikation der Strukturfaktor-Amplitude mit dem Formfaktor in Gl. (5.67) wird die Faltung nur auf der Strukturfaktor-Amplitude $\left(s\left(q_{z}\right)\right.$ und $\left.s^{*}\left(q_{z}\right)\right)$ in Gl. (5.70) und auf dem Strukturfaktor $\left(s\left(q_{z}\right) s^{*}\left(q_{z}\right)\right.$ ) in Gl. (5.71) durchgeführt. Nach dem Faltungstheorem kann die Faltung über $r 2\left(q_{z}\right)$ ( Gl. (5.70) ) mit $G\left(q_{z}\right)$ ( Gl. (5.72) ) näherungsweise geschrieben werden als:

$$
\begin{aligned}
& r 2\left(q_{z}\right) \otimes G\left(q_{z}\right)=\int_{-\infty}^{\infty} r 2\left(q_{z}-t\right) G(t) d t=\int_{-\infty}^{\infty} r 2(t) G\left(q_{z}-t\right) d t \\
& \cong \int_{-\infty}^{\infty}\left[A\left(q_{z}\right) \cdot f^{*}\left(q_{z}\right) s^{*}(t)+A^{*}\left(q_{z}\right) \cdot f\left(q_{z}\right) s(t)\right] G\left(q_{z}-t\right) d t \\
& =A\left(q_{z}\right) \cdot f^{*}\left(q_{z}\right) \int_{-\infty}^{\infty} s^{*}(t) G\left(q_{z}-t\right) d t+A^{*}\left(q_{z}\right) \cdot f\left(q_{z}\right) \int_{-\infty}^{\infty} s(t) G\left(q_{z}-t\right) d t \\
& =A\left(q_{z}\right) \cdot f^{*}\left(q_{z}\right) \sum_{n=0}^{N-1} \exp \left(-i n d q_{z}-\frac{n d}{L}-\frac{n^{2} d^{2}}{4 C}\right) \\
& +A^{*}\left(q_{z}\right) \cdot f\left(q_{z}\right) \sum_{n=0}^{N-1} \exp \left(i n d q_{z}-\frac{n d}{L}-\frac{n^{2} d^{2}}{4 C}\right) \\
& =f^{*}\left(q_{z}\right)\left(\Delta_{\text {sub }} e^{-i q_{z} d_{0}} e^{\frac{-q_{z}^{2} \sigma_{0}^{2}}{2}} a\left(q_{z}\right)+\Delta_{\text {top }} e^{i q_{z}\left(N d+d_{1}\right)} e^{\frac{-q_{z}^{2} \sigma_{1}^{2}}{2}}\right) \sum_{n=0}^{N-1} \exp \left(-i n d q_{z}-\frac{n d}{L}-\frac{n^{2} d^{2}}{4 C}\right) \\
& +f\left(q_{z}\right)\left(\Delta_{\text {sub }} e^{i q_{z} d_{0}} e^{\frac{-q_{z}^{2} \sigma_{0}^{2}}{2}} a\left(q_{z}\right)+\Delta_{\text {top }} e^{-i q_{z}\left(N d+d_{1}\right)} e^{\frac{-q_{z}^{2} \sigma_{1}^{2}}{2}}\right) \sum_{n=0}^{N-1} \exp \left(i n d q_{z}-\frac{n d}{L}-\frac{n^{2} d^{2}}{4 C}\right)
\end{aligned}
$$




$$
\begin{aligned}
& =2 i \cdot f\left(q_{z}\right) \sum_{n=0}^{N-1} e^{-\frac{n^{2} d^{2}}{4 C}-\frac{n d}{L}}\left[\operatorname { c o s } ( q _ { z } n d ) \left(\Delta_{\text {sub }} \sin \left(q_{z} d_{0}\right) e^{\frac{-q_{z}^{2} \sigma_{0}^{2}}{2}} \cdot a\left(q_{z}\right)\right.\right. \\
& \left.+\Delta_{\text {top }} \sin \left(q_{z}\left(N d+d_{1}\right)\right) e^{\frac{-q_{z}^{2} \sigma_{1}^{2}}{2}}\right)+\sin \left(q_{z} n d\right)\left(\Delta_{\text {sub }} \cos \left(q_{z} d_{0}\right) e^{\frac{-q_{z}^{2} \sigma_{0}^{2}}{2}} \cdot a\left(q_{z}\right)\right. \\
& \left.\left.+\Delta_{\text {top }} \cos q_{z}\left(N d+d_{1}\right) e^{\frac{-q_{z}^{2} \sigma_{1}^{2}}{2}}\right)\right]
\end{aligned}
$$

wobei

$$
\begin{aligned}
A\left(q_{z}\right) & =\Delta_{\text {sub }} e^{-i q_{z} d_{0}} e^{\frac{-q_{z}^{2} \sigma_{0}^{2}}{2}} a\left(q_{z}\right)+\Delta_{\text {top }} e^{i q_{z}\left(N d+d_{1}\right)} e^{\frac{-q_{z}^{2} \sigma_{1}^{2}}{2}} \\
A^{*}\left(q_{z}\right) & =\Delta_{\text {sub }} e^{i q_{z} d_{0}} e^{\frac{-q_{z}^{2} \sigma_{0}^{2}}{2}} a\left(q_{z}\right)+\Delta_{t o p} e^{-i q_{z}\left(N d+d_{1}\right)} e^{\frac{-q_{z}^{2} \sigma_{1}^{2}}{2}}
\end{aligned}
$$

Die Faltung über $r 3\left(q_{z}\right)$ (Gl. (5.68) $)$ mit $G\left(q_{z}\right)$ kann auch näherungsweise geschrieben werden als:

$$
\begin{aligned}
& r 3\left(q_{z}\right) \otimes G\left(q_{z}\right)=\int_{-\infty}^{\infty} r 3\left(q_{z}-t\right) G(t) d t=\int_{-\infty}^{\infty} r 3(t) G\left(q_{z}-t\right) d t \\
& \cong\left|f\left(q_{z}\right)\right|^{2} \int_{-\infty}^{\infty} s(t) s^{*}(t) G\left(q_{z}-t\right) d t \\
& =\sqrt{\frac{C}{\pi}} \cdot\left|f\left(q_{z}\right)\right|^{2} \int_{-\infty}^{\infty}\left[\sum_{m=0}^{N-1} \sum_{n=0}^{N-1} \exp \left(i t d(m-n)-\frac{m+n}{L}\right) \cdot \exp \left(-C\left(q_{z}-t\right)^{2}\right)\right] d t \\
& =\left|f\left(q_{z}\right)\right|^{2}\left[\sum_{m=0}^{N-1} \sum_{n=0}^{N-1} \exp \left(i q_{z} d(m-n)-\frac{m+n}{L}-\frac{d^{2}(m-n)^{2}}{4 C}\right)\right] .
\end{aligned}
$$

Nach der Faltung wird die Modellfunktion mit den gleichen Parametern, die durch Anpassung der

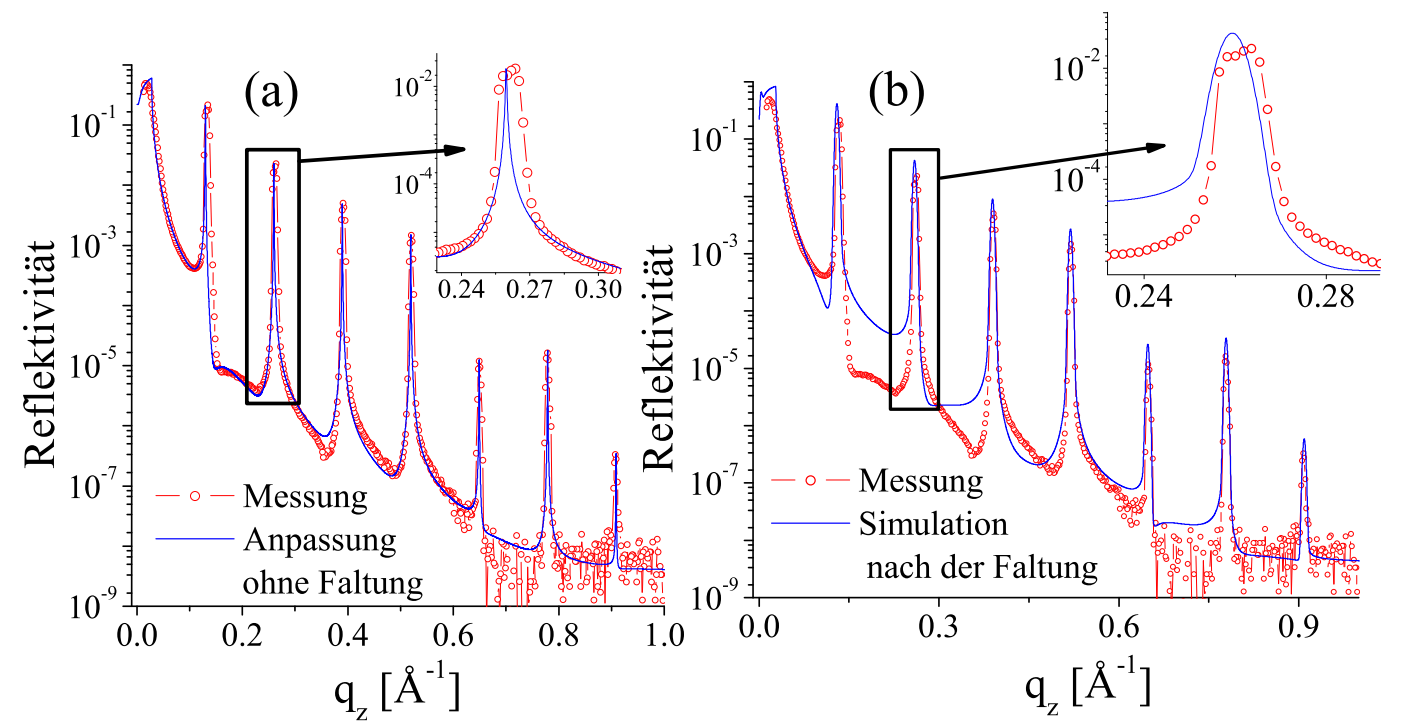

Abbildung 5.10: Vergleich der Anpassung mit und ohne Faltung des Strukturfaktors von reinem DMPC. (a) Die Anpassung der Messkurve ohne Faltung; (b) die Simulation der Messkurve mit Faltung der Strukturfaktor-Amplitude und auf dem Strukturfaktor nach Formulierung der Modellfunktion durch reelle Funktionen. 
Modellfunktion ohne Faltung an die Messkurve ermittelt wurde (siehe Abb. 5.10(a)), simuliert, um die Änderungen der simulierten Kurve durch Faltung zu beobachten; dabei ist der Parameter $C$ gleich $10^{5}$. In Abb. 5.10 wird die angepasste und die simulierte Kurve zusammen mit der Messkurve derselben Probe gegen $q_{z}$ aufgetragen. Beim Vergleich mit der angepassten Kurve ist es klar zu sehen, dass die simulierte Kurve in ihrer Form stark abweicht, die Breite der BraggPeaks jedoch vergrößert ist. Der Grund für die Verformung der Kurve ist die alleinige Faltung der Strukturfaktor-Amplitude bzw. des Strukturfaktors, weil der Formfaktor der Reflektivität für einen Kurvenverlauf eine sehr wichtige Rolle spielt. In Abb. 5.11 werden die Faltungen von $r 2\left(q_{z}\right)$ und $r 3\left(q_{z}\right)$ mit gleichen Parametern ( dabei ist $L=10^{5}, C=10^{5}$ ) jeweils analytisch nur auf der Strukturfaktor-Amplitude bzw. auf dem Strukturfaktor und numerisch (siehe nächsten Abschnitt) auf der ganzen Kurve verglichen, um die Ursache der Verformung der gefalteten Kurve durch alleinige Faltung der Strukturfaktor-Amplitude bzw. des Strukturfaktors zu erkennen. Man sieht hier klar, dass die zwei Verfahren unterschiedliche Kurven ergeben.

(a)

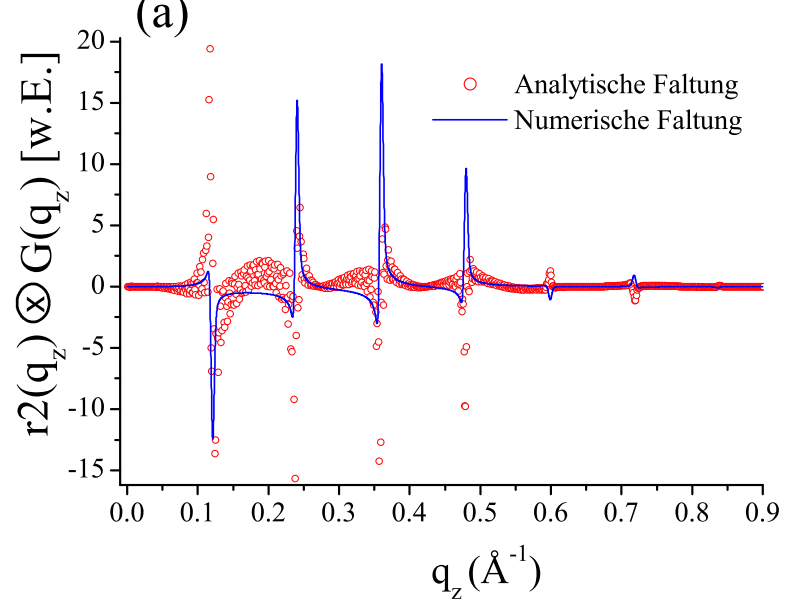

(b)

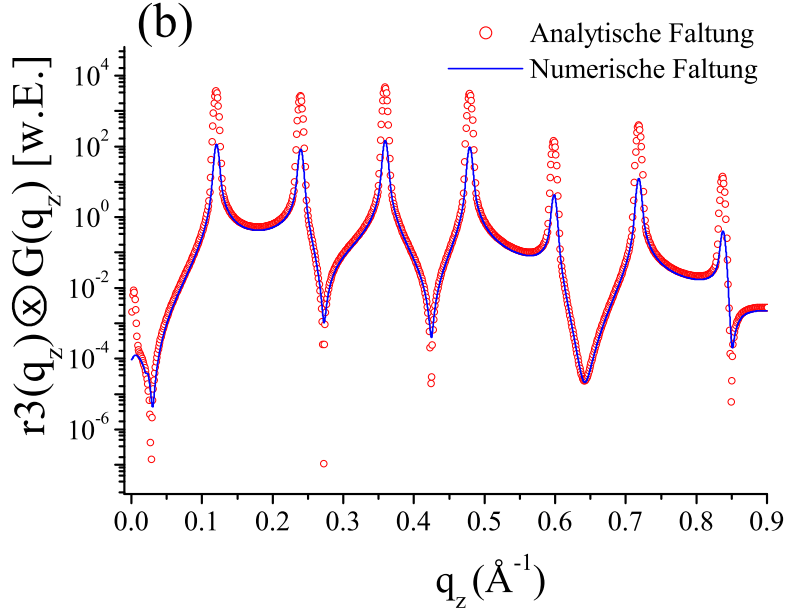

Abbildung 5.11: Die analytischen Faltungen nur auf der Strukturfaktor-Amplitude sowie auf dem Strukturfaktor, und die numerischen Faltungen auf der ganzen Kurve von (a) $r 2\left(q_{z}\right)$ und (b) r3 $\left(q_{z}\right)$ mit gleichen Parametern. Die Unterschiede der Faltungen durch die zwei Verfahren sind hier deutlich zu sehen, vor allem bei $r 2\left(q_{z}\right)$.

\section{Faltung der ganzen Modellfunktion durch numerische Summation:}

Als Resultat der zwei vorangehenden Abschnitte kann man sagen, dass die Faltung nur der Strukturfaktor-Amplitude oder des Strukturfaktors in der Modellfunktion nicht ausreichend ist. Es liegt deshalb der Gedanke nahe, die Faltung auf die ganze Modellfunktion auszudehnen. Wegen der schwierigen Integrationsrechnung der Modellfunktion ist es aber nicht möglich, die Faltung über die Modellfunktion analytisch darzustellen. Einfacher und realisierbar ist es, die Faltung über die Modellfunktion mit der Faltungsfunktion durch numerische Summation durchzuführen. Seien m und n ganze Zahlen, $G_{n}$ die diskrete Faltungsfunktion und $R_{m}$ die diskrete Modellfunktion 


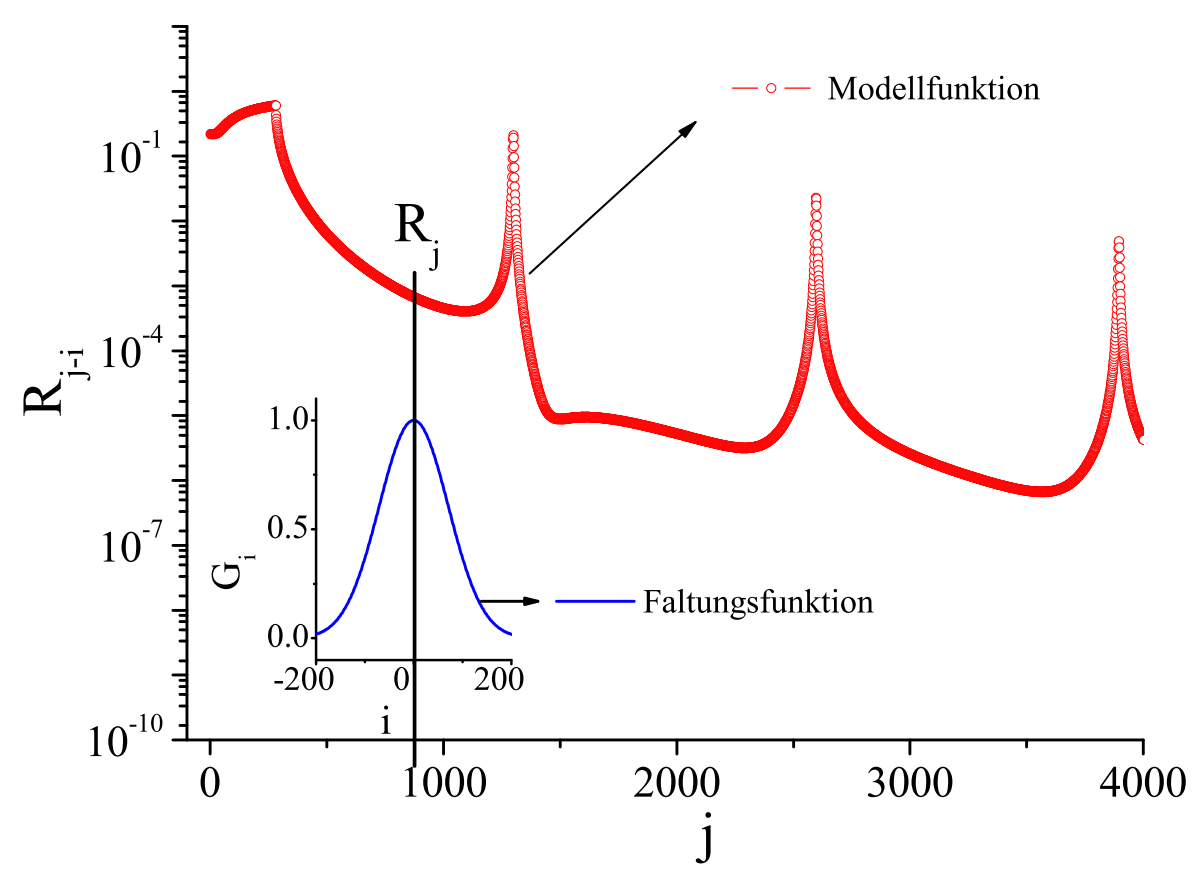

Abbildung 5.12: Veranschaulichung der Faltung der Modellfunktion durch numerische Summation, $N_{0}$ beträgt hier 200.

für die Reflektivität. Man definiere nun:

$$
G_{n}=e^{-C q_{z n}^{2}}, \quad \text { und } \quad R_{m}=R\left(q_{z m}\right), \quad m, n \in \mathbb{Z} .
$$

Die Faltung von $R\left(q_{z}\right)$ mit $G\left(q_{z}\right)$ kann dann geschrieben werden als:

$$
\begin{aligned}
& R^{\prime}\left(q_{z}\right)=R\left(q_{z}\right) \otimes G\left(q_{z}\right)=\int_{-\infty}^{\infty} R\left(q_{z}-t\right) G(t) d t \\
& \Longrightarrow R_{j}^{\prime}=\left(\sum_{i=-N_{0}}^{N_{0}} R_{j-i} \cdot G_{i}\right) /\left(\sum_{i=-N_{0}}^{N_{0}} G_{i}\right), \quad i, j \in \mathbb{Z} ; N_{0} \in \mathbb{N}
\end{aligned}
$$

Bei $j-i \leq 0$ und $j-i \geq j_{\max }$ werden für $R_{j-i}$ folgende mittlere Werte eingesetzt:

$$
\begin{array}{cc}
R_{j-i}=\sum_{k=1}^{N_{0}} R_{k} / N_{0}, & \text { wenn } \quad j-i \leq 0 ; \\
R_{j-i}=\sum_{j=j_{\max }-N_{0}+1}^{j_{\max }} R_{j} / N_{0}, & \text { wenn } \quad j-i \geq j_{\max } .
\end{array}
$$

In Abb. 5.12 wird diese Methode anschaulich gemacht, dabei ist $N_{0}=200$. Nach der Faltung der Modellfunktion durch dieses Verfahren wird auch eine Simulation mit den gleichen Parametern (bis auf den Parameter L), die durch Anpassung (siehe Abb. 5.9(a)) ermittelt wurden, durchgeführt, dabei ist der Parameter $C=10^{5}$. In Abb. 5.13 werden angepasste und simulierte Kurven zum Vergleich illustriert. Es ist deutlich zu erkennen, dass die simulierte Kurve bezüglich der Breite der Bragg-Peaks der gemessenen Kurve ziemlich gut entspricht und dass die Kurvenform im Vergleich zur angepassten Kurve kaum abweicht. 


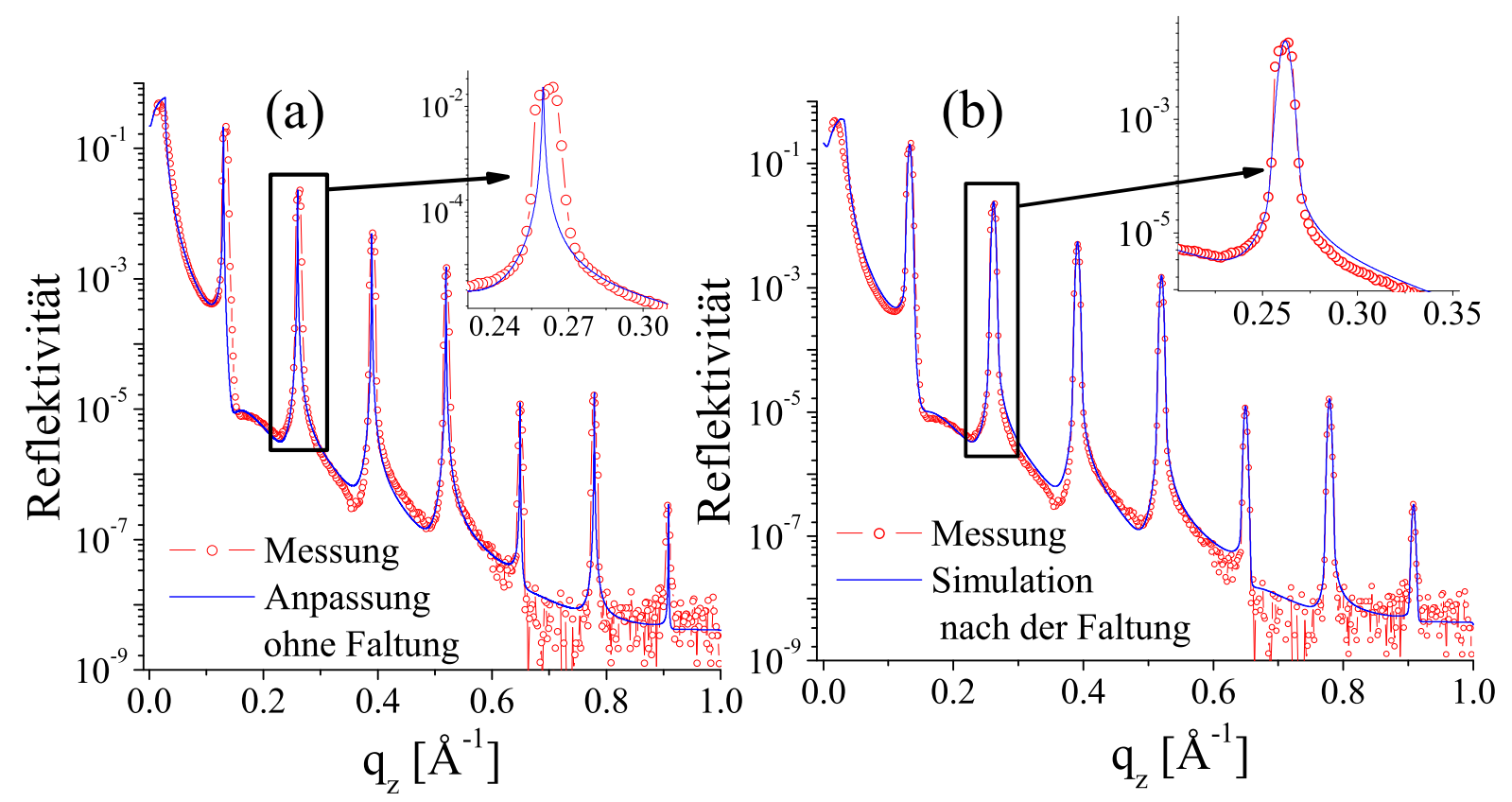

Abbildung 5.13: Vergleich der Anpassung mit und ohne Faltung der Modellfunktion von reinem DMPC mit 20mg/ml. (a) Die Anpassung der Messkurve ohne Faltung; (b) die Simulation der Messkurve mit Faltung der Modellfunktion durch numerische Summation.

Die oben erwähnten drei Fälle für die Faltungen der Modellfunktion weisen darauf hin, dass die Faltung durch numerische Summation an der gesamten Kurve am geeignetsten ist. Daher wird diese Methode zur Anpassung der Reflektivitätskurve mit einer Modellfunktion im nächsten Kapitel verwendet.

\subsubsection{Proben in wässriger Umgebung}

Faltung der Strukturfaktor-Amplitude in einer durch komplexe Funktionen ausgedrückten Modellfunktion:

Die Faltung über die Modellfunktion mit der Faltungsfunktion (Gl. (5.72) ) für Proben in wässriger Umgebung wird der Vollständigkeit halber ebenfalls durchgeführt. Dazu wird die Faltung zunächst wieder auf der Strukturfaktor-Amplitude in Gl. (5.45) mit der Bedeckungsfunktion (siehe Gl. (5.66) ) angewendet, bevor die Modellfunktion durch reelle Funktionen ausgedrückt wird. Man führt eine Simulation mit den gleichen Parametern, die durch Anpassung ermittelt wurden (siehe Abb. 5.14(a)), mittels Modellfunktion mit der gefalteten Strukturfaktor-Amplitude durch, um die Wirkung der Faltung auf die Reflektivitätskurve zu beobachten. Es ist in Abb. 5.14 klar zu erkennen, dass die Faltung der Strukturfaktor-Amplitude keine erkennbare Wirkung auf die Breite der Bragg-Peaks ausgeübt hat. Der Grund dafür ist der gleiche wie in Abschnitt 5.4.1, nämlich, dass die Fläche unter einem Peak durch die Faltung nicht geändert werden kann, so dass die Peakbreite schmaler werden muss, um die gleiche Peakhöhe zu erreichen, dadurch wird die Faltung unwirksam. Die hier dargestellte Kurve ist die Messkurve der Probe aus reinem DMPC, die am D4 Hasylab unter 14\% Polyethyleneglycol (PEG)-Lösung (mit 20000 Molekülmasse) und $\mathrm{T}=30.53^{\circ} \mathrm{C}$ 
gemessen wurde.
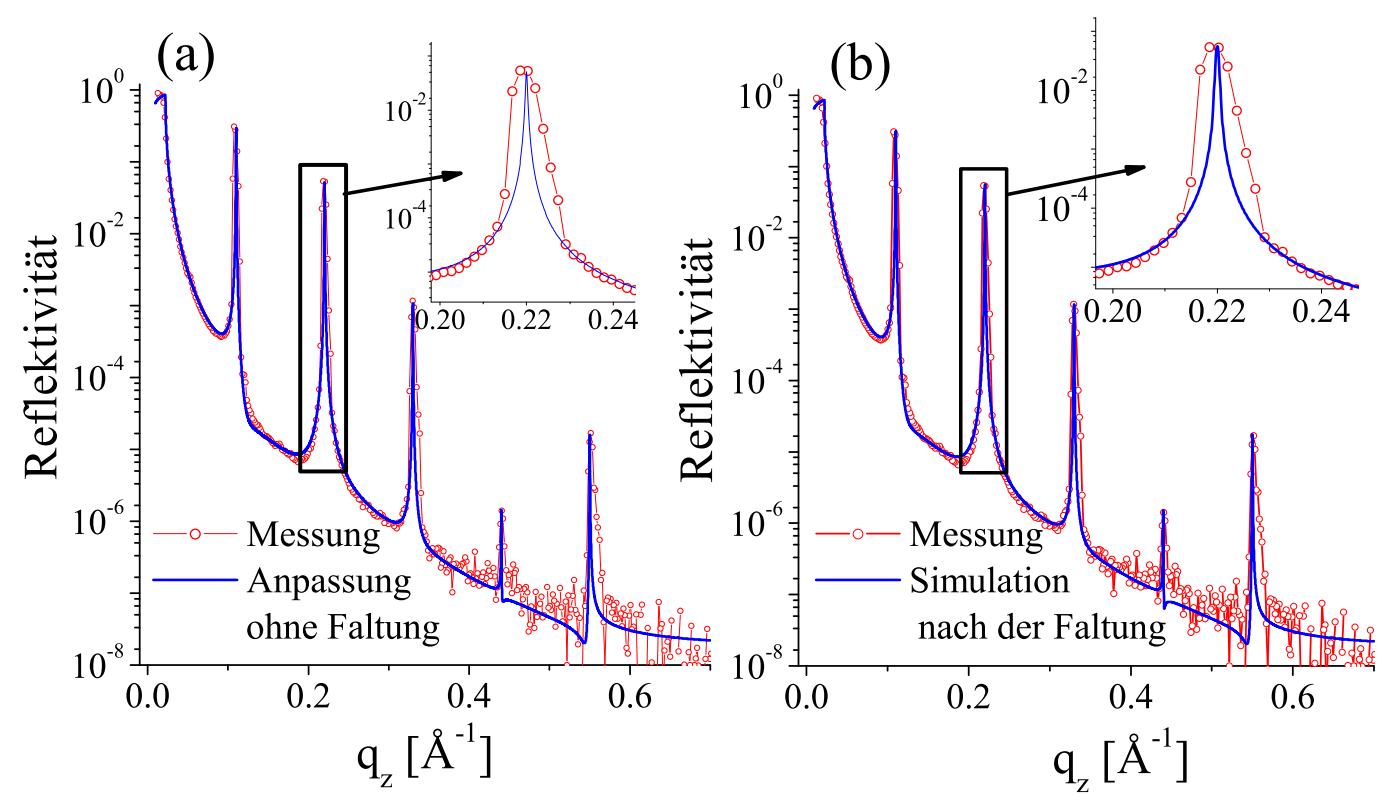

Abbildung 5.14: Reflektivitätskurve der Probe aus reinem DMPC, die unter 14\% PEG-Lösung und einer Temperatur von $30.53^{\circ} \mathrm{C}$ gemessen wurde. (a) Angepasste Kurve mit Messkurve ohne Faltung des Strukturfaktors; (b) Mit gleichen Parametern simulierte Kurve mit Faltung der Strukturfaktor-Amplitude zusammen mit Messkurve. Die Fläche unter einem Peak bleibt nach der Faltung konstant, um die gleiche Peakhöhe zu erreichen, muss die Peakbreite schmaler werden, die Faltung ist somit nicht wirksam.

\section{Faltung der Strukturfaktor-Amplitude in einer durch reelle Funktionen ausgedrückten Mo- dellfunktion:}

Nach dem Ausmultiplizieren der Modellfunktion in Gl. (5.44) wurde die Faltung auf die Strukturfaktor-Amplitude $s\left(q_{z}\right)$ bzw. $s^{*}\left(q_{z}\right)$ und auf dem Strukturfaktor $s\left(q_{z}\right) s^{*}\left(q_{z}\right)$ durchgeführt. Dieser Vorgang geschah durch Faltung des Strukturfaktors in G1. (5.52) und durch Faltung der Strukturfaktor-Amplitude in Gl. (5.53). Nach der Faltung kann der Term $R 2\left(q_{z}\right)$ in G1. (5.52) näherungsweise geschrieben werden als:

$$
\begin{aligned}
& R 2\left(q_{z}\right) \otimes G\left(q_{z}\right)=\int_{-\infty}^{\infty} R 2\left(q_{z}-t\right) G(t) d t=\int_{-\infty}^{\infty} R 2(t) G\left(q_{z}-t\right) d t \\
\cong & \sqrt{\frac{C}{\pi}}\left|f\left(q_{z}\right)\right|^{2} \sum_{m=0}^{N-1} \sum_{n=0}^{N-1} \int_{-\infty}^{\infty}\left[\exp [i t d(m-n)] \exp \left[-0.5 t^{2}\left(\left\langle u_{m}^{2}\right\rangle+\left\langle u_{n}^{2}\right\rangle\right)\right] \exp \left[-C\left(q_{z}-t\right)^{2}\right]\right] d t \\
= & \left|f\left(q_{z}\right)\right|^{2} \sum_{m=0}^{N-1} \sum_{n=0}^{N-1} \sqrt{\frac{2 C}{2 C+\left(\delta_{m}+\delta_{n}\right)}} \cdot \exp \left(-\frac{d^{2}(m-n)^{2}+2 C q_{z}^{2}\left(\delta_{m}+\delta_{n}\right)}{2\left(2 C+\left(\delta_{m}+\delta_{n}\right)\right)}\right) \cdot \exp \left(\frac{2 i C q_{z} d(m-n)}{2 C+\left(\delta_{m}+\delta_{n}\right)}\right),
\end{aligned}
$$

wobei $\delta_{m}=\left\langle u_{m}^{2}\right\rangle$ ist. Im Fall des dicken Lipidfilms kann für alle $\delta_{m}$ der gleiche Wert $\delta$ angenommen werden, weil die Fluktuation aller Membranen näherungsweise gleich gesetzt werden kann. 
(a)

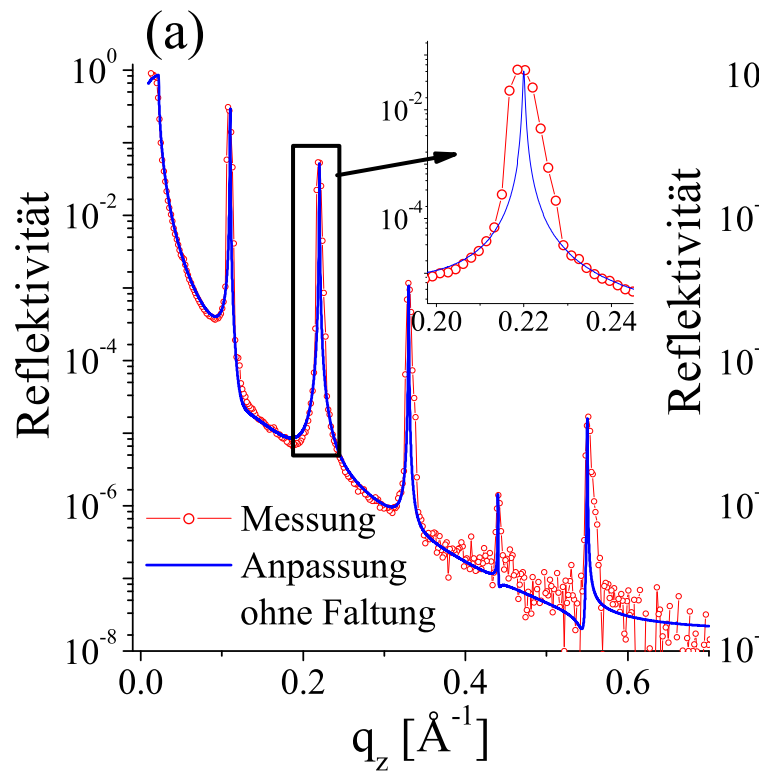

(b)<smiles>[101In]</smiles><smiles>C1CCCCC1</smiles>

Abbildung 5.15: Reflektivitätskurve der Probe aus reinem DMPC, die in einer 14\% PEG-Lösung unter einer Temperatur von $30.53^{\circ} \mathrm{C}$ gemessen wurde. (a) Angepasste Kurve mit Messkurve ohne Faltung des Strukturfaktors; (b) mit gleichen Parametern simulierte Kurve mit Faltung des Strukturfaktors in reeller Form mit Messkurve.

Unter dieser Annahme lässt sich Gl. (5.79) weiter vereinfachen zu:

$$
\begin{aligned}
R 2\left(q_{z}\right) \otimes G\left(q_{z}\right) \cong & \left|f\left(q_{z}\right)\right|^{2} \sum_{m=0}^{N-1} \sum_{n=0}^{N-1} \sqrt{\frac{2 C}{2 C+\left(\delta_{m}+\delta_{n}\right)}} \cdot \\
& \exp \left(-\frac{d^{2}(m-n)^{2}+2 C q_{z}^{2}\left(\delta_{m}+\delta_{n}\right)}{2\left(2 C+\left(\delta_{m}+\delta_{n}\right)\right)}\right) \cdot \exp \left(\frac{2 i C q_{z} d(m-n)}{2 C+\left(\delta_{m}+\delta_{n}\right)}\right) \\
= & \left|f\left(q_{z}\right)\right|^{2}\left[\sqrt{\frac{C}{C+\delta}} \cdot \sum_{k=1}^{N}[\underbrace{2(N-k) \text { Mal vor })}_{(\text {Zeile-Spalten }=k, \text { kommt }} \cos \left(\frac{C}{C+\delta} \cdot q_{z} d k\right)\right. \\
& \left.\exp \left(-\frac{1}{4} \cdot \frac{k^{2} d^{2}}{C+\delta}-\frac{C \delta}{C+\delta} \cdot q_{z}^{2}\right)\right]+\sqrt{\frac{C}{C+\delta}} \cdot \underbrace{\text { exp }\left(-\frac{C}{C+\delta} \cdot q_{z}^{2}\right)}_{\text {Diagonalterme }}]
\end{aligned}
$$

Die Faltung über den Term $R 3\left(q_{z}\right)$ in G1. (5.53) lässt sich näherungsweise schreiben als: 


$$
\begin{aligned}
& R 3\left(q_{z}\right) \otimes G\left(q_{z}\right)=\int_{-\infty}^{\infty} R 3\left(q_{z}-t\right) G(t) d t=\int_{-\infty}^{\infty} R 3(t) G\left(q_{z}-t\right) d t \\
\cong & i \cdot f\left(q_{z}\right) \sum_{n=0}^{N-1} \int_{-\infty}^{\infty}\left[\sin \left(q_{z}\left(n d+d_{0}\right)\right) \cdot \exp \left(-\frac{1}{2} q_{z}^{2}\left(\sigma+\left\langle u_{n}^{2}\right\rangle\right)\right) \cdot \exp \left(-C\left(q_{z}-t\right)^{2}\right) d t\right] \\
= & i \cdot f\left(q_{z}\right) \sum_{n=0}^{N-1} \sqrt{\frac{2 C}{2 C+\sigma^{2}+\left\langle u_{n}^{2}\right\rangle}} \cdot 2 \sin \left(\frac{2 C}{2 C+\sigma^{2}+\left\langle u_{n}^{2}\right\rangle} \cdot q_{z}\left(n d+d_{0}\right)\right) . \\
= & i \cdot f\left(q_{z}\right) \sum_{n=0}^{N-1} \sqrt{\frac{2 C}{2 C+\sigma^{2}+\delta}} \cdot 2 \sin \left(\frac{2 C}{2 C+\sigma^{2}+\delta} \cdot q_{z}\left(n d+d_{0}\right)\right) . \\
& \exp \left(-\frac{1}{2} \cdot \frac{\left(n d+d_{0}\right)^{2}}{2 C+\sigma^{2}+\left\langle u_{n}^{2}\right\rangle}-\frac{1}{2 C} \frac{\left(\sigma^{2}\right.}{2 C+\sigma^{2}+\delta}-\frac{C}{2 C+\sigma^{2}+\delta} \cdot q_{z}^{2}\left(\sigma^{2}+\delta\right)\right) .
\end{aligned}
$$

wobei $\delta=\left\langle u_{n}^{2}\right\rangle$. Nach den Faltungen wird mit gleichen Parametern, die durch Anpassung ermittelt wurden (siehe Abb. 5.15(a)), eine Simulation mit dem gefalteten Strukturfaktor durchgeführt. In Abb. 5.15(b) ist klar zu sehen, dass die simulierte Kurve verbreiterte Bragg-Peaks hat, aber die Kurvenform wird durch die Faltung teilweise verformt. Die Ursache für die Verformung der Kurve ist, wie in Abschnitt5.4.1 erklärt wurde, die einseitige Faltung an $s\left(q_{z}\right)$ (siehe Abb. 5.11), weil der Formfaktor $f\left(q_{z}\right)$ für den Kurvenverlauf eine wichtige Rolle spielt.

\section{Faltung der ganzen Reflektivitätskurve durch eine numerische Summation:}

Die Faltungsmethode durch numerische Summation wird nun auch auf die ganze Modellfunktion angewendet. Die Methode ist die gleiche wie die, die in Abschnitt 5.4.1 vorgestellt wurde. In Abb.
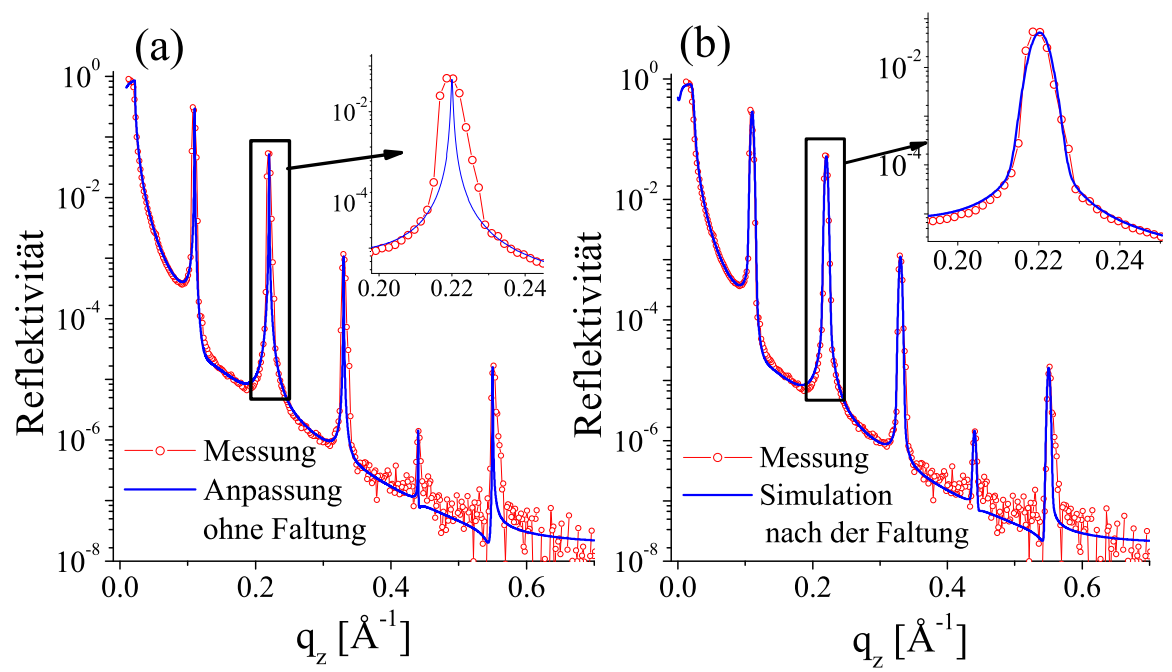

Abbildung 5.16: Die Reflektivitätskurve der Probe aus reinem DMPC, die unter einer 14\% PEG-Lösung und einer Temperatur von $30.53^{\circ} \mathrm{C}$ gemessen wurde. (a) Angepasste Kurve mit Messkurve ohne Faltung der Modellfunktion; (b) Simulierte Kurve mit Faltung der Modellfunktion durch numerische Summation mit Messkurve. 
5.16 wird die simulierte Kurve mit der gemessenen Kurve zusammen dargestellt. Die Probe ist dieselbe wie die, die im letzten Abschnitt vorgestellt wurde. Bei der Summation ist die Summationszahl $N_{0}=200$. Man kann in Abb. 5.16 gut erkennen, dass die Kurvenform der simulierten Kurve im Vergleich mit der angepassten Kurve kaum anders ist, die Breiten der Bragg-Peaks werden sehr gut angepasst. Dieses Ergebnis zeigt, dass bei der Faltung über die Reflektivitätskurve die ganze Kurve gefaltet werden sollte, statt nur über den Strukturfaktor zu falten. Idealer wäre es, die Faltung auf die ganze Kurve analytisch anzuwenden, aber aufgrund der Schwierigkeit der Integrationsberechnung wegen der Komplexität der Modellfunktion ist dies nicht realisierbar. Die Faltungsmethode durch numerische Summation ist deshalb ein realistischer Lösungsansatz, um eine Korrektur des durch die Auflösung der Instrumente bewirkten Effekts zu erreichen.

Im nächsten Kapitel wird die Anpassung an Reflektivitätskurven zur Auswertung der Messdaten verwendet, dabei wird die Faltung über die gesamte Modellfunktion durch numerische Summation durchgeführt. Es wird sich zeigen, dass die Faltung durch numerische Summation eine sehr praktikable Methode ist. 


\section{Kapitel 6}

\section{Auswertung und Ergebnisse}

In diesem Kapitel werden die Ergebnisse der Datenauswertung vorgestellt, und zwar nacheinander für drei Systemklassen: (1) Reine Lipidmembranen, (2) Lipidmembranen in Wechselwirkung mit Alamethicin und (3) Lipidmembranen in Wechselwirkung mit Magainin 2. Dabei wurden parallel und zur vergleichenden Diskussion zwei Methoden verwendet: (i) Die wohl etablierte Methode der Fouriersynthese (FS), und (ii) das in dieser Arbeit entwickelte Reflektivitätsmodell für Lipidmembranen (siehe vorangegangenes Kapitel 5). Die gemessenen Reflektivitätsdaten wurden durch das Verfahren der Fouriersynthese und der Anpassung mit einer Modellfunktion ausgewertet. Dadurch ermittelt man das Elektronendichteprofil der Lipiddoppelschichten. Daraus können einige Strukturinformationen, wie z.B. die Membrandicke (Abstand zwischen zwei Kopfgruppen in Lipiddoppelschicht) und die Wasserschichtdicke, gewonnen werden. Bei der Anpassung kann zusätzlich ein dimensionsloser Elastizitätsparameter $\eta$ (Caillé-Parameter), der vom Kompressionsmodul und vom Biegemodul der Lipidmembranen abhängig ist (siehe Kapitel 5), ermittelt werden, und zwar dann, wenn nennenswerte thermische Fluktuationen der Membranen in den Proben angeregt sind. Systeme, die aus dickem Lipidfilm $(N>200)$ bestehen, werden mit Fouriersynthese und Anpassung behandelt, für Systeme, die aus Oligo-Membranen $(N<20)$ bestehen, wird nur die Anpassung an die Reflektivitätskurven durchgeführt. Die bei der Anpassung ermittelten Parameter werden im Anhang aufgelistet.

\subsection{Einführung einiger charakteristischer Größen}

Um die Struktur des Peptid/Lipid-Systems quantitativ analysieren zu können, führen wir in diesem Abschnitt einige charakteristische Größen ein, die für Lipidmembranen relevant sind. Definiert werden die folgenden Bezeichnungen:

$E_{h}:$ Elektronendichtemaximum der Kopfgruppe,

$\Delta E_{h}:$ Änderung von $E_{h}$,

$E_{w}:$ Elektronendichte der Wasserschicht, 
$\Delta E_{w}:$ Änderung vom $E_{w}$,

$E_{c}:$ Elektronendichteminimum des Kettenbereichs,

$\Delta E_{c}$ : Änderung von $E_{c}$,

$d$ : Periodizität der Lipiddoppelschichten,

$d_{p p}:$ Membrandicke in der Probe,

$E_{m w}=E_{h}-E_{w}:$ Unterschied der Elektronendichte von Kopfgruppe zu Wasserschicht,

$E_{m m}=E_{h}-E_{c}:$ Unterschied des Elektronendichte von Kopfgruppe zu Kettenbereich.

Alle oben aufgelisteten Größen werden in Abb. 6.1 veranschaulicht. Für das Elektronendichteprofil der Lipiddoppelschichten ist das Verhältnis zwischen $E_{m w}$ und $E_{m m}$, also $\frac{E_{m w}}{E_{m m}}$, eine wichtige charakteristische Größe, weil sie für eine Probe intrinsisch konstant ist. Nach der Änderung des

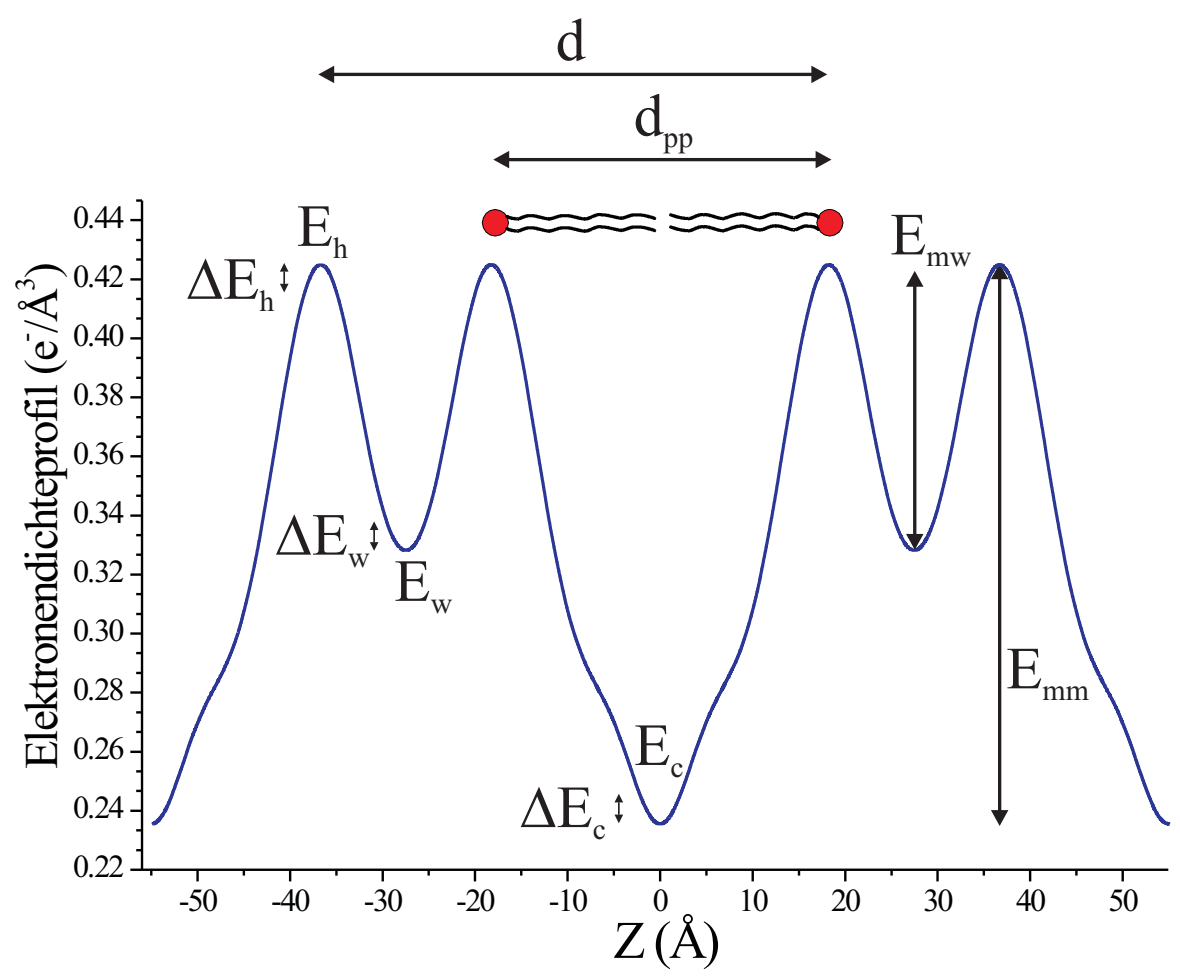

Abbildung 6.1: Zur Erklärung der verwendeten Bezeichnungen zur Analyse der Struktur des Peptid/LipidSystems.

Elektronendichteprofils der Kopfgruppe, der Wasserschicht und des Kettenbereichs lässt sich die Differenz der charakteristischen Größe $E_{m w} / E_{m m}$ für zwei Proben (gestrichene und ungestrichene 
Größe) wie folgt schreiben:

$$
\begin{aligned}
\frac{E_{m w}^{\prime}}{E_{m m}^{\prime}}-\frac{E_{m w}}{E_{m m}} & =\frac{\left(E_{h}+\Delta E_{h}\right)-\left(E_{w}+\Delta E_{w}\right)}{\left(E_{h}+\Delta E_{h}\right)-\left(E_{c}+\Delta E_{c}\right)}-\frac{E_{h}-E_{w}}{E_{h}-E_{c}} \\
& =\frac{\left(E_{h}+\Delta E_{h}-E_{w}-\Delta E_{w}\right)\left(E_{h}-E_{c}\right)-\left(E_{h}-E_{w}\right)\left(E_{h}+\Delta E_{h}-E_{c}-\Delta E_{c}\right)}{\left(E_{h}+\Delta E_{h}-E_{c}-\Delta E_{c}\right)\left(E_{h}-E_{c}\right)} \\
& =\frac{\Delta E_{c}\left(E_{h}-E_{w}\right)+\Delta E_{h}\left(E_{w}-E_{c}\right)-\Delta E_{w}\left(E_{h}-E_{c}\right)}{\left(E_{h}+\Delta E_{h}-E_{c}-\Delta E_{c}\right)\left(E_{h}-E_{c}\right)} .
\end{aligned}
$$

Da $E_{h}>E_{c}$ und $E_{h}+\Delta E_{h}>E_{c}+\Delta E_{c}$ sind, kann Gl. (6.1) im Einzelnen wie folgt behandelt werden.:

1. $\Delta E_{w}=0$ : (Keine Änderung in der Wasserschicht)

$$
\Longrightarrow \quad \frac{E_{m w}^{\prime}}{E_{m m}^{\prime}}-\frac{E_{m w}}{E_{m m}} \begin{cases}<0, & \text { wenn } \Delta E_{c}\left(E_{h}-E_{w}\right)<-\Delta E_{h}\left(E_{w}-E_{c}\right), \\ >0, & \text { wenn } \Delta E_{c}\left(E_{h}-E_{w}\right)>-\Delta E_{h}\left(E_{w}-E_{c}\right) ;\end{cases}
$$

2. $\Delta E_{c}=0:$ (Keine Änderung im Kettenbereich)

$$
\Longrightarrow \quad \frac{E_{m w}^{\prime}}{E_{m m}^{\prime}}-\frac{E_{m w}}{E_{m m}}\left\{\begin{array}{c}
<0, \quad \text { wenn } \frac{\Delta E_{w}}{\Delta E_{h}}>\frac{E_{w}-E_{c}}{E_{h}-E_{c}}, \\
>0, \quad \text { wenn } \frac{\Delta E_{w}}{\Delta E_{h}}<\frac{E_{w}-E_{c}}{E_{h}-E_{c}}
\end{array}\right.
$$

3. $\Delta E_{w}=\Delta E_{h}=0$ : (Keine Änderungen in Wasserschicht und Kopfgruppe)

$$
\Longrightarrow \quad \frac{E_{m w}^{\prime}}{E_{m m}^{\prime}}-\frac{E_{m w}}{E_{m m}}\left\{\begin{array}{cc}
<0, & \text { wenn } \Delta E_{c}<0, \\
>0, & \text { wenn } \Delta E_{c}>0 ;
\end{array}\right.
$$

4. $\Delta E_{w}=\Delta E_{c}=0$ : (Keine Änderungen in Wasserschicht und Kettenbereich)

$$
\Longrightarrow \quad \frac{E_{m w}^{\prime}}{E_{m m}^{\prime}}-\frac{E_{m w}}{E_{m m}}\left\{\begin{array}{cc}
<0, & \text { wenn } \Delta E_{h}<0, \\
>0, & \text { wenn } \Delta E_{h}>0 .
\end{array}\right.
$$

\subsection{Auswertung der Messdaten aus reinen Lipiden}

In diesem Abschnitt wird zuerst die Auswertung der Messdaten aus den Proben aus reinem OPPC mit drei verschiedenen Membranstapeldicken, die bei der Präparation zu ermitteln sind, dargestellt, um den Einfluss der Membranstapeldicke und den Einfluss der Auswertungsmethode auf das Elektronendichteprofil zu beobachten. Gleich wichtig ist auch der Einfluss der unterschiedlichen Kettenlängen und unterschiedlichen Kopfgruppen auf das Elektronendichteprofil. Daher wird die Auswertung bei verschiedenen Lipidproben durchgeführt, um die Änderung des Elektronendichteprofils aufgrund der unterschiedlichen Kettenlängen und unterschiedlichen Kopfgruppen zu ermitteln. Dabei werden Lipide aus DLPC, DMPC, DMPG, DPPC und POPS betrachtet. 


\subsubsection{OPPC bei verschiedenen Membranstapeldicken}

Drei Proben wurden mit einer Stammlösung aus reinem OPPC, die jeweils eine Konzentration von 7, 14 bzw. $20 \mathrm{mg} / \mathrm{ml}$ aufwies, auf Si-Substrat unter Zuhilfenahme eines Spin-Coaters mit einer Drehgeschwindigkeit von 250 Umdrehungen/Min (rpm) präpariert. Dabei wurde das organische Lösungsmittel Chloroform verwendet. Diese drei Proben wurden unter gleichen Bedingungen $\left(\mathrm{RH} \approx 98 \%\right.$ und $\left.\mathrm{T} \approx 45^{\circ} \mathrm{C}\right)$ am Messplatz $\mathrm{D} 4$ Hasylab gemessen, dabei war die Wellenlänge der verwendeten Röntgenstrahlen $\lambda=0.62 \AA$.

\section{Fouriersynthese:}

In Abb. 6.2 werden die gemessenen Reflektivitätskurven (mit angepassten Kurven) und die Periodizität der Lipiddoppelschichten verschiedener Konzentration dargestellt. Zur besseren Darstellung werden die Kurven mit einem bestimmten Faktor skaliert. Die Periodizität der Lipiddoppelschichten wurde durch Gauss'sche Anpassung am 4. Bragg-Peak ermittelt. Durch die Gauss'sche Anpassung wurde zuerst der Mittelpunkt des Bragg-Peaks bestimmt, danach wurde die Periodizität gemäß der Formel $d=4 \cdot 2 \pi / q_{z}$ berechnet. Da der absoluter Fehler von $q_{z}$ bei ca. 0.002 liegt, kann der absoluter Fehler $\delta d$ für die Periodizität nach der Fehlerfortpflanzung $|\delta d / d|=\left(\left|\delta q_{z} / q_{z}\right|+|\delta \theta / \theta|+|\delta G / G|\right)$ abgeschätzt werden, dabei bezeichnet $\delta \theta$ den systematischen Fehler und $\delta G$ den Fehler der Gauss'schen Anpassung. Mit dieser Abschätzung ergibt sich für $\delta d$ ca. $0.1 \AA$ A. Dieser Wert wird in den folgenden Abschnitten als absoluter Fehler für die Periodizität der Lipiddoppelschichten verwendet. Durch Fouriersynthese (siehe Kapitel 4) werden aus den Reflektivitätskurven Elektronendichteprofile ermittelt, dabei werden für die Phasen aller Formfaktoren die gleichen Werte $(--+----)$ angenommen. Die spekularen und diffusen Reflektivitätskurven werden hier mit den Lorentzfaktoren $1 / q_{z}^{2}$ und $1 / q_{z}$ ausgewertet. In Abb. 6.3(a) werden die Elektronendichteprofile, die unter Verwendung der spekularen Reflektivitätskurven ermittelt wurden, mit Angabe der Lipidkonzentration gezeigt; hier werden alle Elektronendichteprofile gemäß der Formel $\rho(z)=a \rho_{0}(z)+b$ mit gleichen Faktoren skaliert und verschoben. Man erkennt, dass alle Elektronendichteprofile der Kopfgruppen gleich sind, während sie in den Wasserschichten und im Kettenbereich etwas voneinander abweichen. Die Membrandicken $\left(d_{p p}\right)$ in den Proben, die durch Elektronendichteprofile aus Abb. 6.3 (a) bestimmt wurden, werden in Abb. 6.3 (b) dargestellt. Man kann hier sehen, dass die Membrandicken ziemlich wenig voneinander abweichen. Der absolute Fehler für die Membrandicke wird gemäß dem Elektronendichteprofil $\rho(z)=\frac{f_{u}(0)}{d}+\frac{1}{\sqrt{X}} \sum \frac{8 m \pi}{2 d^{2}-m^{2} \lambda^{2}} \sqrt{I_{m}} \cos (2 m \pi z / d)$ (siehe Kapitel 4) abgeschätzt. Die Abschätzung ergibt ca. $0.2 \AA$. Dieser absolute Fehler für die Membrandicke wird in den folgenden Abschnitten für alle ermittelten Membrandicken verwendet. In Abb. 6.4 (a) werden auch die Elektronendichteprofile, die aus den diffusen Reflektivitätskurven ermittelt wurden, gegen z aufgetragen. Die durch diese Elektronendichteprofile bestimmte Membrandicke wird in Abb. 6.4 (b) gezeigt. Es stellt sich jedoch bei allen in dieser Arbeit ausgewerteten Kurven heraus, dass die Fouriersynthese der diffusen Reflektivität signifikant von der physikalischen Darstellung abweicht, während die Fouriersynthese der spekularen Reflektivität und die Anpassung mit einer Modellfunktion physikalisch Sinn machen. 


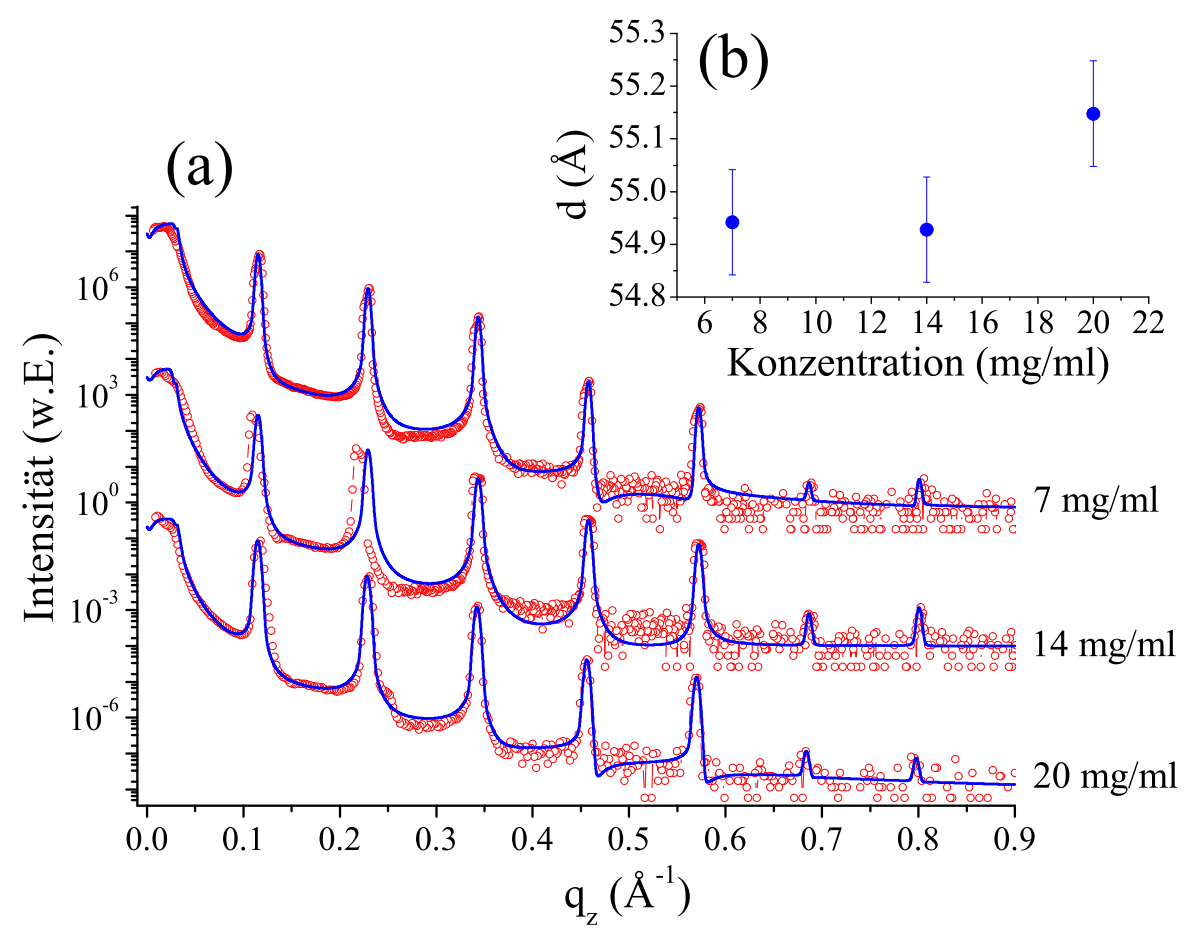

Abbildung 6.2: (a) Die gemessenen Reflektivitätskurven mit den angepassten Kurven (durchgezogen) der Proben aus reinem OPPC; (b) Periodizität der Lipiddoppelschichten.
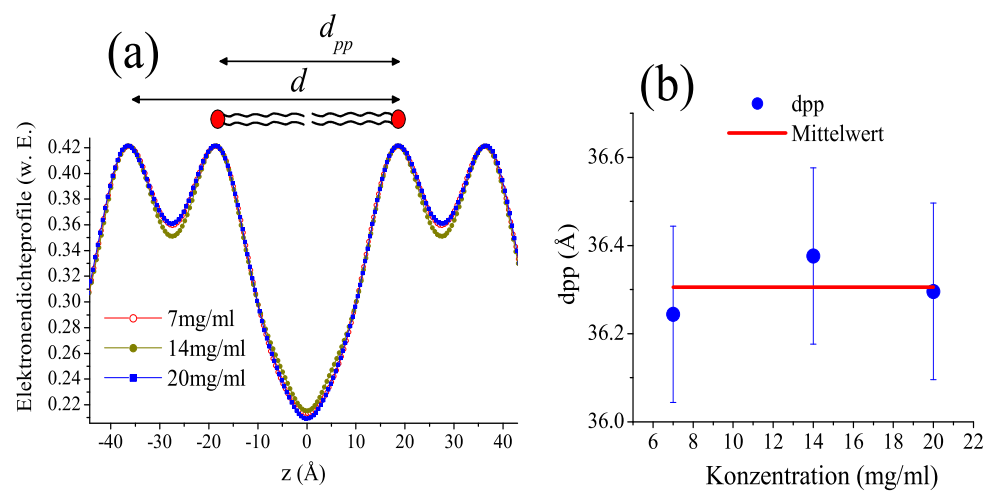

Abbildung 6.3: (a) Elektronendichteprofile von reinem OPPC, die durch Fouriersynthese unter Verwendung spekularer Reflektivität ermittelt wurden, zu verschiedenen Membranstapeldicken; (b) Membrandicke der Proben aus dem Elektronendichteprofil.
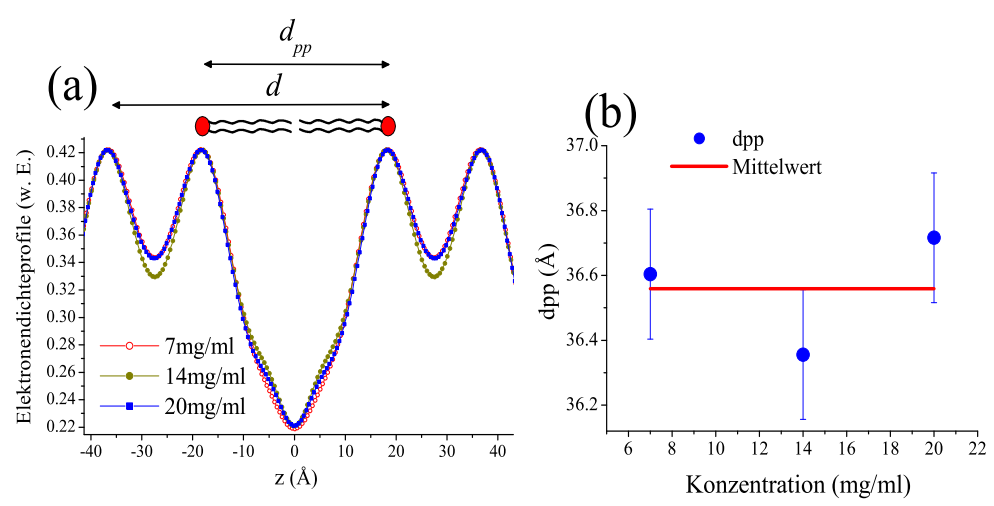

Abbildung 6.4: (a) Elektronendichteprofile von reinem OPPC, die durch Fouriersynthese unter Verwendung diffuser Reflektivität ermittelt wurden, mit verschiedener Membranstapeldicke; (b) Membrandicke der Probe aus dem Elektronendichteprofil. 


\section{Anpassung:}

Die gemessenen Reflektivitätskurven wurden mit der Modellfunktion für die Feuchtigkeitsprobenumgebung (siehe Kapitel 5) angepasst. Abb. 6.2(a) zeigt die angepassten Kurven zusammen mit den gemessenen Kurven. Die durch Anpassung ermittelten Parameterwerte werden in Tabelle 6.1 aufgelistet. Die auftretenden Zeichen haben folgende Bedeutung:

\begin{tabular}{cccccccccccccccc}
\hline Konzentr. & $f_{1}$ & $f_{2}$ & $f_{3}$ & $f_{4}$ & $f_{5}$ & $f_{6}$ & $f_{7}$ & $d_{0}$ & $q_{c}$ & $\Delta_{\max }$ & $\sigma_{0}$ & $L$ & $N$ & $d_{1}$ & $\sigma_{1}$ \\
\hline \hline $7 \mathrm{mg} / \mathrm{ml}$ & -1 & -0.67 & 0.41 & -0.069 & -0.037 & -0.0038 & 0.005 & 21 & 0.029 & 0.19 & 2.2 & 7000 & 500 & 25 & 12 \\
$14 \mathrm{mg} / \mathrm{ml}$ & -1 & -0.66 & 0.4 & -0.14 & -0.08 & -0.01 & -0.014 & 21.5 & 0.028 & 0.2 & 3.0 & 3800 & 500 & 20 & 25 \\
$20 \mathrm{mg} / \mathrm{ml}$ & -1 & -0.65 & 0.37 & -0.09 & -0.065 & -0.007 & -0.0055 & 21.5 & 0.029 & 0.19 & 1.2 & 15000 & 500 & 21 & 25 \\
\hline
\end{tabular}

Tabelle 6.1: Die bei der Anpassung eingesetzten Parameter von drei Proben aus reinem OPPC.

$f_{n}$ : Fourierkoeffizienten des Formfaktors,

$d_{0}$ : Wasserschichtdicke zwischen Substrat und 1. Lipiddoppelschicht,

$q_{c}:$ Kritischer Winkel für externe Totalreflexion des Lipidfilms,

$\Delta_{\max }$ : Amplitude der Elektronendichteschwankung um die mittlere Elektronendichte des Membranstapels,

$\sigma_{0}:$ Rauigkeit der Substrat-Wasser-Grenzfläche,

$L$ : Effektive Domänengröße der Lipiddoppelschichten,

$N$ : Anzahl der Lipiddoppelschichten,

$d_{1}$ : Wasserschichtdicke zwischen N-ter (letzter) Lipiddoppelschicht und Luft,

$\sigma_{1}$ : Rauigkeit der Wasser-Luft-Grenzfläche.

Die durch Anpassung ermittelten Elektronendichteprofile werden in Abb. 6.5 (a) dargestellt. Man sieht auch hier ähnliche Unterschiede wie bei den Elektronendichteprofilen, die durch Fouriersynthese ermittelt wurden. Die Elektronendichten der Kopfgruppen sind fast gleich, während sie in den Wasserschichten und im Kettenbereich etwas voneinander abweichen. Die Membrandicken, die durch Anpassung ermittelt wurden (Abb. 6.5(b)), stimmen innerhalb der Fehlergrenze mit denen überein, die durch die Fouriersynthese der spekularen Reflektivität ermittelt wurden, hingegen weichen sie stark von denen ab, die durch die Fouriersynthese der diffusen Reflektivität ermittelt wurden. 


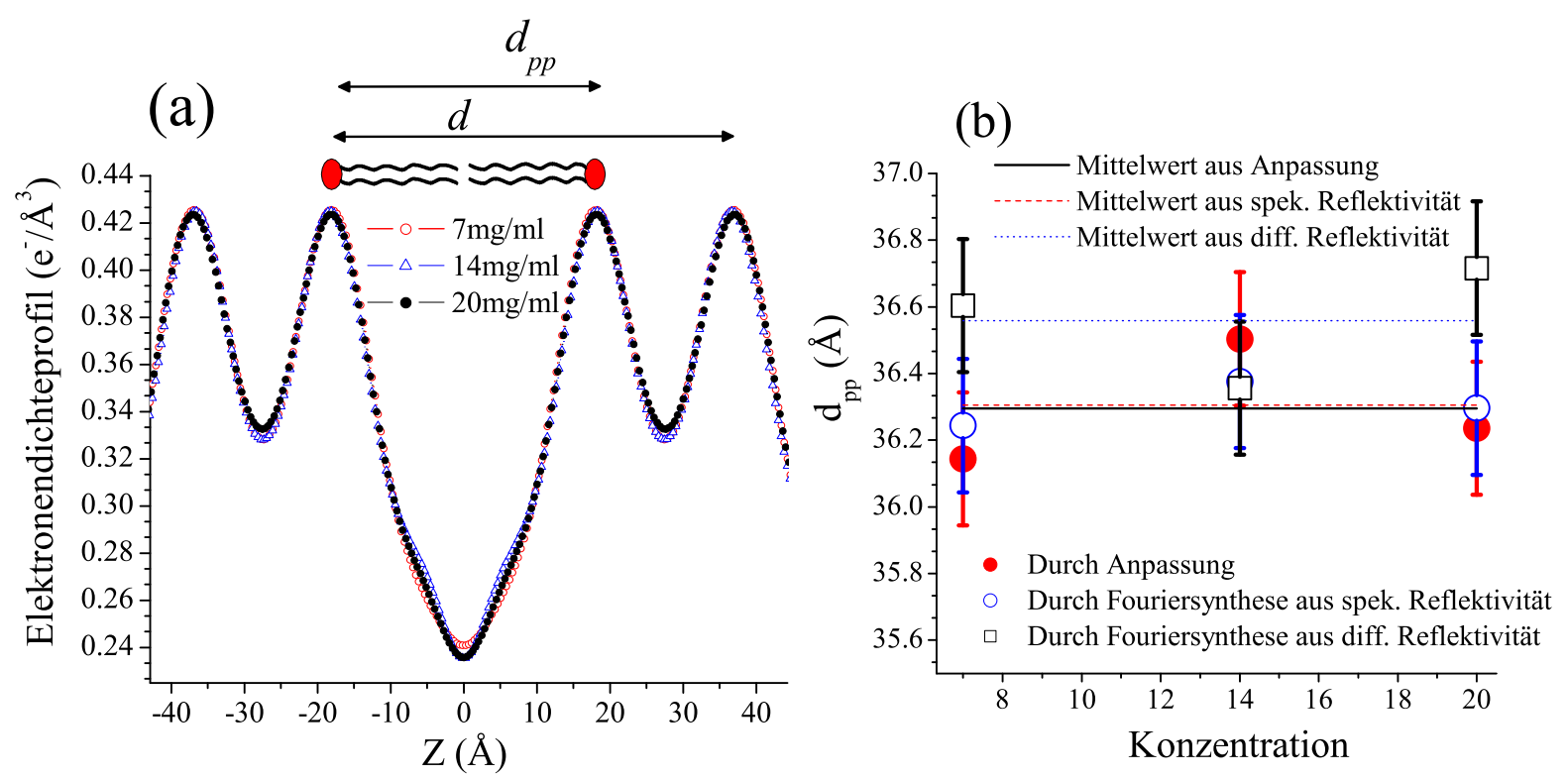

Abbildung 6.5: (a) Durch Anpassung ermittelte Elektronendichteprofile der Proben aus reinem OPPC; (b) Vergleich der Membrandicken in den Proben, die durch Anpassung und Fouriersynthese ermittelt wurden.

\section{Zusammenfassung:}

Aus den hier ermittelten Elektronendichteprofilen erkennt man leicht, dass die Membranstapeldicke in den Proben die ermittelten Elektronendichteprofile wenig beeinflusst. Insbesondere ist dieser Einfluss bei den Elektronendichteprofilen, die durch Anpassung mit einer Modellfunktion ermittelt wurden, klein. Die Änderung der Membrandicke aufgrund unterschiedlicher Membranstapeldicke ist bei den verschiedenen Proben unterschiedlich. Die Mittelwerte der Membrandicken, die durch Anpassung und durch Fouriersynthese aus spekularer Reflektivität ermittelt wurden, stimmen überein, während die Mittelwerte, die durch Anpassung und durch Fouriersynthese aus diffuser Reflektivität ermittelt wurden, stark voneinander differieren (ca. $0.25 \AA$ ). Das weist darauf hin, dass die zwei Verfahren, Anpassung mit einer Modellfunktion und Fouriersynthese aus spekularer Reflektivität, weitgehend konsistente Ergebnisse liefern, während die Fouriersynthese aus diffuser Reflektivität mit Vorsicht betrachtet werden muss.

\subsubsection{Verschiedene Lipide}

Sechs Proben jeweils aus DLPC, DMPC, DMPG, DPPC, OPPC und POPS wurden mit dem organischen Lösungsmittel HFI (Hexafluoro-2-Propanol) (für DLPC, DMPC, DPPC, OPPC und POPS) oder einer Mischung aus TFE/Chloroform im Volumenverhältnis 1:1 (für DMPG) und in verschiedener Lipidkonzentration in einer Stammlösung (40mg/ml für DLPC und DMPC; $10 \mathrm{mg} / \mathrm{ml}$ für die übrigen Lipide) präpariert. Ihre Reflektivitätskurven wurden mit Synchrotronstrahlen am Messplatz D4 Hasylab unter Feuchtigkeit $(\mathrm{RH} \approx 99 \%)$ mit $\mathrm{T}=45^{\circ} \mathrm{C}$ gemessen; dabei hatten die Strahlen eine Wellenlänge von $0.62 \AA$. 


\section{Fouriersynthese:}

In Abb. 6.6 werden alle gemessenen spekularen Reflektivitätskurven der Proben gegen $q_{z}$ aufgetragen. Aus dem 4. Bragg-Peak wurde die Periodizität der Lipiddoppelschichten durch Gauss'sche Anpassung bestimmt, siehe dazu Abb. 6.7. Wie im letzten Abschnitt dargelegt wurde, hat diese Periodizität einen absoluten Fehler von 0.1 A. Unter Verwendung der spekularen und diffusen Reflektivitätskurven wird nun das Verfahren der Fouriersynthese durchgeführt. Mit Hilfe der dadurch ermittelten Parameter können die Elektronendichteprofile der Proben rekonstruiert werden. In Abb. 6.8 und Abb. 6.9 werden die Elektronendichteprofile aus spekularen und diffusen Reflektivitäten dargestellt, dabei wird jedes Profil mit zwei Faktoren (wie in letztem Abschnitt) skaliert und verschoben, um das Elektronendichteprofil an den Kopfgruppen gleich halten zu können. In Tabelle

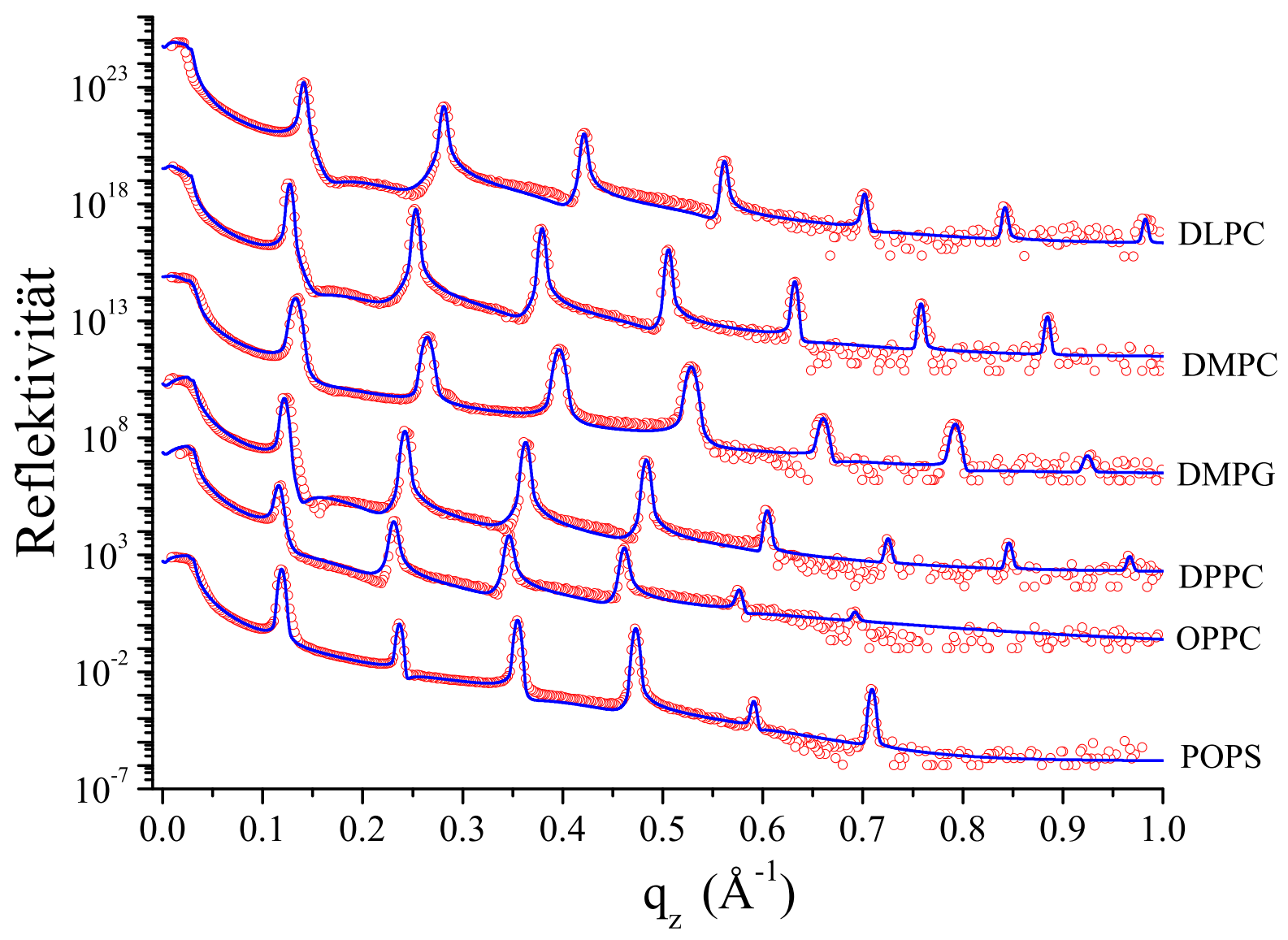

Abbildung 6.6: Gemessene Reflektivitätskurven mit den angepassten Kurven (durchgezogen) der Proben aus verschiedenen Lipiden.

6.2 werden alle ermittelten charakteristischen Größen der Proben aufgelistet. Aus Abb. 6.7 Abb. 6.11 und Tabelle 6.2 ist eindeutig zu erkennen, dass sowohl die Periodizität der Lipiddoppelschichten als auch ihre Membrandicken sich in charakteristischer Weise unterscheiden. 


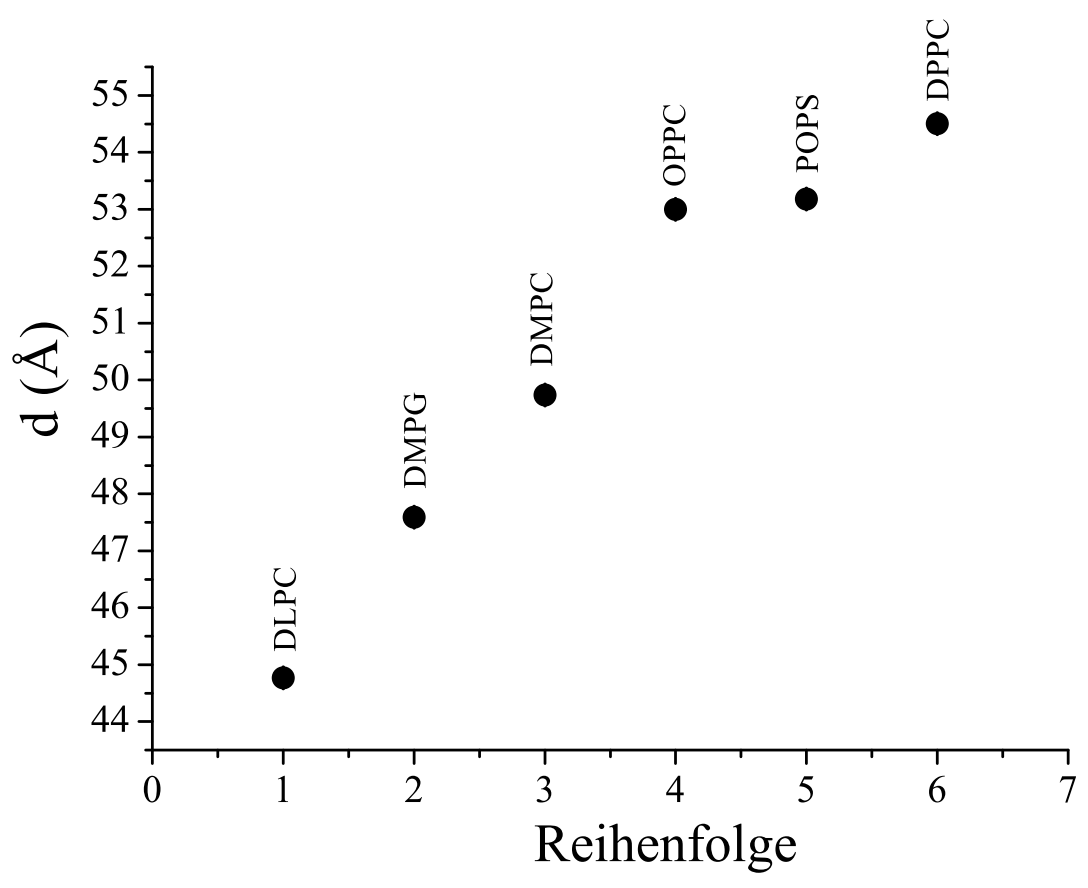

Abbildung 6.7: Periodizität der Lipiddoppelschichten in den Proben aus verschiedenen Lipiden.

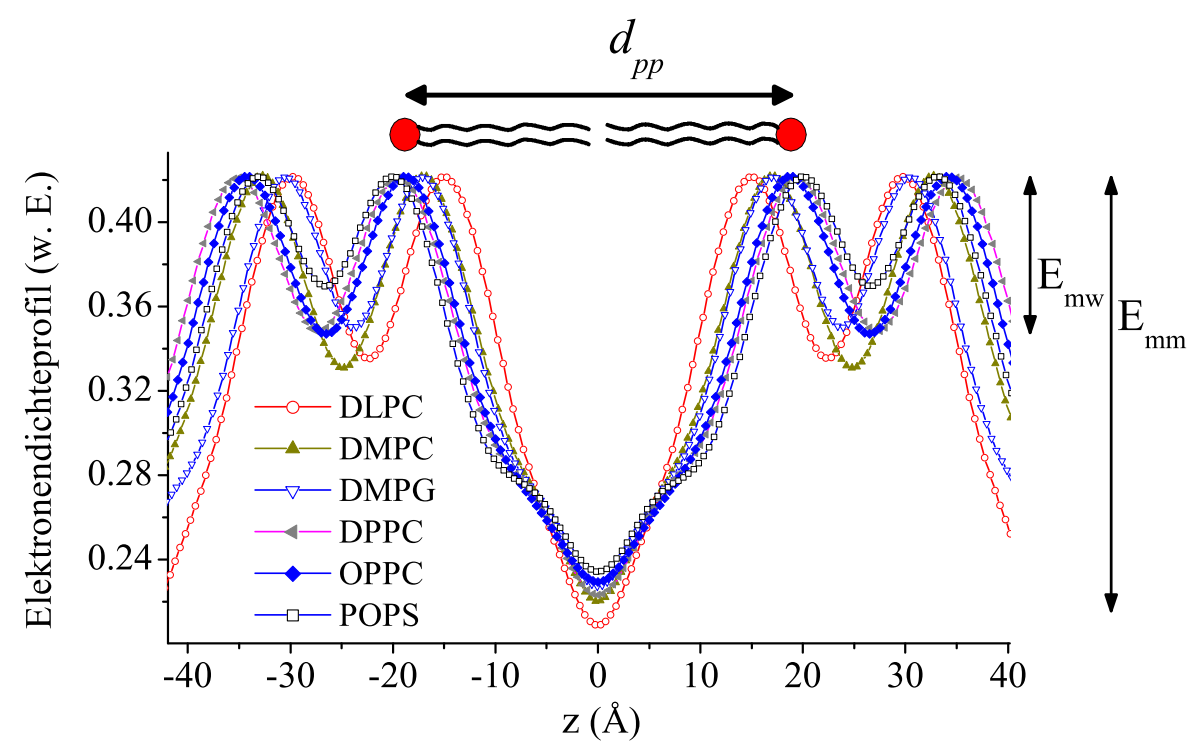

Abbildung 6.8: Die durch Fouriersynthese aus spekularen Reflektivitätskurven ermittelten Elektronendichteprofile verschiedener Lipide.

\section{Anpassung:}

Die spekularen Reflektivitätskurven, die in Abb. 6.6 dargestellt sind, werden mit einer Modellfunktion angepasst. Die dadurch ermittelten Parameter werden in Tabelle C.14 aufgelistet. Aus dieser Tabelle ist zu erkennen, dass die Rauigkeit der Grenzfläche zwischen dem Substrat und der Wasserschicht bei allen Proben fast gleich ist, während die Rauigkeiten der Grenzfläche zwischen Luft und Wasserschicht stark voneinander abweichen. Insbesondere in der Probe aus DMPG 


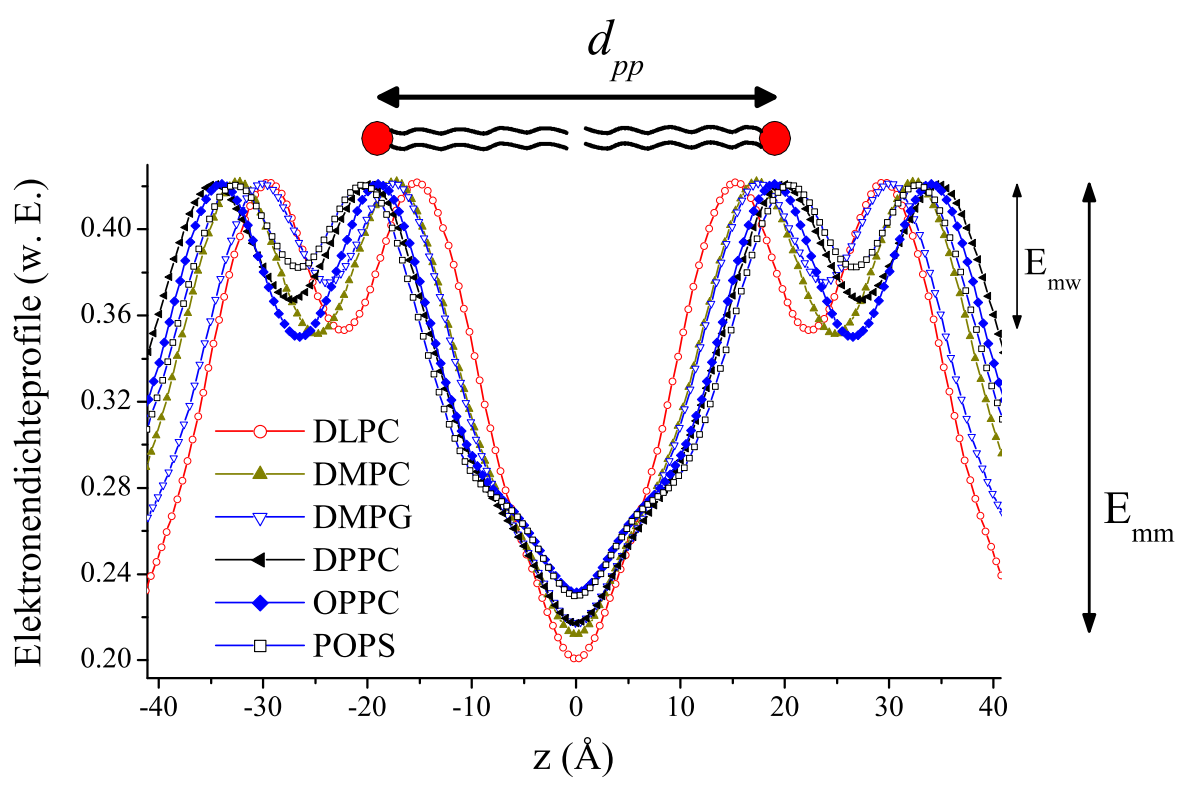

Abbildung 6.9: Die durch Fouriersynthese aus diffusen Reflektivitätskurven ermittelten Elektronendichteprofile verschiedener Lipide.

\begin{tabular}{cccc|cc}
\hline & & spekulare & Reflektivität & diffuse & Reflektivität \\
\hline Lipid & $d[\AA]$ & $d_{p p}[\AA]$ & $E_{m w} / E_{m m}$ & $d_{p p}[\AA]$ & $E_{m w} / E_{m m}$ \\
\hline \hline DLPC & 44.767 & 30.034 & 0.4047 & 30.594 & 0.31046 \\
DMPC & 49.738 & 33.996 & 0.4521 & 34.676 & 0.3372 \\
DMPG & 47.588 & 34.196 & 0.3677 & 35.016 & 0.2254 \\
DPPC & 54.503 & 38.846 & 0.3688 & 39.626 & 0.2626 \\
OPPC & 52.997 & 37.574 & 0.389 & 37.934 & 0.3748 \\
POPS & 53.181 & 40.062 & 0.2772 & 40.942 & 0.2006 \\
\hline
\end{tabular}

Tabelle 6.2: Die durch Fouriersynthese ermittelten charakteristischen Größen der Proben aus verschiedenen Lipiden.

ist diese Rauigkeit ziemlich klein. Der mögliche Grund dafür könnte die unterschiedliche Probenqualität sein. Die Probe aus DMPG wurde mit dem Lösungsmittel TFE/Chloroform und die anderen Proben mit dem Lösungsmittel HFI (Hexafluoro-2-Propanol) präpariert, Die mit dem Lösungsmittel TFE/Chloroform präparierten Proben haben eine bessere Qualität (siehe Kapitel 2). In Abb. 6.6 werden alle angepassten Kurven zusammen mit den Messkurven dargestellt. Durch Anpassung wurden die zunächst zur Rekonstruktion der Elektronendichteprofile benötigten Parameter ermittelt und anschließend die Elektronendichteprofile rekonstruiert. Diese sind in Abb. 6.10 in absoluter Einheit ( Elektronenanzahl/ $\AA^{3}$ ) dargestellt. Es ist klar zu erkennen, dass die Elektronendichteprofile sowohl in den Kopfgruppen als auch im Kettenbereich für jede Probe unterschiedlich sind. Mit den Elektronendichteprofilen werden die Membrandicke $d_{p p}$, das Verhältnis der Elektronendichtedifferenzen zwischen der Kopfgruppe und der Wasserschicht zu den Elektronendichtedifferenzen zwischen der Kopfgruppe und dem Kettenbereich $E_{m w} / E_{m m}$ ermittelt. In Tabelle 6.4 werden diese Parameter aufgelistet. Zum Vergleich der aus Fouriersynthese und 


\begin{tabular}{cccccccccccccccc}
\hline Lipid & $f_{1}$ & $f_{2}$ & $f_{3}$ & $f_{4}$ & $f_{5}$ & $f_{6}$ & $f_{7}$ & $d_{0}$ & $q_{c}$ & $\Delta_{\max }$ & $\sigma_{0}$ & $\mathrm{~L}$ & $\mathrm{~N}$ & $d_{1}$ & $\sigma_{1}$ \\
\hline \hline DLPC & -1 & -0.62 & 0.24 & -0.082 & -0.022 & -0.012 & -0.0085 & 20.6 & 0.026 & 0.2 & 2.0 & 3000 & 500 & 21 & 20 \\
DMPC & -1 & -0.58 & 0.33 & -0.15 & -0.04 & -0.0165 & -0.01 & 23.0 & 0.024 & 0.19 & 2.0 & 18000 & 500 & 22 & 20 \\
DMPG & -1 & -0.3 & 0.245 & -0.139 & 0.0135 & -0.0125 & -0.0027 & 20 & 0.024 & 0.2 & 2.0 & 15000 & 500 & 20 & 2.5 \\
DPPC & -1 & -0.33 & 0.25 & -0.18 & -0.033 & -0.006 & 0.0 & 25 & 0.028 & 0.22 & 1.2 & 1500 & 500 & 18 & 8 \\
OPPC & -1 & -0.4 & 0.35 & -0.195 & 0.0195 & -0.0055 & -0.0058 & 23.5 & 0.028 & 0.2 & 2.0 & 8400 & 500 & 26 & 8 \\
POPS & -1 & -0.135 & 0.25 & -0.22 & -0.0074 & -0.0165 & 0.0 & 15.5 & 0.028 & 0.2 & 2.2 & 32000 & 500 & 15 & 3 \\
\hline
\end{tabular}

Tabelle 6.3: Die durch Anpassung ermittelten Parameter von Proben aus verschiedenen Lipiden.

\begin{tabular}{cccc}
\hline Lipid & $d[\AA]$ & $d_{p p}[\AA]$ & $E_{m w} / E_{m m}$ \\
\hline \hline DLPC & 44.767 & 29.96 & 0.3917 \\
DMPC & 49.738 & 33.916 & 0.4714 \\
DMPG & 47.588 & 34.756 & 0.3343 \\
DPPC & 54.503 & 38.906 & 0.3398 \\
OPPC & 52.997 & 37.04 & 0.4822 \\
POPS & 53.181 & 39.82 & 0.32 \\
\hline
\end{tabular}

Tabelle 6.4: Die durch Anpassung ermittelte charakteristischen Größen $E_{m w} / E_{m m}$ und $d_{p p}$ der Proben aus verschiedenen Lipiden.

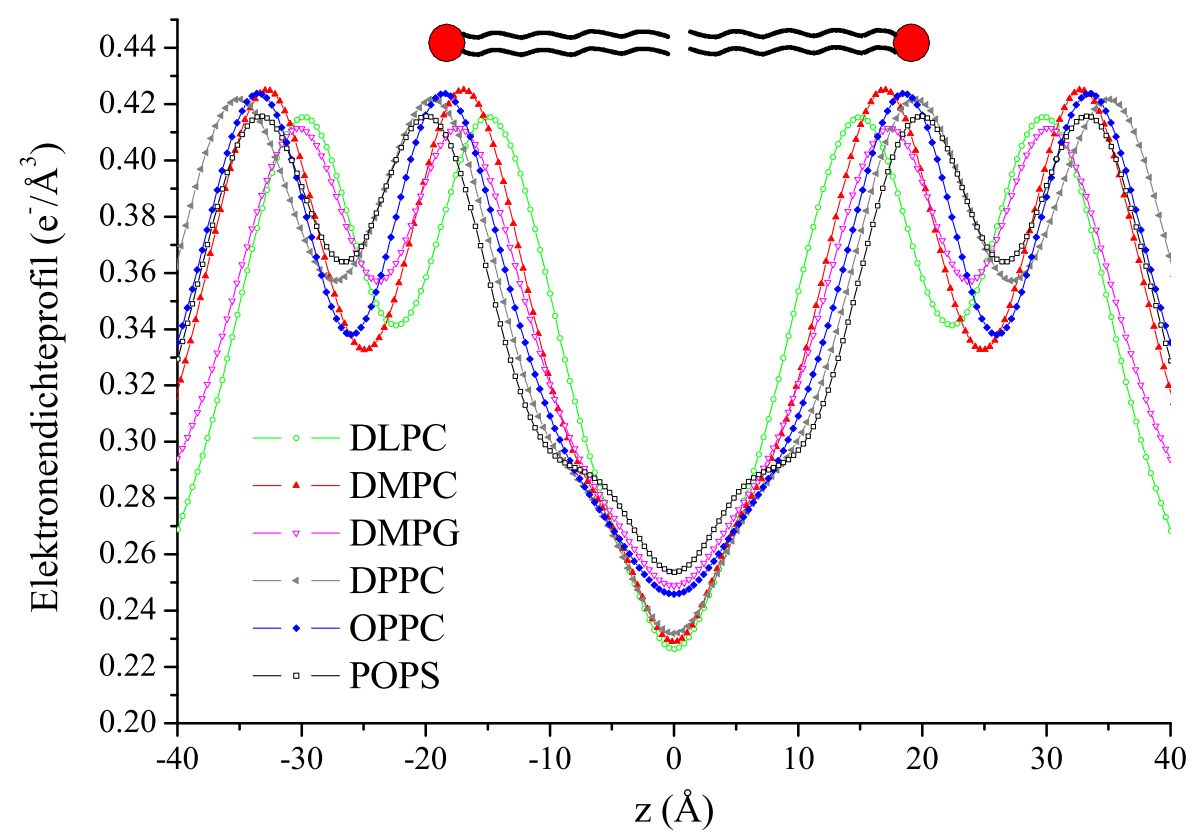

Abbildung 6.10: Die durch Anpassung ermittelten Elektronendichteprofile der Proben aus verschiedenen Lipiden.

Anpassung bestimmten Werte für die Membrandicken werden alle ermittelten Membrandicken in Abb. 6.11 gegen die Periodizität der Lipiddoppelschichten aufgetragen. Vergleicht man die Werte der Membrandicke aus der Anpassung mit denen aus der Fouriersynthese, ist zu erkennen, dass die durch Fouriersynthese aus spekularen Reflektivitäten ermittelten Membrandicken meistens nä- 


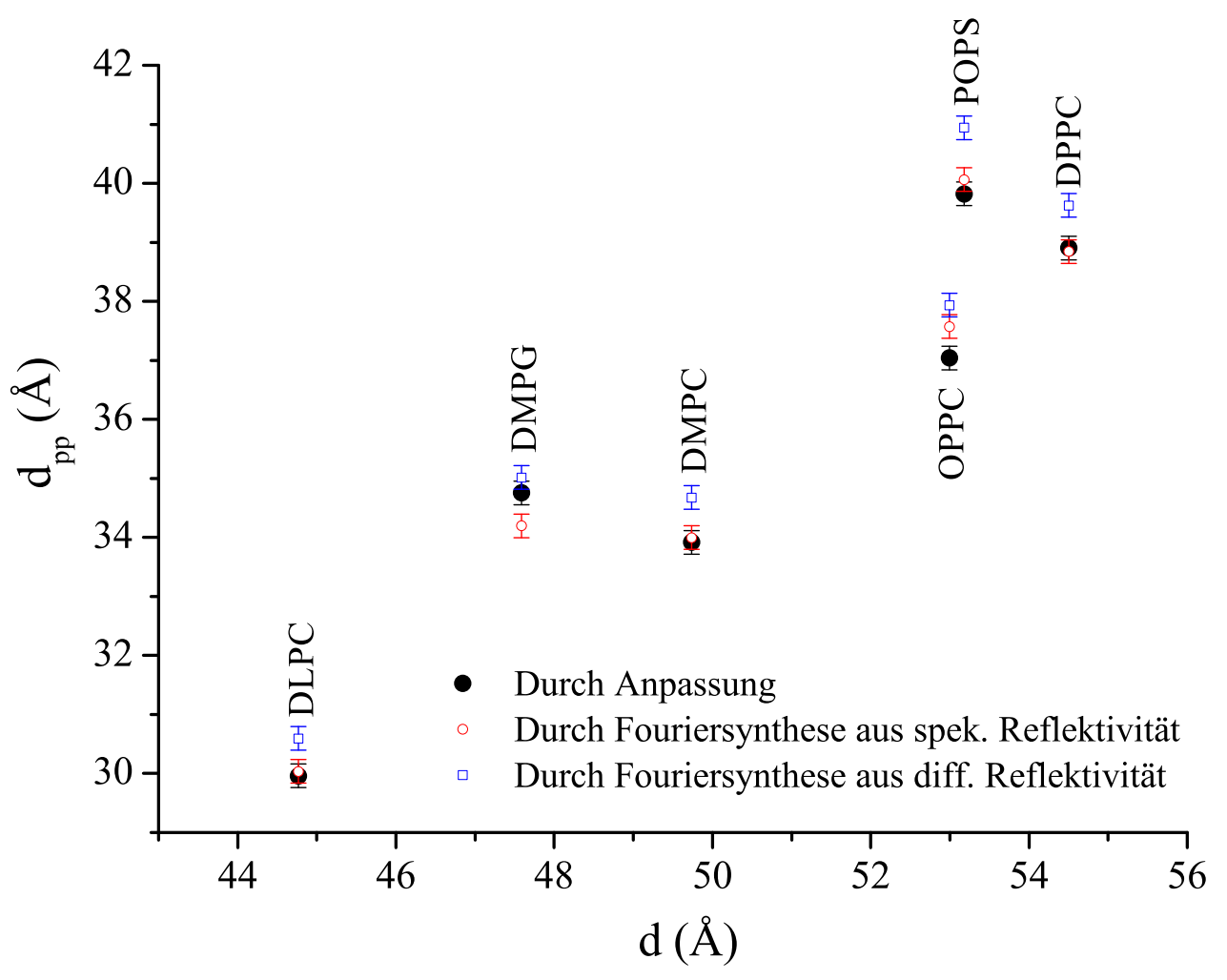

Abbildung 6.11: Vergleich der Membrandicken, die durch Fouriersynthese und Anpassung ermittelt wurden.

her zu denen aus der Anpassung liegen, als die Membrandicken, die durch Fouriersynthese aus diffusen Reflektivitäten ermittelt wurden. Dieses Ergebnis weist darauf hin, dass die Anpassung der Reflektivitätskurve mit der Modellfunktion an die Fouriersynthese aus spekularer Reflektivität besser gelingt, als an die Fouriersynthese aus diffuser Reflektivität. Daher verzichten wir im Folgenden auf die Darstellung der Ergebnisse, die durch Fouriersynthese aus diffuser Reflektivität ermittelt wurden.

\section{Zusammenfassung:}

Die Anpassung mit der Modellfunktion und die Auswertung mittels der Fouriersynthese zeigen ähnliche Ergebnisse. Die Elektronendichteprofile der Kopfgruppen und der Kettenbereiche zeigen bei manchen Lipiden verschieden Charakter, obwohl deren Kopfgruppe oder Ketten vom gleichen Typ sind. Diese Abweichung kann durch die unterschiedliche mittlere Fläche pro Kopfgruppe erklärt werden. Da die Dicken der Lipidkopfgruppen in lamellarer Phase unterschiedlich sind, selbst wenn sie den gleichen Typ (z.B PC) haben [172], haben sie daher unterschiedliche Volumen; daraus ergibt sich die unterschiedliche Elektronendichte der Kopfgruppen. Die Membrandicke, die mit verschiedenen Methoden ermittelt wurde, hat jeweils einen unterschiedlichen Wert. Trotzdem liegen die Werte bei den Proben aus DMPC und DMPG mit gleicher Kettenlänge (14:14; siehe Kapitel 2) nahe beieinander. Bei fast allen Lipiden zeigt die ermittelte Membrandicke bei Anpassung und bei Fouriersynthese aus spekularer Reflektivität einen ähnlichen Wert. 


\subsection{Auswertung der Messdaten aus Alamethicin/Lipid}

In diesem Abschnitt wird die Auswertung der Messreihen zum Alamethicin/Lipid-System durchgeführt, das Ergebnis dargestellt und anschließend die möglichen Schlussfolgerungen diskutiert. Für dieses biologische System wurde Alamethicin in unterschiedlichem Molverhältnis mit verschiedenen einzelnen Lipiden (DLPC, DMPC, DOPC, DPPC und POPC) und gemischten Lipiden (DMPC/DMPG in Molverhältnis von 1:1) mit dem Lösungsmittel Isopropanol auf Si-Substrat präpariert. Eine Probenserie davon aus Alamethicin/DMPC wurde am Messplatz D4 Hasylab unter einer Gewichtskonzentration von 14.2 \% PEG-Lösung (Polyethyleneglycol-Lösung) bei $\mathrm{T}=30^{\circ} \mathrm{C}$ mit einer Wellenlänge von $0.62 \AA$ gemessen. Das Polymer Polyethyleneglycol (PEG) hat eine mittleren Masse von $20000 \mathrm{u}$, unter dieser PEG-Lösung ergibt sich ein osmotischer Druck von 1.95 bar. Das benutzte Verfahren beruht darauf, dass man große Polymere in der Wasserphase löst. Die Polymere müssen so groß sein, dass sie nicht in die nur einige nm dicke Wasserschicht eindringen können [149]. Die übrigen Probenserien wurden unter Feuchtigkeit $(\mathrm{RH} \approx 99 \%)$ bei $\mathrm{T}=45^{\circ} \mathrm{C}$ mit gleicher Wellenlänge am selben Messplatz gemessen. Um den systematischen Fehler möglichst gering halten zu können, wurden alle Proben aus einer Probenserie auf einem Multiprobenhalter (siehe Kapitel 2) fixiert und unter gleichen Bedingungen gemessen. Dabei befanden sich alle Proben in einer physiologisch relevanten $L_{\alpha}$-Phase. Die gemessenen Daten wurden mit dem Verfahren der Fouriersynthese (aus spekularer Reflektivität mit Lorentzfaktor $1 / q_{z}^{2}$ ) und der Anpassung mit einer Modellfunktion ausgewertet. Die Parameter, die durch Anpassung ermittelt wurden, sind im Anhang aufgeführt.

\subsubsection{Alamethicin/DLPC}

In Abb. 6.12(a) werden alle gemessenen Reflektivitätskurven der Probenserie aus Alamethicin/DLPC zusammen mit allen angepassten Kurven dargestellt. Die Konzentrationen von Alamethicin in dieser Probenserie sind 0, 1/100, 1/50 und 1/25. Jede Kurve hat 7 Bragg-Peaks. Die Periodizität der Lipiddoppelschichten in der Probe wird in Abb. 6.12 (b) gezeigt, sie nimmt mit steigender Peptidkonzentration (P/L) deutlich ab.

\section{Fouriersynthese und Anpassung:}

Das Verfahren der Fouriersynthese wurde unter Verwendung der spekularen Reflektivität an dieser Probenserie mit dem Lorentzfaktor $1 / q_{z}^{2}$ durchgeführt. Dadurch wurden die Elektronendichteprofile der Proben ermittelt. Anhand dieser Elektronendichteprofile konnten die Membrandicken in den Proben bestimmt werden. Ebenso wurde durch Anpassung an die gemessenen spekularen Reflektivitätskurven mit einer Modellfunktion die zur Rekonstruktion des Elektronendichteprofils benötigen Parameter ermittelt. In Abb. 6.13 werden die rekonstruierten Elektronendichteprofile dargestellt. Durch diese Elektronendichteprofile konnte wiederum die Membrandicken in den Proben bestimmt werden. Alle Membrandicken, die durch Fouriersynthese und Anpassung ermittelt wurden, werden in Abb. 6.14 zum Vergleich gegen die Alamethicin-Konzentration P/L aufgetra- 


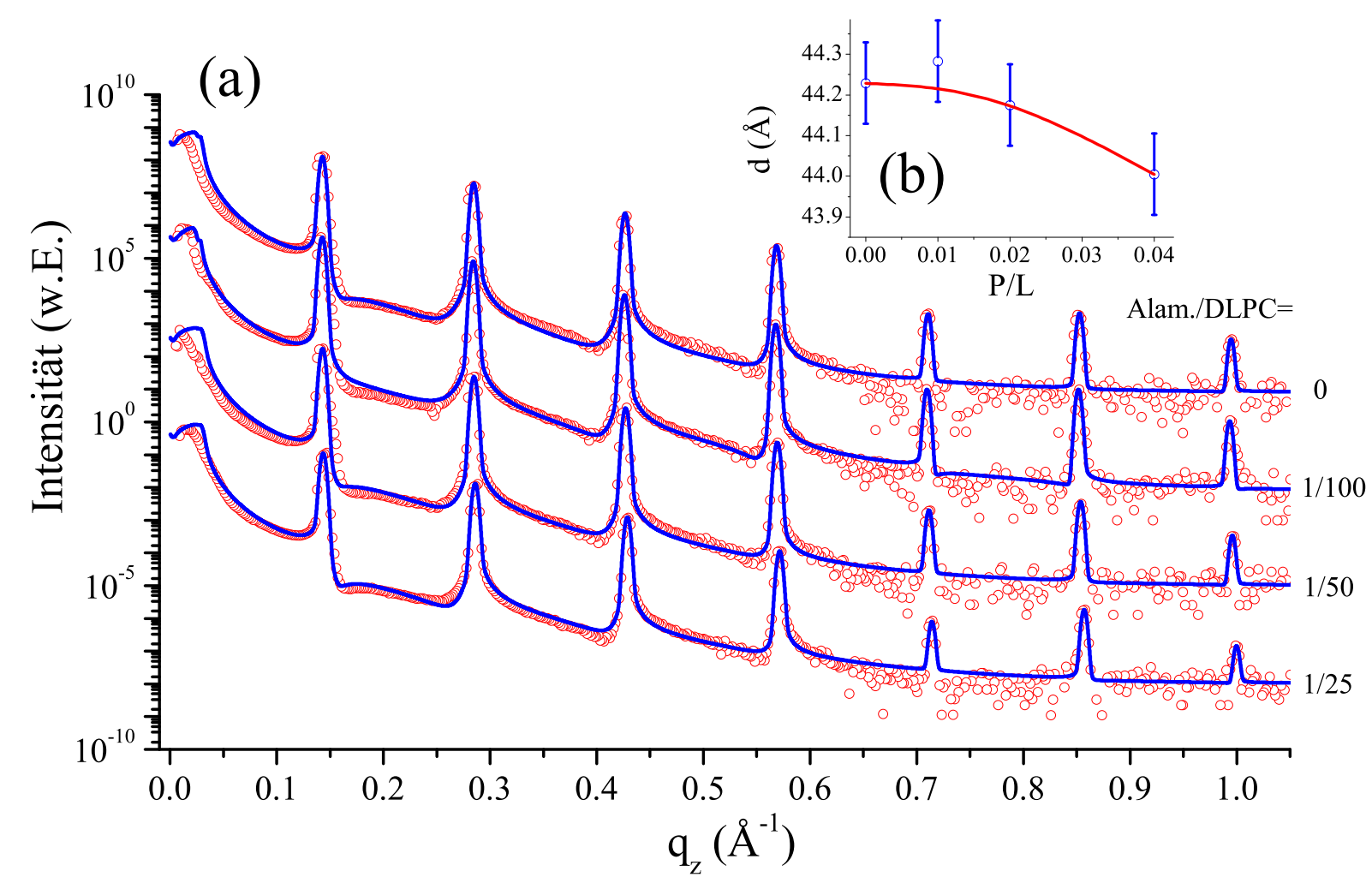

Abbildung 6.12: (a) Gemessene Reflektivitätskurven der Probenserie aus Alamethicin/DLPC mit angepassten Kurven (durchgezogen); (b) Periodizität der Lipiddoppelschichten in der Probe mit parabolischer Anpassung (durchgezogene Kurve) zur besseren Darstellung des Trends.

\begin{tabular}{cc|cc|cc}
\hline & & durch & Anpasssung & $(\mathrm{FS})$ spekulare & Reflektivität \\
\hline $\mathrm{P} / \mathrm{L}$ & $d[\AA]$ & $d_{p p}[\AA]$ & $E_{m w} / E_{m m}$ & $d_{p p}[\AA]$ & $E_{m w} / E_{m m}$ \\
\hline \hline 0 & 44.229 & 29.658 & 0.5947 & 29.978 & 0.4878 \\
$1 / 100$ & 44.283 & 29.486 & 0.5959 & 29.686 & 0.5583 \\
$1 / 50$ & 44.175 & 29.57 & 0.5548 & 29.61 & 0.4987 \\
$1 / 25$ & 44.005 & 29.59 & 0.4953 & 29.89 & 0.4551 \\
\hline
\end{tabular}

Tabelle 6.5: Die durch Fouriersynthese (FS) und Anpassung ermittelten charakteristischen Größen der Proben aus Alamethicin/DLPC.

gen. Sie zeigen keine systematische Änderung in Abhängigkeit von P/L. Die charakteristischen Größen $E_{m w} / E_{m m}$ aus beiden Verfahren werden in Abb. 6.15 zusammen dargestellt. Dabei zeigt $E_{m w} / E_{m m}$ eine abnehmende Tendenz mit steigendem P/L. Diese Eigenschaft zeigt sich auch beim Mittelwert der Membrandicken aus der Anpassung und aus der Fouriersynthese. Alle ermittelten charakteristischen Größen aus beiden Verfahren werden in Tabelle 6.5 aufgelistet. Nach der Fallklassifikation von $E_{m w} / E_{m m}$ in Gl. (6.1) bis Gl. (6.5) betrachten wir nun die charakteristische Größe $E_{m w} / E_{m m}$ zu den beiden Verfahren zusammen mit der Membrandicke $d_{p p}$ :

$E_{m w} / E_{m m}$ nimmt bei $P / L=1 / 100$ bei der Anpassung leicht und bei der Fouriersynthese stark zu, was zum 2. Fall aus Gl. (6.5) gehört, wo nur das Elektronendichteprofil der Kopfgruppe zunimmt; 
dabei nimmt die Membrandicke $d_{p p}$ für beide Verfahren ab. Für die Anpassung nimmt $E_{m w} / E_{m m}$ danach mit steigendem $P / L$ ab, was zum 1. Fall von Gl. (6.2) gehört, wo das Elektronendichteprofil der Kopfgruppe abnimmt und im Kettenbereich dagegen zunimmt. Die Membrandicke nimmt im selben $P / L$-Bereich dagegen zu. Für die Fouriersynthese nehmen $E_{m w} / E_{m m}$ und die Membrandicke andere Änderungstendenzen als bei der Anpassung mit steigendem $P / L$ an. $E_{m w} / E_{m m}$ nimmt bei $P / L=1 / 50 \mathrm{ab}$, was zum 1. Fall von Gl. (6.3) gehört, wo das Elektronendichteprofil der Kopfgruppe und der Wasserschicht zunimmt. Die Membrandicke nimmt dabei ab. Bei $P / L=1 / 25$ nimmt $E_{m w} / E_{m m}$ weiter ab, während die Membrandicke dagegen zunimmt, was zum 2. Fall der Gl. (6.2) gehört, wo das Elektronendichteprofil der Kopfgruppe abnimmt und das der Wasserschicht dagegen zunimmt.

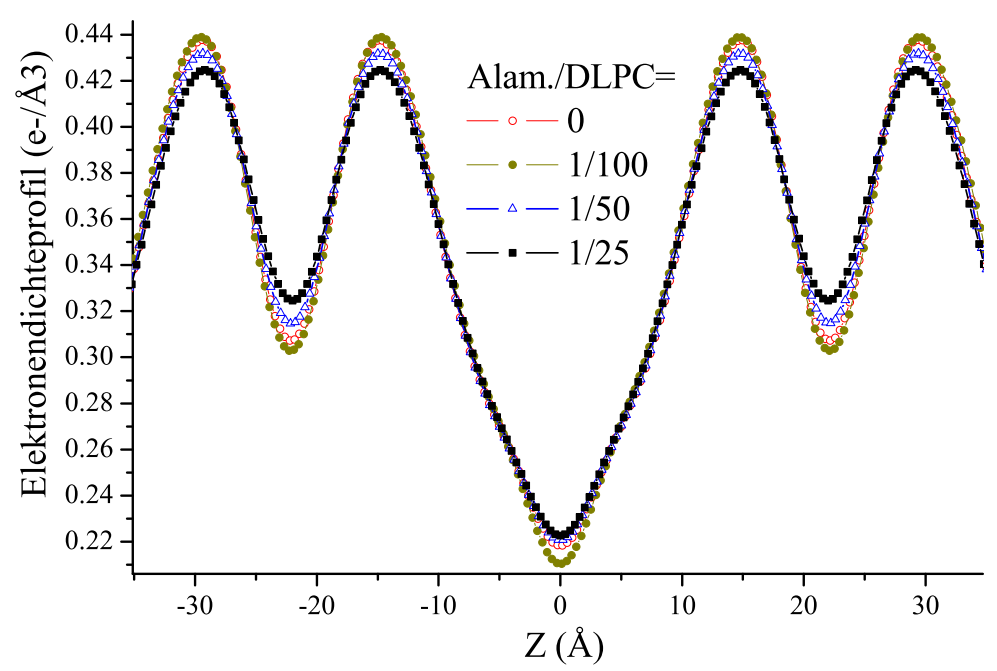

Abbildung 6.13: Durch Anpassung ermittelte Elektronendichteprofile der Proben aus Alamethicin/DLPC.

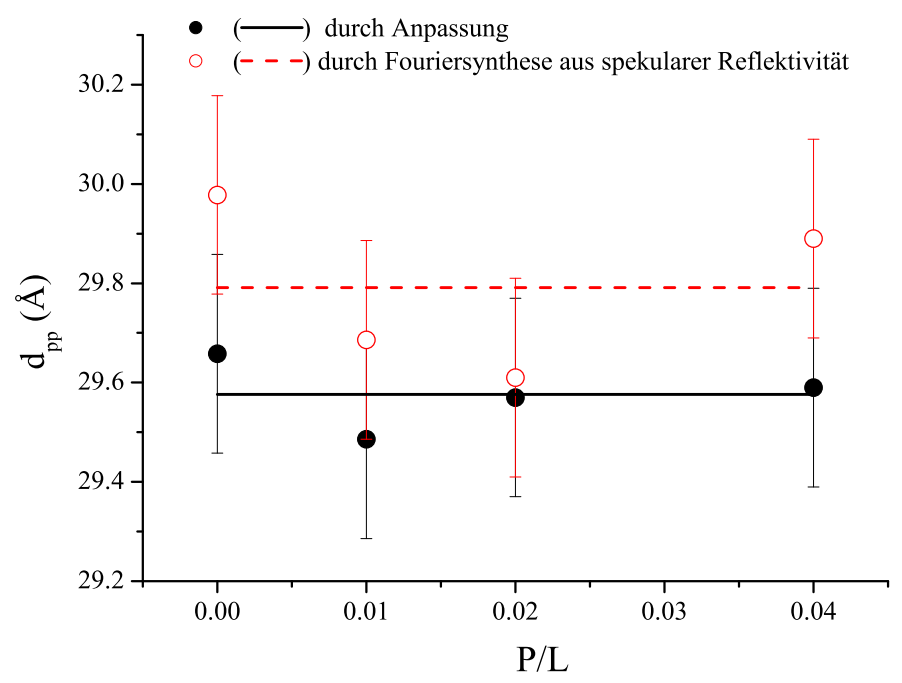

Abbildung 6.14: Vergleich der Membrandicken, die durch Anpassung und Fouriersynthese ermittelt wurden, mit ihrem Mittelwert (durchgezogene bzw. gestrichelte Kurve). 


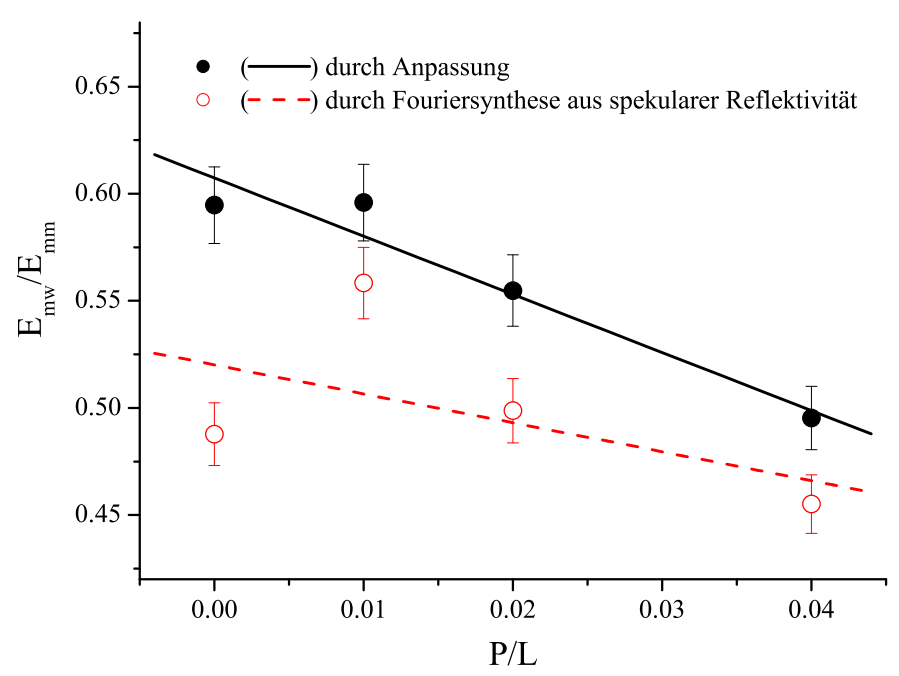

Abbildung 6.15: Vergleich der charakteristischen Größen $E_{m w} / E_{m m}$, die durch Anpassung und Fouriersynthese ermittelt wurden, mit linearer Anpassung (durchgezogene bzw. gestrichelte Kurve).

\subsubsection{Alamethicin/DMPC}

In Abb. 6.16(a) werden alle gemessenen Reflektivitätskurven der Probenserie aus Alamethicin/DMPC zusammen mit den angepassten Kurven dargestellt. Die Konzentrationen von Alamethicin in dieser Probenserie sind 0,1/200, 1/100, 1/50 und 1/25. Jede Kurve hat mindestens 7 Bragg-Peaks. Die Periodizität der Lipiddoppelschichten in der Probe wird in Abb. 6.16(b) gezeigt, sie nimmt mit steigender Peptidkonzentration (P/L) deutlich ab.

\section{Fouriersynthese und Anpassung:}

Durch Fouriersynthese aus spekularer Reflektivität mit Lorentzfaktor $1 / q_{z}^{2}$ wurden die zur Rekonstruktion der Elektronendichteprofile benötigten Parameter ermittelt, anschließend wurde die Elektronendichte rekonstruiert. Anhand dieser Elektronendichteprofile konnten die Membrandicken in den Proben bestimmt werden. Ebenso wurden durch Anpassung an die gemessenen Reflektivitätskurven mit der Modellfunktion die Elektronendichteprofile ermittelt; das Ergebnis wird in Abb. 6.17 gezeigt. Durch diese Elektronendichteprofile wurden auch hier wiederum die Membrandicken in den Proben bestimmt. Alle durch beide Verfahren ermittelten Membrandicken werden zum Vergleich in Abb. 6.18 gegen P/L aufgetragen. Sie zeigen keine systematische Änderung in Abhängigkeit von P/L. Die charakteristischen Größen $E_{m w} / E_{m m}$ aus beiden Verfahren werden in Abb. 6.19 zusammen dargestellt. Dabei liegen $E_{m w} / E_{m m}$ in Abhängigkeit von $P / L$ nahe beieinander . Diese Eigenschaft zeigt sich auch beim Mittelwert der Membrandicken aus Anpassung und Fouriersynthese. Alle ermittelten charakteristischen Größen aus beiden Verfahren werden in Tabelle 6.6 aufgelistet. Betrachtet wird nun $E_{m w} / E_{m m}$ zusammen mit Membrandicke $d_{p p}$ :

$E_{m w} / E_{m m}$ nimmt bei $P / L=1 / 200$ für beide Verfahren zuerst ein wenig zu, was zum 2. Fall in Gl. (6.5) gehört, wo nur das Elektronendichteprofil der Kopfgruppe zunimmt, dabei nimmt die Membrandicke $d_{p p}$ für die Anpassung ab, während sie für die Fouriersynthese zunimmt. $E_{m w} / E_{m m}$ zeigt danach für beide Verfahren eine abnehmende Tendenz mit steigendem $P / L$, die Membrandicke für 


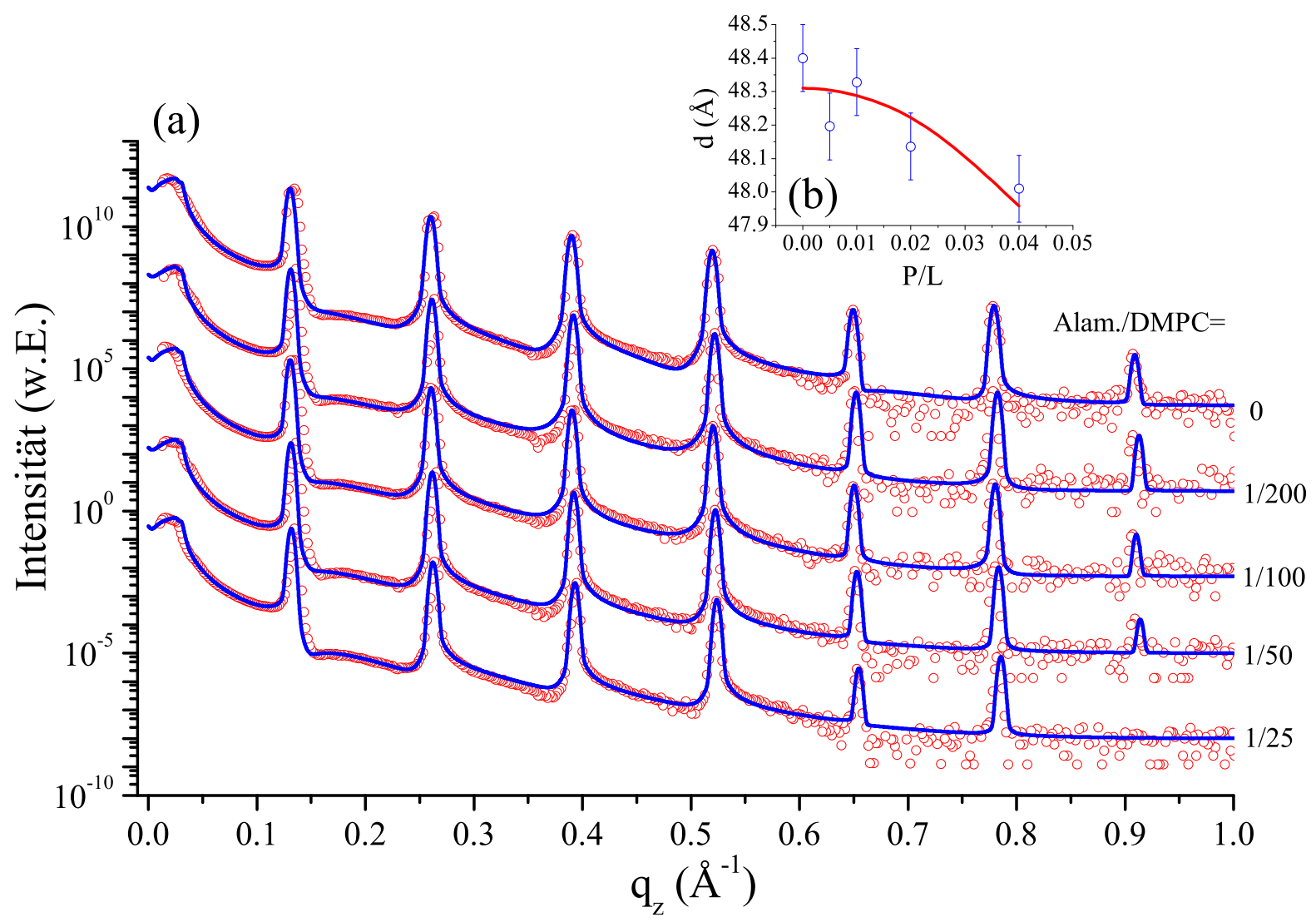

Abbildung 6.16: (a) Gemessene Reflektivitätskurven der Probenserie aus Alamethicin/DMPC mit angepassten Kurven (durchgezogen). (b) Periodizität der Lipiddoppelschichten in der Probe mit parabolischer Anpassung (durchgezogene Kurve) zur besseren Darstellung der Trends.

\begin{tabular}{cc|cc|cc}
\hline & & durch & Anpasssung & (FS) spekulare & Reflektivität \\
\hline $\mathrm{P} / \mathrm{L}$ & $d[\AA]$ & $d_{p p}[\AA]$ & $E_{m w} / E_{m m}$ & $d_{p p}[\AA]$ & $E_{m w} / E_{m m}$ \\
\hline \hline 0 & 48.4 & 33.74 & 0.6126 & 33.636 & 0.5871 \\
$1 / 200$ & 48.196 & 33.592 & 0.6183 & 33.732 & 0.5967 \\
$1 / 100$ & 48.328 & 33.536 & 0.5716 & 33.596 & 0.5169 \\
$1 / 50$ & 48.136 & 33.492 & 0.5722 & 33.692 & 0.5485 \\
$1 / 25$ & 48.01 & 33.8 & 0.4964 & 33.878 & 0.4523 \\
\hline
\end{tabular}

Tabelle 6.6: Die durch Fouriersynthese und Anpassung ermittelten charakteristischen Größen der Proben aus Alamethicin/DMPC.

die Anpassung nimmt mit steigendem $P / L$ bis $P / L=1 / 50 \mathrm{ab}$, während sie für die Fouriersynthese mit steigendem $P / L$ bis $P / L=1 / 100$ abnimmt. Dieses Ergebnis gehört zum 1. Fall in G1. 6.3), wo das Elektronendichteprofil der Kopfgruppe und der Wasserschicht zunimmt. Bei $P / L=1 / 25$ nimmt die Membrandicke für die Anpassung zu. Für die Fouriersynthese nimmt die Membrandicke ab $P / L=1 / 100$ deutlich zu. 


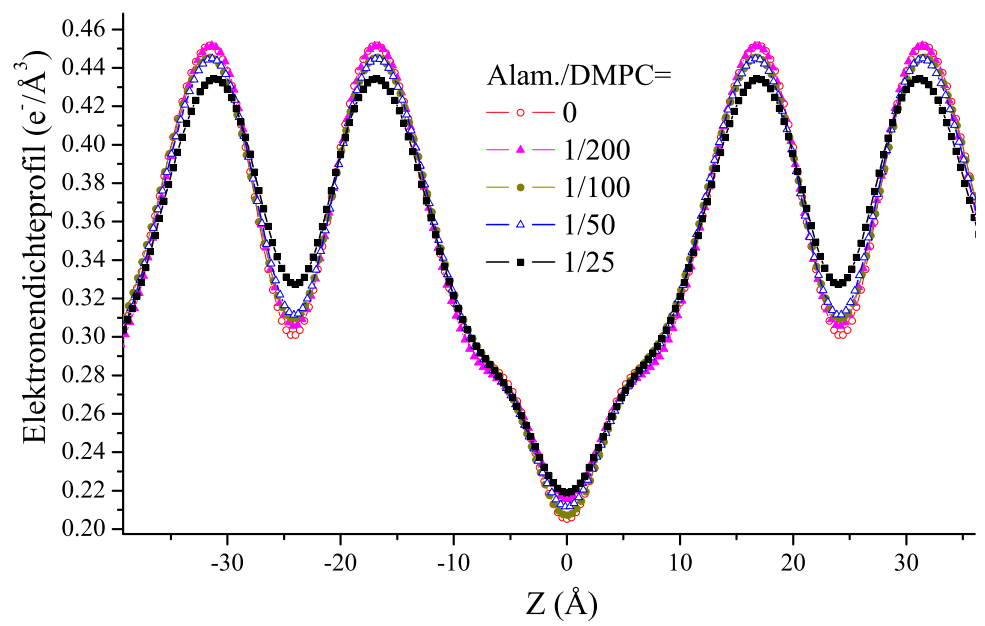

Abbildung 6.17: Durch Anpassung ermittelten Elektronendichteprofile der Proben aus Alamethicin/DMPC.

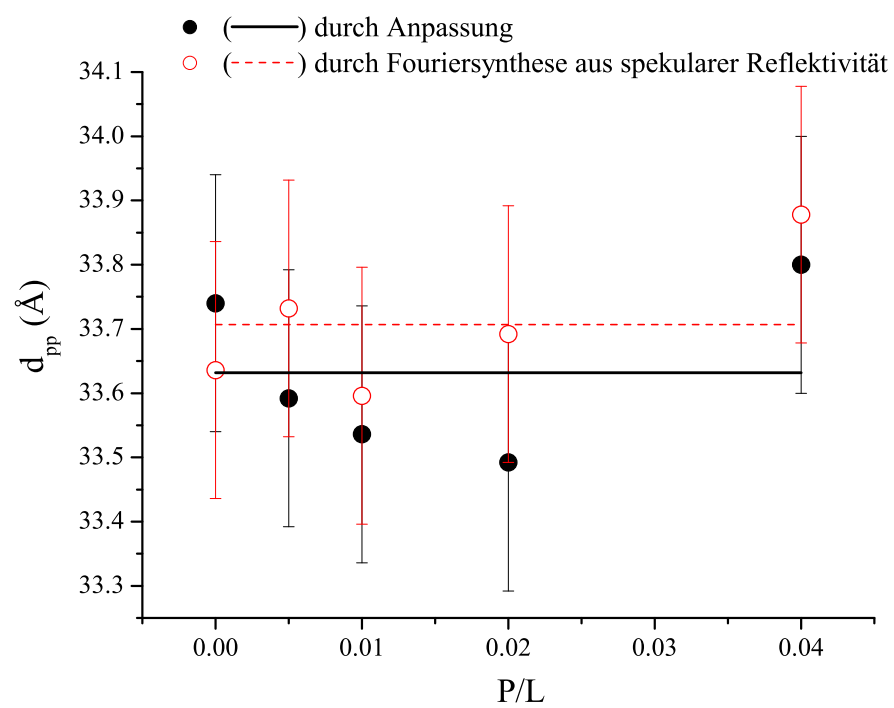

Abbildung 6.18: Vergleich der Membrandicken, die durch Anpassung und Fouriersynthese ermittelt wurden, mit ihrem Mittelwert (durchgezogene bzw. gestrichelte Kurve).

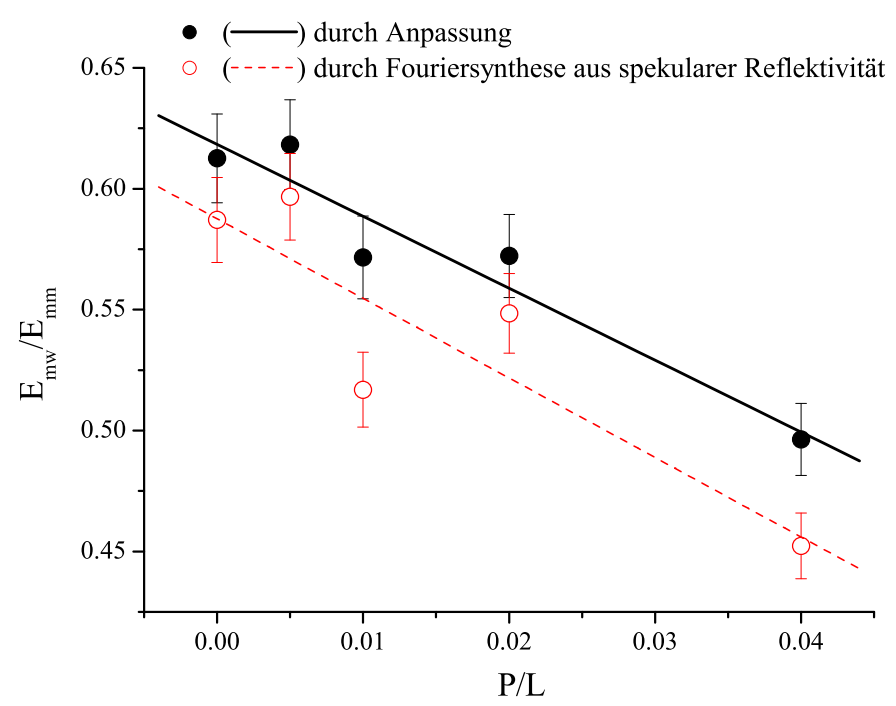

Abbildung 6.19: Vergleich der charakteristischen Größen $E_{m w} / E_{m m}$, die durch Anpassung und Fouriersynthese ermittelt wurden, mit linearer Anpassung (durchgezogene bzw. gestrichelte Kurve). 


\subsubsection{Alamethicin/DMPC+DMPG}

In Abb. 6.20(a) werden alle gemessenen Reflektivitätskurven der Probenserie aus Alamethicin/DMPC+DMPG (Lipidmischung in Molverhältnis von 1:1) zusammen mit den angepassten Kurven gegen $q_{z}$ aufgetragen. Die Konzentrationen von Alamethicin in dieser Probenserie sind 0, $1 / 100$ und 1/25. Jede Kurve hat 7 Bragg-Peaks. Die Periodizität der Lipiddoppelschichten in der Probe wird in Abb. 6.20(b) dargestellt, sie nimmt mit steigendem $P / L$ deutlich $a b$.

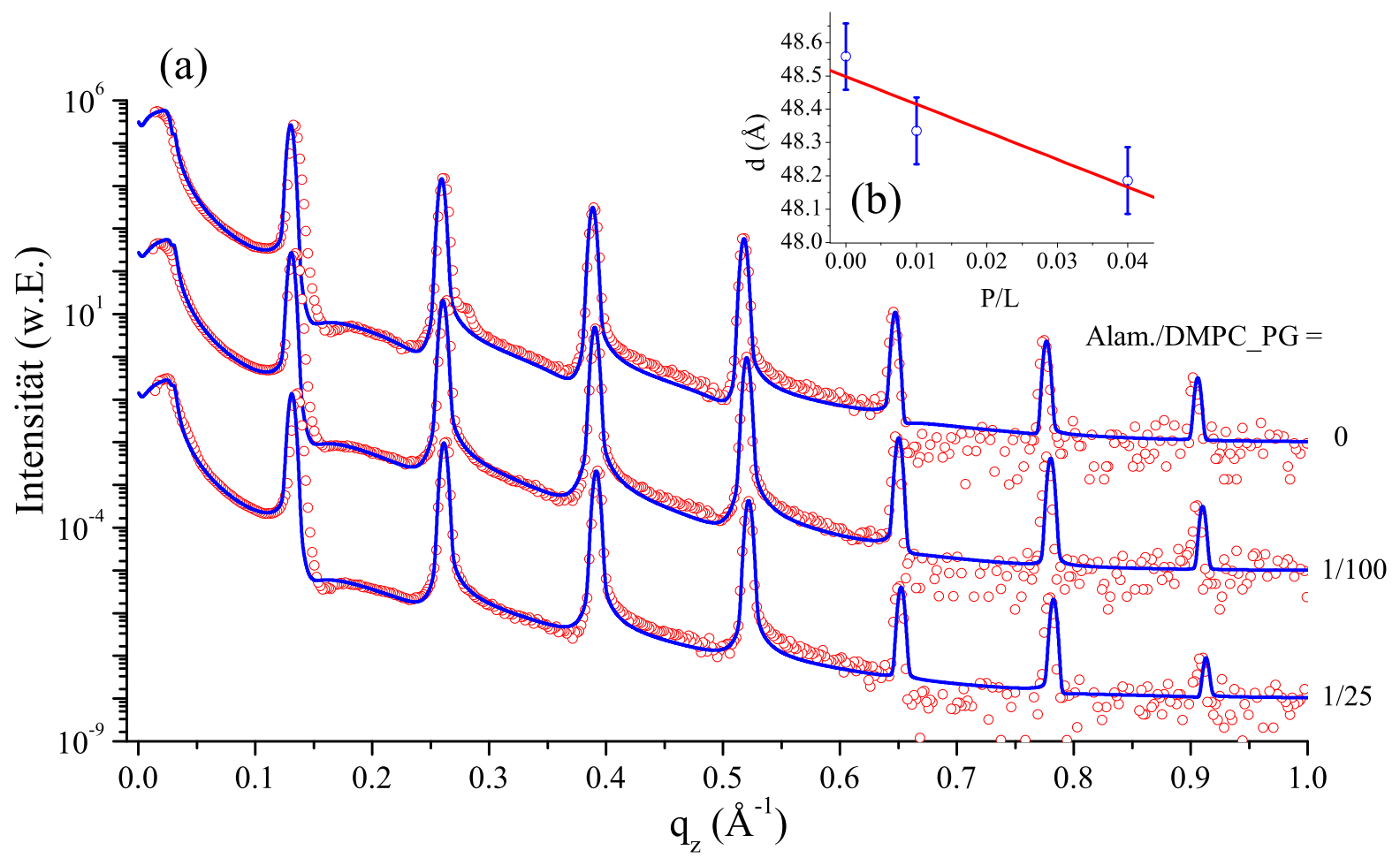

Abbildung 6.20: (a) Gemessene Reflektivitätskurven der Probenserien aus Alamethicin/DMPC-DMPG mit angepassten Kurven (durchgezogen); (b) Periodizität der Lipiddoppelschichten in der Probe mit linearer Anpassung (durchgezogene Kurve).

\section{Fouriersynthese und Anpassung:}

Mit Hilfe der spekularen Reflektivität wurde die Fouriersynthese mit dem Lorentzfaktor $1 / q_{z}^{2}$ durchgeführt. Dadurch wurden die Elektronendichteprofile der Proben ermittelt. Die Membrandicken in den Proben wurden anhand dieser Elektronendichteprofile bestimmt. An den gemessenen Reflektivitätskurven wurde eine Anpassung mit einer Modellfunktion durchgeführt, dadurch wurden die zur Rekonstruktion des Elektronendichteprofils benötigten Parameter ermittelt. Die rekonstruierten Elektronendichteprofile werden in Abb. 6.21 gezeigt. Anhand dieser Elektronendichteprofile konnten wiederum die Membrandicken in den Proben bestimmt werden. Alle durch beide Verfahren ermittelten Membrandicken werden zum Vergleich in Abb. 6.22 gegen P/L aufgetragen, sie zeigen eine abnehmende Tendenz mit steigendem P/L. Die charakteristischen Größen $E_{m w} / E_{m m}$ aus beiden Verfahren werden in Abb. 6.23 zusammen dargestellt. Dabei zeigt $E_{m w} / E_{m m}$ 


\begin{tabular}{cc|cc|cc}
\hline & & durch & Anpasssung & $(\mathrm{FS})$ spekulare & Reflektivität \\
\hline $\mathrm{P} / \mathrm{L}$ & $d[\AA]$ & $d_{p p}[\AA]$ & $E_{m w} / E_{m m}$ & $d_{p p}[\AA]$ & $E_{m w} / E_{m m}$ \\
\hline \hline 0 & 48.558 & 33.896 & 0.4509 & 33.936 & 0.433 \\
$1 / 100$ & 48.335 & 33.53 & 0.5466 & 33.83 & 0.4494 \\
$1 / 25$ & 48.186 & 33.572 & 0.5223 & 33.592 & 0.4976 \\
\hline
\end{tabular}

Tabelle 6.7: Die durch Fouriersynthese und Anpassung ermittelten charakteristischen Größen der Proben aus Alamethicin/DMPC+DMPG.

eine abnehmende Tendenz mit steigendem P/L. Die gleiche Eigenschaft hat auch der Mittelwert der Membrandicken aus der Anpassung und aus der Fouriersynthese. In Tabelle 6.7 werden alle ermittelten charakteristischen Größen aus beiden Verfahren aufgelistet. Im folgenden wird $E_{m w} / E_{m m}$ aus Anpassung und Fouriersynthese zusammen mit der Membrandicke $d_{p p}$ betrachtet:

Bei $P / L=1 / 100$ nimmt $E_{m w} / E_{m m}$ aus beiden Verfahren zu, was zum 2. Fall in Gl. (6.5) gehört, wo das Elektronendichteprofil nur an der Kopfgruppe zunimmt, dabei nimmt die Membrandicke $d_{p p}$ ab. $E_{m w} / E_{m m}$ aus der Anpassung zeigt bei $P / L=1 / 25$ eine Abnahme, die Membrandicke nimmt dabei leicht $\mathrm{zu}(\sim 0.042 \AA)$. Diese kleine Zunahme kann unter Berücksichtigung des Fehlers von $E_{m w} / E_{m m}$ vernachlässigt werden. Damit kann $P / L=1 / 25$ zum 1. Fall in Gl. (6.3) zugeordnet werden, wo das Elektronendichteprofil der Kopfgruppe und der Wasserschicht zunimmt. Für die Fouriersynthese nimmt $E_{m w} / E_{m m}$ bei $P / L=1 / 25$ mit steigendem $P / L$ klar zu, was zum 2 . Fall in Gl. (6.5) gehört, Dabei nimmt die Membrandicke $d_{p p}$ dagegen deutlich ab.

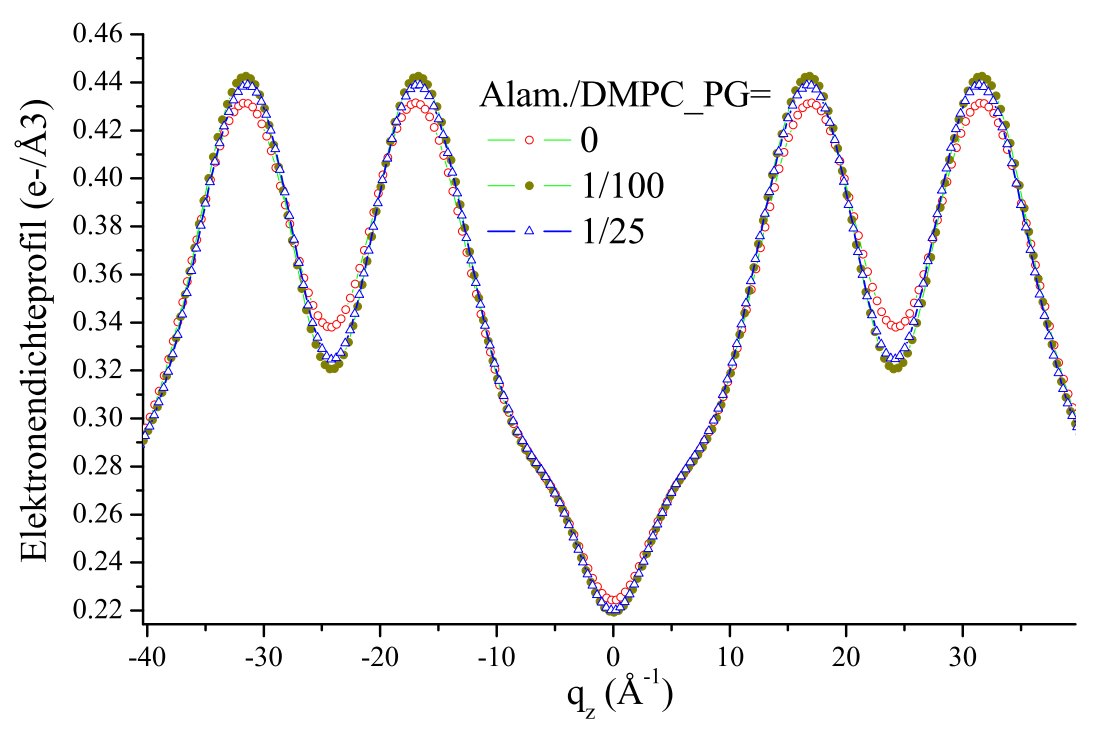

Abbildung 6.21: Durch Anpassung ermittelte Elektronendichteprofile der Proben aus Alamethicin/DMPC$D M P G$. 


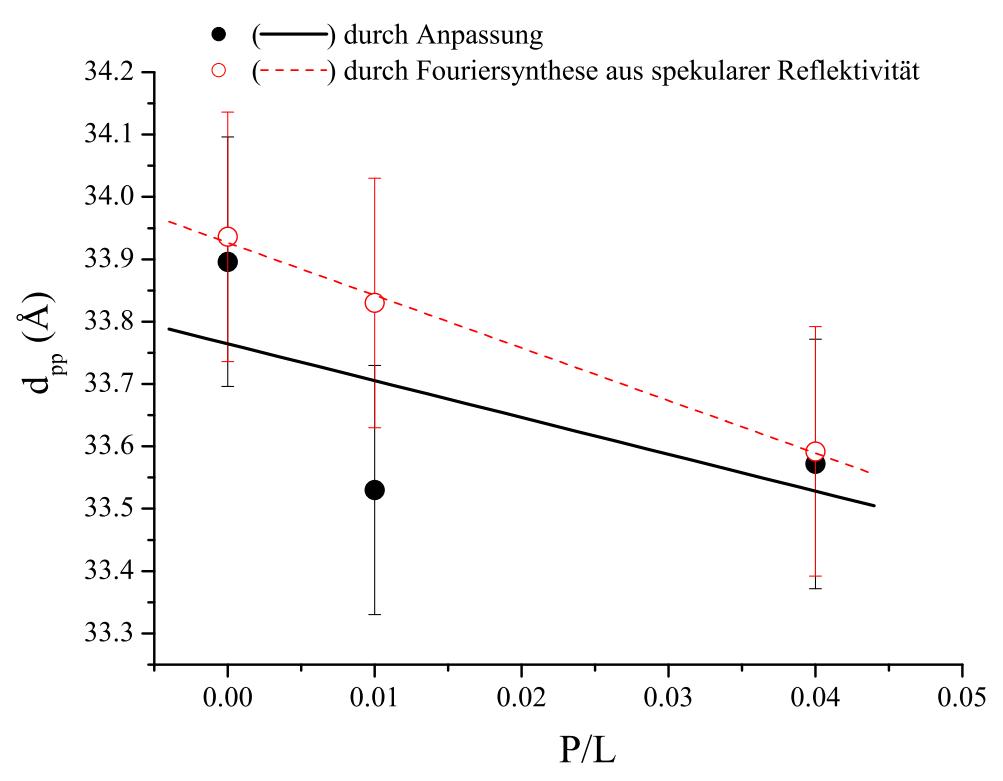

Abbildung 6.22: Vergleich der Membrandicken, die durch Anpassung und Fouriersynthese ermittelt wurden, mit linearer Anpassung (durchgezogene bzw. gestrichelte Kurve).

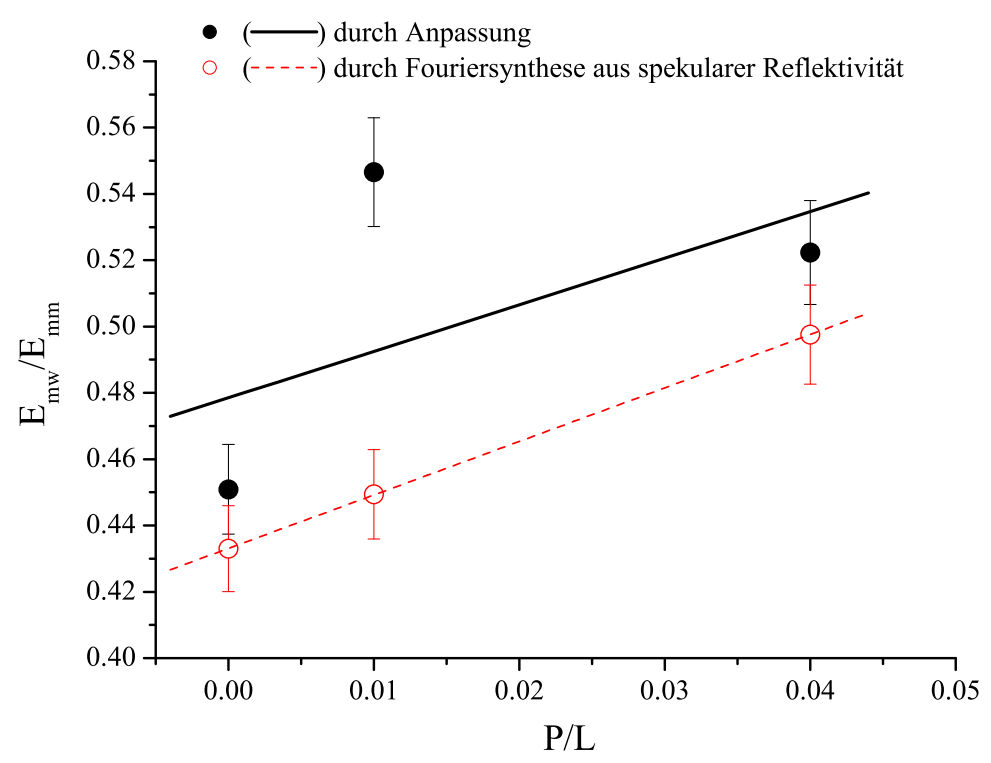

Abbildung 6.23: Vergleich der charakteristischen Größen $E_{m w} / E_{m m}$, die durch Anpassung und Fouriersynthese ermittelt wurden, mit linearer Anpassung (durchgezogene bzw. gestrichelte Kurve).

\subsubsection{Alamethicin/DOPC}

Die gemessenen Reflektivitätskurven der Probenserie aus Alamethicin/DOPC werden zusammen mit den angepassten Kurven in Abb. 6.24(a) dargestellt. Die Probe hat eine Konzentration von Alamethicin von jeweils 0, 1/100 und 1/25. Jede Kurve hat mindestens 6 Bragg-Peaks. In Abb. 6.24(b) wird die Periodizität der Lipiddoppelschichten in den Proben gezeigt, sie nimmt mit steigender Peptidkonzentration deutlich ab. 


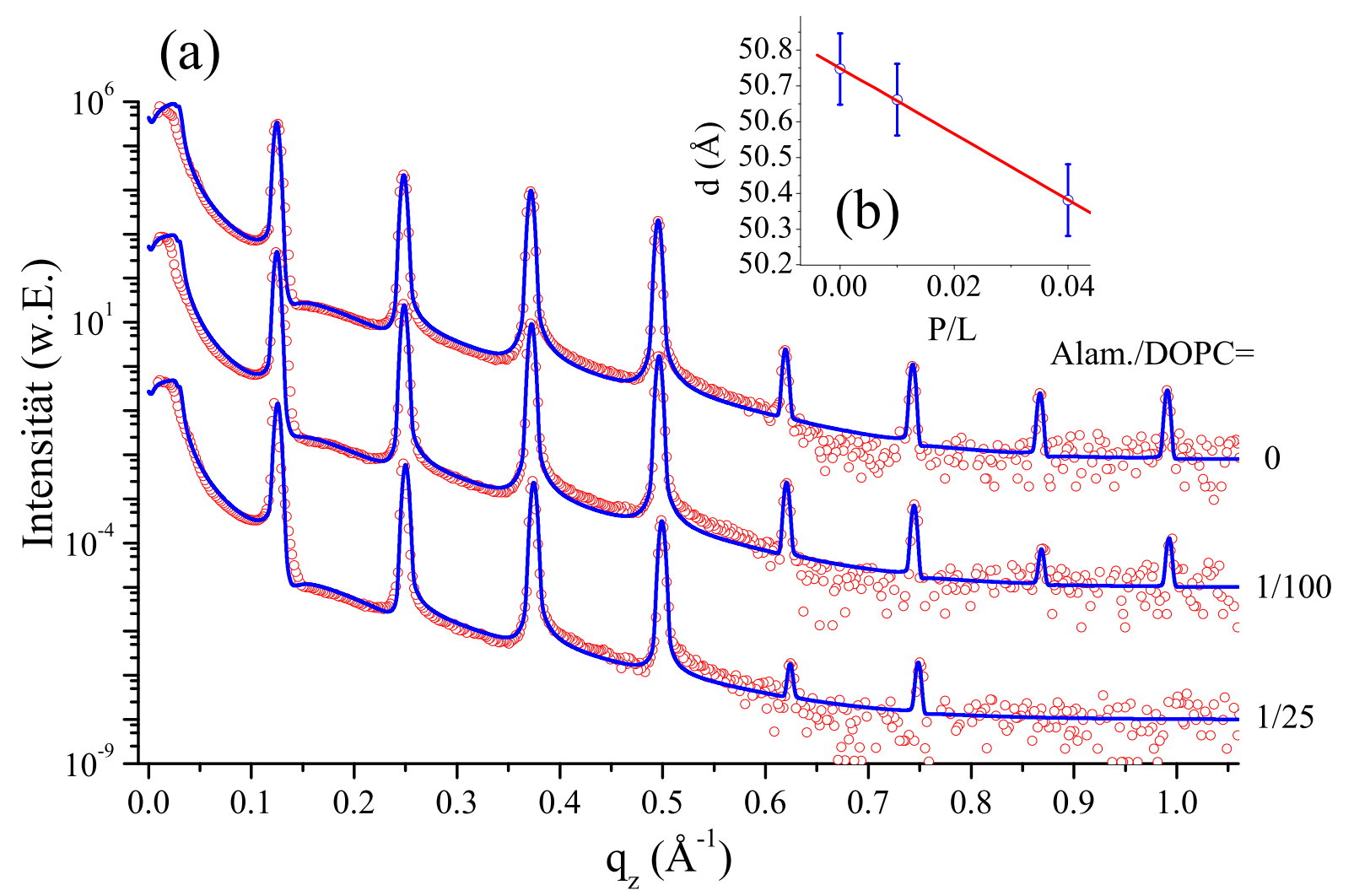

Abbildung 6.24: (a) Gemessene Reflektivitätskurven der Probenserie aus Alamethicin/DOPC mit angepassten Kurven (durchgezogen); (b) Periodizität der Lipiddoppelschichten in den Proben mit linearer Anpassung (durchgezogene Kurve).

\section{Fouriersynthese und Anpassung:}

Durch Fouriersynthese unter Anwendung der spekularen Reflektivität mit Lorentzfaktor $1 / q_{z}^{2}$ wurden Elektronendichteprofile der Proben ermittelt und damit die Membrandicken in den Proben bestimmt. Ebenso wurden durch Anpassung an die gemessenen Reflektivitätskurven mit einer Modellfunktion die Elektronendichteprofile ermittelt. Sie werden in Abb. 6.25 gezeigt. Durch sie konnten wiederum die Membrandicken in den Proben bestimmt werden. Alle durch beide Verfahren ermittelten Membrandicken werden zum Vergleich in Abb. 6.26 gegen P/L aufgetragen. In

\begin{tabular}{cc|cc|cc}
\hline & & durch & Anpasssung & (FS) spekulare & Reflektivität \\
\hline $\mathrm{P} / \mathrm{L}$ & $d[\AA]$ & $d_{p p}[\AA]$ & $E_{m w} / E_{m m}$ & $d_{p p}[\AA]$ & $E_{m w} / E_{m m}$ \\
\hline \hline 0 & 50.747 & 35.494 & 0.6553 & 35.694 & 0.6352 \\
$1 / 100$ & 50.661 & 35.402 & 0.605 & 35.402 & 0.589 \\
$1 / 25$ & 50.381 & 35.542 & 0.4989 & 35.462 & 0.5103 \\
\hline
\end{tabular}

Tabelle 6.8: Die durch Fouriersynthese und Anpassung ermittelten charakteristischen Größen der Proben aus Alamethicin/DOPC.

Abb. 6.27 werden die charakteristische Größen $E_{m w} / E_{m m}$ aus beiden Verfahren dargestellt. Dabei liegen $E_{m w} / E_{m m}$ in Abhängigkeit von $P / L$ einander nahe. Ebenso hat der Mittelwert der Membran- 
dicken aus der Anpassung und aus der Fouriersynthese die gleiche Eigenschaft. Alle ermittelten charakteristischen Größen aus beiden Verfahren werden in Tabelle 6.8 aufgelistet. Betrachtet wird nun $E_{m w} / E_{m m}$ zusammen mit der Membrandicke $d_{p p}$ :

$E_{m w} / E_{m m}$ aus beiden Verfahren nimmt mit steigendem $P / L$ deutlich ab. Die Membrandicke $d_{p p}$ für beide Verfahren nimmt zuerst bei $P / L=1 / 100$ ab (stärker für Fouriersynthese), dann nimmt sie bei $P / L=1 / 25 \mathrm{zu}$ (stärker für die Anpassung). Diese Zunahme kann aber unter Berücksichtigung der Fehlergrenze $( \pm 0.2 \AA)$ vernachlässigt werden, so dass die Membrandicke prinzipiell als unverändert betrachtet werden kann. Die erste Abnahme von $E_{m w} / E_{m m}$ kann mit dem 2. Fall in G1. (6.5) erklärt werden, wo das Elektronendichteprofil nur an der Kopfgruppe zunimmt. Die zweite Abnahme von $E_{m w} / E_{m m}$ kann dem 1. Fall in Gl. (6.3) zugeordnet werden, wo das Elektronendichteprofil an der Kopfgruppe und Wasserschicht zunimmt.

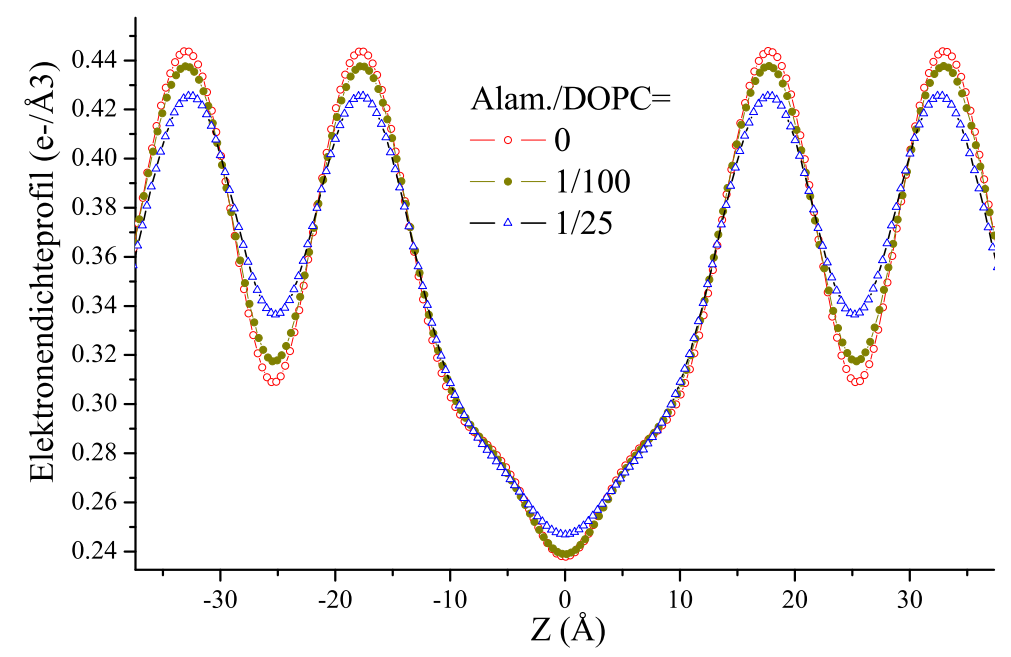

Abbildung 6.25: Durch Anpassung ermittelte Elektronendichteprofile der Proben aus Alamethicin/DOPC.

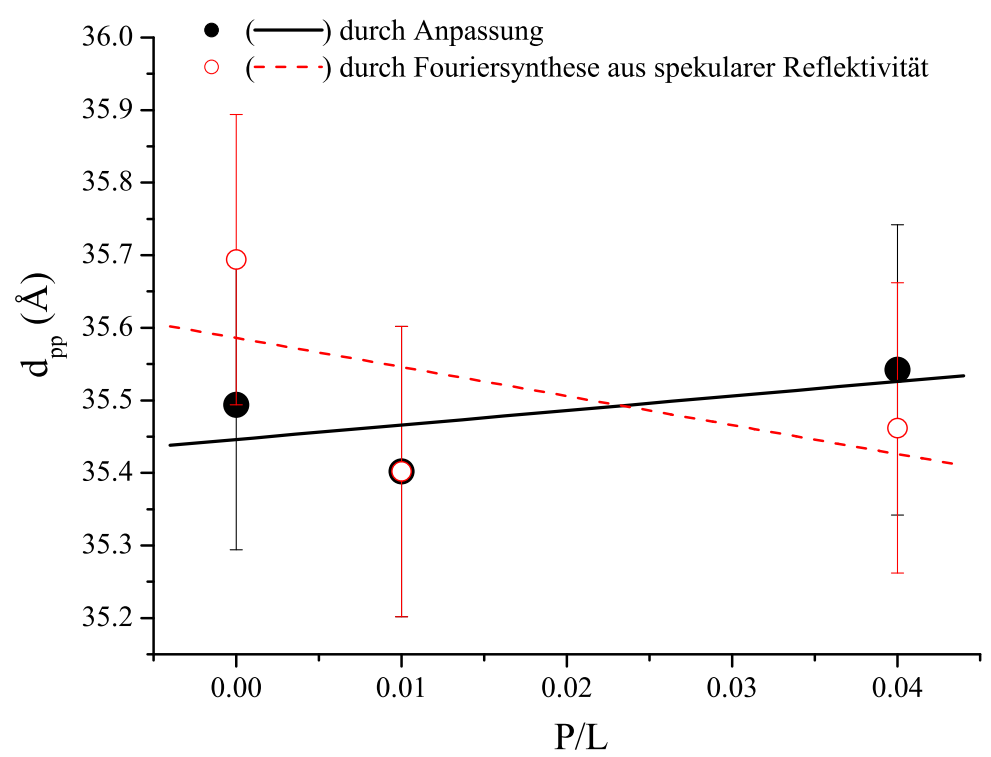

Abbildung 6.26: Vergleich der Membrandicken, die durch Anpassung und Fouriersynthese ermittelt wurden, mit linearer Anpassung (durchgezogene bzw. gestrichelte Kurve). 


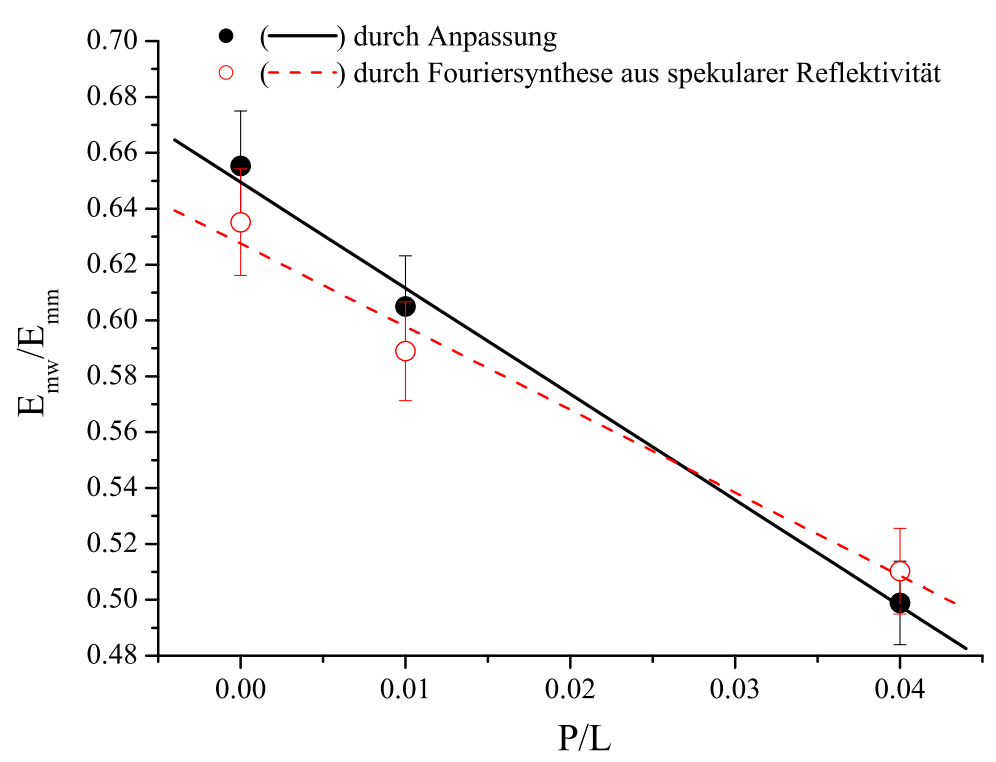

Abbildung 6.27: Vergleich der charakteristischen Größen $E_{m w} / E_{m m}$, die durch Anpassung und Fouriersynthese ermittelt wurden, mit linearer Anpassung (durchgezogene bzw. gestrichelte Kurve).

\subsubsection{Alamethicin/DPPC}

In Abb. 6.28(a) werden alle gemessenen Reflektivitätskurven der Probenserie aus Alamethicin/DPPC zusammen mit den angepassten Kurven gegen $q_{z}$ aufgetragen. Die Konzentrationen von Alamethicin in dieser Probenserie sind 0, 1/100 und 1/25. Jede Kurve hat mindestens 7 BraggPeaks. Die Periodizität der Lipiddoppelschichten in der Probe wird in Abb. 6.28(b) gezeigt, sie nimmt mit steigendem $\mathrm{P} / \mathrm{L}$ deutlich ab.

\section{Fouriersynthese und Anpassung:}

Unter Verwendung der spekularen Reflektivität wurde die Fouriersynthese mit dem Lorentzfaktor $1 / q_{z}^{2}$ durchgeführt. Die Elektronendichteprofile der Proben wurden dadurch ermittelt, woraus wiederum die Membrandicken in den Proben bestimmt wurden. An den gemessenen Reflektivitätskurven wurde eine Anpassung mit einer Modellfunktion durchgeführt, die dadurch erneut ermittelten Elektronendichteprofile werden in Abb. 6.29 gezeigt. Durch sie wurden wiederum die Membrandicken in den Proben bestimmt. Alle durch die beiden Verfahren ermittelten Membrandicken werden zum Vergleich in Abb. 6.30 gegen P/L aufgetragen, sie nehmen mit steigendem $\mathrm{P} / \mathrm{L}$ etwas ab. Die charakteristischen Größen $E_{m w} / E_{m m}$ aus beiden Verfahren werden in Abb. 6.31 zusammen dargestellt. Dabei liegen $E_{m w} / E_{m m}$ in Abhängigkeit von $P / L$ für beide Verfahren nahe beieinander . Diese Eigenschaft zeigt sich auch beim Mittelwert der Membrandicken aus Anpassung und aus Fouriersynthese. In Tabelle 6.9 werden alle ermittelten charakteristischen Größen aus beiden Verfahren aufgelistet. Im folgenden betrachten wir $E_{m w} / E_{m m}$ aus Anpassung und Fouriersynthese zusammen mit der Membrandicke $d_{p p}$ :

$E_{m w} / E_{m m}$ aus beiden Verfahren nimmt bei $P / L=1 / 100$ zuerst zu, was dem 2. Fall in Gl. (6.5) 


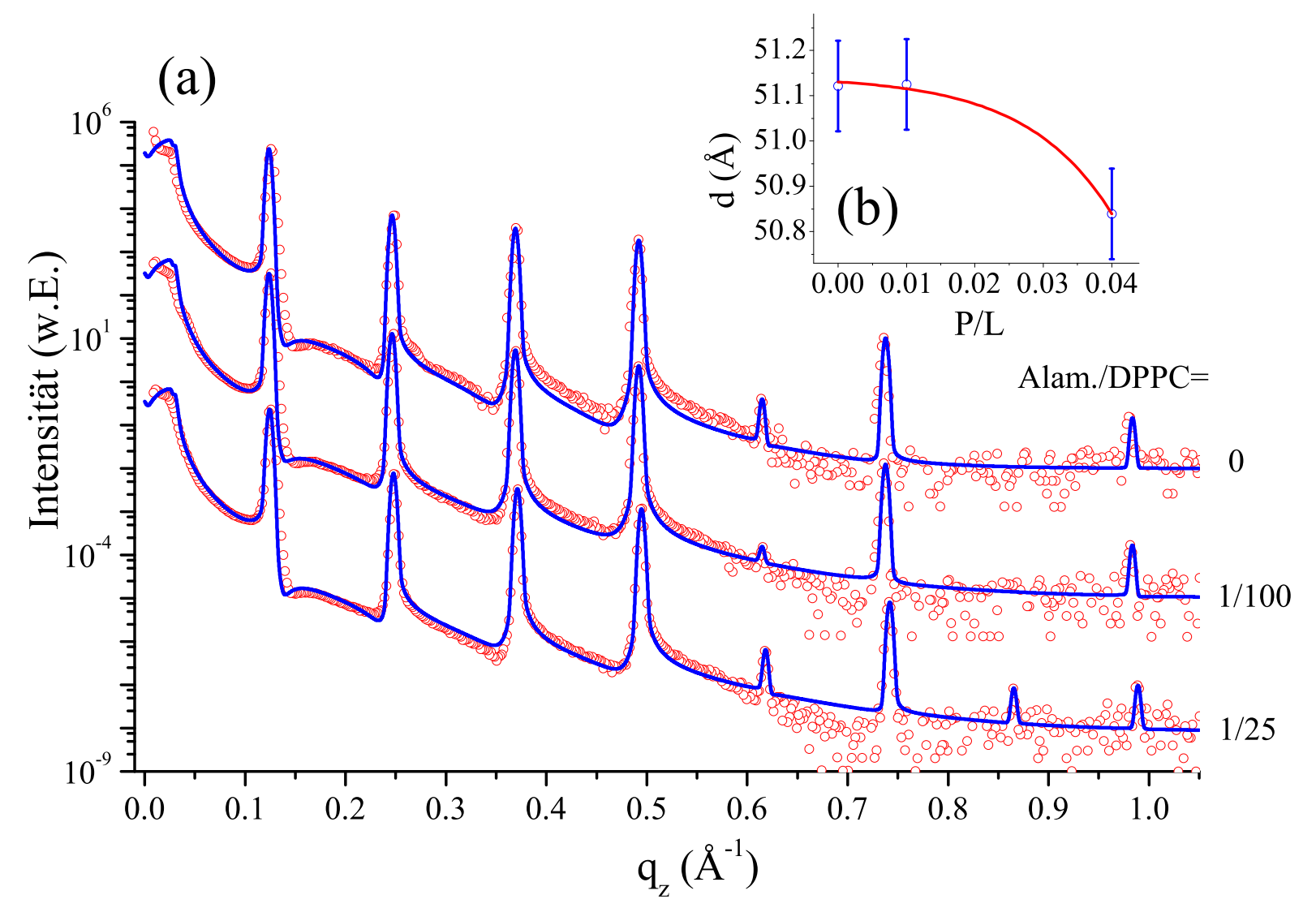

Abbildung 6.28: (a) Gemessene Reflektivitätskurven der Probenserie aus Alamethicin/DPPC mit angepassten Kurven (durchgezogen); (b) Periodizität der Lipiddoppelschichten in der Probe mit exponentieller Anpassung (durchgezogene Kurve) zur besseren Darstellung des Trends.

\begin{tabular}{cc|cc|cc}
\hline & & durch & Anpasssung & (FS) spekulare & Reflektivität \\
\hline $\mathrm{P} / \mathrm{L}$ & $d[\AA]$ & $d_{p p}[\AA]$ & $E_{m w} / E_{m m}$ & $d_{p p}[\AA]$ & $E_{m w} / E_{m m}$ \\
\hline \hline 0 & 51.121 & 37.242 & 0.5336 & 37.282 & 0.512 \\
$1 / 100$ & 51.125 & 36.91 & 0.5649 & 37.05 & 0.516 \\
$1 / 25$ & 50.839 & 36.748 & 0.5131 & 36.938 & 0.4737 \\
\hline
\end{tabular}

Tabelle 6.9: Die durch Fouriersynthese und Anpassung ermittelten charakteristischen Größen der Proben aus Alamethicin/DPPC.

zuzuordnen ist, wo das Elektronendichteprofil nur an der Kopfgruppe zunimmt, dabei nimmt die Membrandicke $d_{p p}$ aus beiden Verfahren ab. $E_{m w} / E_{m m}$ aus beiden Verfahren zeigt bei $P / L=1 / 25$ eine Abnahme, die Membrandicke nimmt dabei leicht ab, was zum 1. Fall in Gl. (6.3) gehört, wo das Elektronendichteprofil der Kopfgruppe und der Wasserschicht zunimmt. 


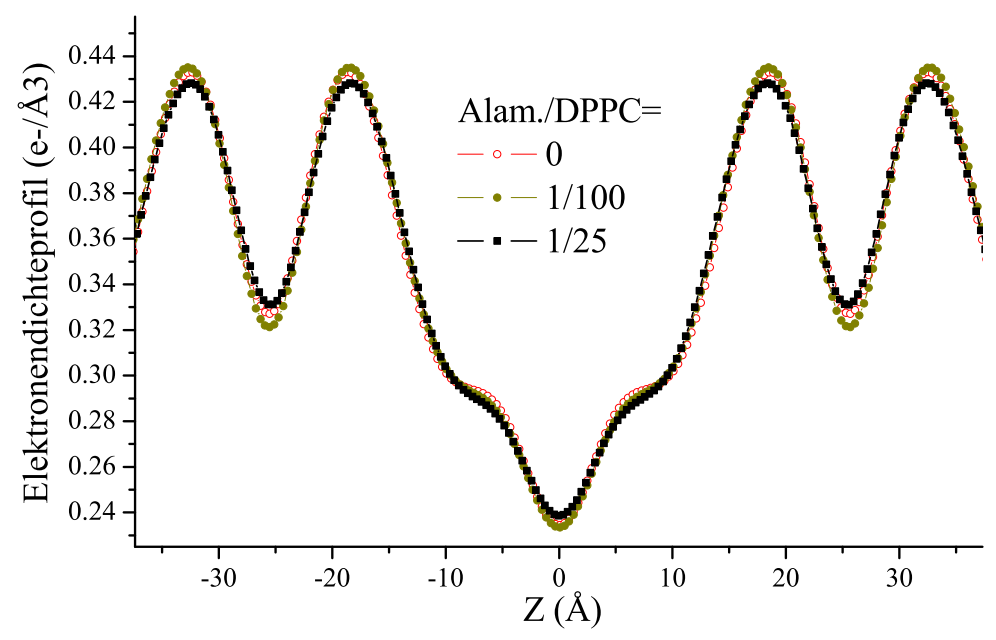

Abbildung 6.29: Durch Anpassung ermittelte Elektronendichteprofile der Proben aus Alamethicin/DPPC.

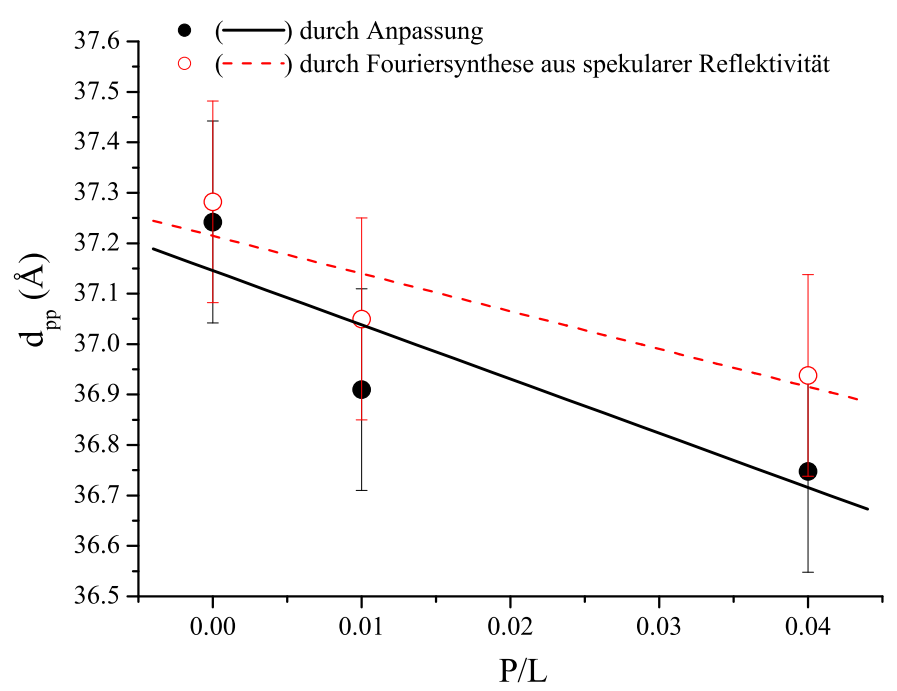

Abbildung 6.30: Vergleich der Membrandicken, die durch Anpassung und Fouriersynthese ermittelt wurden, mit linearer Anpassung (durchgezogene bzw. gestrichelte Kurve).

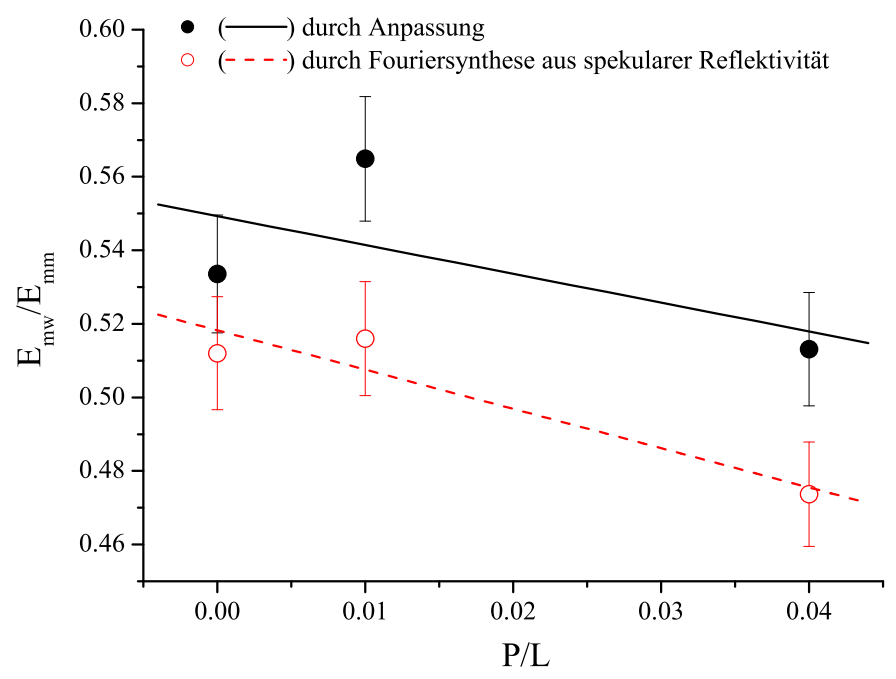

Abbildung 6.31: Vergleich der charakteristischen Größen $E_{m w} / E_{m m}$, die durch Anpassung und Fouriersynthese ermittelt wurden, mit linearer Anpassung (durchgezogene bzw. gestrichelte Kurve). 


\subsubsection{Alamethicin/POPC}

Die gemessenen Reflektivitätskurven der Probenserie aus Alamethicin/POPC werden in Abb. 6.32(a) zusammen mit den angepassten Kurven dargestellt. Diese Probenserie hat Konzentrationen von Alamethicin jeweils von 0, 1/100 und 1/25. Jede Kurve hat mindestens 6 Bragg-Peaks. In Abb. 6.32(b) wird die Periodizität der Lipiddoppelschichten in der Probe gegen z aufgetragen, sie nimmt mit steigender Peptidkonzentration deutlich ab.

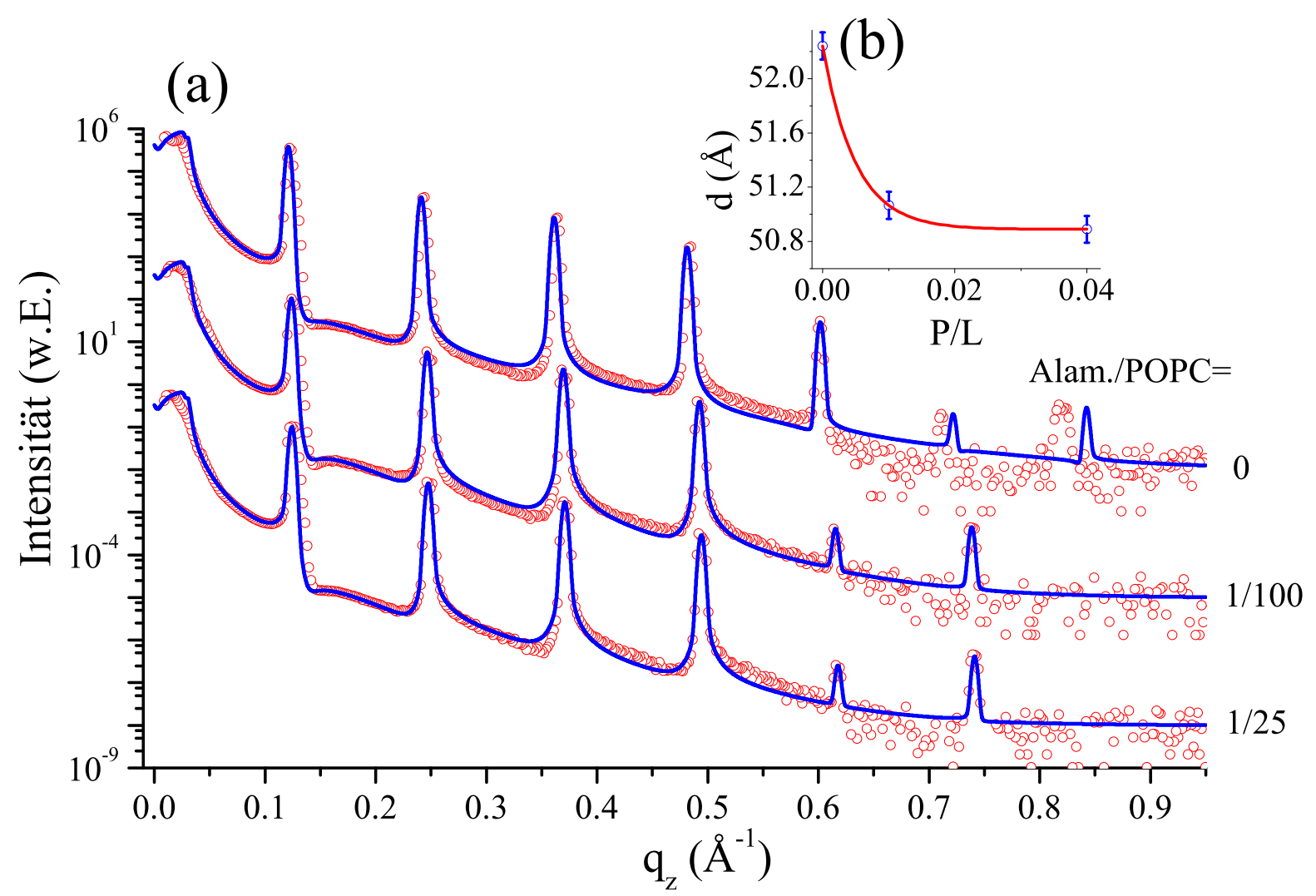

Abbildung 6.32: (a) Gemessene Reflektivitätskurven der Probenserien aus Alamethicin/POPC mit angepassten Kurven (durchgezogen); (b) Periodizität der Lipiddoppelschichten in der Probe mit exponentieller Anpassung (durchgezogene Kurve).

\section{Fouriersynthese und Anpassung:}

Durch Fouriersynthese aus spekularer Reflektivität mit Lorentzfaktor $1 / q_{z}^{2}$ wurden die Elektronendichteprofile der Proben ermittelt. Anhand dieser wurden die Membrandicken in den Proben bestimmt. Weiter wurden durch Anpassung an die gemessenen Reflektivitätskurven mit einer Modellfunktion erneut die Elektronendichteprofile ermittelt. Sie werden in Abb. 6.33 dargestellt. Mit ihnen wurden wiederum die Membrandicken in den Proben bestimmt. Alle durch beide Verfahren ermittelten Membrandicken werden zum Vergleich in Abb. 6.34 dargestellt. Sie zeigen eine abnehmende Tendenz mit steigendem P/L. Die Abbildungen 6.35 und 6.34 zeigen die charakteristische Größe $E_{m w} / E_{m m}$ und die Membrandicke aus beiden Verfahren. $E_{m w} / E_{m m}$ liegen dabei 


\begin{tabular}{cc|cc|cc}
\hline & & durch & Anpasssung & (FS) spekulare & Reflektivität \\
\hline $\mathrm{P} / \mathrm{L}$ & $d[\AA]$ & $d_{p p}[\AA]$ & $E_{m w} / E_{m m}$ & $d_{p p}[\AA]$ & $E_{m w} / E_{m m}$ \\
\hline \hline 0 & 52.242 & 36.264 & 0.5698 & 36.364 & 0.5502 \\
$1 / 100$ & 51.067 & 35.894 & 0.5764 & 36.114 & 0.5281 \\
$1 / 25$ & 50.89 & 35.9 & 0.5237 & 36.04 & 0.4669 \\
\hline
\end{tabular}

Tabelle 6.10: Die durch Fouriersynthese und Anpassung ermittelten charakteristischen Größen der Proben aus Alamethicin/DOPC.

in Abhängigkeit von $P / L$ nahe beieinander. Die gleiche Eigenschaft hat auch der Mittelwert der Membrandicken aus Anpassung und aus Fouriersynthese. Alle durch beide Verfahren ermittelten charakteristischen Größen werden in Tabelle 6.10 aufgeführt. Man betrachte $E_{m w} / E_{m m}$ zusammen mit der Membrandicke $d_{p p}$ :

$E_{m w} / E_{m m}$ aus der Anpassung nimmt zuerst bei $P / L=1 / 100$ ein bisschen zu, die Membrandicke $d_{p p}$ nimmt dabei ab, was dem 2. Fall in Gl. (6.5) zugeordnet werden kann, wo das Elektronendichteprofil nur an der Kopfgruppe zunimmt. Dagegen nimmt $E_{m w} / E_{m m}$ aus der Fouriersynthese bei $P / L=1 / 100 \mathrm{ab}$, dabei nimmt die Membrandicke $d_{p p}$ auch ab. Die Abnahme von $E_{m w} / E_{m m}$ aus der Fouriersynthese gehört auch zum 2. Fall in der Gl. (6.5). Bei $P / L=1 / 25 \mathrm{nimmt} E_{m w} / E_{m m}$ aus beiden Verfahren ab, die Membrandicke jedoch ändert sich dabei kaum, was unter Berücksichtigung der Fehlergrenze als Abnahme der Membrandicke betrachtet werden kann. Damit kann die Abnahme von $E_{m w} / E_{m m}$ aus beiden Verfahren dem 1. Fall in Gl. (6.3) zugeordnet werden, wo das Elektronendichteprofil der Kopfgruppe und der Wasserschicht zunimmt.

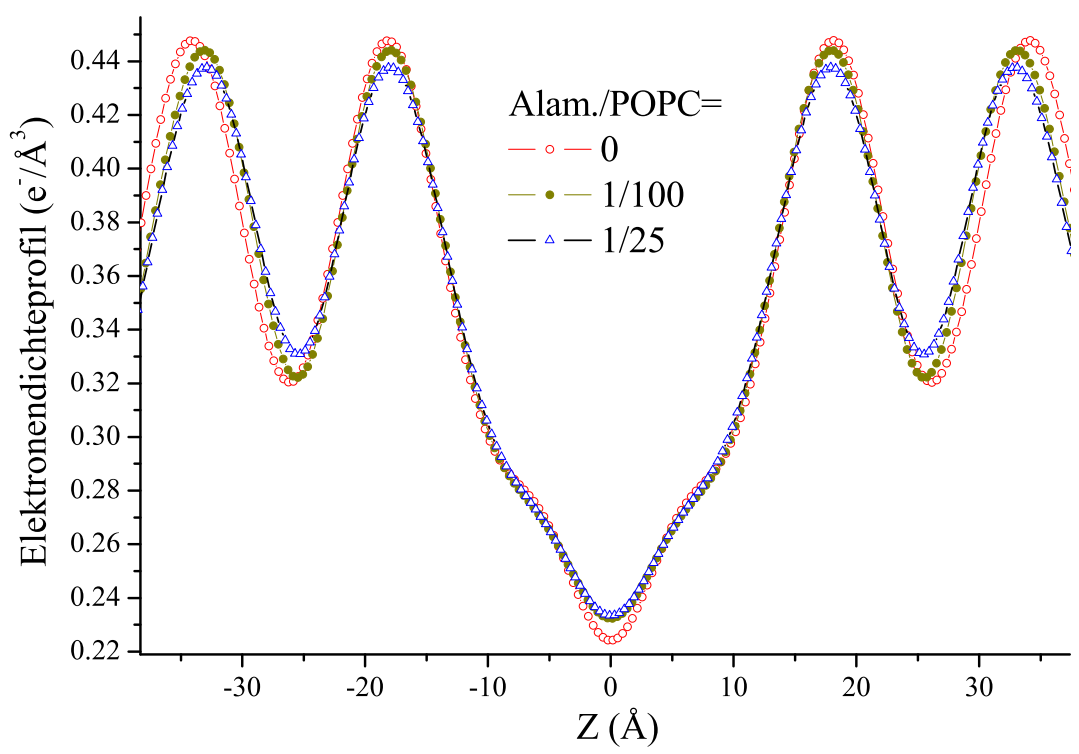

Abbildung 6.33: Durch Anpassung ermittelten Elektronendichteprofile der Proben aus Alamethicin/POPC. 


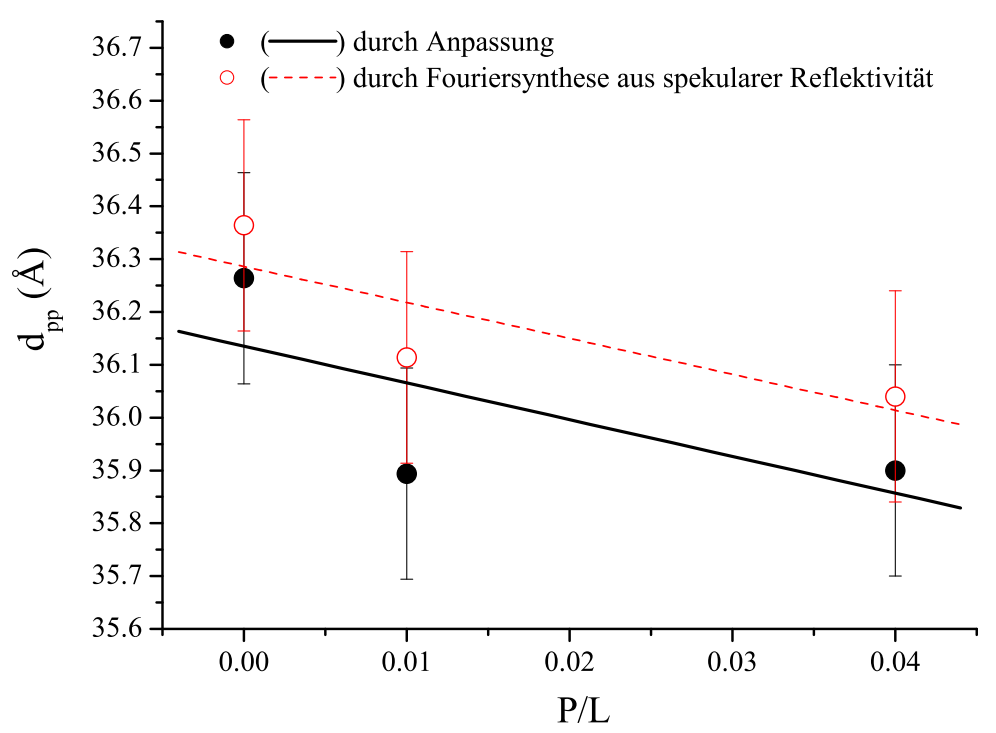

Abbildung 6.34: Vergleich der Membrandicken, die durch Anpassung und Fouriersynthese ermittelt wurden, mit linearer Anpassung (durchgezogene bzw. gestrichelte Kurven).

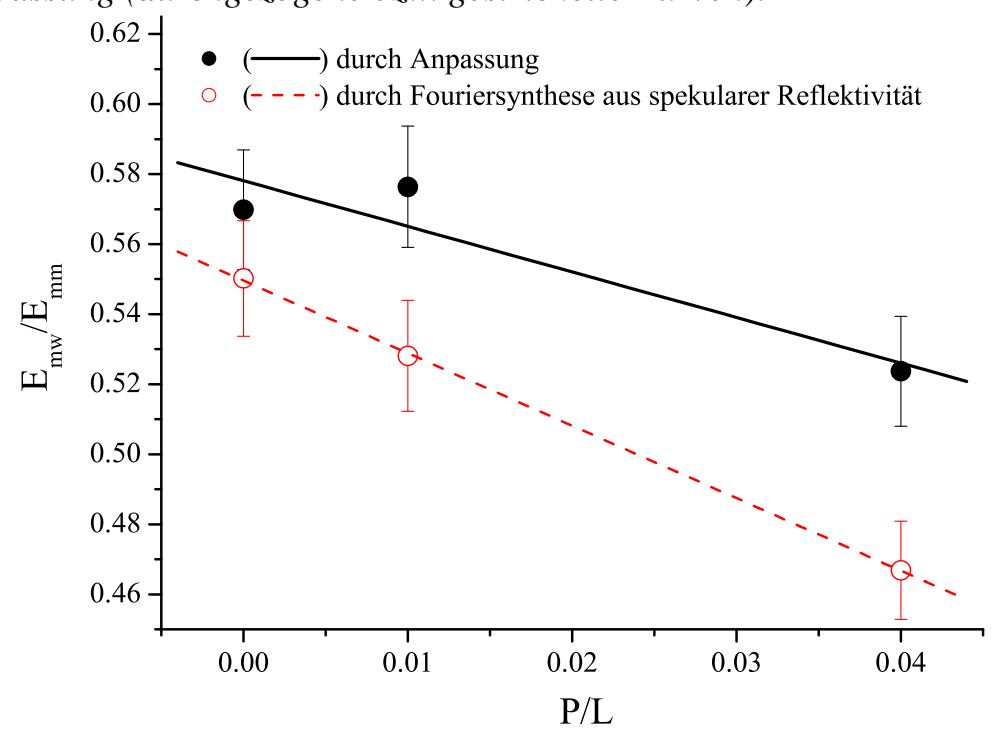

Abbildung 6.35: Vergleich der charakteristischen Größen $E_{m w} / E_{m m}$, die durch Anpassung und Fouriersynthese ermittelt wurden, mit linearer Anpassung (durchgezogene bzw. gestrichelte Kurven).

\subsubsection{Alamethicin/DMPC unter PEG-Lösung}

In Abb. 6.36(a) werden alle unter PEG-Lösung (Polyethyleneglycol-Lösung) mit Gewichtskonzentration von $14.2 \%$ gemessenen Reflektivitätskurven der Probenserie aus Alamethicin/DMPC zusammen mit den angepassten Kurven dargestellt. Das Polymer Polyethyleneglycol (PEG) hat eine mittlere Masse von $20000 \mathrm{u}$, unter dieser PEG-Lösung (mit einer Gewichtskonzentration von $14.2 \%$ ) ergibt sich ein osmotischer Druck von 1.95 bar. Diese Methode beruht darauf, dass man große Polymere in der Wasserphase löst. Die Polymere müssen so groß sein, damit sie nicht in die nur einige nm dicke Wasserschicht eindringen können [149]. Die Konzentrationen von Alamethicin in dieser Probenserie sind 0, 1/200, 1/100, 1/50 und 1/25. Jede Kurve hat mindestens 4 
Bragg-Peaks. Die Periodizität der Lipiddoppelschichten in der Probe wird in Abb. 6.36(b) gezeigt, sie zeigt keine systematische Änderung mit steigender Peptidkonzentration.

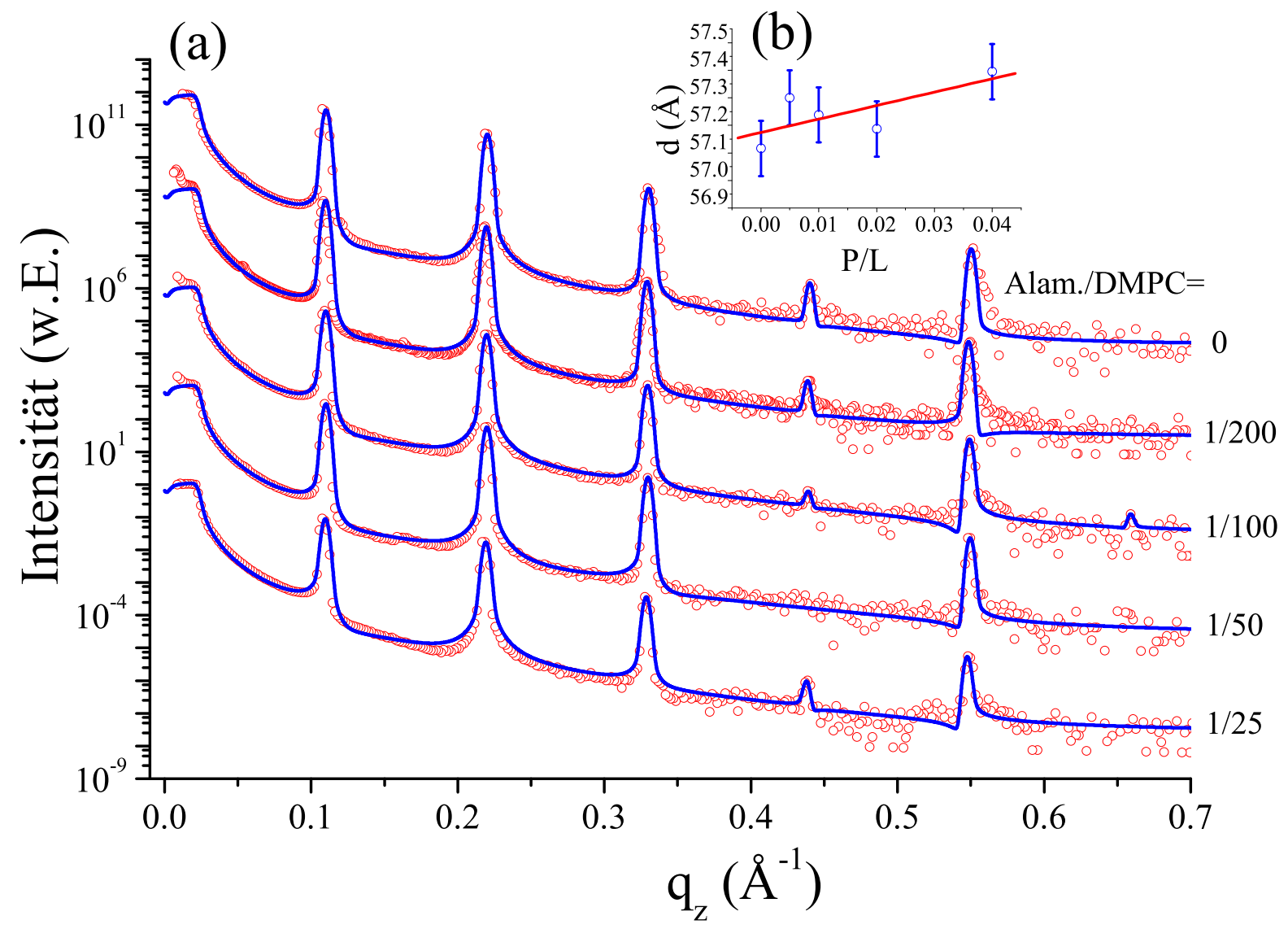

Abbildung 6.36: (a) Gemessene Reflektivitätskurven der Probenserien aus Alamethicin/DMPC unter wässriger PEG-Lösung (mit einer Gewichtskonzentration von $14.2 \%$ ) mit angepassten Kurven (durchgezogen). Unter dieser PEG-Lösung ergibt sich ein osmotischer Druck von 1.95 bar; (b) Periodizität der Lipiddoppelschichten in den Proben mit linearer Anpassung (durchgezogene Kurve) zur besseren Darstellung des Trends.

\section{Fouriersynthese und Anpassung:}

Durch Fouriersynthese unter Anwendung der spekularen Reflektivität wurden die Elektronendichteprofile der Proben ermittelt und damit wiederum die Membrandicken bestimmt. Weiterhin wurde an den gemessenen Reflektivitätskurven eine Anpassung mit einer Modellfunktion durchgeführt. Die dadurch erneut ermittelten Elektronendichteprofile werden in Abb. 6.37 dargestellt. Damit wurden wiederum die Membrandicken in den Proben bestimmt. Alle durch die beiden Verfahren ermittelten Membrandicken werden zum Vergleich in Abb. 6.38 gegen P/L aufgetragen, sie haben keine systematische Änderung mit steigendem P/L. Die charakteristische Größen $E_{m w} / E_{m m}$ aus beiden Verfahren werden in Abb. 6.39 zusammen dargestellt. In Tabelle 6.11 werden alle ermittelten charakteristischen Größen aus beiden Verfahren aufgelistet. Im folgenden betrachten wir $E_{m w} / E_{m m}$ aus Anpassung und Fouriersynthese zusammen mit der Membrandicke $d_{p p}$ : 


\begin{tabular}{cc|cc|cc}
\hline & & durch & Anpasssung & $($ FS) spekulare & Reflektivität \\
\hline $\mathrm{P} / \mathrm{L}$ & $d[\AA]$ & $d_{p p}[\AA]$ & $E_{m w} / E_{m m}$ & $d_{p p}[\AA]$ & $E_{m w} / E_{m m}$ \\
\hline \hline 0 & 57.116 & 35.312 & 0.419 & 35.212 & 0.43 \\
$1 / 200$ & 57.3 & 36.3 & 0.4094 & 35.44 & 0.4167 \\
$1 / 100$ & 57.238 & 35.296 & 0.441 & 35.216 & 0.4382 \\
$1 / 50$ & 57.187 & 35.254 & 0.4518 & 35.64 & 0.3754 \\
$1 / 25$ & 57.395 & 35.43 & 0.426 & 35.31 & 0.4352 \\
\hline
\end{tabular}

Tabelle 6.11: Die durch Fouriersynthese und Anpassung ermittelten charakteristischen Größen der Proben aus Alamethicin/DMPC, die unter PEG-Lösung mit einer Gewichtskonzentration von $14.2 \%$ gemessen wurden.

$E_{m w} / E_{m m}$ nimmt aus beiden Verfahren bei $P / L=1 / 200$ zuerst ab, was zum 1 . Fall in Gl. (6.3) gehört. Die Membrandicke aus der Anpassung nimmt bei $P / L=1 / 200$ sehr stark zu, während sie aus der Fouriersynthese relativ leicht zunimmt. $E_{m w} / E_{m m}$ aus der Anpassung nimmt danach bis zu $P / L=1 / 50 \mathrm{zu}$, was dem 2. Fall in Gl. (6.5) zuzuordnen ist, wo nur das Elektronendichteprofil der Kopfgruppe zunimmt, dabei nimmt die Membrandicke $d_{p p}$ aus der Anpassung bis zu $P / L=1 / 50$ ab. $E_{m w} / E_{m m}$ aus der Fouriersynthese schwankt zwischen $\mathrm{Zu}$ - und Abnahme bis zu $P / L=1 / 25$, was dem 1. Fall in Gl. (6.3), wo das Elektronendichteprofil der Kopfgruppe sowie der Wasserschicht zunimmt, oder dem 2. Fall in Gl. (6.5), wo nur das Elektronendichteprofil der Kopfgruppe zunimmt, zuzuordnen ist. Die Membrandicke aus der Fouriersynthese schwankt auch zwischen Zu- und Abnahme bis zu $P / L=1 / 25$. $E_{m w} / E_{m m}$ aus der Anpassung nimmt bei $P / L=1 / 25$ etwas ab, was zum 1. Fall in Gl. (6.3) gehört, wo das Elektronendichteprofil der Kopfgruppe und der Wasserschicht zunimmt. Die Membrandicke nimmt dabei etwas zu.

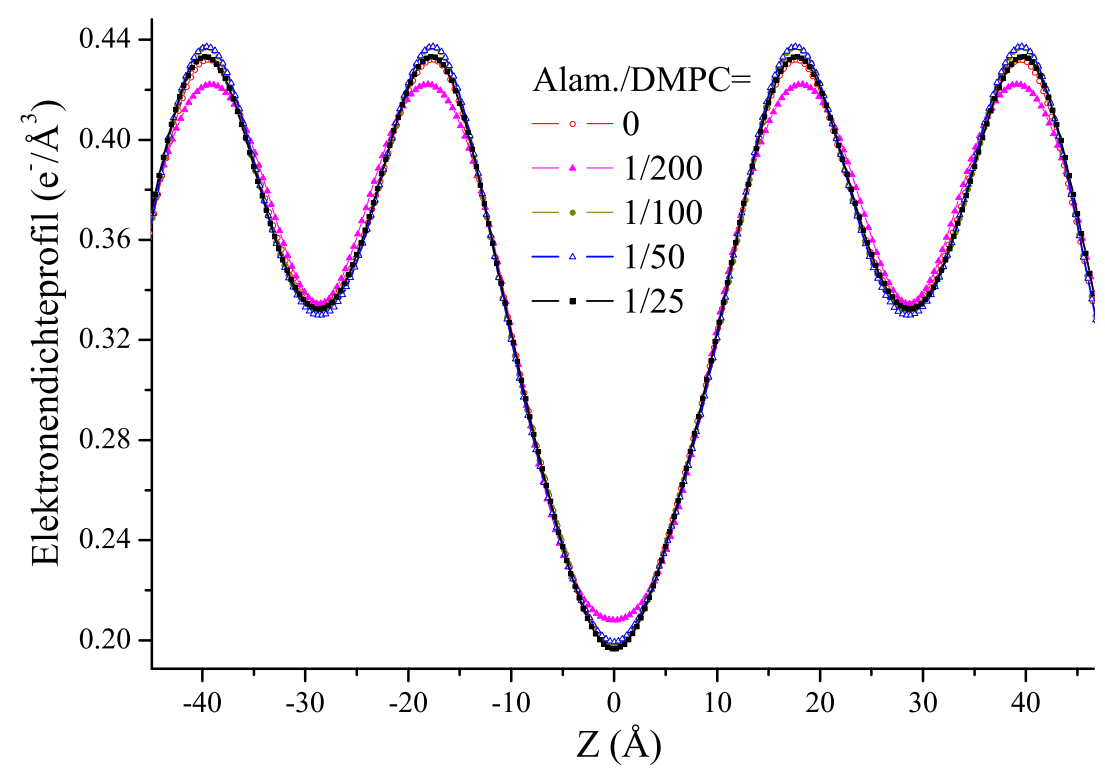

Abbildung 6.37: Durch Anpassung ermittelte Elektronendichteprofile der Proben aus Alamethicin/DMPC. 


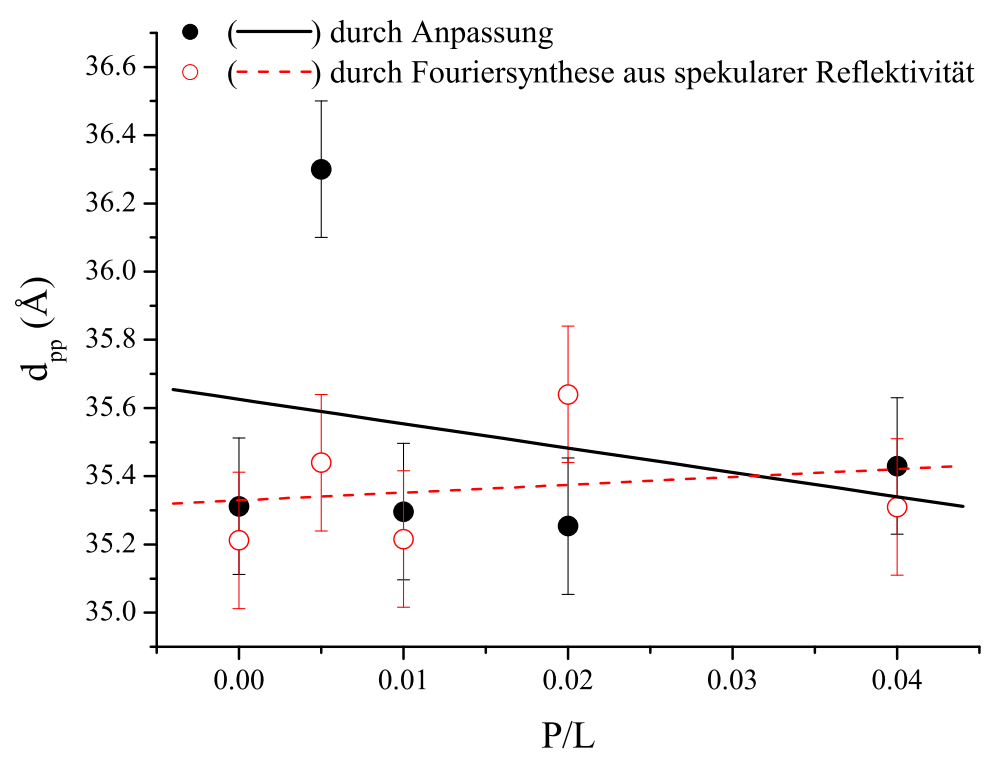

Abbildung 6.38: Vergleich der Membrandicken, die durch Anpassung und Fouriersynthese ermittelt wurden, mit linearer Anpassung (durchgezogene bzw. gestrichelte Kurve).

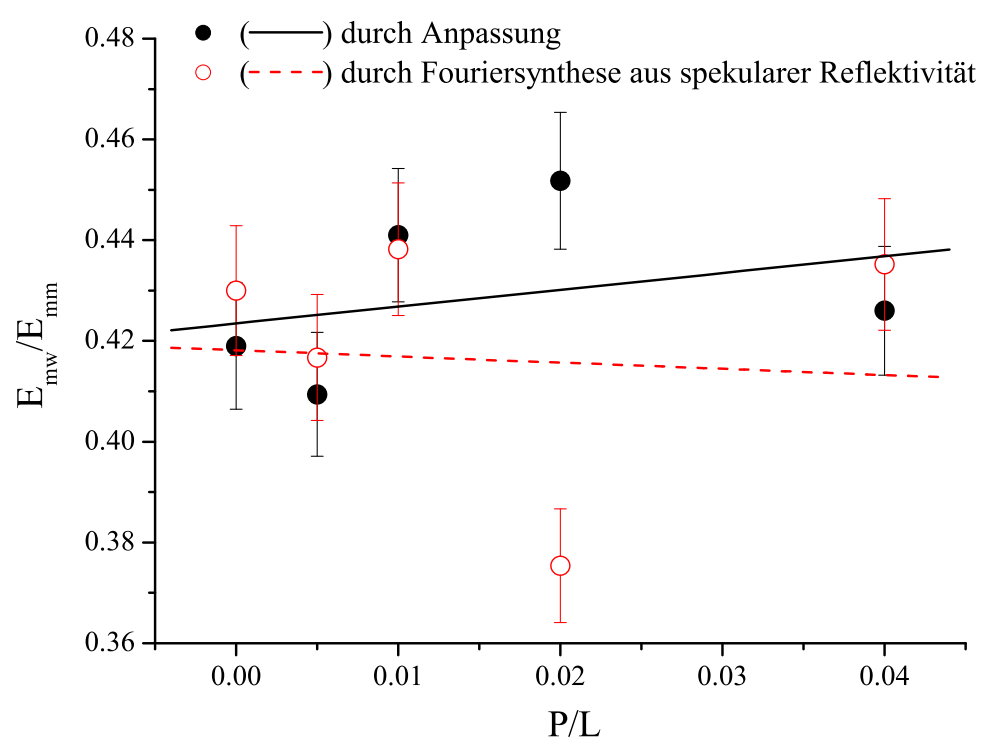

Abbildung 6.39: Vergleich der charakteristischen Größen $E_{m w} / E_{m m}$, die durch Anpassung und Fouriersynthese ermittelt wurden, mit linearer Anpassung (durchgezogene bzw. gestrichelte Kurve).

\subsubsection{Zusammenfassung}

Nach bisheriger Betrachtung von $E_{m w} / E_{m m}$ und der Membrandicke $d_{p p}$ aus dem Alamethicin/Lipid-System kann man im Allgemeinen folgern, dass die Änderungen im Elektronendichteprofil in Abhängigkeit der Peptidkonzentration stark von Lipid zu Lipid zwischen den Lipidarten variiert. Ein eindeutiger Membranverdünnungseffekt wird bei DMPC/DDMPG, POPC und DPPC beobachtet. Für fast alle Lipide (außer DMPC) nimmt die charakteristische Größe $E_{m w} / E_{m m}$ darüber hinaus ab, d.h. das Elektronendichteprofil wird "ausgeschmiert". Ein Membranverdünnungseffekt wurde auch bei Untersuchung der Alamethicin-Pore durch Neutro- 
nenstreuung an Lipidmembranen beobachtet [173]. Für die DMPC-Membranen unter Feuchtigkeit und PEG-Lösung schwankt die Membrandicke um einen im Rahmen der Fehlergrenze konstanten Wert. Für die DMPC-Probenserie, die in der Feuchtigkeitskammer gemessen wurde, nimmt die Membrandicke ab $P / L=1 / 25 \mathrm{zu}$. Das kann ein Hinweis darauf sein, dass zwischen $P / L=1 / 50$ und 1/25 eine kritische Konzentration für eine Konformationsänderung von Alamethicin auftritt. Solch eine kritische Konzentration für die Konformationsänderung ist stark abhängig von der Lipid- und Peptidsorte sowie der Probenumgebung [174][85][173]. Bei dieser kritischen Konzentration lagert sich Alamethicin senkrecht zur Membranoberfläche in die Membran ein, wie in Abb. 6.40(b)(c) schematisch dargestellt wird. Eine solche Konformationsänderung bei $P / L=1 / 25$ kann nur durch seinen hydrophoben Effekt erklärt werden, wenn die Membrandicke $d_{p p}$ nicht größer oder kleiner als die hydrophobe Länge der Peptidhelix ist. Da die hydrophobe Länge von Alamethicin maximal $30 \AA$ ist [44], kann nur für die Probenserie aus Alam./DLPC die Folgerung gezogen werden, dass Alamethicin bei $P / L=1 / 25$ sich möglicherweise senkrecht zur Membranoberfläche in die Membran einlagert. Für andere Probenserien ist es ziemlich schwer,

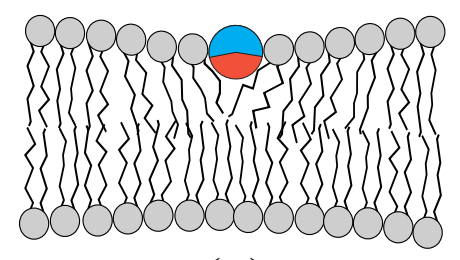

(a)

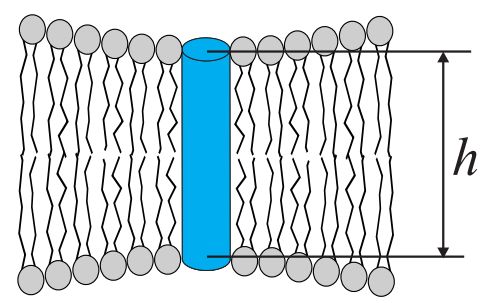

(c)

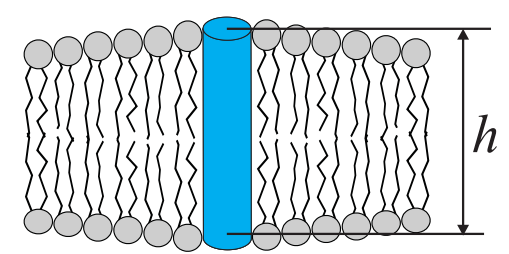

(b)

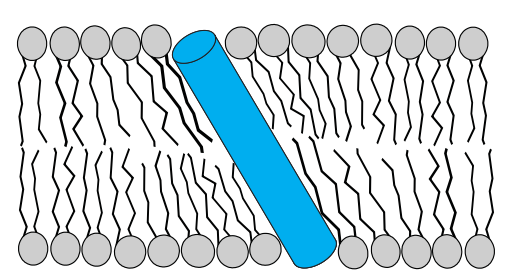

(d)

Abbildung 6.40: Schematische Darstellung der Lokalisierung des Peptids in der Lipidmembran. (a) Das Peptid lagert sich auf der Membranoberfläche an und drückt sich in die Membranoberfläche, dadurch wird die Membrandicke vermindert; (b) Positive hydrophobe Fehlanpassung (engl. hydrophobic mismatch): das Peptid lagert sich senkrecht zur Membranoberfläche in die Membran ein. Da die hydrophobe Länge der Peptidhelix $h$ größer als die Membrandicke ist (bei Alamethicin: $h \approx 30 \AA$ und bei Magainin $2: h \approx 34.5$ $\AA[175]$ ), wird die Membrandicke vergrößert; (c) Negative hydrophobe Fehlanpassung: das Peptid lagert sich senkrecht zu Membranoberfläche in die Membran ein. Da die hydrophobe Länge der Peptidhelix kleiner als die Membrandicke ist, wird die Membrandicke verkleinert; (d) Das Peptid lagert sich gekippt in die Membran ein, die Membrandicke wird dadurch nicht geändert.

eine Vergrößerung der Membrandicke bei $P / L=1 / 25 \mathrm{zu}$ verstehen. Die Membrandicke $d_{p p}$ ist nämlich in allen Fällen größer als hydrophobe Länge der Helix von Alamethicin.

Um die Änderung der Membrandicke $d_{p p}$ und der charakteristischen Größe $E_{m w} / E_{m m}$ mit $P / L$ besser darzustellen, werden in Abb. 6.41 die Steigungen beider Größen gegen die Membrandicke 

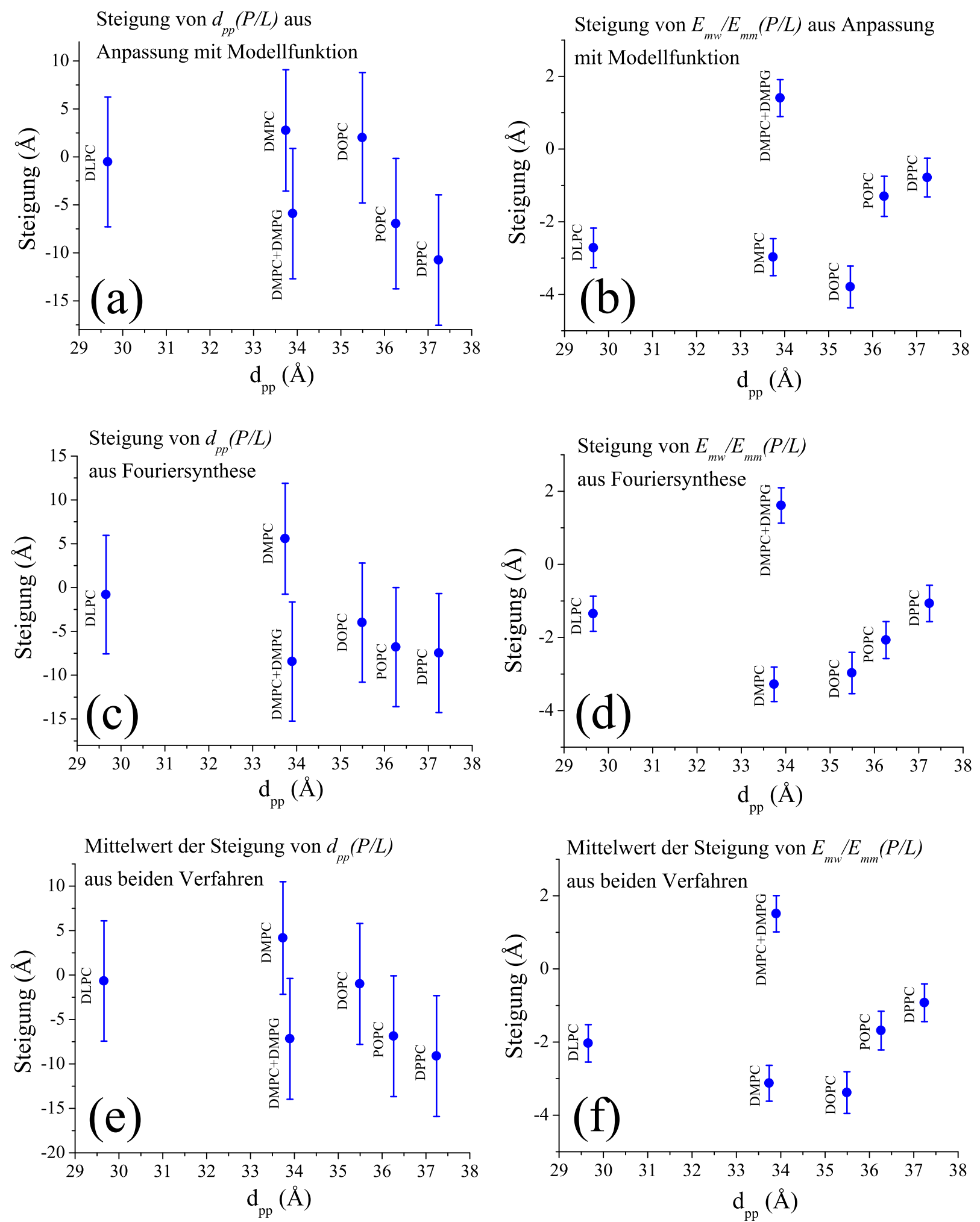

Abbildung 6.41: Steigung von: (a) der Lipiddicke $d_{p p}$ aus der Anpassung; (b) der charakteristischen Grö$\beta e E_{m w} / E_{m m}$ aus der Anpassung; (c) der Lipiddicke $d_{p p}$ aus der Fouriersynthese; (d) der charakteristischen Größe $E_{m w} / E_{m m}$ aus der Fouriersynthese; (e) Mittelwert der Steigung des linearen Fittings der Membrandicke $d_{p p}$ aus beiden Verfahren; $(f)$ Mittelwert der Steigung des linearen Fittings der charakteristischen Größe $E(m w) / E(m m)$ aus beiden Verfahren. 
bei $P / L=0$ aufgetragen. Die Steigung der Membrandicke als Funktion von $P / L$ (also Steigung von $d_{p p}(P / L)$ ) ist innerhalb der Fehlergrenze für beide Auswerteverfahren identisch und für DMPC/DMPG, POPC und DPPC eindeutig negativ, während DLPC, DMPC und DOPC keinen (deutlichen) Membranverdünnungseffekt zeigen. Lässt man das geladene System außer Betracht, so ergibt sich eine Korrelation des Verdünnungseffektes mit der Ausgangsdichte der Membran (bei $P / L=0$ ) derart, dass dickere Lipidmembranen unter Einfluss von Alamethicin eher einen Verdünnungseffekt aufweisen. Insgesamt gesehen bleibt aber fraglich, ob der Effekt eine so große und allgemeingültige Rolle spielt, wie in der Literatur behauptet. Gleichzeitig zeigt sich bei allen untersuchten Lipiden im Elektronendichteprofil ein ähnliches Verhalten darin, dass der maximale Kontrast $E_{m w} / E_{m m}$ (bzw. die hier sogenannte charakteristische Größe) abnimmt, das Profil also "ausgeschmiert" wird. Dies kann auch durch eine zunehmende Unordnung der Lipidmembranen insbesondere in Bezug auf den Gleichgewichtsabstand und die lamellare Ordnung bedingt sein. Dieser Effekt tritt sehr universell auf. Die Steigung von $E_{m w} / E_{m m}(P / L)$ aus beiden Verfahren (Abb. 6.41(b)(d)) zeigt einen ähnlichen Verlauf, was wiederum darauf hindeutet, dass die beiden Verfahren (Anpassung und Fouriersynthese) konsistente Ergebnisse liefern.

\subsection{Auswertung der Messdaten aus Magainin2/Lipid}

In diesem Abschnitt werden die Auswertung und das Ergebnis des Magainin2/Lipid-Systems aus multilamellaren Membranstapeln und aus Oligo-Membranen vorgestellt und anschließend über mögliche Schlussfolgerungen diskutiert. Da am Anfang ein optimales organisches Lösungsmittel zur Präparation nicht gefunden wurde, wurden die Proben aus multilamellaren Membranstapeln mit zwei verschiedenen Lösungsmitteln präpariert: OPPC wurde mit dem organischen Lösungsmittel TFE auf Si-Substrat, DMPC wurde mit einer Mischung von TFE/Chloroform (1:1) auf Glas-Substrat, und gemischte Lipide aus DMPC/DMPG (Molverhältnis von 3:1) wurden mit einer Mischung von TFE/Chloroform (1:1) auf Si-Substrat in unterschiedlicher Konzentration von Magainin 2 präpariert. Die Anzahl der Lipiddoppelschichten in der Probe liegt bei mehreren hundert bis zu tausend. Für die Proben aus Oligo-Membranen wurden unvermischtes Lipid DMPC und POPC sowie eine Mischung aus DMPC/DMPG und POPC/POPS (beide im Molverhältnis 3:1) zur Präparation verwendet. Magainin 2 wurde in unterschiedlicher Konzentration mit einer Mischung aus TFE/Chloroform im Volumenverhältnis 1:1 auf Si-Substrat unter Verwendung einer Lackschleuder (Spin-Coater) präpariert. Die Anzahl der Lipiddoppelschichten in der so präparierten Probe ist weniger als 20. Alle Probenserien wurden auch am Messplatz D4 Hasylab unter Feuchtigkeit $(\mathrm{RH} \approx 99 \%)$ und $\mathrm{T}=45^{\circ} \mathrm{C}$ mit einer Wellenlänge von $0.62 \AA$ gemessen. Durch das Verfahren der Fouriersynthese und der Anpassung mit einer Modellfunktion wurden die gemessenen Reflektivitätskurven aus multilamellaren Membranstapeln ausgewertet. Bei den Proben aus Oligo-Membranen konnte aufgrund der geringeren Anzahl der Bragg-Peaks und der niedrigen Peakhöhe das Verfahren der Fouriersynthese auf die gemessenen Kurven nicht angewendet werden. Daher wurden die gemessenen Reflektivitätskurven aus Oligo-Membranen nur durch Anpassung mit einer Modellfunktion ausgewertet. Da bei den Messdaten der Proben aus Oligo-Membranen kein kritischer Winkel für eine zweite Grenzfläche (zwischen Wasserschicht 
und Luft) zu sehen ist, berücksichtigt die Modellfunktion nur eine Grenzfläche (zwischen Substrat und Wasserschicht). Darüber hinaus wurde wegen der geringen Anzahl der Lipiddoppelschichten die parabolische Bedeckungsfunktion (siehe Kapitel 5) verwendet, um die Reflektivitätskurve besser anzupassen. Die durch Anpassung ermittelten Parameter für alle Proben werden im Anhang aufgeführt.

\subsubsection{Magainin2/DMPC}

In Abb. 6.42(a) und Abb. 6.43(a) werden alle gemessenen Reflektivitätskurven der zwei Probenserien aus Magainin2/DMPC zusammen mit den angepassten Kurven gegen $q_{z}$ aufgetragen. Die Konzentrationen von Magainin 2 in den Proben aus multilamellaren Membranstapeln sind 0, 1/2000, 1/1000, 1/500, 1/200, 1/100 und 1/50, für Proben aus Oligo-Membranen betragen sie 0, 1/200, 1/100, 1/50 und 1/20. Jede Kurve hat 4 oder 5 Bragg-Peaks. Die Periodizität der Lipiddoppelschichten in der Probe wird in Abb. 6.42 (b) und 6.43 (b) dargestellt, für multilamellare Membranstapel zeigt sie eine abnehmende Tendenz mit steigendem P/L, während sie für OligoMembranen eine zunehmende Tendenz mit steigendem P/L hat.

\section{Fouriersynthese und Anpassung:}

Mit Hilfe der spekularen Reflektivität wurde die Fouriersynthese mit Lorentzfaktor $1 / q_{z}^{2}$ an der Probenserie aus multilamellaren Membranstapeln durchführt. Die Elektronendichteprofile der Proben wurden dadurch ermittelt und anschließend die Membrandicken der Proben anhand dieser Profile bestimmt. An den gemessenen Reflektivitätskurven der beiden Probenserien wurde eine Anpassung mit einer Modellfunktion durchgeführt. Bei den multilamellaren Membranstapeln erweist sich die Anpassung für kleines $q_{z}\left(<0.5 \AA^{-1}\right)$ als ziemlich schlecht, die Ursache dafür ist wahrscheinlich die große Rauigkeit des Glas-Substrats, weil bei der Präparation der Proben das GlasSubstrat durch eine Plasmaanlage ca. 30 Sekunden geätzt wurde, um eine hydrophile Oberfläche des Substrates herzustellen. In Abb. 6.44 und Abb. 6.45 werden die durch Anpassung ermittelten Elektronendichteprofile der beiden Probenserien dargestellt. Mit diesen Elektronendichteprofilen wurden wiederum die Membrandicken in den Proben bestimmt. Alle durch die beiden Verfahren ermittelten Membrandicken der beiden Probenserien werden zum Vergleich in Abb. 6.46 gegen $\mathrm{P} / \mathrm{L}$ aufgetragen. Sie zeigen eine abnehmende Tendenz mit steigendem $P / L$. Die charakteristischen Größen $E_{m w} / E_{m m}$ für beide Probenserien werden in Abb. 6.47 dargestellt. In Tabelle 6.12 und Tabelle 6.13 werden alle ermittelten charakteristischen Größen für beide Probenserien aufgelistet. Betrachtet wird nun die Änderung von $E_{m w} / E_{m m}$ in Abhängigkeit von $P / L$ zusammen mit der Membrandicke $d_{p p}$ :

Der Verlauf der charakteristischen Größen $E_{m w} / E_{m m}$ der Probenserie aus multilamellaren Membranstapeln für beide Verfahren ist sehr ähnlich. Bei $P / L=1 / 2000$ und $P / L=1 / 1000$ nimmt $E_{m w} / E_{m m}$ zunächst ab, was zum 1. Fall in G1. (6.3) gehört, wo das Elektronendichteprofil der Kopfgruppe und der Wasserschicht zunimmt. Danach nimmt $E_{m w} / E_{m m}$ bei $P / L=1 / 500 \mathrm{sehr}$ stark zu, was dem 2. Fall in Gl. (6.5) zuzuordnen ist, wo nur das Elektronendichteprofil der Kopf- 


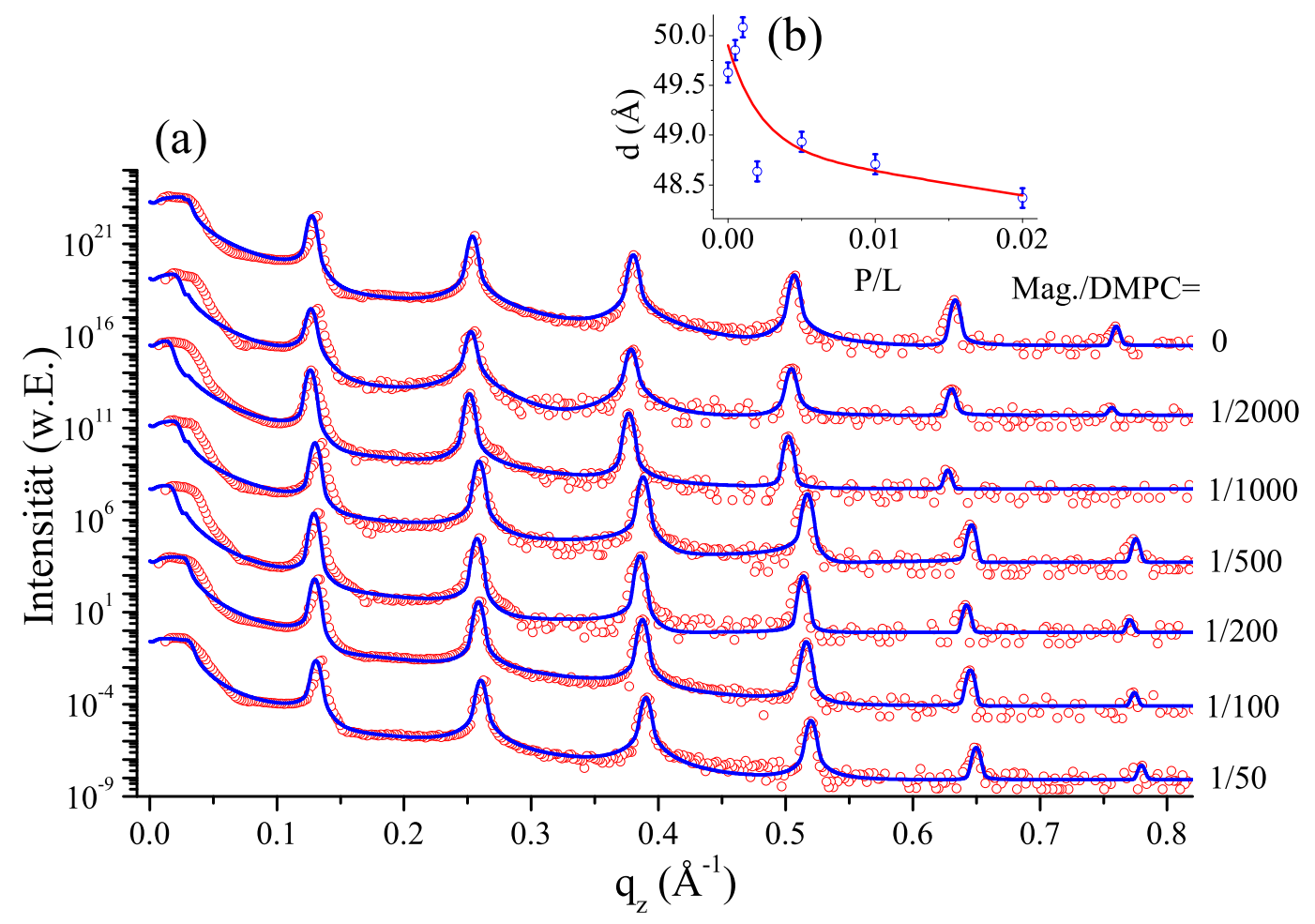

Abbildung 6.42: (a) Gemessene Reflektivitätskurven der multilamellaren Membranstapeln aus Magainin2/DMPC mit den angepassten Kurven (durchgezogen); (b) Periodizität der Lipiddoppelschichten in der Probe mit exponentieller Anpassung (durchgezogene Kurve).

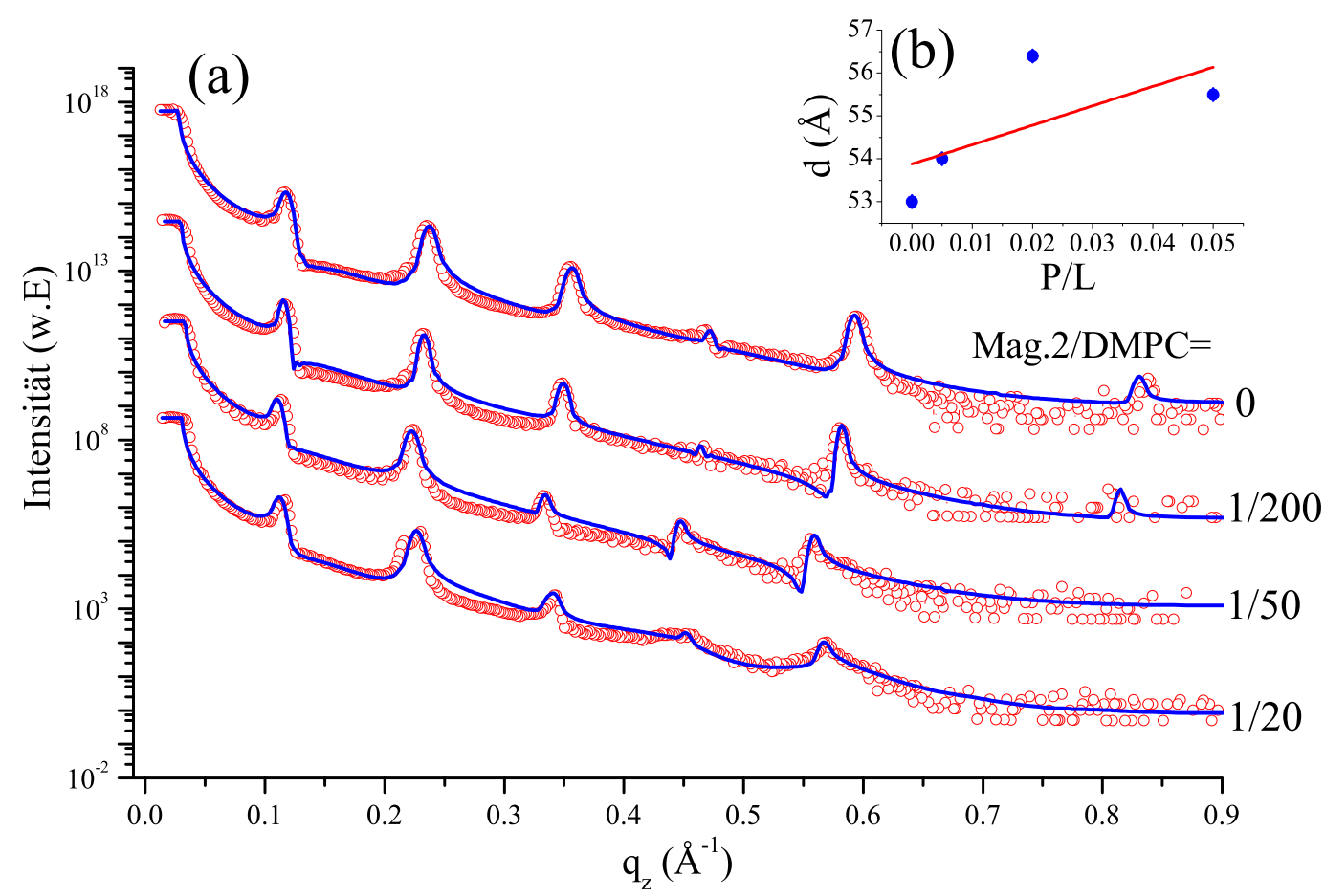

Abbildung 6.43: (a) Gemessene Reflektivitätskurven der Oligo-Membranen aus Magainin2/DMPC mit angepassten Kurven (durchgezogen); (b) Periodizität der Lipiddoppelschichten in der Probe mit exponentieller Anpassung (durchgezogene Kurve). 


\begin{tabular}{cc|cc|cc}
\hline & & durch & Anpasssung & $(\mathrm{FS})$ spekulare & Reflektivität \\
\hline $\mathrm{P} / \mathrm{L}$ & $d[\AA]$ & $d_{p p}[\AA]$ & $E_{m w} / E_{m m}$ & $d_{p p}[\AA]$ & $E_{m w} / E_{m m}$ \\
\hline \hline 0 & 49.629 & 34.358 & 0.4208 & 33.718 & 0.3965 \\
$1 / 2000$ & 49.855 & 35.27 & 0.3803 & 33.81 & 0.379 \\
$1 / 1000$ & 50.085 & 34.89 & 0.3038 & 34.67 & 0.2879 \\
$1 / 500$ & 48.636 & 33.652 & 0.545 & 33.232 & 0.5856 \\
$1 / 200$ & 48.934 & 34.708 & 0.3147 & 33.948 & 0.3112 \\
$1 / 100$ & 48.709 & 33.878 & 0.3667 & 32.938 & 0.3814 \\
$1 / 50$ & 48.368 & 33.136 & 0.4581 & 32.436 & 0.4549 \\
\hline
\end{tabular}

Tabelle 6.12: Die durch Fouriersynthese und Anpassung ermittelten charakteristischen Größen der Proben aus Magainin2/DMPC.

\begin{tabular}{cc|cc}
\hline & & durch & Anpasssung \\
\hline $\mathrm{P} / \mathrm{L}$ & $d[\AA]$ & $d_{p p}[\AA]$ & $E_{m w} / E_{m m}$ \\
\hline \hline 0 & 53 & 33.18 & 0.4678 \\
$1 / 200$ & 54 & 33.6 & 0.4549 \\
$1 / 50$ & 56.4 & 31.52 & 0.352 \\
$1 / 20$ & 55.5 & 33.58 & 0.5317 \\
\hline
\end{tabular}

Tabelle 6.13: Die durch Anpassung ermittelten charakteristischen Größen der Proben aus OligoMembranen von Magainin2/DMPC.

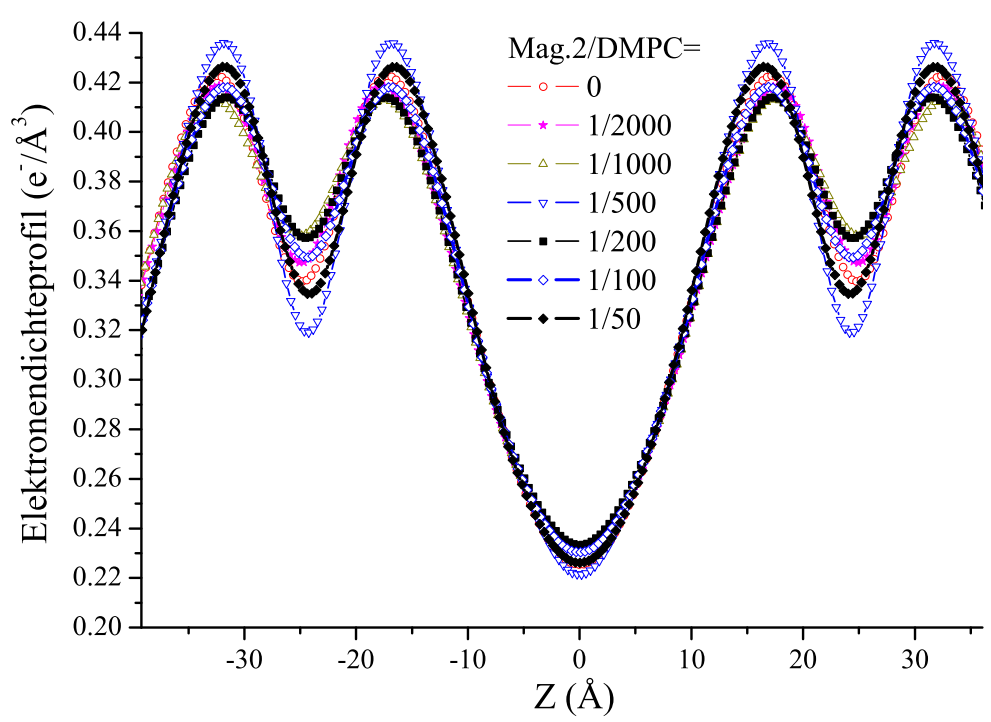

Abbildung 6.44: Die durch Anpassung ermittelten Elektronendichteprofile der Proben aus multilamellaren Membranstapeln von Magainin2/DMPC.

gruppe zunimmt. $E_{m w} / E_{m m}$ nimmt bei $P / L=1 / 200$ wieder ab, danach nimmt $E_{m w} / E_{m m}$ bis zu $P / L=1 / 50$ (wieder mit steigendem $P / L$ ) zu, was wieder zum 2. Fall in Gl. (6.5) gehört, wo nur das Elektronendichteprofil der Kopfgruppe zunimmt. Für die Probenserie aus Oligo-Membranen 


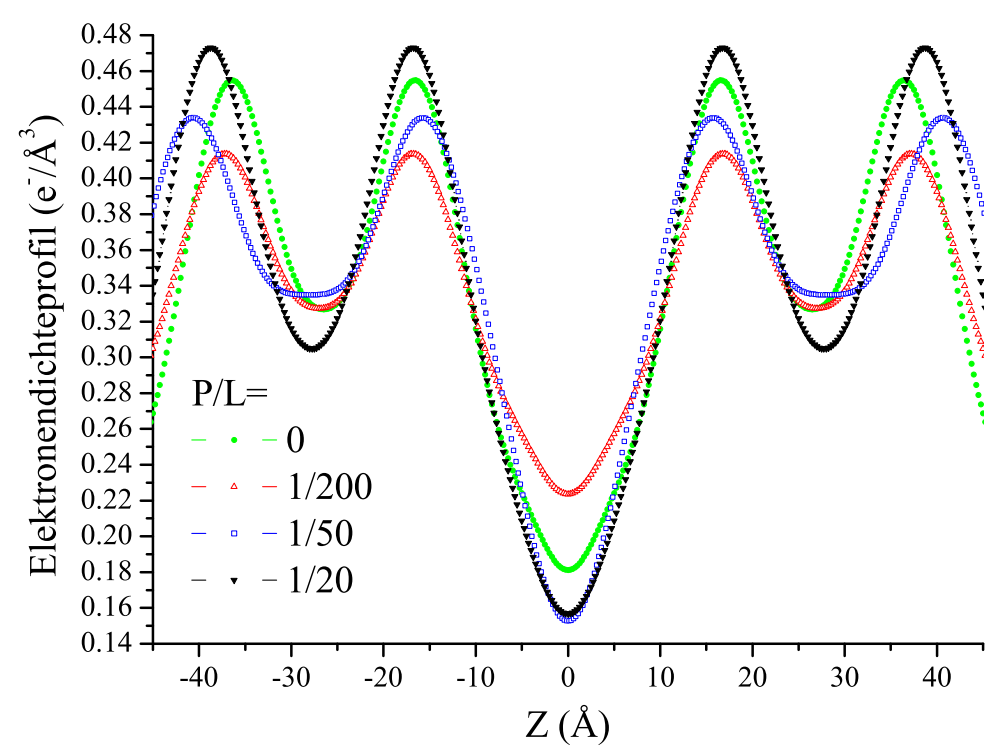

Abbildung 6.45: Die durch Anpassung ermittelten Elektronendichteprofile der Proben aus OligoMembranen von Magainin2/DMPC.

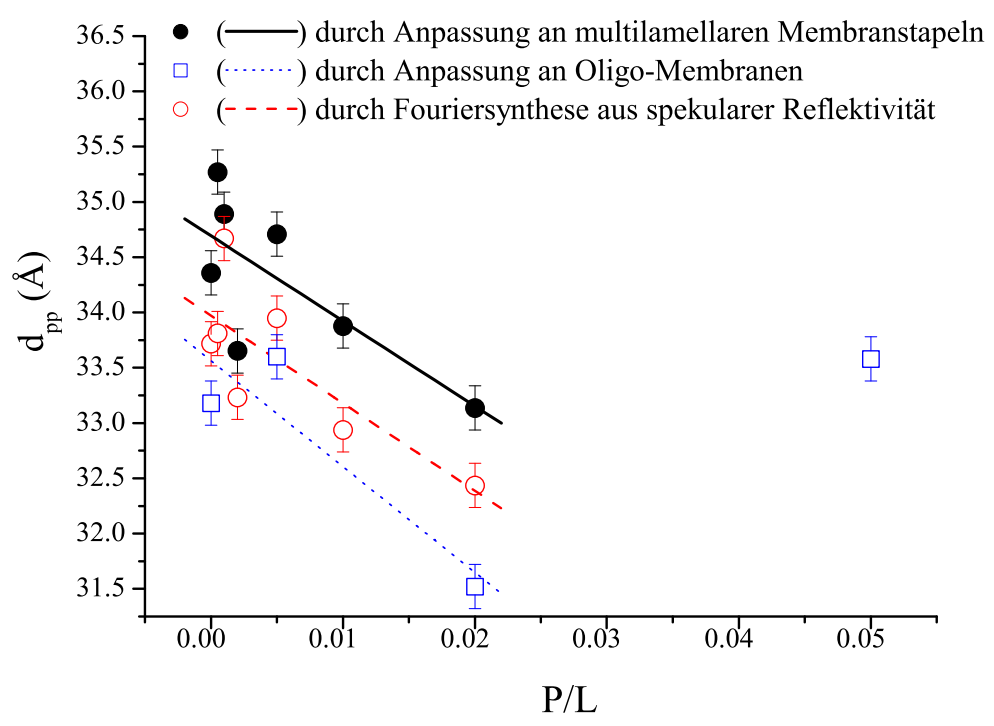

Abbildung 6.46: Vergleich der Membrandicken, die durch Anpassung und Fouriersynthese ermittelt wurden, mit linearer Anpassung (durchgezogene bzw. gestrichelte Kurve).

nimmt $E_{m w} / E_{m m}$ mit steigendem $P / L$ bis $P / L=1 / 50 \mathrm{ab}$, was zum 1 . Fall in Gl. (6.3) gehört, wo das Elektronendichteprofil der Kopfgruppe und der Wasserschicht zunimmt. Bei $P / L=1 / 20$ nimmt $E_{m w} / E_{m m}$ zu. Sowohl für multilamellare Membranstapeln als auch für Oligo-Membranen nimmt die Membrandicke allmählich mit steigendem $P / L$ ab, insbesondere nimmt sie für multilamellaren Membranstapeln im Bereich von $P / L=1 / 200$ bis $P / L=1 / 50$ eindeutig ab und hat bei $P / L=1 / 50$ einen Wert von $33.136 \AA$, welcher kleiner als die Helixlänge von Magainin $2(34.5 \AA)$ ist. Im Gegensatz zu der abnehmenden Tendenz bei multilamellaren Membranstapeln nimmt die Membrandicke der Probe aus Oligo-Membranen bei $P / L=1 / 20$ kräftig zu, was darauf hindeutet, dass es vermutlich eine kritische Peptidkonzentration (zwischen 1/50 und 1/20) für Konformati- 
onsänderung des Peptids in der Membran gibt.

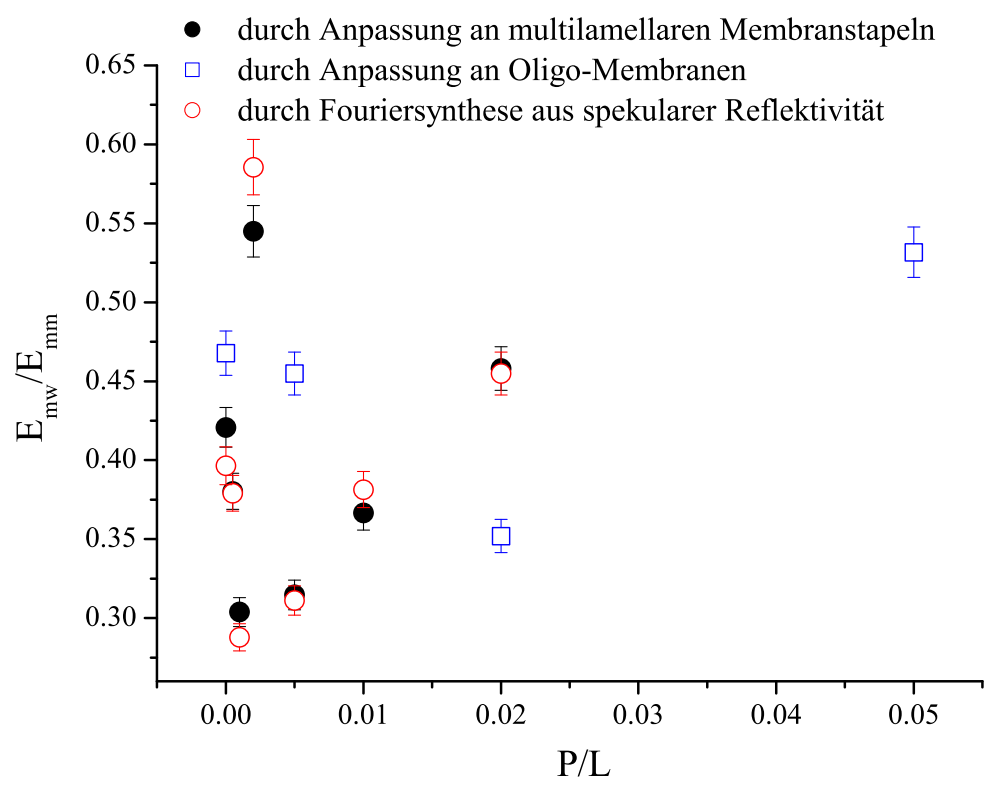

Abbildung 6.47: Vergleich der charakteristischen Größen $E_{m w} / E_{m m}$, die durch Anpassung und Fouriersynthese ermittelt wurden.

\subsubsection{Magainin2/DMPC+DMPG}

Abb. 6.48(a) und Abb. 6.49(a) zeigen alle gemessenen Reflektivitätskurven der Probenserien aus multilamellaren Membranstapeln und Oligo-Membranen von Magainin2/DMPC+DMPG (Lipidmischung in Molverhältnis von 3:1) zusammen mit den angepassten Kurven. Die Konzentrationen von Magainin 2 in beiden Probenserien sind 0, 1/200, 1/50 und 1/20. Jede Kurve hat unterschiedliche Bragg-Peaks in Form und Anzahl. In Abb. 6.48 (b) und Abb. 6.49 (b) wird die Periodizität der Lipiddoppelschichten in den Proben gezeigt, sie nimmt für die Probenserie aus multilamellaren Membranstapeln mit steigendem $P / L$ deutlich zu und zeigt eine zunehmende Tendenz für die Probenserie aus Oligo-Membranen mit steigendem $P / L$.

\section{Fouriersynthese und Anpassung:}

Durch Fouriersynthese aus spekularer Reflektivität mit Lorentzfaktor $1 / q_{z}^{2}$ wurden die Elektronendichteprofile der Proben aus multilamellaren Membranstapeln ermittelt. Anhand dieser Profile konnten die Membrandicken in den Proben bestimmt werden. Durch Anpassung an die gemessenen Reflektivitätskurven aus multilamellaren Membranstapeln mit einer Modellfunktion wurden auch hier die Elektronendichteprofile, die in Abb. 6.50 gezeigt werden, ermittelt. Für die Proben aus Oligo-Membranen ist aus den Unregelmäßigkeiten der gemessenen Kurven zu erkennen, dass die thermische Fluktuation der Lipidmembranen aufgrund der Wechselwirkung zwischen positiv geladenem Magainin 2 (+4 geladen) und negativ geladenem Lipid (DMPG: -1 geladen) verstärkt wurde. Durch Einfügen von Magainin 2 wurde die Abstoßung zwischen den negativ geladenen 


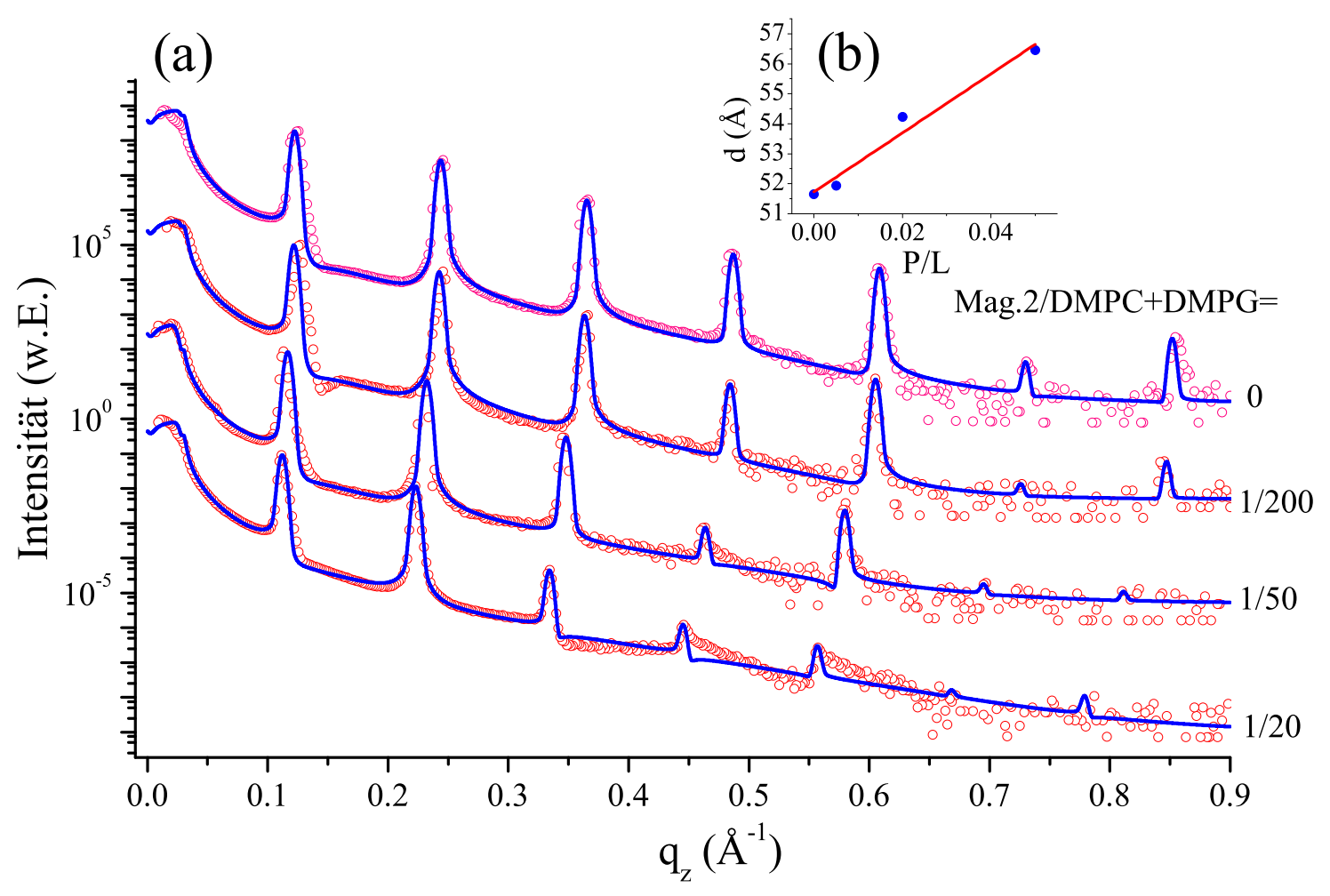

Abbildung 6.48: (a) Gemessene Reflektivitätskurven der Probenserie aus multilamellaren Membranstapeln von Magainin2/DMPC+DMPG(3:1) mit den angepassten Kurven (durchgezogen); (b) Periodizität der Lipiddoppelschichten in der Probe mit linearer Anpassung (durchgezogene Kurve).

(a)

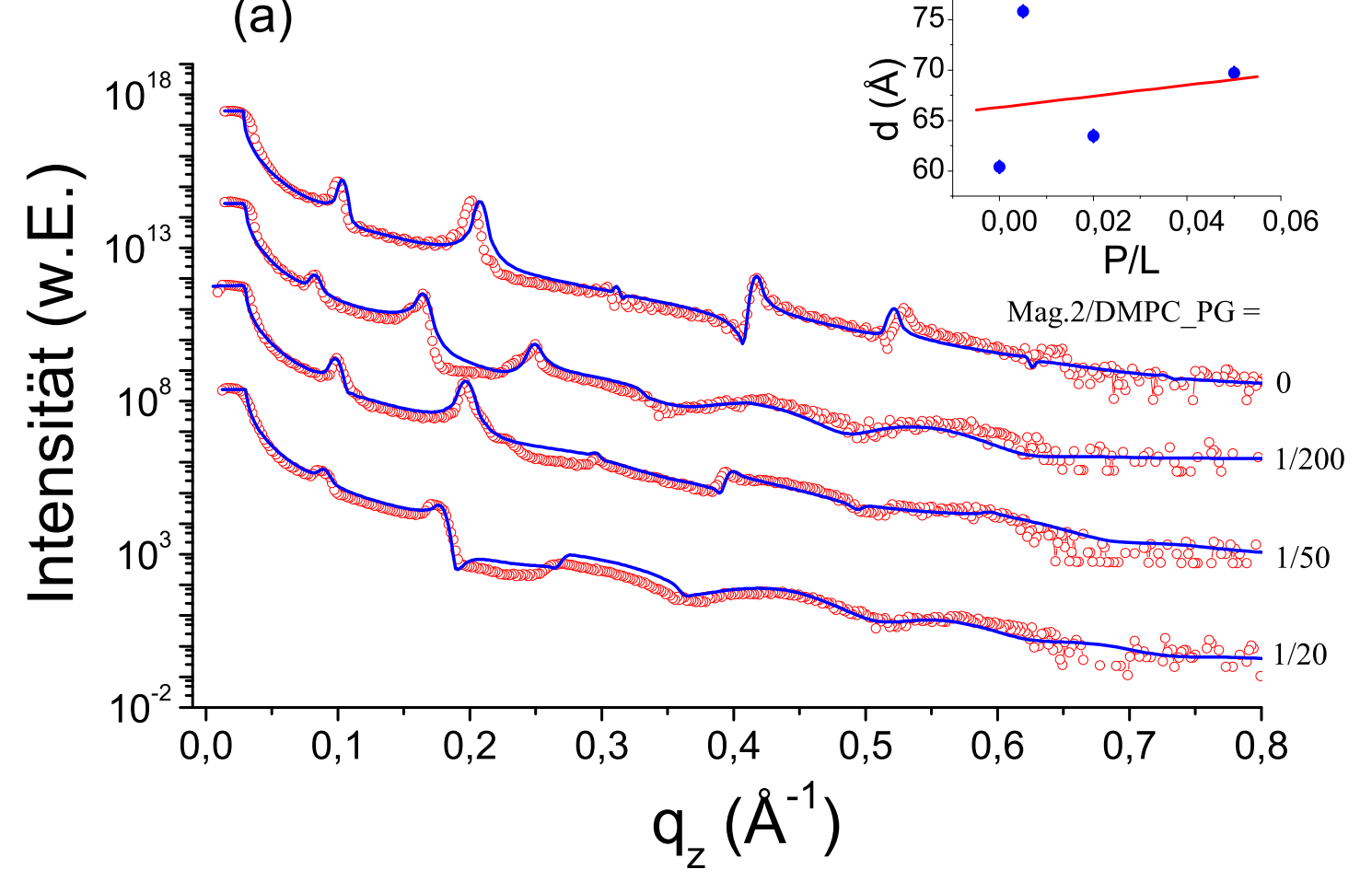

Abbildung 6.49: (a) Gemessene Reflektivitätskurven der Probenserie aus Oligo-Membranen von Magainin2/DMPC+DMPG mit den angepassten Kurven (durchgezogen); (b) Periodizität der Lipiddoppelschichten in der Probe mit exponentieller Anpassung (durchgezogene Kurve) zur besseren Darstellung des Trends. 
Lipidkopfgruppen kompensiert, dadurch wurde die Gleichgewichtslage in den Membranen mehr oder weniger gestört, so dass die thermische Fluktuation (bzw. die Unordnung) der Membranen mit steigendem $P / L$ zunimmt. Dieser Effekt kann offenbar leichter bei Oligo-Membranen als bei multilamellaren Membranstapeln auftreten. Daher wurde an den Reflektivitätskurven der Proben aus Oligo-Membranen eine Anpassung mit einer Modellfunktion, bei der die Fluktuation berücksichtigt wird, durchgeführt. Die Elektronendichteprofile wurden dadurch ermittelt und in Abb.6.51 dargestellt. Aufgrund der geringeren Anzahl der Bragg-Peaks und niedrigen Peakhöhe konnten die Elektronendichteprofile nicht vollständig und sinnvoll rekonstruiert werden. Trotzdem wurden mit

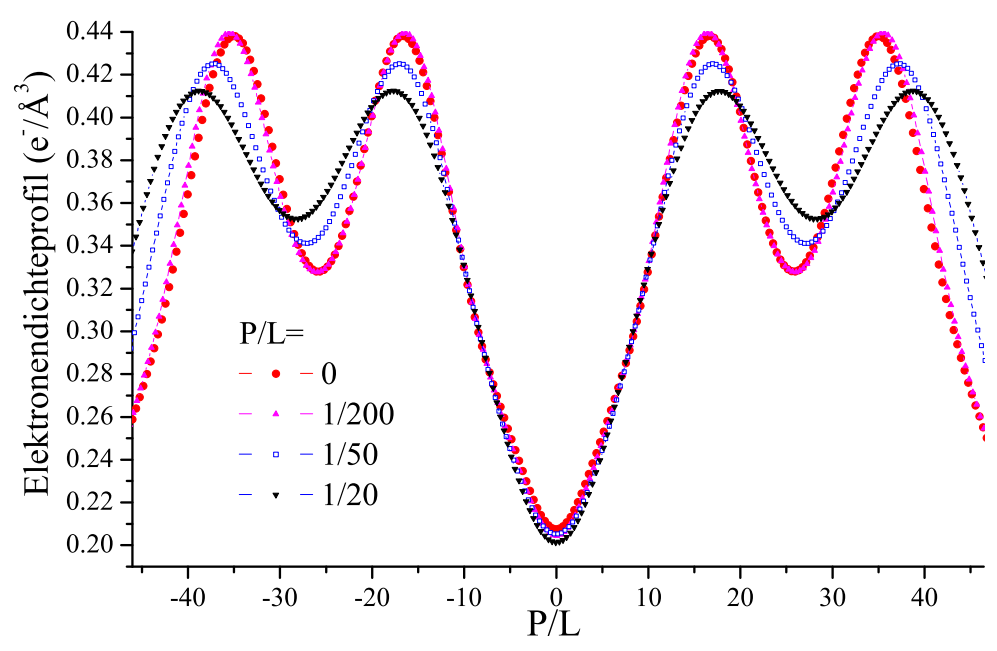

Abbildung 6.50: Die durch Anpassung ermittelten Elektronendichteprofile der Proben aus multilamellaren Membranstapeln von Magainin2/DMPC+DMPG(3:1).

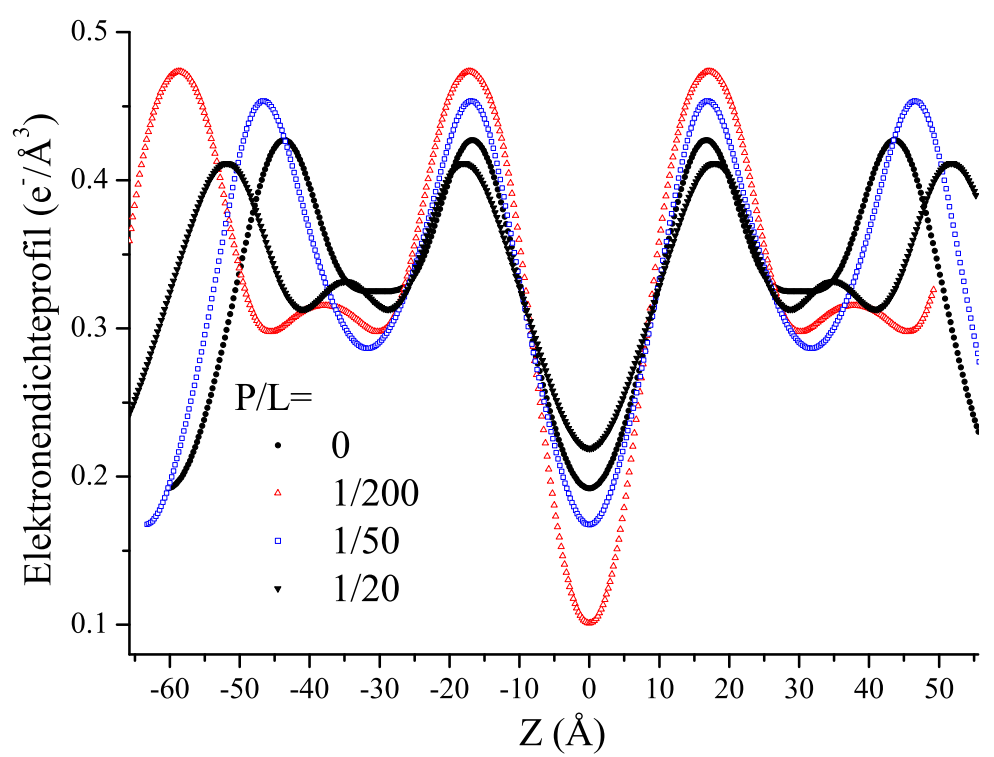

Abbildung 6.51: Die durch Anpassung ermittelten Elektronendichteprofile der Proben aus OligoMembranen von Magainin2/DMPC+DMPG(3:1). Da nur wenige Bragg-Peaks auftreten und die Peakhöhe sehr klein ist, konnten die Elektronendichteprofile nicht vollständig und sinnvoll dargestellt werden, daher sehen die Elektronendichteprofile hier etwas anders aus. 
ihrer Hilfe die Membrandicken in den Proben aus Oligo-Membranen bestimmt. Alle ermittelten Membrandicken der beiden Probenserien werden zum Vergleich in Abb. 6.52 gegen P/L aufgetragen. Sie nehmen mit steigendem P/L zu.

In Abb. 6.53 wird die charakteristische Größe $E_{m w} / E_{m m}$ der multilamellaren Membranstapeln und der Oligo-Membranen aus beiden Verfahren dargestellt. Alle ermittelten charakteristischen Größen aus beiden Probenserien werden in Tabelle 6.14 und Tabelle6.15 aufgelistet. Für Proben aus multilamellaren Membranstapeln nimmt $E_{m w} / E_{m m}$ aus der Anpassung bei $P / L=1 / 200 \mathrm{ab}$, was zum 1. Fall in Gl. (6.3) gehört, wo das Elektronendichteprofil der Kopfgruppe und der Wasserschicht zunimmt. Die Membrandicke aus beiden Verfahren nimmt bei gleicher Peptidkonzentration mit steigendem $P / L$ zunächst im Bereich von $P / L=1 / 200 \mathrm{ab}$. Danach nimmt sie für beide Verfahren wieder zu, sie hat bei $P / L=1 / 20$ einen Wert von mehr als $35 \AA$, welcher größer als die hydrophobe Helixlänge von Magainin 2 ist. Für die Proben aus Oligo-Membranen nimmt $E_{m w} / E_{m m}$ zuerst mit steigendem $P / L$ zu, erst bei $P / L=1 / 20$ nimmt sie ab. Die Membrandicke nimmt zuerst bei $P / L=1 / 200 \mathrm{zu}$, danach nimmt sie bei $P / L=1 / 50 \mathrm{ab}$, aber sie ist immer noch größer als bei $P / L=0$. Bei $P / L=1 / 20$ nimmt die Membrandicke stark zu.

Der sogenannte Caillé-Parameter $\eta$ (siehe Kapitel 5), der die Stärke der thermischen Fluktuation

\begin{tabular}{cc|cc|cc}
\hline & & durch & Anpasssung & $(\mathrm{FS})$ spekulare & Reflektivität \\
\hline $\mathrm{P} / \mathrm{L}$ & $d[\AA]$ & $d_{p p}[\AA]$ & $E_{m w} / E_{m m}$ & $d_{p p}[\AA]$ & $E_{m w} / E_{m m}$ \\
\hline \hline 0 & 51.656 & 33.292 & 0.4778 & 33.532 & 0.4633 \\
$1 / 200$ & 51.939 & 32.878 & 0.4757 & 33.118 & 0.4477 \\
$1 / 50$ & 54.234 & 34.028 & 0.2824 & 33.528 & 0.4806 \\
$1 / 20$ & 56.458 & 35.436 & 0.2836 & 35.716 & 0.2726 \\
\hline
\end{tabular}

Tabelle 6.14: Die durch Fouriersynthese und Anpassung ermittelten charakteristischen Größen der Proben aus multilamellaren Membranstapeln von Magainin2/DMPC+DMPG(3:1).

\begin{tabular}{cc|ccc}
\hline & & durch & Anpasssung & \\
\hline $\mathrm{P} / \mathrm{L}$ & $d[\AA]$ & $d_{p p}[\AA]$ & $E_{m w} / E_{m m}$ & $\eta$ \\
\hline \hline 0 & 60.37 & 33.44 & 0.4346 & 0 \\
$1 / 200$ & 75.78 & 34.28 & 0.4722 & 0.085 \\
$1 / 50$ & 63.48 & 33.78 & 0.584 & 0.045 \\
$1 / 20$ & 69.7 & 35.8 & 0.5125 & 0.105 \\
\hline
\end{tabular}

Tabelle 6.15: Die durch Anpassung ermittelten charakteristischen Größen der Proben aus OligoMembranen von Magainin2/DMPC+DMPG(3:1).

der Membran wiederspiegelt und vom Kompressions- und Biegemodul der Lipidmembranen abhängig ist [169], wurde durch die Anpassung an die Messkurven der Proben aus Oligo-Membranen ermittelt. In Abb. 6.54 wird der Caillé-Parameter $\eta$ gegen $P / L$ aufgetragen. $\eta$ nimmt mit steigen$\operatorname{dem} P / L$ zu. Dieser Effekt kann dadurch erklärt werden, dass durch Einfügen von Magainin 2 die 


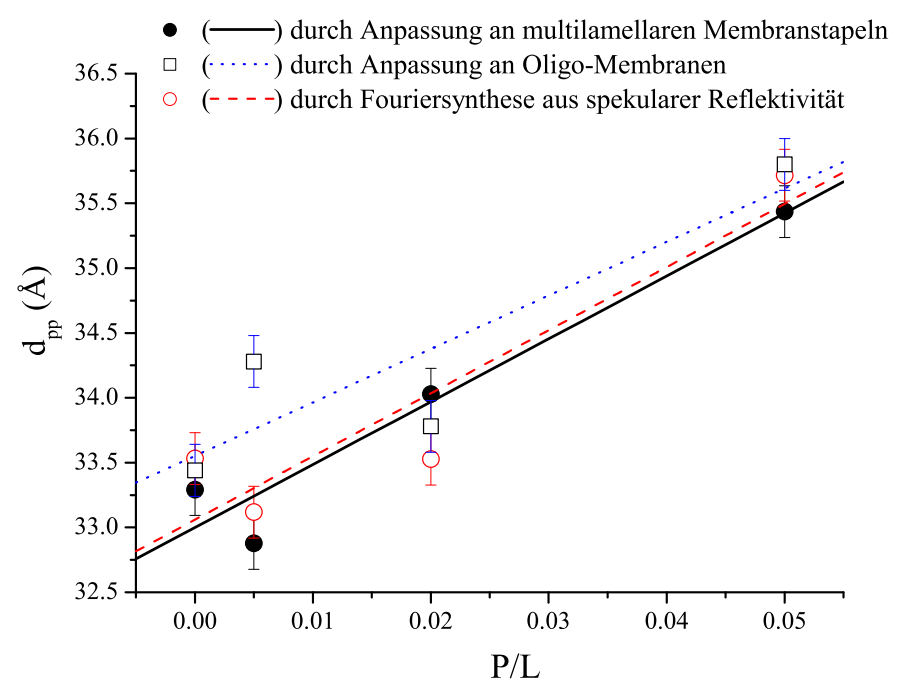

Abbildung 6.52: Vergleich der Membrandicken, die durch Anpassung und Fouriersynthese ermittelt wurden, mit linearer Anpassung (durchgezogene bzw. gestrichelte Kurve).

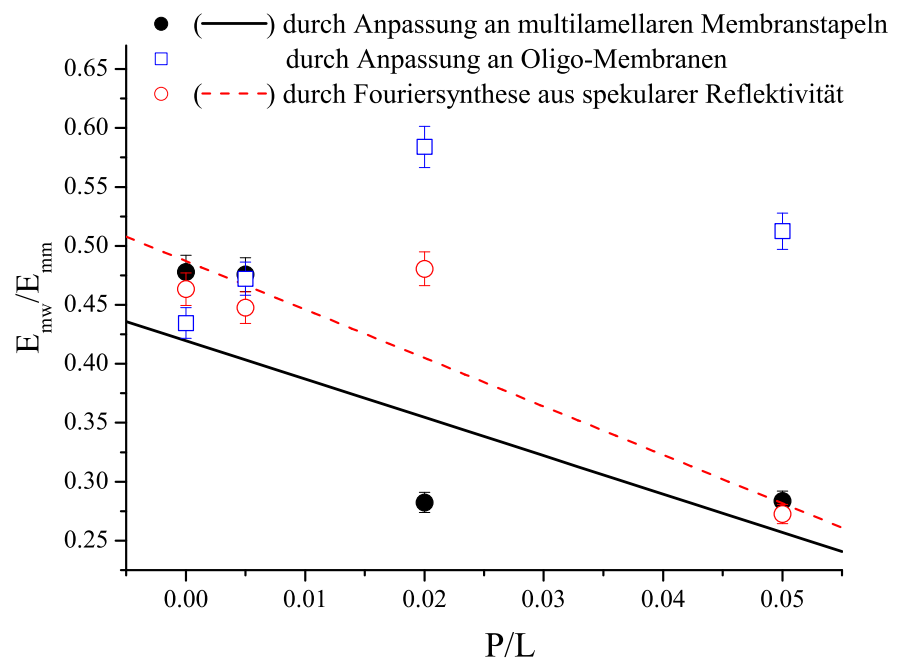

Abbildung 6.53: Vergleich der charakteristischen Größen $E_{m w} / E_{m m}$, die durch Anpassung und Fouriersynthese ermittelt wurden, mit linearer Anpassung (durchgezogene bzw. gestrichelte Kurve).

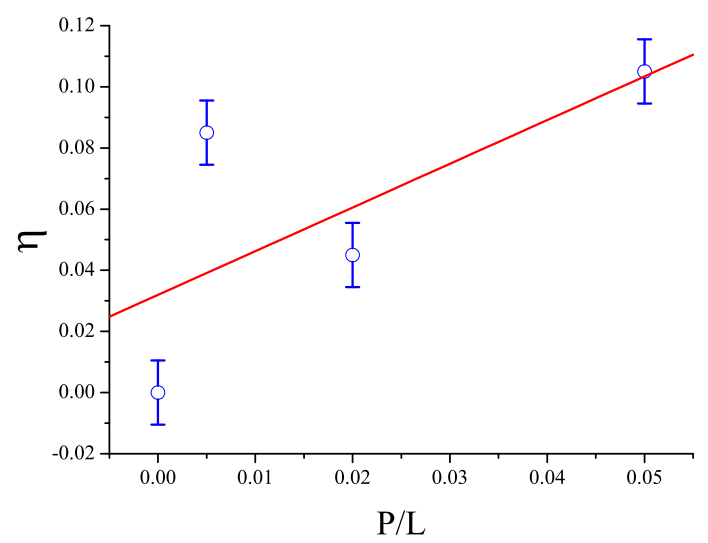

Abbildung 6.54: Caillé-Parameter $\eta$ der Probenserie aus Oligo-Membranen von Magainin 2/DMPC+DMPG(3:1) mit linearer Anpassung (durchgezogene Kurve). 
Abstoßung zwischen den negativ geladenen Lipidkopfgruppen kompensiert wurde, dadurch wurde die Gleichgewichtslage in den Membranen mehr oder weniger gestört, so dass die thermische Fluktuation der Membranen mit steigendem $P / L$ zunimmt. Diese stärker werdende Fluktuation erzeugt Unordnung in den Lipiddoppelschichten. Außerdem ist der Caillé-Parameter $\eta$ proportional zu 1/d (siehe Kapitel 5), das bedeutet ein schwächeres Bragg-Peak mit steigender Periodizität der Lipiddoppelschichten, was in Abb. 6.49 gut zu erkennen ist. Der Caillé-Parameter $\eta$ im vorliegenden Fall liegt im Bereich von 0 bis 0.2; er wurde auch bei voll hydratisierten Lipidmembranen aus DMPC und DPPC in $L_{\alpha}$-Phase in demselben Bereich ermittelt [169][176].

\subsubsection{Magainin2/OPPC}

In Abb. 6.55(a) werden alle gemessenen Reflektivitätskurven der Probenserie aus multilamellaren Membranstapeln von Magainin2/OPPC zusammen mit den angepassten Kurven gezeigt. Die Konzentrationen von Magainin 2 in dieser Probenserie sind 0, 1/1000, 1/200 und 1/50. Jede Kurve hat mindestens 4 Bragg-Peaks. In Abb. 6.55(b) wird die Periodizität der Lipiddoppelschichten in der Probe gezeigt, sie nimmt mit steigendem $P / L$ deutlich ab.

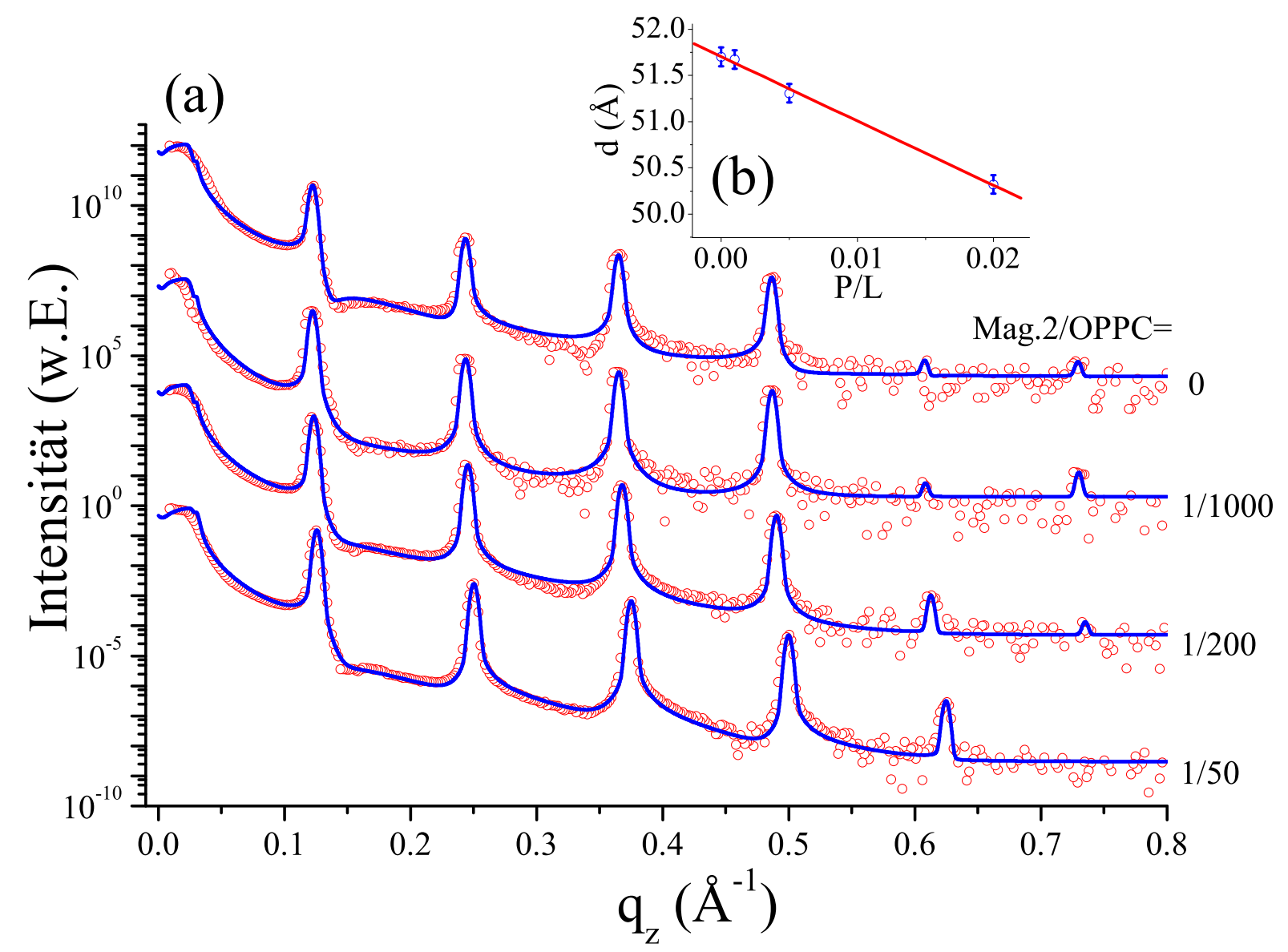

Abbildung 6.55: (a) Gemessene Reflektivitätskurven der Probenserie aus multilamellaren Membranstapeln von Magainin2/OPPC mit den angepassten Kurven (durchgezogen); (b) Periodizität der Lipiddoppelschichten in der Probe mit linearer Anpassung (durchgezogene Kurve). 


\section{Fouriersynthese und Anpassung:}

Durch Fouriersynthese unter Verwendung der spekularen Reflektivitäten mit Lorentzfaktor $1 / q_{z}^{2}$ wurden die Elektronendichteprofile der Proben ermittelt. Anhand dieser wurden die Membrandicken in den Proben bestimmt. An die gemessenen Reflektivitätskurven wurde eine Anpassung mit einer Modellfunktion durchgeführt und dadurch die Elektronendichteprofile, die in Abb. 6.56 gezeigt werden, erneut rekonstruiert. Die Membrandicken in den Proben wurden wiederum mit diesen Elektronendichteprofilen aus der Anpassung bestimmt. Alle ermittelten Membrandicken aus beiden Verfahren werden zum Vergleich in Abb. 6.57 gegen P/L aufgetragen. Sie zeigen eine systematische Abnahme mit steigendem P/L. Abb. 6.58 zeigt die charakteristische Größen $E_{m w} / E_{m m}$ aus beiden Verfahren. Alle ermittelten charakteristischen Größen aus beiden Verfahren

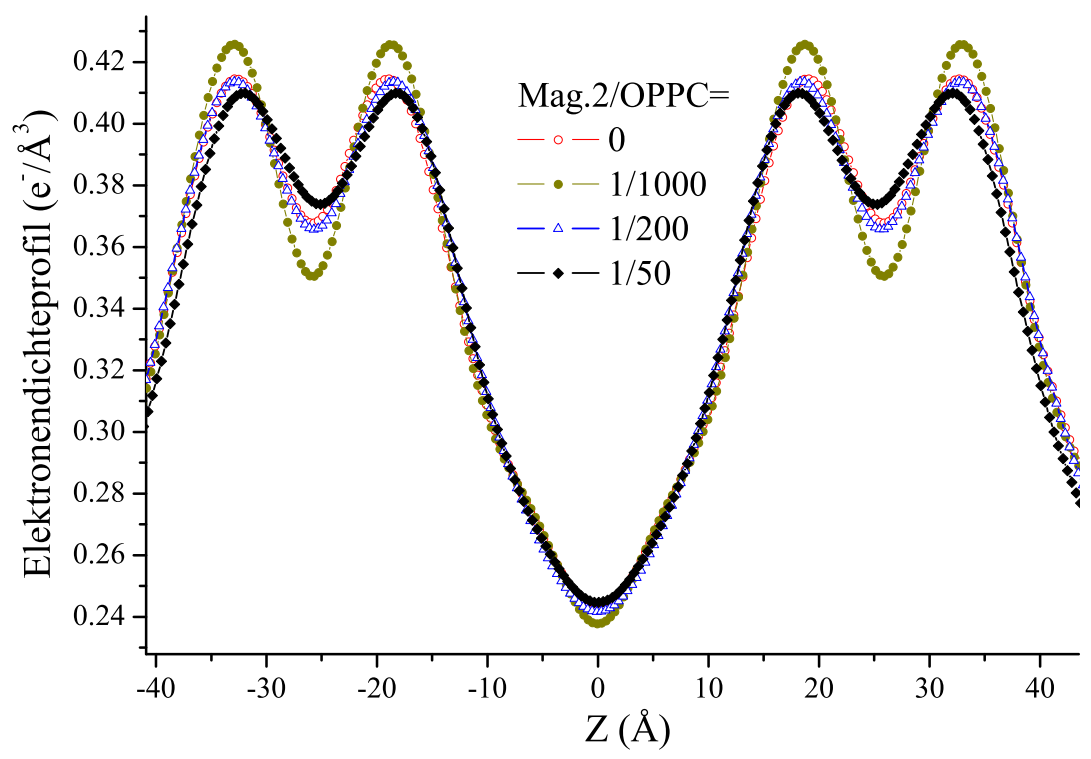

Abbildung 6.56: Durch Anpassung ermittelte Elektronendichteprofile der Proben aus multilamellaren Membranstapeln von Magainin2/OPPC.

\begin{tabular}{cc|cc|cc}
\hline & & durch & Anpasssung & $(\mathrm{FS})$ spekulare & Reflektivität \\
\hline $\mathrm{P} / \mathrm{L}$ & $d[\AA]$ & $d_{p p}[\AA]$ & $E_{m w} / E_{m m}$ & $d_{p p}[\AA]$ & $E_{m w} / E_{m m}$ \\
\hline \hline 0 & 51.701 & 37.962 & 0.2715 & 37.382 & 0.3233 \\
$1 / 1000$ & 51.674 & 37.448 & 0.4005 & 37.168 & 0.4091 \\
$1 / 200$ & 51.307 & 36.974 & 0.2789 & 36.614 & 0.2982 \\
$1 / 50$ & 50.321 & 36.42 & 0.2184 & 36.422 & 0.2301 \\
\hline
\end{tabular}

Tabelle 6.16: Die durch Fouriersynthese und Anpassung ermittelten charakteristischen Größen der Proben aus multilamellaren Membranstapeln von Magainin2/OPPC.

werden in Tabelle 6.16 aufgeführt. Betrachtet wird nun $E_{m w} / E_{m m}$ zusammen mit der Membrandicke $d_{p p}$ :

Sowohl $E_{m w} / E_{m m}$ als auch $d_{p p}$ aus beiden Verfahren haben einen ähnlichen Verlauf; deshalb kön- 
nen die Änderungen von $E_{m w} / E_{m m}$ und von der Membrandicke $d_{p p}$ für beide Verfahren zusammen betrachtet werden. $E_{m w} / E_{m m}$ nimmt bei $P / L=1 / 1000$ für beide Verfahren zunächst zu, was dem 2. Fall in Gl. (6.5) zuzuordnen ist, wo das Elektronendichteprofil nur an der Kopfgruppe zunimmt. Danach nimmt $E_{m w} / E_{m m}$ bis zu $P / L=1 / 50$ ab, was zum 1. Fall in Gl. (6.3) gehört, wo das Elektronendichteprofil an der Kopfgruppe und an der Wasserschicht zunimmt. Die Membrandicke nimmt mit steigendem $P / L$ systematisch ab.

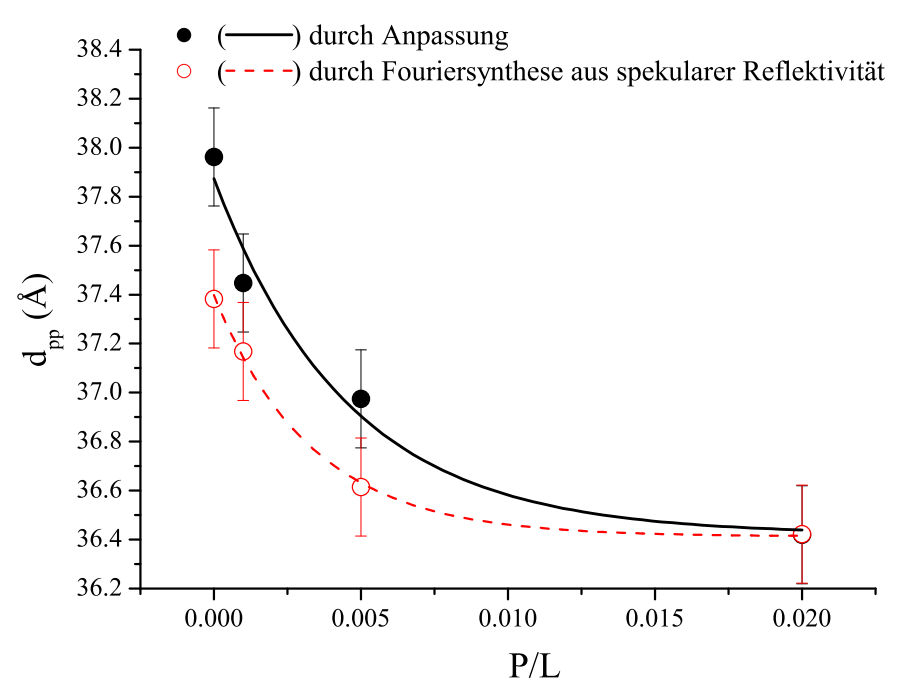

Abbildung 6.57: Vergleich der Membrandicken, die durch Anpassung und Fouriersynthese aus multilamellaren Membranstapeln von Magainin2/OPPC ermittelt wurden, mit exponentieller Anpassung (durchgezogene bzw. gestrichelte Kurve).

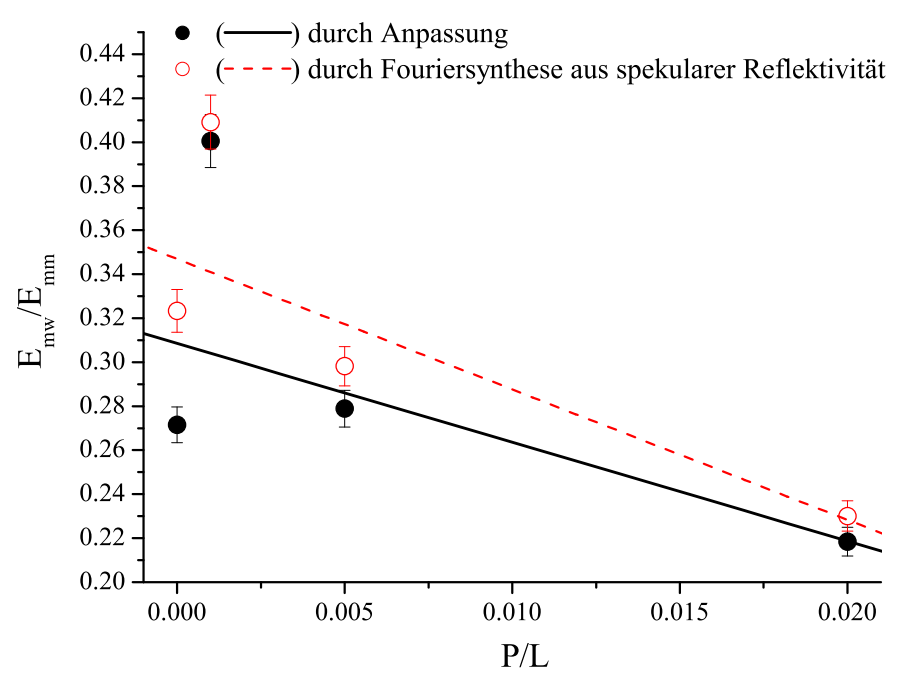

Abbildung 6.58: Vergleich der charakteristischen Größen $E_{m w} / E_{m m}$, die durch Anpassung und Fouriersynthese aus multilamellaren Membranstapeln von Magainin2/OPPC ermittelt wurden, mit linearer Anpassung (durchgezogene bzw. gestrichelte Kurve). 


\subsubsection{Magainin2/POPC}

Die gemessenen Reflektivitätskurven der Probenserie aus Oligo-Membranen von Magainin2/POPC werden mit den angepassten Kurven in Abb. 6.59 (a) dargestellt. Die Konzentrationen von Magainin 2 in dieser Probenserie sind 0,1/200, 1/50 und 1/20. Jede Kurve hat mindestens 5 Bragg-Peaks. Die Periodizität der Lipiddoppelschichten in der Probe wird in Abb. 6.59 (b) gegen $P / L$ aufgetragen, sie nimmt mit steigendem $P / L$ deutlich zu.

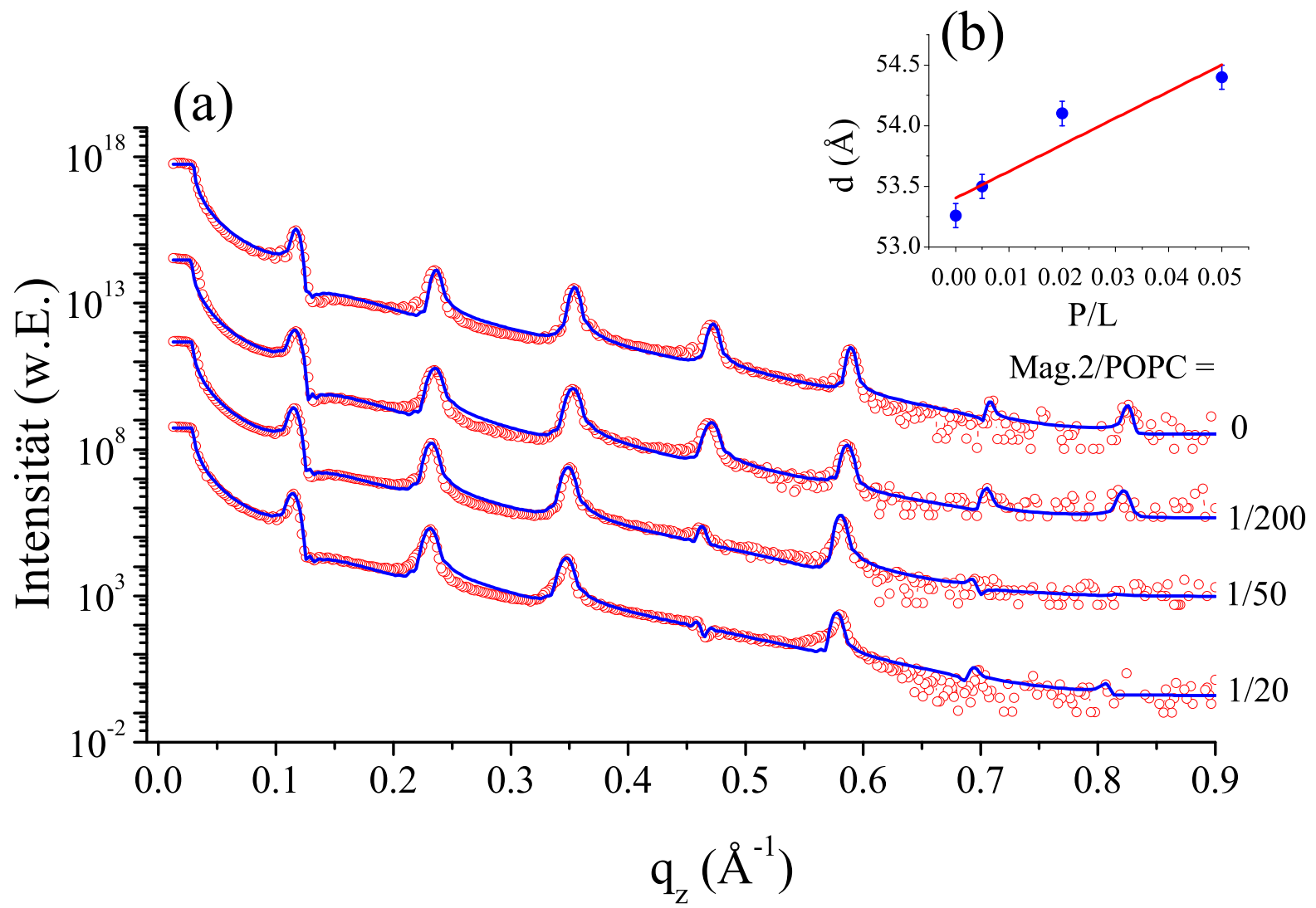

Abbildung 6.59: (a) Gemessene Reflektivitätskurven der Probenserie aus Oligo-Membranen von Magainin2/POPC mit angepassten Kurven (durchgezogen); (b) Die Periodizität der Lipiddoppelschichten in der Probe mit linearer Anpassung (durchgezogene Kurve).

\section{Anpassung:}

Die gemessenen Reflektivitätskurven aus Oligo-Membranen von Magainin2/POPC wurden mit einer Modellfunktion angepasst, dadurch wurden die Elektronendichteprofile der Proben ermittelt. Sie werden in Abb. 6.60 gezeigt. Anhand dieser Elektronendichteprofile wurde die Membrandicke in der Probe bestimmt. Sie wird in Abb.6.61 (a) dargestellt. Mit steigendem $P / L$ nimmt sie zuerst ab, bei $P / L=1 / 20$ nimmt sie zu, ist aber immer noch kleiner als bei $P / L=0$ und $P / L=1 / 200$. In Abb. 6.61(b) wird die charakteristische Größe $E_{m w} / E_{m m}$ dargestellt. Alle ermittelten charakteristischen Größen werden in Tabelle 6.17 aufgelistet. In Abb. 6.61 b) erkennt man, dass $E_{m w} / E_{m m}$ 


\begin{tabular}{cc|cc}
\hline & & durch & Anpasssung \\
\hline $\mathrm{P} / \mathrm{L}$ & $d[\AA]$ & $d_{p p}[\AA]$ & $E_{m w} / E_{m m}$ \\
\hline \hline 0 & 53.26 & 35.92 & 0.5 \\
$1 / 200$ & 53.5 & 35.572 & 0.53 \\
$1 / 50$ & 54.1 & 34.26 & 0.476 \\
$1 / 20$ & 54.4 & 34.76 & 0.4507 \\
\hline
\end{tabular}

Tabelle 6.17: Die durch Anpassung ermittelten charakteristischen Größen der Proben aus OligoMembranen von Magainin2/POPC.

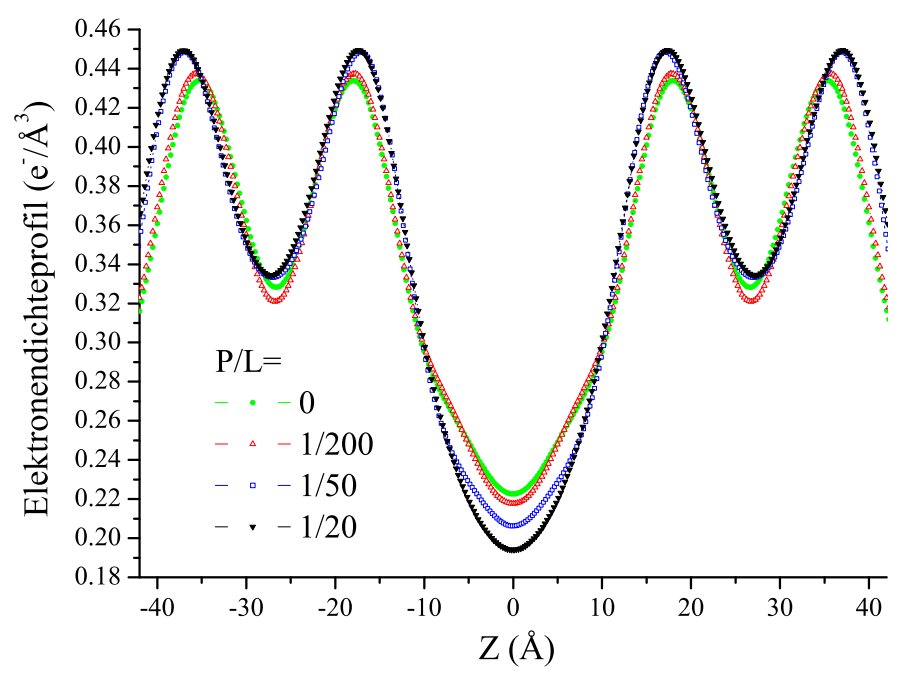

Abbildung 6.60: Die durch Anpassung ermittelten Elektronendichteprofile der Proben aus OligoMembranen von Magainin2/POPC.

zuerst bei $P / L=1 / 200$ zunimmt, was dem 2. Fall in G1. (6.5) zuzuordnen ist, wo das Elektronendichteprofil nur an der Kopfgruppe zunimmt. Danach nimmt $E_{m w} / E_{m m}$ mit steigendem $P / L$ immer ab, was entweder zum 1. Fall in Gl. (6.3) oder zum 1. Fall in Gl. (6.2) gehören kann.
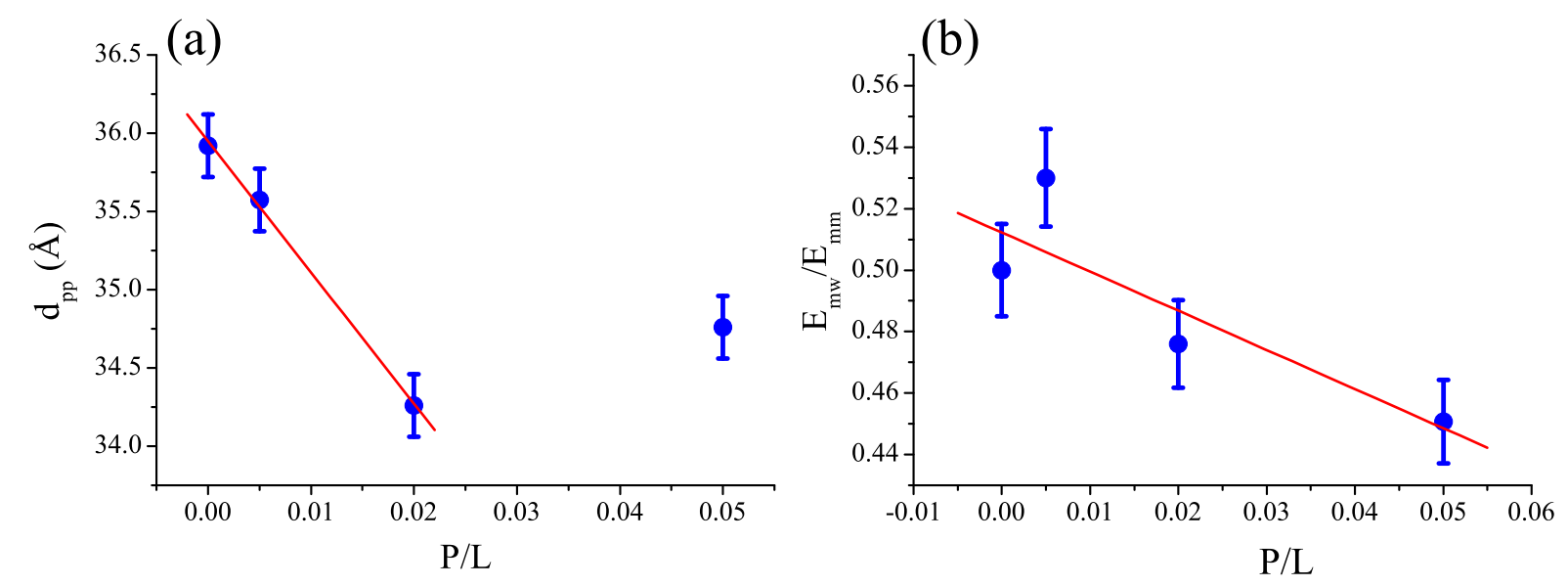

Abbildung 6.61: (a) Membrandicke der Proben aus Oligo-Membranen von Magainin2/POPC und (b) charakteristische Größe $E_{m w} / E_{m m}$; beide wurden durch Anpassung ermittelt. 


\subsubsection{Magainin2/POPC+POPS}

Abb. 6.62(a) zeigt alle gemessenen Reflektivitätskurven der Probenserie aus Oligo-Membranen von Magainin2/POPC+POPS (Lipidmischung in Molverhältnis von 3:1) zusammen mit den angepassten Kurven. Die Konzentration von Magainin 2 in dieser Probenserie ist jeweils 0, 1/200, 1/50 und 1/20. Jede Kurve hat unterschiedliche Bragg-Peaks in Form und Anzahl. Die Periodizität der Lipiddoppelschichten in der Probe wird in Abb. 6.62(b) gezeigt, sie nimmt mit steigender Peptidkonzentration P/L deutlich zu.

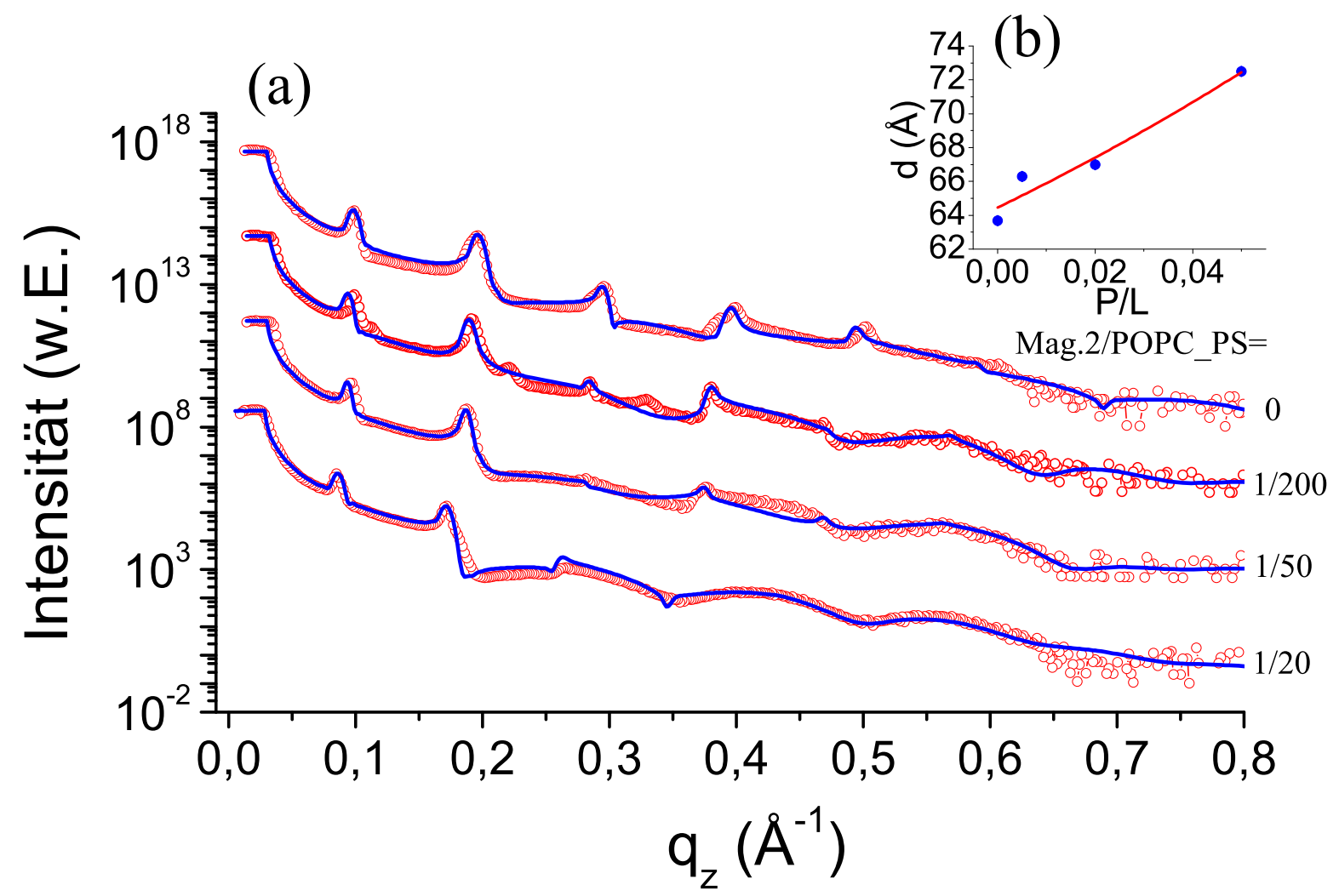

Abbildung 6.62: (a) Gemessene Reflektivitätskurven der Probenserie aus Oligo-Membranen von Magainin2/POPC + POPS (Lipidmischung in Molverhältnis von 3:1) mit den angepassten Kurven (durchgezogen); (b) die Periodizität der Lipiddoppelschichten in der Probe mit exponentieller Anpassung (durchgezogene Kurve).

\section{Anpassung:}

Aus den Unregelmäßigkeiten der gemessenen Reflektivitätskurven ist zu erkennen, dass die thermische Fluktuation der Lipidmembranen aufgrund der Wechselwirkung zwischen positiv geladenem Magainin 2 (+4 geladen) und negativ geladenem Lipid (POPS: -1 geladen) verstärkt wurde. Durch Einfügen von Magainin 2 wurde die Abstoßung zwischen den negativ geladenen Lipidkopfgruppen kompensiert, dadurch wurde die Gleichgewichtslage in den Membranen mehr oder weniger gestört, so dass die thermische Fluktuation (bzw. die Unordnung) der Membranen mit steigen- 
dem $P / L$ zunimmt. Daher wurde an den Reflektivitätskurven der Proben aus Oligo-Membranen

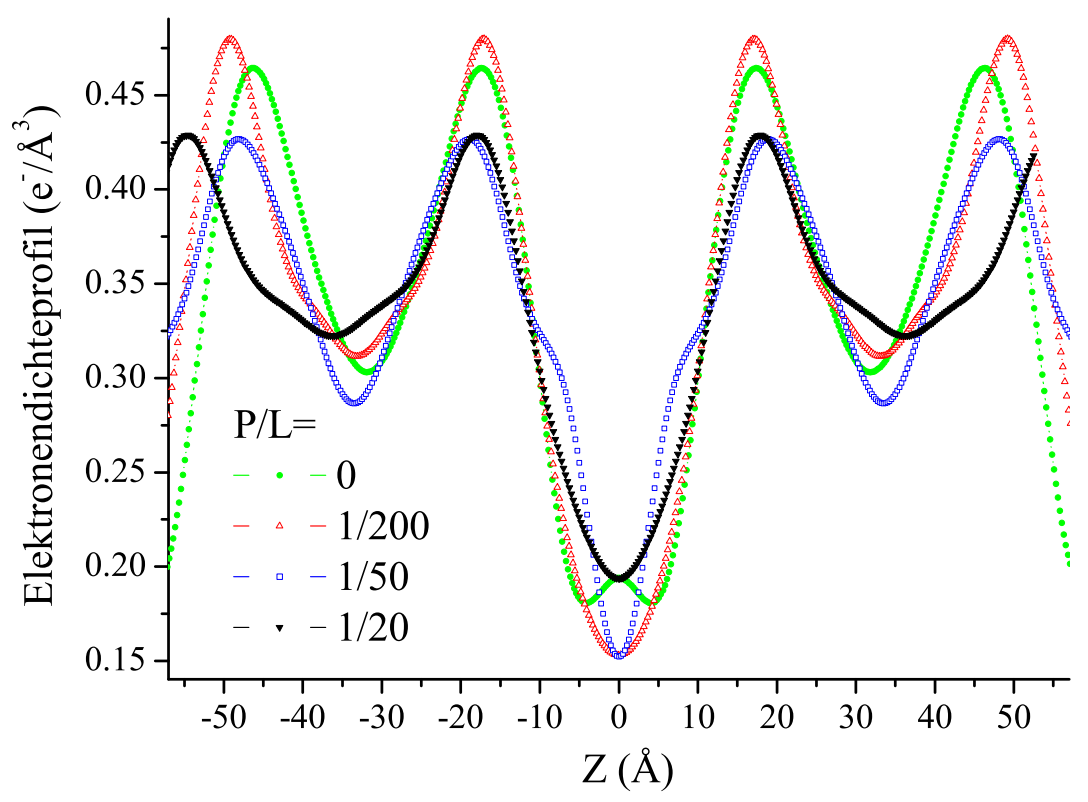

Abbildung 6.63: Die durch Anpassung ermittelten Elektronendichteprofile der Proben aus OligoMembranen von Magainin2/POPC+POPS (3:1).
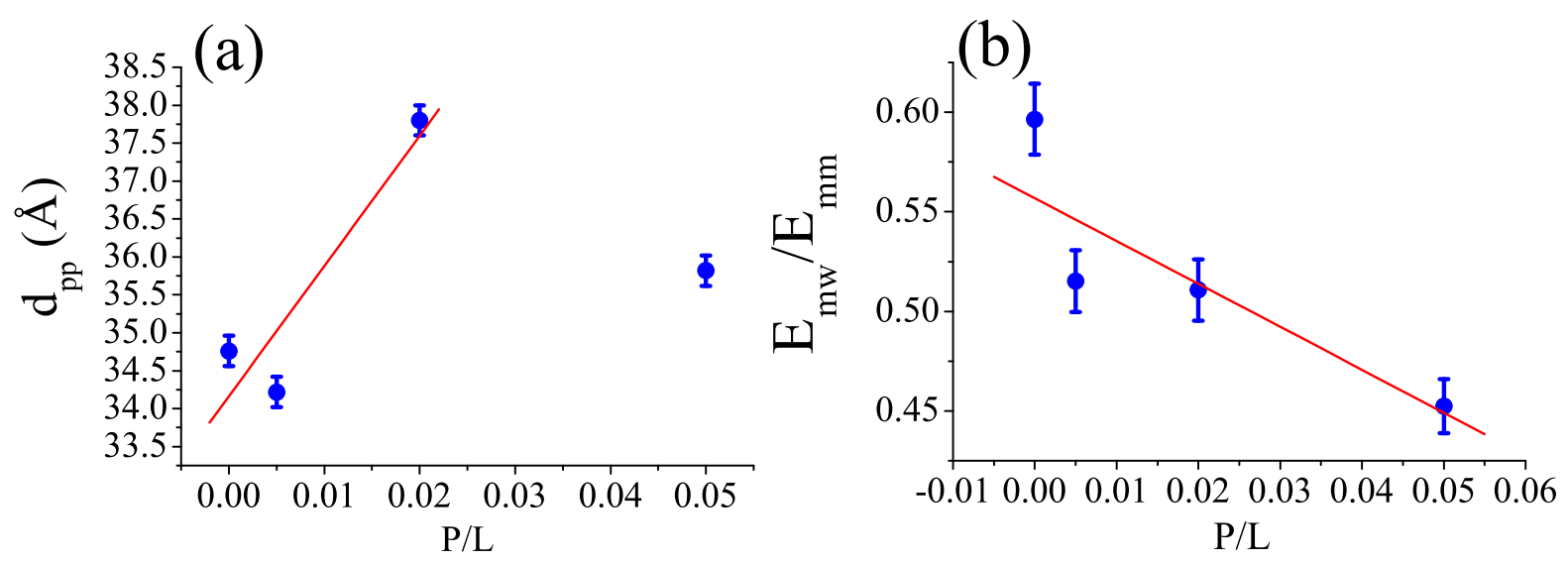

Abbildung 6.64: (a) Die Membrandicken der Proben aus Oligo-Membranen von Magainin2/POPC+POPS und (b) die charakteristischen Größen $E_{m w} / E_{m m}$; beide wurden durch Anpassung ermittelt.

von Magainin2/POPC+POPS eine Anpassung mit einer Modellfunktion, bei der die Fluktuation berücksichtigt wird, durchgeführt. Die Elektronendichteprofile wurden dadurch ermittelt und in Abb. 6.63 dargestellt. Aufgrund der geringeren Anzahl der Bragg-Peaks und niedrige Peakhöhe waren die Elektronendichteprofile nicht vollständig und sinnvoll zu rekonstruieren. Die Membrandicken in den Proben wurden trotzdem mit Hilfe dieser Elektronendichteprofile bestimmt. Die ermittelten Membrandicken werden in Abb. 6.64 dargestellt, sie zeigen keine systematische Änderung mit steigendem $P / L$. In Abb. 6.64(b) wird die charakteristische Größe $E_{m w} / E_{m m}$ gegen $P / L$ aufgetragen. Alle ermittelten charakteristischen Größen werden in Tabelle 6.18 aufgeführt. 


\begin{tabular}{cc|ccc}
\hline & & durch & Anpasssung & \\
\hline $\mathrm{P} / \mathrm{L}$ & $d[\AA]$ & $d_{p p}[\AA]$ & $E_{m w} / E_{m m}$ & $\eta$ \\
\hline \hline 0 & 63.67 & 34.76 & 0.5965 & 0.028 \\
$1 / 200$ & 66.3 & 34.22 & 0.5152 & 0.05 \\
$1 / 50$ & 67 & 37.8 & 0.5107 & 0.07 \\
$1 / 20$ & 72.5 & 35.82 & 0.4525 & 0.1 \\
\hline
\end{tabular}

Tabelle 6.18: Die durch Anpassung ermittelten charakteristischen Größen der dünnen Proben aus OligoMembranen von Magainin2/POPC+POPS.

Aus Abb. 6.64(b) ist leicht zu erkennen, dass $E_{m w} / E_{m m}$ mit steigendem $P / L$ abnimmt. Die Membrandicke nimmt zuerst bei $P / L=1 / 200 \mathrm{ab}$, danach nimmt sie bei $P / L=1 / 50$ stark zu. Bei $P / L=1 / 20$ nimmt sie wieder ab. Durch die Anpassung wurde hier auch der Caillé-Parameter $\eta$, der die Stärke der thermischen Fluktuation der Membran beschreibt und vom Kompressionsund Biegemodul der Lipidmembranen abhängt [169], ermittelt. In Abb. 6.65] wird dieser Parameter dargestellt. $\eta$ nimmt mit steigendem $P / L$ deutlich zu. Dieser Effekt kann dadurch erklärt werden, dass durch zusätzliches Magainin 2 in den Lipidmembranen die Abstoßung zwischen den negativ geladenen Lipidkopfgruppen (PS-Kopfgruppen) kompensiert wurde, dadurch wurde die Gleichgewichtslage in den Membranen mehr oder weniger gestört, so dass die thermische Fluktuation der Membranen mit steigendem $P / L$ zunimmt. Diese verstärkende Fluktuation erzeugt Unordnung in den Lipiddoppelschichten. Darüber hinaus ist der Caillé-Parameter $\eta$ proportional zu $1 / d^{2}$ (siehe Kapitel 5), daraus kann ein schwächeres Bragg-Peak mit steigender Periodizität der Lipiddoppelschichten gefolgt werden, was in Abb. 6.62 klar zu erkennen ist. Im Fall der Oligo-Membranen aus Magainin2/POPC+POPS (3:1) liegt $\eta$ im Bereich von 0 bis 0.2 , er ist auch bei voll hydratisierten Lipidmembranen aus DMPC und DPPC in $L_{\alpha}$-Phase im selben Bereich zu finden [169][176].

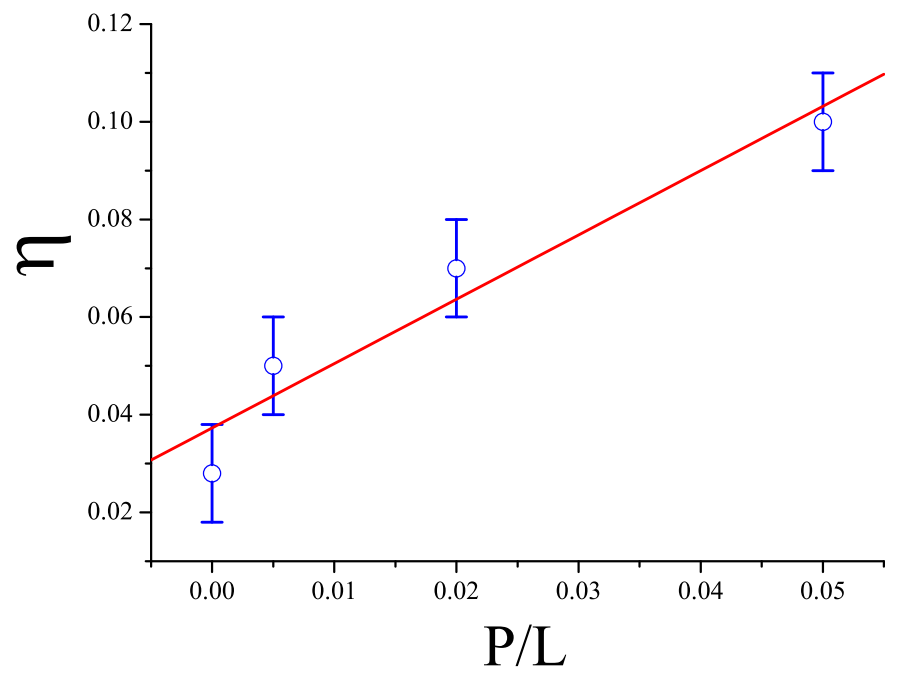

Abbildung 6.65: Caillé-Parameter $\eta$ der Probenserie aus Oligo-Membranen von Magainin2/POPC+POPS mit linearer Anpassung (durchgezogene Kurve). 


\subsubsection{Zusammenfassung}

Bei der Betrachtung der Änderung von $E_{m w} / E_{m m}$ und der Membrandicke $d_{p p}$ aus multilamellaren ungeladenen Membranstapeln mit Magainin 2 wurde der Effekt festgestellt, dass die Membrandicke mit steigender Peptidkonzentration dünner wird. Dieser Effekt kann dadurch erklärt werden, dass das Peptid auf der Membranoberfläche anlagert und sich dabei in die Membranoberfläche drückt. Aufgrund der Elastizität der Lipidmembran wird die Membran dünner [73], wie in Abb. 6.40(a) dargestellt ist. Dieser Effekt wurde in der Literatur bereits bei Magainin beobachtet [73], und zwar ebenfalls durch Röntgenstreuung. Es wurde indirekt auch aus OCD-Experimenten (Orientierter Circulardichroismus) an anderem Peptid/Lipid-System geschlossen [177][178][87]. Für

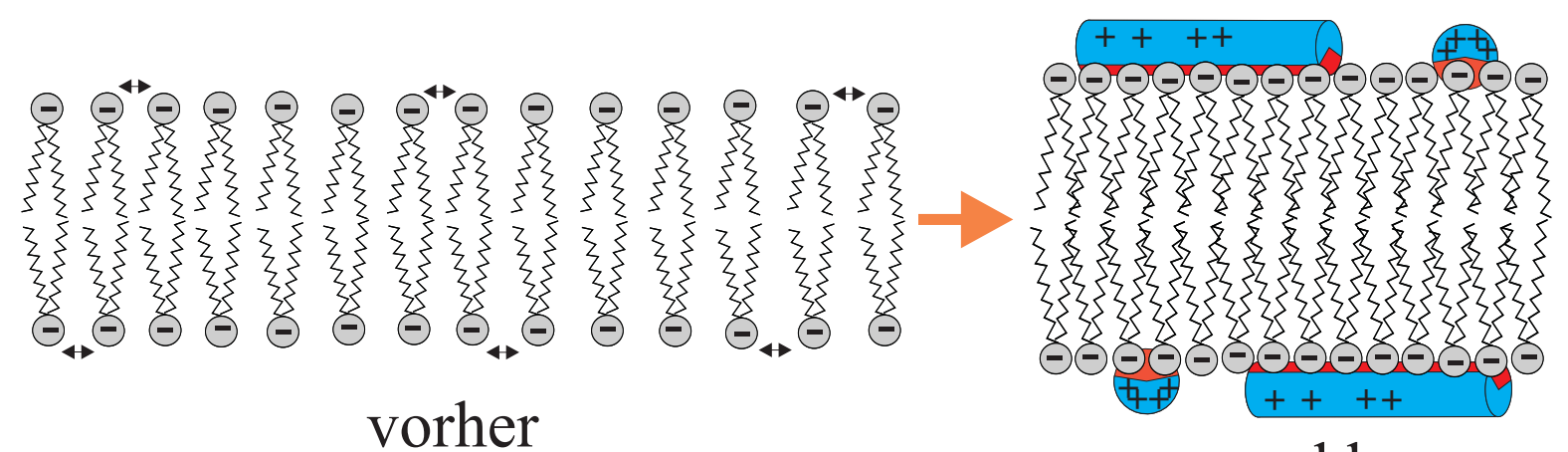

nachher

Abbildung 6.66: Schematische Darstellung der Vergrößerung der Membrandicke durch Wechselwirkung zwischen positiv geladenem Peptid und negativ geladenem Lipid. Durch Abstoßung zwischen den geladenen Lipidkopfgruppen wird der Abstand zwischen benachbarten Lipidmolekülen größer, dadurch wird die Flächenladungsdichte der Membranen erniedrigt. Zur Erhaltung der Massendichte ziehen sich die Lipidketten zusammen. Durch Einfügen von Magainin 2 werden die negativen Ladungen teilweise kompensiert, dadurch wird die Abstoßung der Kopfgruppen verringert und der Abstand zwischen benachbarten Lipidmolekülen wird geringer. Um die Massendichte in der Kettenregion zu halten, dehnen sich die Ketten aus. Im Endeffekt wird die Membran dicker.

Proben mit Membranverdünnungseffekt könnte Magainin 2 bis zu einer kritischen Konzentration auf der Membranoberfläche anlagern [67][48], wie in Abb. 6.40(a) dargestellt ist. Diese kritische Konzentration ist stark abhängig von der Lipid- und Peptidsorte sowie von der Probenumgebung [174][85][173]. Bei voll hydratisierten DMPC/DMPG-Membranen (in Molverhältnis von 3:1) zum Beispiel liegt die kritische Konzentration für Magainin bei etwa 1:30. Dies berichteten Lutdke et al. aus OCD-Experimenten [67]. Oberhalb dieser kritischen Konzentration kann sich Magainin senkrecht zur Membranoberfläche in die Membran einlagern, wie in Abb. 6.40(b) und in Abb. 6.40(c) dargestellt. In unseren Experimenten könnte dies bei der Probe aus multilamellaren Membranstapeln von Magainin2/DMPC mit $P / L=1 / 50$ der Fall sein, weil die Membrandicke aus der Anpassung bei $P / L=1 / 5033.136 \AA$ beträgt und somit kleiner als die Helixlänge von Magainin 2 ist, die etwa $34 \AA$ beträgt [175]. Das entspricht dem in Abb. 6.40(c) dargestellten Modell. Bei den Proben aus nicht geladenen Oligo-Membranen kann man allgemein annehmen, dass sich Magainin 2 bis zu $P / L=1 / 50$ auf der Membranoberfläche anlagert, weil die Elektronendichte der Kopfgruppe und der Wasserschicht zunimmt, während sie im Kettenbereich keine Änderung 
zeigt. Die Membrandicke ist bei $P / L=1 / 50$ noch kleiner als die Helixlänge von Magainin 2 (etwa $34 \AA$ ). Für die Probenserie aus Oligo-Membranen von Magainin2/DMPC ist sie bei $P / L=1 / 20$ etwas größer als bei $P / L=0$, für die Probenserie aus Magainin2/POPC ist sie bei $P / L=1 / 20$ jedoch kleiner als bei $P / L=0$. Daher kann wohl davon ausgegangen werden, dass Magainin 2 sich mit der Konzentration $P / L=1 / 20$ senkrecht zur Membranoberfläche in die Membran einlagert, so dass es die Lipiddoppelschicht durchspannt. Dadurch wird die Membran dicker oder dünner, abhängig von der Membrandicke bei $P / L=0$. Der Wechsel der Orientierung von parallel zu senkrecht zur Membranoberfläche ist in der Literatur durch OCD (Orientierter Circulardichroismus) belegt [67]. Die positive hydrophobe Fehlanpassung (siehe Abb. 6.40(b)) entspricht der Probe aus Oligo-Membranen von Magainin2/DMPC und die negative hydrophobe Fehlanpassung (siehe Abb.6.40(c)) der Probe aus Oligo-Membranen von Magainin2/POPC.

Für Magainin 2 in der geladenen Lipidmembran sieht es jedoch grundlegend anders aus: Die
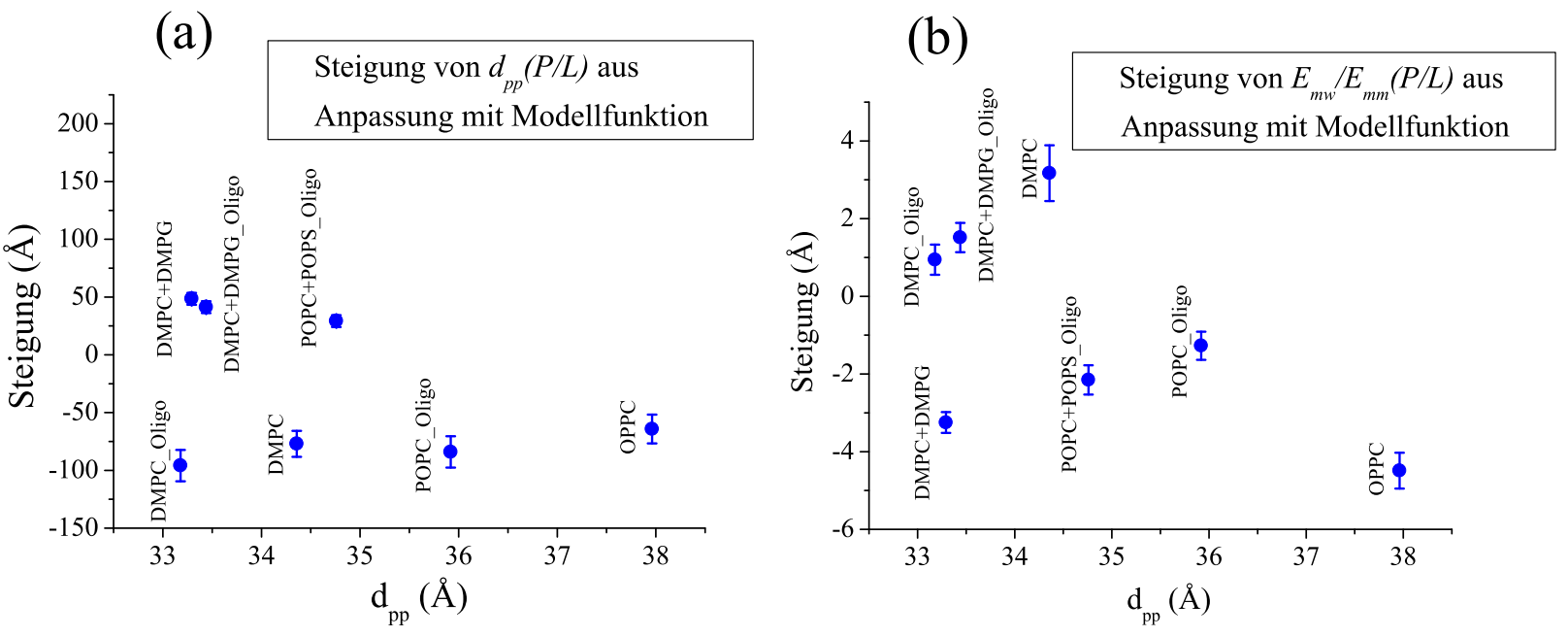

Abbildung 6.67: (a) Steigung der Membrandicke $d_{p p}(P / L)$ aus der Anpassung mit Modellfunktion; (b) Steigung der charakteristischen Größe $E_{m w} / E_{m m}(P / L)$ aus der Anpassung mit Modellfunktion.

Membrandicke nimmt mit steigender Peptidkonzentration immer zu, dies ist bei Proben sowohl aus multilamellaren Membranstapeln als auch aus Oligo-Membranen von Magainin2/DMPC+DMPG und Magainin2/POPC+POPS der Fall. Da DMPG und POPS - 1 geladen sind, wird der Abstand zwischen benachbarten Lipidmolekülen durch Abstoßung zwischen den geladenen Lipidkopfgruppen größer, damit wird die Flächenladungsdichte der Membranen erniedrigt. Um die Massendichte zu erhalten, ziehen sich die Lipidketten zusammen. Nach dem Einfügen von Magainin 2 werden die negativen Ladungen der Kopfgruppen durch positiv (+4) geladene Magainin 2-Moleküle teilweise kompensiert; dadurch wird die Abstoßung der Kopfgruppen verringert und der Abstand zwischen benachbarten Lipidmolekülen folglich geringer. Gleichzeitig dehnen sich die Lipidketten in vertikaler Richtung etwas aus, um die Massendichte in der Kettenregion zu halten; somit wird die Membran dicker, wie in Abb. 6.66 schematisch illustriert wird.

In Abb. 6.67 wird ebenfalls, wie bei Alamethicin/Lipid-Systemen die Steigung von $d_{p p}(P / L)$ und $E_{m w} / E_{m m}(P / L)$ aus der Anpassung mit einer Modellfunktion gegen die Membrandicke bei $P / L=0$ aufgetragen. Für ungeladene Lipide ist die Steigung von $d_{p p}(P / L)$ eindeutig negativ, was 
einen Membranverdünnungseffekt bedeutet. Für geladene Lipide ist sie hingegen positiv, was auf einen Vergrößerungseffekt der Membran hinweist. Die Steigung von $E_{m w} / E m m(P / L)$ zeigt jedoch keine ähnliche Eigenschaft. 


\section{Zusammenfassung}

Der Gegenstand der vorliegenden Arbeit ist die Strukturuntersuchung von Peptid/Lipid-Systemen. Dazu wurden lamellare Membranstapel auf Silizium- und Glassubstraten in verschiedenen Konfigurationen von Lipiden und Peptiden präpariert. Zwei Präparationsverfahren wurden hierzu verwendet, nämlich das Spreiten aus organischen Lösungen sowie die Verwendung der Lackschleuder (Spin-Coating-Verfahren). Mit dem Spin-Coating-Verfahren konnten Proben mit einer kontrollierten Anzahl von Lipiddoppelschichten hergestellt werden. Die untersuchten Peptide waren die Peptidantibiotika Alamethicin und Magainin 2. Für die Methodik und Auswertung unterschied man dicke Membranstapeln mit einer Anzahl $N$ im Bereich mehrerer hundert bis zu tausend Doppelschichten und so genannte Oligo-Stapeln mit $2 \leq N \leq 20$, bei denen sich z.B. ganz andere thermische Fluktuationen oder statische Defekte ergaben. Auch in Bezug auf die instrumentelle Auflösung ergaben sich bei der Datenanalyse in beiden Fällen erhebliche Unterschiede.

Die Reflektivitätsexperimente wurden am Ablenkmagnetmessplatz D4 HASYLAB Hamburg durchgeführt. Bei den Messungen der meisten Proben wurde eine temperierbare Feuchtigkeitskammer verwendet. Damit konnte eine relative Feuchtigkeit (RH) bis zu $99.8 \%$ erzeugt und die Temperatur zwischen $40-60^{\circ} \mathrm{C}$ variiert werden; in diesem Bereich befinden sich die Lipidmembranen in physiologisch relevanter $L_{\alpha}$ Phase. Die Wellenlänge der Strahlen war mit $0.62 \AA$ meist so gewählt, dass Absorption und Strahlenschäden minimiert wurden. Bei der entsprechenden Energie lassen sich Membrane auch in wässriger Lösung gut untersuchen. Zur Analyse der Messdaten wurde eine Modellierung der Reflektivität an Lipidmembranen auf Basis der semi-kinematischen Theorie weiter entwickelt. Da die unterschiedliche Probenumgebung dabei eine wichtige Rolle spielte, wurde die Modellfunktion für beide Fälle getrennt beschrieben. Ferner spielte die Photonenenergie, insbesondere in Hinblick auf Absorptionseffekte, eine Rolle, ebenso natürlich der Messplatz (Röntgengenerator oder Ablenkmagnet), vor allem im Hinblick auf Auflösung und Polarisationseffekte. Alle hier erwähnten Einflussfaktoren wurden bei der Modellierung berücksichtigt.

Die Auswertung erfolgte vergleichend durch die klassische Methode der Fouriersynthese und durch Anpassung mit einer Modellfunktion. Im Fall von Alamethicin wurde bei einigen Lipiden, wie z.B. DLPC, beobachtet, dass die Membrandicke innerhalb der Fehlergrenze unabhängig von der Peptidkonzentration konstant bleibt, während die Membrandicke bei anderen Lipiden, 
z.B. DPPC, mit steigender Peptidkonzentration deutlich abnimmt, so dass sich lipidspezifische Unterschiede ergeben. Der Membranverdünnungseffekt ist aus der Literatur für manche Systeme bekannt [173], und wurde hier in umfangreichen Messserien weitergehen untersucht, aber nicht durchgehend bestätigt. Die Magainin 2/Lipid-Proben zeigen für neutrale Lipide hingegen durchgehend den Verdünnungseffekt, d.h. die Membrandicke wird mit steigender Peptidkonzentration immer dünner, wie auch von Ludtke et al. berichtet [73]. Für negativ geladene Lipidmembranen zeigt Magainin 2 (positiv geladen) hingegen einen drastischen Effekt der Membran-Verdickung: Die Membrandicke vergrößert sich mit zunehmender Peptidkonzentration, was wahrscheinlich auf die durch das Peptid abgeschirmte elektrostatische Abstoßung zwischen den Lipidköpfen zurückzuführen ist. Darüber hinaus zeigen negativ geladene Lipide mit Magainin 2 eine stark zunehmende lamellare Unordnung, quantifiziert durch den Anstieg des Caillé-Parameters mit steigender Peptidkonzentration. Die zu Grunde liegende zunehmende Membranfluktuation bzw. lamellare Unordnung tritt dabei nur für anionische Membranen auf und ist nicht mit einer durch Elektrostatik erhöhten Bindungskonstante zu erklären. Dieser Effekt könnte mit der hohen Spezifität der Wechselwirkung von Magainin 2 mit PG-Kopfgruppen (Phosphatidylglycerol), also eventuell mit der selektiven Toxizität von Magainin 2 zusammenhängen. Magainin greift selektiv bakterielle Zellwände an, lässt aber die Zellmembranen des Wirtsorganismus weitgehend verschont. Bakterielle Membranen enthalten reichlich anionische Phospholipide [47, 48], während z.B. die äußere Zellmembran von Säugetieren hauptsächlich aus zwitterionischen Phospholipiden besteht [5]. Dieser Unterschied in der Zusammensetzung ist wohl für die Wirkung antibiotischer Peptide generell (also auch für die Wirkung von menschlichen Defensinen) relevant.

Aus der Diskussion und Betrachtung der Ergebnisse wird jedoch auch deutlich, dass trotz erfolgreicher Experimente und Modellierung die Konformation und Orientierung der Peptide in der Membran aus Reflektivitätsmessungen alleine nicht bestimmt werden kann. Daher sollte man in Zukunft entweder mit einem schweren Element markierte Peptidmoleküle zur Reflektivitätsmessung verwenden und/oder zusätzlich komplementäre Messungen durchführen, z.B. auch Röntgenbeugung an orientierten Stapeln (also nicht nur das Reflektivitätssignal ausnutzen). Gleichzeitig sollten auch spektroskopische Verfahren wie die OCD (Orientierter Circulardichroismus), Infrarotspektroskopie oder NMR (nukleare magnetische Resonanz) zum Einsatz kommen, damit die Lage und Konformation des Peptids in Lipidmembranen "sichtbar" wird, und so seine Lokalisierung genau bestimmt werden kann. Außerdem ist es notwendig, die Wechselwirkung zwischen Lipidmembranen und Peptiden auf molekularer Ebene auch durch Molekulardynamik-Simulation zu untersuchen, um Experimente besser zu interpretieren und die Konformation des Peptid/Lipid-Systems besser beschreiben zu können. 


\section{Literaturverzeichnis}

[1] T.K. Ritter und C.H. Wong. Kohlenhydrate in der Antibiotikaforschung: ein neuer Ansatz zur Resistenzbekämpfung. Angew. Chem., 113:3616-3641, 2001.

[2] B.F. Gisin, D.G. Davis, Z.K. Borowska, J.E. Hall and S. Kobayashi. Synthesis of the Major Component of Alamethicin. J. Am. Chem. SOC., 103:6373-6377, 1981.

[3] M. Zasloff. Magainins, a class of antimicrobial peptides from Xenopus skin: isolation, characterization of two active forms, and partial cDNA sequence of a precursor. Proc.Nat.Acad.Sci. USA, 84:5449-5453, 1987.

[4] M. Zasloff, B. Martin and H.-C. Chen. Antimicrobial activity of synthetic magainin peptides and several analogues. Proc. Natl. Acad. Sci. USA, 85:910-913, 1988.

[5] K. Matsuzaki. Why and how are peptide-lipid interactions utilized for self-defense? Magainins and tachyplesins as archetypes. Biochimica et Biophysika Acta, 1462:1-10, 1999.

[6] K. Matsuzaki, Y. Mitani, K. Akada, O. Murase, S. Yoneyama, M. Zasloff and K. Miyajima. Mechanism of Synergism between Antimicrobial Peptides Magainin 2 and PGLa. Biochemistry, 37:15144-15153, 1998.

[7] S.J. Singer and G.L. Nicolson. The fluid mosaic model of the structure of cell membranes. Science, 175:720-731, 1972.

[8] http://leaflet.vet.ed.ac.uk/webpage/research/intro/membrane.html, (10. 10. 2004).

[9] J. Marti and F.S. Csajka. Flip-flop dynamics in a model lipid bilayer membrane. Europhys. Lett., 61:409-414, 2003.

[10] H. Lodisch, D. Baltimore, A. Berk, S. Lawrence, P. Matsudaira and J. Darnell. Molekulare Zellbiologie. Walter de Gruyter, Berlin, New York, zweite edition, 1996. Übersetzung aus dem Engl.

[11] http://www.cyberlipid.org/phlip/pgly03.htm\#1, (27. 11. 2004).

[12] A. Watts, K. Harlos, W. Maschke and D. Marsh. Control of the structure and fluidity of phosphatidylglycerol bilayers by pH titration. Biochimica et Biophysica Acta, 510:63-74, 1978. 
[13] J.H. Kleinschmidt and L.K. Tamm. Structural Transitions in Short-Chain Lipid Assemblies Studied by ${ }^{31}$ P-NMR Spectroscopy. Biophys. J., 83:994-1003, 2002.

[14] http://www.upei.ca/ chem351/Lab/lab_01/pKa_Values.pdf, (24. 11. 2004).

[15] K. Lohner and E.J. Prenner. Differential scanning calorimetry and X-ray diffraction studies of the specificity of theinteraction of antimicrobial peptides with membrane-mimic systems. Biochim. Biophys. Acta, 1462:141-156, 1999.

[16] A. Bruce, B. Dennis, A. Johnson, J. Lewis, M. Raff, K. Roberts and P. Walter. Lehrbuch der molekularen Zellbiologie. WILEY-VCH Verlag GmbH, Weinheim, 1 edition, 1999.

[17] R. Koynova and M. Caffrey. Phases and phase transitions of the phosphatidylcholines. Biochimica et Biophysica Acta, 1376:91-145, 1998.

[18] H. Jakubke. Peptide. Spektrum Akademischer Verlag, Heidelberg, 1996.

[19] J. Breckow and R. Greinert. Biophysik. Walter de Gruyter, Berlin, 1994.

[20] D. Eisenberg, R.M. Weiss, T.C. Terwilliger and W. Wilcox. Hydrophobic moments in protein structure. Faraday Symp. Chem. Soc., 17:109-120, 1982.

[21] A. Bruce, A. Johnson, J. Lewis, M. Raff, K. Roberts and P. Walter. Molekular biology of the Cell. Garland Science, New York, 4 edition, 2002.

[22] L.G.M. Gordon and D.A. Haydon. The unit conductance channel of alamethicin. Biochim. Biophys. Acta, 255:1014-1018, 1972.

[23] K. Matsuzaki, O. Marase, N. Fujii and K. Miyajima. Translocation of a Channel-Forming Antimicrobial Peptide, Magainin 2, across Lipid Bilayers by Forming a Pore. Biochemistry, 34:6521-6525, 1995.

[24] C. E. Meyer and F. Reusser. A polypeptide antibacterial agent isolated from Trichoderma viride. Experientia, 23:85-86, 1967.

[25] P. Mueller and D.O. Rudin. Action potentials induced in bimolecular lipid membranes. Nature (London), 217:713-719, 1968.

[26] M. Eisenberg, J.E. Hall and C.A. Mead. The nature of the voltage-dependent conductance induced by alamethicin in black lipid membranes. J. Membr. Biol., 14:143-176, 1973.

[27] G. Boheim. Statistical analysis of alamethicin channels in black lipid membranes. J. Membr. Biol., 19:277-303, 1974.

[28] G. Boheim and J.E. Hall. Oscillation phenomena in black lipid membranes induced by a single alamethicin pore. Biochim. Biophys. Acta, 389:436-443, 1975.

[29] J.E. Hall, I. Vodyanov, T. M. Balasubramanian and G. M. Marshall. Alamethicin. A rich model for channel behavior. Biophys. J., 45:233-247, 1984. 
[30] J.E. Hall. Toward a molecular understanding of excitability. Alamethicin in black lipid films. Biophys. J., 15:934-939, 1975.

[31] G. Baumann and P. Mueller. A molecular model of membrane excitability. J. Supramolec. Struct., 2:538-557, 1974.

[32] L.G. Gordon and D.A. Haydon. Potential-dependent conductances in lipid membranes containing alamethicin. Philos Trans R Soc Lond B Biol Sci., 270:433-447, 1975.

[33] T. Kikukawa and T. Araiso. Changes in lipid mobility associated with alamethicin incorporation into membranes. Arch. of Bioch. and Bioph., 405:214-222, 2002.

[34] G. Schwarz, S. Stankowski and V. Rizzo. Thermodynamic analysis of incorporation and aggregation in a membrane: Application to the pore-forming peptide alamethicin. Biochim. Biophys. Acta, 861:141-151, 1986.

[35] V. Rizzo, S. Stankowski and G. Schwarz. Alamethicin incorporation in lipid bilayers: a thermodynamic study. Biochemistry, 26:2751-2759, 1987.

[36] G.A. Woolley and B.A. Wallace. Temperature dependence of the interaction of alamethicin helixes in membranes. Biochemistry, 32:9819-9825, 1993.

[37] M. Schnur and M. Peckerar. Synthetic Microstructures in Biological Research. Kluwer Academic/Plenum Publishers, New York, 1 edition, 1992.

[38] R.O. Fox and F.M. Richards. A voltage-gated ion channel model inferred from the crystal structure of alamethicin at 1.5-A resolution. Nature (London), 300:325-330, 1982.

[39] C. Toniolo and E. Benedetti. The polypeptide 3 10-helix. Trends Biochem. Sci., 16:350-353, 1991.

[40] I. L. Karle. In Membrane Protein Structure : Experimental Approaches. Oxford University Press, New York, White, S. H., ed.:355-380, 1994.

[41] G. Esposito, J.A. Carver, J. Boyd and I.D. Campbell. High-resolution proton NMR study of the solution structure of alamethicin. Biochemistry, 26:1043-1050, 1987.

[42] J.K. Chugh and B.A. Wallace1. Peptaibols: models for ion channels. Biochemistry, 29:part 4, 566-570, 2001.

[43] M. Barranger-Mathys and D.S. Cafiso. Membrane Structure of Voltage-Gated Channel Forming Peptides by Site-Directed Spin-Labeling. Biochemistry, 35:498-505, 1996.

[44] A. Kessel, D.S. Cafiso and N. Ben-Tal. Continuum solvent model calculations of alamethicinmembrane interactions: thermodynamic aspects. Biophys. J., 78:571-583, 2000.

[45] R.W. Gwadz, D. Kaslow, J.-Y. Lee, L. Maloy, M. Zasloff and L.H. Miller. Effects of magainins and cecropins on the sporogonic development of malaria parasites in mosquitoes. Infect. Immun., 57:2628-2633, 1989. 
[46] R. Cruciani, J. L. Barker, M. Zasloff, H. C. Chen and O. Colamonici. Antibiotic magainins exert cytolytic activity against transformed cell lines through channel formation. Proc.Nat.Acad.Sci. USA, 88:3792-3796, 1991.

[47] A.V. Gomes, A. de Waal, J.A. Berden and H.V. Westerhoff. Electric potentiation, cooperativity, and synergism of magainin peptides in protein-free liposomes. Biochemistry, 32:53655372, 1993.

[48] K. Matsuzaki. Magainins as paradigm for the mode of action of pore forming polypeptides. Biochimica et Biophysika Acta, 1376:391-400, 1998.

[49] K. Matsuzaki, O. Murase, H. Tokuda, S. Funakoshi, N. Fujii and K. Miyajima. Orientational and Aggregational States of Magainin 2 in Phospholipid Bilayers. Biochemistry, 33:33423349, 1994.

[50] K. Matsuzaki, M. Harada, T. Handa, S. Funakoshi, N. Fujii, H. Yajima and K. Miyajima. Magainin 1-induced leakage of entrapped calcein out of negatively-charged lipid vesicles. Biochim. Biophys. Acta, 981:130-134, 1989.

[51] K. Matsuzaki, M. Harada, S. Funakoshi, N. Fujii and K. Miyajima. Physicochemical determinants for the interactions of magainins 1 and 2 with acidic lipid bilayers. Biochim. Biophys. Acta, 1063:162-170, 1991.

[52] T. Wieprecht, M. Dathe, M. Schümann, E. Krause, M. Beyermann and M. Bienert. Conformational and Functional Study of Magainin 2 in Model Membrane Environments Using the New Approach of Systematic Double-D-Amino Acid Replacement. Biochemistry, 35:1084410853, 1996.

[53] K. Matsuzaki, K. Sugishita, M. Harada, N. Fujii and M. Miyajima. Interactions of an antimicrobial peptide, magainin 2, with outer and inner membranes of Gram-negative bacteria. Biochim. Biophys. Acta, 1327:119-130, 1997.

[54] D. Juretic, R.W. Hendler, F. Kamp, W.S. Caughy, M. Zasloff and H.V. Westerho. Magainin 1-induced leakage of entrapped calcein out of negatively-charged lipid vesicles. Biochemistry, 33:4562-4570, 1994.

[55] H. Duclohier, G. Molle and G. Spach. Antimicrobial peptide magainin I from Xenopus skin forms anion- permeable channels in planar lipid bilayers. Biophys. J., 56:1017-1021, 1989.

[56] R.C. Cruciani, J.L. Barker, S.R. Durell, G. Raghunathan, H.R. Guy, M. Zasloff and E.F. Stanley. Magainin 2, a natural antibiotic from frog skin forms ion channels in lipid bilayer membranes. Eur. J. Pharmacol. Mol.Pharmacol. Sect., 226:287-296, 1992.

[57] F.R. Rana, E.A. Macias, C.M. Sultany, M.C. Modzrakowski and J. Blazyk. Interactions between Magainin 2 and Salmonella typhimurium Outer Membranes: Effect of Lipopolysaccharide Structure. Biochemistry, 30:5858-5866, 1991. 
[58] F.R. Rana, C.M. Sultany and J. Blazyk. Interactions between Salmonella typhimurium lipopolysaccharide and the antimicrobial peptide, magainin 2 amide. FEBS Lett., 261:464-467, 1990.

[59] K. Matsuzaki, K. Sugishita, N. Fujii and K. Miyajima. Molecular basis for membrane selectivity of an antimicrobial peptide, magainin 2. Biochemistry, 34:3423-3429, 1995.

[60] S.J. Ludtke, K. He, W.T. Heller, T.A. Harroun, L. Yang and H.W. Huang. Membrane Pores Induced by Magainin. Biochemistry, 35:13723-13728, 1996.

[61] H.-C. Chen, J.H. Brown, J.L. Morell and C.M. Huang. Synthetic magainin analogues with improved antimicrobial activity. FEBS Lett., 236:462-466, 1988.

[62] M.A. Baker, W.L. Maloy, M. Zasloff and L.S. Jacob. Anticancer efficacy of Magainin2 and analogue peptides. Cancer Res., 53:3052-3057, 1993.

[63] P.W. Soballe, W.L. Maloy, M.L. Myrga, L.S. Jacob and M. Herlyn. Experimental local therapy of human melanoma with lytic magainin peptides. Int. J. Cancer, 60:280-284, 1995.

[64] J. Gesella, M. Zasloff and S.J. Opella. Two-dimensional 1H NMR experiments show that the 23-residue magainin antibiotic peptide is an a-helix in dodecylphosphocholine micelles, sodium dodecylsulfate micelles, and trifluoroethanol/water solution . J. of Biom. NMR, 9:127-135, 1997.

[65] M. Jackson, H.H. Mantsch and J.H. Spencer. Conformation of Magainin-2 and Related Peptides in Aqueous Solution and Membrane Environments Probed by Fourier Transform Infrared Spectroscopy. Biochemistry, 31:7289-4496, 1992.

[66] R.W. Williams, R. Starman, K.M.P. Taylor, K. Gable, T. Beeler, M. Zasloff and D. Cove1111. Raman Spectroscopy of Synthetic Antimicrobial Frog Peptides Magainin 2a and PGLa. Biochemistry, 29:4490-4496, 1990.

[67] S.J. Ludtke, K. He and H.W. Huang. Cooperative membrane insertion of magainin correlated with its cytolytic activity. Biochem. Biophy. Acta, 1190:181-184, 1994.

[68] B. Bechinger, M. Zasloff and S.J. Opella. Structure and orientation of the antibiotic peptide magainin in membranes by solid-state nuclear magnetic resonance spectroscopy . Protein Science, 2:2077-2084, 1993.

[69] D. Marion, M. Zasloff and A. Bax. A two-dimensional NMR study of the antimicrobial peptide magainin 2. FEBS Lett., 227:21-26, 1988.

[70] D.J. Hirsh, J. Hammer, W.L. Maloy, J. Blazyk and J. Schaefer. Secondary Structure and Location of a Magainin Analogue in Synthetic Phospholipid Bilayers. Biochemistry, 35:1273312741, 1996. 
[71] K. Matsuzaki, A. Nakamura, O. Murase, K. Sugishita, N. Fujii and K. Miyajima. Modulation of Magainin 2-Lipid Bilayer Interactions by Peptide Charge. Biochemistry, 36:2104-2111, 1997.

[72] R. Brasseur. Differentiation of Lipid-assoiating Helices by Use of Threedimensional Molecular Hydrophobicity Potential Calculation. J. Biol. Chem., 266:16120-16127, 1991.

[73] S. Ludtke, K. He and H.W. Huang. Membrane Thinning Caused by Magainin 2. Biochemistry, 34:16764-16769, 1995.

[74] M. Zasloff. Antibiotic peptides as mediators of innate immunity. Curr. Opin. Immun., 4:2-24, 1992.

[75] C.E. Dempsey. The actions of melittin on membranes. Biochim Biophys Acta., 1031:143$161,1990$.

[76] G. Saberwal and R. Nagaraj. Cell-lytic and antibacterial peptides that act by perturbing the barrier function of membranes: facets of their conformational features, structure-function correlations and membrane-perturbing abilities. Biochim Biophys Acta., 1197:109-131, 1994.

[77] B. Bechinger. Structure and Functions of Channel-Forming Peptides: Magainins, Cecropins, Melittin and Alamethicin. J. Membr. Biol., 156:197-211, 1997.

[78] K. Lohner and R.M. Epand. Membrane Interactions of Hemolytic and Antibacterial Peptides. Adv. Biophys. Chem., 6:53-66, 1997.

[79] Z. Oren and Y. Shai. Mode of action of linear amphipathic a-helical antimicrobial peptides. Biopolymers, 47:451-463, 1998.

[80] W.F. DeGrado, G.F. Musso, M. Lieber, E.T. Kaiser and F.J. Kezdy. Kinetics and mechanism of hemolysis induced by melittin and by a synthetic melittin analogue. Biophys. J., 37:329338, 1982.

[81] M.T. Tosteson, S.J. Holmes, M. Razin and D.C. Tosteson. Melittin lysis of red cells. J. Membr. Biol., 387:35-44, 1985.

[82] E. Gazit, I.R. Miller, P.C. Biggin, M.S.P. Sansom and Y. Shai. Structure and orientation of the mammalian antibacterial peptide cecropin $\mathrm{P1}$ within phospholipid membranes. J. Mol. Biol., 258:860-870, 1996.

[83] M.S.P. Sansom. Peptides and lipid bilayers:- dynamic interactions. Curr. Opin. Colloid Interface Sci., 3:518-524, 1998.

[84] Y. Pouny, D. Rapaport, A. Mor, P. Nicolas and Y. Shai. Interaction of antimicrobial dermaseptin and its fluorescently labeled analogues with phospholipid membranes. Biochemistry, 31:12416-12423, 1992. 
[85] K. He, S.J. Ludtke, H.W. Huang and D.L. Worcester. Antimicrobial Peptide Pores in Membranes Detected by Neutron In-Plane Scattering. Biochemistry, 34:15614-15618, 1995.

[86] M.S.P. Sansom. The biophysics of peptide models of ion channels. Prog. Biophys. molec. Biol., 55:139-235, 1991.

[87] F.Y. Chen, M.T. Lee and H.W. Huang. Evidence for a membrane thinning effect as the mechanism for peptide-induced pore formation. Biophys. J., 84:3751-3758, 2003.

[88] A. Spaar. The Structure of Lipid Membrane and the Conformation of Peptides in Membranes Studied by Surface X-Ray Scattering. Dissertation Universität des Saarlandes, 2003.

[89] G. Ehrenstein and H. Lecar. lectrically gated channels in lipid bilayers. Q. Rev. Biophys., 10:1-34, 1977.

[90] B. Bechinger. The structure, dynamics and orientation of antimicrobial peptides in membranes by multidimensional solid-state NMR spectroscopy. Biochim. Biophys. Acta, 1462:157$183,1999$.

[91] Y. Shai. Mechanism of the binding, insertion and destabilization of phospholipid bilayer membranes by K-helical antimicrobial and cell non-selective membrane-lytic peptides. Biochim. Biophys. Acta, 1462:55-70, 1999.

[92] R.E.W. Hancock and M.G. Scott. The role of antimicrobial peptides in animal defences. Proc. Natl. Acad. Sci. USA, 97:8856-8861, 2000.

[93] H.W. Huang. Action of Antimicrobial Peptides: Two-State Model. Biochemistry, 39:83478352, 2000.

[94] Y. Shai and Z. Oren. From carpetmechanism to de-novo designed diastereomeric cell-selective antimicrobial peptides. Peptides, 22:1629-1641, 2001.

[95] I. Ben-Efraim, D. Bach and Y. Shai. Spectroscopic and functional characterization of the putative transmembrane segment of the minK potassium channel. Biochemistry, 32:23712377, 1993.

[96] M.S.P. Sansom. Alamethicin and related peptaibols-model ion channels. Eur. Biophys. J., 22:105-124, 1993.

[97] E. Gazit, A. Boman, H.G. Boman and Y. Shai. Interaction of the mammalian antibacterial peptide cecropin P1 with phospholipid vesicles. Biochemistry, 34:11479-11488, 1995.

[98] D.P. Tieleman, B. Hess and M.S.P. Sansom. Analysis and Evaluation of Channel Models: Simulations of Alamethicin. Biophysical Journal, 83:2393-2407, 2002.

[99] K. Matsuzaki, O. Murase, N. Fujii and K. Miyajima. An Antimicrobial Peptide, Magainin 2, Induced Rapid Flip-Flop of Phospholipids Coupled with Pore Formation and Peptide Translocation. Biochemistry, 35:11361-11368, 1995. 
[100] L. Yang, T.A. Harroun, T.M. Weiss, L. Ding and H.W. Huang. Barrel-Stave Model or Toroidal Model? A Case Study on Melittin Pores.

[101] E. Fattal, S. Nir, R.A. Parente and F.C.Jr. Szoka. Pore-Forming Peptides Induce Rapid Phospholipid Flip-Flop in Membraned. Biochemistry, 33:6721-6731, 1994.

[102] K. Murzyn and M. Pasenkiewicz-Gierula. Construction of a toroidal model for the magainin pore. J Mol Model, 9:217-224, 2003.

[103] K.L. Piers and R.E. Hancock. The interaction of a recombinant cecropin/melittin hybrid peptide with the outer membrane of Pseudomonas aeruginosa. Mol. Microbiol., 12:951-958, 1994.

[104] A.S. Ladokhin and S.H. White. 'Detergent-like' permeabilization of anionic lipid vesicles by melittin. Biochim Biophys Acta., 1514:253-260, 2001.

[105] H. Ostolaza, B. Bartolom, I. Ortiz de Zfirate, F. de la Cruz and F.M. Gofii. Release of lipid vesicle contents by the bacterial protein toxin $\alpha$-haemolysin . Biochim. Biophys. Acta., 1147:81-88, 1993.

[106] P. Schlieper and E. De Robertis. Triton X-100 as a channel-forming substance in artificial lipid bilayer membranes. Arch. Biochem. Biophys., 184:204-208, 1977.

[107] E.Jr. Grant, T.J. Beeler, K.M.P. Taylor, K. Gable and M.A. Roseman. Mechanism of magainin 2a induced permeabilization of phospholipid vesicles. Biochemistry, 31:9912-9918, 1992.

[108] Z. Oren and Y. Shai. Selective Lysis of Bacteria but Not Mammalian Cells by Diastereomers of Melittin: Structure-Function Study. Biochemistry, 36:1826-1835, 1997.

[109] T.C.B. Vogt and B. Bechinger. The Interactions of Histidine-containing Amphipathic Helical Peptide Antibiotics with Lipid Bilayers. J. Biol. Chem., 274:29115-29121, 1999.

[110] Y. Wu, K. He, S.J. Ludtke and H.W. Huang. X-ray diffraction study of lipid bilayer membranes interacting with amphiphilic helical peptides: diphytanoyl phosphatidylcholine with alamethicin at low concentrations. Biophys. J., 68:2361-2369, 1995.

[111] C. Münster, A. Spaar, B. Bechinger and T. Salditt. Magainin 2 in phospholipid bilayers: peptide orientation and lipid chain ordering studied by X-ray diffraction. Biochimica et Biophysica Acta, 1562:37-44, 2002.

[112] A. Colotto, D.P. Kharakoz, K. Lohner and P. Laggner. Ultrasonic study of melittin effects on phospholipid model membrane. Biophys. J., 65:2360-2367, 1993.

[113] L. Spyracopoulos, A. Yee and J.D.J. O’Neil. Backbone Dynamics of an Alamethicin in Methanol and Aqueous Detergent Solution Determined by Heteronuclear 1H 15N NMR Spectroscopy. Journal of Biomolecular NMR, 7:283-294, 1996. 
[114] L. Silvestro, K. Gupta, J.N. Weiser and P.H. Axelsen. The Concentration-Dependent Membrane Activity of Cecropin A. Biochemistry, 36:11452-11460, 1997.

[115] T. Wieprecht, M. Dathe, R.M. Epand, M. Beyermann, E. Krause, W.L. Maloy, D.L. MacDonald and M. Bienert. Influence of the Angle Subtended by the Positively Charged Helix Face on the Membrane Activity of Amphipathic, Antibacterial Peptides. Biochemistry, 36:1286912880, 1997.

[116] P. Diaz-Achirica, S. Prieto, J. Ubach, D. Andreu, E. Rial and L. Rivas. Permeabilization of the mitochondrial inner membrane by short cecropin-A-melittin hybrid peptides. Eur. $J$. Biochem., 224:257-263, 1994.

[117] H.S. Mchaourab, J.S. Hyde and J.B. Feix. Binding and State of Aggregation of SpinLabeled Cecropin AD in Phospholipid Bilayers: Effects of Surface Charge and Fatty Acyl Chain Length. Biochemistry, 33:6691-6699, 1994.

[118] M. Schümann, M. Dathe, T. Wieprecht, M. Beyermann and M. Bienert. The Tendency of Magainin To Associate upon Binding to Phospholipid Bilayers. Biochemistry, 36:4345-4351, 1997.

[119] I.R. Mellor and M.S.P. Sansom. Ion-channel properties of mastoparan, a 14-residue peptide from wasp venom, and of MP3, a 12-residue analogue. Proc. R. Soc. Lond B Biol. Sci., 239:383-400, 1990.

[120] E.L. Merrifield, S.A. Mitchell, J. Ubach, H.G. Boman, D. Andreu and R.B. Merrifield. Denantiomers of 15-residue cecropin A-melittin hybrids. Int. J. Peptide Protein Res., 46:214220, 1995.

[121] J.D. Lear, Z.R. Wasserman and W.F. DeGrado. Synthetic amphiphilic peptide models for protein ion channels. Science, 240:1177-1181, 1988.

[122] K. Anzai, M. Hamasuna, H. Kadono, S. Lee, H. Ayoagi and Y. Kyrino. Formation of ion channels in planar lipid bilayer membranes by synthetic basic peptides. Biochim. Biophys. Acta, 1064:256-266, 1991.

[123] Y. Higashimoto, H. Kodama, M. Jelokhani-Niaraki, F. Kato and M. Kondo. Structurefunction relationship of model Aib-containing peptides as ion transfer intermembrane templates. J. Biochem., 125:705-712, 1999.

[124] A. Kessel and N. Ben-Tal. Free Energy Determinants of Peptide Association with Lipid Bilayers. Current Topics in Membranes: Peptide-Lipid Interactions. Sydney Simon and Thomas McIntosh, Eds. Academic Press, San Diego., 52:205-253, 2002.

[125] D.M. Engelman and T. A. Steitz. The spontaneous insertion of proteins into and across membranes: the helical hairpin hypothesis. Cell, 23:411-422, 1981. 
[126] F. Jähnig. Thermodynamics and kinetics of protein incorporation into membranes. Proc. Natl. Acad. Sci. USA., 80:3691-3695, 1983.

[127] B. Honig and W.L. Hubbell. Stability of Balt bridgesïn membrane protein. Proc. Natl. Acad. Sci. USA., 81:5412-5416, 1984.

[128] R.E. Jacobs and S.H. White. The nature of the hydrophobic binding of small peptides at the bilayer interface: implications for the insertion of transbilayer helices. Biochemistry, 28:3421$3437,1989$.

[129] M. Milik and J. Skolnick. Insertion of peptide chains into lipid membranes: an off-lattice Monte Carlo dynamics model. Proteins, 15:10-25, 1993.

[130] D.R. Fattal and A. Ben-Shaul. A molecular model for lipid-protein interaction in membranes: the role for hydrophobic mismatch. Biophys. J., 65:1795-1809, 1993.

[131] N. Ben-Tal,A. Ben-Shaul, A. Nicholls and B. Honig. Free-energy determinants of alpha-helix insertion into lipid bilayers. Biophys. J., 70:1803-1812, 1996.

[132] S.H. White and W.C. Wimley. Membrane protein folding and stability: physical principles. Annu Rev Biophys Biomol Struct., 28:319-365, 1999.

[133] G.P. Brady and K.A. Sharp. Entropy in protein folding and in protein-protein interactions. Curr Opin Struct Biol., 7:215-221, 1997.

[134] A.V. Finkelstein and J. Janin. The price of lost freedom: entropy of bimolecular complex formation. Protein Eng., 3:1-3, 1989.

[135] A. Ben-Shaul, N. Ben-Tal and B. Honig. Statistical thermodynamic analysis of peptide and protein insertion into lipid membranes. Biophys J., 71:130-137, 1996.

[136] N. Ben-Tal, B. Honig, C.K. Bagdassarian and A. Ben-Shaul. Association entropy in adsorption processes. Biophys. J., 79:1180-1187, 2000.

[137] R.M. Peitzsch and S. McLaughlin. Binding of acylated peptides and fatty acids to phospholipid vesicles: pertinence to myristoylated proteins. Biochemistry, 32:10436-10443, 1996.

[138] C. Tanford. The Hydrophobic Effect: Formation of Micelles and Biological Membranes. Krieger Publishing Company, 1991.

[139] O.G. Mouritsen and M. Bloom. Mattress model of lipid-protein interactions in membranes. Biophys. J., 46:141-153, 1984.

[140] M. Esmann and D. Marsh. Spin-label studies on the origin of the specificity of lipid-protein interactions in Na+,K+-ATPase membranes from Squalus acanthias. Biochemistry, 24:35723578, 1985.

[141] U. Mennicke and T. Salditt. Preparation of Solid-Supported Lipid Bilayers by Spin-Coating. Langmuir, 18:8172-8177, 2002. 
[142] M. Seul and M.J. Sammon. Preparation of surfactant multilayer films on solid substrates by deposition from organic solution. Thin Solid Films.

[143] http://www.risoe.dk/afm/external/bele/products/wafers.htm, (24. 11. 2004).

[144] J.F. Nagle and S. Tristram-Nagle. Structure of lipid bilayers. Biochim. Biophys. Acta, 1469:159-195, 2000.

[145] C. Muünster, J. Lu, S. Schinzel, B. Bechinger and T. Salditt. Grazing incidence X-ray diffraction of highly aligned phospholipid membranes containing the antimicrobial peptide magainin 2. Eur. J. Biochem., 28:683-688, 2000.

[146] T. Salditt. Habilitationsschrift der Fakultät für Physik. LMU, München, 1999.

[147] Ch. Münster. Dissertation der Fakultät für Physik. LMU, München, 2000.

[148] L. Greenspan. Humidity fixed points of binary saturated aqueous solutions. J. Res. Nat. Bur. Stand. A, 81A:89-96, 1977.

[149] U. Mennicke. Struktur und Fluktuationen festkörpergestützter Phospholipidmembranen. Dissertation Universität Göttingen, 2003.

[150] A.E. Blaurock. Structure of the Nerve Myelin Membrane: Proo of the Low-resolution Profile. J. Mol. Biol., 56:35-52, 1971.

[151] M.F. Perutz. The structure of haemoglobin III. Direct determination of the molecular transform. Proc. Roy. Soc., A, 225:264-286, 1954.

[152] D.L. Worcester and N.P. Franks. Structural Analysis of Hydrated Egg Lecithin and Cholesterol Bilayers II. Neutron Diffraction. J. Mol. Biol., 100:359-378, 1976.

[153] V. Luzzati, A. Tardieu and D. Taupin. A pattern-recognition approach to the phase problem: application to the $\mathrm{X}$-ray diffraction study of biological membranes and model systems. J. Mol. Biol., 64:269-286, 1972.

[154] Y.K. Levine. X-ray diffraction studies of membranes. Progress in Surface Science, 3:279_ $352,1973$.

[155] J.F. Nagle and M.C. Wiener. Relations for lipid bilayers. Connection of electron density profiles to other structural quantities. Biophysical Journal, 55:309-313, 1989.

[156] B.D. Cullity and S.R. Stock. Elements of X-Ray Diffraction. Addison Wesley, 3 edition, 2001.

[157] J. Als-Nielsen and D. McMorrow. Elements of Modern X-Ray Physics. John Wiley \& Sons, Ltd, 2001.

[158] B.E. Warren. X-RAY DIFFRACTION. DOVER PUBLICATION; INC.,NEW YORK, 1990. 
[159] A.E. Blaurock and C.R. Worthington. Treatment of low angle x-ray data from planar and concentric multilayered structures. Biophy. J., 6:305-312, 1966.

[160] C.R. Worthington and A.E. Blaurock. A Structural Analysis of Nerve Myelin. Biophy. J., 9:970-990, 1969.

[161] H. Heller, M. Schaefer and K. Schulten. Molecular Dynamics Simulation of a Bilayer of 200 Lipids in the Gel and in the Liquid-Crystal Phases. J. Phys. Chem., 97:8343-8360, 1993.

[162] R.W. James. Optical Principles of the Diffraction of X-Rays. OxBow Press, WoodbrigeConnecticut, 1982.

[163] E. Hecht. Optik. Addison-Wesley Publishing Company, Bonn, München, 1989.

[164] A. Poniewierski and R. Holyst. Continuous-model description of layer fluctuations in finite smectic systems. Phys. Rev. B, 47:9840-9843, 1993.

[165] S.A. Safran. Curvature elasticity of thin films. Adv. In Phys., 48:395-448, 1999.

[166] D. Constantin, U. Mennicke, C. Li and T. Salditt. Solid-supported lipid bilayers: structure factor and fluctuations. Eur. Phys. J. E, 12:283-290, 2003.

[167] S.K. Sinha. X-ray diffuse scattering as a probe for thin film, and interface structure. J. Phys. III France, 4:1543-1557, 1994.

[168] C. Li, D. Constantin and T. Salditt. Biomimetic membranes of lipid-peptide model systems prepared on solid support. J. Phys.: Condens. Matter, 16:S2439-S2453, 2004.

[169] J.F. Nagle, R. Zhang, S. Tristram-Nagle, W. Sun, H.I. Petrache and RM Suter. X-ray structure determination of fully hydrated $L$ alpha phase dipalmitoylphosphatidylcholine bilayers. Biophys. J., 70:1419-1431, 1996.

[170] A. Braslau, P.S. Pershan, G. Swislow, B.M. Ocko and J. Als-Nielsen. Capillary waves on the surface of simple liquids measured by x-ray reflectivity. Physical Review A, 38:2457-2470, 1988.

[171] T. Salditt, C. Li, A. Spaar and U. Mennicke. X-ray reflectivity of solid-supported, multilamellar membranes. The European Physical Journal E, 7:105-116, 2002.

[172] http://aqueous.labs.brocku.ca/lipid/\#eggPC, (16. 12. 2004).

[173] K. He, S.J. Ludtke, D.L. Worcester and H.W. Huang. Neutron scattering in the plane of membranes: Structure of Alamethicin Pores. Biophysical Journal, 70:2659-2666, 1996.

[174] H.W. Huang. Elasticity of Lipid Bilayer Interacting with Amphiphilic Helical Peptides. J. Phys. II Fiance, 4:1427-1431, 1995.

[175] J.A. Patch and A.E. Barron. Helical Peptoid Mimics of Magainin-2 Amide. J. AM. CHEM. SOC., 125:12092-12093, 2003. 
[176] J.F. Nagle, H.I. Petrache, N. Gouliaev, S. Tristram-Nagle, Y. Liu,R.M. Suter and K. Gawrisch. Multiple mechanisms for critical behavior in the biologically relevant phase of lecithin bilayers. Phys. Rev. E, 58:7769-7776, 1998.

[177] W.T. Heller, K. He, S.J. Ludtke, T.A. Harroun and H.W. Huang. Effect of changing the size of lipid headgroup on peptide insertion into membranes. Biophys. J., 73:239-244, 1997.

[178] F.Y. Chen, M.T. Lee and H.W. Huang. Sigmoidal concentration dependence of antimicrobial peptide activities: a case study on alamethicin. Biophys. J., 82:908-914, 2002. 


\section{Anhang A}

\section{Kalkulation zur Präparation}

\section{Massenberechnung der Proben aus Magainin/Lipid}

\section{Erklärung der Variablen:}

VL: Volumen der Lipidlösung $(\mathrm{ml})$

VP: Volumen der Peptidlösung (ml)

L: $\quad$ Konzentration der Lipidlösung $(\mathrm{mg} / \mathrm{ml})$

$\mathrm{P}$ : $\quad$ Konzentration der Peptidlösung $(\mathrm{mg} / \mathrm{ml})$

WL: Masse des Lipids in der Lipidlösung (mg)

WP: Masse des Peptids in der Peptidlösung (mg)

Lipid: Molekulares Masse des Lipids (g/Mol)

Ala: Molekulares Masse der Alamethicin (g/Mol)

f1: Molverhältnis zwischen Lipid und Peptid

Konstante: $\quad$ L, Lipid, Mag, f1, f2, f3

Unbekannte : VL, VP, P, WL, WP

1. $\mathrm{VP}+\mathrm{VL}=0.22 \quad$ : Menge $(\mathrm{ml})$ auf dem Substrat.

2. $(\mathrm{VL} * \mathrm{~L}) /(\mathrm{VL}+\mathrm{VP})=10 \quad$ : Endkonzentration des Lipids

3. $(\mathrm{VL} * \mathrm{~L} / \mathrm{Lipid}) /(\mathrm{VP} * \mathrm{P} / \mathrm{Mag})=\mathrm{f} 1$

\section{Molmasse:}

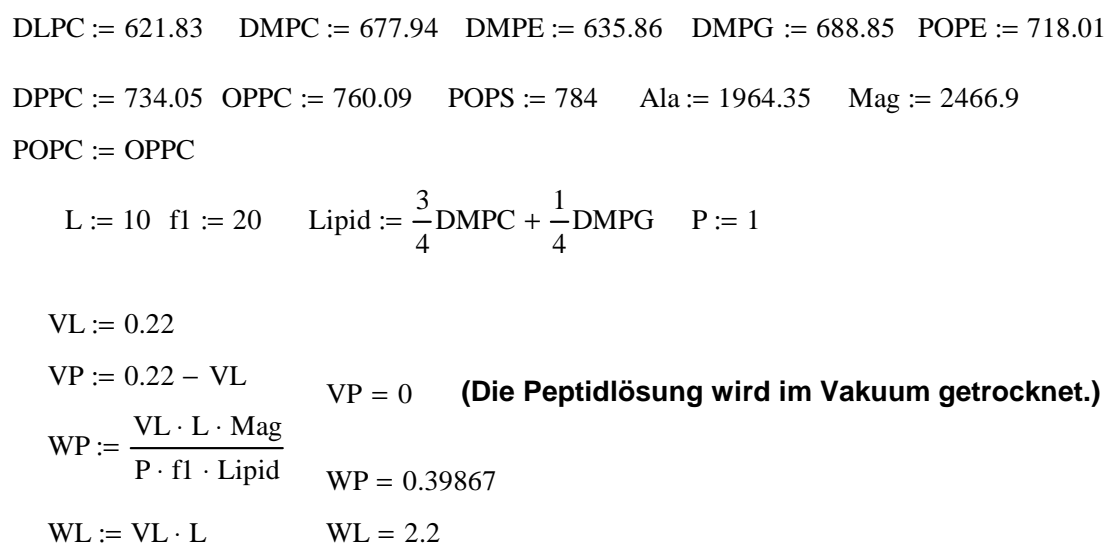




\section{Prüfen:.}

$\begin{array}{lll}\text { Konzentration des Lipids: } & \text { L_conz }:=\frac{\mathrm{WL}}{\mathrm{VP}+\frac{\mathrm{WL}}{\mathrm{L}}} \quad \quad \text { L_conz }=10 \\ \text { Molverhältnis: } & \text { Mol_Verh }:=\frac{\frac{\mathrm{WL}}{\mathrm{Lipid}}}{\frac{\mathrm{WP}}{\mathrm{Mag}}} \quad \text { Mol_Verh }=20\end{array}$

\section{Präparation der Proben mit dünnem Lipidfilm}

\section{Für DMPC mit Magainin2:}

$$
\begin{array}{rlrl}
\mathrm{L}:=5 \quad \mathrm{f} 1 & :=20 \quad \text { Lipid }:=\mathrm{DMPC} & \mathrm{P}:=1 \\
\mathrm{VL} & :=0.11 & \mathrm{VP}=0 \\
\mathrm{VP} & :=0.11-\mathrm{VL} & \mathrm{WP}=0.10007 \\
\mathrm{WP} & :=\frac{\mathrm{VL} \cdot \mathrm{L} \cdot \mathrm{Mag}}{\mathrm{P} \cdot \mathrm{f} 1 \cdot \mathrm{Lipid}} & \mathrm{WL}=0.55 &
\end{array}
$$

Prüfen:

Konzentration des Lipids: $\quad \mathrm{L}_{-}$conz $:=\frac{\mathrm{WL}}{\mathrm{VP}+\frac{\mathrm{WL}}{\mathrm{L}}} \quad \quad \mathrm{L}_{-}$conz $=5$

Molverhältnis:

$$
\text { Mol_Verh }:=\frac{\frac{\text { WL }}{\text { Lipid }}}{\frac{\text { WP }}{\text { Mag }}} \quad \text { Mol_Verh }=20
$$

Für DMPC/DMPG = 1/3 Magainin2:

$$
\begin{array}{rlrl}
\mathrm{L}:=5 & \mathrm{f} 1 & :=20 \quad \text { Lipid }:=\frac{3}{4} \mathrm{DMPC}+\frac{1}{4} \mathrm{DMPG} \quad \mathrm{P}:=1 \\
\mathrm{VL} & :=0.11 & & \\
\mathrm{VP} & :=0.11-\mathrm{VL} & \mathrm{VP}=0 \\
\mathrm{WP} & :=\frac{\mathrm{VL} \cdot \mathrm{L} \cdot \mathrm{Mag}}{\mathrm{P} \cdot \mathrm{f} 1 \cdot \mathrm{Lipid}} & \mathrm{WP}=0.09967 \\
\mathrm{WL} & :=\mathrm{VL} \cdot \mathrm{L} & \mathrm{WL}=0.55
\end{array}
$$


Prüfen:

Konzentration des Lipids: $\quad L_{-}$conz $:=\frac{\mathrm{WL}}{\mathrm{VP}+\frac{\mathrm{WL}}{\mathrm{L}}} \quad \mathrm{L}_{-} \operatorname{conz}=5$

Molverhältnis:

$$
\text { Mol_Verh }:=\frac{\frac{\text { WL }}{\text { Lipid }}}{\frac{\text { WP }}{\text { Mag }}} \quad \text { Mol_Verh }=20
$$

\section{Volumenberechnung für Lipidmischung ohne Peptid}

\section{Deklaration (für Lipidsmischung) :}

V1: Volumen der 1. Lipidlösung (ml)

V2: Volumen der 2. Lipidlösung $(\mathrm{ml})$

L: $\quad$ Konzentration der Lipidlösungen $(\mathrm{mg} / \mathrm{ml})$

DMPC (L1): Molmasse (g/Mol)

DMPE (L2): Molmasse (g/Mol)

Konstanten: DMPC, DMPE (L1, L2)

Unbekannten : V1, V2

- $\quad V 1+V 2=0.11$

- $\frac{V 1 * L / L 1}{V 2 * L / L 2}=\frac{V 1 / L 1}{V 2 / L 2}=1$

Molmasse (g/Mol):

DLPC $:=621.83 \quad$ DMPC $:=677.94$ DMPE $:=635.86$

DPPC $:=734.05 \quad$ OPPC $:=760.09 \quad$ POPS $:=784 \quad$ DMPG_Na $:=688.85$

\section{Für Mischung aus DMPC/DMPE $=1 / 1$ :}
L1 := DMPC
L2 := DMPE
$\mathrm{V} 1:=\frac{0.11 \cdot \mathrm{L} 1}{\mathrm{~L} 1+\mathrm{L} 2}$
$\mathrm{V} 1=0.05676$
$\mathrm{V} 2:=0.11-\mathrm{V} 1$
$\mathrm{V} 2=0.05324$ 


\section{Anhang B}

\section{C-Quelltext des Programms zur Anpassung der Reflektivitätskurve mit numerischer}

\section{Faltung}

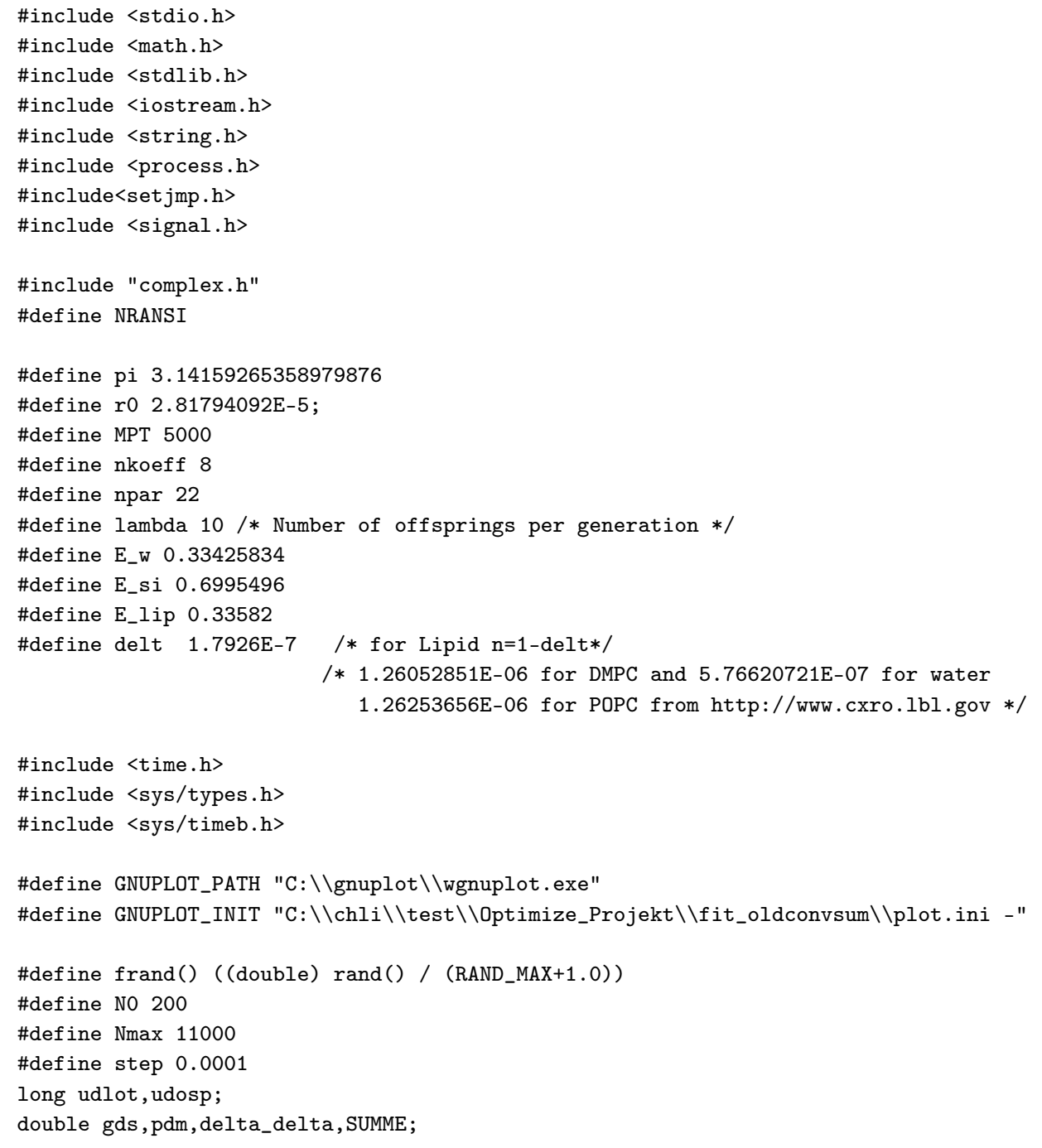


long udsupply[98];

float $x[M P T], q[M P T], Q[N \max ]$;

double y[MPT];

double resid[MPT];

double upper [npar], lower [npar], prec [npar];

double UM [MPT] [MPT];

double res_func $[2 * \mathrm{NO}+2]$, final $[\mathrm{Nmax}+2 * \mathrm{NO}]$, fit $[\mathrm{Nmax}+2 * \mathrm{NO}]$;

double D_E12, D_blank, D_sub,D_top, D_film, d=48.4,lamda $=0.62$, lipid_dicke $=8.5305 \mathrm{e}$, beta $=3.462 \mathrm{e}-10$, qc_lipid=0.028;

/* upper and lower are vectors containing the upper and lower bounds for the parameters

prec the desired accuracy for the respective parameters $* /$

double reslt [npar];

/* result contains final fit parameter */

int ndata;

jmp_buf fitenv;

$/ *--$ square function--*/

double sqr(double w)

\{

return $\mathrm{w} * \mathrm{w}$;

\}

$/ *--$ cube function --*/

double qub(double w)

\{

return $\mathrm{w} * \mathrm{w} * \mathrm{w}$;

\}

/* Generator for uniformly distributed random numbers */

double unidev()

\{

long $a=1366$;

long $\mathrm{c}=150889$;

long $\mathrm{m}=714025$;

int $i$;

$i=1+f l o o r(97 *$ udlot $/ \mathrm{m})$;

udlot $=$ udsupply $[i]$;

udosp $=(\mathrm{a} *$ udosp $+\mathrm{c}) \% \mathrm{~m}$;

udsupply $[i]=$ udosp;

return ((double)udlot / (double $) \mathrm{m})$;

/* Generator for normal distributed random numbers */

double gaussdev()

double s,v1,v2, retval;

if $($ gds $<9)$

\{

retval $=$ gds

$\operatorname{gds}=10$

\}

else 


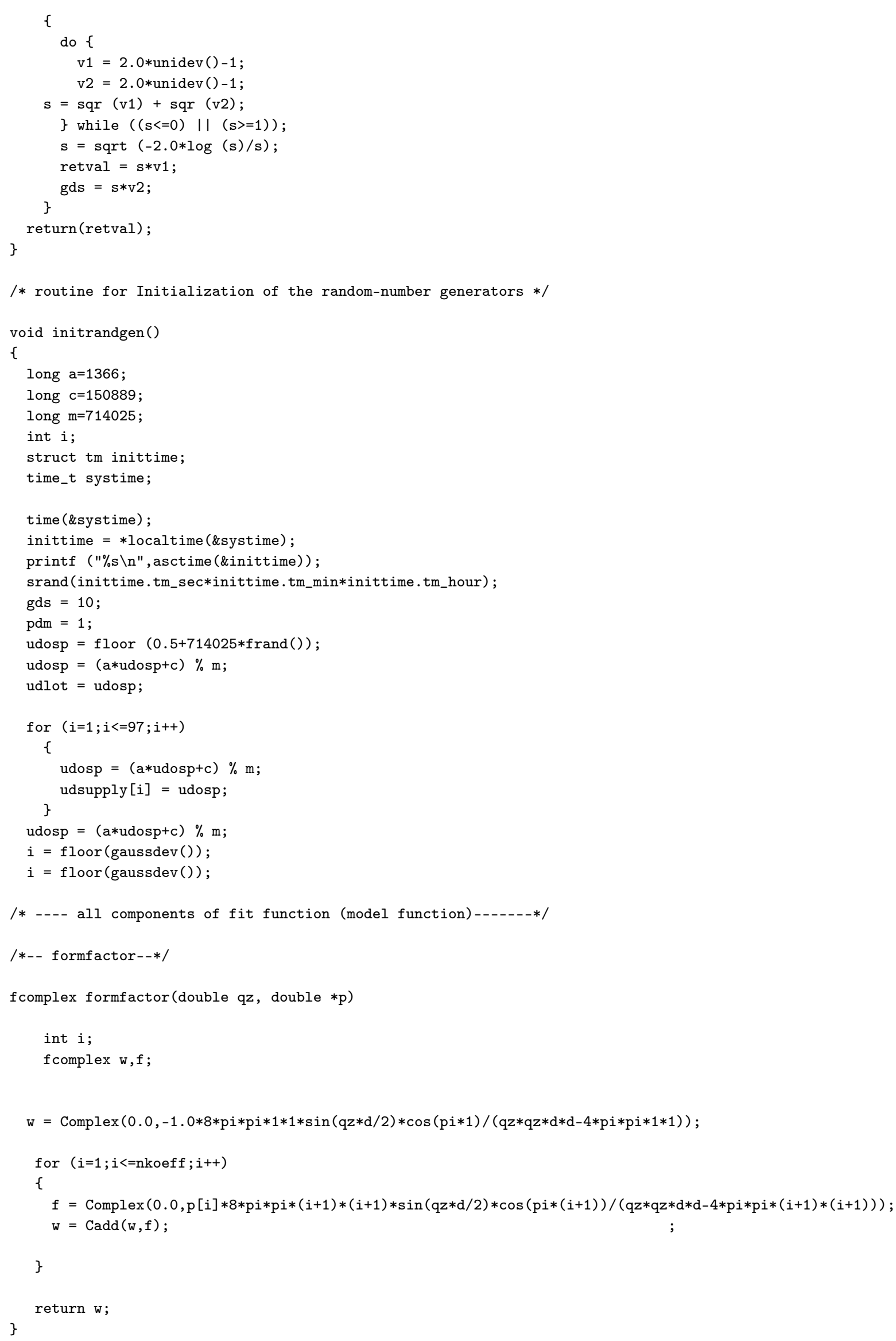




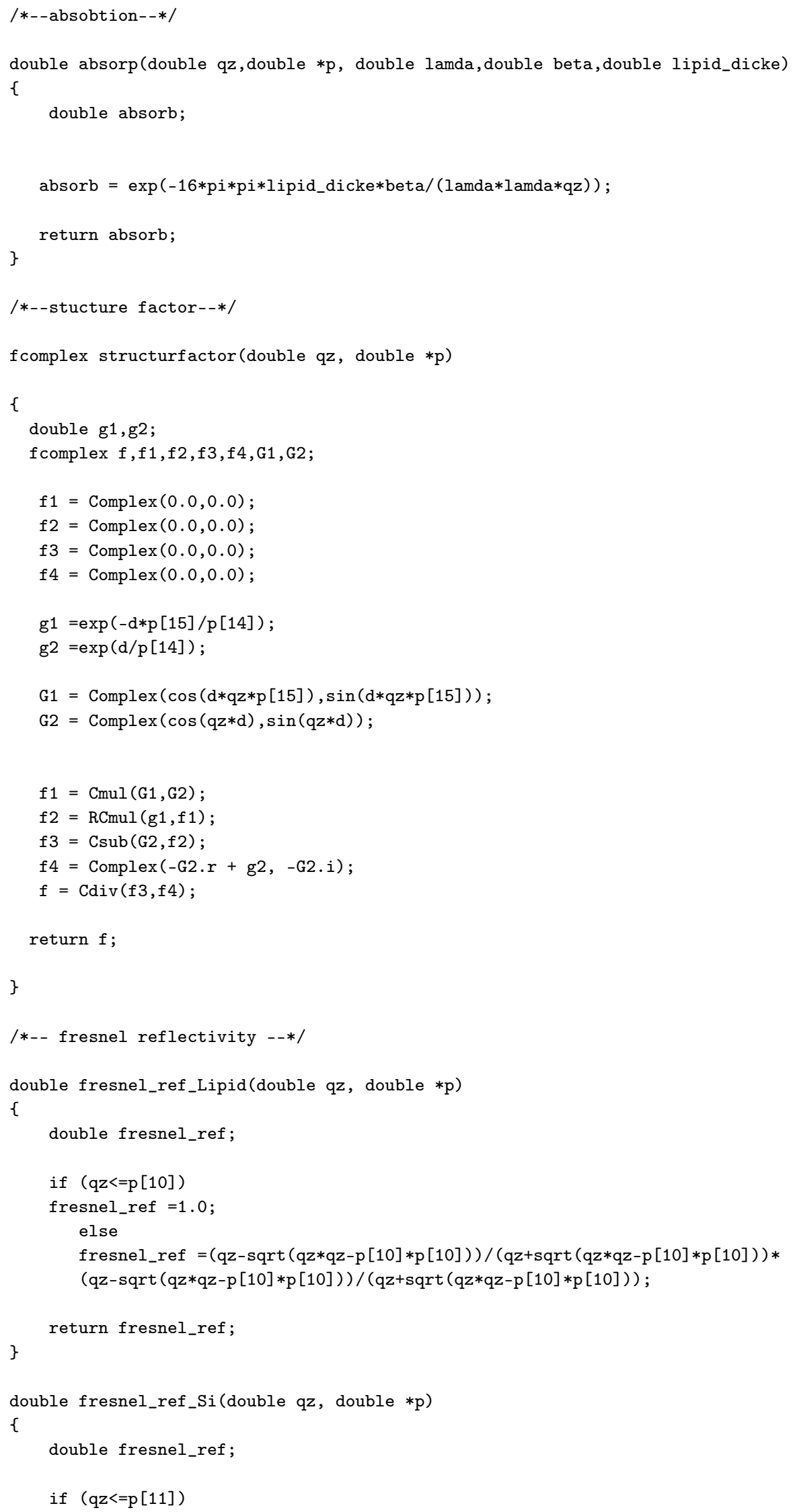




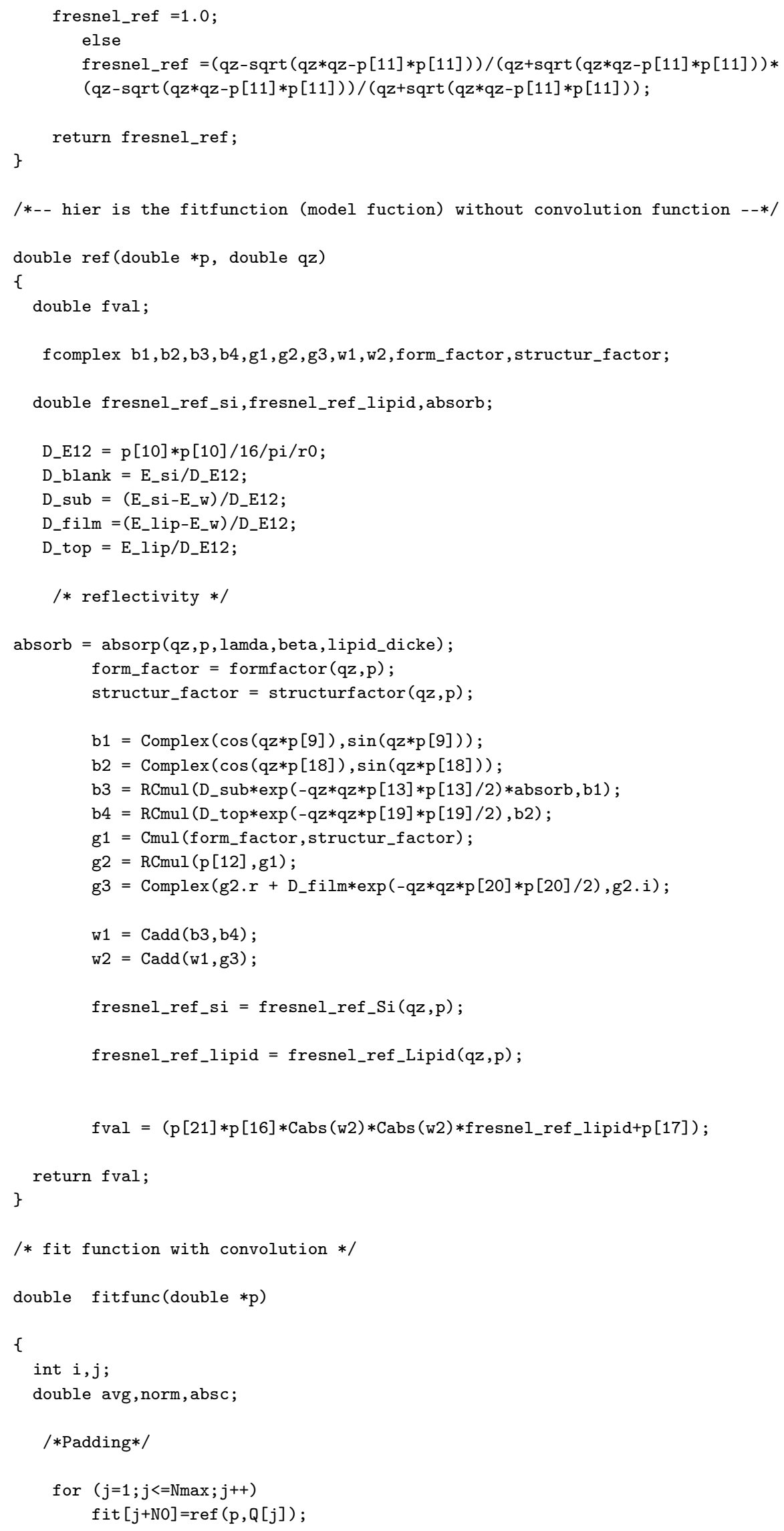




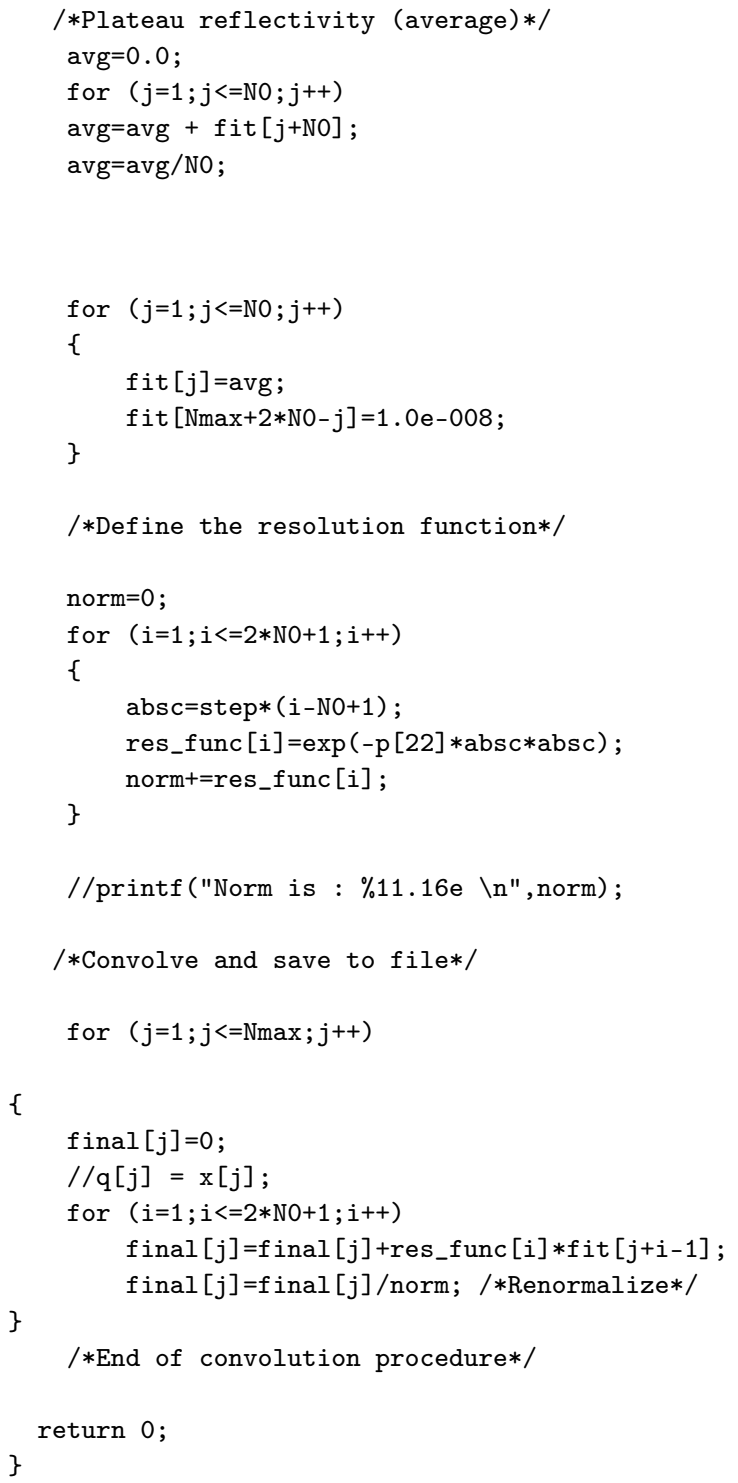




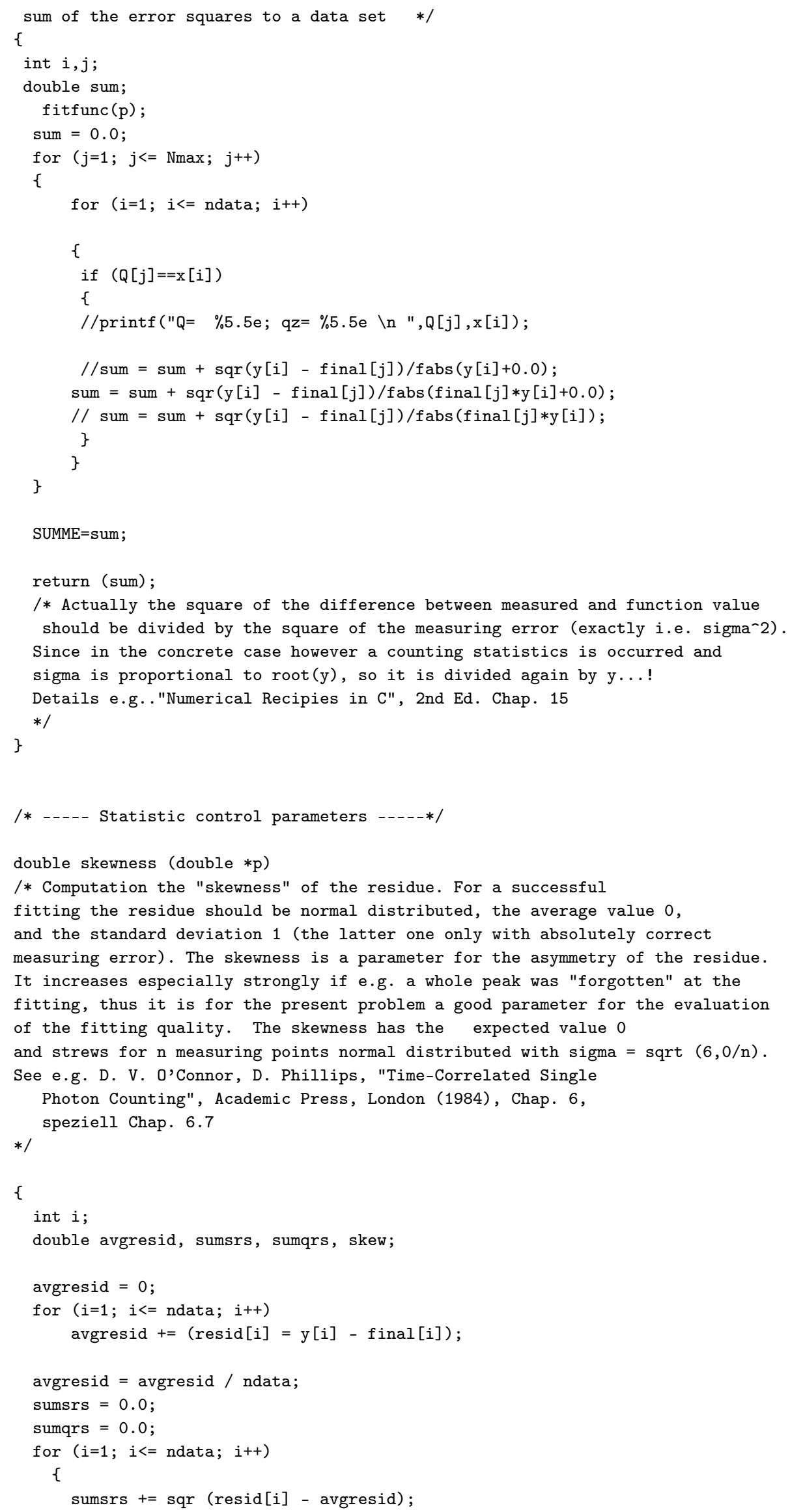




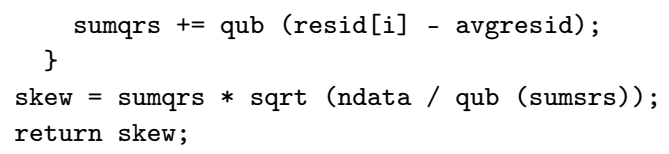


/* Get function inforamtion */

$\mathrm{n}=$ npar; /* npar: global, number of parameters $* /$

ok $=1$;

FITERROR $=0$;

/* Allocate memory for locally used vectors */

$\mathrm{a}=($ double $*)$ malloc $\left(\left(\right.\right.$ size_t $\left._{-}\right)$sizeof $($double $\left.) *(n+1)\right)$;

$\mathrm{b}=($ double $*)$ malloc $(($ size_t $)$ sizeof $($ double $) *(n+1))$;

elter $=($ double $*)$ malloc $(($ size_t $)$ sizeof $($ double $) *(n+1))$;

stepfactor $=($ double* $)$ malloc $(($ size_t $)$ sizeof $($ double $) *(n+1))$;

gen $=($ double $*)$ malloc $(($ size_t $)$ sizeof $($ double $) *(n+1))$;

ye $=($ double $*)$ malloc $(($ size_t $)$ sizeof $($ double $) *(n+1))$;

$\mathrm{m}=($ double $*)$ malloc $\left(\left(\right.\right.$ size_t $\left._{-}\right)$sizeof $($double $\left.) *(n+1)\right)$;

oldelter $=($ double $*)$ malloc $(($ size_t $)$ sizeof $($ double $) *(n+1))$;

for $(i=0$; $i<$ lambda; $i++)$

kind $[i]=($ double $*)$ malloc $(($ size_t $)$ sizeof $($ double $) *(n+1))$;

/* Install floating point exception handler */

/*signal (SIGFPE,fperror_catch_during_evs); */ /* Specific to UNIX */

/* local longjump marker */

if (setjmp (fitenv) ==0) /* Specific to UNIX */

/* Regular execution: setjmp() returns 0 . After longjmp to this point setjmp() returns something else than $0 * /$

\{

/* regular execution $->$ do the fit $* /$

\{ for $(i=1 ; i<=n ; i++)$

/* create first parent (starting point) */

stepfactor $[i]=$ fabs (upper [i] - lower [i]);

/* global: upper and lower are vectors containing

the upper and lower bounds for the parameters */

$\mathrm{a}[\mathrm{i}]=$ lower $[\mathrm{i}]$;

$\mathrm{b}[\mathrm{i}]=\operatorname{upper}[\mathrm{i}]$;

$/ / \operatorname{printf}(" \% \mathrm{~d} \% 5.5 \mathrm{e} \% 5.5 \mathrm{e} \backslash \mathrm{n} ", \mathrm{i}, \mathrm{a}[\mathrm{i}], \mathrm{b}[\mathrm{i}]$ );

elter $[i]=(a[i]+b[i]) / 2.0 ; / *$ Mittenstart $* /$

$\mathrm{m}[\mathrm{i}]=0$;

$\operatorname{gen}[i]=\operatorname{prec}[i]$;

/* global: prec contains the desired accuracy for the respective parameters */

$$
\}
$$

/* Do some math in order to compute the esimated number of generations required - According to some very elementary considerations of I. Rechenberg, TU Berlin. The number of generations computed by this method is an estimate for ideally suited problems, in real problems the number is often way too small! */

cl $=2.0 /($ double $)$ npar;

$\mathrm{ck}=1$;

delta $=1.53875 / \operatorname{sqrt}(12.0)$;

sigma $=1.0 /$ sqrt $($ npar $)$;

sum $=0$;

for $(i=1 ; i<=n ; i++)$

sum $=$ sum $+\operatorname{sqr}($ gen $[i] /$ stepfactor $[i])$;

eps $=$ sqrt $($ sum $/($ double $)$ npar $)$;

$\mathrm{g}=4.0 * \mathrm{npar} / \mathrm{sqr}(1.53875) * \log (1.0 / \operatorname{sqrt}(6.0) / \mathrm{eps}) ;$

$\mathrm{g}=2.0 * \mathrm{~g}$;

if $(g<0)$

$\mathrm{g}=1.0$;

ig=ceil $(\mathrm{g})$;

printf (" \%d steps estimated till result $\backslash \mathrm{n} ", \mathrm{ig}) ;$

/* Do first evaluation of $\operatorname{srs} *$ /

qe $=$ mainsrs (elter);

stepcount $=0$;

/* Do evolution */ 


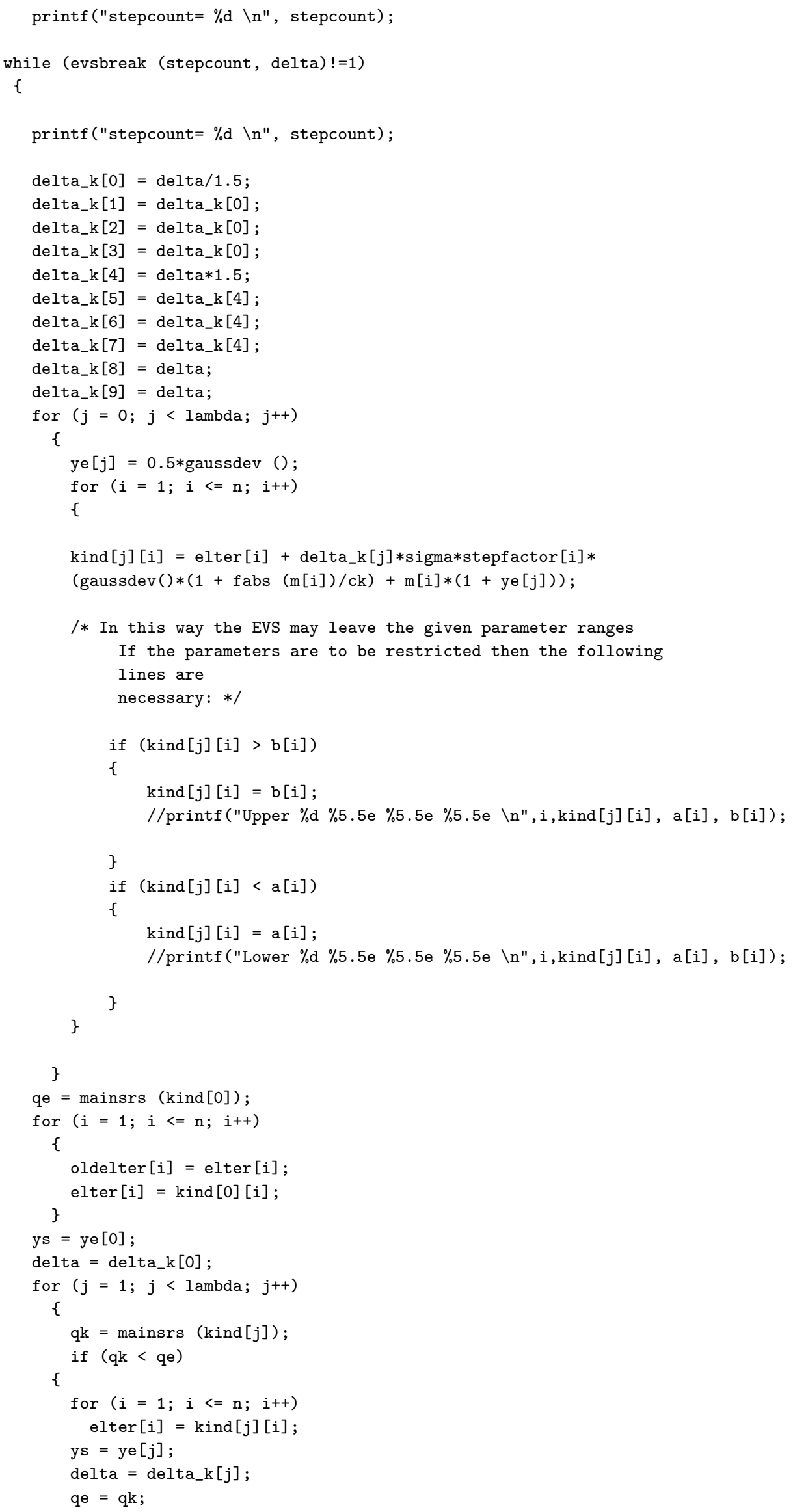




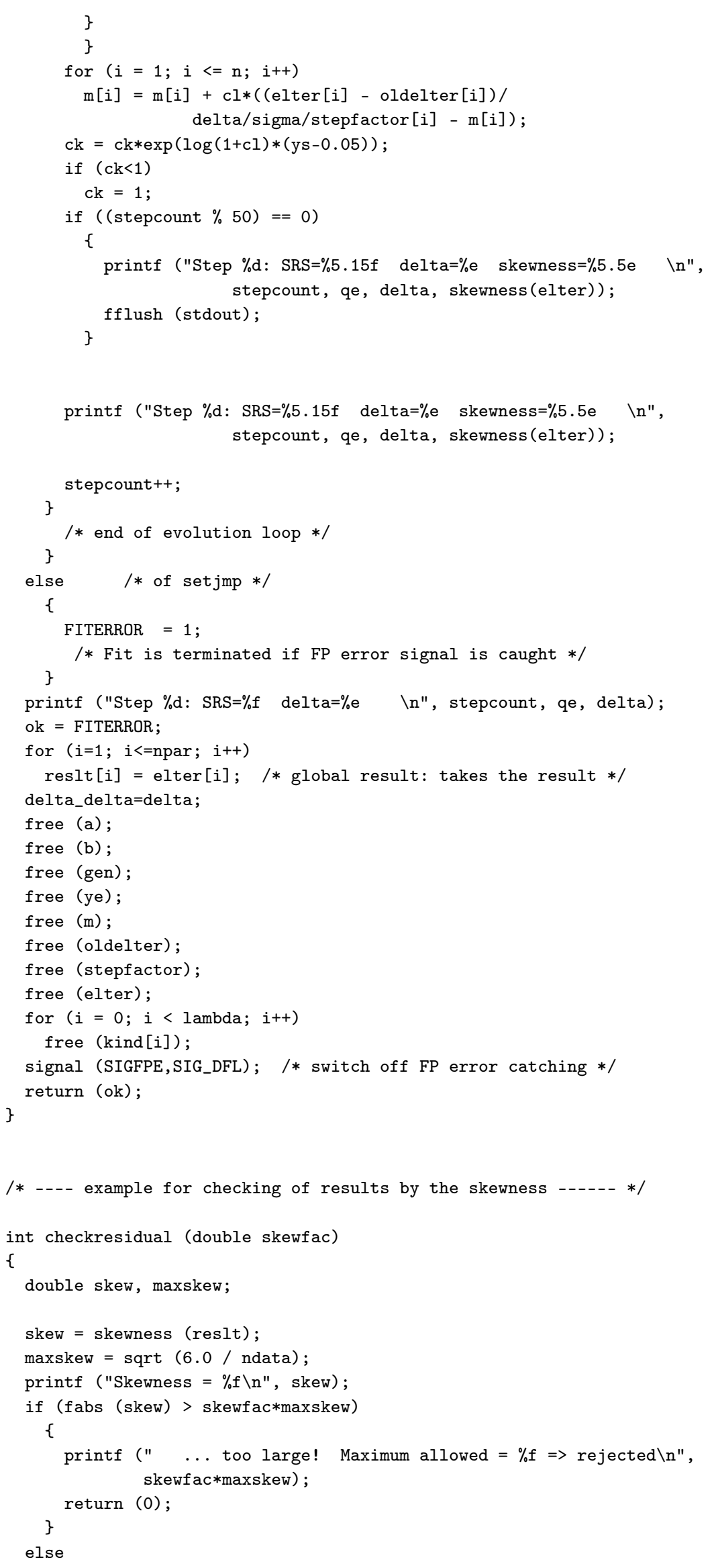




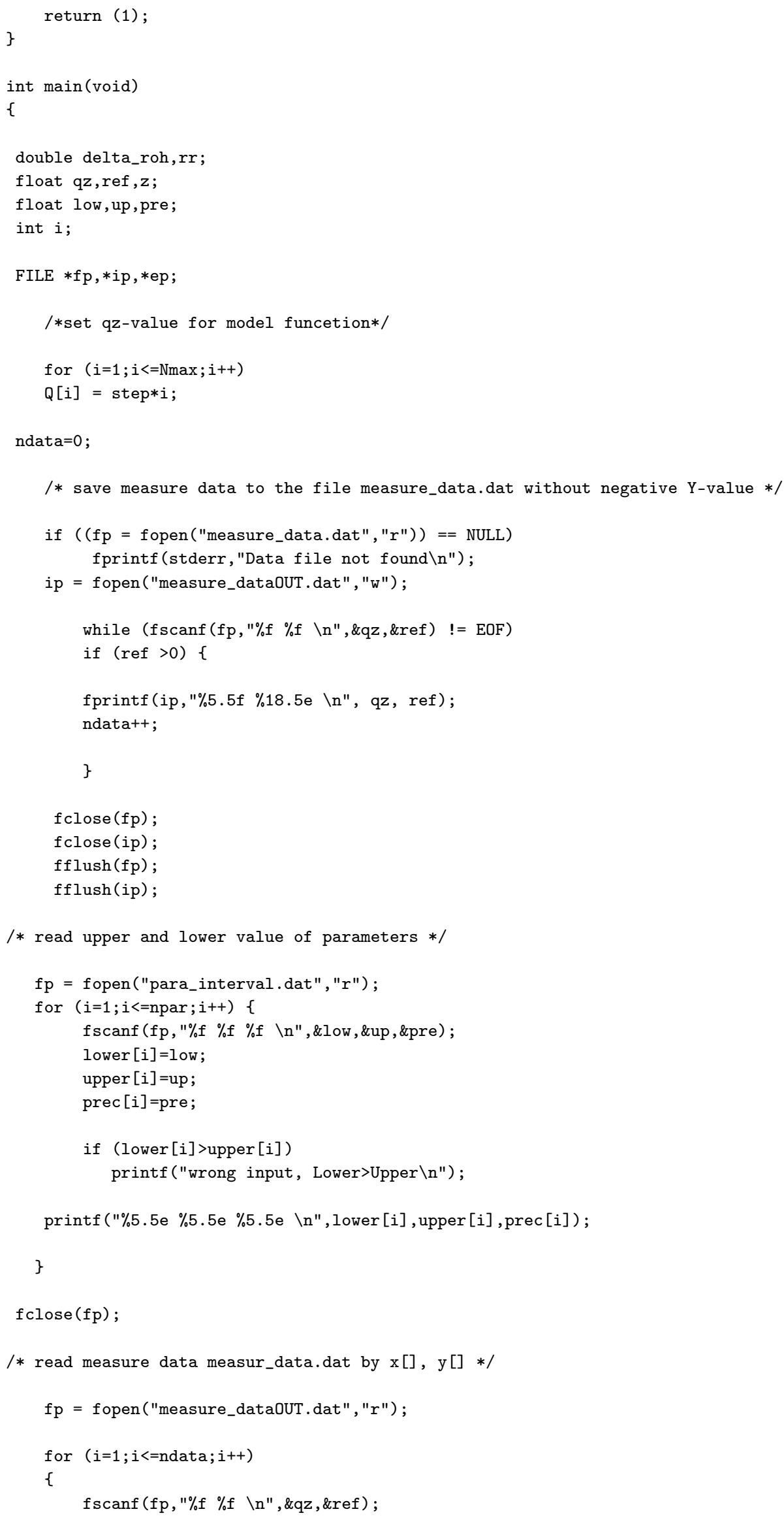




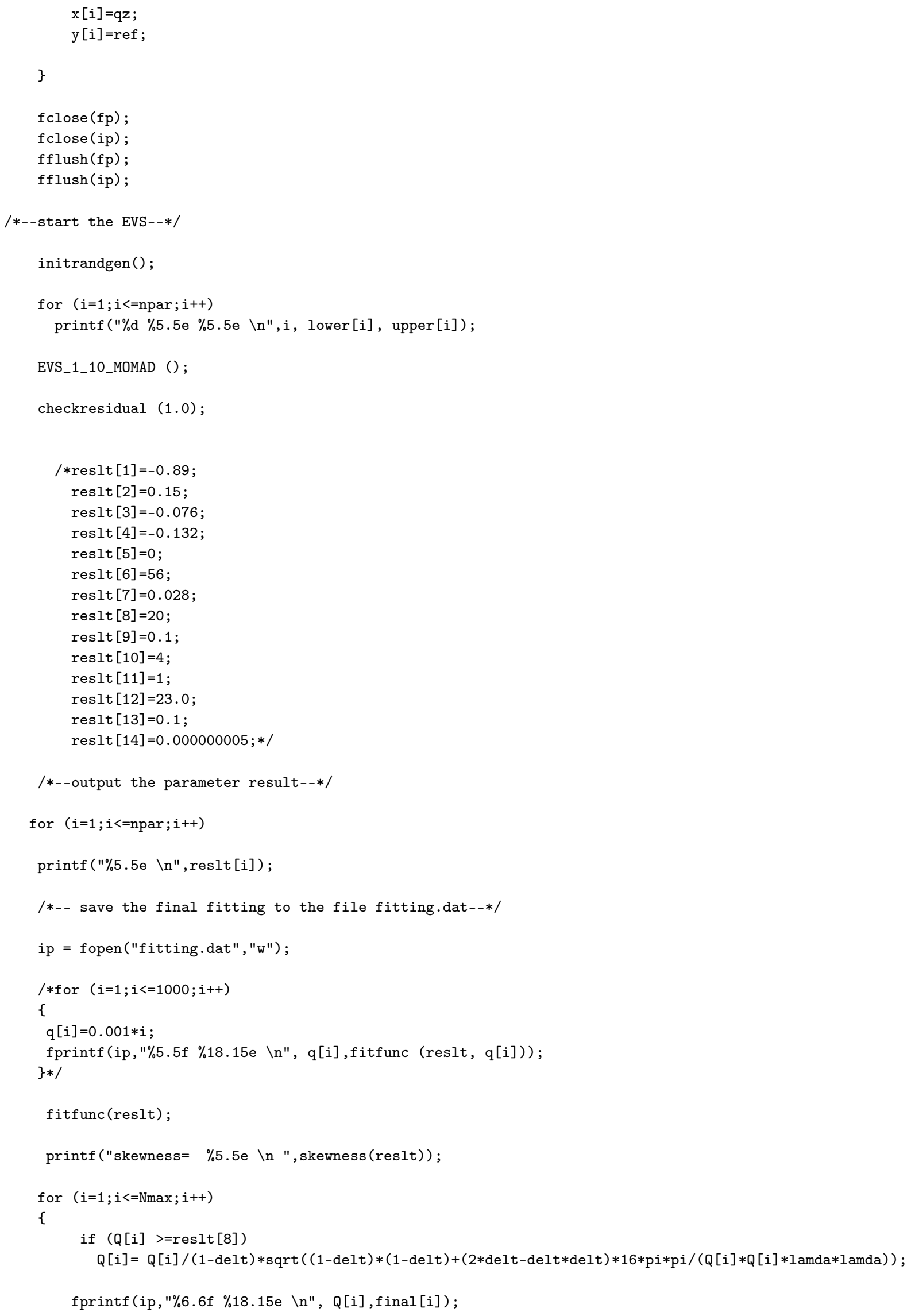


\}

fclose(ip);

fflush(ip);

/*--save the final parameter to the file parameter_list.dat--*/

$f p=$ fopen("parameter_list.dat", "a");

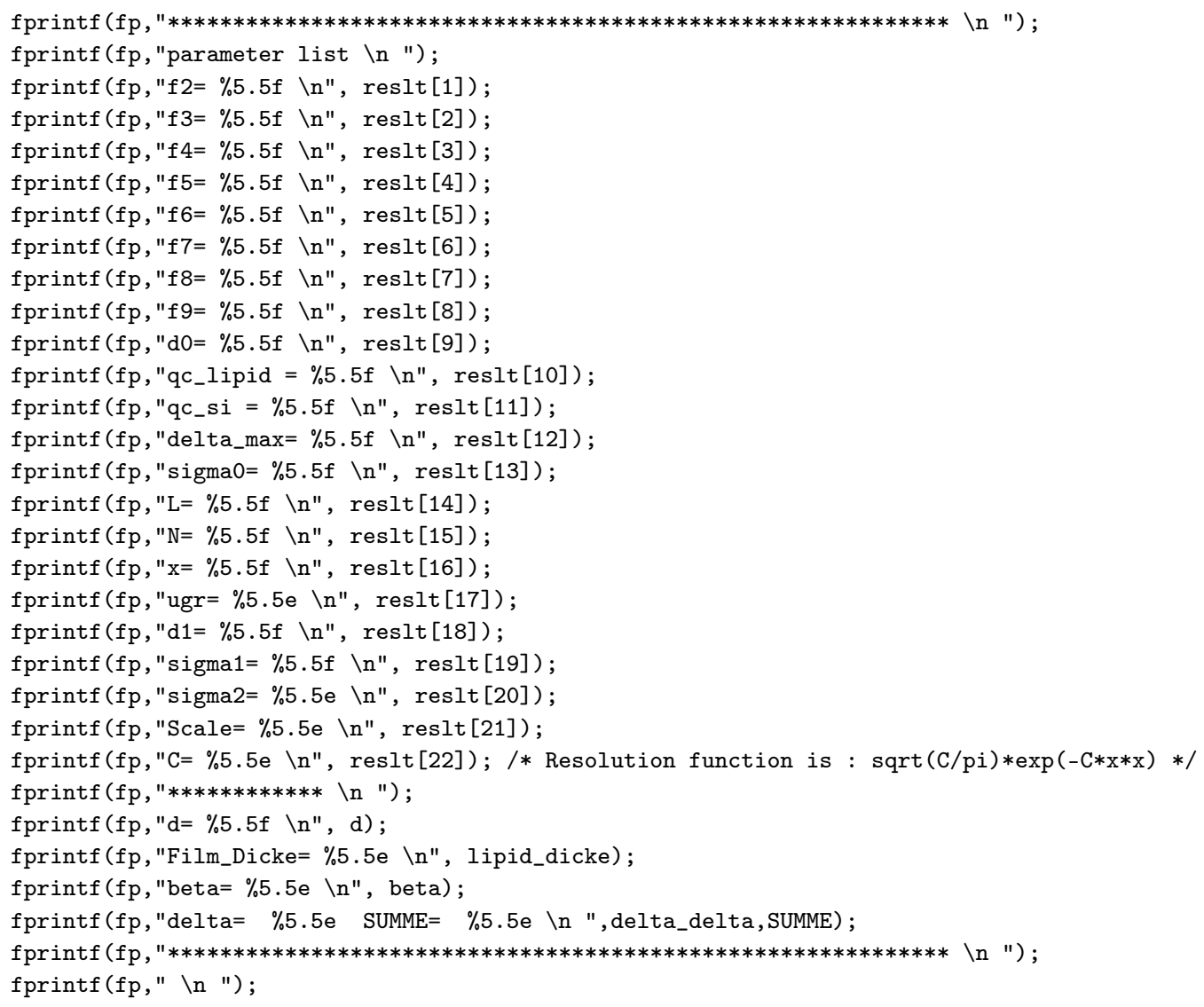


/*--start to plot the measure data and fitting with gnuplot--*/

_execlp(GNUPLOT_PATH, GNUPLOT_PATH, GNUPLOT_INIT, NULL) ;

free (x);

free (y);

free (q);

free (Q);

free (res_func);

free (final);

free (fit);

\#undef NRANSI

return 0 ;

\} 


\section{Anhang C}

\section{Parameterliste für die Anpassungen der Reflektivitätskurven}

\section{C.1 Alamethicin/Lipid}

Alamethicin/DLPC:

\begin{tabular}{cccccccccccccccc}
\hline $\mathrm{P} / \mathrm{L}$ & $f_{1}$ & $f_{2}$ & $f_{3}$ & $f_{4}$ & $f_{5}$ & $f_{6}$ & $f_{7}$ & $d_{0}$ & $q_{c}$ & $\Delta_{\max }$ & $\sigma_{0}$ & $\mathrm{~L}$ & $\mathrm{~N}$ & $d_{1}$ & $\sigma_{1}$ \\
\hline \hline 0 & -1 & -0.8 & 0.42 & -0.18 & -0.02 & -0.025 & -0.0115 & 24.5 & 0.026 & 0.2 & 1.5 & 30000 & 1000 & 24.5 & 5 \\
$1 / 100$ & -1 & -0.87 & 0.4 & -0.19 & -0.024 & -0.029 & -0.011 & 23.0 & 0.026 & 0.2 & 1.5 & 1000000 & 1000 & 23 & 2.5 \\
$1 / 50$ & -1 & -0.76 & 0.38 & -0.15 & -0.017 & -0.028 & -0.0098 & 24.5 & 0.026 & 0.2 & 1.5 & 31000 & 1000 & 25.0 & 4.0 \\
$1 / 25$ & -1 & -0.7 & 0.32 & -0.13 & -0.013 & -0.025 & -0.0077 & 24.5 & 0.026 & 0.2 & 1.5 & 16000 & 1000 & 24.5 & 4.0 \\
\hline
\end{tabular}

Tabelle C.1: Die durch Anpassung ermittelten Parameter von Proben aus Alamethicin/DLPC.

\section{Alamethicin/DMPC:}

\begin{tabular}{cccccccccccccccc}
\hline $\mathrm{P} / \mathrm{L}$ & $f_{1}$ & $f_{2}$ & $f_{3}$ & $f_{4}$ & $f_{5}$ & $f_{6}$ & $f_{7}$ & $d_{0}$ & $q_{c}$ & $\Delta_{\max }$ & $\sigma_{0}$ & $\mathrm{~L}$ & $\mathrm{~N}$ & $d_{1}$ & $\sigma_{1}$ \\
\hline \hline 0 & -1 & -0.65 & 0.45 & -0.33 & -0.038 & -0.053 & -0.0085 & 22.5 & 0.028 & 0.22 & 2.0 & 28000 & 500 & 22.0 & 3.2 \\
$1 / 200$ & -1 & -0.6 & 0.48 & -0.3 & -0.035 & -0.042 & -0.0085 & 21.0 & 0.028 & 0.22 & 2.0 & 32000 & 1000 & 21.5 & 3.2 \\
$1 / 100$ & -1 & -0.65 & 0.4 & -0.28 & -0.032 & -0.04 & -0.006 & 21.0 & 0.028 & 0.22 & 2.0 & 20000 & 1000 & 21.5 & 3.2 \\
$1 / 50$ & -1 & -0.62 & 0.41 & -0.27 & -0.028 & -0.04 & -0.0055 & 22.0 & 0.028 & 0.22 & 2.0 & 34000 & 1000 & 21.0 & 2.5 \\
$1 / 25$ & -1 & -0.52 & 0.34 & -0.23 & -0.018 & -0.034 & 0.0 & 22.0 & 0.028 & 0.22 & 2.0 & 24000 & 1000 & 21.0 & 2.5 \\
\hline
\end{tabular}

Tabelle C.2: Die durch Anpassung ermittelten Parameter von Proben aus Alamethicin/DMPC. 


\section{Alamethicin/DMPC+DMPG (1:1):}

\begin{tabular}{|c|c|c|c|c|c|c|c|c|c|c|c|c|c|c|c|}
\hline $\mathrm{P} / \mathrm{L}$ & $f_{1}$ & $f_{2}$ & $f_{3}$ & $f_{4}$ & $f_{5}$ & $f_{6}$ & $f_{7}$ & $d_{0}$ & $q_{c}$ & $\Delta_{\max }$ & $\sigma_{0}$ & $\mathrm{~L}$ & $\mathrm{~N}$ & $d_{1}$ & $\sigma_{1}$ \\
\hline 0 & -1 & -0.475 & 0.33 & -0.19 & -0.033 & -0.018 & -0.0078 & 22.5 & 0.029 & 0.22 & 2.0 & 41000 & 1000 & 22.5 & 2.0 \\
\hline $1 / 100$ & -1 & -0.56 & 0.41 & -0.24 & -0.035 & -0.024 & -0.0076 & 22.0 & 0.028 & 0.22 & 2.0 & 27000 & 1000 & 21.5 & 3.0 \\
\hline $1 / 25$ & -1 & -0.54 & 0.38 & -0.23 & -0.028 & -0.024 & -0.0055 & 21.0 & 0.028 & 0.22 & 1.5 & 27000 & 1000 & 21.7 & 2.3 \\
\hline
\end{tabular}

Tabelle C.3: Die durch Anpassung ermittelten Parameter von Proben aus Alamethicin/DMPC+PG.

\section{Alamethicin/DOPC:}

\begin{tabular}{|c|c|c|c|c|c|c|c|c|c|c|c|c|c|c|c|c|}
\hline $\mathrm{P} / \mathrm{L}$ & $f_{1}$ & $f_{2}$ & $f_{3}$ & $f_{4}$ & $f_{5}$ & $f_{6}$ & $f_{7}$ & $f_{8}$ & $d_{0}$ & $q_{c}$ & $\Delta_{\max }$ & $\sigma_{0}$ & $\mathrm{~L}$ & $\mathrm{~N}$ & $d_{1}$ & $\sigma_{1}$ \\
\hline 0 & -1 & -0.52 & 0.52 & -0.32 & -0.014 & -0.011 & 0.006 & -0.0075 & 23.0 & 0.027 & 0.2 & 2.0 & 27000 & 1000 & 21.5 & 2.0 \\
\hline $1 / 100$ & -1 & -0.51 & 0.47 & -0.27 & -0.0125 & -0.008 & 0.0028 & -0.0045 & 22.0 & 0.028 & 0.2 & 2.0 & 35000 & 1000 & 22.0 & 2.3 \\
\hline $1 / 25$ & -1 & -0.41 & 0.39 & -0.19 & -0.0055 & -0.0068 & 0.0 & 0.0 & 22.0 & 0.028 & 0.2 & 1.8 & 27000 & 1000 & 22.0 & 2.5 \\
\hline
\end{tabular}

Tabelle C.4: Die durch Anpassung ermittelten Parameter von Proben aus Alamethicin/DOPC.

\section{Alamethicin/DPPC:}

\begin{tabular}{|c|c|c|c|c|c|c|c|c|c|c|c|c|c|c|c|c|}
\hline $\mathrm{P} / \mathrm{L}$ & $f_{1}$ & $f_{2}$ & $f_{3}$ & $f_{4}$ & $f_{5}$ & $f_{6}$ & $f_{7}$ & $f_{8}$ & $d_{0}$ & $q_{c}$ & $\Delta_{\max }$ & $\sigma_{0}$ & $\mathrm{~L}$ & $\mathrm{~N}$ & $d_{1}$ & $\sigma_{1}$ \\
\hline 0 & -1 & -0.35 & 0.37 & -0.36 & -0.0065 & -0.04 & 0.0 & -0.0062 & 23.0 & 0.028 & 0.2 & 1.8 & 40000 & 1000 & 25.0 & 2.5 \\
\hline $1 / 100$ & -1 & -0.41 & 0.4 & -0.35 & -0.003 & -0.038 & 0.0 & -0.0057 & 23.0 & 0.028 & 0.2 & 1.4 & 29000 & 1000 & 23.0 & 3.2 \\
\hline $1 / 25$ & -1 & -0.37 & 0.37 & -0.29 & -0.0085 & -0.036 & 0.0038 & -0.0049 & 23.5 & 0.028 & 0.2 & 1.4 & 21000 & 1000 & 22.5 & 3.0 \\
\hline
\end{tabular}

Tabelle C.5: Die durch Anpassung ermittelten Parameter von Proben aus Alamethicin/DPPC.

\section{Alamethicin/POPC:}

\begin{tabular}{ccccccccccccccccc}
\hline $\mathrm{P} / \mathrm{L}$ & $f_{1}$ & $f_{2}$ & $f_{3}$ & $f_{4}$ & $f_{5}$ & $f_{6}$ & $f_{7}$ & $f_{8}$ & $d_{0}$ & $q_{c}$ & $\Delta_{\max }$ & $\sigma_{0}$ & $\mathrm{~L}$ & $\mathrm{~N}$ & $d_{1}$ & $\sigma_{1}$ \\
\hline \hline 0 & -1 & -0.52 & 0.45 & -0.27 & -0.045 & -0.004 & -0.006 & 0.0 & 22.0 & 0.028 & 0.22 & 1.5 & 21000 & 1000 & 23.0 & 2.3 \\
$1 / 100$ & -1 & -0.47 & 0.45 & -0.25 & -0.0105 & -0.0121 & 0.0 & 0.0 & 23.0 & 0.028 & 0.22 & 2.0 & 7000 & 1000 & 22.0 & 3.0 \\
$1 / 25$ & -1 & -0.44 & 0.4 & -0.22 & -0.0082 & -0.012 & 0.0 & 0.0 & 22.5 & 0.028 & 0.22 & 2.0 & 9000 & 1000 & 22.0 & 3.5 \\
\hline
\end{tabular}

Tabelle C.6: Die durch Anpassung ermittelten Parameter von Proben aus Alamethicin/POPC. 


\section{Alamethicin/DMPC unter PEG-Lösung:}

\begin{tabular}{ccccccccccccc}
\hline $\mathrm{P} / \mathrm{L}$ & $f_{1}$ & $f_{2}$ & $f_{3}$ & $f_{4}$ & $f_{5}$ & $f_{6}$ & $d_{0}$ & $q_{c}$ & $\Delta_{\max }$ & $\sigma_{0}$ & $\mathrm{~L}$ & $\mathrm{~N}$ \\
\hline \hline 0 & -1 & -0.86 & 0.19 & -0.0087 & -0.038 & 0.0 & 23.0 & 0.022 & 0.22 & 2.6 & 32000 & 1000 \\
$1 / 200$ & -1 & -0.8 & 0.175 & -0.0065 & 0.035 & 0.0 & 23.0 & 0.023 & 0.22 & 2.6 & 34000 & 1000 \\
$1 / 100$ & -1 & -0.88 & 0.22 & -0.0051 & -0.056 & 0.0035 & 23.0 & 0.023 & 0.22 & 2.0 & 14000 & 1000 \\
$1 / 50$ & -1 & -0.89 & 0.23 & 0.0 & -0.045 & 0.0 & 22.0 & 0.023 & 0.22 & 2.2 & 20000 & 1000 \\
$1 / 25$ & -1 & -0.88 & 0.19 & -0.011 & -0.039 & 0.0 & 22.8 & 0.0225 & 0.22 & 2.3 & 7000 & 1000 \\
\hline
\end{tabular}

Tabelle C.7: Die durch Anpassung ermittelten Parameter von Proben aus Alamethicin/DMPC unter 14\% PEG-Lösung.

\section{C.2 Multilamellare Membranstapeln aus Magainin2/Lipid}

\section{Magainin2/OPPC:}

\begin{tabular}{ccccccccccccccc}
\hline $\mathrm{P} / \mathrm{L}$ & $f_{1}$ & $f_{2}$ & $f_{3}$ & $f_{4}$ & $f_{5}$ & $f_{6}$ & $d_{0}$ & $q_{c}$ & $\Delta_{\max }$ & $\sigma_{0}$ & $\mathrm{~L}$ & $\mathrm{~N}$ & $d_{1}$ & $\sigma_{1}$ \\
\hline \hline 0 & -1 & -0.26 & 0.21 & -0.12 & 0.005 & -0.006 & 21.0 & 0.028 & 0.22 & 2.5 & 5000 & 700 & 26.0 & 6.0 \\
$1 / 1000$ & -1 & -0.32 & 0.29 & -0.19 & 0.0055 & -0.0115 & 22.0 & 0.028 & 0.22 & 3.5 & 8500 & 800 & 22.0 & 18.0 \\
$1 / 200$ & -1 & -0.31 & 0.22 & -0.09 & 0.005 & -0.0018 & 21.7 & 0.028 & 0.22 & 3.0 & 10000 & 800 & 22.0 & 12.0 \\
$1 / 50$ & -1 & -0.26 & 0.2 & -0.072 & -0.0073 & 0.0 & 22.2 & 0.028 & 0.22 & 3.5 & 12000 & 1000 & 22.0 & 12.0 \\
\hline
\end{tabular}

Tabelle C.8: Die durch Anpassung ermittelten Parameter von Proben aus Magainin2/OPPC.

\section{Magainin2/DMPC:}

\begin{tabular}{ccccccccccccccc}
\hline $\mathrm{P} / \mathrm{L}$ & $f_{1}$ & $f_{2}$ & $f_{3}$ & $f_{4}$ & $f_{5}$ & $f_{6}$ & $d_{0}$ & $q_{c}$ & $\Delta_{\max }$ & $\sigma_{0}$ & $\mathrm{~L}$ & $\mathrm{~N}$ & $d_{1}$ & $\sigma_{1}$ \\
\hline \hline 0 & -1 & -0.56 & 0.26 & -0.1 & 0.026 & -0.0057 & 21.2 & 0.028 & 0.22 & 3.6 & 6500 & 1000 & 20.0 & 15.0 \\
$1 / 2000$ & -1 & -0.48 & 0.24 & -0.095 & 0.033 & -0.01 & 22.0 & 0.028 & 0.22 & 5.0 & 2500 & 1000 & 24.0 & 20.0 \\
$1 / 1000$ & -1 & -0.45 & 0.2 & -0.063 & 0.009 & 0.0 & 21.0 & 0.028 & 0.22 & 3.0 & 15000 & 1000 & 22.0 & 18.0 \\
$1 / 500$ & -1 & -0.64 & 0.36 & -0.165 & 0.03 & -0.015 & 19.0 & 0.028 & 0.22 & 2.0 & 12000 & 1000 & 20.0 & 12.0 \\
$1 / 200$ & -1 & -0.42 & 0.21 & -0.08 & 0.016 & -0.007 & 18.0 & 0.026 & 0.22 & 4.0 & 20000 & 1000 & 24.0 & 25.0 \\
$1 / 100$ & -1 & -0.49 & 0.24 & -0.08 & 0.017 & -0.0045 & 20.0 & 0.024 & 0.22 & 3.2 & 10000 & 1000 & 21.0 & 25.0 \\
$1 / 50$ & -1 & -0.59 & 0.3 & -0.095 & 0.022 & -0.008 & 20.0 & 0.026 & 0.22 & 3.5 & 4800 & 1000 & 22.0 & 35.0 \\
\hline
\end{tabular}

Tabelle C.9: Die durch Anpassung ermittelten Parameter von Proben aus Magainin2/DMPC. 


\section{Magainin2/DMPC+DMPG(3:1):}

\begin{tabular}{cccccccccccccccc}
\hline $\mathrm{P} / \mathrm{L}$ & $f_{1}$ & $f_{2}$ & $f_{3}$ & $f_{4}$ & $f_{5}$ & $f_{6}$ & $f_{7}$ & $d_{0}$ & $q_{c}$ & $\Delta_{\max }$ & $\sigma_{0}$ & $\mathrm{~L}$ & $\mathrm{~N}$ & $d_{1}$ & $\sigma_{1}$ \\
\hline \hline 0 & -1 & -0.78 & 0.31 & -0.069 & -0.055 & -0.00275 & -0.0077 & 22.0 & 0.028 & 0.22 & 2.8 & 18000 & 1500 & 22.0 & 2.5 \\
$1 / 200$ & -1 & -0.83 & 0.295 & -0.04 & -0.06 & -0.0016 & -0.0053 & 22.0 & 0.028 & 0.22 & 2.5 & 14000 & 1500 & 22.0 & 3.0 \\
$1 / 50$ & -1 & -0.77 & 0.18 & -0.011 & -0.027 & -0.002 & -0.0016 & 22.0 & 0.028 & 0.22 & 2.5 & 22000 & 1500 & 22.0 & 2.0 \\
$1 / 20$ & -1 & -0.72 & 0.065 & -0.014 & -0.008 & -0.002 & -0.002 & 22.0 & 0.028 & 0.22 & 2.5 & 10000 & 1500 & 20.0 & 2.0 \\
\hline
\end{tabular}

Tabelle C.10: Die durch Anpassung ermittelten Parameter von Proben aus Magainin2/DMPC+DMPG(3:1).

\section{C.3 Oligo-Membranen aus Magainin2/Lipid}

\section{Magainin2/DMPC:}

\begin{tabular}{cccccccccccccccccc}
\hline $\mathrm{P} / \mathrm{L}$ & $f_{1}$ & $f_{2}$ & $f_{3}$ & $f_{4}$ & $f_{5}$ & $f_{6}$ & $f_{7}$ & $d$ & $q_{c}$ & $d_{0}$ & $\Delta_{\max }$ & $\sigma$ & $\alpha$ & $\beta$ & $\mathrm{N}$ & $\eta$ \\
\hline \hline 0 & -1 & -0.82 & 0.32 & 0.012 & -0.08 & -0.00001 & -0.014 & 53 & 0.028 & 22.72 & 0.17 & 2.9 & 1.43 & 2 & 15 & 0.0 \\
$1 / 200$ & -1 & -0.864 & 0.278 & 0.0052 & -0.08 & 0.0 & -0.014 & 54 & 0.03 & 22.33 & 0.1 & 3.0 & 1.91 & 2 & 19 & 0.0 \\
$1 / 50$ & -1 & -1.1475 & -0.08 & 0.06 & -0.07 & 0.0 & 0.0 & 56.4 & 0.0335 & 21.7 & 0.1 & 3.0 & 1.4 & 2 & 15 & 0.0 \\
$1 / 20$ & -1 & -1.07 & 0.3 & 0.025 & -0.08 & 0.0 & 0.0 & 55.5 & 0.031 & 23.0 & 0.14 & 3.0 & 1.2 & 2 & 15 & 0.025 \\
\hline
\end{tabular}

Tabelle C.11: Die durch Anpassung ermittelten Parameter von Proben aus Oligo-Membranen von Magainin2/DMPC.

\section{Magainin2/POPC:}

\begin{tabular}{ccccccccccccccccc}
\hline $\mathrm{P} / \mathrm{L}$ & $f_{1}$ & $f_{2}$ & $f_{3}$ & $f_{4}$ & $f_{5}$ & $f_{6}$ & $f_{7}$ & $d$ & $q_{c}$ & $d_{0}$ & $\Delta_{\max }$ & $\sigma$ & $\alpha$ & $\beta$ & $\mathrm{N}$ & $\eta$ \\
\hline \hline 0 & -1 & -0.53 & 0.4 & -0.135 & -0.047 & 0.0042 & 0.0077 & 53.26 & 0.03 & 23.15 & 0.13 & 3.0 & 1.78 & 2 & 19 & 0.0 \\
$1 / 200$ & -1 & -0.6 & 0.4078 & -0.15 & -0.053 & 0.0095 & 0.015 & 53.5 & 0.0282 & 23.54 & 0.146 & 3.0 & 1.947 & 2 & 15 & 0.0 \\
$1 / 50$ & -1 & -0.67 & 0.39 & 0.019 & -0.079 & -0.004 & -0.0012 & 54.1 & 0.029 & 23.0 & 0.155 & 3.0 & 1.9 & 2 & 15 & 0.0 \\
$1 / 20$ & -1 & -0.67 & 0.33 & -0.0015 & -0.045 & 0.003 & 0.003 & 54.4 & 0.03 & 23.5 & 0.16 & 3.0 & 1.9 & 2 & 14 & 0.0 \\
\hline
\end{tabular}

Tabelle C.12: Die durch Anpassung ermittelten Parameter von Proben aus Oligo-Membranen von Magainin2/POPC. 


\section{Magainin2/DMPC+DMPG(3:1):}

\begin{tabular}{ccccccccccccccccc}
\hline $\mathrm{P} / \mathrm{L}$ & $f_{1}$ & $f_{2}$ & $f_{3}$ & $f_{4}$ & $f_{5}$ & $f_{6}$ & $f_{7}$ & $d$ & $q_{c}$ & $d_{0}$ & $\Delta_{\max }$ & $\sigma$ & $\alpha$ & $\beta$ & $\mathrm{N}$ & $\eta$ \\
\hline \hline 0 & -1 & -1.3 & 0.0028 & 0.149 & -0.07 & 0.003 & -0.001 & 60.37 & 0.0283 & 21.6 & 0.11 & 3.0 & 1.426 & 2 & 19 & 0.0 \\
$1 / 200$ & -1 & -2.9 & -1.4 & 0.17 & -0.1 & -0.005 & 0.09 & 75.78 & 0.03 & 21.0 & 0.07 & 3.7 & 1.0 & 2 & 13 & 0.085 \\
$1 / 50$ & -1 & -1.9 & 0.0 & 0.15 & -0.04 & -0.05 & 0.0 & 63.48 & 0.03 & 23.0 & 0.09 & 3.1 & 1.5 & 2 & 13 & 0.045 \\
$1 / 20$ & -1 & -2.0 & -0.462 & 0.39 & -0.2 & 0.0 & 0.0 & 69.7 & 0.031 & 20.5 & 0.05 & 3.3 & 1.0 & 2 & 12 & 0.105 \\
\hline
\end{tabular}

Tabelle C.13: Die durch Anpassung ermittelten Parameter von Proben aus Oligo-Membranen von Magainin2/DMPC+DMPG(3:1).

\section{Magainin2/POPC+POPS(3:1):}

\begin{tabular}{ccccccccccccccccc}
\hline $\mathrm{P} / \mathrm{L}$ & $f_{1}$ & $f_{2}$ & $f_{3}$ & $f_{4}$ & $f_{5}$ & $f_{6}$ & $f_{7}$ & $d$ & $q_{c}$ & $d_{0}$ & $\Delta_{\max }$ & $\sigma$ & $\alpha$ & $\beta$ & $\mathrm{N}$ & $\eta$ \\
\hline \hline 0 & -1 & -1.3 & 0.21 & 0.28 & 0.1 & 0.02 & 0.02 & 63.67 & 0.031 & 20.8 & 0.12 & 3.0 & 1.67 & 2 & 14 & 0.028 \\
$1 / 200$ & -1 & -1.5 & -0.08 & 0.33 & 0.03 & -0.1 & 0.02 & 66.3 & 0.033 & 25.0 & 0.1 & 3.6 & 1.6 & 2 & 15 & 0.05 \\
$1 / 50$ & -1 & -1.6 & 0.03 & -0.238 & -0.246 & -0.2 & -0.0213 & 67 & 0.031 & 23.0 & 0.08 & 4.5 & 1.5 & 2 & 18 & 0.07 \\
$1 / 20$ & -1 & -1.5 & -0.27 & 0.25 & 0.076 & -0.096 & -0.01 & 72.5 & 0.029 & 23.1 & 0.09 & 3.0 & 2.2 & 2 & 12 & 0.1 \\
\hline
\end{tabular}

Tabelle C.14: Die durch Anpassung ermittelten Parameter von Proben aus Oligo-Membranen von Magainin2/POPC+POPS(3:1). 


\section{Anhang D}

\section{Eichung des Feuchtigkeitssensors}

1. Eichkurve für den Feuchtigkeitssensor von Typ HIH-3610-003.

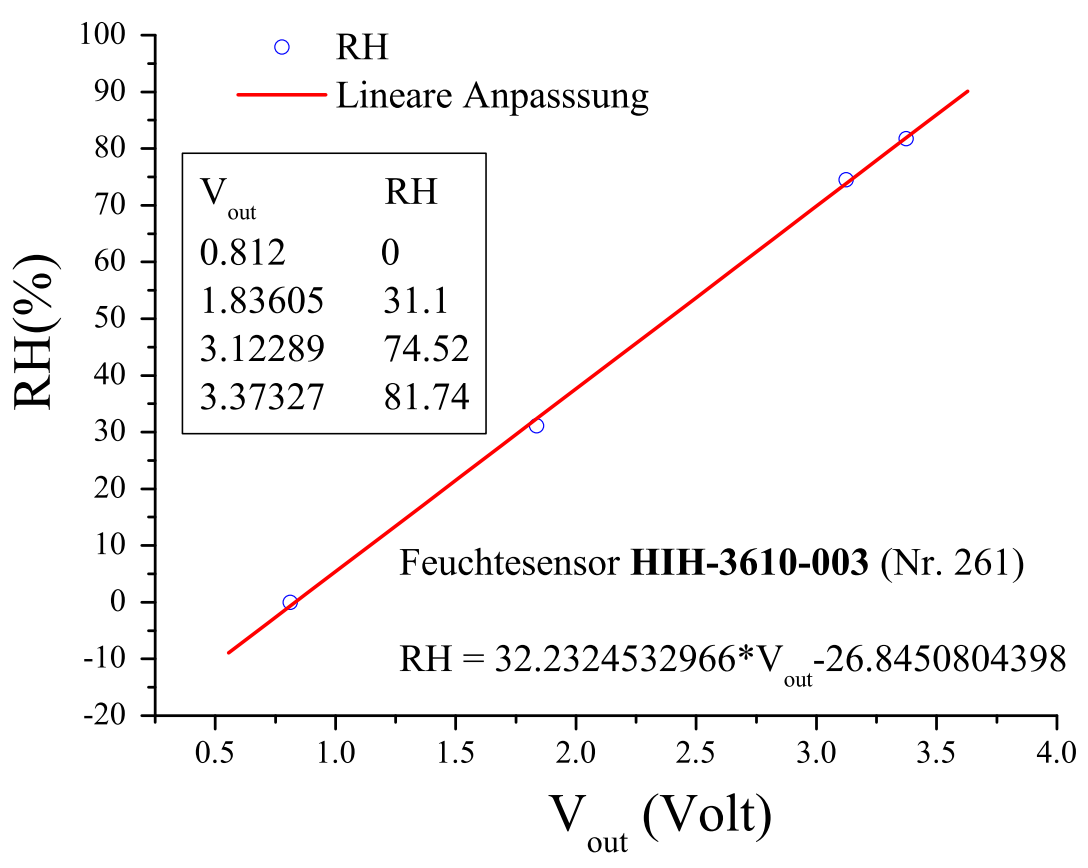


2. Relative Feuchtigkeit bei gesättigter Salzlösung.

(Aus http://www.omega.com/temperature/Z/pdf/z103.pdf)

\begin{tabular}{|c|c|c|c|c|c|c|c|}
\hline \multicolumn{8}{|c|}{ Relative Humidity (\%RH) } \\
\hline \multicolumn{2}{|c|}{ Temperature } & \multicolumn{2}{|c|}{$\begin{array}{l}\text { Lithium } \\
\text { Chloride }\end{array}$} & \multicolumn{2}{|c|}{$\begin{array}{c}\text { Potassium } \\
\text { Acetate }\end{array}$} & \multicolumn{2}{|c|}{$\begin{array}{c}\text { Magnesium } \\
\text { Chloride }\end{array}$} \\
\hline \multicolumn{2}{|c|}{$\begin{array}{c}0 \\
5 \\
10 \\
15 \\
20 \\
25 \\
30 \\
35 \\
40 \\
45 \\
50 \\
55 \\
60 \\
65 \\
70 \\
75 \\
80 \\
85 \\
90 \\
95 \\
100\end{array}$} & \multicolumn{2}{|c|}{$\begin{array}{l}11.23 \pm 0.54 \\
11.26 \pm 0.47 \\
11.29 \pm 0.41 \\
11.30 \pm 0.35 \\
11.31 \pm 0.31 \\
11.30 \pm 0.27 \\
11.28 \pm 0.24 \\
11.25 \pm 0.22 \\
11.21 \pm 0.21 \\
11.16 \pm 0.21 \\
11.10 \pm 0.22 \\
11.03 \pm 0.23 \\
10.95 \pm 0.26 \\
10.86 \pm 0.29 \\
10.75 \pm 0.33 \\
10.64 \pm 0.38 \\
10.51 \pm 0.44 \\
10.38 \pm 0.51 \\
10.23 \pm 0.59 \\
10.07 \pm 0.67 \\
9.90 \pm 0.77\end{array}$} & \multicolumn{2}{|c|}{$\begin{array}{l}23.28 \pm 0.53 \\
23.40 \pm 0.32 \\
23.11 \pm 0.25 \\
22.51 \pm 0.32 \\
21.61 \pm 0.53\end{array}$} & \multicolumn{2}{|c|}{$\begin{array}{l}33.66 \pm 0.33 \\
33.60 \pm 0.28 \\
33.47 \pm 0.24 \\
33.30 \pm 0.21 \\
33.07 \pm 0.18 \\
32.78 \pm 0.16 \\
32.44 \pm 0.14 \\
32.05 \pm 0.13 \\
31.60 \pm 0.13 \\
31.10 \pm 0.13 \\
30.54 \pm 0.13 \\
29.93 \pm 0.16 \\
29.26 \pm 0.18 \\
28.54 \pm 0.21 \\
27.77 \pm 0.25 \\
26.94 \pm 0.29 \\
26.05 \pm 0.34 \\
25.11 \pm 0.39 \\
24.12 \pm 0.46 \\
23.07 \pm 0.52 \\
21.97 \pm 0.60\end{array}$} \\
\hline \begin{tabular}{|c|} 
Temperature \\
${ }^{\circ} \mathrm{C}$
\end{tabular} & $\begin{array}{l}\text { Potassium } \\
\text { Carbonate }\end{array}$ & $\begin{array}{l}\text { Magnesium } \\
\text { Nitrate }\end{array}$ & & & $\begin{array}{l}\text { Potassium } \\
\text { Chloride }\end{array}$ & $\begin{array}{l}\text { Potassium } \\
\text { Nitrate }\end{array}$ & $\begin{array}{l}\text { Potassium } \\
\text { Sulfate }\end{array}$ \\
\hline $\begin{array}{c}0 \\
5 \\
10 \\
15 \\
20 \\
25 \\
30 \\
35 \\
40 \\
45 \\
50 \\
55 \\
60 \\
65 \\
70 \\
75 \\
80 \\
85 \\
90 \\
95 \\
100\end{array}$ & $\begin{array}{l}43.13 \pm 0.66 \\
43.13 \pm 0.50 \\
43.14 \pm 0.39 \\
43.15 \pm 0.33 \\
43.16 \pm 0.33 \\
43.16 \pm 0.39 \\
43.17 \pm 0.50\end{array}$ & $\begin{array}{l}60.35 \pm 0.55 \\
58.86 \pm 0.43 \\
57.36 \pm 0.33 \\
55.87 \pm 0.27 \\
54.38 \pm 0.23 \\
52.89 \pm 0.22 \\
51.40 \pm 0.24 \\
49.91 \pm 0.29 \\
48.42 \pm 0.37 \\
46.93 \pm 0.47 \\
45.44 \pm 0.60\end{array}$ & $\begin{array}{l}75.5 \\
75.6 \\
75.6 \\
75.6 \\
75.4 \\
75.2 \\
75.0 \\
74.8 \\
74.6 \\
74.5 \\
74.4 \\
74.4 \\
74.5 \\
74.7 \\
75.0 \\
75.5 \\
76.2\end{array}$ & $\begin{array}{l}=0.34 \\
=0.27 \\
0.22 \\
=0.18 \\
=0.14 \\
=0.12 \\
=0.11 \\
=0.12 \\
=0.13 \\
=0.16 \\
=0.19 \\
=0.24 \\
=0.30 \\
=0.37 \\
=0.45 \\
=0.55 \\
=0.65\end{array}$ & $\begin{array}{l}88.61 \pm 0.53 \\
87.67 \pm 0.45 \\
86.77 \pm 0.39 \\
85.92 \pm 0.33 \\
85.11 \pm 0.29 \\
84.34 \pm 0.26 \\
83.62 \pm 0.25 \\
82.95 \pm 0.25 \\
82.32 \pm 0.25 \\
81.74 \pm 0.28 \\
81.20 \pm 0.31 \\
80.70 \pm 0.35 \\
80.25 \pm 0.41 \\
79.85 \pm 0.48 \\
79.49 \pm 0.57 \\
79.17 \pm 0.66 \\
78.90 \pm 0.77 \\
78.68 \pm 0.89 \\
78.50 \pm 1.0\end{array}$ & $\begin{array}{l}96.33 \pm 2.9 \\
96.27 \pm 2.1 \\
95.96 \pm 1.4 \\
95.41 \pm 0.96 \\
94.62 \pm 0.66 \\
93.58 \pm 0.55 \\
92.31 \pm 0.60 \\
90.79 \pm 0.83 \\
89.03 \pm 1.2 \\
87.03 \pm 1.8 \\
84.78 \pm 2.5\end{array}$ & $\begin{array}{l}98.77 \pm 1.1 \\
98.48 \pm 0.91 \\
98.18 \pm 0.76 \\
97.89 \pm 0.63 \\
97.59 \pm 0.53 \\
97.30 \pm 0.45 \\
97.00 \pm 0.40 \\
96.71 \pm 0.38 \\
96.41 \pm 0.38 \\
96.12 \pm 0.40 \\
95.82 \pm 0.45\end{array}$ \\
\hline
\end{tabular}




\section{Anhang E}

\section{Kalkulation der Strahldivergenz}

\section{Divergenz-Rechnung}

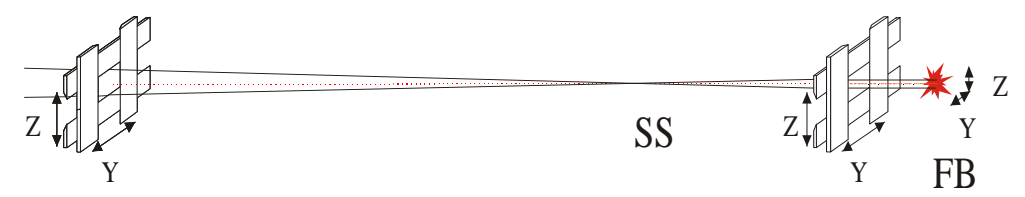

EB

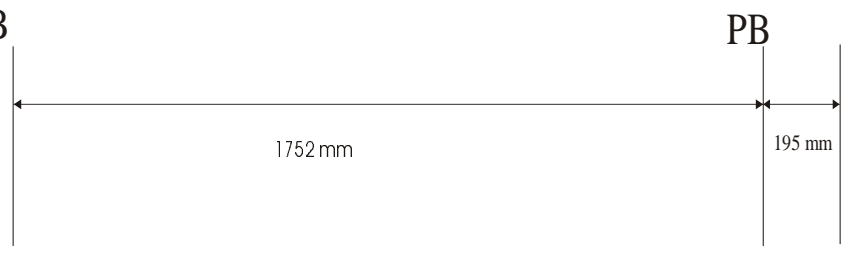

SS: Strahlschnitt
FB_y $:=0.4$
FB_z $:=1.2$
PB_y $:=10$
PB_z $:=5$
EB_y $:=1$
EB_z $:=1$

Abstand_FB_PB := 195

Abstand_PB_EB := 1752

Divergenz in Y-Richtung:
Abstand_FB_EB := Abstand_FB_PB + Abstand_PB_EB
Abstand_FB_SS_y $:=$ Abstand_FB_EB $\cdot\left(\frac{\mathrm{EB} \_\mathrm{y}}{\mathrm{FB} \_\mathrm{y}}+1\right)^{-1}$
$\operatorname{Div} \_y:=\operatorname{atan}\left[\frac{\frac{\text { FB_y }}{2}}{\text { (Abstand_FB_SS_y) }}\right]$
Div_y $=3.595 \times 10^{-4} \mathrm{rad}$
Div_y_deg $:=$ Div_y $\frac{180}{\pi}$
Div_y_deg $=0.0206$ Grad
Abstand_EB_Probe $:=150$ 
Strahlbreite_y an der Probe :

Strahlbreite_y $:=2 \cdot \tan ($ Div_y $) \cdot$ Abstand_EB_Probe + EB_y

Strahlbreite_y $=1.108$

Strahlbreite_y vor EB:

div_PB_y $:=\operatorname{atan}\left(\frac{\text { PB_y }+ \text { FB_y }}{\text { Abstand_FB_PB }}\right) \quad$ div_PB_y $\frac{180}{\pi}=3.053$

Strahlbreite_EB_y $:=\tan ($ div_PB_y $) \cdot$ Abstand_PB_EB + PB_y

Strahlbreite_EB_y $=103.44$

\section{Divergenz in Z-Richtung:}

$$
\begin{aligned}
& \text { Abstand_FB_SS_z := Abstand_FB_EB } \cdot\left(\frac{\mathrm{EB} \_z}{\mathrm{FB} \_\mathrm{Z}}+1\right)^{-1} \\
& \text { Div_z }:=\operatorname{atan}\left[\frac{\frac{\mathrm{FB} \_\mathrm{z}}{2}}{(\text { Abstand_FB_SS_z })}\right] \\
& \text { Div_z_deg }:=\text { Div_z } \frac{180}{\pi} \\
& \text { Div_z }=5.65 \times 10^{-4} \quad \mathrm{rad} \\
& \text { Div_z_deg }=0.032 \quad \text { Grad }
\end{aligned}
$$

\section{Strahlbreite $z$ an der Probe :}

Strahlbreite_z $:=2 \cdot \tan ($ Div_z $) \cdot$ Abstand_EB_Probe + EB_z

Strahlbreite_z $=1.169$

Strahlbreite_z vor EB:

div_PB_z $:=\operatorname{atan}\left(\frac{\text { PB_z }+ \text { FB_z }}{\text { Abstand_FB_PB }}\right) \quad$ div_PB_Z $\frac{180}{\pi}=1.821$

Strahlbreite_EB_z $:=\tan ($ div_PB_z $) \cdot$ Abstand_PB_EB + PB_Z 


\section{Anhang F}

\section{Der Lorentzfaktor in der klassischen Pulverstreuung und der Effekt der endlichen Braggbreite}

Man betrachte nach Cullity einen Bragg-Peak, der am Bragg-Winkel $\theta_{B}$ vorliegt (Abb. F.1(a)). Die integrierte Intensität, die unter dem Bragg-Peak liegt, ist proportional zur maximalen Intensität $I_{\max }$ und der Breite $B$ des $F W H M$. In Abb.F.1(a) sieht man, dass die Intensität neben dem Bragg-Winkel immer noch vorkommt. Dies kommt dadurch zustande, dass die Strahlen eine Divergenz haben und die Kristalle der Probe nicht perfekt geordnet sind. Sei die Probe um einen sehr kleinen Winkel $\Delta \theta$ um den Bragg-Winkel gedreht, so dass die Intensität immer noch im Bereich des Bragg-Peaks liegt (Abb.F.1 (c)). Diese Position entspricht dem Einfallswinkel $\theta_{1}=\theta_{B}+\Delta \theta$ und dem Ausfallswinkel $\theta_{2}=\theta_{B}-\Delta \theta$. Betrachtet wird nun eine einzelne Ebene von Atomen in der atomaren Skala (Abb. F.1(d)), weil die beiden Strahlen, die durch die erste Atomebene einerseits und durch die andere Atomebene andererseits gestreut werden, in Phase sind. Der Abstand zweier benachbarter Atome sei $a$ und die Länge der Atomebene sei $N a$. Der Gangunterschied zwischen zwei Strahlen 1 und 2, die durch zwei benachbarte Atome gestreut werden, kann geschrieben werden als:

$$
\begin{aligned}
\Delta_{12} & =A D-B C \\
& =a \cos \theta_{2}-a \cos \theta_{1} \\
& =a\left[\cos \left(\theta_{B}-\Delta \theta\right)-\cos \left(\theta_{B}+\Delta \theta\right)\right]
\end{aligned}
$$

Nach der Vereinfachungsprozedur und dem Ersetzen von $\sin \Delta \theta$ durch $\Delta \theta$ (für $\alpha \rightarrow 0, \sin \alpha \rightarrow \alpha$ ) kann die Gl.(F.1) geschrieben werden als:

$$
\Delta_{12}=2 a \Delta \theta \sin \theta_{B}
$$

Der gesamte Gangunterschied aller benachbarten Atome in der Ebene ist dann $N$ mal $\Delta_{12}$. Wenn dieser gesamte Gangunterschied gerade gleich einer Wellenlänge wäre, wäre die gestreute Intensität gleich Null [156]. Also ist die Bedingung für die Null-Streuintensität dann

$$
2 N a \Delta \theta \sin \theta_{B}=\lambda \quad \Rightarrow \quad \Delta \theta=\frac{\lambda}{2 N a \sin \theta_{B}} .
$$




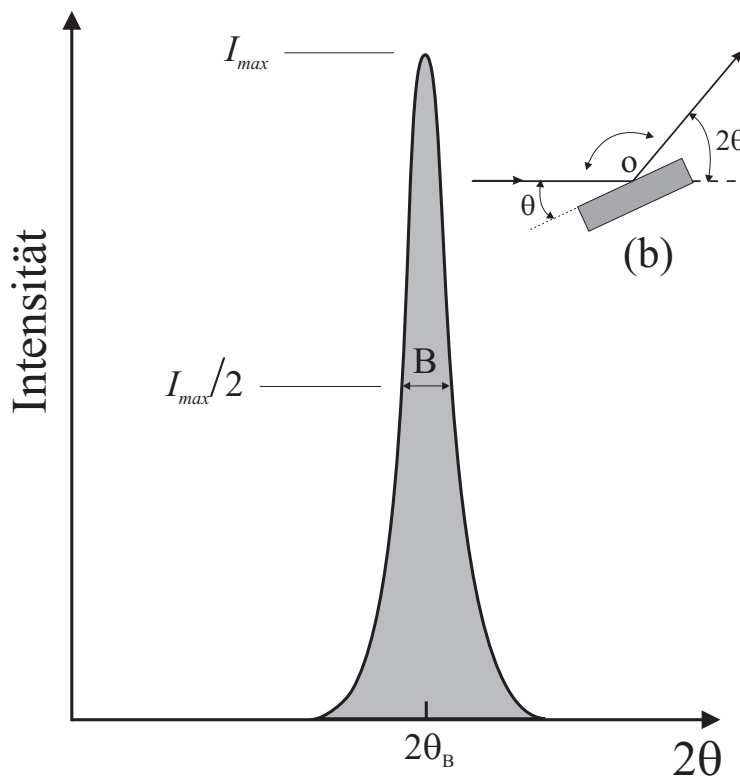

(a)

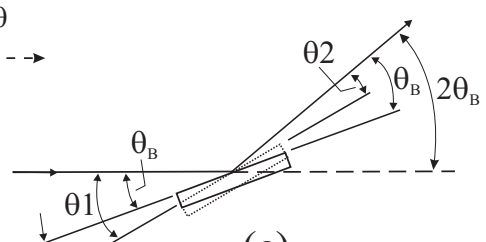

$\Delta \theta$

(c)

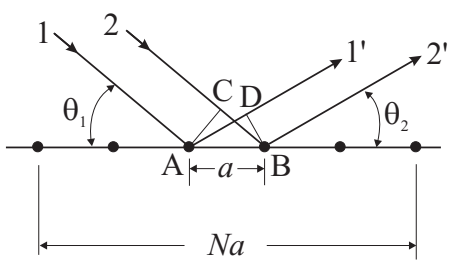

(d)

Abbildung F.1: (a) Die integrierte Intensität unter dem Bragg-Peak (graue Fläche). (b) Probendrehung um die Achse durch den Punkt O und senkrecht zu Papierebene. (c),(d) Geometrie der Streuung in fester Richtung während der Probendrehung.

Diese Gleichung zeigt einen Winkelbereich der Probenrotation, innerhalb dessen eine mögliche Strahlstreuung in der Richtung $2 \theta_{B}$ vorkommt. Da $I_{\max }$ von diesem Winkelbereich abhängig ist, ist $I_{\text {max }}$ proportional zu $1 / \sin \theta_{B}$. Die Breite $B$ des $F W H M$ ist auch abhängig von Bragg-Winkel $\theta_{b}$, und zwar proportional zu $1 / \cos \theta_{B}$ [156]. Für nicht orientierte Kristalle (Pulver) ist die Anzahl der Atome, deren Winkelorientierung nah an dem Bragg-Winkel sind, nicht konstant, obwohl die Orientierung der Atome völlig willkürlich ist. Die Zahl der Atome, die nah zum Bragg-Winkel orientiert sind, ist proportional zu $\cos (\theta)$. Außerdem können die gestreuten kegelförmigen Strahlen bei der Pulvermessung nicht alle durch den Detektor empfangen werden, sondern nur ein Teil davon, deswegen muss noch ein weiterer Faktor für der Pulvermessung berücksichtigt werden. Im Allgemeinen wird insgesamt folgender Lorentzfaktor $L_{z}$ zur Korrektur der Streuintensität von Kristallen verwendet [158],[156].

$$
L_{z}= \begin{cases}1 / \sin 2 \theta & \text { für orientierte Kristalle } \\ 1 /\left(\sin ^{2} \theta \cos \theta\right) & \text { für nicht orientierte Kristalle (Pulver) }\end{cases}
$$

wobei $\theta$ der Einfallswinkel ist. 


\section{Danksagung}

An dieser Stelle möchte ich mich herzlich bei allen bedanken, die mir mein Studium und die Vollendung meiner Promotion ermöglichten:

Herrn Prof. Dr. Tim Salditt, meinem Doktorvater, sei aufrichtig gedankt für die mir gebotene Möglichkeit zur Promotion, für die Aufmerksamkeit, die er mir trotz großer zeitlicher Inanspruchnahme entgegenbrachte, sowie für die fachliche Unterstützung bei der Anfertigung sowohl der Diplom- als auch der Doktorarbeit. Er wies mir nicht nur durch das stetige, wohlwollend-kritische Gespräch, sondern auch durch sein großes persönliches Engagement während der Arbeit am Sychrotron immer wieder den Weg, wobei er mir vieles über die Messtechnik der Reflektivität beibrachte. Ohne seine Anregung und Förderung wäre diese Dissertation nicht zustande gekommen.

Herrn PD Dr. Helmut Grubmüller fühle ich mich für die Übernahme des Zweitgutachtens zu Dank verpflichtet.

Allen Mitarbeitern in der Arbeitsgruppe möchte ich danken für ihre Hilfsbereitschaft und die angenehme Arbeitsatmosphäre. Insbesondere gilt mein Dank Frau Dr. Ulrike Mennicke sowie den Doktoranden Herrn Ansgar Jarre und Herrn Christoph Ollinger, zu denen ich während der Promotionszeit trotz des stetig zunehmenden Arbeitspensums immer ein gutes Verhältnis hatte und auf deren fachlichen und auch nicht fachlichen Rat ich mich stets verlassen konnte.

Für viele fruchtbare Diskussionen und für seine Unterstützung, insbesondere bei der Faltungsfunktion und bei der Korrektur der Formeln, möchte ich Herrn Dr. Doru Constantin danken.

Den Herren Hans-Joachim Düben, Thorsten Gronemann, Peter Nieschalk, Jens Wegner und Christian Fuhse vom Institut für Röntgenphysik möchte ich für die Unterstützung beim Reflektometeraufbau und bei der Vorbereitung der Messzeit danken.

Weiter möchte ich nicht versäumen, allen Mitarbeitern am ehemaligen Lehrstuhl Salditt an der Universität des Saarlandes für die ausgezeichnete Arbeitsatmosphäre und die gegenseitige Unterstützung zu danken, besonders Frau Eva Zaslosz, Frau Judith Rech und Herrn Dr. Alexander 
Spaar sowie Herrn Schmitt von der Werkstatt.

Für die Unterstützung und Hilfestellungen während der Messzeiten sei den Herren Dr. Hermann Franz und Dr. Dmitri Novikov von HASYLAB gedankt.

Herrn Dipl.-Inform. Albert Bücherl und Herrn Dr. theol. Peter Häger aus München möchte ich besonders danken für ihre moralische Unterstützung und für die stete Hilfsbereitschaft. Sie sind mir die größte Unterstützung gewesen während meines ganzes Studiums und auch während der Promotionszeit. Darüber hinaus schulde ich Albert Bücherl ein herzliches "Dankeschön", für das großartige Korrekturlesen und die stilistische Beratung bei der Anfertigung dieser Arbeit; durch seinen vollen "Einsatz" konnte die Untersuchung in dieser Form termingerecht vorgelegt werden. Peter Häger verdanke ich den Feinschliff der Enddurchsicht vor der Drucklegung.

Ganz besonders danke ich meiner Frau, die meiner Arbeit viel Verständnis und Geduld entgegengebracht und mich jederzeit in aller Form unterstützt hat.

Schließlich möchte ich die Gelegenheit nutzen, Herrn Abtprimas Dr. Notker Wolf OSB, dem ehemaligen Erzabt von St. Ottilien, meinen herzlichen Dank dafür auszusprechen, dass er mir das Studium in Deutschland ermöglicht und mir in vielfältiger Weise persönlich beigestanden hat. Seine immerwährende Fürsorge und Ermutigung gab mir die Kraft und auch die feste Motivation, das Studium und die Promotion zielstrebig durchzuführen. Diese Arbeit sei daher Abtprimas Dr. Notker Wolf OSB gewidmet. 


\section{Lebenslauf}

$\begin{array}{ll}\text { Name: } & \text { Chenghao Li } \\ \text { Geburtsdatum: } & \text { 16.01. } 1962 \\ \text { Geburtsort: } & \text { Jilin, VR China } \\ \text { Familienstand: } & \text { Verheiratet } \\ \text { Staatsangehörigkeit: } & \text { Chinesisch } \\ \text { Nationalität: } & \text { Koreanisch }\end{array}$

$\begin{array}{ll}1970-1976 & \begin{array}{l}\text { Grundschule, Yanji, Jilin VR China } \\ \text { Mittelschule, Yanji, Jilin VR China } \\ 1976-1979\end{array} \\ \begin{array}{l}\text { Gymnasium, Yanji, Jilin VR China } \\ 1981-1981\end{array} & \begin{array}{l}\text { Mathematik-Studium an Yanbian Universität, Jilin VR China } \\ \text { Bachelor der Wissenschaften } \\ 1985\end{array} \\ \begin{array}{l}\text { Lehrer für Mathematik an der Yanbian Industrie-Fachschule, } \\ \text { Jilin VR China }\end{array} \\ \begin{array}{l}\text { Deutschkurse für Ausländer bei der Universität München } \\ 1991-1993\end{array} \\ \begin{array}{l}\text { Studium der Wirtschaftmathematik an der Universität Augsburg } \\ 1994-1994\end{array} & \begin{array}{l}\text { Physik-Studium an der Ludwig-Maximilians-Universität München } \\ \text { Vordiplom in Physik }\end{array} \\ 2097 & \text { Diplom in Physik }\end{array}$

2000 - $2002 \quad$ Wissenschaftlicher Angestellter an der Universität des Saarlandes Seit 2002 Wissenschaftlicher Angestellter am Institut für Röntgenphysik der Universität Göttingen 